
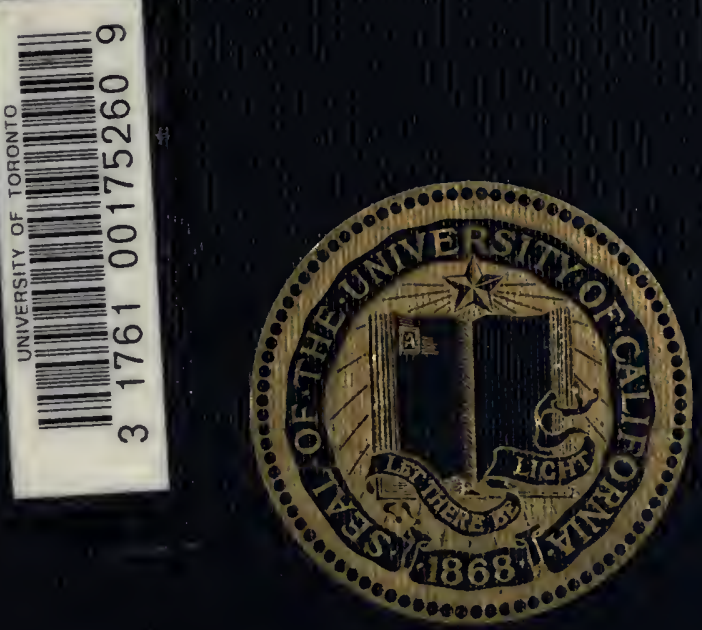
Digitized by the Internet Archive in 2007 with funding from Microsoft Corporation 


$$
\text { sin }
$$






\section{SEMICENTENNIAL PUBLICATIONS}

OF THE

\section{UNIVERSITY OF CALIFORNIA}

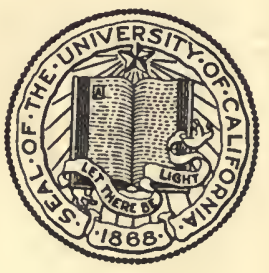

$1868-1918$ 



\title{
MISCELLANEOUS STUDIES
}

\author{
IN \\ AGRICULTURE \\ AND \\ BIOLOGY
}

$$
\frac{168043}{15.12 .21}
$$





\section{CONTENTS}

Pages

A Synopsis of the Aphididae of California, by Albert F. Swain

Mutation in Matthiola, by Howard B. Frost $223-333$

Ocean Temperatures, their Relation to Solar Radiation and Oceanic Circulation, by George F. MeEwen

Changes in the Chemical Composition of Grapes during Ripening, by F. T. Bioletti, W. V. Cruess, and H. Davi 



\section{A SYNOPSIS \\ OF THE \\ APHIDIDAE OF CALIFORNIA}

BY

ALBERT F. SWAIN

[University of California Publications in Entomology, Vol. 3, No. 1, pp.1-221, pls. 1-17] 


\title{
A SYNOPSIS
}

\section{OF THE \\ APHIDIDAE OF CALIFORNIA}

BY

\author{
ALBERT F. SWAIN
}

\section{CONTENTS}

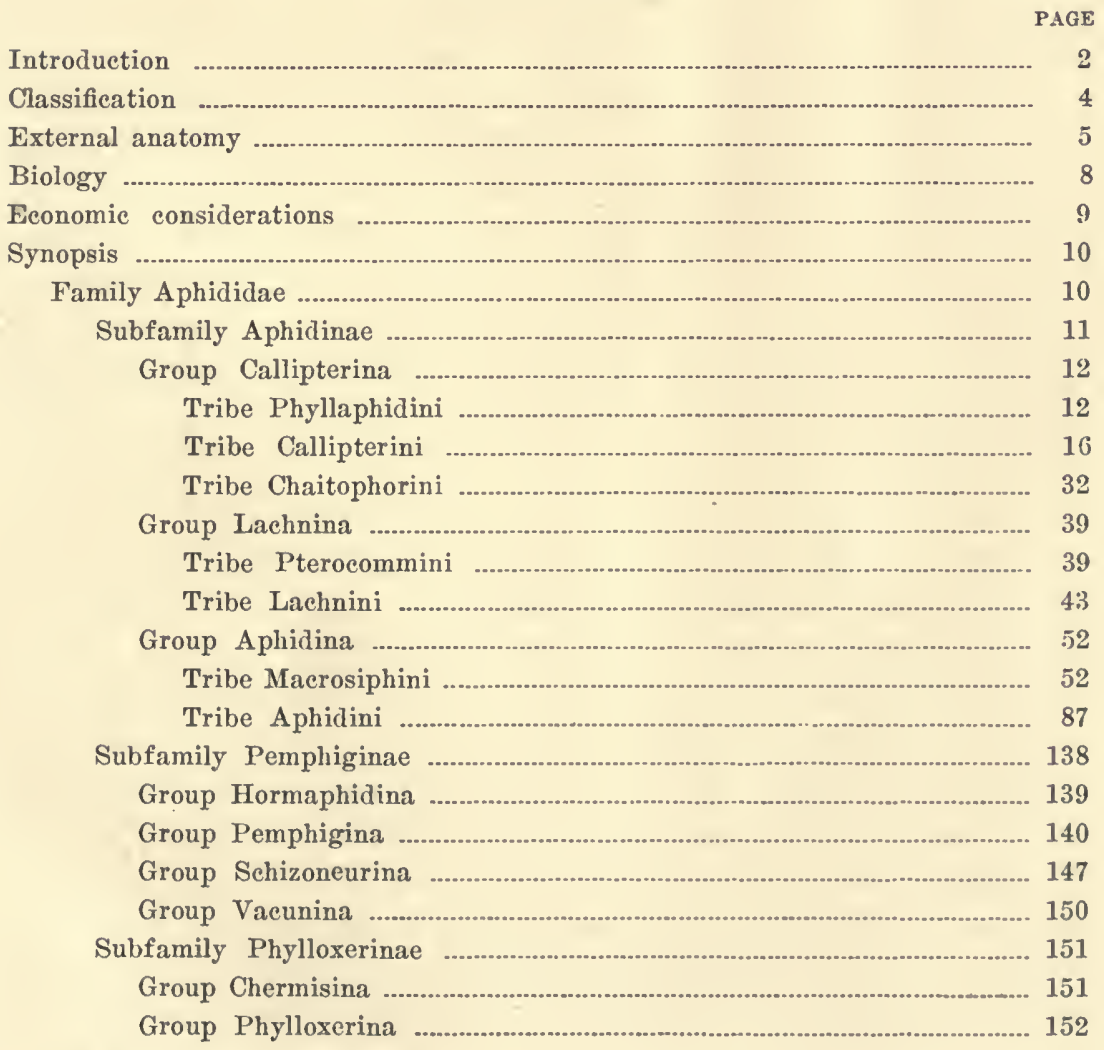


Appendix 1. Keys to the genera and tribes of Aphididae; a translation from

P. Van der Goot .......................................................................... 15.

Appendix 2. Host plant list .......................................................................... 159

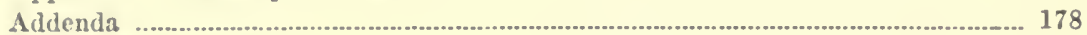

Explanation of plates ................................................................................ 180

Inlex to genera aud species ............................................................................... 215

\section{INTRODUCTION}

In recent years considerable attention has been paid to the Aphididae in the United States, and in Europe as well, and a large amount of literature is the result. In California, W. T. Clarke was the first to make any systematic studies of these insects and his paper, published in 1903, embodies the results of these studies. He listed forty-thrce species, ten of which were described as new. Two or three of his new species are known at present, but the remainder are unknown. Unfortunately his collcction was destroyed in the earthquake of April, 1906, so now it is practically impossible to determine his new species with any degree of accuracy. Following this, there was a period of six years in which there were no publications concerning the Aphididae of California, except some economic bulletins from the Experiment Station. In 1909, both E. O. Essig and W. M. Davidson published the results of their earlier studies. Since then both have added papers occasionally. During 1912 and shortly before, Harold Morrison made an extensive study of the species in the vicinity of Stanford University. He has kindly placed a report of his studies in the author's hands, with permission to publish the records in this paper. The author has been studying the Californian species continuously since 1914.

At present there are about one hundred and eighty species known to occur in California. This number will undoubtedly be greatly increased as further studies are made, since to datc only a comparatively small part of the state has been covered by collectors. Very extensive collections have bcen made in Ventura County and in the vicinity of Pomona College, Los Angeles County, by Essig. The San Francisco Bay region, particularly in the vicinity of the University of California and Stanford University, has bcen carefully surveyed for aphids, collections having bcen made by Clarke, Davidson, Essig, Morrison, Ferris, and the author. Davidson, Clarke, and Essig have made a few observations in the Sacramento Valley, particularly in Placer and Sacramento counties. The author made a number of 
observations in the vicinity of Fresno during May and June, 1915, and more or less extensive observations and collections during 1916 and 1917 in San Diego, Riverside, Orange, Los Angeles, and San Bernardino counties. In addition to these, reports come to the College of Agriculture occasionally from the State Insectary and the various county horticultural commissioners. A summary of the above statements shows that extensive collecting has been done only in the territory adjacent to San Francisco Bay, and throughout southern California. The whole northern half of the state, the great interior valleys of the Sacramento and San Joaquin rivers, and the desert sections of the southeastern part of the state are as yet unexplored. Undoubtedly many interesting species will be found in these parts.

The author wishes to express his appreciation of the aid rendered by various people during the past three years of study. To Harold Morrison of the Federal Board of Horticulture is due especial thanks for his assistance during the early part of the author's study, for his collection notes, and for the use of his extensive collections of Stanford University vicinity and Indiana; to E. O. Essig of the University of California for his continuous advice and assistance, for the use of his large collections of Californian species, and for the reading of this manuscript; to W. M. Davidson of the Bureau of Entomology, U. S. Department of Agriculture, for his many notes and determinations and for the use of his collection; to A. C. Baker, J. J. Davis, C. P. Gillette, A. S. Maxson, E. M. Patch, and H. F. Wilson for their many determinations and suggestions; to $\dot{R}$. W. Doane of Stanford University for the permission to work over his collection of Utah aphids and for permitting his students to use the keys included in this paper, thereby finding the weak points in the keys; and finally to G. F. Ferris of Stanford University for collections and advice.

In this paper the author has brought together all the present records of California Aphididae. He has included keys for the determination of the subfamilies, groups, genera, and species, together with such illustrations as are necessary for an understanding of the keys. The discussion of each species includes a bibliography of the California literature (exclusive of the merely economic and popular), together with a citation of the original description and the best available description, a list of host plants and localities, and a discussion of the synonomy, life history, and habits so far as they are known. The descriptions of certain species are not readily accessible and of others not at all adequate. Such species have been redescribed 
by the author in so far as it was possible to obtain specimens. Incidentally it may be stated that the author has personally collected by far the larger number of the species recorded in this paper. In other cases the fact is noted. A host plant index (appendix 2) is also included.

The system of elassification followed is the one most generally accepted by American aphidologists at the present time. The keys to the species have been formulated by the author, those to the genera and higher groups have to a large extent becn adapted from other workers, particularly Wilson and Essig (Aphidinae), Börner (Phylloxerinae), and Tullgren (Pemphiginae). The papers of Baker, Clarke, Davidson, Davis, Essig, Gillette, Oestlund, Patch, Pergande, Williams, Wilson, and other American aphidologists have been found invaluable. Of the works of the European aphidologists, those of Börner, Buckton, Del Guercio, Koch, Mordwilko, Tullgren, and Van der Goot have been in constant use. The classification suggested by Van der Goot ("Zur Systematik der Aphiden," in Tijdschrift voor Entomologie, vol. 56, p. 1913) has proved interesting, and although the author has not felt at liberty to accept it in full, a translation of his keys to the groups and genera has been included herewith (appendix 1), which, it is hoped, will be of assistance in the making of determinations.

\section{CLASSIFICATION}

The Aphididae belong to the order Homoptera, being closely related to the Psyllidae, or jumping plant lice, the Aleyrodidae, or white flies, and the Coccidae, or scale insects. The Aphididae, or plant lice, are small, soft-bodied insects, ranging from less than one to five or six millimeters in length. Typically there are four forms: the apterous and the alate viviparous females, and the sexual forms, the oviparous females and the males. There is considerable variation from the above in different groups and species, as will be pointed out under the discussions of the various species. The alate viviparous females are the individuals most commonly taken by the collector and the ones that usually show the best characters for determinations. In the keys in this paper all characters refer to the alate viviparous females (the alates) unless otherwise mentioned. 


\section{EXTERNAL ANATOMY}

The body ${ }^{1}$ consists typically of three divisions, the head, thorax, and abdomen. In the apterous forms the mesothorax and metathorax are closely fused with the abdomen, while the prothorax and head are distinct. In the alate forms the mesothorax and metathorax are fused together and appear as a distinct division, the body appearing to consist of four divisions, viz., the head, the prothorax, the mesothorax and metathorax, and the abdomen.

The head bears a pair of compound eyes, usually three ocelli, a pair of three to six jointed antennae, and the beak. Of these, the antennae show the best characters for determinations, not only of species but of higher groups. They are either mounted on distinct tubercles (Macrosiphini, certain Callipterini) or appear to arise from the front of the head. They consist of from three to six segments, the terminal one of which is usually provided with a projection or spur. They are six-segmented in the Aphidinae (except Essigella and Cerosipha), five- or six-segmented in the Pemphiginae (except in the stem mothers of certain genera), and three-segmented in the Phylloxerinae (except in Chermisina, in which the alate forms have fivesegmented and the sexual forms four-segmented antennae). The spur of the terminal segment may be equal to or longer than the segment (Aphidinae, in the Macrosiphini it attains its greatest length, often being as much as ten times the length of the base); it may be merely a short thumblike process (Pcmphiginae, Lachnini, and certain Callipterini); or it may be apparently lacking (Phylloxerinae). The two basal segments are always short, and quite regular in all species. The remaining segments show the greatest diversity, particularly in number, size, and shape. Sensoria are always present on some of the segments. There is one primary sensorium always present at the distal end of the terminal segment, and when the antennae consist of more than three segments, one also at the distal end of the penultimate segment. These sensoria are fairly large and clear (sometimes furnished with a hairy fringe) and are more or less circular. The accessory sensoria are a group of small indistinct sensoria, which number from three to six, and which are located in close proximity

1 For a fuller discussion of the external characters consult the following papers: Vickerey, R. A., A comparative study of the external anatomy of plant lice, 12th Rept. Minnesota State Entomologist 1908; Sanborn, C. E., Kansas Aphididae, Kansas Univ. Sei. Bull., vol. 3, 1904; Mordwilko, Alexander, Keys to the groups and genera of the Aphididae, Ann. Mus. Zool. Imp. Acad. Sci. St. Petersburg, vol. 13, pp. 362-364, 1908. 
to the primary sensorium on the terminal segment. Secondary sensoria are usually present in the alate forms, but oftentimes absent in the apterac of certain species. When present they are always on the third segment, but in antennae consisting of five or six segments, they may be present upon the fourth, fifth, and even sixth seginents. In the Pemphiginae they are arch-like or half rings, or form complete rings about the segments. In the Aphidinae they are circular, oval, or transversely linear, but are never rings or half rings. The shape and number vary considerably, and are of specific importance. The number may vary from as few as three or four (Myzocallis maureri Swain), to as many as forty to fifty on the third segment, and many also on the fourth and fifth (Myzus braggii Gillette). Unfortunately these highly important characters were overlooked or not taken into consideration by the carlier workers. The beak is four-jointed and seems to arise from between the fore legs. It is always present (except in the scxes of ccrtain of the Phylloxerinae), but is seldom of specific importance (except to distinguish Aphis bakeri Cowen from Aphis senecio Swain, and in certain of the Lachini). It may be very short, as in Aphis bakeri Cowen, where it reaches only slightly beyond the first coxa, or it may be very long as in Stomaphis, where it is from one and onc-half to two times as long as the body. In leaf-feeding species it is usually short, while in bark-feeding forms it is longer. This is naturally necessary, for those that live on thick bark must have a longer beak in order to reach through to the plant juices.

The thorax consists of three divisions, the last two of which are usually more or less fused together, and considered as one; the two divisions being called, in this paper, the prothorax and the thorax. On the lateral margins of the prothorax there is sometimes a pair of small tubercles. These are not present in all species, however, and they differ considerably in size in the various species. There are three pairs of fairly long and slender legs (except in Phylloxcrinae. where the legs are greatly atrophicd, approaching those of the Coccinae in size). Typically the legs consist of four joints, the coxa, the femora, the tibia, and the tarsus. In some genera the tarsi may be atrophied (Atarsos, Mastapoda). The comparative lengths of the first and second segment of the tarsi are sometimes of generic importance (Lachnini), and the comparative lengths of the hind tarsi and the cornicles are oftentimes of specific importance (Aphis, Pterocomma). A small empodial hair is found between the claws in the Aphidinae. In the Callipterina it is leaf-shaped or spatula-like. In 
the Aphidina and Lachnina it is hair-like, usually being as long as the claws (except in the Pterocommini, in which it is considerably shorter than the claws). The wings are membraneous and hyaline (except in certain Callipterini, Lachnini, and Macrosiphini), and are held roof-like over the body when at rest (except Monellia, Phylloxerinae, Hormaphidina, in which they lie flat on the abdomen). The veins of the fore wings are as follows: the costal and subcostal are almost parallel with the anterior margin; the radial extends from the posterior margin of the stigma to the outer margin of the wing, being either curved or straight; the discoidals, three in number, extend from the subcostal to the posterior margin of the wing. The outer or third discoidal (media, cubitus of some authors) may be simple (Hormaphidina, Pemphigina), absent (Phylloxerinae), once-branched (Schizoneurina), or twice-branched (Aphidinae, except Toxoptera). On the anterior margin of the fore wing is a dusky spot located between the wing margin and the subcostal veins, and between the distal ends of the costal and subcostal veins, known as the stigma or Pterostigma. It is usually trapezoidal in shape, and does not extend to the tip of the wing (except in Longistigma and Mindarus, in which it reaches well beyond the tip of the wing). The hind wings have one longitudinal and either one or two transverse veins. ${ }^{2}$ In the Pemphiginae and Phylloxerinae dorsal wax glands are sometimes present on the thorax, in which case their number, shape, and position are of more or less specific importance.

The abdomen consists of nine more or less similar segments. The coloration of the various segments, especially in species in which the color is variegated, is sometimes of specific importance. In certain species wax glands are present on the abdomen (Phylloxerinae, and particularly the stem mothers of Pemphiginae) and may be of use in making determinations. In the Aphidinae the presence or absence and location of small lateral and dorsal tubercles are often important. The anal segment consists of an anal plate and a cauda. The cauda may not be separated from the abdomen (Pemphiginae, Lachnina), or it may be short and conical (Aphidini), short and globular, being constricted in the middle (Callipterina), or it may be long and ensiform or sickle-shaped (Macrosiphini). The anal plate is usually well rounded, being half-moon-shaped, or it may be emarginate or bilobed (Callipterina). On the sixth (or fifth?) segment is a pair

2 For a full discussion of the venation see Patch, Edith M., Homologies of the wing veins of the Aphididae, Psyllidae, Aleurodidae, and Coccidae, Ann. Entom. Soc. Am., vol. 2, pp. 101-136, June, 1909. 
of short tubular processes, the eornicles (honey tubes, neetaries of some authors). These are quite valuable charaeters, both specific and generie. In the Phylloxerinac and most of the Pemphiginae they are lacking, but in the Aphidinae they are always present, and show a great diversity of form. They may be merely pores (certain Callipterini, Cerosipha cupressi Swain, Lachnus taxifolia Swain), they may be cylindrieal, yet quite short (ecrtain Calliptcrini, Chaitophorini); they may be short and eylindrical or conical (Aphidini); they may be truncate, cone-shape (Lachnini); they may be clavate and long (certain Callipterina, Pterocommini, Macrosiphini); or they may be long and cylindrieal (particularly in Macrosiphum and Myzus).

\section{BIOLOGY}

Considerable variety is exhibited in the habits, life history, and methods of reproduetion, as well as in the structure and body form. Reproduetion is almost entirely parthenogenetie, although eertain specics at eertain times have a sexual reproduction. Fewer speeics have sexual reproduetion in California than in colder elimates, due to the fact that mild weather throughout the winter permits them to live over, and henee the eggs are unnecessary. Many speeies produce generation after generation parthenogenetieally, and are most abundant in the spring and early summer, but gradually disappear toward midsummer, due partially to their predaeeous and parasitic enemies, and partially, undoubtedly, to the heat of the summer. Other species regularly produee sexual forms in the fall, which lay eggs that hatch the next spring. The forms hatehing from the eggs are wingless (exeept in Callipterini) and usually of a different form from the later generations, and are known as the fundatrix or stem mother. The fundatrix is always viviparous. Her progeny eonsists either of all apterous or partly apterous and partly alate viviparous females (fundatrigenia), whieh in turn produee other generations of fundatrigeniae. The last asexual generation in the fall, which gives birth to the sexual forms (sexuales), are known as sexupara, and are usually alate. Oftentimes in the seeond or third and even fourth generation there is a definite migration from one speeies of host plant to another, where the aphids live over the summer (virgogenia), the sexupara returning to the original species of host in the fall to give birth to the sexuales, which lay their eggs there. Aphis malifoliae Fiteh represents an example of this habit, the winter host being apple, the summer plantain. Oftentimes the fall migrants (sexupara) of certain 
species differ considerably in structure from the spring migrants (fundatrigenia). This is particularly noticeable in the Pemphiginac. Many species are confined throughout the season to one species of host, others to one or two or a few species, while still others may live on any of a number of hosts (Aphis senecio Swain, Rhopalosiphum persicae (Sulz.)). All sustenance is derived from the plant juices of the various hosts, but each species is usually confined more or less definately to fecding on some certain part of the plant. Some live entirely upon the leaves, some on the stems of the leaves and small twigs, some on the trunks and larger branches, some on the roots, some on the flower heads and racemes of the host, and still others feed on almost any part of the plant. The greater number of species are free living, but certain of the Aphidinae form pseudogalls (Aphis pomi De Geer, Aphis malifoliae Fitch, Phyllaphis coweni (Cockerell)), while the Pemphiginae and Chermisina form true galls. Nearly all of the Pemphigina spend at least part of the season on various species of Populus, the Schizoncurina on Ulmus, while the Lachnini and Chermisina are practically confined to the conifers. The Aphidinae are found mostly on deciduous trees and herbaceous plants, although some live on conifers (Myzaphis abietinus (Walker), Nectarosiphon morrisoni Swain).

\section{ECONOMIC CONSIDERATIONS}

From an economic standpoint most of the species are of no importance, although there are many that are well known pests of cultivated crops. For example the woolly apple aphis (Eriosoma lanigera) is a world-wide pest of considerable importance to the apple. The green and the rosy apple aphis (Aphis pomi, A. malifoliae) do a large amount of injury in certain localities, and are cxtremely difficult to control. The rose aphis (Macrosiphum rosae) is known the world over, and although living unprotected and easily killed with any of the common contact insecticides, it is recognized by everyone who has grown roses in the dooryard as an extremely troublesome pest. The walnut aphis (Chromaphis juglandicola), the cabbage aphis (Aphis brassicae), the green peach aphis or greenhouse aphis (Rhopalosiphum persicae) are all well known pests. The common contact insecticides are usually efficient for their control. Many species are kept well in check by their predaceous and parasitic enemies, the ladybirds, the syrphid flies, the lacewings, and the braconids. Of the ladybirds, probably the most efficient in California are Coccinella californica 
Mann., IIippodamia convergens Gucrin, and Scymnus nebulosus Leeonte. Of the syrphid flics, those consuming the largest number of aphids and the most abundant in the state $^{3}$ are Catabomba pyrastri Osten-Sacken, Allograpta obliqua Say, Syrphus arcuatus Fallen, S. americanus Wied., S. opinator Will., and Eupeodes volucris OstenSaeken. Chrysopa californica Coq. and Sympherobius angustus Banks are the most important aphid enemies among the laeewings. Among the Braeonidae there are two very common speeies in California, Lysiphlebus testaceipes Cresson and Diaretus rapae Curtiss. Others have been reared by the author and will be mentioned later. The author wishes to thank Dr. L. O. Howard and Mr. A. B. Gahan of the Bureau of Entomology for their kindness in identifying the various hymenopterous parasites of aphids sent to them.

\section{SYNOPSIS}

\section{Family Aphididae Passerini}

Passerini, Gli Afidi, 1860.

The family Aphididae Passerini is divided into three subfamilies (following Alexander Mordwilko), which are: Aphidinae Buckton, Pemphiginac Mordwilko, and Phylloxerinae Dreyfus. Van der Goot considers but two subfamilies: Aphidinae v. d. G. and Chermisinae v. d. G. His subfamily Aphidinae includes both the Aphidinae and Pemphiginae of Mordwilko, while his Chermisinae is the same as Mordwilko's Phylloxerinae. Following is a translation of Van der Goot's descriptions of the two subfamilies:

Subfamily Aphidinae v. d. G.: Body very often without distinct groups of glands for the secretion of wax. Antennae usually six- or seven-jointed [when the terminal process of the sixth segment is longer than the segment he considers it as the seventh segment]. Only in a few cases are the apterous forms with three-segmented antennae. The primary sensoria usually have a distinet "haarkranz" [hairy fringe?]. Cornicles almost always and cauda of ten present. Fore wings with four veins, the cubitus or media I very often divided: hind wings usually with two cross-veins. Vivi-oviparous: the sexuales mostly of the usual form.

Subfamily Chermisinae v. d. G.: Body almost always with distinct groups of glands for the production of wax. Antennae three-segmented, often evidently fivesegmented. Sensoria always without "haarkranz." Cornicles always absent. Fore wings with three veins; hind wings with only one small vein. Always only oviparous: sexuales dwarfish, with or without beak.

${ }^{3}$ Davidson, W. M., Syrphidae in California, Jour. Econ. Ent., vol. 9, pp. 454$457,1916$. 
The latter subfamily has been considered by the author as Phylloxerinae Dreyfus; the former as two subfamilies, Aphidinae Buckton and Pemphiginae Mordwilko. Mordwilko gives the following characters for these two subfamilies :

Subfamily Pemphiginae Mordw.: Antennae of the alate forms five- or sixsegmented, the third bearing a specifically definite number of transverse or archlike sensoria; short, usually not longer than the head and thorax. The apterous parthenogenetic females have four- to six-segmented antennae, but these are sometimes reduced to three or even to two segments. The fore wings of the alate forms have four transverse veins, of which the third or cubital vein [third discoidal] is either simple or once-branched. The hind wings have one or two transverse veins. The cornicles are either entirely absent or very slightly developed, and in the latter case may not be present in all the forms of one species.

Subfamily Aphidinae Buckton: Antennae always six-segmented, except in the stem mother of some species, and in the genus Sipha Passerini. [This genus is not represented in California. In Essigella Del Guercio, Cerosipha Del Guercio, and Trifidaphis Del Guercio, three Californian genera described since the publication of Mordwilko's paper, the antennae are but five-segmented.] The last antennal segment often ends in a long thread-like filament which may be longer than the segment. Antennae with a long filament are mostly from half the length of the body to longer than the body. The antennal filament is characteristic only for this subfamily; some genera of the groups Lachnina and Callipterina have a very short filament, and the antennae are not longer than the head and thorax. The sensoria are small and are shaped like dots, circles, or transverse holes, but never archlike or half-rings. Segment 3 bears the largest number, especially in the alate forms. The cubitus [third discoidal] of the fore wings is usually twice-branched although there are some exceptions, as Toxoptera Koch. Most species have long cylindrical cornicles which are often clavate in the middle. Sometimes they may be greatly reduced or poorly developed, and, as in Lachnina and Callipterina, they may be replaced by cupola-shaped elevations. A cauda is usually present, being conicle, ensiform, or globular, although in Lachnina it is not evident. The sexual forms have beaks, and become quite large.

\section{Subfamily Aphidinae Buckton}

Buckton, Mono, British Aphides, 1883.

This subfamily is divided into three groups, following Carl Börner (Sorauer, Paul, Handbuch der Pflanzenkrankheiten, vol. 3, p. 664, 1913). Börner considers the family Aphididae as a superfamily, and divides it into four families; so this subfamily Aphidinae he considers a family, and the various groups as subfamilies. Below is a translation of his key:

1. Claws with spatula-like or leaf-shaped empodial hairs (fig. 1). Cornicles variously formed, bare. Pubescence of larvae as in Aphidina. The majority of the species live free and monophagous on trees, only seldom on herbaceous. plants, and never migrate collectively Group Callipterina 
2. Antennae with short terminal joint (fig. 3), (except in Pterocommini, but then the cauda is not tail-like). Body ridges with more than six longitudinal rows of hairs. Hairy covering mostly thick. Cauda not lengthened tail-like, anal plate widely rounded (fig. 5). Wax glands either present or lacking. Mostly strongly monophagous forms, at times of remarkable size. Found mostly on tree growths and without change of hosts Group Lachnina

- Terminal joint of antennae always with a long, slender filamentous projection (fig. 4). Body ridges of young larvae at most with only six longitudinal rows of hairs, which may be increased after the first molt. Cauda either short or lengthened tail-like, anal plate widely rounded (fig. 6). Species monophagous or polyphagous, many with a change of host plants. On tree or herbaceous growths Group Aphidina

\section{Group Callipterina Mord (Subfamily Callipterinae Börner)}

Mordwilko, Ann. Imperial Acad. Sci., St. Petersb., 1908.

Börner, in Sorauer, Handbuch der Pflanzenkrankheiten, vol. 3, p. 664, 1913.

According to Börner this group consists of two tribes, the Phyllaphidini and the Callipterini. He divides the Callipterini into two groups, the Callipterini and the Chaitophori. The author has followed lim to a certain extent, but has given each of the last two groups equal rank with the Phyllaphidini, and thus considers this group, Callipterina, as consisting of three tribes. Below is a key to the same:

1. Wax glands with faceted pore fields present. Antennae as in Lachnina (fig. 13). Pubescence delicate Tribe Phyllaphidini

- Wax glands lacking or without faceted pore fields. Pubeseence often very remarkable. Terminal joint of the antennae often lengthened into a bristle (fig. 30) 2

2. Anal plate more or less emarginate or bilobed (fig. 7), except in Euceraphis Koch Tribe Callipterini

- Anal plate widely, truncate or rounded (fig. 8) ..................Tribe Chaitophorini

\section{Tribe Phillaphidini Börner}

Börner, in Sorauer, Handbuch der Pflanzenkrankheiten, vol. 3, p. 664, 1913.

This tribe Phyllaphidini consists of but one genus, Phyllaphis Kocl, which is represented in California by three species.

\section{Genus Phyllaphis Koch}

Koch, Die Pflanzenläuse, p. 248, 1857. Type Aphis fagi Linn.

\section{Key to CaLifornia SPECIES}

1. Alate viviparous females unknown. Wing venation of alate males similar to that of Eriosoma spp. (fig. 17). Forming pseudogalls on edges of leaves or living free in masses of white flocculence on leaves of Quercus spp. 
- Alate riviparous females common. Venation normal, the third discoidal being twice-branched. Not on Quercus spp.

2. Antennae short, stout, with oval transverse sensoria (fig. 13). Forming galls on Arctostaphylos spp. (and Arbutus spp.) coweni (Ckll.)

- Antennae longer and narrower with circular sensoria (figs. 9, 14-17). Living under thick masses of white floceulence on Fagus spp. fagi (Linn.)

\section{Phyllaphis coweni (Ckll.) \\ Figure 13}

Cockerell, Can. Ent., vol. 37, pp. 391-392. 1905. Pemphigus (orig. desc.). Davidson, Jour. Econ. Ent., vol. 4, pp. 559, 1911. Cryptosiphum tahoense n.sp. (desc.).

Davidson, Jour. Econ. Ent., vol. 5, p. 404, 1912 (list).

Essig, Pom. Jour. Ent. Zool., vol. 7, pp. 187-195, 1915 (dese.).

Records.-Arctostaphylos manzanita; Oakville, Napa County, February, 1913 (E. L. Branzigan); Mount Diablo, Contra Costa County (Davidson); Jasper Ridge, Santa Clara County, October, 1914 (E. A. Cornwell); Pine Hills, San Diego County, June, 1916.4 A. pumella, A. tomentosa, Lake Tahoe, August, 1911 (Davidson): A. glauca, Alpine, San Diego County, June, 1916.

This species is found more or less abundantly throughout the state wherever its host plants occur. Essig (1915) states it is found throughout the Rocky, Sierra Nevada, and Coast Range mountains, being more abundant in the central and northern parts of the state. The author has found it to be extremely abundant in the Cuyamaca and Laguna mountains in the extreme southern part of the state. The insects can be found at any time of the year in the galls on manzanita although most abundantly in the early fall. Collections by the author in June showed that the stem mothers and young virgogeniae only were present. A few weeks later the alate females were abundant, while in August the sexuales begin to appear. However, the alate viviparous females have been found in October and in February. This species forms galls on the leaves, and flower and fruit stalks of its host. Usually there is but one gall to a leaf, although sometimes four or five may be found. When first formed these galls are concolorous with the leaves; but as they become older they turn more and more reddish in color, until when mature they are a very bright red.

\section{Phyllaphis fagi (Linn.)}

Figures 9 to 12

Linnaeus, Syst. Nat., vol. 2, p. 735, 1735. Aphis (orig. dese.).

Davidson, Jour. Econ. Ent., vol. 3, p. 376, 1910 (list).

Records.-Fagus sp., Palo Alto, 1910 (Davidson); Fagus sylvatica, Stanford University, April to May, 1915.

\footnotetext{
4 Records in which no collector's name is mentioned refer to collections made by the author.
} 
This species has been taken only in the vicinity of Stanford University, where it infests copper beach (Fagus sylvatica). It may be easily recognized by the masses of whitish floceulence on the under side of the leaves. Each mass contains one individual, which is entirely lidden by it. In looking up the literature of this spccies the author found that there has been no description of it published in America, so below is included a brief description of specimens taken near Stanford University on April 28 and May 29, 1915.

Alate viviparous female.-Prevailing color dark green, covered with a whitish floceulence. This flocculence consists of wax threads as much as $3 \mathrm{~mm}$. long. Head dusky, with frontal margin black. Eyes red. Antennae dusky, except II and basal onc-third of III, which are pale. Beak pale with apex and joints dusky. Thorax dusky green with lobes black. Abdomen dark green with a row of black spots on each margin and about seven black transverse dorsal bands. Cornicles black. Cauda and anal plate concolorous with abdomen with distal margins slightly darker. First and second femora pale with apices only dusky; third femora dusky throughout. First tibiae pale with apex dusky; second and third dusky throughout. Tarsi black. Wings hyaline, stigma gray.

Head twice as wide as long, furnished with many small wax glands. Antennae reaching to the cornicles or to the base of the cauda, sct on small tubercles (fig. 12). III is the longest segment, followed by IV, V, and VI. VI spur is mercly a thumb-like projection (fig. 16). The usual primary and accessory sensoria are present on V and VI. Secondary sensoria are found only on III (fig. 9). These are fairly large, almost circular, and placed in a single row along the segment. They number from four to seven, five being the average. The beak is short, reaching but slightly beyond the first coxae. The wings are normal, with a twice-branched third discoidal. The cornicles are merely small pores. The cauda is short and knobbed, the anal plate emarginate or bilobed (fig. 11).

Measurements: Body length 2.0 to $2.4 \mathrm{~mm}$., width 0.8 to $1.04 \mathrm{~mm}$., antennae total 1.55 to $2.06 \mathrm{~mm}$., III 0.591 to $0.77 \mathrm{~mm}$., IV 0.34 to 0.47 mm., V 0.27 to $0.39 \mathrm{~mm}$., VI 0.19 to $0.25 \mathrm{~mm}$., cornicles (diameter) $0.05 \mathrm{~mm}$.

Apterous viviparous female.-Prevailing color under floceulence pale yellowish green. Light brown markings as follows: two rows of four spots each across the prothorax, one large spot on each margin and one on the dorsum of the thorax, four spots on each abdominal 
segment, two dorsal and two marginal. Antennae pale except VI, apical two-thirds of $\mathrm{V}$, and apical one-third of IV. Legs pale with light brown spots at joints; tarsi black. Cauda small and conicle, cornicles not evident.

Measurements : Body length 2.9 to $3.0 \mathrm{~mm}$., width 0.96 to $1.2 \mathrm{~mm}$., antennae total $1.26 \mathrm{~mm}$., III $0.36 \mathrm{~mm}$., IV $0.32 \mathrm{~mm} ., \mathrm{V} 0.204 \mathrm{~mm}$, VI $0.205 \mathrm{~mm}$.

\section{Phyllaphis quercicola Baker}

Figures 14 to 20

Clarke, Can. Ent., vol. 35, p. 248, 1903. Schizoneura querci (Fitch) (list). Davidson, Jour. Econ. Ent., vol. 3, p. 374, 1910. S. querci (Fitch) (list). Davidson, Pom. Jour. Ent., vol. 3, p. 398, 1911. S. querci (Fitch) (list). Davis, Ent. News, vol. 22, p. 241, 1911. Phyllaphis querci (Fitch) (biblig.) Davidson, Jour. Econ. Ent., vol. 7, p. 127, 1914. P. querci (Fitch) (note). Gillette, Ent. News, vol. 25, p. 274, 1914. Phyllaphis sp. (list).

Baker, Ent. News, vol. 27, p. 362, 1916. P. quercicola n.n. for $P$. querci (Fitch) of Davis.

Records.-Quercus agrifolia; Placer, Contra Costa, Santa Clara counties (Davidson, Clarke) ; Stanford University, April, 1915; Berkeley, September, 1915 ; Wynola, San Diego County, June, 1916; Charter Oak, Los Angeles County, November, 1916. Quercus lobata, Stanford University (Davidson); Q. wistizenii, Placer County (Davidson); Q. dumosa, San Diego, August, 1915; Quercus sp., Spreckels, Monterey County, 1913 (Gillette).

This is a very common species of woolly aphis on the oaks, particularly the live oak, through southern and central California. According to Davidson.(1914) the stem mothers oceur in pseudogalls on the edges of the leaves. The second generation lice, when mature, leave these galls to live on the upper and lower surfaces of the leaves, unprotected except for their woolly covering. The sexes, apterous oviparous females and alate males, occur late in the fall. The viviparous generations are all apterous. The writer has observed the stem mothers as late as August in San Diego County, while he has found the viviparous females on the under side of the leaves as early as mid-June in Berkeley.

The identity of this species has never been definitely established. It was thought to be the species described by Fitch (Rept. Ins. N. Y., vol. 5, p. 804, 1859) as Eriosoma querci, but in 1916 Baker pointed out the identity of Eriosoma querci Fitch, proving it to be identical with a species of Anoecia found on Cormus and formerly considered to be A. corni Fab. Baker's decision is that the Quercus-Cornus species of the eastern United States is Anoecia querci (Fitch) and 
is distinct from our western one. In 1911 Davis described a spceies of woolly aphis from oak under the name of Phyllaphis querci (Fitch) stating that it is the same one as listed by Davidson. Baker proposes the name Phyllaphis quercicola for this specics described by Davis. Consequently it is so listed in this paper. This species is not a typical Phyllaphis, but it fits that genus better than any other so is placed there provisionally. The figures (14-20) are from a specimen of alate male in the Davidson collection in Stanford University.

\section{Tribe Callipterini Wilson}

Wilson, Can. Ent., vol. 42, p. 253, 1910.

The genera included in this tribe differ somewhat as considered by various entomologists. Since Wilson has worked out the synonomy of the various gencra very well he is followed in prefercnce to some of the Europcan authors, although there are some points in which he is mistaken. For instance, he places Pterocallis Passerini, Callipteroides Mordwilko, Tuberculatus Mordwilko, Subcallipterus Mordwilko, and Therioaphis Walker as synonyms of Myzocallis Passerini. In regard to this, he states, "In 1894 Mordwilko used A. coryli Goetze as the type of his genus Callipteroides, but as this species..." Hc is mistaken in this, for in the paper referred to, Mordwilko used A. coryli Goetzc as the type of the genus Myzocallis Passerini, and in 1908 he gave as the type of Callipteroides, Callipterus nigritarsus Heyden (betulae Koch). If nigritarsus Heyden is a synonym of betulae Koch, as Mordwilko indicates, then Callipteroides is a synonym of Euceraphis Walker, for C. betulae Koch certainly falls into this genus, as described by Wilson himself. The key to the California genera below is adapted from Wilson's key (Can. Ent., vol. 42, pp. 253-254, 1910).

\section{Key to Californta Genera of Callipterini}

1. Antennal tubereles prominent (fig. 21 ); antennae always exceedingly long.... 2

- Antennal tubereles wanting or very small (fig. 22); antennae variable, sometimes shorter than the body.

2. Cornicles very long and large (figs. 23-24)

- Cornicles very short and more or less constricted in the middle ........................ 5

- Cornicles little more than pores (fig. 25). Wings held horizontal at rest.

Monellia Oestlund

3. Cornicles distinct, usually being longer than broad in the middle (fig. 26) 6

- Cornicles little more than pores, and broader than long (fig. 25). Wings held horizontal at rest Monellia Oestlund 
4. Cornicles one-fourth the length of the body or more, swollen in the middle (fig. 24) Drepanosiphum Koch

- Cornicles large and nearly one-fourth the length of the body, swollen at the base and tapering toward the middle (fig. 23) .....Drepanaphis Del Guercio

5. Inner side of antennal tubercles about one-half the length of the inner side of the first antennal joint (fig. 29)

Euceraphis Walker

- Inner side of antennal tubereles more than one-half the length of the inner side of the first antennal segment (figs. 27-28)

Calaphis Walsh

6. Antennae longer than body, except in Callipterinella, with VI spur not much shorter than VI base (fig. 31)

- Antennae shorter than the body, with VI spur very short, often being little more than a nail-like process (fig. 34)

7. VI spur considerably longer than VI base, being one and one-half to two times as long. Anal plate emarginate but not deeply bilobed.

Callipterinella Van der Goot

- VI spur about equal to or shorter than VI base. Anal plate deeply bilobed 8

8. VI spur and VI base subequal (fig. 31). Cornicles twice as long as broad in the middle and constricted in the middle (figs. 26, 32).

Myzocallis Passerini

- VI spur shorter than VI base (fig. 30). Cornicles much broadened at base (fig. 33)

Eucallipterus Schouteden

9. VI spur less than one-half the length of VI base (fig. 34). Cornicles not longer than broad at the base, and constricted in the middle (fig. 35).

Chromaphis Walker

- VI spur at least one-half as long at VI base (figs. 63, 66). Cornicles short, about as long as broad and placed on a broad base

Callipterus Koch

\section{Genus Drepanosiphum Koch}

Koch, Die Pflanzenläuse, p. 201, 1855. Type Aphis palantanoides Sehrank.

\section{Drepanosiphum platanoides (Schrank)}

Figures 21, 24, 36

Schrank, Fauna Boic., vol. 2, p. 1206, 1801. Aphis (orig. dese.).

Wilson, Jour. Econ. Ent., vol. 2, p. 349, 1909 (dese. ala. vivi., ala. ovi. females).

Davidson, Jour. Econ. Ent., vol. 3, p. 377, 1910 (list).

Essig, Pom. Jour. Ent., vol. 4, p. 759, 1912 (list).

Records.-Acer macrophyllum, A. negundo; Berkeley, 1915 (Essig); Stanford University, October, 1914, April, 1915; A. pseudoplatanus, Stanford University, November, 1914 (Morrison); A. saccharum, Berkeley, June, 1915; Platanus racemosus, Stanford University (Davidson); Acer sp., San Lorenzo, 1908 (Wilson).

This is a very common species in the San Francisco Bay region on various species of maples, and on box elder and western sycamore. In April the alate and apterous viviparous females are abundant, remaining so throughout the summer and early fall. In the later fall (October and November) the sexes appear. Just where the eggs 
are laid the author is unable to say. A curious fact is that the oviparous females are alate as well as apterous. The author has never seen the alate forms, but Wilson (1908) describes them.

\section{Genus Drepanaphis Del Guereio}

Del Guereio, Rivista di patologia vegetable, vol. 4, pp. 49-53, 1909. Type Siphonophora acerifolii Thomas.

\section{Drepanaphis acerifolii (Thomas)}

Figures 23, 37

Thomas, Illinois Lab. Nat. Hist., Bull. 2, p. 4, 1878. Siphonophora (orig. dese.).

Clarke, Can. Ent., vol. 35, p. 249, 1903. Drepanosiphum (list).

Sanborn, Kan. Univ. Sci., Bull. 3, p. 45, 1904. Drepanosiphum (dese. ala.). Davidson, Jour. Econ. Ent., vol. 2, p. 303, 1909. Drepanosiphum (list).

Davidson, Jour. Econ. Ent., vol. 3, p. 380, 1910. Macrosiphum (list).

Essig, Pom. Jour. Ent., vol. 4, p. 760, 1912 (list).

Essig, Mon. Bull., Cal. Comm. Hort., vol. 3, p. 85, 1914 (list).

Essig, Mon. Bull., Cal. Comm. Hort., vol. 3, p. 445, 1914 (list).

Records.-Acer sp.: Stanford University (Davidson); Sacramento (Essig); Hanford, Fresno County (B. V. Sharp) ; A. macrophyllum, A. saccharinum, Berkeley, July to October, 1915; Riverside, October, 1916; A. dasycarpum, A. platanoides, Berkeley, 1915 (Essig); Quercus sp. (live oak), Berkeley (Clarke) (?).

This is as common a species on maple in the San Francisco Bay region as the preceding one. It has also been taken in the Sacramento and the San Joaquin valleys, and in southern California. It is a species easily recognized by its dark markings and the dorsal tubercles on the first and second abdominal segments.

\section{Genus Calaphis Walsh}

Figure 28

Walsh, Proc. Ent. Soc. Phila., vol. 1, p. 301, 1863. Type C. betulella n.sp.

\section{Calaphis betulaecolens (Fitch)}

F'igures $27-38$

Fiteh, Cat. Homop. N. Y., p. 66, 1851. Aphis (orig. dese.).

Clarke, Can. Ent., vol. 35, p. 249, 1903. Callipterus (list).

Davidson, Jour. Econ. Ent., vol. 2, p. 301, 1909. Callipterus (list).

Davidson, Jour. Econ. Ent., vol. 3, p. 376, 1910. Calliptcrus (list).

Essig, Pom. Jour. Ent., vol. 3, p. 556, 1911 (syn.).

Davidson, Jour. Econ. Ent., vol. 5, p. 404, 1912 (dese. sexes).

Essig, Pom. Jour. Ent., vol. 4, p. 760, 1912 (list).

Essig, Mon. Bull., Cal. Comm. Hort., vol. 3, p. 445, 1914 (list).

Baker, Proc. Ent. Soc., Washington, vol. 18, p. 186, 1916 (dese.).

Records.-Betula sp., Alameda, Contra Costa, Santa Clara counties (Clarke, Davidson, Essig, Morrison, and the author). 
This is a common speeies of aphid on birch (Betula spp.) in the San Francisco Bay region. In the early part of March the eggs begin to hatch. In 1915 at Stanford University eggs began to hatch on March 8, the process continuing for several days. A month later both alate and apterous females were quite abundant; the alate females being undoubtedly the stem mothers, the apterae belonging to the second generation. Viviparous generations appeared throughout the summer. During August the sexes, alate males and apterous oviparous females, occurred. In 1914 the sexes and sexupara were noticed on August 28. Egg laying occurred shortly afterward, the eggrs being laid in the crotches of the twigs and under the curled edges of the bark. Bireh is the only reeorded host plant.

\section{Genus Euceraphis Walker}

Walker, The Zoologist, p. 2001, 1870. Type Aphis betulae Koch.

Key to California Species

1. Body light green; third joint of antennae with about 13-18 sensoria on basal one-half (fig. 39)

gillettei Dvdn.

- Body yellow with dark markings on head and thorax, and often with as many as eight black transverse stripes on the abdomen (the number varies between none and eight); third antennal segment with 19-25 sensoria (fig. 40) betulae (Koch)

\section{Euceraphis betulae (Koeh)}

Figures 29, 40

Koch, Die Pflanzenläuse, p. 217, 1855. Callipterus (orig. desc.).

Davidson, Jour. Econ. Ent., vol. 5, p. 405, 1913 (dese. ovi. female).

Davidson, Jour. Econ. Ent., vol. 7, p. 129, 1914 (desc. stem mother).

Records.-Betula sp.: Oakland (Davidson); Palo Alto, March to April, 1915.

Davidson lists this speeies, deseribing the stem mother and oviparous female from the San F'ranciseo Bay region. The author found it in Palo Alto during Mareh and April, 1915, on Betula alba. Aceording to Davidson the stem mothers hateh from the eggs about the middle of February, feeding on the stems until the leaves open in Mareh. The viviparous generations oecur during the summer. He took the oviparous females in November. His deseription of the stem mother gives three dusky transverse bands on the abdomen. The author has found this to be variable, the number ranging from none to eight. 


\title{
8. Euceraphis gillettei Davidson
}

\author{
Figurè 39
}

Clarke, Can. Ent., vol. 35, p. 248, 1903. Lachnus alnifoliae Fitch (list). Davidson, Jour. Econ. Ent., vol. 2, p. 300, 1909. L. alnifoliae Fitch (list). Davidson, Jour. Econ. Ent., vol. 3, p. 375, 1910. L. alnifoliae Fitch (list). Essig, Pom. Jour. Ent., vol. 4, p. 773, 1912. Lachnus alnifoliae Fitch (list).

Essig, Pom. Jour. Ent., vol. 4, p. 773, 1912. Lahnus alnifoliae Fiteh (note). Davidson, Jour. Econ. Ent., vol. 8, p. 421, 1915 (orig. dese.).

Records.-Alnus rhombifolia; Berkeley (Clarke), Stanford University, San Jose, Walnut Creek (Davidson), Stanford University, March, 1915.

This specics was reported from alder by Clarke and Davidson as Lachnus alnifoliae Fitch. Essig, in his Host plant list of California Aphididae, lists Callipterus alnifoliae (Fitch) on Alnus rhombifolia, but later states that this citation should be Lachnus alnifoliae Fitch. Therefore he referred to this new species of Davidson. The author took both apterous and alate viviparous females of this species on Alnus rhombifolia, along the banks of the San Francisquito Creek, near Stanford University, on March 19, 1915. During the spring it was quite common there.

\section{Genus Eucallipterus Schouteden}

Schouteden, Mem. Soc. Ent. Belg., vol. 12, 1906. Type Aphis tiliae Linn. Kex to California Species

1. Wings hyaline; III pale except at the apex, with 5-7 sensoria on the basal one-fifth (fig. 41) flava (Dvdn.)

2. Wings with veins clouded; III with apical one-fifth and basal one-half dusky, and with about 13-15 sensoria on the basal one-half (fig. 42).

tiliae (Linn.)

\section{Eucallipterus flava (Davidson)}

Figure 41

Davidson, Jour. Econ. Ent., vol. 5, p. 406, 1912. Euceraphis (orig. desc.). Davidson, Jour. Econ. Ent., vol. 8, p. 423, 1915 (desc. sexes).

Records.-Alnus rhombifolia; San Jose, Walnut Creek (Davidson), Stanford University (Morrison).

This is an uncommon species in the San Francisco Bay region on Alnus rhombifolia, occurring on the under side of the leaves. The author has never collected it, but has specimens from Davidson, taken 
in April, 1913, near Walnut Creek, Contra Costa County. According to Davidson the sexes appear in October, egg laying occurring during the first part of November. The eggs are laid at the axils of the new buds and on the twigs or canes. These hatch the following spring, the stem mothers being found in the early part of April.

\section{Eucallipterus tiliae (Linn.)}

Figures 7, 30, 33, 42, 50

Linnaeus, Syst. Nat., vol. 2, p. 734, 1735. Aphis (orig. desc.).

Davis, Ann. Ent. Soc. Amer., vol. 2, p. 33, 1909. Callipterus (desc., biblio.). Davidson, Jour. Econ. Ent., vol. 2, p. 302, 1909. Callipterus (iist).

Davidson, Jour. Econ. Ent., vol. 3, p. 372, 1910. Callipterus (list).

Davidson, Jour. Econ. Ent., vol. 3, p. 376, 1910. Callipterus (list).

Essig, Pom. Jour. Ent., vol. 4, p. 763, 1912 (list).

Records.-Tilia americana, Tilia europea; Stanford University (Davidson), Berkeley, August, 1914 (Essig) ; Stanford University, April to May, 1915; Berkeley, June, 1915.

In the San Francisco Bay region this very pretty aphid is quite common on basswood or linden. The author has taken it throughout April, May, and June. Essig found it abundantly in August. It is very easily recognized when found at rest on the under side of the leaves of its host by the two black lines extending from the front of the head along the margins of the thorax and joining with the costal margins of the wings. It so appears that these lines are continuous from the front to the tip of the wings.

\section{Genus Myzocallis Passerini}

Passerini, Gli Afidi, p. 28, 1860. Type Aphis coryli Goetze.

\section{Key to California Species}

1. Wings hyaline

- Wings not hyaline, with portions shaded (fig. 262) ............................................... 2

2. Costal cell of wings hyaline (figs. 266, 267) ............................................................. 3

- Costal cell of forewings dusky or shaded (figs. 263, 264) ................................. 5

3. First discoidal vein dusky, otherwise the wing is hyaline. VI with spur shorter than base. Apical one-half of III dusky (fig. 47). Cornicles pale. Found on Alnus spp. alnifoliae (Fitch)

- Wings not as above (figs. 266, 267). VI with spur either equal to or longer than base. III with less than apical one-half dusky 4

4. Cornicles pale. Abdomen without dusky dorsal markings. On Quercus spp. maureri Swain

- Cornicles dusky (fig. 62). Abdomen with dusky dorsal markings. On Castanea spp. and Quercus spp. davidsont Swain 
5. Cornicles pale. Wings with greater portion cloudy (fig. 262). Antennae witl only tips of III to VI dusky. On Quercus spp.................discolor (Monell)

- Cornicles pale with apex dusky. Wings with dusky band along costal inargin (fig. 263). Antennae with tips of III and IV, apical one-half of $\mathrm{V}$, and all of VI and spur dusky. On Quercus spp. bellus (Walsh)

6. Abdomen with four spine-like tubercles on the dorsum of the first segnient. VI with base and spur subequal, III being considerably longer than botls. Cornicles pale, small, and inconspicuous. On Ulmus spp.

ulmifolii (Monell)

- Abdomen without tubercles as above 7

7. III shorter than VI (base and spur). On Quercus spp.......punctatus (Monell)

- III not shorter than VI (base and spur) .................................................... 8

8. VI with spur about twice as long as base (fig. 44). Cornicles pale. On Corylus spp. coryli (Goetze)

- VI with spur at most only slightly longer than base

9. III with apex only dusky (figs. 57, 58). Cauda pale 9

9. III ivith apex oniy ausky (figs. 57, 58). Cauda pale ......................... 10 dusky throughout (fig. 208) or with apex and a band near the base dusky (fig. 48). Cauda dusky 11

10. Cornicles pale. Antennae longer than body. Sensoria on III (two or three in number) small and located close to the base of the segment (fig. 57). On Pasania spp. pasaniae Dvin.

- Cornicles dusky, at least apical one-half. Antennae not longer than the body. Sensoria on III (five or more in number) fairly large and on basal twothirds of segment (fig. 58). On Quercus spp. quercus (Kalt.)

11. Abdomen with dusky dorsal markings. III dusky throughout (fig. 268). On Arundo spp.

arundinariae Essig

- Abdomen without dusky dorsal markings. III with apex and band near base dusky (fig. 48). On Arundo spp. arundicolens (Clarke)

\section{Myzocallis alnifoliae (Fitch)}

\section{Figure 47}

Fitch, Cat. Homop. N. Y., p. 67, 1851. Lachnus (orig. desc.).

Essig, Pom. Jour. Ent., vol. 4, p. 764 (762), 1912. M. alni (Fabr.) (desc. viviparae).

Baker, Jour. Econ. Ent., vol. 10, p. 421, 1917 (note).

Records.-Alnus rhombifolia; Santa Paula (Essig).

Only once has this species been taken in California, by Essig in August, 1911, near Santa Paula, Ventura County. At that time it was very abundant on the under side of the leaves, causing a large amount of sooty mold.

\section{Myzocallis arundicolens (Clarke)}

Figures 22, 48, 51, 52

Clarke, Can. Ent., vol. 35, p. 249, 1903. Callipterus (orig. dese.).

Davidson, Jour. Econ. Ent., vol. 2, p. 301, 1909. Callipterus (list).

Davidson, Jour. Econ. Ent., vol. 3, p. 376, 1910. Callipterus (list).

Essig, Pom. Jour. Ent., vol. 4, p. 762, 1912 (list, in part).

Essig, Univ. Calif. Publ. Entom., vol. 1, p. 305, 1917 (dese.). 
Records.-Bamboo, Berkeley (Clarke, Essig); Arundinaria japonica, Berkeley, June, 1915.

In the San Francisco Bay region and in the Sacramento Valley this species is often found infesting the upper and lower surfaces of the leaves of various bamboos, particularly species of Arundinaria, Bambusa, and Phyllostachys, and the giant reed (Arundo donax). Reports list it from Alameda, Sacramento, San Francisco, and Santa Clara counties. The species described by Davidson (1914) as Eucallipterus arundicolens (Clarke) and reported from southern California by Essig (1912) proves to be distinct, and was described by Essig (1917) as $M$. arundinariae. The following brief description. is from a collection madc by the author on June 9, 1915, from Arundinaria japonica on the campus of the University of California in Berkeley.

Alate viviparous female.-(Second generation?) Prevailing color, pale yellow. Head twice as wide as long, pale yellow, with prominent red eyes. Antennal tubercles absent. Antennae longer than body; formula III, IV, V, VI spur, VI base, I, II. Segments all pale except the margins of I and II, the apices of III, IV, V, and a band about one-sixth the length of III a short distance from the base of III (fig. 48), which are black, and VI which is slightly dusky. There are five or six transverse secondary sensoria on III, located in the dark band. The usual primary sensoria are present on V and VI, and the usual accessor sensoria on VI. Beak pale and short, reaching only to the middle of the first coxac. Thorax and abdomen normal, pale ycllow, without tubercles or dusky markings. Cornicles (fig. 51) pale, short, broader at base than at apex. Cauda short, constricted in the middle, with distal end black. Anal plate (fig. 52) pale, deeply bilobed. Wings normal, hyaline, with the first and second discoidal veins and the base of the stigmal vein darker than the others. There is a perceptible shading at the tip of each vein.

Measurements: Body length 1.326 to $2.023 \mathrm{~mm}$. (av. $1.644 \mathrm{~mm}$.), width of thorax 0.51 to $0.68 \mathrm{~mm}$. (av. $0.612 \mathrm{~mm}$.), antennae total 2.839 to $3.077 \mathrm{~mm}$. (av. $2.9299 \mathrm{~mm}$.), III 0.8925 to $0.986 \mathrm{~mm}$. (av. $0.9324 \mathrm{~mm}$.), IV 0.578 to $0.663 \mathrm{~mm}$. (av. $0.6423 \mathrm{~mm}$.), V 0.527 to $0.561 \mathrm{~mm}$. (av. $0.5403 \mathrm{~mm}$.), VI base 0.306 to $0.323 \mathrm{~mm}$. (av. 0.3103 mm.), VI spur 0.34 to $0.425 \mathrm{~mm}$. (av. $0.3691 \mathrm{~mm}$.), cornicle 0.595 to $0.765 \mathrm{~mm}$. (av. $0.7002 \mathrm{~mm}$.), cauda $0.153 \mathrm{~mm}$., wing length 2.25 to $3.96 \mathrm{~mm}$. (av. $2.9097 \mathrm{~mm}$.), widtlı 1.02 to $1.122 \mathrm{~mm}$. (av. $1.071 \mathrm{~mm}$.), expansion 6.341 to $6.97 \mathrm{~mm}$. (av. $6.6555 \mathrm{~mm}$.). 


\section{Myzocallis arundinariae Essig}

Figure 268

Essig, Pom. Jour. Ent., vol. 4, p. 762, 1912. M. arundicolens (Clarke) (in part).

Davidson, Jour. Econ. Ent., vol. 7, p. 129, 1914. Eucallipterus arundicolens (Clarke) (dese. viviparae).

Essig, Univ. Calif. Publ. Entom., vol. 1, pp. 302-305, 1917 (orig. dese.).

Records.-Arundo sp., San Francisco Bay region (Davidson); Arundinaria japonica, Santa Barbara (Essig); Riverside, January to May, 1917; Arundo donax, San Diego, April to June, 1916.

This is the commonest bamboo-infesting species in southern California and parts of eentral California. For some time it was considered as $M$. arundicolens (Clarke) but this past year Essig pointed out the differenees, deseribing it as a new speeies.

\section{Myzocallis bellus (Walsh)}

Figures 45,46

Walsh, Proc. Ent. Soc. Phila., vol. 1, p. 299, 1862. Aphis (orig. dese.).

Essig, Pom. Jour. Ent. Zool., vol. 7, pp. 195-200, 1915. Callipterus (dese.).

Records.-Quercus agrifolia, Alhambra, Los Angeles County (Essig); Ventura (Essig).

Two eolleetions have been made of this speeies in California, both in southem California, in January, 1912, in Alhambra, and in May, 1913, in Ventura. Both of these eonsisted only of the alate females (stem mothers), and were deseribed by Essig.

\section{Myzocallis davidsoni Swain}

Figures 60, 61, 62, 267

Clarke, Can. Ent., vol. 35, p. 249, 1903. Callipterus castaneae Fitch (list). Davidson, Jour. Econ. Ent., vol. 3, p. 376, 1910. Callipterus castaneae (Buekton) (list).

Davidson, Jour. Econ. Ent., rol. 5, p. 405, 1912. Calaphis castaneae (Buckton) (dese. sexuales).

Essig, Pom. Jour. Ent., vol. 4, p. 760, 1912. Calaphis castaneae (Fiteh) (list).

Swain, Trans. Am. Ent. Soc., vol. 44, p. 1, 1918 (orig. desc.).

Records.-Castanea sp., Berkeley (Clarke, Essig, Swain), Stanford University (Daridson, Swain), San Jose (Davidson); Quercus pedunculata, Berkeley (Swain, Essig).

This speeies was first reported in California by Clarke as Callipterus castancae Fiteh and later by Davidson as Callipterus castaneae 
Buckton. Recently the author described the species from specimens taken in Berkeley on chestnut and oak. It cannot be the Callipterus castancae of Fitch, because the latter is really a Calaphis. It may be the same species that Buckton had when describing his Callipterus castaneae, in which case his name would be dropped as Fitch's species has priority, and is replaced by the author's name, $M$. davidsoni. It is more or less common throughout the San Francisco Bay region on chestnuts, and in one case on two specimens of Quercus pedunculata in Berkeley. The stem mothers appear during the late spring, in April and May. Viviparous generations are produced throughout the summer, the sexuales occurring in October and November.

\section{Myzocallis coryli (Goetze)}

Figures $43,44,53,54$

Goetze, Ent. Beiträge, vol. 2, p. 311, 1778. Aphis (orig desc.).

Clarke, Can. Ent., vol. 35, p. 249, 1903. Callipterus (list).

Davis, Jour. Econ. Ent., vol. 3, p. 417, 1910. Callipterus (desc.).

Essig, Pom. Jour. Ent., vol. 4, p. 762, 1912 (list).

Records.-Corylus sp., Berkeley (Clarke); Corylus rostrata, San Francisco Bay region (Davidson); C. rostrata var. californica, C. maxima, Berkeley, August, 1914, June to July, 1915.

In the San Francisco Bay region this species is quite common on alder. During the seasons of 1914 and 1915 the author observed it to be very abundant on species of alder on the University of California campus. He has never found it in the south, however.

\section{Myzocallis discolor (Monell)}

Figures 262, 263

Monell, U. S. Geol. Geog. Surv., Bull. 5, p. 30, 1879. Callipterus (orig. dese.).

Williams, Univ. Neb. Studies, vol. 10, p. 115, 1910. Callipterus (dese.). Record.-Quercus macrocarpa, Sacramento, October, 1916 (Davidson).

The author received specimens of this species from Davidson, which werc found in October, 1916, on Quercus macrocarpa in Sacramento. The determination was made by Davis. Below are a few descriptive notes to supplement Williams' description listed above.

Alate viviparous female.-Antennae about as long as body, III the longest segment, followed by IV, VI, and V. VI spur is slightly longer than the base. The antennae are rather slender as compared 
with other species of this genus. Primary sensoria are present on $\mathrm{V}$ and VI as usual, and accessory sensoria on VI. There are about seven sceondary sensoria on III (fig. 262), which are more or less oval to circular, and located on the basal two-thirds of the segment. The cornicles, cauda, and anal plate are typical of the genus.

Measurements: Body length 1.28 to $1.37 \mathrm{~mm}$., antenna total 1.41 mm., III 0.459 mm., IV 0.306 mm., V 0.264 mm., VI $0.289 \mathrm{~mm}$. (base $0.119 \mathrm{~mm}$., spur $0.17 \mathrm{~mm}$. ), cornicles $0.68 \mathrm{~mm}$., wing length 2.074 to $2.414 \mathrm{~mm}$., width 0.68 to $0.833 \mathrm{~mm}$. The two dusky transverse bands across the fore wings (fig. 263) constitute the most distinguishing character. The branching of the third discoidal is quite variable.

\section{Myzocallis punctatus (Monell)}

Monell, U. S. Geol. Geog. Surv., Bull. 5, p. 31, 1879. Callipterus (orig. desc.).

Clarke, Can. Ent., vol. 35, p. 249, 1903. Callipterus hyalinus Monell (list).

Essig, Pom. Jour. Ent., vol. 4, p. 762, 1912. M. hyalinus (Monell) (list). Record.-Quercus imbricata, Berkeley (Clarke).

This is a doubtful species, reported only by Clarke from Quercus imbricata in Berkeley. It is the author's opinion that this is the same species listed by Davidson as M. quercus (Kalt.).

\section{Myzocallis maureri Swain}

Figures 55, 56, 266

Swain, Trans. Am. Ent. Soc., vol. 44, p. 4, 1918 (orig. desc.).

Records.-Quercus agrifolia, Berkeley (Swain); Quercus kelloggii, Julian, San Diego County (Swain).

This species has been taken in Berkeley and in the Cuyamaca Mountains of San Diego County by the author. Essig has also taken it in Berkeley. It is never abundant, but the author has observed it several times and in several places in the localities mentioned.

\section{Myzocallis pasaniae Dvdn.}

Figure 57

Davidson, Jour. Econ. Ent., vol. 8, p. 424, 1915 (orig. dese.).

Records.-Pasania densiflora, Stevens Creek Canyon, Santa Clara County (Davidson), Berkeley, February, 1915 (Essig).

This is a species found occasionally on tanbark oak in the San Francisco Bay region. The author has never taken it but has specimens from Davidson and Essig. 


\section{Myzocallis quercus (Kalt.)}

Figures $31,32,58$

Kaltenbach, Monog. d. Pflanzenläuse, p. 98, 1843. Aphis (orig. desc.). Davidson, Jour. Econ. Ent., vol. 2, p. 302, 1909. Callipterus (list). Davidson, Jour. Econ. Ent., vol. 3, p. 376, 1910. Callipterus (list). Davidson, Pom. Jour. Ent., vol. 3, p. 399, 1911. Callipterus (list). Essig, Pom. Jour. Ent., vol. 4, p. 762, 1912 (list).

Davidson, Jour. Econ. Ent., vol. 7, p. 130, 1914 (desc.).

Records.-Quercus agrifolia; Stanford University, San Jose, Penryn, Placer County (Davidson); Q. lobata, Santa Clara County (Davidson); Berkeley, 1915 (Essig) ; Q. pedunculata, Berkeley, August, 1914; Q. douglasii, Stanford University, November, 1910, April, 1911 (Morrison); Q. robur, Oakland (Davidson).

This is a variable species more or less common in the San Francisco Bay region and in the Sacramento Valley on various species of oaks. When he first reported it Davidson was doubtful of its identity. Later, however, it was identified by Peter Van der Goot ${ }^{5}$ as this species.

\section{Myzocallis ulmifolii (Monell)}

Figure 59

Monell, U. S. Geol. Geog. Surv., Bull. 5, p. 29, 1879. Callipterus (orig. desc.).

Davidson; Jour. Econ. Ent., vol. 2, p. 301, 1909. Callipterus (list).

Davidson, Jour. Econ. Ent., vol. 3, p. 376, 1910. Callipterus (list).

Essig, Pom. Jour. Ent., vol. 4, p. 762, 1912 (list).

Records.-Ulmus sp., Stanford University (Davidson), Ulmus americana, Walnut Creek, October, 1913 (Davidson).

Davidson reports this as common on elms in the San Francisco Bay region. However, the author has never collected it. The following brief descriptive notes are from an alate viviparous female, taken in Walnut Creek by Davidson. The most distinguishing character is the presence of a pair of small but prominent tubercles on the middorsum of the first and second abdominal segments. The usual primary and accessory sensoria are present on V and VI. Secondary sensoria (fig. 59) are present on the basal one-half to two-thirds of III. These are transversely linear or oval, and number about six. The cornicles are very short, bcing fully as broad at the apex as long. Cauda and anal plate normal. Wings normal, radial vein indistinct, first discoidal eurving toward base of wing. Body length $1.836 \mathrm{~mm}$., width of thorax $0.578 \mathrm{~mm}$., antennae total 1.309 to $1.326 \mathrm{~mm}$., III

5 In 1917 George Shinji (Ent. News, vol. 27, February, 1917) deseribed three species, M. essiggi n.sp., M. woodworthi n.sp., and $M$. hyalinus (Monell), all of which are undoubtedly but varieties of this species, M. quercus (Kalt.). 
$0.442 \mathrm{~mm}$., IV 0.255 to $0.272 \mathrm{~mm}$., V 0.221 to $0.2465 \mathrm{~mm}$., VI $0.255 \mathrm{~mm}$. (base $0.136 \mathrm{~mm}$., spur $0.119 \mathrm{~mm}$.), cornicles height $0.034 \mathrm{~mm}$., diameter at apex $0.034 \mathrm{~mm}$., wing length 1.581 to $1.768 \mathrm{~mm}$., width 0.663 to $0.68 \mathrm{~mm}$., expansion $3.825 \mathrm{~mm}$.

\section{Genus Chromaphis Walker}

Walker, The Zoologist, p. 2001, 1870. Type Lachnus juglandicola Kalt.

23. Chromaphis juglandicola (Kalt.)

Figures 34,35

Kaltenbach, Monog. d. Pflanzenläuse, p. 151, 1843. Lachnus (orig. desc.). Essig, Pom. Jour. Ent., vol. 1, p. 51, 1909. Callipterus (desc. vivi.).

Essig, Pom. Jour. Ent., vol. 4, p. 763, 1912 (list).

Davidson, U. S. Dept. Agr., Bull. 100, pp. 2-19, 1914 (dese. all forms).

Records.-Juglans regia; San Franciseo Bay region, southern California.

This walnut aphis is the most abundant and injurious of the species attacking walnut in California. It is more or less abundant throughout the San Francisco Bay region, while in southern California during certain seasons it is an important pest. Davidson (1914) has described all the forms and studied the life history carefully, so but little comment is necessary. In 1915 the author observed the young stem mothers on March 22 in Sunnyvale, Santa Clara County. Three weeks later the second generation was well advanced. From the first of May on, in 1916, the viviparae were abundant oll walnuts throughout San Diego County, from nursery stock in San Diego to a few cultivated trees at Santa Ysabel (altitude 3000 feet). From the middle of October until well into December, 1916, the sexuales were found throughout Los Angeles and Riverside counties.

\section{Genus Callipterus Koch}

Koch, Die Pflanzenläuse, p. 208, 1855. Type Aphis juglandis Kalt.

The two members of this genus in California have been considered heretofore as species of Monellia Oestlund (genus 10), but according to Davis ${ }^{6}$ they can not be so considered for in Monellia the wings are laid flat on the abdomen when at rest. This is found only in Monellia caryella (Fitch). Incidentally it may be remarked that the species known by that name in California does not have that habit, so should really be placed in this genus, Callipterus Koch. However, as it is identical with eastern specimens, except for this habit, the author

6 Essig, E. O., Beneficial and Injurious Insects of California, Mon. Bull. Cal. Comm. Hort., vol. 4, p. 83, 1915. 
has thought best to retain it in Monellis, at least for the time being. Kex to California Species

1. VI spur about equal to or slightly longer than VI base. Tibiae mostly pale. caryae Monell

- VI spur shorter than VI base. Tibiae entirely dark. Considerably larger than preceding species californicus (Essig)

\section{Callipterus californicus (Essig)}

Figures 63, 64

Essig, Pom. Jour. Ent., vol. 4, p. 767, 1912. Monellia (orig. dese.).

Davidson, U. S. Dept. Agr., Bull. 100, p. 34, 1914. Monellia (list, key to walnut aphids).

Records.-Juglans californica (California black walnut); Santa Paula.

In 1912 Essig described this species from specimens taken near Santa Paula in July, 1911. No other definite collections are known to the writer, although Essig reports it as more or less abundant on the California black walnut throughout the southern part of the state. Davidson has not found it in the San Francisco Bay region, nor has the author ever observed it, either in the bay region or in southern California.

\section{Callipterus caryae Monell}

Figures 65, 66

Monell, U. S. Geol. Geog. Surv., Bull. 5, p. 31, 1879 (orig. desc.).

Clarke, Can. Ent., vol. 35, p. 249, 1903 (list).

Davidson, Jour. Econ. Ent., vol. 2, p. 301, 1909 (list).

Davidson, Jour. Econ. Ent., vol. 3, p. 376, 1910 (list).

Essig, Pom. Jour. Ent., vol. 4, p. 764, 1912. Monellia (list).

Davidson, U. S. Dept. Agr., Bull. 100, pp. 19-26, 1914. Monellia (desc. all forms).

Records.-Juglans regia, J. californica; Berkeley, Stanford University, San Jose, San Francisco Bay region.

This species is morc or less common in the San Francisco Bay region on walnuts. Davidson has described all the forms and noted its life history. The author has not taken the species.

\section{Geinus Monellia Oestlund}

Oestlund, Minn. Geol. Nat. Hist. Surv., Bull. 4, p. 44, 1887. Type Aphis caryella Fitch.

This genus, as described by Oestlund, differs from Callipterus particularly in the position of the wings when the insects are at rest. In Callipterus they are held roof-like over the body as is usual in aphids. but in Monellia they are laid flat on the abdomen. It includes but the one species, $M$. caryella (Fitch). 


\title{
26. Monellia caryella (Fitch)
}

\author{
Figures 25, 67, 68
}

Fitch, Insects N. Y., vol. 1, p. 163, 1855. Aphis (orig. desc. apt. vivi.). Fitch, Ins. N. Y., vol. 3, p. 448, 1856. Callipterus (first dese. ala. vivi.). Davidson, Jour. Econ. Ent., vol. 7, p. 132, 1914 (list).

Davidson, U. S. Dept. Agr., Bull. 100, pp. 26-34, 1914 (desc. all forms).

Records.-Juglans californica, J. Nigra, J. regia; San Jose, Walnut Creek (Davidson); Stanford University, May to June, 1915.

A more or less common species on both the native black walnut, and the cultivated walnut in the San Francisco Bay region. This species, while very similar to the preceding species, is probably the more common of the two. The following table of differences is taken from Davidson : ${ }^{7}$

Form

Alate viviparous female

Pupa of viviparous

female

Oviparous female
Callipterus caryae Monell

Antennal joint III very slightly thickened basally.

Sensoria on antennal joint III occupying basal half or twothirds.

Antennal joint VI and its spur or filament subequal, or VI less than spur.

Dusky knee spots often present.

Four longitudinal rows of capitate spines.

Smaller than viviparous female.

Four longitudinal rows of cipitate spines.
Monellia caryella (Fiteh)

Antennal joint III quite noticeably thickened

- for its basal half.

Sensoria on antennal joint III oceupying basal third.

Antennal joint VI onethird as long again as its spur or filament.

Dusky knee spots absent.

Six longitudinal rows of capitate spines.

Larger than viviparous female.

Six longitudinal rows of capitate spines.

This species is distinct from the preceding and according to Morrison, who has examined eastern species, is structurally identical except in the matter of the wings. He writes as follows:

7 Davidson, W. M., Walnut aphides in California, U. S. Dept. Agr., Bull. 100, p. 28, 1914. 
I made a very careful study of specimens from California, sent me by Davidson, and of specimens collected both in Indiana and New York (type locality). I was unable to find any structural differences that would definitely separate the two lots of specimens, with the exception of the position of the wings. These are laid flat when at rest in the eastern specimens, but are not so in the Californian specimens, according to Davidson. In spite of this apparent agreement, I feel that the two must be distinct.

'If this is the case, that the wings are not laid flat at rest, this species must belong to the genus Callipterus, and therefore cannot be Monellia caryella (Fitch). However, the author has not had an opportunity to study this carefully, so leaves it as it is, calling this California species Monellia caryella (Fitch).

Because of the fact that all the species of aphids on walnut are so closely related, and so very similar in structure, a key to separate them, one from another, is given here. This key is adapted from Davidson. ${ }^{8}$

1. Cornicles quite evident, about as long as wide.

Chromaphis juglandicola (Kalt.)

- Cornicles barely perceptible, considerably wider than long

2. Tibiae of alate viviparae entirely dusky ...........Callipterus californicus (Essig)

- Tibiae of alate viviparae mostly pale 3

3. VI spur longer than VI base. Oviparous females with four longitudinal rows of capitate hairs

Callipterus caryae Monell

- VI spur shorter than VI base. Oviparous females with six longitudinal rows of capitate hairs Monellia caryella (Fitch)

11. Genus Callipterinella Van der Goot

Van der Goot, Zur Systematic der Aphiden, 1913. Type Aphis (Callipterus) betularius Kaltenbach.

\section{Callipterinella annulata (Koch)}

Koch, Die Pflanzenläuse, p. 1855. Chaitophorus (orig. desc.).

Gillette, Jour. Econ. Ent., vol. 3, p. 367, 1910, Chaitophorus betulae (Buekton) (list).

Davidson, Jour. Econ. Ent., vol. 10, p. 292, 1917 (desc.).

Records.-Betula alba; Oakland, Walnut Creek (Davidson).

This species has been reported by Davidson as infesting the leaves and shoots of the white birch in the San Francisco Bay region. It is unknown to the author.

8 Ibid., p. 35. 


\section{Tribe Chaitophorini Wilson (Lachnidea Mordw. and Chaitopheri Mordw.)}

Wilson, Can. Ent., vol. 42, pp. 385-387, 1910.

This tribe as considered by Wilson contains the following genera: Arctaphis, Chaitophorus, Symydobius, Thomasia, and Sipha. The author has followed Wilson's classification, having added, however, two genera deseribed later by Essig: viz., Micrella and Fullawaya. Essig's genus Eichochaitophorus is a synonym of Arctaphis Walker (see discussion under no. 27). Mordwilko's groups Lachnoidea and Chaitophori are both included in this one tribe. In the former, Mordwilko includes Symydobius and Pterochlorus, and in the latter, Cladobius, Melanoxanthus, and Chaitophorus. Both Cladobius and Melanoxanthus are included in this paper in the tribe Pterocommini, being synonyms of the genus Pterocomma Buckton. Following is a description of the tribe Chaitophorini as given by Wilson (op. cit.) :

Antennae, except in Sipha, always six-segmented; in Sipha there are but five. Length variable; antennal tubercles wanting; antennae, legs, and body covered with hair-like bristles. Fore wings with two oblique veins and cubitus always twice forked; hind pair with two cross veins. Nectaries (cornicles) variable in length and size, but never longer than one-tenth the length of the body. The genera in this tribe are somewhat similar to those in the tribe Callipterini, but are easily distinguished by the shorter and heavier antennae and legs, as well as by the finer and more hair-like bristles.

The following key to the Californian genera has been adapted from Wilson and Essig:

1. Spur of sixth antennal segment at least three times as long as the segment 2

- Spur not three times as long as the segment. Cauda broadly rounded and without knobbed tip

2. Spur more than five times as long as the segment; cornicles longer than the base of the sixth segment

Chaitophorus Koch

- Spur of sixth segment not more than five times as long as the segment; cornicles not longer than the base of the sixth segment

3. Cauda a knob on a quadrangular base (fig. 69). Spur about fire times as long as sixth segment

Arctaphis Walker

- Cauda tapering to a blunt tip which is usually straight across, not being rounded or constricted at the base (fig. 70). Spur but slightly more than three times as long as the sixth segment

Micrella Essig

4. Spur of sixth segment shorter or scarcely longer than the segment; antennae nearly as long as the body

Symydobius Mordwilko

- Spur considerably longer than sixtl segment; antennae about one-half the length of the body

5. Cornicles absent; body with lateral tubercles ............................ullawaya Essig
- Cornicles present; lateral body tubercles wanting ...................Thomasia Wilson 


\section{Genus Chaitophorus Koch}

Koch, Die Pflanzenläuse, p. 1, 1854. Type Aphis aceris Linn.

There are at present no species of this genus in California; most of the species hitherto placed in it are now considered as belonging to the genus Thomasia Wilson.

\section{Genus Arctaphis Walker}

Walker, The Zoologist, p. 2000, 1870. Type aphis populi Linn.

This genus as defined by Wilson is represented in California by two species: $A$. viminalis (Monell) and A. populifolii (Essig). The latter was placed by Essig in a new genus, Eichochaitophorus, but there is not enough difference between these to warrant a new genus.

\section{Key to California Species}

1. Wings hyaline. Three-nine large sensoria on third antennal segment (fig. 71). IV half as long against as $\mathrm{V}$ populifolii (Essig)

- Wings subhyaline. About ten rather small sensoria on III. IV but very little longer than $\mathrm{V}$ viminalis (Monell)

\section{Arctaphis populifolii (Essig)}

Figures 69, 71

Essig, Pom. Jour. Ent., vol. 4, p. 722, 1912. Eichochaitophorus (orig. desc.).

Davidson, Jour. Econ. Ent., vol. 3, p. 375, 1910. Chaitophorus populifoliae (Fiteh) (desc. male).

Davidson, Pom. Jour. Ent., vol. 3, p. 399, 1911. Chaitophorus populifoliae (Fitch) (list).

Records.-Populus trichocarpa, Santa Paula (Essig), Berkeley, September, 1915; Populus fremontii, Stanford University and Penryn, Placer County (Davidson); Menlo Park, San Mateo County, October, 1914 (Morrison); Berkeley, September, 1915; El Cajon, San Diego County, June, 1916; Riverside, October, 1916.

In 1912 Essig described this species from specimens taken on Populus trichocarpa at Santa Paula, and placed it in a new genus, Eichochaitophorus. He separated this genus from Arctaphis for the following reasons :

According to Wilson the cauda [in Arctaphis] is a knob on a quadrangular base. The anal plate is broadly rounded. In the new genus [Eichochaitophorus] the style has a distinct neck and is situated on a very distinct conical base. The anal plate is deeply notched in the middle so as to make it somewhat forked as in the genus Callipterus. 
Although the anal plate is somewhat notched, there is scarcely difference enough to warrant the forming of a new genus. In fact, in many specimens one cannot tell whether or not a notch is present. As to the cauda, consisting of the tip, a distinct neck, and a distinctly conical base, this is not greatly different from a cauda consisting of a knobbed tip on a quadrangular base. The only practical difference is in the base, being conical in one and quadrangular in the other. In populifolii (Essig) the base seems to be conical, yet one cannot be certain unless the specimen is mounted exactly.

This species, A. populifolii (Essig), as stated above, was described from specimens taken on Populus trichocarpa at Santa Paula. In 1910 Davidson found a species on Populus fremonti at Stanford University, and the following year at Penryn, Placer County, which he listed as Chaitophorus populifoliae (Fitch). A careful study of specimens from Davidson and the cotypes of Essig's species convinced the author that they were identical. Morrison writes that Davidson's specimens are not C. populifoliae (Fitch), so Essig's species is distinct. In September, 1915, the author observed a great number of specimens of this species on a weeping elm (Ulmus sp.) in Berkelcy, which was in close proximity to some populars. However, none were seen to be feeding on the elm, all being restless and wandering over the leaves and branches. In southern California this is often found infesting the empty galls of Thecabius populimonilis Riley, such having been observed in San Diego and Riverside counties.

\section{Arctaphis viminalis (Monell) ?}

Monell, U. S. Geol. Geog. Surv., Bull. 5, p. 31, 1879. Callipterus (orig. desc.).

Clarke, Can. Ent., vol. 35, p. 248, 1903. Chaitophorus (list).

Davidson, Jour. Econ. Ent., vol. 3, p. 375, 1910. Chaitophorus (list).

Davidson, Pom. Jour. Ent., vol. 3, p. 398, 1911. Chaitophorus (list).

Essig, Pom. Jour. Ent., vol. 4, p. 716, 1912. Thomasia (list, key to Californian species of Thomasia).

Patch, Maine Agr. Exp. Sta., Bull. 213, p. 80, 1913. Chaitophorus (desc.).

Records-Salix spp.;' Watsonville, Santa Cruz County, and Newcastle, Placer County (Clarke); Penryn, Placer County, and Stanford University (Davidson).

This species has been reported from Placer, Santa Clara, and Santa Cruz counties on various species of willow. The true Chaitophorus viminalis Monell is an Arctaphis, but whether or not the western species is the same as the eastern is a question. The author has never seen specimens of either and is therefore unable to make 
any further comment. He once thought the western species was identical with Thomasia salicicola (Essig), to which Morrison considers it very closely related, but Davidson assures him the two are distinct.

\section{Genus Micrella Essig}

Essig, Pom. Jour. Ent., vol. 4, p. 716, 1912. Type M. monella n.sp.

\section{Micrella monella Essig}

Figures 70,72

Essig, Pom. Jour. Ent., vol. 4, p. 717, 1912 (orig. dese.).

Records._Salix lasiolepis, Oxnard (Essig); S. laevigata, Santa Paula (Essig).

This species was taken twice by Essig, who described it, in 1910 near Oxnard, and in 1911 near Santa Paula. Since then it has never again been found. The author has had access to cotype spęcimens in Essig's collection.

\section{Genus Fullawaya Essig}

Essig, Pom. Jour. Ent., vol. 4, p. 735, 1912. Type F. saliciradicis n.sp.

\section{Fullawaya saliciradicis Essig}

Figure 75

Essig, Pom. Jour. Ent., vol. 4, p. 737, 1912 (orig. dese.).

Record.-Salix laevigata, Santa Paula, August, 1911 (Essig).

On the roots of willow near Santa Paula, Essig once found a large number of aphids, the greater part of which were apterae, although a few alates were present. Unable to identify them with any known species, or to fit them into any genus, he described them as this species. Since then they have not been taken. The author has had access to cotype specimens in Essig's collection.

\section{Genus Thomasia Wilson}

Wilson, Can. Ent., vol. 42, p. 386, 1910. Type Chaitophorus populicola Thomas.

This genus is separated from Chaitophorus principally by the comparative lengths of the antennae and the comparative lengths of the spur of the sixth antennal segment. In Chaitophorus (type Aphis aceris Linn.) the antennae are almost as long as the body, and the spur of the sixth segment is over five times as long as the base. In this genus the antennae are but about one-half as long as the body. and VI spur is but slightly longer than VI base. 


\section{Key to California Species}

1. Wings hyaline populicola (Thomas)

- Wings with veins clouded (fig. 275) negundinis (Thomas)

2. III longer than VI (including spur)

- III not longer than VI (including spur)

3. IV with secondary sensoria crucis Essig

- IV without secondary sensoria salicicola Essig

\section{Thomasia crucis Essig}

Figure 76

Essig, Pom. Jour. Ent., vol. 4, p. 742, 1912 (orig. desc.). Records.-Salix macrostachya, Santa Paula, August, 1911 (Essig).

Essig once found this species on the leaves of willow near Santa Paula. Since then it has never again been taken. The author has had access to cotype specimens in Essig's collection.

\section{Thomasia negundinis (Thomas)}

Thomas, Ill. Lab. Nat. Hist., Bull. 2, p. 10, 1878. Chaitophorus (orig. desc.).

Sanborn, Kan. Univ. Sci., Bull. 3, p. 35, 1904. Chaitophorus (desc.).

Davidson, Jour. Econ. Ent., vol. 3, p. 376, 1910. Chaitophorus (list).

Essig, Pom. Jour. Ent., vol. 4, p. 716, 1912 (list).

Records.-Acer negundo, Stanford Unirersity (Davidson); Salt Marshes, Palo Alto, May, 1912 (Morrison).

This species of Thomasia is quite common on box elder in the vicinity of Stanford University and Palo Alto. The author has never taken specimens, nor had access to any. Morrison writes that although he has never had access to eastern specimens of T. negundinis (Thos.) for comparison he is not able to convince himself that the western species is negundinis. The author is unable to form any opinion at present, having never seen specimens, hence lists the species as Davidson has done.

\section{Thomasia populicola (Thomas)}

Figures 77, 275

Thomas, Ill. Lab. Nat. Hist, Bull. 2, p. 10, 1878. Chaitophorus (orig. desc.).

Essig, Pom. Jour. Ent., vol. 1, p. 98, 1909. Chaitophorus (dese.).

Essig, Pom. Jour. Ent., vol. 4, p. 716, 1912 (list).

Records.-Populus spp., Salix spp., Santa Paula (Essig) ; Riverside, May, 1917; Populus sp., Canton, Broadwater County, Montana, July, 1915, R. W. Haegele; Edna Cañon, Boxelder County, Utah, August, 1916, R. W. Doane. 
This species has been reported by Essig from Ventura County. The author has never taken the alates, but has had the opportunity of examining Essig's specimens, and specimens from Montana and Utah taken by Haegele and Doane. It is easily distinguished from other members of the genus by the broad, dark wing veins.

\section{Thomasia salicicola (Essig)}

Figure 78

Essig, Pom. Jour. Ent., vol. 3, p. 532, 1911. Chaitophorus (orig. dese.).

Davidson, Jour. Econ. Ent., vol. 3, p. 375, 1910. Chaitophorus nigrae Oestlund (?) (list).

Davidson, Pom. Jour. Ent., vol. 3, p. 398, 1911. Chaitophorus nigrae Oestlund ( 9 ) (list).

Essig, Pom. Jour. Ent., vol. 4, p. 619, 1912 (note).

Essig, Pom. Jour. Ent., vol. 4, p. 716, 1912 (list).

Records.-Salix laevigata, Santa Paula (Essig), Salix nigra, Lakeside, San Diego County, April, 1916; Populus trichocarpa, Santa Paula (Essig); Salix sp., San Jose, Stanford University, Penryn, Placer County (Davidson), Fillmore, Ventura County, March, 1911 (Essig).

Essig reported this from Ventura County, and the author has found it in San Diego County. It was observed to be in large colonies on the leaves and leaf petioles of the tender growth of willow, in company with Siphocoryne carpreae (Fabr.). Specimens taken by Davidson and listed as Chaitophorus nigrae Oestlund prove to be identical with this species.

\section{Genus Symydobius Mordwilko}

Mordwilko, Rap. Lab. Zool. Kap. Imp. Vareh. Univ., 1895. Type Aphis oblonga Heyden.

\section{Key to California Species}

1. Anal plate half-moon-shaped

- Anal plate bilobed (fig. 271); cornicles pale, appearing white in life; antennae with about six to eight secondary sensoria on III, and one or two on IV (fig. 272) chrysolepis Swain

2. Spur of VI but a short thumb-like projection; sensoria on III numbering about six to ten; none on IV agrifoliae Essig

- Spur of VI longer, being equal to or longer than base of VI; fifteen to twenty sensoria on III, one or two on IV (figs. 73, 74)

3. Antennae for the most part dark, being dark brown or black; spur and base of VI equal, lateral abdominal tubercles present in apterae.

- Antennate for the most part pale, being light brown or amber; spur of VI usually slightly longer than base; apterae without lateral abdominal tubercles salicicorticis Essig 


\section{Symydobius agrifoliae Essig}

Essig, Univ. Calif. Publ. Entom., vol. 1, pp. 311-317, 1917 (orig. dese.). Records.-Quercus agrifolia; Santa Paula (Essig).

This interesting aphid was taken in Ventura County on live oak during 1911. It differs from other members of this genus in the extremely short spur of the sixth antennal segment. The coloration is very similar to that of the next species, but the length of VI spur and the fact that the anal plate is not bilobed serves to distinguish it.

\section{Symydobius chrysolepis Swain}

Figures 269 to 274

Swain, Trans. Am. Ent. Soc., vol. 44, p. 6, 1918 (orig. dese.).

Records.-Quercus chrysolepis; Alpine, San Diego County (Swain).

This is a medium sized, brownish colored aphid found in 1916 infesting the terminal twigs and leaf petioles of maul oak in San Diego County. Its pale white cornicles are very conspicuous, and serve as a distinguishing character. The anal plate is bilobed, a character not found in other members of the genus, and one which may be sufficient for the separation of the species (and S. albisiphus Davis, in which the anal plate is also bilobed) from Symydobius into a new genus. However, the author believes it best to retain them in this genus at present. The apterous females were found to be heavily parasitized by the chalcid fly, Closterocerus utahensis Crawford var. californicus Girault.

\section{Symydobius macrostachyae Essig}

Figure 73

Essig, Pom. Jour. Ent., vol. 4, p. 727, 1912 (orig dese.).

Records._Salix macrostachya; Santa Paula (Essig), Fresno, June, 1915.

'Twice has this species been taken, once by Essig near Santa Paula and once by the author along the San Joaquin River near Fresno. It is found in fairly large colonies on the younger stems of willow. These colonies consist for the most part of aptcrae, only a very few alates bcing present. 


\section{Symydobius salicicorticis Essig}

Figure 74

Essig, Pom. Jour. Ent., vol. 4, p. 731, 1912 (orig. desc.).

Record.-Salix laevigata; Santa Paula (Essig).

Together with specimens of Fullawaya saliciradicis Essig, this was taken on willow along the Santa Clara River near Santa Paula in August, 1911. The colonies are found on the bark near the surface of the ground either just above or just below it. Essig reports that it is preyed upon quite extensively by the larvae of an undetermined species of syrphus fly. The author has had access to cotype specimens in Essig's collection.

\section{Group Lachnina Passerini}

Passerini, Gli Afidi, 1860.

In this group there are included two tribes, Lachnini Del Guercio and Pterocommini Wilson, following Wilson. Mordwilko places but the one tribe Lachnini in this group, including the genus Pterocomma Buckton in the tribe Chaitophori. However, to the author the grouping followed here seems more natural. The following key is adapted in part from Börner (Sorauer, Pflanzenkrankheiten, vol. 3, p. 665, 1913):

Sixth antennal segment with a short, thick (thumb-like) projection. Cornicles conical (fig. 91) or wart-like. Empodial hair short, and oftentimes indistinguishable (fig. 79) Tribe Lachnini Sixth antennal segment with a slender projection (VI spur) which is about as long as the segment (VI base). Cornicles cylindrical or clavate (figs. 81, 82). Empodial hair practically as long as the claws (fig. 80). Tribe Pterocommini

\section{Tribe Pterocommini Wilson}

Wilson, Ann. Ent. Soc. Am., vol. 8, pp. 347-358, 1915.

This tribe, as considered by Wilson, contains but the one genus, Pterocomma Buckton. In a former paper (Can. Ent., vol. 43, p. 384, 1910) he recognized two genera: the one, Melanoxantherium Schouteden, in which the cornicles were swollen or vasiform, and the other, 
Pterocomma Buckton, in which the cornicles were cylindrical. He states in his later paper: ". . . after having further studied the group I am of the opinion that such a divsion is illogical, and if a division is necessary each species should form a different genus. It, therefore, scems more practical to confinc all the species to a single gemus.' The characters of this tribe and genus are as follows:

Antennae with six segments and reaching near the base of the abdomen. Wings normally with renation as in Aphis. Nectaries [cornicles] short, but clavate. Cauda short and broadly rounded at the tip as in Lachnini. Entire body, antennae, and legs covered with long hairs as in Lachnini. As has already been pointed out by Oestlund, this group appears intermediate between the Chaitophorini and the Lachnini. Their havits and actions being in different ways similar to both.

\section{Genus Pterocomma Buckton}

Buckton, Monog. Brit. Aphides, vol. 2, p. 143, 1879. Type P. pilosa Buckton.

\section{Key to California Species}

1. Cornicles abruptly constricted at distal end, and without a distinct flange (fig. 81), the diameter of the opening being less than the diameter of the smallest part of the cornicle. Wing veins broad and shaded.

flocculosa (Weed)

- Cornicles not so abruptly constricted and with a distinct flange. Wing veins normal

2. Cornicles about twice as long as their greatest diameter....smithiae (Monell)

- Cornicles considerably longer than greatest diameter, and longer than hind tarsus populifoliae (Fitch)

\section{Pterocomma flocculosa (Weed)}

\section{Figure 81}

Weed, Insect Life, vol. 3, p. 291, 1891. Melanoxanthus (orig. dese.). Wilson, Ann. Ent. Soc. Am., vol. 8, p. 350, 1915 (dese.).

Records._Salix sp., Berkeley, March, 1915; 1916 (Essig).

In his paper on Pterocomma Wilson states that this species does not occur on the Pacific Coast. However, in March, 1915, the author found it rather abundantly on willow on the campus of the University of California in Berkeley. During the 1916 season Essig observed it to be quite common in Berkeley. The species is easily recognized in life by the white cottony flocculence covering the colonies on the bark. 


\section{Pterocomma populifoliae (Fitch)}

Figures 82,83

Fitch, Cat. Homop. N. Y., p. 66, 1851. Aphis (orig. dese.).

Davidson, Jour. Econ. Ent., vol. 2, p. 300, 1909. Cladobius rufulus n.sp. (dese.).

Davidson, Jour. Econ. Ent., vol. 3, p. 375, 1910. Cladobius rufulus Dvdn. (list).

Essig, Pom. Jour. Ent., vol. 4, p. 786, 1912. Melanoxantherium rufulum (Dvdn.) (dese.).

Wilson, Ann. Ent. Soc. Am., vol. 8, p. 353, 1915. Pterocomma populea (Kalt.) (dese.).

Baker, Can. Ent., vol. 48, pp. 280-282, 1916 (dese.).

Records._Salix sp.; Stanford University (Davidson); Santa Paula (Essig); Walnut Creek, March, 1915 (Davidson); Grossmont, San Diego County, March, 1916; Lakeside, San Diego County, April, 1916; Stanford University, May, 1912 (Morrison); Populus sp.; Stanford University (Davidson); Palo Alto, Mareh, 1915; Populus caroliniana, Banning, Riverside County, April, 1917.

This is a widely distributed species in California on various speeies of poplars and willows. Davidson first found it in 1909, deseribing it as a new species. In 1915 Wilson stated that it was synonymous with $P$. populea (Kalt.), but speeimens sent him by the anthor he determined as $P$. bicolor (Oestlund). According to his paper the cornicles of populea (Kalt.) are about equal in length to the hind tarsi. Californian specimens have the cornieles eonsiderably longer than the hind tarsi, but not twiee as long as he states they are in bicolor (Oestlund). His figures of the antennae show that in populea VI base and spur are subequal, and in bicolor the spur is considerably longer than the base. The latter is true for the Californian speeies. His eolor notes of populea fit the Californian species very well. Baker identified Aphis populifoliae Fitch as a Pterocomma and plaees rufulus (Davidson) as a synonym. From a study of speeimens taken in Santa Paula, Grossmont, Lakeside, Stanford University, and Walnut Creek, the author finds that Baker's deseription of populifoliae fits this speeies very well. Below are the measurements in microns of four alate speeimens, together with the measurements of eornieles, antennae, and hind tarsi of one from Lakeside. (This was preserved for several months in aleohol before being mounted for study, and had shrunk considerably.)

An examination of the following table shows that in the California speeimens the eornieles are always eonsiderably longer than the hind tarsi, but never twiee as long, and that the spur of six is always longer than the base, exeept in one case. This speeimen is eonsiderably 


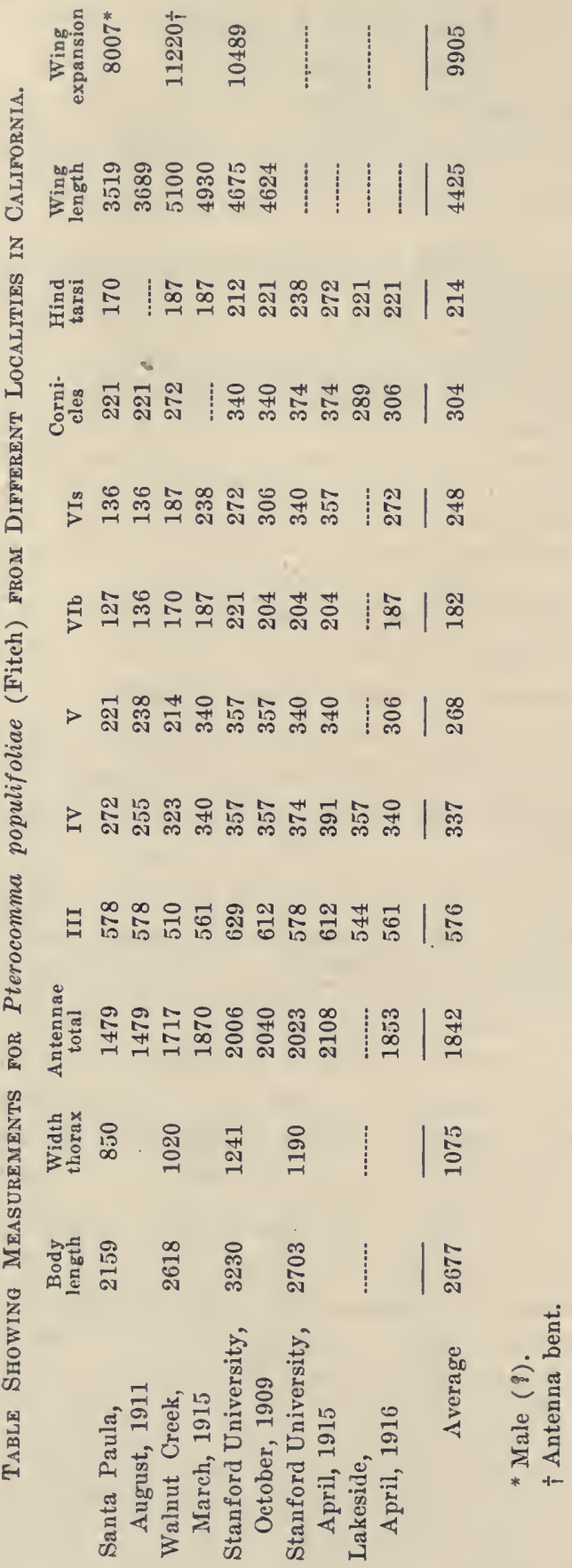


smaller than the others and has many more secondary sensoria, being a male. From this evidence this species is the same as Baker lists as $P$. populifoliae (Fitch) and should be so considered. The author has reared a number of specimens of a species of Aphidius from material obtained near Stanford University in May, 1915.

\section{Pterocomma smithiae (Monell)}

Monell, U. S. Geol. Geog. Surv., Bull. 5, p. 32, 1879. Chaitophorus (orig. desc.).

Davidson, Jour. Econ. Ent., vol. 2, p. 300, 1909. Cladobius salicti (Harris) (list).

Davidson, Jour. Econ. Ent., vol. 3, p. 375, 1910. Cladobius salicti (Harris) (list).

Essig, Poin. Jour. Ent., vol. 4, p. 786, 1912. Melanoxantherium salicti (Harris) (list).

Wilson, Ann. Ent. Soc. Am., vol. 8, p. 355, 1915 (desc.).

Records.—Salix spp., Stanford University (Däidson, Morrison).

Both Davidson and Morrison have taken this species in the vicinity of Stanford University on various species of willow. According to Wilson, with whom Morrison and Baker agree, this is P. smithiae (Monell), the salicti of Harris being synonymous. The sexuales were observed by Davidson in October, the eggs hatching in January.

\section{Tribe Lachnini Del Guercio}

Del Guercio, Redia, vol. 5, 1908.

This tribe is represented in California by three genera, viz., Essigella Del Guercio, Tuberolachnus Mordwilko, and Lachnus Burmeister, while there are six genera included in the tribe as it is here considered. Following is a brief characterization of the tribe adapted from Mordwilko :

The body and appendages are very hairy; and usually quite large. The cauda is absent, the cornicles cupola-shaped, being black or brown in color. Sometimes they are reduced to mere pores or not fully developed [Lachnus taxifolia Swain]. The antennae in general are not longer than the head and thorax, six-jointed [except in Essigella Del Guercio], with the spur of the sixth segment very short, not being as long as the segment itself. The beak is almost always elongated, generally reaching to or beyond the middle of the abdomen. All this group possess the anatomical peculiarity that the narrowed hind end of the stomach is covered with the intestine. The stigma of the fore wing is elongate linear [in Longistigma Wilson it reached past the tip of the wing (fig. 89)]. The cubitus is twicebranched. 
All the California species with the exception of Tuberolachnus viminalis (Fonse.), which lives on willow, are found on conifers-Pinus sp., Pseudotsuga sp., or Picea sp.

Following is a key to the genera, adapted from Del Guercio, Wilson and Essig. In this key are included not only the California genera but the other three as well, in that an understanding of the characters is thus made easier.

1. Antennae six-segmented 2

- Antennae five-segmented (fig. 83) Essigella Del Guereio

2. Stigma exceptionally long, reaching beyond the tip of the wing (fig. 84).

Longistigma (Wilson)

- Stigma not exceptionally long, not reaching beyond the tip of the wing (fig. 85)

3. First joint of the hind tarsus much shorter than half the second (fig. 86) .... 4

- First joint of the hind tarsus equal to or slightly longer than half the second (fig. 87) Eulachnus Del Guercio

4. Abdomen with horn-like tubercle on median dorsum between the cornicles, (Sometimes this cannot be made out in specimens mounted in balsam, but it is always readily discernible in fresh or alcoholic material).

Tuberolachmus Mordwilko

- Abdomen without horn-like tubercle 5

5. Bases of first and second discoidal close together; third discoidal often very faint; wings slightly if ever clouded (fig. 85) Lachnus Burmeister

- Bases of first and second discoidals not so close together as in Lachnus Burm.; third discoidal plain; wings often darkly clouded ......Pterochlorus Rondani

\section{Genus Essigella Del Guercio}

Del Guercio, Rev. di patal. veg., vol. 3, p. 328, 1909. Type Lachnus californicus Essig.

\section{Essigella californica (Essig)}

Figures 3, 5, 83

Essig, Pom. Jour. Ent., vol. 1, p. 1, 1909. Lachnus (orig. dese.).

Del Guercio, Pom. Jour. Ent., vol. 1, p. 73, 1909 (translation by C. F. Baker of Del Guercio's paper listed above).

Essig, Pom. Jour. Ent., vol. 4, p. 773, 1912 (list).

Essig, Pom. Jour. Ent., vol. 4, p. 780, 1912 (dese.).

Records.-Pinus radiata; Claremont, Los Angeles County, and Santa Paula (Essig); Pinus sabiniana, Stanford University, March, 1915; Pinus spp., Stanford Unirersity, Mareh and April, 1912 (Morrison); Ontario, San Bernardino County, January, 1917.

This eurious little aphid, described by Essig from specimens taken in Claremont, Los Angeles County, on Pinus radiata, has since been found in several parts of the state. Wilson has taken it in Oregon on Pseudotsuga taxifolia, and Patch in Maine on Pinus strobus. It 
is a small, slender, long-legged aphid, that clings fast to the pine needles and is extremely difficult to see. However, if a branch of pine is struck sharply and with considerable force over a white paper or cloth, a large number of these aphids will jar off.

\section{Genus Tuberolachnus Mordwilko}

Mordwilko, Ann. Mus. Zool. d. l'Acad. Imp. Sci., vol. 13, p. 374, 1908. Type Aphis viminalis Fonse.

\section{Tuberolachnus viminalis (Fonsc.)}

Figure 86

Boyer de Fonscolmbe, Ann. Ent. Soc. France, vol. 10; p. 162, 1841. Aphis (orig. dese.).

Davidson, Jour. Econ. Ent., vol. 2, p. 299, 1909. Lachnus (list).

Davidson, Jour. Econ. Ent., vol. 3, p. 374, 1910. Lachnus (list).

Davidson, Pom. Jour. Ent., vol. 3, p. 398, 1911. Lachnus dentatus Le Baron (list).

Essig, Pom. Jour. Ent., vol. 4, p. 774 (772), 1912 (list).

Records.-Salix spp., Stanford University and Penryn, Placer County (Davidson); Ventura County (Essig); Stanford University, November, 1914; Berkeley, July, 1915; Riverside, July, 1916.

This extremely large aphid, which lives in large colonies on the branches of various species of willows, is found throughout the San Francisco Bay region, Sacramento Valley, and southern California, although it is not at all common. Davidson reports considerable parasitization by a species of Epherdius, and Essig infection from some bacterial or fungus disease. The large size and the presence of a dorsal abdominal tubercle are distinguishing characters.

\section{Genus Lachnus Burmeister}

Burmeister, Handbuch d. Entomologie, p. 91, 1835. Type Lachnus faciatus, n.sp.

This is the third largest genus of aphids in regard to the number of species in California. All the species are to be found on various conifers, usually feeding through the bark of the branches or trunk. Characters for distinguishing the species are hard to obtain, and those used by the author in the following key are of no value except with specimens of the alate viviparae. This key is not at all adequate, and is offered here merely as an aid. The author understands that Wilson is preparing a monograph of this genus, which will undoubtedly prove quitc valuable. 


\section{Key to California Species}

1. Beak reaching considerably beyond the third coxa ......................................... 2

- Beak at most barely reaching to the third coxa ............................................... 8

2. Beak reaching almost to or, even beyond the tip of the abdomen ................... 3

- Beak not reaching to the tip of the abdomen ................................................... 4

3. First joint of hind tarsus more than one-third as long as the second joint. Legs black except the base of the femora and a broad ring near the base of the tibiae .....................................................................ponderosa Williams

- First joint of hind tarsus scarcely more than one-fourth as long as the second joint. Legs pale at the base of the femora and tibiae, black at tips.

oregonensis Wilson

4. Body exceptionally large, being over $4 \mathrm{~mm}$. long, usually about $5 \mathrm{~mm}$., and over $2 \mathrm{~mm}$. wide

5

- Body of average size, being from $2.5 \mathrm{~mm}$. to $3 \mathrm{~mm}$. long, and from 0.75 to $1.2 \mathrm{~mm}$. wide .......................................................................................................... 7

5. Third segment of antennae with many sensoria (eight or more), (figs. 88, 89)

- Third joint of antennae with but few or no sensoria, at most with one or two. First joint of hind tarsus a little less than half as long as the second. On Pinus sabiniana. sabinianus n.sp.

6. Third joint of antennae with about 8-12 sensoria (fig. 88). Tibiae with a pale ring near the base. First joint of hind tarsus searcely more than one-third the length of the second. On Picea sp. vanduzei n.sp.

- Third joint of the antennae with 19-20 sensoria (fig. 89). Tibiae without pale ring near base. First joint of hind tarsus almost one-half the length of the second. On Pinus sp. and Abies sp.............................. ferrisi Swain

7. Beak not reaching to the middle of the abdomen. Segment three of the antennae almost as long as the fourth, fifth, and sixth together. Apex of stigma meeting the margin of the wing in an acute angle, and not terminated by a distinct vein (fig. 92). On Pseudotsuga taxifolia.

pseudotsugae Wilson

- Beak reaching beyoud the middle of the abdomen. Third antennal segment not nearly so long as the fourth, fifth, and sixth together. Apex of stigma meeting the wing margin in an obtuse angle, and terminated by a distinct vein (fig. 93). Apterous viviparous females with a distinctive pattern on dorsum of abdomen. On Thuya occidentalis ........tujafilinus (Del Guercio)

8. First joint of hind tarsus longer than one-fourth the second .......................... 10

- First joint of hind tarsus less than one-fourth the second ................................ 9

9. Third antelnal segment without sensoria (fig. 94). Body robust, being of the usual Lachnus shape. Third discoidal twice-branched, only occasionally once-branched. On Abies grandis occidentalis Davidson

- Third antennal segment with several irregular sensoria (fig. 95). Body long and narrow, being somewhat the shape of Essigella californica (Essig). Third discoidal simple or once-branched. On Pinus sp.

pini-radiatae Davidson

10. Cornicles very poorly developed, seemingly absent in some cases (fig. 103). Segment three of antennae with five-seven large circular sensoria which are hardly distinguishable (fig. 106). On Pseudotsuga taxifolia.

taxifolia Swain

- Cornicles normal (fig. 97), being quite conspicuous. Third antennal segment with two-four clearly defined sensoria (fig. 101). On Picca glehni.

glehnus Essig 


\section{Lachnus ferrisi Swain}

Figures 89, 91

Davidson, Jour. Econ. Ent., vol. 2, p. 299, 1909. Lachnus abietis Fitch (list).

Davidson, Jour. Econ. Ent., vol. 3, p. 374, 1910. Lachnus abietis Fitch (list).

Essig, Pom. Jour. Ent., vol. 4, p. 773, 1912. Lachnus abietis Fitch (list).

Swain, Trans. Am. Ent. Soc., vol. 44, p. 9, 1918.

Records.-Abies concolor, Stanford University (Davidson); Pinus sp., Stanford University (Swain).

This large lachnid, recently described by the author, has been found only in the vicinity of Stanford University, in 1909 and 1910 by Davidson on lowland fir, and in 1915 by Ferris on some young pine trees. Since then it has not been observed.

\section{Lachnus glehnus Essig}

Figures 96,97

Essig, Pom. Jour. Ent. Zool., vol. 7, pp. 180-187, 1915 (orig. desc.).

Record.-Picea glehni, Sacramento (Essig).

Essig described this species from specimens taken on a Japanese spruce in Capitol Park, Sacramento, in 1912. At the time it was so abundant that control measures were deemed necessary. The author has had access to the type specimens in Essig's collection.

\section{Lachnus occidentalis Davidson}

Davidson, Jour. Econ. Ent., vol. 2, p. 300, 1909 (orig. dese. apterae).

Davidson, Jour. Econ. Ent., vol. 3, p. 374, 1910 (list).

Essig, Pom. Jour. Ent., vol. 4, p. 773, 1912 (list).

Wilson, Can. Ent., vol. 44, p. 193, 1912 (dese. all forms).

Records.-Abies grandis, Stanford University (Davidson, Morrison, Ferris and the author); Abies concolor, Corvallis, Oregon (Wilson).

This species is practically always present on a lowland fir tree in the cactus garden of the Stanford University grounds. Wilson has found it in the vicinity of Corvallis, Oregon, on white fir. Davidson states that it is heavily preyed upon by the larvae of Syrphus arcuatus and Syrphus opinator. 


\section{Lachnus oregonensis Wilson}

Wilson, Trans. Am. Ent. Soc., vol. 12, p. 103, 1915 (orig. dese.).

Record.-Pinus contorta, Oregon and California (Wilson).

There has been no published record of this species from California. Wilson wrote the author some time ago that he had taken it in this state, although he gave no definite locality. The author has never seen specimens.

\section{Lachnus pini-radiatae Davidson}

Figure 95

Davidson, Jour. Econ. Ent., vol. 2, p. 299, 1909 (orig. desc.).

Davidson, Jour. Econ. Ent., vol. 3, p. 374, 1910 (list).

Davidson, Pom. Jour. Ent., vol. 3, p. 398, 1911 (list).

Essig, Pom. Jour. Ent., vol. 4, p. 773, 1912 (list).

Essig, Pom. Jour. Ent., vol. 4, p. 785, 1912 (descriptive note).

Records.-Pinus radiata, Stanford University (Davidson), August, 1914, April, 1915 (author), March, 1916 (K. B. Brown); Pinus ponderosa, Bowman, Placer County, November, 1911 (H. H. Bowman), Berkeley, March, 1915 (Geo. Shinji); Pinus sabiniana, Penryn, Placer County (Davidson).

This is a fairly small, slender-bodied, long-legged lachnid found infesting the needles of various pines in the San Francisco Bay region and in the Sacramento Valley. They are easily recognized on the needles by the whitish mass of flocculence which covers their bodies.

\section{Lachnus ponderosa Williams}

Figure 104

Williams, Univ. Neb. Studies, vol. 10, p. 106, 1910 (orig. dese.).

Davidson, Jour. Econ. Ent., vol. 7, p. 127, 1914 (list).

Record.-Pinus ponderosa jeffreyi, Tallac, Eldorado County (Davidson).

Davidson's is the only report of this species in California. The identification of his specimens was verified by Davis. One specimen the author saw was quite small, being much smaller than the others taken by Davidson.

\section{Lachnus pseudotsugae Wilson}

Figures 92, 98

Wilson, Can. Ent., vol. 44, pp. 159, 302, 1912 (orig. dese.). Record.-Pseudotsuga taxifolia; Oregon, California (Wilson). 
Wilson wrote the author some time ago that he had taken this species in California, although he gave no definite locality or collection record. The author has had the opportunity to study cotype specimens.

\section{Lachnus sabinianus n.sp.}

\section{Record.-Pinus sabiniana, San Francisco (Compere).}

In March, 1915, Harold Compere of the California State Insectary found a small infestation of a species of Lachnus on Digger Pine in the Golden Gate Park, San Francisco. Since this one collection, the spccies has not again been observed. Being unable to identify the species with any described in America, a description is herewith appended, the species being named after its host plant, Pinus sabiniana. All the specimens, including the types are in the collections of E. O. Essig and of the University of California, Berkeley. The specimens were all mounted in Canadian balsam.before color notes were taken, so those in the following description are only approximately correct.

Alate viviparous female.-Rich chestnut-amber to dark brown. Antennal segments I and II, amber; III, yellowish with tips darker; IV, V, and VI, dark yellow to dusky. Prothorax, chestnut-brown. Thoracic lobes very dark brown to black. Beak, pale with tips dusky. Cornicles, black. Cauda and anal plate with distal margins black. Fcinora, chestnut-brown with base amber; tibiae, brown with amber ring near the base; tarsi, amber. Wing veins, grayffi stigma, dusky gray.

Measurements: Body $4.2 \mathrm{~mm}$. long and $1.7 \mathrm{~mm}$. wide at thorax. Antennae reach to base of abdomen, without secondary sensoria. I, $0.10 \mathrm{~mm}$. ; II, $0.09 \mathrm{~mm}$. ; III, $0.50 \mathrm{~mm}$. ; IV, $0.25 \mathrm{~mm}$.; V, $0.19 \mathrm{~mm}$.; VI, $0.08 \mathrm{~mm}$; total, $1.21 \mathrm{~mm}$. Beak reaches to the base of the cornicles. Cornicles medium sized and of the usual Lachnus shape, being

Apterous viviparous female.-Chestnut-brown in color with black dorsal spots on abdomen. Antennal segments I and II, dark; III, dusky ycllow with tip dark; IV, V, and VI slightly darker. Beak reaches to the base of the cornicles. Coxae, black; femora, black with basal one-fifth paler; tibiae, black with pale ring near base; tarsi, black. Cornicles, black and conspicuous. They measure $5.2 \mathrm{~mm}$. in length and $3.3 \mathrm{~mm}$. in width. 


\section{5:3. Lachnus taxifolia Swain}

Figures 99-103

Swain, Traus. Am. Ent. Soc., vol. 44, p. 11, 1918.

Records.-Pseudotsuga taxifolia, Sacramento (Essig), Berkeley and San Franciseo (Shinji).

This is a fairly common species found in colonies on the branches and trunks of Douglas fir in the San Francisco Bay and Sacramento Valley. It is interesting particularly because of the atrophied cornicles.

\section{Lachnus tujafilinus (Del Guercio)}

Figures 93, 105

Del Guercio, Redia, vol. 5, p. 287, 1909. Lachneilla (orig. desc.).

Essig, Pom. Joụr. Ent., vol. 3, p. 541, 1911. Lachnus juniperi DeGeer (dese.).

Essig, Pom. Jour. Ent., vol. 4, p. 773, 1912. Lachnus juniperi DeGeer (list).

Davidson, Jour. Econ. Ent., vol. 7, p. 127, 1914 (list).

Records.-Thuya occidentalis, Claremont, Santa Paula (Essig); Palo Alto, Walnut Creek (Davidson); Stanford University, March, 1912 (Morrison); San Diego, March, 1916; Riverside, October, 1916, March, 1917.

This oddly marked Lachnus is more or less common throughout California wherever arborvitae is cultivated. The apterous females are the most common, and are easily recognized by the odd markings on the dorsum of the abdomen (see Essig's illustrations). Occasionally the alate females are found, Davidson finding some in April, Morrison and the author in March. The author has observed the larvae of Coccinella californica feeding on them in Riverside.

\section{Lachnus vanduzei n.sp.}

Figure 88

Records.-Picea sp., Berkeley, September, 1914 (Essig, E. P., Van Duzee).

In September, 1914, E. P. Van Duzee collected a few specimens of a large Lachnus on a species of spruce in Strawberry Canyon, near Berkeley. Later in the same month Essig found specimens on the same tree. The following fall the author hunted for the species, 
but was unable to find any specimens, the tree on which it was first found having been cut down. In the following description the color notes are not absolutely accurate, as they were taken from material mounted in balsam. This specics is named after its first collector, Mr. E. P. Van Duzee, of the University of California. Type specimens are in the collection of the University of California.

Alate viviparous female.-The alate viviparous females are of a dark muddy color, as near as can be judged from the mounted specimens. The antennae are: I and II, dusky; III and IV, pale with apical half dusky; V, pale with the apex or apical third dusky; VI, pale with the apcx and spur dusky. The measurements of the segments are: I, $0.09 \mathrm{~mm}$.; II, $0.07 \mathrm{~mm}$; III, $0.5 \mathrm{~mm}$.; IV, $0.26 \mathrm{~mm}$.; V, $0.27 \mathrm{~mm}$.; VI, $0.16 \mathrm{~mm}$. The sensoria are located as follows: III, 10-12; IV, $2-3 ; \mathrm{V}, 2-3 ; \mathrm{VI}, 1$. They arc large and circular, and quite evenly distributed in a line on each segment. The beak reaches to the base of the cauda. The coxae are black, the femora amber on the basal half and black on the apical; the tibiae are black with an amber ring near the base, the tarsi ale black. The first joint of the hind tarsus is not one-third the length of the sccond, the first measuring $0.08 \mathrm{~mm}$., and the second $0.26 \mathrm{~mm}$. The wings are quite large, with a very distinct stigma. The costal vein is grayish-brown, the subcostal brown. The stigma is long and brown, the stigmal vein being pale brown and slightly curved throughout its entire length. The first and second discoidals are distinct and pale brown, the second discoidal being slightly curved near the tip. The third discoidal is indistinct and twice-branched, the angles of the branches being very acute.

Apterous viviparous female.-Prevailing color, amber-brown, with the abdomen mottled gray, brown, and black. The head is brown with anterior margin amber. The antennae are colored as follows: I, amber; II, amber; III, amber with tip dusky; IV, amber with tip dusky; V, amber with apical two-thirds dusky; VI, dusky. The beak reaches to the base of the cauda. The femora arc brown with the bases amber, the tibiae and tarsi brown. The first joint of the hind tarsus is scarcely more than one-third the length of the second. In four tarsi measured, the relative lengths of the joints were: 0.07 to $0.23 \mathrm{~mm}$.; 0.08 to $0.23 \mathrm{~mm}$.; 0.08 to $0.28 \mathrm{~mm}$.; and 0.07 to $0.25 \mathrm{~mm}$. The cornicles are conspicuous and dark, the cauda well rounded and dark on its posterior edge. The lengths of the antennal segments are: I, $0.1 \mathrm{~mm}$.; II, $0.1 \mathrm{~mm}$. ; III, 0.56 to $0.57 \mathrm{~mm}$. ; IV, 0.21 to $0.23 \mathrm{~mm}$. ; $\mathrm{V}, 0.22$ to $0.28 \mathrm{~mm}$.; VI, 0.15 to $0.16 \mathrm{~mm}$. 


\section{Group Aphidina Wilson}

Wilson, Ann. Ent. Soc. Am., vol. 3, p. 314, 1910.

This group as considered by Wilson consists of three tribes: Triehosiphini, Maerosiphini, and Aphidini. The first of these contains two genera found only in the Asiatic islands, so it will not be eonsidered in this paper. This group eontains quite closely related genera, and in many eases it is quite hard to distinguish between them. Following is a brief extraet from Wilson's paper (eited above) :

In studying closely related genera the development of the external characters may be placed in five divisions: (1) the antennae and spur; (2) the antennal tubercles; (3) the development of the nectaries [cornicles]; (4) the development of the cauda; (5) the development of the wing venation. In a group of insects as pliable as the present one, any one or two of these characters may be either under-or over-developed and it is necessary to place the genera according to the greatest development. Of all the characters which show this variation the wings show what may be true of all these characters.

The two tribes have been separated from one another on the eharaeter of the antennal tubercles, as Wilson says in the same paper:

The division is made between species with distinct antennal tubercles and those having none or at the most indistinct tubercles. However, should a certain species have distinct antennal tubereles with the other characters [of the Macrosiphini] wanting, then it would have to go into the next tribe [Aphidini].

The keys to the tribes and genera below have been formulated by the author, following, however, those of Wilson, Van der Goot, and Mordwilko.

1. Antennal tubercles well formed. Antennae usually as long as or longer than the body. Apterae often with sensoria on the third antennal segment. Body never with lateral tubercles on the seventh abdominal segment. Cornicles variable but usually about one-fourth the length of the body or longer Tribe Macrosiphini

- Antennal tubercles absent or more or less indistinct. Antennae seldom longer than the body. Apterae seldom with sensoria on the third antennal segment. Body with lateral tubercles on at least the seventh abdominal seg. ment Tribe Aphidini

\section{Tribe Macrosiphini Wilson}

Wilson, Ann. Ent. Soc. Am., vol. 3, p. 314, 1910.

To a large extent the author has followed Wilson in the plaeing of the genera, but in a few eases he has not. This is noticeable in Toxoptera, which is eonsidered by Wilson as belonging to this tribe, 
while the author feels that it is better associated with the Aphidini, inasmuch as the antennal tubercles are very small and more or less indistinct and as the antennae are scarcely as long as the body. Van der Goot's genus, Myzaphis, has been accepted for the two species, Myzus rosarum (Walker) and Aphis abietina Walker, and is included with the Aphidini. The species Aphis nymphaeae Linn., which Wilson uses as the type of Rhopalosiphum, has been taken from this genus and placed in Siphocoryne, chiefly because of the apparent absence of antennal tubercles and of the presence of distinct tubercles on the seventh abdominal segment. Therefore Aphis persicae Sulzer takes the place as type of the genus Rhopalosiphum.

\section{Key to California Genera}

1. Cornicles cylindrical, or at most but very slightly swollen on one side (figs. 122, 152)

- Cornicles distinctly swollen toward apex, or clavate (figs. 109, 113, 119) ...... 2

2. Antennal tubercles very large and tapering but not gibbous on the inner side; the bases of the antennae being more or less approximate (fig. 107).

Nectarosiphon Schouteden

- Antennal tubercles distinet, but not large and tapering as above, being more or less toothed or gibbous on the inner side; the bases of the antennae not approximate (figs. 108, 111)

3. Antennal tubercles short and wedge-shaped, the outer side not evident (fig. 108). Cauda ensiform and of medium size. Antennae at most but slightly longer than the body

Rhopalosiphum Koch

- Antennal tubereles short, but not wedge-shaped (fig. 111). Antennae considerable longer than the body. Cauda very large and long.

Amphorophora Buckton

4. Antennal tubercles large and as long on the outer as on the inner side (fig. 106)

- Antennal tubercles with outer side shorter than inner, or not evident (figs. 112, 115, 116)

5. Cornicles tapering, longer than cauda which is ensiform (fig. 152). Wing venation regular, with third discoidal twice-branched.

Macrosiphum Passerini

- Cornicles and cauda variable. Wing venation irregular and very striking with veins either wanting or combined, and shaded

6. Antennal tubereles with short upper inner angle. Cauda shorter than cornieles and tapering. Stigmal and third discoidal veins meet in a broad dark band, giving the wing the appearance of having a closed triangular cell (fig. 110)

Idiopterus Davis

- Antennal tubercles with small rounded tubercle at the upper inner angle. Cornicles slightly constricted in the middle and at the tip. Wing venation variable, but usually the stigmal and third discoidal veins are partly joined and form a distinct, closed, four-sided cell .......Pentalonia Coquerel

7. Antennal tubercles and first antennal segment with a strong tooth on the inner side of each (figs. 115, 116). Cauda short and tapering (fig. 118). Cornicles cylindrical and tapering slightly with tip outcurved (fig. 117).

Rhorodon Passerini 
- Antennal tubereles with a distinet but not prominent blunt projection forming the inner angle (fig. 112), but the prominent teeth as above are lacking. Cauda short, tapering, and usually triangular (fig. 121). Cornicles as above, being cylindrical, with a slight tapering from base to apex, and often slightly outeurved at tip (fig. 122)

Myzus Passerini

\title{
21: Genus Amphorophora Buckton
}

Buckton, Monog. Brit. Aphides, 1876. Type A. ampullata n.sp.

\section{Key to Californian Species?}

Cornicles pale, or at most slightly dusky, swollen and vasiform (fig. 113). VI spur longer than III, the latter with $35-45$ sensoria rubi (Kalt.)

Cornicles black, greatly dilated in apical one-half (fig. 161). VI spur shorter than III, latter with 13-17 sensoria ..latysiphon Davidson

\section{Amphorophora latysiphon Davidson}

Figure 161

Davidson, Jour. Econ. Ent., vol. 5, p. 408, 1912 (orig. desc.).

Records.-Vinca major, San Jose (Davidson); Courtland, Contra Costa County (Davidson); Stanford University, 1912 (Morrison, Essig). Convolvulus arvensis, San Jose (Davidson). Solanum tuberosum, Walnut Creek, Contra Costa County, 1915 (Davidson).

This species has been found sparingly in the San Francisco Bay region on periwinkle, morning-glory, and potato tubers, although it has never seemed to be common. The author has not collected it, his only specimens being some taken by Essig on periwinkle near Stanford University. The odd shape of the cornicles is a distinguishing character.

\section{Amphorophora rubi Kalt.}

\author{
Figures 111, 113, 162
}

Kaltenbach, Monog. d. Pflanzenläuse, p. 23, 1843. Aphis (orig. desc.).

Davidson, Jour. Econ. Ent., vol. 5, p. 411, 1912 (list).

Shinji, Can. Ent., vol. 49, p. 52, 1917 (list).

Records.-Rubus parviflorus; San Jose (Davidson): Rubus spp., Walnut Creek, 1915 (Davidson); Berkeley (Shinji).

This species has been taken a few times on thimble-berry in the San Francisco Bay region. Davidson writes that he has also found it on blackberry and loganberry in the vicinity of Walnut Creek,

${ }^{9}$ G. O. Shinji (Can. Ent., vol. 49, p. 51, 1917) deseribed an aphid from Ciculta virosa var. californica in Berkeley, which he called Amphorophora cicutae n.sp. The author has never seen specimens, so does not feel that he can recognize this as a good species. Of some half dozen new (?) species described by Shinji the author has found none, on examining specimens, that are good species, hence he cannot recognize this one at present. 
Contra Costa County. The author has recently received specimens from Gillette of an alate viviparous female and apterous oviparous females taken in the vicinity of Fort Collins, Colorado. Inasmuch as the descriptions of this species are inadequate and not readily accessible it has been thought best to give here brief descriptions of the different forms. As no color notes were received with the specimens they must necessarily be omitted.

Alate viviparous female (from Fort Collins, Colorado).-Antennae half as long again as the body, dusky, and placed on small but distinct tubercles. From the mounted material it appears as if III were dusky, IV, pale with extreme tip dusky; V, pale with apical one-third dusky; and VI dusky. VI spur is the longest segment, followed by III, IV, V, VI base, I, and II. The usual primary and accessory sensoria are present on VI base, and the primary sensorium on V. Secondary sensoria are present only on III. These are small, circular, irregular-sized, and irregularly placed along the whole length of the segment. The number (35 to 40 ) is such as to make the segment appear tuberculate. The beak is quite large and long, reaching to or slightly beyond the third coxae. The thorax is dusky. The wings fairly large, and normal. The second branch of the third discoidal vein arises nearer to the base of the first branch than to the apex of the wing. Normally the measurements are as follows: From the base of the second branch of the third discoidal to the tip of the wing is about $0.8 \mathrm{~mm}$., from the base of the first branch to the base of the second $0.4 \mathrm{~mm}$., from the apex of the. first branch to the apex of the second $0.29 \mathrm{~mm}$. In one case the base of the second branch was 1.02 $\mathrm{mm}$. from the apex of the wing, and but $0.034 \mathrm{~mm}$. from the base of the second, while the apices of the two branches were but $0.187 \mathrm{~mm}$. apart. The legs are long, femora pale with apical one-fourth dusky, tibiae and tarsi dusky. The abdomen is pale with some slight dorsal dark markings, these being indistinct in the mounted specimens. The cornicles are fairly long, clavate on the apical one-half or two-thirds, dusky throughout, and with the extreme tip reticulated. In length they are somewhat shorter than III, but longer than IV. The cauda is pale, short, and triangular, being about equal in length to the hind tarsi.

Measurements : body length, $1.785 \mathrm{~mm}$.; antennae total, $2.788 \mathrm{~mm}$.; III, $0.68 \mathrm{~mm}$.; IV, $0.51 \mathrm{~mm}$.; V, 0.408 to $0.425 \mathrm{~mm}$; VI, base, 0.12 mm.; VI, spur, 0.867 to $0.884 \mathrm{~mm}$; cornicles, 0.578 to $0.646 \mathrm{~mm}$; cauda, $0.102 \mathrm{~mm}$; hind tarsi, $0.102 \mathrm{~mm}$; wing length, $3.128 \mathrm{~mm}$; width, $1.292 \mathrm{~mm}$; cxpansion, $6.8 \mathrm{~mm}$. 
Apterous oviparous female (Fort Collins, Colorado).-Pale throughout, with many small hairs seattered over the body. Most of these hairs are simple, but some especially on the front of the head and on the bases of the antennac, are eapitate. Antennac slightly longer than the body, palc, with VI and the apiecs of the other segments dusky. VI spur and III are subequal or either one may be slightly longer than the other. These are followed by IV, V, VI base, I, and II. The usual primary and acessory sensoria are present on VI base, and the primary sensorium of V. Secondary sensoria are preselt only on III, and number about nine or ten. These are small, circular, but varying in size, and are arranged in a more or less even line along the basal onc-half to two-thirds of the segment. Beak pale, with tip dusky, quite large and long, reaching to or beyond the third coxae. Thorax and legs normal, except the hind tibiae which are quite long, and furnished with a large number of sensoria. These sensoria cover practically the whole joint. Cornicle very long and large, curved outward, pale, with apex dusky, and with distinct reticulations at the extreme tip. They are markedly larger than in the alate viviparous females, being considerably longer than the third antennal segment, and in some cases even half as long again. The cauda is small, pale, and triangular, although somewhat larger in the viviparous female.

Measurements : body length, $2.04 \mathrm{~mm}$.; width of thorax, $0.595 \mathrm{~mm}$.; antennae total, $2.446 \mathrm{~mm}$. ; III, 0.646 to $0.697 \mathrm{~mm}$.; IV, 0.442 to 0.459 mm.; V, 0.356 to $0.374 \mathrm{~mm}$; VI, base, $0.136 \mathrm{~mm}$.; VI, spur, $0.663 \mathrm{~mm}$; cornicles, 0.918 to $0.952 \mathrm{~mm}$. ; cauda, $0.187 \mathrm{~mm}$. ; hind tarsi, $0.136 \mathrm{~mm}$.

\section{Genus Idiopterus Davis}

Davis, Ann. Ent. Soc. Am., vol. 2, p. 198, 1909. Type, I. neprelepidis n.sp.

\section{Idiopterus nephrelepidis Davis}

Figure 110

Davis, Ann. Ent. Soc. Am., vol. 2, p. 198, 1909 (orig. desc.).

Davidson, Jour. Econ. Ent., vol. 3, p. 376, 1910 (list).

Essig, Pom. Jour. Ent., vol. 3, p. 538, 1911 (list).

Records.-Nephrolepis exaltata, Santa Paula (Essig), Palo Alto, April, 1915, San Diego, March to May, 1916; Riverside, February, 1917: Cyrtonium fulcotum, Berkeley, March, 1915 (Essig) ; ferns (unidentified species of house ferns), Stanford University (Davidson, Morrison); Viola sp., Claremont (Essig).

This small black aplid is often found in houses and nurseries, and occasionally out of doors, on the fronds of various kinds of house 
ferns, particularly the Boston fern. Essig has also found it on violets in the vicinity of Pomona College. The alate females have the wings beautifully marked with black and white.

\section{Genus Macrosiphum Passerini}

Passerini, Gli Afidi, 1860. Type Aphis rosae Linn.

\section{Key to California Species \\ Alate viviparous females}

1. Cornieles slightly clavate on one side, somewhat as in Rhopalosiphum.

- Cornicles not clavate tulipae (Monell)

2. III as long as V and VI (base and spur) sonchella (Monell)

- III not as long comparatively

3. III pale, IV, V, and VI dusky jasminum (Clarke)

- Not so; if IV, V, and VI are dusky then III is also, except perhaps the base; or if III is pale throughout then at least the greater part of IV and $V$ are also pale 4

4. VI (base and spur) shorter than III, but V and VI together are longer than III baccharadis (Clarke)

- VI (base and spur) not shorter than III 5

5. Secondary sensoria on III, IV, and V. Cornicles not reticulated.

heucherae (Oestlund)

- No secondary sensoria on $\mathrm{V}$ 6

6. Secondary sensoria on both III and IV. Cornicles with tips at least reticulated (fig. 152) 7

- No secondary sensoria on IV 10

7. Cornicles and cauda subequal in length, the former being more or less bottleshaped sanborni Gillette

- Cornicles longer than cauda 8

8. Cauda light green. Secondary sensoria only occasionally present on IV and then very small and indistinet .........................................................rosae (Linn.)

- Cauda dark (brown or black). Seven or more distinct secondary sensoria on IV

9. Body with eapitate setae, especially on head and antennae.

artemisiae (Fonsc.)

- Body without capitate setae. Abdomen with dark dorsal markings.

lactucae (Kalt.)

10. Cornicles with at least tips reticulated (fig. 132) ............................................ 14

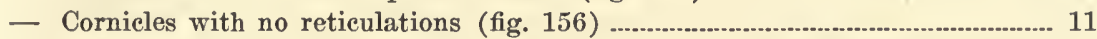

11. Body with fan-shaped setae ............................................artemisicola (Williams)

- Body without fan-shaped setae ...................................................................................... 12

12. Distal two-thirds of cornicles black ................................orthocarpus (Dvdn.)

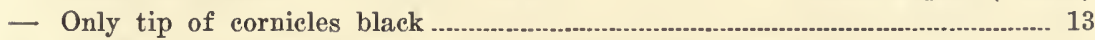

13. Cornicles long and slender. About 18 secondary sensoria in a row on III (fig. 130) pisi (Kalt.)

- Cornicles shorter and heavier. About 25 to 30 sensoria seattered irregularly along III (fig. 157) dirhodum (Walker)

14. Cornicles with more than apical one-half reticulate (fig. 149). ludovicianae (Oestlund)

- Cornicles with less than apical one-half reticulated (fig. 128) ......................... 15 
15. Cornicles dusky for practically their entire length

- Cornicles with less than apical one-half dusky.

16. Cornicles considerably longer than III, with apical portion curved outward. About a dozen, medium-sized sensoria in a straight line along basal twothirds of III (fig. 131) californicum (Clarke)

- Cornicles not considerably longer than III 17

17. Cornicles and VI spur subequal, the former fairly long, slightly curved outward and slightly swollen before the tip (fig. 128) .........stanleyl Wilson

- Cornicles considerably shorter than VI spur, and not swollen before the tip 18

18. Secondary sensoria in a fairly straight line on III. Body not pulverulent 19

- Body covered with a slight pulverulence. III with about 30 fairly largesized sensoria, more or less seattered along the entire length (fig. 143).

albifrons Essig

19. Cornicles about half the length of VI spur and considerably shorter than III, the latter with about 20 to 30 secondary sensoria pteridis Wilson

- Cornicles about two-thirds as long as VI spur and slightly shorter than III, the latter with about 15 sensoria (fig. 133) ...............cucurbitae (Thomas)

20. Ground or basal color of abdomen green ...................................................... 21

- Ground or basal color of abdomen red, brown, or black ....................................... 24

21. Cornicles green, sometimes dusky at apex ...-.....................solanifolii (Ashmead)

- Cornicles black ....................................................................................................... 22

22. III with a small number (9-15) of secondary sensoria on basal one-half (fig. 135); longer than VI spur granarium (Kirby)

- III with some 30 or more sensoria scattered along its entire length (figs. 151, $159)$; subequal to or shorter than VI spur

23

23. Cornicles and III subequal. Tibiae with apices only dusky ........rosae (Linn.)

- Cornicles longer than III. Tibiae dusky throughout.

rudbeckiae (Fiteh) n.var. madia

24. Cauda pale

- Cauda dusky

25. III and VI spur subequal rosae (Linn.)

- III shorter than VI spur 26

26. Cauda about one-half as long as cornicles, the latter shorter than IV. chrysanthemi (Oestlund)

- Cauda slightly more than one-half as long as cornicles, the latter equal to or longer than IV rudbeckiae (Fitch)

27. III and VI spur subequal 28

- III longer than VI spur taraxici (Kalt.)

28. Body yellowish-brown in color; legs same except tarsi and tips of tibiae and femora which are dusky to black valerianae (Clarke)

- Body dark reddish-brown to black in color; legs dusky throughout.

ambrosiae (Thomas)

\section{Apterous viviparous females 10}

1. Cornicles clavate on one side, somewhat as in Rhopalosiphum.

- Cornicles not so, being cylindrical or subcylindrical

tulipae (Monell)

10 Only the species of which there are specimens available to the author, or of which there are adequate descriptions, are included in this key. The species represented in the author's collection are marked with an asterisk $\left({ }^{*}\right)$. The author recognizes the great difficulty in separating the apterae of various species, particularly in this genus, and offers this key merely as a slight aid toward the recognition of the better known species. 
2. III without or at most with only a few secondary sensoria (0-12)

- III with several (over 12) secondary sensoria scattered along the greater part of its length

3. Cornicles short and tapering, being somewhat bottle-shaped and not distinctly longer than the cauda ....................................................sanborni Gillette*

- Cornicles normal, being cylindrical and considerably longer than the cauda 4

4. III and IV with secondary sensoria heucherae (Oestlund)

- IV without secondary sensoria

5. General body color dark, being red, wine, brown or black 5

- General color lighter, usually being a shade of green ...................................... 8

6. Cauda black. Legs black, except the bases of the femora ......taraxici (Kalt.)

- Cauda pale. Legs with at least the bases of the femora and tibiae not black 7

7. Legs green, except tarsi and apices of femora and tibiae. Cauda not more than half the length of the cornicles. Not more than ten to twelve sensoria on the basal one-third of III. rosae (Linn.)*

- Legs black, except bases of femora and tibiae, which are light brown. Cauda more than half the length of the cornicles. A considerable number of sensoria scattered over more than the basal one-half of III.

rudbeckiae (Fitch)*

8. Cornicles subequal to or shorter than III. Body covered with a whitish pulverulence

- Cornicles distinctly longer than III. Body without whitish pulverulence .... 10

9. Cornicles, except tip, and cauda green; the former subequal in length to III and about twice as long as cauda albifrons Essig*

- Cornicles black, cauda yellow or light brown; the former considerably shorter than III and not twice as long as cauda ..................ludovicianae (Oestlund)*

10. Cauda quite broad and blunt at end. Cornicles with not more than apical onesixth reticulated rosae (Linn.)*

- Cauda slender and pointed. Cornicles with apical one-fourth reticulated. rudbeckiae (Fitch) n.var. madia*

11. Body covered with eapitate or fan-shaped setae ................................................. 12

- Body without specialized setae ........................................................................... 14

12. Setae with fan-shaped tips and thickly covering the body. Cornicles slender and imbricated for their entire length artemisicola (Williams)*

- Setae capitate and only sparsely covering body 13

13. Cornicles fairly stout, with tips reticulated, and about twice as long as cauda. artemisiae (Fonsc.)

- Cornicles slender, with no reticulations, and considerably more than twice the length of the cauda pteridis Wilson

14. Cornicles with tips at least reticulated .................................................................. 16

- Cornicles with no reticulations .................................................................................... 15

15. Cornicles very long and slender. Antennae considerably longer than body. pisi (Kalt.)*

- Cornicles shorter and heavier. Antennae at most but slightly longer than body dirhodum (Walker)*

16. Cornicles for the most part dusky or black ..................................................... 17

- Cornicles mostly pale or green ............................................................................ 19

17. Cornicles and III subequal. Body not pulverulent ......................................... 18

- Cornicles considerably shorter than III. Body more or less pulverulent. ludovicianae (Oestlund)* 
18. III with but two or four sensoria near base; longer than VI spur.

granarium (Kirby)*

- III with six or so sensoria on basal one-half; shorter than or equal to VT spur rosae (Linn.)*

19. Cornicles longer than III ................................................................................. 20

- Cornicles at most subequal to III .................................................................... 21

20. Antennae pale, except VI and the apices of III to V. Cornicles slightly swollen near distal end stanleyl Wilson*

- Antennae dusky, except III, basal part of IV, and perhaps the extreme base of V. Cornicles long, slender, and out-curved ........californicum (Clarke)*

21. Cauda broad, and blunt, with the sides almost parallel and about half as long as cornicles

lactucae (Kalt.)*

- Cauda slender-pointed, and more than half as long as cauda 22

22. VI spur and III subequal solanifolii (Ashmead)*

- VI spur considerably longer than III cucurbitae (Thomas)*

\section{Macrosiphum albifrons Essig}

Figures 143, 144

Davidson, Jour. Econ. Ent., vol. 2, p. 304, 1909. Macrosiphum sp. (list).

Essig, Pom. Jour. Ent., vol. 3, p. 543, 1911 (orig. desc.).

Records.-Lupinus sp., Santa Paula (Essig); Stanford University (Davidson); Jasper Ridge, Coast Range Mountains, Santa Clara County, April, 1912 (V. G. Sterens); Berkeley, April, 1915 (Geo. Shinji); Mount Hood, Oregon, August, 1916 (E. A. MeGregor).

This large, flocculent aphid is found occasionally infesting various lupines throughout the Pacific Coast, from southern California north, well into Oregon. The author has specimens from Berkeley and Oregon, although he has never collected it himself.

\section{Macrosiphum ambrosiae (Thomas)?}

Thomas, Ill. Lab. Nat. Hist., Bull. 2, p. 4, 1878. Siphonophora (orig. dese.).

Sanborn, Kans. Univ. Sci., Bull. 3, p. 74, 1904 (desc.).

Records.-Helianthus annuus; Orange (T. D. A. Cockerell); San Diego, April, 1916.

In 1915 the author received a few specimens of this species from T. D. A. Cockerell from Orange, and in 1916 he collected it once on sunflower in Exposition Park, San Diego. At first it was thought to be $M$. sonchi (Linn.); and was so reported by Cockerell. Since then it was identified by J. J. Davis as probably M. ambrosiae (Thomas). 


\section{Macrosiphum artemisiae (Fonsc.)}

Figures 142, 145

Boyer de Fonseolmbe, Ann. Ent. Soc. France, vol. 10, p. 162, 1841. Aphis (orig. desc.).

Essig, Pom. Jour. Ent., vol. 3, p. 546, 1911. Macrosiphum frigidae (Oest.) (dese.).

Daridson, Jour. Econ. Ent., vol. 3, p. 133, 1914. Macrosiphum frigidae (Oest.) (list).

Wilson, Trans. Amer, Ent. Soc., vol. 41, p. 97, 1915 (desc.).

Records.-Artemisia californica; Santa Paula (Essig); Walnut Creek, Contra Costa County (Davidson).

Occasionally this species is found infesting the tender shoots of the common California sage brush. It is characterized by the presence of capitate hairs scattered sparsely over the body, particularly of the apterous female. The synonomy above is after Wilson, who lists M. frigidae (Oestlund) as a synonym of artemisiae (Fonsc.).

\section{Macrosiphum artemisicola (Williams)}

Figures 146, 147

Williams, Univ. Neb. Studies, vol. 10, p. 73, 1910. Siphonophora (orig. dese.).

Wilson, Trans. Am. Ent. Soc., vol. 41, p. 96, 1915 (desc.).

Records.-Artemisia tridentata, A. vulgaris; Oregon (California) (Wilson).

Although there is no published record of the presence of this species in California it is included here on Wilson's authority. He stated to the author that he had found it in California, although he failed to give any date or locality record. This is characterized by the fan-shaped setae which thickly cover the body of the apterae, and which are present on the ventral side of the abdomen of the alates. The author has specimens taken by R. W. Haegele in the summer of 1915 on Artemisia sp. near Canton, Montana.

\section{Macrosiphum baccharadis (Clarke)}

Clarke, Can. Ent., vol. 35, p. 254, 1903. Nectarophora (orig. dese.).

Record.-Baccharis sp., Berkeley (Clarke).

This species is one of those described by Clarke, but since then unknown. It is possible that it is M. rudbeckiae (Fitch), which is so common on Baccharis throughout California. 


\title{
64. Macrosiphum californicum (Clarke)
}

\author{
Figures 131, 132
}

Clarke, Can. Ent., vol. 35, p. 254, 1903. Nectarophora (orig. desc. apterae). Davidson, Jour. Econ. Ent., vol. 2, p. 304, 1909 (list).

Davidson, Jour. Econ. Ent., vol. 3, p. 380, 1910 (list).

Davidson, Pom. Jour. Ent., vol. 3, p. 398, 1911 (list).

Essig, Pom. Jour. Ent., vol. 3, p. 548, 1911. M. laevigatae, n.sp. (orig. desc.).

Records.-Salix sp.; Newcastle, Placer County (Clarke); Stanford University and Penryn, Placer County (Davidson); Stanford University, November, 1914 (Morrison), May, 1915; Berkeley, April, 1915 (Shinji); August, 1915, Salix laevigata; Sauta Paula (Essig); Riverside, May, 1917.

Clarke deseribed the apterous females of a species of Nectarophora (Macrosiphum) from specimens taken on willow in Plaeer County. Beeause of the extremely long eornieles it is possible to identify this with speeimens taken since throughout the San Franeiseo Bay region on various speeies of willows. Essig's $M$. laevigatae from Santa Paula is the same speeies, having been eompared by the author with specimens from Stanford University and Berkeley. Morrison has taken the males and oviparous females of this speeies in the vieinity of Stanford University in November, 1914. The author has reared speeimens of Aphidius polygonaphis Fiteh, and Praon simulans Prov. from this speeies taken in Berkeley.

\section{Macrosiphum chrysanthemi (Oest.)}

Oestlund, 14th Rep. Geol. Surv. Minn., vol. 22, 1886. Siphonophora (orig. desc.).

Davidson, Jour. Econ. Ent., vol. 5, p. 411, 1912 (list).

Record.-Undetermined species of Compositae; Courtland (Davidson).

This is a doubtful speeies taken by Davidson at one time from an undetermined composite near Courtland. The author is entirely unacquainted with the speeies.

\section{Macrosiphum cucurbitae (Thos.)}

Figures 133, 134

Thomas, 8th Ann. Rep. Illinois St. Ent., p. 66, 1879. Siphonophora (orig. desc.).

Record.-Cucurbita sp., Hayward, Alameda County, July, 1915 (Roy E. Campbell); Los Angeles, May, 1917. 
In July, 1915, Roy E. Campbell of the Bureau of Entomology, sent the author specimens of a Macrosiphum sp. from squash in Hayward. In 1917 the author found the same species abundantly on squash in Los Angeles. These the author identified as being specimens of $M$. cucurbitae (Thomas). Later J. J. Davis verified the determination. This is a new record for California. As the available descriptions of this species are quite inadequate, the author gives herewith a few descriptive notes taken from these specimens..

Alate viviparous female.-Antennae longer than the body, placed on distinct frontal tubercles, dusky except I, II, and extreme base of III. The spur of VI is the longest segment, followed by III, which is about four-fifths as long. IV and $\mathrm{V}$ are subequal, and almost as long as III. The usual primary and accessory sensoria are present on V and VI. Secondary sensoria are present on III (fig. 133), bcing small, circular, numbering about 14 to 15 , and arranged in a fairly even row along the whole length of the segment. Beak pale with dusky tip, reaching to the second coxae. Thorax and abdomen green, the thoracic lobes not conspicuously darkened. Cornicles (fig. 134) green with apical one-third dusky, equal to or slightly longer than III, imbricated with tip reticulated. Cauda large, pale, vasiform, slightly more than half the length of the cornicles, reaching to their apices. Wings and legs normal.

Measurements: Body length, $2.3 \mathrm{~mm}$. ; antennac total, 3.25 to 3.35 mm.; III, 0.685 to $0.714 \mathrm{~mm}$; IV, 0.629 to $0.646 \mathrm{~mm}$.; V, 0.603 to $0.612 \mathrm{~mm}$. ; VI, base, 0.136 to $0.153 \mathrm{~mm}$. ; VI, spur, 0.935 to $0.696 \mathrm{~mm}$. ; cornicles, 0.714 to $0.731 \mathrm{~mm}$; cauda, $0.408 \mathrm{~mm}$.

\section{Macrosiphum dirhodum (Walker)}

\section{Figures 156, 157}

Walker, Ann. Nat. Hist., (2), vol. 3, p. 43, 1848. Aphis (orig. dese.). Theobald, Jour. Econ. Biol., vol. 8, p. 128, 1913 (dese.). Patch, Maine Agr. Exp. Sta., Bull. 233, p. 268, 1914 (note). Gillette, Jour. Econ. Ent., vol. 8, p. 103, 1915 (note).

Record.-Rose, Santa Ysabel (3000 feet altitude), San Diego County, May, 1916; Riverside, April, 1917.

The author found this species sparingly on rose near Santa Ysabel, San Diego County, in May, 1916, and again in April, 1917, in Riverside. According to Gillette, this species passes the winter on rose, and the summer on various grains and grasses, as $M$. rosae (Linn.) 
may do. These are the only records of it in California. The author has compared it with specimens taken by $\mathrm{R}$. W. Doane in 1915 on grain in Utah.

\section{Macrosiphum granarium (Kirby)}

Figures 135, 148

Kirby, Linn. Soc. Trans., vol. 4, p. 238, Aphis (orig. dese.). Davidson, Jour. Econ. Ent., vol. 5, p. 411, 1912 (list).

Theobald, Jour. Econ. Biol., vol. 8, p. 58, 1913 (dese.).

Davidson, Mon. Bull., Cal. Comm. Hort., vol. 6, p. 65, 1917 (note).

Records.-Graminaceae (various species); San Jose (Davidson); Stanford University, January to May, 1915; Berkeley, March, 1915: Typha latifolia (Davidson).

This is a more or less common species of Macrosiphum on various grains and grasses in the San Francisco Bay region during the winter and spring. In late spring and early summer, as the grasses begin to dry out, it leaves them for the eat-tail rush or California tule (Davidson, 1917). In the late fall or early winter it returns to the grains and grasses, where it passes the winter in the viviparous forms.

\section{Macrosiphum heucherae (Thomas)}

Thomas, 8th Ann. Rep. Illinois St. Ent., p. 66, 1879. Siphonophora (orig. desc.).

Davidson, Jour. Econ: Ent., vol. 8, p. 427, 1915 (desc.).

Record.-Heuchera hartwegi, Redwood Canyon, Contra Costa County (Davidson).

In the latter part of May, 1914, Davidson found all the forms, including the apterous and alate viviparous females, the apterous oviparous females, the alate males, and eggs on the flower stalks of alum root in Contra Costa County. Since his deseription no record has been made concerning the species. The author is unacquainted with it, having never seen specimens.

\section{Macrosiphum jasmini (Clarke)}

Clarke, Can. Ent., vol. 35, p. 252, 1903. Nectarophora (orig. dese.). Record.-Jessamine, Berkeley (Clarke).

Since Clarke's description of the apterous viviparous females of this species it has never been found. Its identity is, therefore, unknown to the author. 


\section{Macrosiphum lactucae (Kalt.)}

Kaltenbach, Monog. d. Pflanzenläuse, p. 199, 1857. Nectarophora (orig. dese.).

Sanderson, Can. Ent., vol. 33, p. 69, 1901. Nectarophora (dese.).

Essig, Univ. Calif. Publ., Entom., vol. 1, p. 328, 1917 (list).

Record.-Cicorium intybus, Rutherford; Napa County, 1916 (Essig).

This species has been taken only by Essig on chicory in Napa County during June, 1916. As its determination is doubtful the author gives herewith a brief description of the alate female.

Body pale to green, with the following parts more or less dusky: head, antennae, prothorax, thoracic lobes, apex of beak, tarsi, apical one-fifth to one-fourth tibiae, apical one-half femora, cornicles, anal plate, marginal spots on the abdominal segments, submarginal spots of the second and third abdominal segments, dorsal bands on the fourth and fifth, and the dorsum of the remaining abdominal segments. Eyes red.

The antennal tubercles are prominent and project rectangularly inward. A prominent frontal tubercle is present on the apex. The antennae are about half as long again as the body. The usual primary and accessory sensoria are present. On III there are from thirty-five to forty-five circular secondary sensoria; on IV from five to fifteen secondary sensoria. These two segments appear tuberculate. The beak reaches beyond the second coxae. The cornicles are longer than the cauda, and subequal in length to the fourth antennal segment. They are subcylindrical and fairly stout. The cauda is long and ensiform, reaching to the tip of the cornicles. The wings and venation are normal.

Measurements (of three specimens) : Body length, 1.836 to 1.955 $\mathrm{mm}$.; width of thorax, 0.765 to $0.833 \mathrm{~mm}$; antennae, total, 2.805 to $2.992 \mathrm{~mm}$.; III, 0.680 to $0.697 \mathrm{~mm}$.; IV, 0.441 to $0.527 \mathrm{~mm}$.; V, 0.391 to $0.425 \mathrm{~mm}$.; VI, base 0.085 to $0.119 \mathrm{~mm}$.; VI, spur 0.952 to 1.105 $\mathrm{mm}$. ; cornicles, 0.441 to $0.493 \mathrm{~mm}$.; cauda, 0.238 to $0.272 \mathrm{~mm}$. ; hind tarsi, 0.136 to $0.153 \mathrm{~mm}$; wing, length, 3.145 to $3.315 \mathrm{~mm}$.; width, 0.952 to $1.139 \mathrm{~mm}$.; expansion, 7.36 to $7.87 \mathrm{~mm}$.

\section{Macrosiphum ludovicianae (Oestund)}

\section{Figures 136, 148}

Oestlund, Minn. Geol. Nat. Hist. Surv., vol. 14, p. 23, 1886. Siphonophora (orig. dese.).

Davidson, Jour. Econ. Ent., vol. 7, p. 136, 1914 (list).

Wilson, Trans. Am. Ent. Soc., vol. 12, p. 98, 1015 (desc.). 
Records.-Artemisia heterophylla; Walnut Creek, Contra Costa County (Davidson), Berkeley, 1915 (Shinji); Artemisia dracunculoides, Convolvulus sp., Stachys bullata, Berkeley, 1915 (Shinji).

This species is quite common in the San Francisco Bay region on various species of sagebrush. George Shinji has taken it also on hedgenettle and bindweed in Berkeley. It is distinguished from other sageinfesting species of Macrosiphum by the fact that the body of the apterous females is covered with pointed setae as opposed to the fanshaped setae of $M$. artemisicola (Williams), and the capitate setae of $M$. artemisiae (Fonsc.).

\section{Macrosiphum orthocarpus Davidson}

Davidson, Jour. Econ. Ent., vol. 2, p. 304, 1909 (orig. desc.).

Davidson, Jour. Econ. Ent., vol. 3, p. 380, 1910 (list).

Record.-Orthocarpus purpurascens; Stanford University (Davidson).

Since Davidson found the specimens on owl-clover from which he described this specics, it has not again been taken.

\section{Macrosiphum pisi (Kalt.)}

Figures 130, 150

Kaltenbach, Monog. d. Pflanzenläuse, p. 23, 1843. Aphis (orig. dese.).

Davidson, Jour. Econ. Ent., vol. 2, p. 304, 1909 (list).

Davidson, Jour. Econ. Ent., vol. 3, p. 380, 1910 (list).

Essig, Pom. Jour.'Ent., vol. 2, p. 336, 1910. Nectarophora (desc.).

Branigan, Mon. Bull. Cal. Comm. Hort., vol. 4, p. 285, 1915. M. destructor (Johnson) (list).

Davis, U. S. Dept. Agr., Bull. 276, p. 11, 1915 (list).

Records.-Pisum sativum; Claremont, Santa Ana, and Ventura (Essig); Alameda County (Brannigan); El Cajon, San Diego County, May, 1916: Lathyrus odoratus; Stanford University (Davidson, Morrison); San Diego, October, 1916: Viola sp.; Claremont, Santa Ana, Ventura (Essig); Medicago sp.; Holtville, Imperial County (V. L. Wildermuth): Psorales macrostachya; Santa Paula (Essig).

The pea aphis is quite common throughout the state, especially on garden and sweet peas. It has been taken a few times on other plants, such as alfalfa, violets, and leather-root, but it is uncommon. This species is readily distinguished by its bright, shining green color, large size, and long, slender, imbricated, but non-reticulated cornicles. 


\section{Macrosiphum pteridis Wilson}

Figures 317, 318

Wilson, Trans. Am. Ent. Soc., vol. 41, p. 101, 1915 (orig. desc.).

Records.-Pteris aquilina; Walnut Creek, Contra Costa County, 1915 (Davidson).

This species has been found by Davidson on the fronds of common brake in the San Francisco Bay region. Wilson reported it as present throughout southern and western Oregon. There are a few specimens of the alate females in the author's collection, received from Davidson.

\section{Macrosiphum rosae (Linn.)}

Figures 106, 151, 152

Linnaeus, Syst. Nat. vol. 4, p. 73, 1735. Aphis (orig. desc.).

Clarke, Can. Ent., vol. 35, p. 254, 1903. Nectarophora (list).

Davidson, Jour. Econ. Ent., vol. 2, p. 304, 1909 (list).

Davidson, Jour. Econ. Ent., vol. 3, p. 380, 1910 (list).

Davidson, Pom. Jour. Ent., vol. 3, p. 399, 1911 (list).

Essig, Pom. Jour. Ent., vol. 5, p. 550, 1911 (desc.).

Carnes, Mon. Bull. Cal. Comm. Hort., vol. 1, p. 398, 1912 (list).

Records.-Rose; through California from Humboldt County south to San Diego County (Clarke, Davidson, Morrison, Essig, Ferris, Shinji, the author).

This is the common pink and green aphid of roses, known the world over. The apterae are found most abundantly in the late winter and early spring on the buds and stems of rose. As the alates are matured they fly away; supposedly either to other rose bushes or to various grains and grasses. This past spring (1917) it has been very abundant in the vicinity of Riverside, but the previous spring (1916) in San Diego it was rare. There the most abundant rose aphis was Myzaphis rosarum (Walker).

\section{Macrosiphum rudbeckiae (Fitch)}

Fitch, Cat. Homop. N. Y., p. 66, 1851. Aphis (orig. desc.).

Essig, Pom. Jour. Ent., vol. 3, p. 400, 1911. Aphis (desc.).11

Davidson, Jour. Econ. Ent., vol. 7, p. 137, 1914 (list).

Records.-Ambrosia psilostachya; Santa Paula (Essig); Baccharis viminalis; Santa Paula (Essig), Riverside, September, 1916; Dipsacus fullonum; San Jose (Davidson): Helianthus annuus; Riverside, September, 1916; Salix sp.; Chrysanthemum; Arlington, Riverside County, September, 1916; undetermined species of Compositae; Redwood Canyon, Contra Costa County, July, 1914 (R. W. Haegele).

11 In the drawings accompanying this description by Essig the following mistakes are noticeable: the third discoidal vein of the forewings is twice-branched instead of once-branched, and the third antenal segment of the apterous female bears several secondary sensoria instead of none, as figured. 
'This reddish-colored Macrosiphum is distributed abundantly through the San Francisco Bay region and southern California on various Compositae. In one case the author found it doing considerable damage to chrysanthemums by stunting and distorting the buds. Onec he found it infesting the tender leaves and stalks of willow. The author reared specimens of Diaretus rapae Curt. from an infestation of this species taken on willow.

77a. Macrosiphum rudbeckiae (Fitch) var. madia n.var.

Figures 153, 154

In September, 1915, the author found a specics of Macrosiphum infesting the heads of tarweed (Madia sativa) on the campus of the University of California, Berkeley. Specimens of Praon simulans Prao. were rcared from this collection. Mounted specimens are almost identical with $M$. rudbeckiae (Fitch), but in life they differ in the coloration. Because of this it has been thought best to describe it herewith as a color variety of $M$. rudbeckiae, naming the varicty, madia, after its host plant.

Host: Madia sativa.

Locality: Berkeley, California.
Date: September 12, 1915. Collection number: AFS 70-15.

Alate viviparous female.-Prevailing color: dark-grcen, slightly pruinose. Head brownish (fuscous), about as long as broad, with distinct antennal tubercles. Antennae black, except I and II and the base of III, which are concolorous with the head. The spur is slightly longer than III ; IV is next in length, followed by V, VI, and I, which are subequal, and II, which is the shortest segment. The spur is about six times as long as the base of VI. The usual primary sensoria are present on V and VI, and the usual accessory sensoria on VI. IV is without sensoria, III has 25-35 irregularly arranged, various-sized secondary sensoria placed along the whole length of the segment (fig. 154). The thorax is fuscous; the prothorax with rather distinct lateral tubercles. The beak is slightly dusky with the apical one-third black, reaching to the second coxae. The abdomen is greenish with a slight pulverulence, making it appear pruinose. The cornicles are long, slightly tapering, black except the basal one-third, which is concolorous with the abdomen, apical one-fifth reticulate (fig. 153). The cauda is long and pointed, pale (slightly reddish?), about onehalf as long as the cornicles. The legs are black except the basal half of the femora and the coxae, which are greenish. The wings and venation are normal. 
Measurements : Body length (exclusive of cauda), $2.11 \mathrm{~mm}$. ; width of thorax, $0.91 \mathrm{~mm}$. Antennae: total, $2.07 \mathrm{~mm}$.; I, $0.12 \mathrm{~mm}$.; II, $0.09 \mathrm{~mm}$. ; III, $0.76 \mathrm{~mm}$; IV, $0.55 \mathrm{~mm}$; V, $0.47 \mathrm{~mm}$; VI, $0.12 \mathrm{~mm}$; spur, $0.78 \mathrm{~mm}$. ; cornicles, $0.91 \mathrm{~mm}$. ; cauda, $0.45 \mathrm{~mm}$; beak, $0.89 \mathrm{~mm}$.; hind tarsus, $0.14 \mathrm{~mm}$. Wing: length, $3.6 \mathrm{~mm}$; width, $1.25 \mathrm{~mm}$; expansion, $8.11 \mathrm{~mm}$.

\section{Macrosiphum sanborni Gillette}

Figures 141, 155

Sanborn, Kans. Univ., Sci. Bull. 3, p. 73, 1904. Macrosiphum chrysanthemi (desc. ala. vivi.).

Gillette, Can. Ent., vol. 11, p. 65, 1908 (orig. desc. apt. vivi.).

Records.-Chrysanthemum; Stanford University, May, 1915; Riverside, March, 1917.

Twice has the author found this species: once a small infestation in the greenhouse of Stanford University, and once abundantly out of doors in Riverside. It is an interesting species in that it does not fit well into any known genus. Except for the cornicles it fits Macrosiphum and has been so considered. The cornicles are, however, short, being scarcely longer than the cauda, and are somewhat bottle-shaped, being considerably smaller at the apex than at the base.

\section{Macrosiphum solanifolii (Ashmead)}

Figures 137-140, 159-160

Ashmead, Can. Ent., vol. 12, p. 91, 1881. Siphonophora (orig. dese.).

Clarke, Can. Ent., vol. 35, p. 252, 1903. Nectarophora citrifolii (Ashmead) (list).

Davidson, Jour. Econ. Ent., vol. 31, p. 380, 1910. Macrosiphum citrifolii (Ashmead) (list).

Essig, Pom. Jour. Ent., vol. 3, p. 592, 1911. Macrosiphum citrifolii (Ashmead) (desc.).

Davidson, Jour. Econ. Ent., vol. 5, p. 411, 1912 (list).

Patch, Maine Agr. Exp. Sta., Bull. 242, 1915 (dese.).

Records.-Citrus sp.; Azusa, Los Angeles County (Clarke); Lindsey, Tulare County (Clarke); Santa Paula (Essig); Disporum hookeri; Berkeley, May, 1915 (Shinji) : Solanum nigrum; Stanford University, October, 1916 (Ferris) : Fuchsia sp.; Berkeley, July, 1915: Sonchus asper and S. oleraceus; Stanford University, February, 1915: apple; Stanford University, May, 1915; El Cajon, San Diego County, July, 1916: Atriplex sp.; Berkeley, September, 1915: Oxalis corniculata, Riverside, February, 1917: Deinandra fasciculata, Riverside, February, 1917: Erodium moschatum; Pasadena, April, 1917 (R. E. Campbell); Riverside, April, 1917. 
'This "pink and green aphid of potato" is distributed throughout California on a large variety of plants. It is recognizable by the long reticulated cornicles and black antennae. When the author first examined specimens of Macrosiphum citrifolii (Ashmead) in Essig's collection he was struck with its resemblance to this spccies. In fact, after considerable study he could not find any constant differences. This was in 1915 in Berkeley. This past spring (1917) he had the opportunity in Riverside of making some transfer tests with specimens from oxalis. Migrants were placed under muslin bags on sucker growth of orange. It was observed that these settled there readily and produced young, demonstrating that the citrus species is the same as the other. On the strength of this Macrosiphum citrifolii (Ashmead) is listed as a synonym of this species.

\section{Macrosiphum sonchella (Monell)?}

Monell, U. S. Geol. Geog. Surv., Bull. 5, p. 21, 1879. Siphonophora (orig. dese.).

Clarke, Can. Ent., vol. 35, p. 252, $1903 . \quad$ Nectarophora (list).

Davidson, Jour. Econ. Ent., vol. 2, p. 304, 1909 (list).

Davidson, Jour. Ėeon. Ent., vol. 2, p. 380, 1910 (list).

Records.-Sonchus sp.; Berkeley, Newcastle, and Palo Alto (Clarke); Stanford University (Davidson).

According to Morrison the species listed as this by Davidson is not Macrosiphum sonchella (Monell), although he cannot say what it is. Consequently Clarke probably referred to the same species as did Davidson. As the author has never seen specimens he can make no statement as to its identity, so lists it as it has been heretofore.

\section{Macrosiphum stanleyi Wilson}

Figures 128, 158

Wilson, Proc. Ent. Soc. Brit. Columbia, January, 1915 (orig. dese.).

Record.-Sambucus callicarpa californica; Berkeley, June, 1915.

From the early part of June, 1915, until the middle of August, this species was very abundant on an elderberry tree in the Botanical Gardens of the University of California. By the latter part of August all specimens had disappeared. Since then the author has never seen the species. J. J. Davis kindly identified these specimens. 


\section{Macrosiphum taraxici (Kalt.)}

Kaltenbach, Monog. d. Pflanzenläuse, p. 30, 1743. Aphis (orig. dese.). Theobald, Jour. Econ. Biol., vol. 7, p. 77, 1913 (desc.).

Record.-Taraxacum officinale; California (Wilson).

H. F. Wilson stated to the author that he had taken this species on dandelion (Taraxacum officinale) in California, although he gave no date or loeality record.

\section{Macrosiphum tulipae (Monell)}

Monell, U. S. Geol. Geog. Surv., Bull. 5, p. 19, 1879. Siphonophora (orig. dese.).

Davidson, Jour. Econ. Ent., vol. 3, p. 380, 1910 (list).

Records.—Tulipa sp.; Stanford University (Davidson); Liriodendron sp.; Berkeley, 1915 (Essig, Shinji).

This speeies is not known to the author. It has been found on tulips and on the tulip trees in the San Franeiseo Bay region by Davidson, Essig, and Shinji.

\section{Macrosiphum valerianae (Clarke)}

Clarke, Can. Ent., vol. 35, p. 253, 1903. Nectarophora (orig. dese.). Record.-Valeriana officinialis; Berkeley (Clarke).

In 1903 Clarke deseribed this speeies from specimens taken on heliotrope in Berkeley. Sinee then it has not again been found.

\section{Genus Myzus Passerini}

Passerini, Gli Afidi, 1860. Type Aphis ribes Linnaeus.

This genus is very closely related to Rhopalosiphum Koch, the principal difference being in the shape of the cornicles. However, some speeies fall easily into one or the other genus, depending entirely upon what form one has. In this respect Rhopalosiphum persicae (Sulz.) is particularly notieeable, the spring migrants having the elavate eornieles of Rhopalosiphum, the fall migrants having the cylindrieal cornicles of Myzus. The author has followed Van der Goot in taking out of this genus $M$. rosarum (Walker) and plaeing it in the genus Myzaphis v.d.G. 'The antennal tubereles are lacking, thus plaeing the species in the Aphidini instead of the Maerosiphini. There are at present ten speeies of Myzus known to oceur in California. Following is a key to them : 


\section{Key to the California Species}

\section{Alate viviparous females}

1. Secondary sensoria present on III only 5

- Secondary sensoria present on other segments as well as on III ...................... 2

2. Secondary sensoria on III, IV, and V

- Secondary sensoria on III and IV, none on V fragaefolii Cockerell

3. Cornicles dusky for entire length cynosbati (Oestlund)

- Cornicles mostly pale 4

4. Thoracic lobes distinetly darker than general body color, being black or dark brown aquilegia Essig

- Thoracic lobes at most only slightly darker than body, being a pale brown.

5. Body black throughout braggil Gillette

- Body not black throughout cerasi (Fabricius)

6. Cornicles pale exeept at extreme tip 6

- Cornicles with more than tip dusky 7

7. VI spur longer than III, the latter with but 9 to 12 sensoria.

varians Davidson

- VI spur at most equal to III, the latter with 18 to 26 sensoria.

8. Cornicles longer than either IV or V

lycopersici (Clarke)

- Cornicles not longer than either IV or $\mathrm{V}$

9. VI spur longer than II 9

- VI spur shorter than III circumflexum (Buckton)

10. III with 15 to 25 sensoria (fig. 178) ribifolii Davidson

- III with but 9 to 12 sensoria rhamni (Fonse.) varians Davidson

\section{Apterous viviparous female}

1. Body covered with eapitate hairs

- Body not covered with capitate hairs except on head and antennae ................ 5

2. Secondary sensoria on III .................................................................................. 3

- No secondary sensoria on III .................................................................................. 4

3. Cornicles dusky ribifolii Davidson

- Cornicles pale except tip aquilegiae Essig

4. Cornicles almost twice as long as III. Body fairly large sized.

- Cornicles but slightly longer than III. Body small sized.

braggii Gillette

fragaefolii Cockerell

5. Secondary sensoria on III

- No secondary sensoria on III

6. VI spur longer than III. Several sensoria seattered along the whole length of III cynosbati (Oestlund)

- VI spur at most equal to III. Only a few (1-3) sensoria at base of III. lycopersici (Clarke)

7. III longer than cornicles. Dorsum of abdomen with dusky markings, shaped somewhat as a horseshoe circumflexum (Buckton)

- III at most equal to cornicles. Abdomen not marked as above 8

8. Body black throughout cerasi (Fabricius)

- Body not black throughout 9

9. VI spur almost twice as long as III varians Davidson

- VI spur but slightly longer than III rhamni (Fonse.) 


\section{Myzus aquilegiae Essig}

Shinji, Can. Ent., vol. 40, p. 49, 1917. Myzus sp. (list).

Essig, Univ. Calif. Publ. Entom., vol. 1, p. 314, 1917 (orig. dese.).

Records.-Aquilegia truncata; Berkeley, 1916 (Essig): A. vulgare, Inverness, Marin County (Shinji).

'This speeies was reeently described by Essig from speeimens found on eolumbine on the eampus of the University of California, Berkeley. The author has had access to eotype speeimens, although he has never eolleeted it himself.

\section{Myzus braggii Gillette}

Figure 176

Gillette, Can. Ent., vol. 11, p. 17, 1908 (orig. desc.).

Davidson, Jour. Econ. Ent., vol. 5, p. 409, 1912. Phorodon carduinum (Walker) (list).

Records.-Cynara scolymus; Courtland, Oakland, and San Jose (Davidson); Riverside, January and February, 1917.

The author found this speeies during the early spring of 1917 infesting the leaves of artiehoke in Riverside. 'The determination of specimens was verified by C. P. Gillette. Davidson reported Phorodon carduimum (Walker) from artiehoke in the San Franeiseo Bay region. His speeimens were determined by J. Monell, but P. Van der Goot was doubtful as to its identity. Davidson himself has decided that the speeies is Myzus braggii Gillette. There is no doubt but that the species on artiehoke in California is $M$. braggii Gillette, but whether or not this is the same as $P$. carduinum (Walker) is uncertain.

\section{Myzus cerasi (Fabrieius)}

Figures 112, 121, 122, 179, 307

Fabricius, Syst. Nat., p. 734. Aphis (orig. dese.).

Clarke, Can. Ent., vol. 35, p. 252, 1903 (list).

Gillette, Jour. Econ. Ent., vol. 1, p. 362, 1908 (desc.).

Newman, Mon. Bull. Calif. Comm. Hort., vol. 4, p. 446, 1915 (list).

Shinji, Can. Ent., vol. 49, p. 49, 1917 (list).

Records.-Prunus cerasi; Susanville, Lassen County (Newman); Berkeley, 1914, 1915, and 1916 (Essig, Shinji); Riverside, 1914 (Sharp); Fresno, June, 1915: Prunus domestica; Berkeley (Clarke). 
'The black cherry aphis is found oceasionally throughout California, but seldom in large enough numbers to be injurious. It infests the terminal leaves of cherry, and sometimes other species of Prunus, causing them to curl to a certain extent. Eggs are laid in the late fall and early winter in the crevices of the bark and near the bases of the buds. These hatch the following spring about the time the buds are opening. The first few generations consist entirely of apterous females. In the early summer the alate females appear, and continue to do so in each succeding generation until fall. In fact, after the first of July, or thereabouts, the majority of the lice produced are alate until the sexes appear in the fall. The first alate females taken by the author were on June 7, 1915. However, on April 25, 1916, Essig found a few alate females in Berkeley. In August, 1914, the apterae were also found in Berkeley.

Van der Goot makes this species out of the genus Myzus, using it as the type of his genus Myzoides. The author is inclined to follow him inasmuch as this is quite different from other members of this genus, approaching Aphis in its robust form and separated from that only by the length of the cornicles and presence of antennal tubercles. However, it has so long been considered as a species of Myzus that it is best to leave it so. It is not a good policy usually to form a new genus for one species, especially when it has for so long been considered as a member of another genus.

\section{Myzus circumflexus (Buckton)}

Figure 175

Buekton, Monog. Brit. Aphides, vol. 1, p. 130, 1875. Siphonophora (orig. desc.).

Gillette, Can. Ent., vol. 40, p. 19, 1908. Mr. vincae, n.sp. (dese.).

Davidson, Jour. Econ. Ent., vol. 3, p. 380, 1910. M. vincae Gill. (list).

Shinji, Can. Ent., vol. 49, p. 49, 1917 (list).

Record.-Vinca major; Stanford University (Davidson, Morrison), Berkeley, 1915 (Shinji), Los Angeles, March, 1917; Aesculus californicus, Alopecurus pratensis, Asparagus, spp., Ceanothus sp., Cerastium viscosum, Cheiranthus chieri, Cyrtonium falcatum, Digitalis purpurea, Fuchsia sp., Gladiolus sp., Plantago sp., Senecio mikanioides, Sisymbrium sp., Solanum spp., Stachys bullata, Tropaeolum sp., Symphoricarpus racemosus; Berkeley, 1915, 1916 (Essig, Shinji): Viola tricolor; Stanford University, Narch, 1915; Berkeley, 1915 (Essig, Shinji): Riohardia africana; Pomona, 1909 (Essig); Stanford University, March, 1915; Berkeley, March, 1915 (Essig); San Diego, May, 1916; Los Angeles, March, 1917.

This very common aphid is found in the spring on a large variety of host plants throughout California. At times it may become so 
abundant as to cause some considerable damage to its host. On March 4, 1917, the author observed it on periwinkle in Los Angeles in such numbers as to stunt the flowers and to cause all the plants to appear black and sticky. The apterae of this species are readily recognized by the black horseshoe-shaped marking on the dorsum of the abdomen.

\section{Myzus cynosbati (Oestlund)}

Oestlund, Minn. Geol. and Nat. Hist. Surv., Bull. 4, p. 81, 1887. Nectarophora (orig. dese.).

Davidson, Jour. Econ. Ent., vol. 10, p. 294, 1917 (note).

Shinji, Can. Ent., vol. 49, p. 49, 1917. M. ribis (Linn.) (list).

Records.-Ribes vulgare; Walnut Creek (Davidson); Ribes glutinosum, $R$. menziesii; Berkeley, April, 1915 (Shinji).

This speeies has been taken but a few times in the San Francisco Bay region; once on cultivated red currant in company with Aphis neomexicana pacifica, once on wild flowering currant, and once on wild canyon gooseberry. Furthermore, only the sexapura (migrants) and sexuales have been taken. Davidson writes that this is true cynosbati of Oestlund and not the species described by Davis (Ann. Ent. Soc. Am., vol. 2, p. 38, 1909), as Macrosiphum cynosbati (Oest.), which is not that species but some other. Shinji listed M. ribis (Iinn.), but his specimens prove to be the sexuales of this species.

\section{Myzus fragaefolii Cockerell}

Figure 177

Cockerell, Can. Ent., vol. 33, p. 101, 1901 (orig. desc.).

Davidson, Jour. Econ. Ent., vol. 7, p. 135, 1914 (desc. sexuales).

Records.-Fragaria chiloensis; Walnut Creek, Contra Costa County (Davidson); Berkeley, March to September, 1915; Palo Alto, April, 1915; Ontario, April, 1917; Buena Park, Orange County, May, 1917 (R. K. Bishop); Santa Barbara, May, 1917; Rialto, San Bernardino County, May, 1917 (A. B. Snow): F. californicus; Pine Hills, San Diego County, June, 1916.

On the under side of the leaves of native and eultivated strawberries this small yellowish aphid is often found, both in the San Francisco Bay region and in southern California. Seldom does it become abundant, although several records of its abundance were received from various parts of the south during the spring of 1917 . Several growers have thought it bad enough to spray for it. During the late winter (January and February) the scxuales appear and the eggs are laid. These hatch in a short time, and during the rest of the year the alate and apterous viviparae are found. 


\section{Myzus lycopersici (Clarke)}

Clarke, Can. Ent., vol. 35, p. 253, 1903. Nectarophora (orig. dese.).

Davis, Can. Ent., vol. 46, p. 123, 1914 (desc.).

Record.-Lycopersicum esculentum; Berkeley (Clarke).

Only once has this species been found in California. Davis in 1914 described a specics from tomato in Idaho, Montana, and Oregon which he believed to be this one. It may be, and it may not be so. That can never be decided for the types of Clarke's species are all lost.

\section{Myzus rhamni (Clarke)}

Figure 178

Clarke, Can Ent., vol. 35, p. 254, 1903. Nectarophora (orig. dese.).

Shinji, Can. Ent., vol. 49, p. 49, 1917. M. rhamni (Boyer) (list).

Records.-Rhamnus californicus; Berkeley (Clarke), Berkeley, March, 1915 (Shinji).

In March, 1915, George Shinji took a species of Myzus from coffeeberry in Berkeley. This fits Clarke's description of Nectarophora rhamni, in so far as the description goes. The author considers it to be the same species as described by Clarke, inasmuch as it was collected in the same locality and on the same host plant.

Wilson (Can. Ent., vol. 44, p. 156, 1912) describes a species from Rhamnus purshiana in Oregon as M. rhamni (Boyer), listing Clarke's species as a synonym. This is the same species as taken by Shinji in Berkeley, but it is doubtful if it is the species described by Boyer de Fonscolombe. Specimens in the author's collection from Rhamnus in Colorado are determined by Gillette and Bragg to be Aphis rhamni Fonse. These are certainly different from the coast species, the former being an Aphis closely related to $A$. enonomii Fabr., the latter a Myzus. From this evidence the author cannot follow Wilson in placing Nectarophora rhamni Clarke as a synonym of Aphis rhamni Fonsc., considering both as Myzus, but he considers them as distinct, Clarke's species being a Myzus, Fonscolombe's an Aphis.

\section{Myzus ribifolii Davidson}

Davidson, Jour. Econ. Ent., vol. 10, p. 294, 1917 (orig. dese.).

Record.-Ribes glutinosum; Redwood Canyon, Contra Costa County (Davidson). 
Davidson reeently deseribed all forms of this species from speeimens taken during Mareh, April, and May, 1913, 1914, and 1915, on wild flowering currant in Redwood Canyon, Contra Costa County. The author is unaequainted with the species.

\section{Myzus varians Davidson}

Davidson, Jour. Econ. Ent., vol. 5, p. 409, 1912 (orig. desc.). Record.-Clematis ligusticifolia; San Jose (Davidson).

Davidson found this species on the under side of the leaves of wild elematis, or Yerbade chivato, near San Jose, and later in Walnut Creek, Contra Costa County. The author is unacquainted with the species.

\section{Genus Nectarosiphon Schouteden}

Schouteden, Aphidologische Notizen, Leipzig, 1901. Type Macrosiphum rubicola Oestlund, n.n. for Macrosiphum Oestlund, preoceupied.

\section{Key to California Species}

1. Body quite large, being about 3 to $4 \mathrm{~mm}$. in length. Wings with dusky spot near tip rubicola (Oestlund)

- Body not so large, being only about $1.5 \mathrm{~mm}$. long. Wings without dusky spot near tip morrisoni Swain

\section{Nectarosiphon rubicola (Oestlund)}

Figures 107, 109, 123

Oestlund, Minn. Geol. Nat. Hist. Surv., vol. 14, p. 27, 1886. Macrosiphum (orig. desc.).

Davidson, Jour. Econ. Ent., vol. 7, p. 136, 1914. Amphorophora (list).

Records.-Rubus nutkanus; Contra Costa County (Davidson) ; Berkeley (Essig, Shinji).

This speeies is sometimes found infesting the tender leaves and shoots of thimbleberry in the San Francisco Bay region. 'The most distinctive eharacter which readily separates it from Amphorophora $r u b i$ (Kalt.) is the presence of a dusky patch near the tip of the forewing. This was originally described by Ocstlund as the type of his genus Macrosiphum. However, this name was preoccupied by Macrosiphum Passerini, so Schouteden proposed the name Nectarosiphon for this genus. Davidson listed this species as Amphorophora, and Morrison writes that he has never been able to satisfy himself why 
this is not Amphorophora instead of Nectarosiphon. There is considerable difference in the antenual tubercles of this species and species of Amphorophora, although otherwise they are quite similar. 'The author believes that slight as the difference is it should be recognized for it is through the shape and size of the antennal tubereles that the different genera of the Macrosiphini are recognized in a large part. In this species the tubercles are large and distinct and neither gibbous nor toothed on the inner side, and with the outer side quite evident, while in Amphorophora they are small and distinctly toothed on the inner side, with the outer side a mere line, or not at all evident.

\section{Nectarosiphon morrisoni Swain}

Figures 124 to 127

Swain, Trans. Am. Ent. Soc., vol. 44, p. 8, 1918.

Rccords.-Cupressus macrocarpa; San Franciseo (Compere, Morrison), San Diego (Swain): C. guadalupensis; San Diego (Swain).

In Golden Gate Park, San Francisco, and in Exposition Park, Sau Diego, this species has been taken on cypress. The small, slender, long-legged apterae are found infesting the terminal leaves of the host. Occasionally an alate female is seen. In San Diego, the apterae. were found in company with Cerosipha cupressi Swain.

\section{Genus Pentalonia Coquerel}

Coquerel, Ann. Ent. Soc. France, vol. 7, p. 239, 1860. Type P. nigronervosa n.sp.

\section{Pentalonia nigronervosa Coquerel}

Coquerel, Ann. Ent. Soc. France, vol. 7, p. 239, 1860 (orig. desc.).

Wilson, Jour. Econ. Ent., vol. 2, p. 346, 1909 (dese.).

Record.-Pelargonium sp.; Stanford University (Morrison).

'The following note concerning this species is from Morrison:

Pentalonia nigroncrvosa Coquerel. See Wilson, Jour. Econ. Ent., 1909. In the Davidson collection (belonging to Stanford University) there is a single glycerine jelly mount of this species. I have been able to see enough of it to be certain of its identity with that described by Wilson in the Journal (above). The record is from geranium, and Davidson once told me that he found it in alcohol in the laboratory [of Stanford University] at the time he began his study of the Aphididae. I believe the record should be published. 


\section{Genus Phorodon Passerini}

Passerini, Gli Afidi, 1860. Type P. humuli Schr.

No attempt has been made to formulate a key to the California species of this genus, owing to the fact that the author has specimens of but one species, and that the description of the other is quite inadequate. Four species have been reported from this state, two of which prove to be species of other genera and one of which is very doubtful. Phorodon carduinum (Walker) as reported by Davidson, is Myzus braggi Gillette. Phorodon galeopsidis (Kaltenbach), also reported by Davidson, is Rhopalosiphum hippophoaes Koch. There is much diversity of opinion concerning the specific determination of these species and of Myzus elaeagni Del Guercio. One might refer to Gillette's paper on Rhopalosiphum hippophoaes Koch and Myzus braggii Gillette. Davis writes that he is not prepared to be quoted. Davidson lists $P$. galeopsidis and $R$. hippophoaes as synonyms. He states that his specimens listed as $P$. carduinum Walker were determined by Monell, but that Van der Goot is doubtful, while he himself believes them to be $M$. braggii Gillette. He has been followed in so listing them. This then leaves but two species reported from California.

\section{Phorodon humuli (Schrank)}

Figures 115 to 118

Schrank, Fauna Boica, vol. 2, p. 110, 1801-02. Aphis (orig. desc.). Clarke, Can. Ent., vol. 35, p. 252, 1903 (list).

Clarke, Calif. Agri. Exp. Sta., Bull. 160, 1904 (econ.).

Parker, U. S. Dept. Agri., Bull. 111, 1913 (econ.).

Vosler, Mon. Bull., Cal. Conm. Hort., vol. 2, p. 668, 1913 (list).

Records.-Humulus spp.; Berkeley (Clarke); Placer County' (Vosler) ; Berkeley, July to September, 1915: Prunus domestica; Berkeley, March to April, 1915 (Essig, Shinji); (Parker).

This is the common hop plant louse found throughout the central part of the state. During the summer it is common on hops, but in the fall the sexupara migrate to plum, where the eggs are laid. These eggs hatch the following spring into stem mothers which feed on the opening buds of plum. During later generations, probably about the third or fourth, alate fundatrigeniae appear, which leave the plum and migrate to hop. Here the summer generations are produced until well into the fall. Parker states that the normal life cycle is as just stated, but that it is also possible, and it oceasionally oceurs, that this 
aphid may live the entire year upon hops, or on plum, generation after generation of parthenogenetic females being produced.

\section{Phorodon scrophulariae Thomas}

Thomas, Ann. Rep. Ill. St. Ent., vol. 8, p. 72, 1879 (orig. dese.).

Clarke, Can. Ent., vol. 35, p. 252, 1903 (list).

Record.-Scrophularia sp., Berkeley (Clarke).

This is a doubtful species, reported by Clarke as present on Scrophularia in Berkeley, and by Dr. Thomas in 1879 on a species of plant which he thought to be Scrophularia in Illinois. Since Clarke's record it has never been found, although Morrison states that he has spent considerable time examining the common Scrophularia plants in the vicinity of Stanford University, but to no avail. The author attempted to find it many times in the vicinity of San Diego during 1916, and in the vicinity of Riverside in 1917, with no success.

\section{Genus Rhopalosiphum Koch}

Koch, Die Pflanzenläuse, p. 23, 1854. Type Aphis persicae Sulz.

This genus is very closely related to Myzus, and is distinguished only by the shape of the cornicles. This distinction is variable, however, as in some species certain forms have the clavate cornicles of Rhopalosiphum while other forms have the cylindrical cornicles of Myzus. This is particularly true in the case of Rhopalosiphum persicae (Sulz.) and Myzus braggii Gillette. However, most aphidologists separate these two genera, so the author feels that it is best to do so.

\section{Key to California Species \\ Alate viviparous females}

1. Ground color dark (olive-green, wine, brown, and so forth)

- Ground color light, usually green (this does not refer to the dark markings on head, thorax, or abdomen, but rather to the ground color of the abdomen)

2. Wing veins with smoky borders and tips (fig, 164). IV with a few small sensoria violae Pergande

- Wing veins without smoky borders or tips, and IV without sensoria.

rhois Monell

3. Antennae distinctly tuberculate, with sensoria on both III and IV (figs. 170, 279)

- Antennae not tuberculate, and IV without sensoria, or at most with but a few small ones (figs. 167, 168) 
4. VI spur slightly longer than III (figs. 279, 281). Cornicles quite large and heavy (figs. 282, 284) .........................................................................

- VI spur about twice as long as III. Cornicles comparatively small and slender (fig. 165)

hippophoaes Koch.

5. First discoidal vein with distinet, smoky border, second diseoidal bordered slightly so (fig. 166)

nervatum Gillette

- First and second discoidal without smoky borders 6

6. Abdomen with dusky dorsal markings. III with a few (10-12) sensoria (fig. 168)

persicae Sulz.

- Abdomen without dusky dorsal markings. III with many (24-30) sensoria (fig. 167) corylinum Davidson

Apterous viviparous females 12

1. Ground color dark (olive-green, wine, brown) 2

- Ground color light (green, and so forth)

2. Cornicles large and stout, longer than III

- Cornicles smaller and more slender, shorter than III ..............-violae Pergande

3. Cornicles longer than III. 4

- Cornicles shorter than III. 5

4. VI spur eonsiderably longer than III, and subequal to cornicles.

nervatum Gillette

- VI spur about equal to III, and distinetly shorter than cornicles.

5. III with secondary sensoria

hippophoaes Koch.

- III with no secondary sensoria lactucae (Kalt.) persicae (Sulz.)

\section{Rhopalosiphum corylinum Davidson}

Figure 167

Davidson, Jour. Econ. Ent., vol. 7, p. 134, 1914 (orig. dese.). Records.-Corylus rostrata; Walnut Creek, Contra Costa County (Davidson): Physocarpus capitatus; (Davidson).

This species was originally described from specimens of alate viviparae and pupae taken on wild hazelnut near Walnut Creek. Davidson writes that he has found it quite common on ninebark in the San Francisco Bay region. The author has never taken the species, but has had access to cotype specimens in Essig's collection.

\section{Rhopalosiphum hippophoaes Koch Figures 165,170}

Koch, Die Pflanzenläuse, p. 28, 1854 (orig. desc.).

Davidson, Jour. Econ. Ent., vol. 7, p. 136, 1914. Phorodon galeopsidis Kalt. (list).

Gillette, Jour. Econ. Ent., vol. 8, p. 375, 1915 (synonomy).

Record.-Polygonum sp.; San Jose (Davidson).

$12 R$. corylinum Dvdn. is omitted from this key as the apterous female was never described and specimens are not available to the author. 
Davidson reported this species as present on knotweed in the vicinity of San Jose, under the name $P$. galeopsidis Kalt. Later he followed Gillette in placing it as a synonym of $R$. hippophoaes Koch. The author has never collected it, but has had access to specimens from Davidson in San Jose, and Davis in Oak Park, Illinois. For a full discussion of the synonymy of this species sce Gillette's paper listed above.

\section{Rhopalosiphum lactucae (Kalt.)}

Figures 277 to 285

Kaltenbach, Monog. d. Pflanzenläuse, p. 37, 1843. Aphis (orig. dese.). Davidson, Jour. Econ. Ent., vol. 3, p. 277, 1910 (list).

Records.-Sonchus spp.; Stanford University (Davidson); Stanford University, May to July, 1915; Walnut Creek, May, 1915 (Davidson); Berkeley, July, 1915; Lemon Grove, San Diego County, January, 1916; Riverside, January to May, 1917; Los Angeles, April, 1917 : Asclepias sp.; Corvallis, Oregon, November, 1913 (Moznette).

This is a common species infesting the heads of sow thistle throughout the San Francisco Bay region and southern California. In November, 1913, G. F. Moznette took it on milkweed in Corvallis, Oregon. This collection consisted entirely of alate females, that may have been the sexupara. Inasmuch as the identity of this species is doubtful there is given below a brief description drawn from specimens of nine alates and eight apterae taken on Sonchus spp. at Stanford University in May, 1915, in Walnut Creek in May, 1915, in Berkeley in July, 1915, and in Lemon Grove in January, 1916, and on Asclepias sp. in Corvallis, Oregon, in November, 1913. This latter collection is by George F. Moznette of Corvallis.

Alate viviparous female.-Prevailing color is apple green with the head dark green to black, the prothorax apple green, the thoracic lobes black. The abdomen is apple green with three pair of dusky marginal spots on segments one, two, and three, respectively, and with a larger dusky patch on the dorsum of segments four, five, and six, being between the cornicles. The cornicles and cauda are luteous with the extreme tip of the former dusky. The antennae are dusky throughout. The legs are luteous with the tarsi and tips of the femora and tibiae dusky.

The head is about twice as broad as long, with a distinct frontal tubercle (fig. 278). The antennae are set on distinct tubercles and are between one and one-fourth to one and one-half times as long 
as the body. The relative lengths of the segments are as follows: the spur is the longest, being followed by III, which is subequal but never longer. IV is about one-half the length of the spur and slightly longer than V. II is slightly longer than VI, which is about equal to I. Sensoria are arranged as follows (figs. 279-281) : on V and VI are the usual primary and accessory sensoria; on $\mathrm{V}$ in addition to the primary sensoria, there are at times as many as seven small circular secondary sensoria, located about the middle of the segment. The number of these sensoria range from none to seven, two and three being the usual number; on IV there are from six to twelve irregular secondary sensoria (fig. 280), placed irregularly along the whole length of the segment; on III there are between thirty and forty irregularly placed and irregularly sized sensoria (fig. 279) scattered along the whole length of the segment. The usual number is from thirty-six to thirty-nine. The prothorax is without lateral tubercles. The beak is of medium length, reaching to slightly beyond the second coxae. The cornicles (fig. 282) are fairly large and clavate on one side. At the widest point they are slightly less than one-fifth the length. The tip is slightly wider than the base. They are about the same length as the fourth antennal segment, although in some cases they may be slightly longer, and in others slightly shorter, but in all cases longer than the fifth antennal segment. The cauda (fig. 283) is long and fairly large, not quite reaching to the tip of the cornicles, being about one-half as long as the cornicles and one-half as long again as the hind tarsi. The wings and venation are normal, the forewings being about twice as long as the body.

Measurements: Body length, 1.48 to $1.87 \mathrm{~mm}$; width, 0.73 to 0.82 mm.; antennae total, 2.35 to $2.51 \mathrm{~mm}$.; III, 0.544 to $0.697 \mathrm{~mm}$.; IV, 0.306 to $0.425 \mathrm{~mm}$; V, 0.218 to $0.357 \mathrm{~mm}$.; VI, 0.085 to $0.119 \mathrm{~mm}$; spur, 0.68 to $0.799 \mathrm{~mm}$. ; cornicles, 0.323 to $0.459 \mathrm{~mm}$; cauda, 0.187 to $0.255 \mathrm{~mm}$.; hind tarsi, 0.136 to $0.153 \mathrm{~mm}$. ; wing length, 3.4 to $3.8 \mathrm{~mm}$.; wing width, 1.2 to $1.5 \mathrm{~mm}$; wing expansion, 8.0 to $8.3 \mathrm{~mm}$. The average measurements are as follows: body length, $1.74 \mathrm{~mm}$.; width, $0.768 \mathrm{~mm}$.; antennae total, $2.445 \mathrm{~mm}$.; III, $0.645 \mathrm{~mm}$.; IV, $0.382 \mathrm{~mm}$.; V, $0.328 \mathrm{~mm}$.; VI, $0.107 \mathrm{~mm}$. ; spur, $0.753 \mathrm{~mm}$. ; cornicles, $0.403 \mathrm{~mm}$; cauda, $0.248 \mathrm{~mm}$; hind tarsi, $0.139 \mathrm{~mm}$.; wing length, $3.6 \mathrm{~mm}$.; width, $1.32 \mathrm{~mm}$.; expansion, 8.1.

Apterous viviparous female.-Prevailing color pale green with the head paler, being almost luteous or of a pale yellowish green color. The eyes are red. The antennae, except the apices of segments three 
to six inelusive, the legs, exeept the tarsi and tips of the tibiae, the cauda, and the eornieles, except the tip, are all luteous. Sensoria are as follows: on V. and VI the usual primary sensoria, on VI the aecessory sensoria, and on III (fig. 278), from nine to eleven small, circular irregularly placed seeondary sensoria. IV is without sensoria. The antennae are considerably longer than the body, the spur and III being subequal and the longest segments. Sometimes the spur is slightly longer than III. $\mathrm{V}$ is about one-half as long as III or the spur, and about four-fifths as long as IV. I and VI are subequal, being about one-seventh as long as the spur. The cornicles (fig. 284), are elavate, quite large, usually being slightly more than one-fifth the length of the body and over three times the length of the hind tarsi. The cauda (fig. 285) is long, siekle-shaped, and a little more than one-half as long as the cornicles.

Measurements: Body lengtl, 1.7 to $2.18 \mathrm{~mm}$.; width of abdomen, 0.82 to $1.73 \mathrm{~mm}$.; antennae total, 2.32 to $2.48 \mathrm{~mm}$; III, 0.646 to $0.714 \mathrm{~mm}$; IV, 0.391 to $0.425 \mathrm{~mm}$.; V, 0.323 to $0.34 \mathrm{~mm}$.; VI, 0.102 $\mathrm{mm}$.; spur, 0.646 to $0.782 \mathrm{~mm}$.; eornieles, 0.459 to $0.493 \mathrm{~mm}$.; cauda, 0.238 to $0.272 \mathrm{~mm}$. ; hind tarsi, 0.136 to $0.153 \mathrm{~mm}$. The average measurements are as follows : body length, $1.87 \mathrm{~mm}$.; width, $0.99 \mathrm{~mm}$. ; antennae total, $2.39 \mathrm{~mm}$; III, $0.674 \mathrm{~mm}$; IV, $0.408 \mathrm{~mm} . ; \mathrm{V}, 0.334$ mm.; VI, $0.102 \mathrm{~mm}$; spur, $0.7099 \mathrm{~mm}$; eornieles, $0.473 \mathrm{~mm}$. ; eauda, $0.255 \mathrm{~mm}$; hind tarsi, $0.1445 \mathrm{~mm}$.

\section{Rhopalosiphum nervatum Gillette}

Figures 166, 169, 171

Gillette, Can. Ent., vol. 40, p. 63, 1908 (orig. desc.).

Davidson, Jour. Econ. Ent., vol. 3, p. 378, 1910. R. arbuti, n.sp. (desc.). Davidson, Jour. Econ. Ent., vol. 7, p. 134, 1914 (list).

Records.-Arbutus menziesii; Stanford University, San Jose, Walnut Creek (Davidson); Sacramento (Essig); Stanford University, February to May, 1915; Berkeley, September, 1915: Arbutus unedo; Redlands, February, 1917; Rosa spp.; Walnut Creek (Davidson); Berkeley, February, 1915 (Essig).

In 1910 Davidson described a species of Rhopalosiphum, which he named arbuti, from specimens taken on madrone in the vicinity of Stanford University. Sinee then it lias been found quite commonly on madrone throughout the San Franeisco Bay region, and once on a strawberry tree in Silva Park, Redlands. It was noticed by the author that the alate females were very scarce at all times, although the apterae and nymphs were often quite abundant. Later, when 
studying specimens while working up a key to the species of Rhopalosiphum, he found that structurally this species was identical with Rhopalosiphum nervatum Gillette. The latter had been taken on roses in the San Francisco Bay region. The identical structure and the scarcity of alates on madrone led to a belief that they were the same species. However, it was too late in the season (October, 1915) to try any transfer tests. No opportunity was found to try migration tests until in February, 1917, when the species was taken in Redlands. Two alate females were reared in the laboratory and then placed under a muslin bag on a rose bush, out of doors. A few days later these were examined and several young larvae observed. No further observations were made for two weeks, when it was found that the bag had been ripped off by the severe winds. Although this test was not a complete success the author feels confident of the identity of this species.

\section{Rhopalosiphum persicae ${ }^{13}$ (Sulz.)}

Figures 108, 119, 120, 168

Sulzer, Kan. Ins., p. 105, 1761. Aphis (orig. dese.).

Clarke, Can. Ent., vol. 35, p. 252, 1903. Rhopalosiphum dianthi (Schrank) (list).

Gillette, Jour. Econ. Ent., vol. 1, p. 359, 1908. Myzus (desc.).

Davidson, Jour. Econ. Ent., vol. 2, p. 303, 1909. R. dianthi (Schrank), $R$. achyrantes Monell, and Myzus (list).

Davidson, Jour. Econ. Ent., vol. 3, p. 377, 1910. R. tulipae Thomas (list). Davidson, Jour. Econ. Ent., vol. 3, p. 378, 1910. $R$. dianthi (Schr.) (list). Davidson, Jour Econ. Ent., vol. 3, p. 379, 1910. Myzus (list).

Essig, Pom. Jour. Ent., vol. 3, p. 598, 1911. Myzus (dese.).

Records.-Throughout California by Clarke, Davidson, Essig, Ferris, Morrison, and the author on Abutilon sp., Amaranthus retroflexus, Amsinckia respectabilis, Bougainvillaea sp., Brassica spp., Capsella bursa-pastoris, Capsicum annuum, Catalpa sp., Chcnopodium murale, Citrus spp., Cynoglossum grande, Cyticus prolifcrus, Geranium carolinianum, Hedcra helix, Lycopersioum csculentum, Malva parviflorus, Oxalis oregona, Prunus spp., Ranunculus californicus, Raphanus sativus, Rumex spp., Sambucus glauca, Sanicula menziesii, Senecio vulgarc, Solanum tuberosum, Sonchus spp., Tropaeolum sp., Tulipa sp., Vinca major.

This green peach aphis is one of the most common aphids found in the state. It is most abundant in the spring, at which time it will be found on almost any plant. According to Gillette various species

13 George Shinji (Can. Ent., vol. 49, p. 49, 1917) recently deseribed an aphid from specimens taken on Godetia amacna in Berkeley, which he named Myzus godetiae n.sp. The author has not seen specimens of this species, but from the description and figures, it is in all probability Rhopalosiphum persicae (Sulz.). 
of Prumus are the winter hosts in Colorado, while during the summer it migrates to other plants. In California, however, winter eggs are not laid, the viviparous females living the year round. So far as the author has observed in over three years, only the form with elavate eornicles is found in California.

\section{Rhopalosiphum rhois Monell}

Figure 173

Monell, U. S. Geol. Geog. Surv., Bull. 5, p. 27, 1879 (orig. dese.).

Davis, Can. Ent., vol. 46, p. 165, 1914. $R$. howardi (Wils.) (dese.).

Essig, Univ. Calif. Publ. Ent., vol. 1, p. 330, 1917. R. howardi (Wils.) (list).

Ibid., p. 334, 1917 (list).

Records.-Rhus diversiloba; Berkeley, April, 1915; Avena sativa, Berkeley, (Essig).

This species has been taken in Berkeley on poison oak and grasses. Essig reported it recently as $R$. howardi (Wils.), but according to Gillette $^{14}$ this is a synonym of $R$. rhois Monell, Rhus being the winter host, and various species of Graminaceae the summer hosts.

This species does not seem to be a typical Rhopalosiphum, being quite close to Siphocoryne nymphaeae Linn., but yet not fitting the generic description of Siphocoryne exaetly. Consequently it is best to list it as has been done heretofore as Rhopalosiphum. .

\section{Rhopalosiphum violae Pergande}

Figures 164, 174

Pergande, Can. Ent., vol. 32, p. 29, 1900 (orig. desc.).

Essig, Pom. Jour. Ent., vol. 1, p. 4, 1909 (dese.).

Davidson, Jour. Econ. Ent., vol. 2, p. 303, 1909 (list).

Davidson, Jour. Econ. Ent., vol. 3, p. 277, 1910 (list).

Records.-Viola spp.; Claremont, Santa Paula (Essig); Stanford University (Davidson); Palo Alto, May, 1915; Santa Ana, February, 1917; Riverside, April, 1917.

This beautiful little aphid is found more or less abundantly in the spring on the under side of the leaves of violets throughout the state. The dark red color and broad blaek wing veins serve to distinguish it readily from other aphids.

14 Gillette, Jour. Econ. Ent., vol. 8, p. 100, 1915. 


\section{Tribe Aphidini Wilson}

Wilson, Ann. Ent. Soe. Am., vol., 3, p. 331, 1910.

Following is a brief characterization of this tribe, from Wilson:

The characters which separate this tribe from the previous one [Macrosiphini] are taken as follows: Antennae shorter than the body, or when as long as the body the cornicles and cauda are very short; antennal tubercles, when present, are indistinct, or else the cornicles and cauda are small; when the cornicles are very long or large the development is limited and the other characters are used to place the genera.

The California genera included by Wilson in this tribe are Aphis, Cerosipha, Coloradoa, Hyalopterus, Liosomaphis, and Siphocoryne [Hyadaphis]. In addition to these the author includes Toxoptera because of the small and indistinct antennal tubereles and the short cornicles, and Myzaphis because of the absence of antennal tubercles. The key to the California genera has been formulated by the author, following Wilson, Mordwilko, and Van der Goot.

1. Antennae five-segmented

Cerosipha del Guercio

- Antennae six-segmented 2

2. Cornicles much shorter than cauda Hyalopterus Koch

- Cornicles about as long as or longer than cauda 3

3. Cornicles cylindrical, tapering, or conical, not distinctly clavate (fig. 182), except in Coloradoa and Myzaphis, in which they may be slightly clavate at the apex (fig. 315)

- Cornicles distinctly clavate (figs. 183, 184) 4

4. Cornicles long and strongly clavate on one side (fig. 184). Antennae shorter than body, with VI spur not longer than I.II .................iosomaphis Walker

- Cornicles slender and but slightly clavate (fig. 183). Antennae never much shorter than body, with VI spur longer than III (fig. 258) or with a supra. caudal tubercle (figs. 255, 256)

Siphorcoryne Passerini.

5. Third discoidal vein but one-branched (fig. 276). Body without lateral tubercles. Cauda long and prominent, being about as long as cornicles.

Toxoptera Koch

- Third discoidal vein twice-branched. Body with or without lateral tubercles. Cauda usually distinctly shorter than cornicles

6. Front of head with a very distinct tubercle (figs. 308, 313). Body long without lateral tubercles. Cornicles long and often slightly swollen near apex

Myzaphis Walker and Coloradoa Wilson

7. Front of head without prominent tubercle (fig. 233). Body more rounded with lateral tubercles on prothorax and seventh abdominal segment, and oftentimes on some of the anterior abdominal segments Aphis Linn. 


\section{Genus Aphis Linn.}

Linnaeus, Syst. Nat., 1748. Type Aphis rumicis Linn.

\section{Key to California Species \\ Alate viviparous females}

1. Abdomen with floceulent masses of wax. Antennae considerably shorter than body, and VI spur shorter than III alamedensis Clarke

- Abdomen without such flocculent masses of wax (except perhaps Aphis cooki Essig)

2. Antennae one and one-half times as long as the body, or more.

houghtonensis Throop

- Antennae not so much longer than body; when longer, which is seldom, but slightly so mori Clarke

3. Abdomen pale yellowish green. Found only on Morus sp.

- Abdomen darker being black, dark green, yellow. Not found on Morus sp. 4

4. Abdomen dark-green with an orange band between the cornicles.

angelicae Koch

- Abdomen without such an orange band between the cornicles (sometimes there is a slight orange or reddish coloring between the cornicles of the apterae of Aphis avenae Fabr., but it is not constant)

5. Abdomen sage-green with faint lateral spots. III with apical one-half conspicuously darkened and with six large sensoria. VI spur less than one-half as long as III. On Atriplex spp.

tetrapteralis Cockerell

- Not with above combination of characters .......................................................... 6

6. IV with secondary sensoria (fig. 244) ............................................................ 7

- IV without secondary sensoria (fig. 204) ....................................................... 27

7. Cornicles and hind tarsi subequal ......................................................................... 8

- Cornicles considerably longer than hind tarsi ................................................. 17

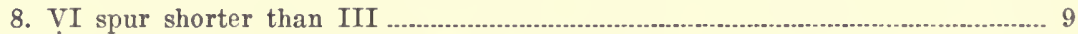

- VI spur equal to or longer than III ................................................................. 13

9. Cornicles short and tapering

- Cornicles short and incrassate ..............................................pseudobrassicae Davis

10. V with secondary sensoria. Body slightly pulverulent ......................cooki Essig

- V without secondary sensoria. Body not pulverulent .....................-................ 11

11. Less than 12 secondary sensoria on III, arranged in a more or less even line 12

- About 20 to 25 secondary sensoria on III, arranged irregularly along segment (fig. 244) senecio Swain

12. III with 9 to 12 sensoria. $\mathrm{V}$ and VI base subequal, each being shorter than

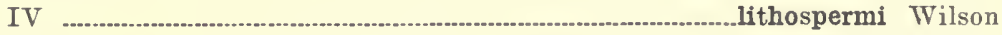

- III with 5 to 9 sensoria. IV and $\mathrm{V}$ subequal, each being longer than VI

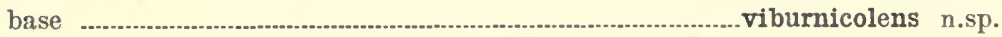

13. Cornicles shorter than hind tarsi. A large black species in life being marked with white bars and cross bands on the abdomen .................albipes Oestlund

- Cornicles and hind tarsi subequal. Body color greenish ................................. 14

14. Root-infesting species. Antennae short, scarcely reaching the middle of the abdomen middletonii Thomas

- Aërial species. Antennae reaching to base of the cornicles, or as long as body

15. Cornicles incrassate. A medium-sized species ............pseudobrassicae Davis
- Cornicles cylindrical and tapering slightly. A smaller-sized species ........... 16 
16. Cauda shorter than hind tarsi. III with 11 to 15 sensoria seattered irregularly along segment (fig. 294) .............................................marutae Oestlund

- Cauda longer than hind tarsi. III with 5 to 9 more or less evenly arranged sensoria viburnicolens n.sp.

17. Cornicles equal to or longer than III .................................................................. 18

- Cornicles not as long as III ....................................................................... 19

18. Cauda, cornicles, and III subequal. Second branch of third discoidal vein

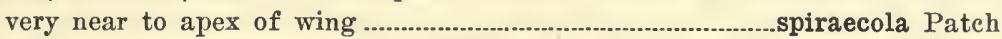

- Cauda considerably shorter than cornicles or III, the last two being subequal. Second branch of third discoidal about midway between base of first branch and apex of wing oenotherae Oestlund

19. Fore wing with the second branch of the third discoidal arising very near to the apex of the wing. (In a few eases the second branch is not found, but never in both wings) (fig. 191). avenae Fabr.

- Venation of fore wing normal (fig. 187) 20

20. Antennae longer than body persicae-niger Smith

- Antennae not longer than body 20

21. A pair of small tubercles present on the middle of the seventh and eighth abdominal segments malifoliae Fitch

- Such tubercles not present 22

22. V with secondary sensoria. VI spur longer than III 23

- V without secondary sensoria. VI spur at most equal to III 25

23. Beak searcely reaching second coxae maidis Fitch

- Beak reaching beyond second coxae, even to or beyond the third ................... 24

24. Cornicles longer than cauda (figs. 194, 195) and more than twice as long as hind tarsi sambucifoliae Fitch

- Cornicles and cauda subequal; the former not more than twice as long as

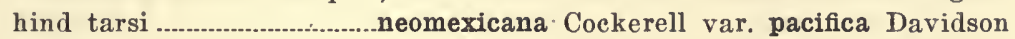

25. Cauda and hind tarsi subequal. III with a few large sensoria (fig. 232). Abdomen green with dark dorsal markings ramona Swain

- Cauda longer than hind tarsi. III with several sensoria. Abdomen black or dark brown 26

26. Cornicles more than twice as long as hind tarsi, often almost three times as long. VI spur and cornicles subequal, hind tarsi and. VI base subequal.

hederae Kalt.

- Cornicles never more than twice as long as hind tarsi, usually considerably less. Hind tarsi usually slightly longer than VI base, and VI spur longer than cornicles

euonomi Fabr.

27. Cornicles distinctly knobbed, the tip being widened to twice the width of the rest of the cornicles

frigidae Oestlund

- Cornicles normal 28

28. Fore wing with the second branch of the third discoidal arising very near the apex of the wing (fig. 188) salicicola Thomas

- Fore wing with venation normal (fig. 187) ........................................................ 29

29. Cornicles distinctly longer than cauda ................................................................ 31

- Cornicles at most equal to cauda ............................................................................. 30

30. Cornicles short and swollen throughout apical one-half (fig. 203). Antennae as long as or longer than the body. brassicae Linn.

- Cornicles short and slender, and slightly clavate on one side. Antennae searcely two-thirds as long as the body ......................... atriplicis Linn.

31. Abdomen without lateral tubercles on anterior segments. Cauda short and broad, with rounded tip, and almost as long as the cornicles ......cardui Linn.

- Abdomen with lateral tubercles on at least one of the anterior segments .... 32 
32. VI spur shorter than III .

- VI spur not shorter than III.

33. Cornicles about three times as long as eauda. medicaginis Koch

- Cornicles not three times as long as cauda.

34. Cauda more than one-half as long as cornicles.

- Cauda not more than one-half as long as cornicles.

35. III with four or five fairly large sensoria

- III with many irregular sensoria

oregonensis Wilson

36. III with 20 or more sensoria, IV with none .............................................. 37

- III with less than 20 sensoria, usually 14 or 15 . IV usually with one or two, or. more sensoria euonomi Fabr.

37. IV about one-third longer than V. Cornicles about four times as long as broad at base. On Heraclium spp..........................................heraclil Cowen

- IV but about one-sixth longer than V. Cornicles about three times as long as broad at base. On Yucca sp. ............................................Yuccae Cowen

38. A few (about 10) equal-sized sensoria on III (fig. 222). A large yellow species with distinct dark markings .................................................nerii Fonse.

- About 20 irregular sensoria on III (fig. 211). Not yellow ........................... 39

39. Cornicles slightly more than twice as long as hind tarsi ............................... 40

- Cornicles not twice as long as hind tarsi ...............................................cari Essig

40. Hind tarsi slightly longer than cauda .......................................ceanothi Clarke

- Hind tarsi shorter than eauda .......................................................cornifoliae Fiteh

41. VI spur one and one-half or more times as long as III ............setariae Thomas

- VI spur never so much longer than III ............................................................... 42

42. III with a few large eircular sensoria (5-10) (figs. 226, 290) ................... 43

- III with several (15 or more) irregular sensoria ............................................... 45

43. Beak reaching to or beyond third coxae. IV never with sensoria.

- Beak not reaching third coxae .............................................................................. 44

44. VI spur longer than III (fig. 226). Small size ............................pomi de Geer

- VI spur subequal to or shorter than III (figs. 289, 290). Medium to large

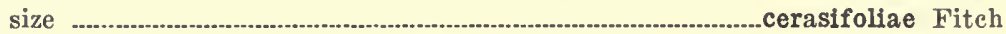

45. Cornicles twice as long as cauda. Femora of all three pairs of legs similarly colored cari Essig

- Cornicles longer than cauda, but not twice as long. Femora of first pair of legs pale, of second and third pair black euonomi Fabr.

\section{Apterous viviparous females 15}

1. Cornicles shorter than hind tarsi 2

- Cornicles equal to or longer than hind tarsi 4

2. VI spur longer than III. White bars and bands on abdomen in life.

albipes Oestlund

- VI spur not longer than III. Abdomen not as above 3

3. Cornicles and cauda subequal. Beak not reaching to second coxae. Pulverulent brassicae Linn.

- Cornicles shorter than cauda. Beak reaching to or beyond second coxae. Not pulverulent atriplicis Linn.

15 In this key only those species are included of which there are specimens in the author's collection or of which there are adequate deseriptions available. The following species are therefore omitted: Aphis alamedensis Clarke, A. houghtonensis Throop, A. mori Clarke, A. neomexicana Cockerell, A. oenotherae Oestlund, and A. tetrapteralis Cockerell. 
4. Cornieles and hind tarsi subequal

- Cornicles longer than hind tarsi.

5. Secondary sensoria on III and IV. Root species middletonif Thomas

- No secondary sensoria. Aërial species - 6

6. III longer than VI spur 7

- III shorter than or at most equal to VI spur 8

7. IV and cornicles subequal

- IV shorter than cornicles. Pulverulent lithospermi Wilson

8. IV and cornicles subequal. Antennae considerably more than one-half the length of the body 9

- IV shorter than cornicles. Antennae at most one-half the length of the body.

9. Cornicles twice as long as cauda and slightly swollen before the tip. senecio Swain

avenae Fabr.

- Cornicles not twice as long as cauda, cylindrical, and tapering toward tip.

marutae Oestlund

10. Cornicles less than twice as long as hind tarsi 11

- Cornicles twice as long as or longer than hind tarsi 21

11. Secondary sensoria on III and IV. Root-infesting species.

- No secondary sensoria. Aërial species ......................................................................... 12

12. VI spur longer than III ......................................................................................... 13

- VI spur at most equal to III .............................................................................. 16

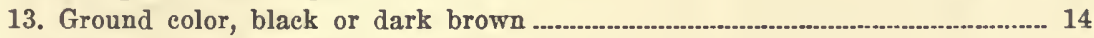

- Ground color, a shade of green .................................................................................... 15

14. VI spur one and one-half to two times as long as III. Apex only of femora dusky setariae Thomas

- VI spur but slightly longer than III. Apical one-half of femora dusky. medecaginis Koch

15. Pale green. Cornicles and cauda subequal. Dark, mottled green. Cornicles twice as long as cauda or longer avenae Fabr.

16. VI spur considerably shorter than III .................................................................. 17

- VI spur almost as long as III .............................................................................. 18

17. Cornicles swollen toward tip ...........................................pseudobrassicae Davis

- Cornicles eylindrical and tapering toward tip ..............................ramona Swain

18. Cornicles but slightly longer than hind tarsi ........................................................ 19

- Cornicles about one and one-half times as long as hind tarsi .......................... 20

19. Dark green. Cornieles at least three times as long as broad at base.

maidis Fiteh

- Pale green. Cornicles at most twice as long as broad at base.

20. Dark green to reddish yellow. On 'Yucca spp. senecio Swain

- Black or very dark brown with black dorsal bands and spots. On various plants euonomi Fabr.

21. Cornicles distinctly knobbed at tip frigidae Oestlund

- Cornicles normal 22

22. VI spur longer than II ....................................................................................... 23

- VI spur at most equal to III .................................................................................... 25

23. Pale green with dusky dorsal abdominal markings ..........calendulleola Monell

- Not colored as above, either not green, or if green with dusky dorsal abdominal markings 
24. Bright yellow with black markings. Cornicles at least three times as long as hind tarsi. nerii Fonse.

- Dark green with black markings. Cornicles but about twice as long as hind tarsi cardui Linn.

25. Cornicles longer than III .................................................................................. 26

- Cornicles at most equal to III ........................................................................... 29

26. III considerably longer than VI spur .......................................................... 27

- III subequal to or but slightly longer than VI spur ....................................... 28

27. Black. Cornicles about three times as long as hind tarsi. III one and onehalf times as long as VI spur sambucifoliae Fitch

- Green, pale to apple. Cornicles about four times as long as hind tarsi. III almost twice as long as VI spur .......................................salicicola Thomas

28. Cornicles subequal to or but slightly longer than III, and about twice as long as cauda prunorum Fabr.

- Cornicles one and one-half to two times as long as III, and about four times as long as cauda oregonensis Wilson

29. Cornicles considerably shorter than III 30

- Cornicles subequal to or but slightly shorter than III

30. III and IV spur subequal 37

- III longer than VI persicae-niger Smith

31. Cornicles at least twice as long as cauda 31

- Cornicles not twice as long as cauda 36

32. Pale green, pulverulent 32

- Dark green, brown, or black, not pulverulent .cerasifoliae Fitch

33. Cornicles about three times as long as hind tarsi 33

- Cornicles not three times as long as hind tarsi

34. III with a few small secondary sensoria

- No secondary sensoria

35. Cornicles considerably more than twice as long as hind tarsi. inal tubercles only on first and seventh segments Cornicles at most but slightly more than twice as long as hind tarsi. Lateral tubercles usually on more than first and seventh segments...euonomi Fabr.

36. Antennae about as long as body. Cornicles more than twice as long as Cauda cari Essig

- Antennae but about one-half as long as body. Cornicles but about twice as long as cauda gossypii Glover

37. III considerably longer than VI spur ................................................................. 38

- III and VI spur subequal ................................................................................... 40

38. A pair of dorsal abdominal tubercles on sixth and seventh segments.

- No dorsal abdominal tubercles on sixth and seventh segments ......................... 39

39. Cornicles green, cylindrical, tapering slightly toward tip, and fairly straight. Cauda about one and one-half times as long as hind tarsi. Abdomen without dusky dorsal markings ramona Swain

- Cornicles black, cylindrical, curved outward. Cauda and hind tarsi subequal. Abdomen with dusky dorsal markings seanothi Clarke

40. VI spur slightly longer than III. Cornicles and cauda subequal.

viburnicolens n.sp.

- VI spur slightly shorter than III. Cornicles one and one-half times as long as cauda .pomi De Geer 


\section{Aphis alamedensis Clarke}

Clarke, Can. Ent., vol. 35, p. 251, 1903 (orig. dese.).

Record.-Prunus äomestica; Berkeley (Clarke).

This is an unknown species described from specimens taken by Clarke on greengage plum in Berkeley. Davidson suggests that it might be Aphis cardui Linn. (pruni Koch) from its brief description.

\section{Aphis albipes Oestlund}

Figures 198 to 200

Oestlund, Geol. Nat. Hist. Surv. Minn., Bull. 4, p. 52, 1887 (orig. dese.).

Williams, Univ. Neb. Studies, vol. 10, p. 119, 1910 (dese.).

Davidson, Jour. Eeon. Ent., vol. 3, p. 376, 1910 (list).

Records.-Symphoricarpus racemosus; Stanford University (Davidson); Congress Springs, Santa Clara County, July, 1915 (MeCracken); Berkeley, July, 1915 (Shinji).

This species is found at times curling the leaves of snowberry in the San Franciseo Bay region. 'Dr. MeCracken noted in connection with the infestation at Congress Springs, "they are quite prettily patterned with white bars and cross-bars." This is usually enough to distinguish them.

\section{Aphis angelicae Koch.}

Koch, Die Pflanzenläuse, p. 521, 1854 (orig. dese.).

Wilson, Jour. Econ. Ent., vol. 2, p. 348, 1909 (dese.).

Record.-Angelica sp., Hedera sp.; California (Wilson).

Wilson reported this species from California, but gave no locality or date. It is unknown to the author.

\section{Aphis atriplicis Iinn.}

Linnaeus, Fauna Sweden, p. 1000, 1761 (orig. dese.).

Hayhurst, Ann. Ent. Soe. Am., vol. 2, pp. 88-100, 1909 (desc.).

Davidson, Jour. Eeon. Ent., vol. 5, p. 407, 1912 (dese. sexuales apterous viviparae).

Davidson, Jour. Econ. Ent., vol. 7, p. 133, 1914 (dese. fundatrix).

Records.-Chenopodium album, C. murale; San Jose, Walnut Creek (Davidson). 
This has been reported twice from pigweed or goosefoot in the San Francisco Bay region, where Davidson states that it is very common. The sexes occur in October. Davidson believes that there is an alternate host, but as to what it might be, he is uncertain. The author has never collected specimens, but has had access to material taken by R. W. Doane on Chenopodium in Utah in August, 1916.

\section{Aphis avenae Fabr.}

Figures 191, 201, 202

Fabricius, Ent. Syst., p. 736, 1775 (orig. desc.). Clarke, Can. Ent., vol. 35, p. 254, 1903 . Nectarophora (list). Davidson, Jour. Econ. Ent., vol. 3, p. 377, 1910. Siphocoryne (list). Essig, Pom. Jour. Ent., vol. 3, p. 465, 1911. A. padi Linn. (list). Essig, Pom. Jour. Ent., vol. 4, p. 790, 1912. A. maidis Fitch (dese). Smith, Mon. Bull. Cal. Comm. Hort., vol. 3, p. 116, 1914 (list). Davidson, Mon. Bull. Cal. Comm. Hort., vol. 6, p. 65, 1917 (note).

Records.-Graminaceae (various spp.) ; California, December to May (Davidson, Essig, Morrison, author): Phalaris arundinacea; Stanford University, May to July, 1915: Dracaena draco; Stanford University, June, 1915: Musa sapientum; San Diego, March, 1916: Typha latifolia; (Davidson).

This is an abundant species through the state, occurring during the late winter and spring on grasses and grains, migrating to other hosts as these become ripened and dried.

The life history of this species, according to Davis (U. S. Dept. Agr., Bull. 111, April, 1914), is somewhat as follows :

The spring colonies on grains and grasses originate from viviparous females which passed the winter on the grains and grasses, or from spring migrants from the apples or related fruits; i.e., the progeny of the aphids hatching from eggs laid the previous fall on such trees. As the weather becomes cooler they seek the lower parts or the roots of wheat and other plants of the grass family, and here pass the winter as viviparous females; or the winged fall migrants from the grain may seek such trees as the apple, where the true sexes are produced.

Undoubtedly the most common method of wintering over in California is on the roots and lower parts of the grains and grasses. This species has never been collected on apples or other related trees in this state, nor have the eggs ever been observed. During the early spring it is found abundantly on the grains and small grasses, in January and February in the southern part of the state, and during April and May in the central part. As the grains ripen and the stalks and leaves become hardened, it seems that the aphids migrate to other varieties of grass which remain soft and green later, as canary grass and reed grass and corn, or even to such hosts as the 
dragon tree, cat-tail rush, and the banana. But the winter is spent as viviparous females on the grains and grasses.

This species has been confused many times with other species infesting grains, such as Macrosiphum granarium (Kirby) and Toxoptera graminum (Rond.). As the latter does not occur in this statc it cannot be confused here with Aphis avenae Fabr. Clarke listed this as Nectarophora avenac Fabr., so it appears that he might have had Macrosiphum granarium (Kirby) in mind, as it is highly improbable that he could have confused Aphis avenae Fabr. with a species of Macrosiphum (Nectarophora). The cornicles of avenae Fabr., the absence of antennal tubercles, and the irregular venation make it quite easily distinguishable. The cornicles are quite short, as compared with a species of Macrosiphum, and distinct antennal tubercles are entirely lacking. The third discoidal vein of the forewing is typically twice-branched, but the second is close to the apex of the wing, and sometimes is entirely lacking. The only other species of Aphis in this state with this character is Aphis salicicola 'Thomas, found on willows. These two are readily distinguished from each other by the comparative lengths of the cornicles, which are considerably longer in salicicola Thomas than in avenae Fabr.

\section{Aphis brassicae Linnaeus}

Figures 203, 204

Linnaeus, Syst. Nat., vol. 2, p. 734, 1735 (orig. desc.).

Clarke, Can. Ent., vol. 35, p. 250, 1903 (list).

Davidson, Jour. Econ. Ent., vol. 2, p. 302, 1909 (list).

Davidson, Jour. Econ. Ent., vol. 3, p. 376, 1910 (list).

Davidson, Pom. Jour. Ent., vol. 3, p. 399, 1911 (list).

Essig, Pom. Jour. Ent., vol. 3, p. 523, 1911 (dese.).

Record.-Cruciferae (various spp.); throughout California.

During the late winter and spring cruciferous plants are often heavily infested with this species. Of the cultivated plants cabbages and radishes secm to be most heavily infested; while the wild mustard and radish often have the entire flower clusters covered with these aphids. Oftentimes in the colonies of this species arc also found Aphis pseudobrassicae Davis, Rhopalosiphum lactucae (Kalt.), and $R$. persicae (Sulz.). In southern California the colonies are always attacked by the braconid fly, Diaretus rapae Curtiss, and a large percentage of the individuals destroyed. As summer comes on these parasites and such predators as syrphids and ladybirds usually get the best of the aphids, which disappear to a large extent until fall. 


\section{Aphis calendulicola Monell}

Monell, U. S. Geol. Geog. Surv., Bull. 5, p. 23, 1879 (orig. dese.).

Clarke, Can. Ent., vol. 35, p. 250, 1903 (list).

Record.-Calendula officinale; Berkeley (Clarke).

This species has not been recognized since Clarke's report of it on marigold. It is possible that he had Aphis senecio Swain, which is very common on marigolds throughout the state.

\section{Aphis cardui Linn.}

Figures 208, 209

Linnaeus, Syst. Nat., vol. 2, p. 735, 1735 (orig. desc.).

Carnes, Mon. Bull. Cal. Comm. Hort., vol. 1, p. 399, 1912. Aphis pruni (list).

Davidson, Jour. Econ. Ent., vol. 5, p. 407, 1912 (list).

Pàteh, Maine Agr. Exp. Sta., Bull. 233, p. 263, 1914 (desc.).

Records.-Cirsium sp.; San Jose (Davidson); Berkeley, June, 1915: Prunus domestica; Orangevale, Sacramento County (Carnes); Walnut Creek (Davidson); Berkeley, March, 1916 (Essig).

According to Patch this thistle aphid is the same as the one infesting plums and formerly known as $A$. pruni Koch. Both are abundant in the San Francisco Bay region, pruni being found in the fall and spring on plum, cardui during the summer on thistle. The author has attempted no transfer tests, so accepts Patch's statement as authority for the synonymy. It is certain that structurally these are strietly identieal.

\section{Aphis cari Essig}

Essig, Univ. Calif. Publ. Entom., vol. 1, pp. 317-321, 1917 (orig. dese.).

Record.-Carum kelloggii; Rutherford, Napa County (Essig); Angelica tomentosa; Berkeley (Essig).

Essig recently described this from specimens taken on wild anise in Rutherford. The author has seen cotype specimens, but has never collected the species.

\section{Aphis ceanothi Clarke}

Figures 210, 211

Clarke, Can. Ent., vol. 35, p. 250, 1903 (orig. desc.).

Davidson, Jour. Econ. Ent., vol. 2, p. 302, 1909 (list).

Davidson, Jour. Econ. Ent., vol. 3, p. 377, 1910 (list).

Essig, Pom. Jour. Ent., vol. 3, p. 525, 1911. Aphis ceanothi-hirsuti n. sp. (desc.). 
Records.-Ceanothus integerrimus; Colfax, Placer County (Clarke); Witeh Creek, San Diego County, June, 1916: C. cuneatus; Stanford University (Davidson), November, 1910 (Morrison), October, 1915 (R. A. Vickerey): C. thysiflorus; Bear Creek Gulch, Santa Clara County, April, 1911 (Morrison): C. hirsuti; Santa Paula (Essig).

This is a widely distributed species, having been found on Ceanothus as far north as Placer County, and as far south as San Diego County. It is seldom abundant, however. The species that Essig described as A. ceanothi-hirsuti n.sp. is undoubtedly the same as Clarke described.

\section{Aphis cerasifoliae Fitch}

\section{Figtures 288 to 292}

Fitch, Rept. Ins. N. Y., vol. 1, p. 131, 1855 (orig. dese.).

Patch, Maine Agr. Exp. Sta., Bull. 233, p. 260, 1914 (dese.).

Reeord.-Prunus emarginata; Wynola, San Diego County, June, 1916.

This aphid was found abundantly curling the terminal leaves of wild cherry near Wynola (3700 feet altitude), San Diego County, in June, 1916. Alate and apterous viviparous females as well as nymphs were abundant in the curled leaves. The apterae and nymphs were slightly pulverulent. This species corresponds very closely to Aphis cerasifoliae Fitch as described by Patch (op. cit.), although there are some minor differences. Following is a copy of Patch's description of the Maine specimens of this species:

- This well defined species is common on both the native choke cherry, Prunus virginiana, and the western $P$. demissa Walp. introduced in a nursery row on our campus.

Apterous female.-Head, pale green or water whitish, beak short, extending to second coxae, eyes, antennae with I, II and III concolorous with head, distal half darker to black, III with no sensoria, proportions as shown in figure; prothorax pale green, lateral tubercles present; thorax green with dark green middorsal line, femora and tibiae pale and tarsi black; abdomen pulvernlent, pale green with dark green median line and dark green transverse lines between segments, lateral tubercles present, cornicles pale with dusky tips, slender, slightly tapering, and approximately twice the tarsus in length, cauda white with dark tip; conical, being broad at base and abruptly tapering.

Nymphs and pupae are also pulverulent and have dark green middorsal and transverse intersegmental line, though these are not always well defined in the pupa which has two lateral dark green lines on thorax.

Alate female. Head black, beak short, not reaching to second coxae, eyes black, antennae dark, III with from about 12 to 18 large sensoria about the size of the terminal one on V, IV with from none to several sensoria like those on III, proportions of joints as shown in the figure; prothorax green with black transverse band, lateral tubereles present; thorax black, wings iridescent with slender brown veins and large dusky stigma with pointed tip; commonly though not 
always with second branch very short, abdomen glabrous, rather bright though not vivid green, median line dark green, sutural lines dark green ending in marginal green dots, cornicles dark, cauda green.

Aphis cerasifoliae is gregarious on the ventral surface of the terminal leaves badly curling and deforming them. A copious amount of honeydew is present, and ants are usually found attending a colony of this species.

The specimens from Wynola agree very well with this description, although as stated above, there are a few minor points of difference. However, as Dr. Patch writes: "It seems too close to cerasifoliae to give it a distinct name," and "if the appearance in life answers my description of cerasifoliae I should be inclined to call it that. It happens to be a species as characteristic alive as dead." Following are the notes the author took of its appearance alive, before he suspected its identity: "Alates, apterae and nymphs abundant on terminal leaves curling them badly. Large amount of honeydew and many ants in attendance. Apterae and nymphs pulverulent." These notes agree exactly with Patch's notes, cited above.

Following is a brief description of specimens taken at Wynola on July 8:

Aptcrous viviparous female.-Prevailing color pale apple green, pulverulent. Head luteous. Thorax and abdomen pale green with middorsal longitudinal stripe darker green. Antennae with the three basal joints luteous, the three apical joints shading into black. Primary sensoria on $\mathrm{V}$ and VI, accessory sensoria on VI, no secondary sensoria. III and spur are subequal, or III slightly the longer. IV and $\mathrm{V}$ subequal and a little more than one-half as long as III. In some cases IV is slightly longer than V. VI is about one-fourth as long as its spur, longer than I, which in turn is longer than II. The antennae are longer than the body. Cornicles long, slightly tapering, pale with tip dusky, about equal in length to the fifth antennal segment and about twice the length of the hind tarsus. Cauda long, conical, and about two-thirds the length of the cornicles, pale with tip dusky. Lateral tubercles are present on the first and seventh abdominal segments and on one other of the abdominal segments, in some cases on the second, in others! on the third, and in others on the fourth.

Measurements (of specimens mounted in Canadian balsam) : Body length, 1.5 to $1.53 \mathrm{~mm}$; body width (abdomen), $0.247 \mathrm{~mm}$.; antennae total, 1.445 to $1.734 \mathrm{~mm}$. (av. $1.6082 \mathrm{~mm}$.) ; I, 0.085 to $0.117 \mathrm{~mm}$. (av. $0.0987 \mathrm{~mm}$.) ; II, $0.068 \mathrm{~mm}$. ; III, 0.408 to $0.467 \mathrm{~mm}$. (av. 0.4335 mm.) ; IV, 0.238 to $0.306 \mathrm{~mm}$. (av. $0.272 \mathrm{~mm}$.) ; V, 0.221 to $0.233 \mathrm{~mm}$. (av. $0.224 \mathrm{~mm}$.) ; VI, 0.1105 to $0.119 \mathrm{~mm}$. (av. $0.1169 \mathrm{~mm}$.) ; spur, 
0.408 to $0.45 \mathrm{~mm}$. (av. $0.4186 \mathrm{~mm}$.) ; cornicles, 0.221 to $0.255 \mathrm{~mm}$. (av. $0.2401 \mathrm{~mm}$.) ; cauda, $0.15 \mathrm{~mm}$; hind tarsi, 0.12 to $0.135 \mathrm{~mm}$. (av. $0.1275 \mathrm{~mm}$.).

Alate viviparous female.-Prevailing color pale to apple green Head, antennae, thorax, marginal spots on abdomen, cornicles, tip of cauda, femora, and tarsi all black. Antennae (fig. 289, 290) with the usual primary sensoria on $\mathrm{V}$ and VI and the usual accessory sensoria on VI. IV without sensoria and III with from 6 to 11 fairly large circular secondary sensoria, the usual number being 8 (fig. 290). In this character it differs most markedly from the Main specimens, which have from 12 to 18 sensoria on III and from none to several on IV. The antennae are slightly shorter than the body although practically of the same length. III is the longest segment, closely followed by the spur, then by IV, V, VI, I and II. III and the spur are subequal, or either one or the other may be slightly the longer. In Patch's drawing $\mathrm{V}$ is a little longer than IV. In the California specimen IV is always slightly the longer of the two. In all the California specimens the antennal segments are all a little shorter than in the Maine material. Lateral tubercles are present on the prothorax; they are always present on the seventh abdominal segment, and may be present on any of the first few segments of the abdomen as well. In one case they were observed on the second and seventh segments, in another on the second, third, and seventh, in still another on the fourth, fifth, and seventh, and in a fourth case on the first, second, third, fourth, and seventh segments (fig. 292). The wings and venation are normal, with the second branch of the cubitus arising nearer to the tip of the wing than to the base of the first branch (fig. 291). However, it is not quite so close to the wing tip as in the Maine specimens. The cornicles (fig. 292) are long and cylindrical. They are equal to or slightly shorter than $\mathrm{V}$, and from one and one-half to two times as long as the hind tarsi. The cauda (fig. 292) is more or less ensiform, about one-half as long as the cornicles, reaching to the tip of the cornicles, and subequal to or slightly shorter than the hind tarsi.

Measurements (of specimens mounted in Canadian balsam) : Body .length, 1.53 to $1.65 \mathrm{~mm}$. (av. $1.585 \mathrm{~mm}$.) ; width of thorax 0.697 to $0.765 \mathrm{~mm}$. (av. $0.731 \mathrm{~mm}$.), antennae total, $1.568 \mathrm{~mm}$.; I, 0.068 to $0.085 \mathrm{~mm}$. (av. $0.0765 \mathrm{~mm}$.) ; II, $0.051 \mathrm{~mm}$.; III, 0.331 to $0.408 \mathrm{~mm}$. (av. $0.3644 \mathrm{~mm}$.) ; IV, 0.238 to $0.289 \mathrm{~mm}$. (av. $0.2817 \mathrm{~mm}$.) ; V, 0.221 to $0.247 \mathrm{~mm}$. (av. $0.2295 \mathrm{~mm}$.) ; VI base, 0.085 to $0.111 \mathrm{~mm}$. (av. 
$0.1015 \mathrm{~mm}$.) ; VI spur, $0.391 \mathrm{~mm}$. ; cornicles, 0.204 to $0.246 \mathrm{~mm}$. (av. $0.2179 \mathrm{~mm}$.) ; cauda, 0.103 to $0.119 \mathrm{~mm}$. (av. $0.1084 \mathrm{~mm}$.) ; hind tarsi, $0.136 \mathrm{~mm}$.

\section{Aphis cooki Essig}

Figures 212 to 214

Essig, Pom. Jour. Ent., vol. 2, p. 323, 1910. Aphis gossypii Glover (desc.). Essig, Pom. Jour. Ent., vol. 3, p. 587, 1911 (orig. desc.).

Record.-Citrus sp., Pomona (Essig).

In 1909, C. H. Vary, county horticultural inspector in Pomona, found a few orange trees heavily infested with this aphid. Prompt control measures were taken and since then it has never again been observed. Essig first thought it to be Aphis gossypii Glover and described it under that name. Later, however, he found it to be an undescribed species, so named it Aphis cooki n.sp. after Dr. A. J. Cook.

\section{Aphis cornifoliae Fitch}

Fitch, Cat. Homop. N. Y., p. 65, 1851 (orig. dese.).

Records.-Cornus pubescens, Sanicula menziesii; San Franeiseo Bay region (Davidson).

A species comparing very favorably with this has been taken by Davidson a number of times in the San Francisco Bay region. The fall and winter is spent on dogwood, the summer on gambleweed. Davidson writes as follows :

This aphid [from Sanicula] certainly appears to be very close to what I have called (after Gillette) cornifoliae. Moreover, I have noticed that the two plants, dogwood and Sanicula, frequently grow near each other and that there appeared to be a migration of alates from the former just about the time there was a migration of the alates to the latter.

This migration took place the latter part of April in 1916.

\section{Aphis crataegifolii Fitch}

Fitch, Cat. Homop. N. Y., p. 66, 1851 (orig. desc.).

Sanborn, Kan. Univ. Sci. Bull. 3, p. 53, 1904 (desc.).

Davidson, Jour. Econ. Ent., vol. 3, p. 377, 1910 (list).

Record.-Crataegus oxycantha; San Jose, Palo Alto (Davidson).

This has been reported more or less abundant on hawthorne in the San Francisco Bay region. According to A. C. Baker this is a good and distinct species and not a synonym of Aphis pomi De Geer, as formerly believed. 


\section{Aphis euonomi Fabr.}

Figures 182, 187, 190, 205 to $207,236,237$

Fabricius, Syst. Ent., p. 736, 1794 (orig. desc.).

Davidson, Jour. Econ. Ent., vol. 2, p. 302, 1909. A. rumicis Linn. (list, in part?).

Essig, Mon. Bull. Cal. Comm. Hort., vol. 4, p. 446, 1915. A. rumicis Linn. (list).

Records-Althaea rosea, Berkeley, June, 1915; Hisbiscus moscheutos, Berkeley, July, 1915: Maytenus boaria, Berkeley, July, 1915; Mesembryanthemum equilaterale, Stanford University, June, 1915; Silybum marianum, Stanford University, July, 1915: Urtica holoserica, Menlo Park, San Mateo County, January, 1915: Calendula officinale, Orange, February, 1917: Anthemis sp., Pasadena, April, 1917: Papaver sp., El Cajon, San Diego County, May, 1916 (Aphis papaveris Fabr. ?): Vicia faba, Stanford University (Davidson), Oxnard (Essig, 1915), Montebello, Los Angeles County, December, 1916, Riverside, January to May 1917 (Aphis fabae Scop.?): Rumex spp., Palo Alto, January, 1912 (Davidson), Stanford University, March, 1912 (Morrison), March, 1915, Ventura County, May, 1917 : Phaseolus spp., Ventura County, May, 1917 (Aphis rumicis Linn.?).

There has been a great deal of confusion regarding the identity of this species of aphid, and as yet its synonomy is not worked out satisfaetorily. The following is offered only provisionally by the author. The eommon black aphid has usually been eonsidered as Aphis rumicis Linn., Aphis euonomi Fabr. being taken as a synonym, but aeeording to Gillette, Linnaeus' deseription calls for an aphid "brassy brown in eolor, and not blaek aeeording to the popular opinion; and its food plant should be species of Rumex." He eonsiders the common black species to be Aphis euonomi Fabr., as does Mordwilko in the European form. The author follows these two aphidologists in placing Aphis rumicis Linn. of American authors (and later European authors) as a synonym of Aphis enonomi Fabr. He (i.e., Gillette) writes, "whether or not it is synonymous with rumicis we are not eertain, but we very mueh doubt this being the ease." As long ago as 1894, Osborn and Sirrine (Iowa Agr. Sta., Bull. 26, p. 904 , 1894) proved that the species which wintered in Iowa on Euonymus migrated to Rumex and other plants in the summer. In California the author has been unable to find it at any time upon Euonymus, although this is a very common ornamental plant, espeeially in the vieinity of Riverside. This may be due, however, to the mild winter elimate of southern California, which permits plant liee to live throughout the winter, thus not neessitating the laying of eggs. Coneerning the identity of the California speeies the author believes the form deseribed briefly below to be Aphis euonomi Fabr. The 
one following is probably the same species, and is the one described as Aphis papaveris by Fabricius. The species from Vicia faba is probably the species described as Aphis fabae Scop., which may be synonymous with Aphis enonomi Fabr., but again may not be. The author tried a few transfer tests this spring (1917) with the form from Vicia, attempting to colonize it on Hedera helix and on Rumex spp., with negative results. Of course, this does not prove that it will not colonize on these plants, although the author has come to the conclusion that the Hedera species is entirely different, being Aphis hederae Kalt. Dr. Patch ${ }^{16}$ in her interesting paper on aphid ecology makes the following statement regarding migration tests, which, it seems to the author, it is well to remember when making such tests:

If an investigator fails in one hundred attempts to colonize thistle with migrants from plum, that will not be a safe reason for him to conclude that he is not working with Aphis cardui, or that this thistle aphid has nothing to do with the leaf deformations of the plum in the spring. It has been my experience that negative data with aphids under such conditions are just no data at all. If the structural characters are such as warrant the migration test in the first place, they warrant a patient continuation even in the face of repeated failures.

On the other hand (and this is a most encouraging and stimulating circumstance in connection with aphid migration tests), a single success goes a long way to prove the case. Barring complications, a single success is enough, and repetitions and verifications are needed only as safeguards in that respect.

The third description is from specimens taken on Rumex spp. and although slightly different from the one considered as Aphis enonomi Fabr., it may be the same, and it may be Aphis rumicis Linn., but of this the author is doubtful.

In the bean fields of Ventura County, this black bean aphis is very abundant, and often does considerable damage. In May, 1917, the bean plants were just beginning to appear, and as yet were not infested with the aphis. However, the native dock was quite heavily infested. It seems that the aphis lives over the winter on dock and perhaps on other native plants, migrating in the early summer to the beans. Here it lives throughout the summer, returning to dock when the beans have been harvested and the plants plowed under. Horticultural Commissioner A. A. Brock, of Ventura County, places great hope in the efficiency of Hippodamia convergens Guérin as a controlling factor. In the spring of 1917 he collected a vast number of these ladybird beetles in Sespe Canyon and turned them loose in the bean fields just as the aphids were beginning to appear. At the present time the results are unknown.

16 Patch, Edith M., Concerning problems in Aphid ecology, Jour. Econ. Ent., vol. 9, pp. 44-51, 1917. 
The following brief description was made from specimens collected from the first six host plants listed above, and is the one considered as Aphis euonomi Fabr.

Alate viviparous female.-Color apparently black, but on close examination it seems that the ground color is a very dark brown, covered with a blackish tinge, with the following parts decidedly black: head, antennae, thoracic lobes, marginal spots and transverse bands on the abdomen, cornicles, tarsi, coxae, tips of tibiae, and apical one-half to two-thirds of the middle and hind femora. The tibiae and fore femora are pale, appearing whitish in life. The antennae are shorter than the body, III being the longest segment, followed closely by VI spur. In one case VI spur was slightly longer than III and in another equal to III. In all other specimens III was the longer segment. IV and $\mathrm{V}$ are subequal, $\mathrm{V}$ usually being slightly the shorter. There are from eleven to twenty-one secondary sensoria on III, of irregular size. These are seattered along the whole length of the segment, the distal five or six being in a more or less even line. The usual number is about twelve to fourteen. The number of secondary sensoria on IV range from none to seven, the modal number being two. In one specimen only were sensoria absent from IV; in another, one antenna had seven, the other having two, while in a third, onc antenna had five, the other six. When there are more than two or three sensoria, they are all quite small, and can be clearly distinguished only by the higher power of a microscope. Two is the usual number, being located about the middle of the segment. $\mathrm{V}$ is usually without secondary sensoria, the primary sensorium being always present, however. In one specimen the antennae had one or two very small secondary sensoria on $\mathrm{V}$, and in another specimen one antenna had one small sensorium, the other none. The usual primary and accessory sensoria are present on VI base. Lateral abdominal tubereles are always present on the seventh segment, usually on the first, and often on the second, third, fourth, or fifth. There are always at least three pair of these tubercles, and oftentimes more. One specimen had tubercles on the first, second, third, fourth, and seventh segments. The cornicles are black, imbricated, and taper noticeably from base to apex. They are quite constant in length, the variation being not more than $0.05 \mathrm{~mm}$. in all the specimens examined. They are about half as long again as the hind tarsi. The eauda is concolorous with the abdomen, short and conical or ensiform, and subequal in length to the hind tarsi. The wings are normal, with the typical Aphis venation. 
Measuremeuts: Body length, 1.53 to $1.989 \mathrm{~mm}$. (av. $1.74 \mathrm{~mm}$.$) ;$ width of thorax, 0.68 to $0.918 \mathrm{~mm}$. (av. $0.765 \mathrm{~mm}$.) ; antennae total, 1.122 to $1.36 \mathrm{~mm}$. (av. $1.272 \mathrm{~mm}$.) ; III, 0.289 to $0.425 \mathrm{~m} . \mathrm{m}$ (av. 0.3648 mm.) ; IV, 0.1955 to $0.272 \mathrm{~mm}$. (av. $0.2266 \mathrm{~mm}$.) ; V, 0.187 to 0.221 mm. (av. $0.1885 \mathrm{~mm}$.) ; VI, base 0.102 to $0.136 \mathrm{~mm}$. (av. $0.1119 \mathrm{~mm}$.) ; VI, spur 0.289 to $0.357 \mathrm{~mm}$. (av. $0.3145 \mathrm{~mm}$.) ; cornicles, 0.1785 to $0.221 \mathrm{~mm}$. (av. $0.2118 \mathrm{~mm}$.) ; cauda, 0.136 to $0.162 \mathrm{~mm}$. (av. 0.14875 mm.) ; hind tarsus, 0.136 to $0.152 \mathrm{~mm}$. (av. $0.1372 \mathrm{~mm}$.).

Specimens taken by the author in May, 1916, on Papaver sp. (cultivated poppy) near El Cajon, San Diego County, seem to him to be Aphis papaveris Fabr. (Genera Insectorum, p. 303, 1717), and probably are the same as the above species, although they may be different. There are from thirteen to fifteen irregular secondary sensoria on III as above, but IV and $V$ are without secondary sensoria, with onc exception, in which there was one small scnsorium near the middle of IV. The cauda is equal to the hind tarsi, the cornicles bcing longer, and about the same comparative length as above. The third antennal segment appears to be longer in comparison than above in some specimens. Lateral abdominal tubercles are present on the first, third, and seventh abdominal segments.

Measurements: Body length, 1.486 to $1.908 \mathrm{~mm}$. (av. $1.711 \mathrm{~mm}$.); width of thorax, 0.595 to $0.765 \mathrm{~mm}$. (av. $0.68 \mathrm{~mm}$.) ; antennac total, 1.224 to $1.343 \mathrm{~mm}$. (av. $1.2878 \mathrm{~mm}$.) ; III, 0.323 to $0.374 \mathrm{~nm}$. (av. $0.3536 \mathrm{~mm}$.) ; IV, 0.2125 to $0.22 \mathrm{~mm}$. (av. $0.2193 \mathrm{~mm}$.) ; $\mathrm{V}, 0.187$ to $0.204 \mathrm{~mm}$. (av. $0.2024 \mathrm{~mm}$.) ; VI, base 0.102 to $0.119 \mathrm{~mm}$. (av. 0.1054 mm.) ; VI, spur 0.255 to $0.34 \mathrm{~mm}$. (av. $0.2992 \mathrm{~mm}$.) ; cornicles, 0.187 to $0.221 \mathrm{~mm}$. (av. $0.204 \mathrm{~mm}$.) ; cauda, 0.136 to $0.153 \mathrm{~mm}$. (av. 0.142 mm.) ; hind tarsus, $0.119 \mathrm{~mm}$.

Specimens taken by the author near Montebello, Los Angeles County, in December, 1916, and in Riverside from January to May, 1917, on Vicia faba seem to be somewhat different from the foregoing, yet are very nearly identical. Gillette considers that they might possibly be Aphis fabae Scop., which may or may not be synonymous witl Aphis euonomi Fabr. Supcrficially, the coloring seems to be the same, although on close observation it appears to be a very dark green in ground color, covered with a blackish tinge. The legs are colored as above, however.

Specimens from Rumex appear to have considerably more brown in the ground color than the preceding varieties. Secondary sensoria are located as follows: III, 14 to 24 (av. 18); IV, 4 to 7 (av. 5); V, 
I to 4 (av. 3). Lateral abdominal tubercles could be found only on the first and seventh segments.

Alate viviparous female.-Measurements: Body length, 1.768 to $2.142 \mathrm{~mm}$. (av. $1.942 \mathrm{~mm}$.) ; width of thorax, 0.782 to $1.054 \mathrm{~mm}$. (av. $0.918 \mathrm{~mm}$.) ; antennae total, 1.445 to $1.581 \mathrm{~mm}$. (av. $1.496 \mathrm{~mm}$.) ; III, 0.357 to $0.408 \mathrm{~mm}$. (av. $0.394 \mathrm{~mm}$.); IV, 0.255 to $0.323 \mathrm{~mm}$. (av. $0.286 \mathrm{~mm}$.) ; V, 0.204 to $0.255 \mathrm{~mm}$. (av. $0.233 \mathrm{~mm}$.) ; VI, base 0.136 to $0.153 \mathrm{~mm}$. (av. $0.139 \mathrm{~mm}$.) ; VI, spur 0.289 to $0.323 \mathrm{~mm}$. (av. $0.306 \mathrm{~mm}$.) ; cornicles, 0.187 to $0.255 \mathrm{~mm}$. (av. $0.219 \mathrm{~mm}$.) ; cauda, 0.136 to $0.17 \mathrm{~mm}$. (av. $0.153 \mathrm{~mm}$.) ; hind tarsus, 0.119 to $0.153 \mathrm{~mm}$. (av. $0.147 \mathrm{~mm}$.).

Apterous viviparous female.-Measurements : Body length, 2.278 to $2.448 \mathrm{~mm}$. (av. $2.3403 \mathrm{~mm}$.) ; antennae total, 1.309 to $1.598 \mathrm{~mm}$. (av. $1.4382 \mathrm{~mm}$.) ; III, 0.306 to $0.408 \mathrm{~mm}$. (av. $0.3502 \mathrm{~mm}$.) ; IV, 0.221 to $0.306 \mathrm{~mm}$. (av. $0.2618 \mathrm{~mm}$.) ; $\mathrm{V}, 0.206$ to $0.255 \mathrm{~mm}$. (av. 0.238 mm.) ; VI, base 0.119 to $0.17 \mathrm{~mm}$. (av. $0.1394 \mathrm{~mm}$.) ; VI, spur 0.289 to $0.34 \mathrm{~mm}$. (av. $0.306 \mathrm{~mm}$.) ; cauda, 0.17 to $0.204 \mathrm{~mm}$. (av. $0.187 \mathrm{~mm}$.) ; cornicle, 0.255 to $0.323 \mathrm{~mm}$. (av. $0.289 \mathrm{~mm}$.) ; hind tarsus, 0.153 to $0.17 \mathrm{~mm}$. (av. $0.167 \mathrm{~mm}$.).

\section{Aphis frigidae Oestlund}

Oestlund, Geol. Nat. Hist. Surv. Minn., vol. 14, p. 46, 1886 (orig. dese.). Davidson, Jour. Econ. Ent., vol. 7, p. 132, 1913 (dese. stem mother).

Records.-Artemisia californica; Walnut Creek, Contra Costa County (Davidson).

In company with Macrosiphum artemisiae (Fonse.) this species is found on sagebrush in the San Francisco Bay region. Wilson reports it from Oregon, so probably it is distributed along the coast from the bay north. In the course of observations in. southern California during a period of two years the author has been unable to find any aphids infesting sagebrush.

\section{Aphis gossypii Glover}

Figures 192, 193, 215

Glover, Pat. Off. Rec., p. 62, 1854 (orig. desc.).

Clarke, Can. Ent., vol. 35, p. 250, 1903 (list).

Essig, Pom. Jour. Ent., vol. 1, p. 47, 1909. Aphis citri Ashmead (desc.).

Essig, Pom. Jour. Ent., vol. 3, p. 590, 1911 (desc.).

Cook, Mon. Bull. Cal. Comm. Hort., vol. 1, p. 65, 1912 (list).

Carnes, Mon. Bull. Cal. Comm. Hort., vol. 1, p. 398, 1912 (list).

Weldon, Mon. Bull. Cal. Comm. Hort., vol. 2, p. 597, 1913 (list).

Davidson, Mon. Bull. Cal. Comm. Hort., vol. 6, p. 65, 1917 (note). 
Records.-Cucumis spp.; Neweastle, Placer County, Watsonville, Santa Cruz County (Clarke); Imperial County (Weldon); San Diego County, June, 1916: Cucurbita spp.; Alpine, San Diego Connty, June, 1916: Citrus spp.; Santa Paula, Claremont (Essig), Acampo, San Joaquin County (Carnes), San Diego, March, 1916 (R. R. McLean); Whittier, May, 1917: Heracleum lanatum; Berkeley, March, 1915 (Essig) : Begonia; Stanford University, February, 1912 (Morrison), Riverside, January, 1917; Punica granatum, Stanford University, April, 1911 (Davidson): Helianthus; Santa Ysabel, San Diego County, May, 1916: Pcrsea gratissima; Avondale, San Diego County, August, 1916; Chrysanthemum; Ontario, January, 1917; Eschscholtzia californica; Ontario, January, 1917: Anthemis spp.; Pasadena, April, 1917 (R. E. Campbell): Pyrus spp.; Santa Cruz County (Volek), Nevada County (Norton).

The melon or cotton aphis is distributed throughout the state and is found on a large number of host plants. On melons it is often a considerable pest, particularly in the Imperial Valley. In the apple sections of Santa Cruz and Nevada counties it often becomes abundant enough upon the young trees to cause considerable damage, according to County Horticultural Commissioners Volck and Norton. In San Diego County the author found an infestation on young avocado trees which was very severe. Oftentimes it becomes quite abundant in nurseries and greenhouses.

\section{Aphis hederae Kalt.}

Kaltenbach, Monog. d. Pflanzenläuse, p. 89, 1843 (orig. dese.).

Davidson, Jour. Econ. Ent., vol. 2, p. 302, 1909. A. rumicis Linn. (list in part).

Essig, Pom. Jour. Ent., vol. 2, p. 335, 1910 (desc.).

Davidson, Jour. Econ. Ent., vol. 3, p. 376, 1910. A. rumicis Linn. (list).

Records.-Hedera helix; Stanford University (Davidson), March, 1912 (Morrison); Claremont, Los Angeles County (Essig); San Jose, May, 1911 (Davidson, Morrison); Oakland, November, 1916 (Davidson); Berkeley, April, 1915; Lemon Grove, San Diego County, March, 1916; Riverside, October, 1916: Chcnopodium sp., Walnut Creek, Contra Costa County, May, 1915 (Davidson).

Throughout the San Francisco Bay region and southern California a small dark brown to black aphid is often found in colonies on the tender shoots of English ivy. Essig described it as Aphis hederae Kalt., but later it was believed to be Aphis rumicis Linn. (A. euonomi Fabr.). However, a careful study of a large series of specimens of this aphid from ivy and of $A$. euonomi Fabr. from a number of different host plants has convinced the author that they are distinct. Gillette is of the same opinion. Consequently the species from ivy in California is Aphis hederae Kalt. In the author's collection there is a specimen from Chenopodium sp. taken by Davidson that appears to be the same species. The most noticeable difference between this 
and Aphis euonomi Fabr. is in the length of the cornicles, which are very much longer in this species. Measurements of specimens of the alates from Oakland, Walnut Creek, San Jose, and Riverside are herewith given:

Measurements: Body length, 1.411 to $1.768 \mathrm{~mm}$. (av. $1.621 \mathrm{~mm}$.) ; width of thorax, 0.714 to $0.782 \mathrm{~mm}$. (av. $0.748 \mathrm{~mm}$.) ; antennae total, 1.411 to $1.549 \mathrm{~mm}$. (av. $1.499 \mathrm{~mm}$.) ; III, 0.323 to $0.391 \mathrm{~mm}$. (av. 0.365 mm.) ; IV, 0.272 to $0.323 \mathrm{~mm}$. (av. $0.2914 \mathrm{~mm}$.) ; V, 0.221 to $0.272 \mathrm{~mm}$. (av. $0.2518 \mathrm{~mm}$.) ; VI, base 0.119 to $0.136 \mathrm{~mm}$. (av. $0.311 \mathrm{~mm}$.) ; VI, spur 0.306 to $0.34 \mathrm{~mm}$. (av. $0.323 \mathrm{~mm}$.) ; cauda, $0.136 \mathrm{~mm}$.; cornicle, 0.306 to $0.34 \mathrm{~mm}$. (av. $0.3252 \mathrm{~mm}$.) ; third tarsus, 0.119 to $0.136 \mathrm{~mm}$. (av. $0.1237 \mathrm{~mm}$.).

It will be seen that the cornicles are considerably more than twice as long as the hind tarsi, in some cases practically three times, while in A. euonomi Fabr., they are scarcely twice as long as the hind tarsi. In $A$. euonomi Fabr. the hind tarsi are longer than the base of VI, while the cornicles are shorter than VI spur. In A. hederae Kalt. VI spur and the cornicles are subequal or on the average the cornicles are very slightly longer, while VI base and the hind tarsi are also subequal, the tarsi being shorter on the avcrage. The secondary sensoria in $A$. hederae Kalt. are small, irregular in size, and are scattered more or less irregularly along III but in a fairly even row along IV and V. They appear very much the same as in A. euonomi Fabr. There are from thirteen to twenty on III, seventeen being the average; from five to nine on IV, seven and eight being the usual number; and usually one on $\mathrm{V}$, although in a few cases there appear to be none.

\section{Aphis heraclei Cowen}

Cowen, Hemip. Colo., p. 120, 1895 (orig. dese.).

Essig, Univ. Calif. Publ. Entom., vol. 1, p. 339, 1917 (list).

Record.-Heracleum montezzamum; Berkeley (Essig).

Recently Essig reported having taken this species on Heracleum in Berkeley. The author has specimens from Essig, although he has never collected it himself. This is the only report of the species since Cowen's original report and description.

\section{Aphis houghtonensis Troop?}

Troop, Ent. News, vol. 17, p. 59, 1906 (orig. dese.).

Davidson, Jour. Econ. Ent., vol. 7, p. 132, 1914 (list).

Record.-Ribes sanguineum; Contra Costa County (Davidson). 
Davidson reported a species of Aphis infesting the terminal leaves of wild currant in the canyons of Contra Costa County. He identified it provisionally as this species as he was uncertain. The author is unacquainted with it.

\section{Aphis lithospermi Wilson}

Wilson, Trans. Am. Ent. Soc., vol. 41, p. 100, 1915 (orig. desc.).

Record.-Lithospermum pilosum; California (Wilson).

There is no definite record of this species in California, but it is listed here because Wilson added it to a list of the California Aphididae submitted to him by the author.

\section{Aphis maidis Fitch}

Figures 216 to 218

Fitch, Insects N. Y., vol. 1, p. 318, 1855 (orig. desc.).

Clarke, Can. Ent., vol. 35, p. 251, 1903 (list).

Davidson, Jour. Econ. Ent., vol. 5, p. 408, 1912 (list).

Records.-Corn; Watsonville, Berkeley (Clarke) ; San Jose (Davidson) ; Lakeside, San Diego County, April, 1916; Chula Vista, San Diego County, August, 1916: sorghum; Julian, San Diego County, August, 1916 (H. M. Armitage); Corona, Riverside County, September, 1916.

Only occasionally is this corn aphis found in California, where it infests the ears and tassels and leaves of corn and some of the sorghums. Never has it been observed as injurious as is sometimes reported from the middle western states.

\section{Aphis malifoliae Fiteh}

Figures 248 to 250

Fitch, Trans. N. Y. State Agr. Soc., vol. 5, p. 14, 1854 (orig. desc.). Clarke, Can. Ent., vol. 35, p. 252, 1903. Aphis sorbi Kalt. (list).

Carnes, Mon. Bull. Cal. Comm. Hort., vol. 1, p. 400, 1912. A. sorbi Kalt. (list).

Weldon, Mon. Bull. Cal. Comm. Hort., vol. 3, p. 188, 1914. A. sorbi Kalt. (list).

Baker and Turner, Jour. Agr. Res., vol. 7, pp. 321-343, 1916 (complete account).

Records.-Pyrus malus, $P$. communis; Central and northern California; Orange County, May, 1917. 
This is one of the most injurious of our California species of Aphis, being found in practically all of the apple-growing regions of the state, and in most of them necessitating some control measures. It has been reported on apple and pear in the following counties: Humboldt, Orange, Placer, Sacramento, Santa Clara, Shasta, Tehama, Nevada, Inyo, Santa Cruz, and Alameda. Probably it is present wherever apples are grown, with the exception of the southern California districts where it has never been observed. The apple is the primary host, and only occasionally has it been taken on pear. In May, 1917, Roy K. Bishop found it in Orange County, this being the first report of it south of the Tehachapi.

The life history of this Aphis in California is as follows:

In the fall and early winter the eggs are laid in the crotches of the twigs. These hatch in the following spring, the exact time depending upon the weather conditions but it is usually as the buds are beginning to show green, or as they are beginning to open. The author has observed the young stem mothers on the young buds of the apple in the latter part of March, although he has never been able to find the eggs, either those yet unhatched or those from which the stem mothers have already hatched. Horticultural Commissioner Weatherby of Humboldt County writes that he has found the eggs hatching as early as February 24. He goes on to state that the eggs of Aphis pomi De Geer do not hatch until considerably later. Horticultural Commissioner Norton of Nevada County has made the following observations :

The eggs of Aphis sorbi [malifoliae] are laid on the buds, or sometimes on the spurs close to the buds. At first they are hard to see as they are small and light green, but later they turn to a shiny black, when they ean be more readily detected. The young aphids hatch as soon as the buds begin to swell, which time varies with the season. I have found them sometimes as early as the first of March and at other times as late as the middle of April.

The stem mothers feed upon the plant juices through the buds, sometimes appearing on the outer surface of the buds and at other times crawling down into the unfolding leaves, as is the case with Aphis pomi De Geer. In a few weeks thesc are mature and begin to deposit live young. All of this second generation are apterous females so far as the author has been able to observe. On April 12, 1915, he found several colonies of these aphids in the apple orchard at Stanford University, each colony consisting of a stem mother and several young apterous viviparous females. These females mature in a few weeks 
and a third generation is begun. The most usual place to find the sceond and third generations is in the eurled terminal leaves of the plant. These leaves are curled very similarly to those by the green apple aphis (Aphis pomi De Geer), but they are curled a great deal tighter. Winged females may appear in this third generation, but it is most usual to find them in the fourth. Horticultural Commissioner Volck of Santa Cruz County states that he has counted four generations before the summer migration. During May, 1915, the author colleeted many colonics of this Aphis and placed them in vials in the laboratory. Many others he attempted to colonizc on some apple seedlings. Owing to various causes he was unable to make any successful colonizations on the apple trees, one of the chief causes bcing the destructive work of coccincllid larvae. Also during the first few days of June he was forced to be absent from town and on his return found that the gardener had "cleaned" the trees, for "they were all covered with lice." Until May 25 no alate females had been found, but on that date two appeared in the laboratory. On May 10, 1917, alates were found in Orange County.

These alate females of the fourtl (perhaps sometimes they appear in the third) gencration migrate from the apple to some unknown host. At Stanford University in 1915 the migration began about the first of June and continued for some two or tliree weeks. On June 20 only two or three colonies, each consisting of but a very few individuals, were found where a month before there had been literally hundreds. The curled leaves still hung on the trees and in each curled leaf the moulted skins of the aphid were abundant. From Commissioner Norton of Nevada County comes the statement that he has known the migrants "to leave the trees as early as the middle of June, but the migration usually takes place between the first and the fifteenth of July. Where they go I have never becn able to find out, as I have never observed them on any other host plant.',

According to O. E. Bremner, Horticultural Commissioner of Sonoma County, the migration takes place there during June. This is the same as in Santa Clara County. In Orange County in 1917 the alate females appeared about the first of May. Migration began almost immediately and continued for two or three weeks. By May 24 only a very few aphids remained. This is fully a month earlier than migration takes place north of the Tehachapi. Incidentally the spring of 1917 was exceedingly eool and the summer very late. In normal years one would expect the aphids to leave the apple two or three weeks earlier. 
The summer host plant of this aphid is as yet unknown in California. During June, 1915, the author spent many hours in seareh of this host plant, but to no avail. He examined every kind of plant within two or three hundred yards of the apple orchard at Stanford University, but on none was he able to find any aphid that could possibly be the summer form of Aphis malifoliae Fitch. Bremner reports having found isolated individuals on pigweed (Amaranthus retroflexus) in Sonoma County, but believes this to be accidental for he has never observed them to deposit young on this plant. Davidson writes that he has been able to colonize them in the laboratory on the leaves of plantain (Plantago spp.), in fact has been able to have them reproduce in such large numbers as to kill the plants. On May 28, 1915, the author placed two alate females from apple leaves on eaeh of two specimens of Plantago hirtella under bell jars in the laboratory at Stanford University. On returning to town on June 10 he found that the plants were in a dying condition, owing to a laek of proper care during his absence. However, he found many young liee present, all of which were alive and feeding. The adult alate females had already died. By June 16 the liee had moulted once, but then the plants were practically dead. He left Stanford within a few days not to return, so was unable to begin fresh experiments along this line. In his seareh for the alates in the field he was partieularly careful to examine elosely every plantain plant in the vicinity, but could find no trace of this aphid on them. Davidson also reports the same laek of success. Consequently, although the alates will deposit young on plaintain in the laboratory it cannot very well be the natural summer host in this state. Baker and Turner have proven that Plantago lanceolata is the summer host in Virginia. W. H. Britain has observed a definite migration to plaintain in Nova Seotia (Proe. Ent. Soc. Nova Seotia, vol. 1, pp. 16-30, 1915). Ineidentally he has been able to breed it throughout the summer on apple. In Orange County, in the vieinity of the known infestations, the author was unable to find any plaintain whatsoever. On inquiring of Roy K. Bishop, the eounty lortieultural eommissioner, it was learned that plaintain is very searee in that eounty, except very near to the coast, and that it is exeeedingly doubtful if there is any in the vicinity of the known aphid infestations.

The fall migrants begin to return to the apple some time during the fall and deposit living males and females. From Nevada County eomes the report that the migrants return to the apple "between the twentieth of September and the first of Oetober." Davidson lias taken the oviparous females and the alate males on Deeember 5 (1912) at 
Sebastopol; Morrison has taken the sexes at Stanford University on December 16 (1910); Moznette of the Oregon station has taken the migrants as late as the middle of November at Corvallis, Oregon. Consequently, egg laying probably occurs from the middle of October well into December in the various parts of California. Commissioner Norton states: "The first eggs that I have seen were observed about the fifteenth of October. However, they continue egg laying, in favorable years, well along into November."

The injury caused by this aphid is done entirely in the spring of the year, before the summer migration, and consists in the curling of the terminal leaves. The colonies are found usually in the leaves surrounding a cluster of apples, and although most of the feeding is on the leaves themselves oftentimes they feed upon the fruit. In such a case the fruit (according to Weldon, "Apple Growing in Califormia," Mon. Bull. Cal. Comm. Hort., p. 86, 1915) "is injured to such an extent that it becomes stunted and not only fails to mature, but is distorted so badly that the variety may not be recognizable." In Nevada County, Commissioner Norton reports: "The purple aphis unless controlled lessens the apple crop from ten to fifteen per cent." This is a higher percentage, undoubtedly, than is common throughout the state, but it shows how serious the pest may be.

\section{Aphis marutae Oestlund}

Figures 293 to 299

Oestlund, Minn. Geol. Nat. Hist. Surv., vol. 14, p. 40, 1886 (orig. desc.).

Records.-Silybum marianum; Grossmont, San Diego County, April, 1916: Centaurea melitensis; El Cajon, San Diego County, May, 1916.

In April, 1916, the author observed a small aphid on milk thistle near Grossmont, San Diego County, and later on tacalote in the El Cajon Valley. It infested the smaller leaves, the leaf petioles, and the base of the flowers. Large numbers of ants were in attendance, but it was preyed upon extensively by the larvae and adults of Coccinella californica. A considerable number of adults of Lysiphlebus testaceipes Cresson were reared from colonies of this aphid. Being unknown to the author specimens were sent to J. J. Davis and E. O. Essig, both of whom determined the species to be Aphis marutae Oestlund. Inasmuch as Oestlund's descriptions are the only ones available, a brief description is given below of specimens taken May 1, 1916, on Silybum marianum in San Diego County. 
Alate viviparous female.-Prevailing color pale to olive green. Head and prothorax dark olive green, thoracic lobes almost black. Abdomen pale green with marginal spots and patch on dorsum dusky. Legs pale except tarsi, apex of tibiae, and apical two-thirds of femora. Antennae, cornicles, and cauda dusky. Beak pale at base and dusky at tip.

Head (fig. 293) not quite as long as broad, with a prominent tubercle at apex of front and small but distinet projections from head on inner side of first antennal segments. Antennae about same length as body or slightly longer or slightly shorter (figs. 294-295). III and the spur are about equal or III slightly longer, never shorter than spur. IV about one-half as long as III. V either shorter or equal to IV. VI shorter than $\mathrm{V}$ and about one-third as long as spur. I and II subequal and slightly shorter than VI. The usual primary sensoria are present on V and VI and the accessory sensoria on VI. III is tuberculate and IV is slightly so. IV has from two to six small, circular secondary sensoria and III from eleven to fifteen irregularly placed (fig. 294). The beak reaches considerably beyond the second coxae, in some cases almost to the third.

The prothorax is without lateral tubercles. The wings are about twice as long as the body with normal venation. The stigmal vein is curved its entire length, the second branch of the cubitus arises about midway between the tip of the wing and the base of the first branch.

The abdomen is without lateral tubercles in so far as the author can discern. The cornicles (fig. 299) are short and taper slightly from base to apex. They are about equal in length to the third tarsi, are almost one-half as wide at base as long, and about one-third as wide at apex as long. The cauda (fig. 298) is short and blunt (conical) and about two-thirds as long as the cornicles. The anal plate is half-moon-shaped and dusky at its distal edge.

Measurements (of specimens in Canada balsam): Body length, 0.918 to $1.02 \mathrm{~mm}$. (av. $0.9248 \mathrm{~mm}$.) ; width (thorax), 0.34 to $0.442 \mathrm{~mm}$. (av. $0.4082 \mathrm{~mm}$.) ; antennae total, 0.885 to $1.02 \mathrm{~mm}$. (av. $0.942 \mathrm{~mm}$.); I, 0.034 to $0.051 \mathrm{~mm}$. (av. $0.037 \mathrm{~mm}$.) ; II, 0.034 to $0.051 \mathrm{~mm}$. (av. $0.048 \mathrm{~mm}$.) ; III, 0.225 to $0.2975 \mathrm{~mm}$. (av. $0.2601 \mathrm{~mm}$.) ; IV, 0.117 to $0.17 \mathrm{~mm}$. (av. $0.152 \mathrm{~mm}$.) ; V, 0.1105 to $0.136 \mathrm{~mm}$. (av. $0.1346 \mathrm{~mm}$.); VI, 0.068 to $0.102 \mathrm{~mm}$. (av. $0.0833 \mathrm{~mm}$.); spur, 0.204 to $0.272 \mathrm{~mm}$. (av. $0.2295 \mathrm{~mm}$.); cornicles 0.0850 to $0.119 \mathrm{~mm}$. (av. $0.0978 \mathrm{~mm}$.); cauda, 0.0595 to $0.068 \mathrm{~mm}$. (av. $0.0624 \mathrm{~mm}$.) ; hind tarsi, 0.085 to $0.102 \mathrm{~mm}$. (av. $0.0901 \mathrm{~mm}$.) ; wing length, 1.921 to $1.955 \mathrm{~mm}$. '(av. $1.928 \mathrm{~mm}$.) ; wing width, $0.661 \mathrm{~mm}$.; wing expansion, $4.556 \mathrm{~mm}$. 
Apterous viviparous female.-'The apterae are quite similar to the alates except that the thorax is not dark, and that the second, third, and basal three-fourths of the fourth antennal segments are pale. There are no secondary sensoria (fig. 296) and no lateral tubercles on prothorax and abdomen (fig. 297). The individuals are slightly larger and the proportions of the antenual segments differ slightly from the alates. The measurements of specimens mounted in Canada balsam are as follows:

Measurements: Body length, 1.00 to $1.04 \mathrm{~mm}$. (av. $1.026 \mathrm{~mm}$.) ; width (abdomen), 0.595 to $0.629 \mathrm{~mm}$. (av. $0.6064 \mathrm{~mm}$.); antennae total, 0.561 to $0.697 \mathrm{~mm}$. (av. $0.6151 \mathrm{~mm}$.) ; III, 0.102 to $0.136 \mathrm{~mm}$. (av. $0.1218 \mathrm{~mm}$.) ; IV, 0.0765 to $0.1105 \mathrm{~mm}$. (av. $0.0906 \mathrm{~mm}$.) ; V, 0.068 to $0.085 \mathrm{~mm}$. (av. $0.0765 \mathrm{~mm}$.) ; VI, 0.595 to $0.0765 \mathrm{~mm}$. (av. $0.068 \mathrm{~mm}$.) ; spur, 0.1615 to $0.1785 \mathrm{~mm}$. (av. $0.1711 \mathrm{~mm}$.) ; cornicles, 0.0765 to $0.11 \mathrm{~mm}$. (av. $0.0935 \mathrm{~mm}$.) ; cauda, $0.0595 \mathrm{~mm}$.; hind tarsi, $0.102 \mathrm{~mm}$. (Description from nine specimens of apterae). It will be noticed that in the apterae the antennae are but about two-thirds as long as the body, while in the alates they are almost as long as the body. Furthermore, in the apterae the spur of the sixth anteinal segment is always longer than III while in the alates it is equal to III at the most, and in many cases shorter.

\section{Aphis medicaginis Koch}

Figure 189

Koch, Die Pflanzenläuse, p. 94, 1854 (orig. desc.). Davidson, Jour. Econ. Ent., vol. 2, p. 302, 1909 (list). Davidson, Jour. Econ. Ent., vol. 3, p. 376, 1910 (list).

Essig, Pom. Jour. Ent., vol. 3, p. 527, 1911 (desc.).

Records.-Medicago hispida; Stanford University (Davidson), April, 1914 (R. W. Haegele) : Astragalus leucopsis; Nordhoff, Ventura County (Essig) : Vicia faba, lima bean, Pasadena (R. E. Campbell).

This small dark Aphis has been found occasionally in California, particularly on alfalfa and beans. Such other plants as loco weed, licorice, sagebrush, locust, and others are said to be hosts. The author has never collected it himself, but has had access to specimens taken by Essig, Haegele, and Campbell. Davidson has reared the braconid fly, Lysipheebus testaceipes Cresson, from this aphid. 


\section{Aphis middletonii Thomas}

Figures 219, 220

Thomas, 8th Ann. Rep. Ill. St. Ent., p. 99, 1879 (orig. dese.).

Records.-Amaranthus retroflexus; Santa Paula, August, 1911 (Essig): Ranunculus californicus; Julian, San Diego County, June, 1916: Hemizonia rudis; Stanford University, 1916 (Ferris): Helianthus annuus; Riverside, September, 1916.

In the fall of the year this species is rather eommon on the roots of various plants in California. The individuals are small green aphids, eovered with a slight pulverulence. They are very similar' to Aphis maidis-radicis Forbes, with which they have often been eonfused, and differ partieularly in the presence of secondary sensoria on the fourth antennal segment of the apterae. Below are a few deseriptive notes taken from speeimens mounted in balsam, eolleeted in 1916 in Julian and Riverside, and in 1911 near Santa Paula:

Alate viviparous female.-Greenish, pruinose. Head, antennae, thorax, marginal spots on abdomen, eornicles, cauda, apieal one-half femora, apices tibiae, tarsi, and apex of beak, black. Antemue reach to the base of the second abdominal segment; III being the longest segment, followed by VI spur. IV and V are subequal, VI base slightly shorter. The usual primary and aceessory sensoria are prescnt. Secondary sensoria oceur on III and IV (fig. 220). There are nine to twelve on III, and one to four on IV. The average numbers are eight and two respectively. The beak reaches to the third coxae. Prominent lateral tubercles are present on the first and seventh abdominal segments, as well as on the prothorax. The cornicles are short and taper slightly toward the apex. They are subequal in length to the hind tarsi, and very slightly larger than the cauda. The wings are normal, with the second braneh of the third diseoidal arising nearer to the apex of the wing than to the base of the first branch.

Measurements: Body length, 1.65 to $1.7 \mathrm{~mm}$. (av. $1.674 \mathrm{~mm}$.); width of thorax, $0.561 \mathrm{~mm}$.; antenuac total, 0.816 to $0.918 \mathrm{~mm}$. (av. $0.884 \mathrm{~mm}$.) ; III, 0.204 to $0.255 \mathrm{~mm}$. (av. $0.2338 \mathrm{~mm}$.) ; IV, 0.11 to $0.119 \mathrm{~mm}$. (av. $0.1169 \mathrm{~mm}$.) ; V, 0.11 to $0.136 \mathrm{~mm}$. (av. $0.1275 \mathrm{~mm}$.); VI, base 0.085 to $0.102 \mathrm{~mm}$. (av. $0.0986 \mathrm{~mm}$.) ; VI, spur $0.204 \mathrm{~mm}$.; cauda, $0.102 \mathrm{~mm}$.; cornieles, 0.1275 to $0.136 \mathrm{~mm}$. (av. $0.1332 \mathrm{~mm}$.); hind tarsus, 0.119 to $0.136 \mathrm{~mm}$. (av. $0.1303 \mathrm{~mm}$.) ; wing length, 1.904 to $2.38 \mathrm{~mm}$. (av. $2.159 \mathrm{~mm}$.) ; width, 0.731 to $0.85 \mathrm{~mm}$. (av. 0.815 mm.) ; expansion, 4.3 to $5.1 \mathrm{~mm}$. (av. $4.717 \mathrm{~mm}$.). 
Apterous viviparous female.-These are very similar to the alate females, only slightly larger. The antennae are dusky throughout except the base of III. They reach to the base of the first abdominal segment. III is the longest segment. VI spur is next, being about two-thirds as long. IV, V, and VI base are subequal, with V somewhat shorter than the others. The usual primary and accessory sensoria are present on V and VI. III has two or three small secondary sensoria located in the apical onc-third of the segment. IV has from one to threc in the apical one-half. The prothorax and the first and seventh abdominal segments each have a pair of conspicuous lateral tubcreles. The cornicles are black and somewhat larger than in the alates, being slightly longer than the hind tarsi. The cauda is a little shorter than the hind tarsi.

Measurements: Body length, 1.632 to $1.785 \mathrm{~mm}$. (av. $1.708 \mathrm{~mm}$.) ; width of thorax, 0.748 to $0.85 \mathrm{~mm}$. (av. $0.799 \mathrm{~mm}$.) ; antennae total, 0.867 to $0.969 \mathrm{~mm}$. (av. $0.9265 \mathrm{~mm}$.) ; III, 0.2465 to $0.289 \mathrm{~mm}$. (av. $0.2635 \mathrm{~mm}$.) ; IV, 0.102 to $0.136 \mathrm{~mm}$. (av. $0.119 \mathrm{~mm}$.) ; V, 0.102 to $0.119 \mathrm{~mm}$. (av. $0.1105 \mathrm{~mm}$.) ; VI, base $0.119 \mathrm{~mm}$; VI, spur 0.1615 to $0.187 \mathrm{~mm}$. (av. $0.17 \mathrm{~mm}$.) ; cornicles, 0.153 to $0.17 \mathrm{~mm}$. (av. 0.1615 $\mathrm{mm}$.) ; cauda $0.119 \mathrm{~mm}$; hind tarsus, $0.136 \mathrm{~mm}$.

\section{Aphis mori Clarke}

Clarke, Can. Ent., vol. 35, p. 251, 1903 (orig. dese.).

Record.-Morus sp., Berkeley (Clarke).

This is a rather doubtful species, described by Clarke from specimens taken on mulberry in Berkeley. Since the original description it has never again been observed.

\section{Aphis neomexicana Ckll. var. pacifica Dvdn.}

Figures 300, 302

Davidson, Jour. Econ. Ent., vol. 10, p. 293, 1917 (orig. desc. var.).

Records.-Ribes rubrum; Walnut Creek, Contra Costa County, and San Jose (Davidson).

Davidson described this variety from specimens found curling the leaves of cultivated red currant in Walnut Creek in June, 1915. What he takes to be the same species he had already collected in San Jose in May, 1912. The author has specimens from him, but has never collected any himsclf. 


\section{Aphis nerii Fonsc.}

Figures 221, 222

Boyer de Fonscolombe, Ann. Ent. Soc. France, vol. 10, p. 167, 1841 (orig. desc.).

Davidson, Jour. Econ. Ent., vol. 3, p. 377, 1910 (list).

Davidson, Jour. Econ. Ent., vol. 3, p. 377, 1910. A. lutescens Monell (list).

Davidson, Pom. Jour. Ent., vol. 3, p. 399, 1911. A. lutescens Monell (list).

Essig, Pom. Jour. Ent., vol. 3, p. 401, 1911. A. lutescens Monell (desc.).

Essig, Pom. Jour. Ent., vol. 3, p. 530, 1911 (desc.)

Branigan, Mon. Bull. Cal. Comm. Hort., vol. 4, p. 53, 1915 (list).

Records.-Asclepias mexicana; Stanford University (Davidson); Stanford University, October, 1910 (Morrison); Penryn, Placer County (Davidson); southern California (Essig); Berkeley, July to September, 1915: Nerium oleander; southern California (Essig); Sacramento (Branigan); Berkeley, August to December, 1915; San Diego, 1916.

In the late spring, summer, and early fall milkweeds throughout the state are often seen to be infested with a bright yellow and black aphid. In the fall and early winter this same species is found infesting oleanders. Where oleanders are present but no milkweeds this aphid can be found from spring until winter on the oleander, as observed during 1916 in San Diego.

Heretofore the species on oleander and milkweed have been considered as distinct, the former being called $A$. lutescens Monell, the latter $A$. nerii Fonsc. According to a note from J. J. Davis the species on milkweed could not be A. lutescens Monell. Following are extracts from his letters concerning this point:

I am wondering whether you have ever found winged specimens on Asclepias that do not bear the black markings at the base of the cornicles. All the specimens that I have collected and which Mr. Monell has collected in recent years have these black markings at the base of the cornicles in the winged forms. However, in referring to an old note from Mr. Monell, he says that it would seem hardly possible that he could have missed these dark spots if they had been present in the specimens from which he drew his deseription for Aphis lutescens, and remarks further that he is not sure that he has ever seen A. lutescens alive since he first described it. I am wondering if lutescens is not really asclepiadis of Passerini and whether our other common species on Asclepias and Nerium is not nerii Fonse.

During the summer of 1915 the author found this species on Asclepias in the Botannical Gardens at the University of California. During July and August it was quite abundant; in fact, it was especially thick on the stems and undersides of the leaves and blossoms. However, in the latter part of August it scemed to be getting less 
and less numerous. No sign of parasites was present, and the predaeeous enemies were not more abundant than usual, so a search for the eause was made. Within fifty feet of the milkweed plants several oleanders were found and on them was notieed a large yellow speeies of Aphis. This supposedly was Aphis nerii Fonse. In the laboratory the author eould find no struetural differenee whatsoever between this speeies and the one on Asclepias, so he eontinued to wateh them earefully on the hosts. As the days passed the Asclepias beeame freer and freer of the infestation, while the Nerium beeame more and more heavily infested. This eontinued through September and into Oetober, by whieh time the Asclepias had died down and ineidentally no aphids were left. The Nerium was very heavily infested then. This was taken as a good proof that these were the same speeies. Later Essig told the author that the summer before (1914) he had made transfer tests in the laboratory of speeimens from Asclepias to Nerium and that they thrived there and bred well. This faet and the observations above mentioned were noted in a letter to Davis. Following is his answer :

I have your letter relative to Aphis asclepiadis and nerii, and am interested in your observations. In 1914, Theobald described a species under the name of Aphis nigrepes, which he now places as a rariety of asclepiadis. He considers nerii as distinet from asclepiadis because the latter lacks the black patches at the base of the cornicles. Passerini's asclepiadis is entirely different from Fitelh's Aphis asclepiadis. Fitch's name has priority for, as you will notice, it was described in 1851. This being the case, Passerini's name will have to fall and be replaced by Aphis lutescens of Monell, which according to Mr. Monell's data does not bear the black patches around the base of the cornicles.

This would seem to indieate that the California speeies on Asclepias is Aphis nerii Fonse. and not A. lutescens Monell, as brouglut out by Essig's experiment and by the author's observation. Consequently this Californian speeies is Aphis nerii Fonse., with Asclepias for its summer host and Nerizm for the winter host.

\section{Aphis oenotherae Oestlund}

Oestlund, Minn. Geol. Nat. Hist. Surv., Bull. 4, p. 62, 1887 (orig. dese.). Clarke, Can. Ent., vol. 35, p. 252, 1903 (list).

Record.-Oenothera bectiana; Epilobium sp., Berkeley (Clarke).

In 1903 Clarke reeorded finding this speeies on primrose and willow herb in Berkeley. Sinee then it has not been observed in Califormia. The author has had the opportunity to study speeimens from Minnesota, taken by A. C. Maxson. 


\section{Aphis oregonensis Wilson}

Wilson, Trans. Am. Ent. Soc., vol. 41, p. 92, 1915 (orig. desc.).

Record.-Artemisia tridentata, California (Wilson).

Wilson stated to the author that he had taken this species in California although he gave no locality or date records. On the strength of his statement it is included among the California aphids. The author has never seen specimens of it.

\section{Aphis persicae-niger Smith}

Figures 223, 224

Smith, Ent. Am., p. 101, 1890 (orig. dese.).

Clarke, Can. Ent., vol. 35, p. 252, 1903 (list).

Gillette, Jour. Econ. Ent., vol. 1, p. 308, 1908 (dese.).

Weeks, Mon. Bull. Cal. Comm. Hort., vol. 1, p. 244, 1912 (list).

Jones, Mon. Bull. Cal. Comm. Hort., vol. 1, p. 318, 1912 (list).

Carnes, Mon. Bull. Cal. Comm. Hort., vol. 1, p. 399, 1912 (list).

Wood, Mon. Bull. Cal. Comm. Hort., vol. 2, p. 570, 1913 (list).

Records.-Prunus spp.; throughout California.

This species is ordinarily found infesting the tender twigs and leaves of peach in the spring and early summer. Occasionally it is found on nectarine, plum, and cherry. There are two records of its occurrence on cherry known to the author; one in San Jose in May, 1912, by Davidson, and one in El Cajon, San Diego County, in May, 1916, by the author. Definite reports of its presence on peach come from Los Angeles, Placer, Riverside, San Benito, San Bernardino, San Diego, Santa Clara, and Tchama counties. In May, 1916, the author observed it doing considerable damage to a young peach orchard in the El Cajon Valley, San Diego County. Many of the twigs and some of the larger branches were killed back for several inches, due to the ravages of this insect.

The Hippodamia ladybird and the larvae of a syrphid fly were abundant and devouring vast numbers of the aphids. However, it is not often that this appears abundant enough to cause any great amount of damage.

Its life history, although not thoroughly worked out, is interesting. The following brief summary is from Essig : ${ }^{17}$

The insect winters over on the roots of the peach trees, where it may also bo found in the summer. The first aphids appear above ground very early in the

17 Essig, E. O., Beneficial and injurious inseets of California; ed. 2. Suppl. Mon. Bull. Cal. Comm. Hort., vol. 4, pp. 91-92, 1915. 
spring and begin attacking the tender leaflets, shoots and suckers, usually those at the base of the tree or nearest the ground. These first plant lice are all wing. less. As soon as the buds, young fruit, and leaves appear they are promptly attacked, the entire crop often being entirely ruined. The leaves are curled and weakened, while the young fruit is so distorted as to be killed or rendered unfit for market. During the months of April and May winged migratory females appear, which start colonies on other trees. The work continues until about the middle of July, when most of the lice leave the tops and again go to the roots.

\section{Aphis pomi De Geer}

Figures 225 to 227

De Geer, Memoires, vol. 3, p. 173, 1773 (orig. desc.).

Davidson, Jour. Econ. Ent., vol. 2, p. 301, 1909 (list).

Davidson, Jour. Econ. Ent., vol. 3, p. 377, 1911 (list). Aphis mali Fabr.

Weatherby, Mon. Bull. Cal. Comm. Hort., vol. 1, p. 318, 1912 (list).

Carnes, Mon. Bull. Cal. Comm. Hort., vol. 1, p. 399, 1912 (list).

Branigan, Mon. Bull. Cal. Comn. Hort., vol. 4, p. 285, 1915 (list).

Hurdley, Mon. Bull. Cal. Comm. Hort., vol. 4, p. 445, 1915 (list).

Baker and Turner, Jour. Agr. Res., vol. 5, pp. 955-995, 1916 (complete account).

Records.-Pyrus malus; Crataegus oxycantha; Catalpa sp.; California.

In California this species has been reported on apple and hawthorn (Crataegus sp.) at Stanford University by Davidson and Morrison; in Humboldt County by Weatherby; at Santa Rosa by Carnes; and by others in Orange, Placer, Sonoma, Santa Cruz, Sau Bernardino, and Monterey' counties. Horticultural Commissioner Armitage states that it has never been found in San Diego County, and Horticultural Commissioner Norton writes that it is unknown in Nevada County. These are the only two of the apple growing regions of the state in which it is not known. The author has found it at Stanford University on apple, catalpa, pear, and hawthorn, and at Marysville on catalpa. Gillette lists loquat, quince, and flowering crab as additional hosts. It seems to prefer the apple to other hosts, and it is on the apple that its greatest injury is done. Gillette states: "Among the apple trees it has its preference. Missouri Pippin seems to be its first choice, while Rome Beauty, Black Twig, Ben Davis, and a few others are second choice, and the Northern Spy is scarcely attacked." The fact that the Northern Spy is almost immune is interesting in that this variety is also quite immune to the devastations of the woolly aphis (Eriosoma lanigera Hausman).

The life history of this aphid is quite similar to that of many other species, and is as follows : 
The eggs are laid in the fall of the year, probably during the latter part of October, throughout November, and on into December. They are laid for the most part on the smooth bark of the suckers and water sprouts of the newer shoots. The author has found them in the crotches of the twigs and stems where the bark is rougher, but this is not the usual place. These eggs hatch in the spring about the time the buds begin to show green. In California this is usually during March, although some seasons it is as early as the middle of February, depending entirely upon the weather conditions. These stem-mothers at first feed on the young buds, until the latter have opened enough to allow the aphids to crawl down into the curled leaves. Here they feed for two or three weeks, when they mature and begin depositing living young. This second generation consists chiefly of apterous females, which mature in from two to four weeks and in turn produce young. The following generations are in large part alate females which migrate to other trees and there form new colonies. The alates are most common at Stanford University during the latter part of May and during the month of June. After June they seem to lessen in number, perhaps due to the predaceous and parasitic enemies. The first alates that the author has found in the spring were taken at Stanford University on April 13, 1914. In the fall, often as early as October, sexual males and females begin to appear, the males being apterous, the females alate. Thesc mate and very soon the female lays its eggs. Egg laying begins usually in the latter part of October, just as the leaves are beginning to fall, and continues into December after the trees are bare. These eggs hatch in the spring into stem mothers, and the life cycle is completed.

\section{Aphis prunorum Dobr.}

Figures 228 to 230

Dobrowljansky, Zur Biol. d. Blattläuse d. Abstbaume u. Bürenstaucher, 1913 (orig. desc.).

Patch, Maine Agr. Exp. Sta., Bull. 233, p. 262, 1914 (desc. note).

Records.-Prunus domestica; Walnut Creek (Davidson); San Francisco, April, 1915 (Shinji).

A species of Aphis, supposed to be this species, has been taken on prune and plum in the San Francisco Bay region. It agrees very well with Dr. Patch's description listed. However, it may prove to be synonymous with Siphocoryne nymphaeae (Linn.). 


\section{Aphis pseudobrassicae Davis}

Figure 231

Davis, Can. Ent., vol. 46, p. 231, 1914 (orig. desc.).

Records.-Brassica spp.; Walnut Creek (Davidson), San Diego, Riverside: Raphanus sp., Riverside, September, 1916, June, 1917: Matthiola annua, Riverside, February to May, 1917.

Oftentimes in the spring this falsc cabbage aphis is found in large colonies on radish, mustard, and so forth. Davidson has taken it in the San Franciseo Bay region, and the author throughout southern California. The first few times that it was observed by the author colonies of Aphis brassicae Linn. were also abundant. This led the author to doubt its validity, and to undertake some breeding experiments. In February, 1917, two colonies were started, each from one alate female. They were followed through thrce generations, with the result that all the individuals proved to be this species. At the same time a colony of Aphis brassicae Linn. was started from one alate. All the progeny of this individual proved to be the same. A. pseudobrassicae Davis differs from $A$. brassicae Linn. in the following major points :

A. pseudobrassicae Davis:

Apterae not pulverulent.

Cornicles of apterae longer than hind tarsi.

IV of alates with sensoria.
A. brassicae Linn.: Apterae pulverulent.

Cornicles of apterae shorter than hind tarsi.

IV of alates without sensoria.

\section{Aphis ramona Swain}

Figures 232 to 235

Swain, 'Trans. Am. Ent. Soc., vol. 44, p. 14, 1918 (orig. desc.).

Records.-Ramona stachyoides; Nordhoff and Santa Paula, Ventura County (Swain).

This speeies has been taken twiee in Ventura County by Essig. It was described by the author from the speeimens taken by Essig on blaek sage.

\section{Aphis rubiphila Patch}

Patch, Maine Agr. Exp. Sta., Bull. 233, p. 269, 1914 (orig. desc.).

$$
\text { Records.-Rubus spp.; San Jose, May, } 1916 \text { (Davidson). }
$$

In the summer of 1916 Davidson found a speeies of Aphis infesting loganberries and blaekberries in San Jose, whieh was determined by Dr. Pateh as A. rubiphila Pateh. Essig believes this to be a synonym 
of A. gossypii Glover, but as the author has not had an opportunity to study specimens he believes it best to recognize it as a distinct species at present.

\section{Aphis salicicola Thomas}

Figures 188, 238, 237

Thomas, Ill. Lab. Nat. Hist., Bull. 2, p. 8, 1879 (orig. desc.).

Williams, Univ. Neb. Studies, vol. 10, p. 139, 1910 (desc.).

Davidson, Jour. Econ. Ent., vol. 5, p. 408, 1912 (list).

Records.—Salix laevigata; Berkeley, June, 1915: Salix, sp.; San Jose (Davidson).

This is an uncommon species, found in the San Francisco Bay region on willow. The individuals are found in large colonies on the terminal shoots and lcaves. These colonies consist in large part of apterae, there being but a very few alates. The species is quite easily recognized by the long cornicles and by the very short second branch of the third discoidal vein.

\section{Aphis sambucifoliae Fitch}

Figure 240

Fitch, Cat. Homop. N. Y., p. 66, 185 (orig. dese.).

Sanborn, Kan. Univ. Sci. Bull. 3, p. 52, 1904 (desc.).

Records._Sambucus glauca; Oakland, April, 1915 (Essig); Berkeley, July, 1915.

In 1915 this spccies was taken twice, once by Essig in Oakland and once by the author in Berkeley. This medium-sized black aphid occurs in large colonics on the tender shoots and flower heads of the common elderberry. In southern California the author has examined hundreds of eldcrberry trees for this form, but has never found it. Only once has he found any aphid on elderberry in the south, and these proved to be Rhopalosiphum persicae (Sulz.).

\section{Aphis senecio Swain}

Figures 2, 4, 6, 241 to 245

Davidson, Jour. Econ. Ent., vol. 2, p. 302, 1909. Aphis sp. (list). Davidson, Jour. Econ. Ent., vol. 3, p. 377, 1910. A. bakeri Cowen (list). Davidson, Jour. Econ. Ent., vol. 7, p. 133, 1914. A. bakeri Cowen (list). Swain, Trans. Am. Ent. Soc., vol. 44, p. 16, 1918.

Records.--Abutilon sp.; Stanford University, February, 1915: Ambrosia psilostachya; Berkeley, 1915 (Essig) : Amsinckia spp.; Stanford University, 1909 (Davidson), 1912 (Morrison); Berkeley, 1915 (Essig): Anthemis spp.; San 
Franciseo Bay region, 1914 (Davidson); Pasadena, May, 1917 (Roy E. Campbell): Artemisia spp.; San Franeisco Bay region, 1914 (Davidson); Berkeley, 1915 (Fssig): Aster sp.; San Diego, January, 1916; Ontario, January, 1917 : Baccharis pilularis; Berkeley, 1915 (Essig), Stanford University, 1916 (Ferris): Calendula officinale; Berkeley, 1915 (Essig); San Diego, Mareh, 1916; Riverside and Orange, Yebruary, 1917: Chrysanthemum sp.; Berkeley, 1914 (Essig); Octo. ber, 1915; Menlo Park, San Mateo County, Marel, 1915; San Diego, January, 1916; La Jolla, February, 1916; Ontario, January, 1917: Cytisus proliferus; Berkeley, 1915 (Essig): Gnapholium sp.; Walnut Creek, 1914 (Davidson): Grindelia cuneifolia; Walnut Creck, 1915 (Davidson): Helianthus annuus; San Frat. ciseo Bay region, 1914 (Davidson): Kumex sp.; Stanford University, March, 1915: Salix sp.; Berkeley, 1915 (Essig): Senecio spp.; Stanford University, 1909, 1910, 1914 (Davidson); Santa Paula, 1911 (Essig); Palo Alto, February, 1915.

This is a very common species throughout California, occurring on many host plants, particularly the Compositae. It is found most commonly in the early spring on asters, marigolds, and chrysanthemums in southern California, and on German ivy and amsinckia in the San Francisco Bay region. For somctime it was believed to be Aphis bakeri Cowen, but its varicty of host plants so widely different from those of bakeri, led to its being identified as a distinct species. It is one of the most common in the state, as a glanec at the collection records will show.

\section{Aphis setariae Thomas}

Figures 246,247

Thomas, Ill. Lab. Nat. Hist., Bull. 2, p. 5, 1878 (orig. dese.).

Williams, Univ. Neb. Studies, vol. 10, p. 141, 1910 (dese.).

Record.-Prunus domestica; San Franciseo Bay region (Davidson).

In some parts of the country this plum louse becomes abundant enough to cause serious damage, but it has never been observed to be so in California. Davidson writes that he has found it sparingly a few times in the San Francisco Bay region. The author has never collected it, but has had access to specimens from Morrison, taken in Indiana.

\section{Aphis spiraecola Patch}

Pateh, Maine Agr. Exp. Sta., Bull. 233, p. 270, 1914 (orig. dese.).

Records.-Spiraea spp.; Stanford University, 1912 (Morrison); Walnut Creek, Contra Costa County, 1916 (Davidson).

In the San Francisco Bay region there is a small aphid very similar to Aphis pomi De Greer found attacking meadowsweet. Davidson and Morrison, who have both observed it, believe it to be this species. The following bricf descriptive notes are from alate females 
taken by Dr. Patch on cultivated spiraea in Orono, Maine. Thesc notes are included here as there is no adequate description of this species, the only ones ${ }^{18}$ being very meager notes indeed .

Alate viviparous females.-Body rather long and narrow, head normal with no antennal tubercles. Antennae shorter than body, reaching to about the base of the fourth abdominal segment. VI spur the longest segment, followed by III, which is about two-thirds as long. Following III are IV, V, and VI base. The usual primary sensoria are present on $\mathrm{V}$ and VI, and the accessory sensoria on VI. The secondary sensoria are fairly large and circular. There are six or seven in an even line along the whole length of III. On IV there may be one or two near the middle, or there may be none. Prominent lateral tubercles are present on the prothorax and on the first and seventh abdominal segments. The cornicles are fairly long, slender, and taper slightly toward the apex. They are from one and one-lialf to two times as long as the hind tarsi, and subequal to or very slightly longer than the cauda. The cauda is fairly long, ensiform, slightly constricted before the tip. The wings are normal, with the second branch of the third discoidal nearer the apex of the wing than the base of the first branch.

Measurements: Body length, 1.19 to $1.33 \mathrm{~mm}$.; width of thorax, 0.544 to $0.561 \mathrm{~mm}$. ; antennae total, 0.85 to $0.918 \mathrm{~mm}$. III, 0.17 to $0.1785 \mathrm{~mm}$.; IV, 0.136 to $0.153 \mathrm{~mm}$.; V, 0.1275 to $0.1445 \mathrm{~mm}$.; VI, base 0.0935 to $0.102 \mathrm{~mm}$. ; VI, spur 0.238 to $0.255 \mathrm{~mm}$. ; cornicles, 0.1785 to $0.187 \mathrm{~mm}$. ; cauda, $0.17 \mathrm{~mm}$. ; hind tarsus, $0.102 \mathrm{~mm}$. ; wing length, 1.97 to $2.04 \mathrm{~mm}$; width, 0.748 to $0.782 \mathrm{~mm}$.; expansion, $4.55 \mathrm{~mm}$.; from base of first branch of third discoidal to wing tip, 0.578 to 0.68 $\mathrm{mm}$. f from base of second branch to wing top, 0.17 to $0.255 \mathrm{~mm}$.

\section{Aphis tetrapteralis Cockerell}

Cockerell, South. Cal. Acad. Sci., Bull. 1, p. 4, 1902 (orig. dese.).

Record.-Atriplex canescens tetraptera; La Jolla (Cockerell).

This species has been observed but once, when described by Cockerell. He writes: "It differs from Aphis atriplices Linn. by its smaller size, mode of life, and shorter coruicles. It seems to be rclated to Aphis monardae Ocstlund." In 1916 the author spent considerable time hunting for this species in the vicinity of La Jolla, but in vain.

18 Patch, Edith M., Maine Aphids of the Rose Family, Maine.Agr. Exp. Sta., Bull. 233, p. 270, 1914, Aphis spiraecole n.n.; Gillette, C. P., Plant louse notes, Family Aphididae. Jour. Econ. Ent., vol. 3, p. 404, 1910. Aphis spiracella Schout. 


\section{Aphis viburnicolens n.sp.}

Records.-Viburnum tinus; Riverside, February to May, 1917 ; Redlands, February, 1917; Orange, February, 1917: Laurus rotoundifolia, Riverside, March, 1917.

In the early spring there is a small green and black aphid that attacks in great numbers the racemes of laurustinus and laurel in Southern California. In fact, it is so abundant at times as to seriously injure the plants by preventing them from flowering. The leaves and buds are very sticky and coverce with the sooty mold fungus. During April, 1917, all the aphids left the laurel and laurustinus, but the alteruate host has as yet not been observed. Specimens were sent to Gillette and Patch for determination, but neither could identify them. Dr. Patch wrote as follows:

This insect is not spiraecola, a slide of which I am sending you.

spiraecola

Cornicles longer than III

VI spur longer than III

VI spur longer than IV and V

IV subequal to $\mathrm{V}$ sp.

Cornicles shorter than III

VI spur subequal to III

VI spur subequal to IV and V IV longer than $\mathrm{V}$

I do not know this species. I do not have spiraeella Schout. for comparison.

Gillctte stated concerning this spccies: "This is a species of Aphis close to, but almost certainly distinct from, spiraeella Schout., and so far as we know, may be new.",

From this it would appear that the species from laurustinus and laurel is a ncw species, and it is described herewith as such. ${ }^{19}$ Cotype specimens are in the author's private collection, in the collection of the University of California in Berkeley, and of the Citrus Experiment Station in Riverside.

Alate viviparons female.-Prevailing color green. Head and thorax dusky brown to black. Antennae dusky to black. Beak light brown with tip black. Tibiae, femora of fore legs, and basal onc-half of femora of middle and hind legs brown; tarsi, tips of tibiae, tips of fore femora, and apical one-half of middle and hind femora black. Abdomen pale to apple green, sometimes with a few dusky marginal spots. Cornicles and cauda black.

19 The species reported by Davidson (Jour. Econ. Ent., rol. 3, p. 377, 1910) as Aphis mali Fabr. from Laurus laurustinus (Viburnum tinus?) and by Essig (Injurious and Beneficial Insects of California, Mon. Bull. Cal. Comm. Hort., Supp. vol. 4, p. xlvi, 1915) as Aphis pomi De Geer from laurustinus, are probably this species. 
Head normal, with frontal and antennal tubereles absent. Antennae short, reaching only to the second abdominal segment. III and VI spur subequal; IV and V subequal and about three-fourths as long as III or VI spur. The usual primary sensoria are present on V and VI, and the aecessory sensoria on VI. Secondary sensoria are found on III and IV, from five to nine on the former and from one to four on the latter. Cornicles short, subcylindrical, and tapering from base toward apex. Cauda fairly long, ensiform, with a slight constriction in the middle. the cauda is slightly longer than the hind tarsi, and the cornicles a little longer than the eauda. Lateral tubereles are present on the prothorax, and on the first, fourth, and seventh abdominal segments. The cornicles are subequal to IV or V. The hind tarsi are somewhat longer than VI base. The wings are fairly large, with regular venation, the sccond joint of the third discoidal arising about half way between the tip of the wing and the base of the first joint.

Measurements : Body length, 1.214 to $1.479 \mathrm{~mm}$. (av. $1.372 \mathrm{~mm}$.) ; width of thorax, 0.476 to $0.578 \mathrm{~mm}$. (av. $0.5338 \mathrm{~mm}$.) ; antennae total, 0.733 to $0.918 \mathrm{~mm}$. (av. $0.8925 \mathrm{~mm}$.) ; III, 0.187 to $0.230 \mathrm{~mm}$. (av. $0.2067 \mathrm{~mm}$.) ; IV, 0.136 to $0.161 \mathrm{~mm}$. (av. $0.1473 \mathrm{~mm}$.) ; V, 0.119 to $0.153 \mathrm{~mm}$. (av. $0.1416 \mathrm{~mm}$.) ; VI, base 0.085 to $0.102 \mathrm{~mm}$. (av. 0.0877 mm.) ; VI, spur 0.204 to $0.230 \mathrm{~mm}$. (av. $0.216 \mathrm{~mm}$.) ; cornicles, 0.127 to $0.153 \mathrm{~mm}$. (av. $0.1422 \mathrm{~mm}$.) ; cauda, 0.110 to $0.136 \mathrm{~mm}$. (av. 0.1252 $\mathrm{mm}$.) ; hind tarsi, 0.102 to $0.119 \mathrm{~mm}$. (av. $0.1023 \mathrm{~mm}$.) ; wing length, 1.921 to $2.397 \mathrm{~mm}$. (av. $2.167 \mathrm{~mm}$.) ; width, 0.799 to $0.935 \mathrm{~mm}$. (av. $0.8704 \mathrm{~mm}$.) ; expansion, 4.42 to $5.304 \mathrm{~mm}$. (av. $4.875 \mathrm{~mm}$.).

Apterous viviparous female.-General eolor green with the following dusky to blaek: head, antennae, apcx of beak, eornicles, cauda, distal margin anal plate, tarsi, and tips of tibiae. Legs, exeept tarsi and tips of tibiac, dusky brownish green. Antennae reaeh to the base of the sceond abdominal segment. The various segments are proportionally the same as in the alates. The beak reaches to the distal margin of the first eoxae or almost to the apieal margin of the third eoxae. Lateral body tubercles are present on the prothorax and first, second, and seventh abdominal segments. Sometimes they are also present on the third, fourth, or fifth abdominal segments as well. The eornieles and eauda are subequal, eaeh slightly longer than the hind tarsi, and of the same form as in the alates.

Measurements : Body length, 1.326 to $1.462 \mathrm{~mm}$. (av. $1.3685 \mathrm{~mm}$.) ; width of thorax, 0.595 to $0.68 \mathrm{~mm}$. (av. $0.6975 \mathrm{~mm}$.) ; antennae total 
0.731 to $0.782 \mathrm{~mm}$. (av. $0.748 \mathrm{~mm}$.) ; III, 0.153 to $0.187 \mathrm{~mm}$. (av. $0.170 \mathrm{~mm}$.) ; IV, 0.119 to $0.136 \mathrm{~mm}$. (av. $0.1224 \mathrm{~mm}$.) ; V, $0.119 \mathrm{~mm}$. ; VI, base $0.085 \mathrm{~mm}$.; VI, spur 0.136 to $0.1995 \mathrm{~mm}$. (av. $0.1632 \mathrm{~mm}$.); cornicles, 0.153 to $0.1995 \mathrm{~mm}$. (av. $0.170 \mathrm{~mm}$.) ; cauda, 0.136 to 0.170 mm. (av. $0.162 \mathrm{~mm}$.) ; hind tarsi, 0.102 to $0.119 \mathrm{~mm}$. (av. $0.114 \mathrm{~mm}$.).

\section{Aphis yuccae Cowen}

Figures 303 to 305

Cowen, Colo. Agr. Exp. Sta., Bull. 31, p. 122, 1895 (orig. desc.).

Williams, Univ. Neb. Studies, vol. 10, p. 145, 1910. Aphis yuccicola n.sp. (desc.).

Records.-Fucca mohavensis; Moorpark, Ventura County, April, 1916 (F. M. Trimble); San Diego, May, 1916.

In April, 1916, Hortieultural Inspector F. M. Trimble of Ventura County sent the author a few specimens of the alate and apterous viviparous females of this species, taken on Spanish dagger in Moorpark. In the latter part of the next month the author found a few apterae on the leaves of Spanish dagger in Golden Hill Park, San Diego. There were only a few individuals present at that time, but there was evidence of an earlier heavy infestation. Following are a few notes to supplement Williams' excellent description of this species.

III is the longest segment of the antennae, followed by VI spur, which is about three-fourths as long. IV is next, being a little over one-half as long as III and about five-sixths as long as VI spur. V is slightly shorter than IV and is followed closely by VI base, which is about one-half the length of the spur. The usual primary sensoria are present on V and VI and the accessory sensoria on VI (fig. 303). The apterae have no secondary sensoria, while the alates along the whole length of III (fig. 304) have about twenty-five irregularly placed sensoria of irregular size. VI is without sensoria. Lateral tubercles are present on the prothorax and on the first and seventh abdominal segments. The cornicles (fig. 305) are long and slightly tapering, being but slightly shorter than the spur of the sixth antennal segment and about twice as long as the hind tarsi. The cauda (fig. 305 ) is ensiform or sickle-shaped and about three-fourths as long as the cornicles. In length it is about equal to the fifth antennal segment and one-half again as long as the hind tarsi. 
Alate viviparous females.-Measurments: Body length, 1.78 to 1.9 mm. (av. $1.86 \mathrm{~mm}$.) ; width, (thorax), $0.95 \mathrm{~mm}$.; antennae total, 1.38 to $1.51 \mathrm{~mm}$. (av. $1.449 \mathrm{~mm}$.) ; III, 0.34 to $0.425 \mathrm{~mm}$. (av. $0.391 \mathrm{~mm}$.) ; IV, 0.238 to $0.273 \mathrm{~mm}$. (av. $0.256 \mathrm{~mm}$.) ; V, 0.212 to $0.229 \mathrm{~mm}$. (av. $0.219 \mathrm{~mm}$.) ; VI, 0.136 to $0.17 \mathrm{~mm}$. (av. $0.155 \mathrm{~mm}$.) ; spur, 0.255 to $0.306 \mathrm{~mm}$. (av. $0.289 \mathrm{~mm}$.) ; eornieles, 0.255 to $0.2975 \mathrm{~mm}$. (av. 0.275 mm.) ; eauda, 0.2125 to $0.238 \mathrm{~mm}$. (av. $0.225 \mathrm{~mm}$.) ; hind tarsi, 0.153 mm.; wing length, 3.06 to $3.4 \mathrm{~mm}$. (av. $3.19 \mathrm{~mm}$.) ; wing width, 1.27 to $1.46 \mathrm{~mm}$. (av. $1.338 \mathrm{~mm}$.) ; wing expansion, $7.48 \mathrm{~mm}$.

30. Genus Toxoptera Koeh.

Koch, Die Pflanzenläuse, p. 253, 1857. Type Aphis aurantii Fonse.

152. Toxoptera aurantii (Fonse.)

Figures 114, 163, 276

Boyer de Fonscolombe, Ann. Ent. Soc. France, vol. 10, 1841. Aphis (orig. desc.).

Essig, Pom. Jour. Ent., vol. 3, p. 601, 1911. T. aurantiae Koch (desc.).

Davis, U. S. Dept. Agr., Bur. Ent., Tech. Ser., Bull. 25, pt. 1, p. 8, 1912.

Records.-Citrus spp.; throughout eitrus sections of southern and central Califoruia (Essig, author); San Jose (Davidson).

This is the eommon blaek louse of the eitrus trees, and is found at almost any time of the year on the younger and more tender leaves of various speeies of Citrus. It is more or less heavily preyed upon by the braeonid fly, Lysiphlebus testaceipes Cresson. In faet, the author has notieed several infestations in which fully ninety-five per eent of the individuals were parasitized. Besides these the syrphid flies eause great havoc among colonies. Of these the author has reared Allograpti obliqua Say from a eolony taken in the vieinity of $\mathrm{El}$ Cajon, San Diego County. Never does this speeies beeome abundant enough to seriously damage trees, due undoubtedly to the effeetive work of its predaeious and parasitie enemies. Only in the spring are they found to any great extent, although occasionally throughout the year small infestation ean be notieed. 


\section{Genus Hyalopterus Koeh}

Koch, Die Pflanzenläuse, p. 17, 1854. Type Aphis arundinis Fabricius ( $A$. pruni Fabr.).

\section{Hyalopterus arundinis (Fabr.)}

Figures 181, 185, 186

Fabricius, Ent. Syst., vol. 4, p. 212, 1749. Aphis (orig. desc.).

Clarke, Can. Fint., vol. 35, p. 247, 1903 (list).

Davidson, Jour. Econ. Ent., vol. 2, p. 303, 1909 (list).

Davidson, Jour. Econ. Ent., vol. 3, p. 377, 1910 (list).

Essig, Mon. Bull. Cal. Comm. Hort., vol. 2, p. 569, 1913 (list).

Essig, Mon. Bull. Cal. Comın. Hort., vol. 3, p. 624, 1913. A. prunifoliae Fitch (list).

Weldon, Mon. Bull. Cal. Comm. Hort., rol. 2, p. 630, 1913 (list).

Weldon, Mon. Bull. Cal. Comm. Hort., vol. 3, p. 378, 1914 (list).

Patch, Maine Agr. Exp. Sta., Bull. 233, 266, 1914 (dese.).

Davidson, Mon. Bull. Cal. Comm. Hort., vol. 6, p. 64, 1917 (note).

Records.-Prunus spp., Phalaria arundinacea, Phragmites communis, Typha latifolia; central California.

During the spring and early summer of the year this "mealy-plum louse" is often very abundant on various species of Prunus in the central part of the state, espeeially in the San Franeiseo Bay region and the Sacramento Valley. As summer continues all the aphids desert the plum for other host plants, where they remain until fall. The summer hosts in California so far known are reed grass, canary grass, and tule, or eat-tail rush. In the Santa Clara Valley there is a feeling among the prune growers that this aphid is the cause of the splitting of the prunes, which is often quite extensive. However, this remains to be proven.

\section{Genus Liosomaphis Walker}

Walker, The Zoologist, p. 1119, 1868. Type Aphis berberidis Kalt.

\section{Liosomaphis berberidis (Kalt.)}

Figures 184, 251, 252

Kaltenbach, Monog. d. Pflanzenläuse, p. 85, 1843. Aphis (orig. desc.).

Davis, Ann. Ent. Soc. Am., vol. 1, p. 254, 1908. Rhopalosiphum (dese.).

Davidson, Jour. Econ. Ent., vol. 3, p. 378, 1910. Rhopalosiphum (list).

Records.-Berberis vulgaris; Stanford University (Davidson); February to May, 1915; Berkeley, June to August, 1915.

This speeies is found throughout the year on the lower sides of the leaves of barberry in the San Francisco Bay region. The apterae are often very abundant, but the alates are always quite searee. This 
species is similar to species of Rhopalosiphum, particularly in the shape of the cornicles and cauda, but owing to the absence of antennal tubercles it falls into the tribe Aphidini instead of Macrosiphini. Hence Walker's genus Liosomaphis is maintained for this species.

\section{Genus Siphocoryne Passerini}

Passerini, Gli Afidi, 1860. Type Aphis pastinacae Linn. (xylostei Schrank).

There has been much diversity of opinion concerning this genus, some aphidologists considering it as Siphocoryne Passerini, some as Hyadaphis Kirkaldy, and some as a synonym of Rhopalosiphum Koch. This last is incorrect as this is most certainly not a Macrosiphini for the antennal tubercles are lacking. In 1904 Kirkaldy proposed the name Hyadaphis to replace Siphocoryne, but in the author's opinion this is uncalled for, so he maintains the original name, Siphocoryne Passerini.

There have becn reported from various parts of California eight species of Siphocoryne as follows: capreae (Fabr.), conii (Dvdn.), foeniculi (Schrank), nymphaeae (Linn.), pastinacae (Linn.), salicis (Monell), umbellulariae (Dvdn.), and xylostei (Schrank). There are, however, really but three species; capreae (Fabr.), nymphaeae (Linn.) and pastinacae (Linn.). According to Gillette, ${ }^{20}$ S. salicis Monell is a synonym of S. capreae (Fabr.), and xylostei (Schr.) of pastinacae (Linn.). Davidson ${ }^{21}$ states that $S$. conii (Dvdn.) is a synonym of xylostei (Schr.), and therefore it is the same as pastinacae (Linn.). Morrison writes that the specimens Davidson called S. foeniculi (Schr.) are capreae (Fabr.), and those he described as Hyadaphis umbellulariae n.sp. are S. pastinacae (Linn.). These two species, pastinacae (Linn.) and capreae (Fabr.), have been greatly confused but Gillette ${ }^{22}$ has worked out their synonymy quite satisfactorily. The following key for distinguishing them is from his paper.

Joints 4, 5, 6, and antennal spur subequal, the spur usually distinetly the longest, cornicles fully three-fourths as long as third joint of the antenna, a small tubercle on the alate form and a large one on the apterous individuals always present

capreae

20 Gillette, C. P., Two Rhopalosiphum species and Aphis pulverulens n.sp., Jour. Econ. Ent., vol. 4, pp. 320-325, 1911.

21 Davidson, W. M., Plant louse notes from California, Jour. Econ. Ent., vol. 7, p. $133,1914$.

22 Gillette, C. P., Two Rhopalosiphum species and Aphis pulverulens n.sp., Jour. Econ. Ent., vol. 4, pp. 320-325, 1911. 
Joint 623 of the antenna distinctly shorter than 5, the fourth still shorter and its spur nearly as long as joints 4,5 , and 6 combined, cornicles seldom much exceeding one-half the third joint of the antenna in length, and a supra-caudal tubercle or spine entirely absent

pastinacae

Aphis nymphaeae Linn. has usually been considered by Amcrican aphidologists as a species of Rhopalosiphum, but the presence of lateral body tubercles, the short, robust body, and the absence of antennal tubercles place it in the Aphidini ratler than the Macrosiphini. Therefore, it must be considered as belonging to this genus. Baker ${ }^{24}$ has recently recognized it as belonging here.

\section{Key to Californian Species}

1. A small spine or tubercle present at the distal end of the body just above the cauda (figs. 255, 256) capreae (Fabr.)

- No supra-caudal tubercle or spine

2. General color pale green. VI spur as long as IV, V and VI base combined. Cornicles at most but slightly more than one-half the length of III.

pastinacae (Linn.)

- General color dark brown, wine, or black. VI spur not as long as IV, V and VI base combined, although longer than any two together. Cornicles and III subequal.

nymphaeae (Linn.)

\section{Siphocoryne capreae Fahr.}

Fabricius, Ent. Syst., p. 211, 1794. Aphis (orig. desc.). Clarke, Can. Ent., vol. 35, p. 252, 1903. S. foeniculi (Pass.) (list). Davidson, Jour. Econ., vol. 2, p. 303, 1909. S. salicis Monell (list). Davidson, Jour. Econ. Ent., vol. 3, p. 377, 1910. S. foeniculi (Pass.), (list). Davidson, Jour. Econ. Ent., vol. 3, p. 377, 1910. S. salicis Monell (list). Essig, Pom. Jour. Ent., vol. 3, p. 534, 1911. Hyadaphis pastinacae (Linn.) (desc.).

Records.-Foeniculum vulgare; Berkeley and Newcastle (Clarke), Stanford University (Davidson): Carum spp.; Cicuta virosa; Santa Paula, Berkeley (Essig) : Salix laevigata; Santa Paula (Essig), Brea Canyon, Los Angeles County, April, 1917; Riverside, May, 1917:- Salix nigra; Lakeside, San Diego County, April, 1916: Salix sp., Stanford University (Davidson).

This species is found more or less abundantly in the spring on the tender shoots and leaves of willows, migrating in early.summer to various species of Umbelliferae. It is more common than S. pastinacae (Linn.), which species is also found on Umbelliferae in the summer, but which passes the fall, winter, and spring on honeysuckle.

23 In all the author's specimens, VI is shorter than V. which in turn is shorter than IV, while VI spur is nearly as long as the three together.

24 Baker, A. C. and Quaintance, A. L. Aphids injurious to orchard fruits, currant, gooseberry and grape, U. S. Dept. Agr., Farmers' Bulletin 804, p. 21, 1917. 


\section{Siphocoryne nymphaeae Linn.}

Figure 172

Linnaeus, Syst. Nat., vol. 2, p. 734, 1735. Aphis (orig. dese.). Davidson, Jour. Econ. Ent., vol. 3, p. 377, 1910. Rhopalosiphum (list). Essig, Pom. Jour. Ent., vol. 4, p. 793, 1912. Rhopalosiphum (dese.).

Davidson, Mon. Bull. Cal. Comm. Hort., vol. 6, p. 65, 1917. Rhopalosiphum (note).

Records.-Polygonum sp., Alisma sp., Potamogeton sp.; San Franciseo Bay region (Davidson): Typha latifolia; Santa Paula (Essig), San Franciseo Bay region (Davidson): Nymphaea sp.; San Francisco Bay region (Davidson), Fresno, June, 1915: Prunus domestica; Berkeley, 1916 (Essig).

This aphid occurs throughout the summer months on various semiaquatic plants, lily, tule, and so forth. In the fall it migrates to plum, where eggs are laid. The first two or three generations in the spring occur on plum, but about June there is a migration to its summer host plants. So far it has been found in southern California only in Ventura County.

The species listed as Aphis prunorum Dobr. (see no. 140) may be this species. Essig believes it is, but the author is not certain so does not list it as a synonym.

\section{Siphocoryne pastinacae Linn.}

Figures 266 to 270

Linnaeus, Syst. Nat., p. 451, 1735. Aphis (orig. desc.). Davidson, Jour. Econ. Ent., vol. 2, p. 304, 1909. S. xylostei (Schr.) (list). Davidson, Jour. Econ. Ent., vol. 2, p. 304, 1909. S. conii n.sp. (dese.). Davidson, Jour. Econ. Ent., vol. 3, p. 377, 1910. S. xylostei (Schr.) and S. conii Drdn. (list).

Davidson, Jour. Econ. Ent., vol. 4, p. 599, 1911. Hyadaphis umbellulariae n.sp. (desc.).

Davidson, Pom. Jour. Ent., vol. 3, p. 399, 1911. S. conii Dvdn. (list).

Davidson, Jour. Econ. Ent., vol. 7, p. 133, 1914. S. xylostei (Schr.) (list).

Records.-Lonicera sp.; Stanford University (Davidson), Claremont (Essig), Berkeley, April, 1915: Umbellularia californica; San Jose (Davidson) : Conium maculatum; Stanford University, Penryn, Placer County, and San Jose (Davidson).

This aphid occurs on honeysuckle during the winter and spring, and on various semiaquatic plants in the summer. It has been taken in southern California, in the San Francisco Bay region, and in the Sacramento Valley. 


\section{Genus Myzaphis Van der Goot}

Van der Goot, Zür Systematik der Aphiden, Tijdserift voor Entomologie, vol. 56, p. 96, 1913. Type Aphis rosarum Walker.

The author believes that this genus of Van der Goot's should be aecepted for the two following speeies: Aphis abietina Walker and Aphis rosarum Walker. A. rosarum has usually been considered as belonging to the genus Myzus, but the absence of antennal tubereles exeludes it from that genus (see figs. 306-308, 313). The cornicles and eauda are not typical of Aphis, and these together with the distinetive frontal tuberele on the head and the absence of lateral body tubereles distinguish it from Aphis. Consequently this genus should be recognized. Following is a key for separating the two known speeies, both of whieh oeeur in California:

Cornicles slightly clavate (figs. 312,315 ), shorter than III. III tuberculate, IV without sensoria (fig. 309). Found on Rosa spp. ........................rosarum (Walker) Cornicles cylindrical (fig. 197), equal to or longer than III. III with 9 to 12 rather large secondary sensoria, IV with 1 to 4 (fig. 196). On conifers.

abietina (Walker)

\section{Myzaphis abietina (Walker)}

Figures 196, 197

Walker, Ann. Mag. Nat. Hist., vol. 3, p. 301, 1848. Aphis (orig. dese.). Wilson, Proc. Ent. Soc. Brit. Columbia, June, 1915 (desc.).

Record.-Picea excelsa; San Francisco, March, 1915 (Compere).

The only report of this speeies in Ameriea is that of Wilson, who found it on spruee (Picea sp.) at Vancouver, British Columbia. On Mareh 26, 1915, Harold Compere of San Franeisco took a number of speeimens of this speeies on the twigs of Norway spruce (Picea excelsa) in Golden Gate Park, San Franciseo. The speeimens are in Essig's and the author's eollections.

\section{Myzaphis rosarum (Walker)}

Figures 308 to 317

Walker, Ann. Mag. Nat. Hist., vol. 3, 1848. Aphis (orig. desc.).

Davidson, Jour. Econ. Ent., vol. 3, p. 379, 1910. Myzus (list)

Records.-Rosa spp.; Stanford University (Davidson); Santa Paula (Essig), San Diego, March to July, 1916.

This species has been reported in the San Franciseo Bay region by Davidson and in Santa Paula by Essig. In the Bay region it is rather scarce and is seeond to Macrosiphum rosae (Linn.) in abundance on roses. The author has taken it at Stanford University in 1915, and in San Diego several times in 1916. In San Diego in 1916 it was by far the most abundant rose-infesting aphid. The author 
has observed it in such numbers on roses as to cover the undersides of practically all the leaves and the calyx cups of the flowers. In some cases the buds were stunted and the flowers unshapely from its effect. In the rose garden of the Panama-California International Exposition these aphids were of considerable importance, necessitating continual care to keep them under control.

Since there is no adequate description of this species in the American aphid literature the author describes it herewith. The following description was drawn from ten specimens of alate and eight of apterae, collected in Santa Paula, Stanford University, and San Diego.

Alate viviparous female.-Color notes (taken from notes made at the time of collection of specimens at Stanford in March, 1915): Head, antennae, and thoracic plates black. Abdomen pale apple green with smoky blotch on dorsum. Legs: apical two-thirds of femora smoky, basal one-third pale, tibiae pale except dusky tip, tarsi dusky. Cornicles green (dusky), cauda pale apple green.

Head is twice as wide as long with a fairly distinct tubercle on the front (fig. 308). Antennal tubercles are lacking or very indistinct. Antennae reach almost to the base of the third abdominal segment (figs. 309, 310). III is the longest segment, followed by IV, spur, V, and VI. The spur and IV are practically equal. Of sixteen antennae examined, in three, the spur and IV were equal, in ten, IV was slightly longer than the spur, while in three, the spur was slightly longer than IV. V is slightly shorter than the spur, and VI slightly shorter than V. However, IV, spur, V, and VI are all almost equal. On V and VI are the usual primary sensoria, and VI the accessory sensoria (fig. 300 ). III is tuberculate, being furnished with a large number of irregularly placed secondary sensoria (fig. 309). IV is without any sensoria. The beak reaches almost to the second coxae.

The prothorax is without lateral tubercles. The wings are normal, being about twice the length of the body. The second branch of the cubitus arises nearer the apex of the wing than the base of the first branch (fig. 311). In but one of seventeen specimens examined was the origin of the second branch of the cubitus nearer the base of the first branch than the tip of the wing. In this specimen the measurements were : $0.561 \mathrm{~mm}$. from tip of wing to base of first branch and $0.289 \mathrm{~mm}$. from tip of wing to base of second branch.

The abdomen is long and narrow and is without lateral body tubercles. The cornicles (fig. 312) are long, being but slightly shorter than the third antennal segment, and over twice as long as the hind tarsi. They are slightly clavate on the inner side. The cauda (fig. 
312 ) is long and pointed (ensiform), being slightly more than one-half as long as the cornieles and about one-half as long again as the hind tarsi.

Measurcments: Body length, 1.19 to $1.41 \mathrm{~mm}$. (av. $1.28 \mathrm{~mm}$.); width of thorax, 0.459 to $0.527 \mathrm{~mm}$. (av. $0.487 \mathrm{~mm}$.) ; antennae total, 0.85 to $1.156 \mathrm{~mm}$. (av. $1.027 \mathrm{~mm}$.) ; III, 0.255 to $0.34 \mathrm{~mm}$. (av. 0.317 mm.) ; IV, 0.1275 to $0.2295 \mathrm{~mm}$. (av. $0.1768 \mathrm{~mm}$.) ; V, 0.119 to 0.17 mm. (av. $0.1365 \mathrm{~mm}$.) ; VI, 0.085 to $0.119 \mathrm{~mm}$. (av. $0.1095 \mathrm{~mm}$.); spur, 0.119 to $0.204 \mathrm{~mm}$. (av. $0.1695 \mathrm{~mm}$.) ; cornicles, 0.238 to 0.306 mm. (av. $0.2574 \mathrm{~mm}$.) ; cauda, 0.136 to $0.187 \mathrm{~mm}$. (av. $0.1588 \mathrm{~mm}$.); hind tarsi, 0.119 to $0.136 \mathrm{~mm}$. (av. $0.1205 \mathrm{~mm}$.) ; wing length, 2.482 to $2.72 \mathrm{~mm}$. (av. $2.5483 \mathrm{~mm}$.) ; wing width, 0.884 to $1.02 \mathrm{~mm}$. (av. $0.9396 \mathrm{~mm}$.) ; wing expansion 5.423 to $5.967 \mathrm{~mm}$. (av. $5.5836 \mathrm{~mm}$.). From tip of wing to base of first branch of cubitus 0.561 to $1.037 \mathrm{~mm}$. (av. $0.8041 \mathrm{~mm}$.) ; from tip of wing to base of second branch of cubitus, 0.17 to $0.34 \mathrm{~mm}$. (av. $0.2907 \mathrm{~mm}$.).

Apterous viviparous female.-Head about as long as broad with a large prominent tubercle on the front, this tubercle being considerably larger than in the alate form; in some individuals it is fully as large as the first antennal segment (fig. 313). Antennal tubereles small but distinct, similar to those of the alate. Antennae (fig. 314) short, reaching only to the third coxae. III is the longest segment, followed by the spur, IV, VI, and V. These are all subequal, the formula of the averages being spur, IV, VI, and V. The formulae for seven antennae are S, VI (V, IV) ; S, (VI, V, IV) ; S, V, IV, VI ; S, IV (V, VI) ; S, (IV, V), VI; IV (V, VI, S) ; (S, VI, IV), V. The usual primary sensoria are present, but there are no secondary sensoria. The beak is short, reaching only to the second coxae.

The prothorax is without tubercles. The thorax is normal, as are the legs. The abdomen is long and narrow, without lateral tubercles, and without long capitate hairs as found in some species of Myzus. The cornicles (fig. 315) are long, cylindrical, and slightly tapering toward the apex, or slightly clavate at apex. They are over twice as long as the third antennal segment and over three times as long as the hind tarsi (fig. 317), and half as long again as the cauda. The cauda (fig. 316) is long and ensiform, being slightly more than twice the length of the hind tarsi, and about two-thirds the length of the cornicies.

Measurements : Body length, 1.275 to $1.615 \mathrm{~mm}$. (av. $1.428 \mathrm{~mm}$.) ; width of thorax, 0.493 to $0.748 \mathrm{~mm}$. (av. $0.6375 \mathrm{~mm}$.) ; antenuae total, 0.544 to $0.731 \mathrm{~mm}$. (av. $0.6239 \mathrm{~mm}$.) ; III, 0.153 to $0.238 \mathrm{~mm}$. (av. 
$0.178 \mathrm{~mm}$.) ; IV, 0.068 to $0.119 \mathrm{~mm}$. (av. $0.0855 \mathrm{~mm}$ ) ; V, 0.068 to $0.102 \mathrm{~mm}$. (av. $0.0833 \mathrm{~mm}$.) ; VI, 0.068 to $0.119 \mathrm{~mm}$. (av. $0.085 \mathrm{~mm}$.) ; spur, 0.085 to $0.136 \mathrm{~mm}$. (av. $0.117 \mathrm{~mm}$.) ; cornicles, 0.306 to 0.442 mm. (av. $0.3655 \mathrm{~mm}$.) ; cauda, 0.204 to $0.272 \mathrm{~mm}$. (av. $0.2338 \mathrm{~mm}$.) ; hind tarsi, $0.102 \mathrm{~mm}$. (Note : no color notes were taken of the apterae at the time of collection and as all the spccimens were killed in alcohol, dehydrated in xylene and mounted in Canadian balsam, it is impossible to give any color notes.)

\section{Genus Coloradoa Wilson}

Wilson, Ann. Ent. Soc. Am., vol. 3, p. 323, 1910. Type Aphis rufomaculata Wilson.

This genus was described by Wilson in 1910 to contain the species Aphis rufomaculata Wilson. After examining specimens of this species recently, the author is of the opinion that Coloradoa and Myzaphis are synonymous, for there docs not seem to be enough difference between this species and the two specics of Myzaphis to warrant a separation of genera. However, the author does not feel certain concerning the point, so lists both these genera. Should they later prove to be synonymous, Myzaphis would have to be dropped and replaced by Coloradoa. There is but one species belonging to this genus.

\section{Coloradoa rufomaculata Wilson}

Wilson, Ent. News, vol. 14, p. 261, 1908. Aphis (orig. desc.). Record.-Chrysanthemum, cultivated; Sacramento, April, 1917 (Davidson).

The author has recently received specimens of this species from Davidson taken on chrysanthemum in Sacramento.

\section{Genus Cerosipha Del Guercio}

Del Guercio, Nouve relazione agraria di Firenze, vol. 2, p. 116, 1909. Type C. passeriniana $\mathrm{n} . \mathrm{sp}$.

\section{Cerosipha cupressi Swain}

Swain, Trans. Am. Ent. Soc., vol. 44, p. 19, 1918 (orig. dese.).

Records.-Cupressus guadelupensis; San Diego, 1916; Riverside, 1917; C. macrocarpa, San Diego, 1916.

This species, recently described by the author, has been taken by him several times in San Diego and Riverside on blue cypress and Monterey cypress. It is an extremely interesting little aphid, differing considerably from any other species known to the author, both in habits and appearance. Its five-jointed antennae, long cauda, atrophied cornicles, and convexity of abdomen are quitc distinctive. 


\section{Subfamily Pemphiginae Mordwilko ${ }^{23}$}

Mordwilko, Ann. Mus. Zool. Imp. Acad. Sei. St. Petersburg, vol. 13, pp. 362-364, 1908.

A sumnary of Mordwilko's description of this subfamily has already been given. The latest and probably the most complete systematic work on this subfamily that has been done is that of Dr. Albert Tullgren of Stoekholm, Sweden, in his paper, "Aphidologische Studien I" in 1909. Tulgren divides this subfamily into six tribes, viz: Vaeunina, Hormaphidina, Mindarina, Pemphigina, Schizoneurina, and Anoecina. In the tribe Vacunina he places Vacuna Heyden and Glyphina Koch; in Hormaphidina is the one genus Hamamelistes Shimmer; in Mindarina is the one genus Mindarus Koch; in Pemphigina he places Asiphum Koch, Pachypappa Koch, Prociphilus Koch, Thecabius Koch, and Pemphigus Hartig; in Schizoneurina he places the two genera, Schizoneura Hartig, and Tetraneura Hartig; and finally in the Anoeciina is found the one genus Anoecia Koch. It ean be seen that he uses several of Koch's genera which have not heretofore been generally used, namely: Prociphilus Koeh, Thecabius Koch, Asiphum Koch, and so forth. Lately there has been a tendency among American aphidologists to accept these genera, and thus to divide up the larger genus Pemphigus into these smaller ones. Mordwilko in his keys divides this subfamily into four groups, namely: Hormaphidina, Pemphigina, Schizoneurina, and Vacunina. In Hormaphidina he includes besides the genus Hamamilestes Shimmer, the genera Hormaphis Osten-Sacken and Cerataphis Liehtenstein. In Pemphigina he includes Pcntaphis Heyden, Tetraneura Hartig, Pemphigus Hartig, Aploneura Passerini, Rhizoctonus Horvath, and Paracletus Heyden. In Schizoneurina he plaees Löwia Lichtenstein, Colopha Monell, Pachypappa Koch, Schizoncura Hartig, Anoecia Koch, and Mindarus Koch. In Vacunina he includes but the one genms Vacuna Heyden, which he does not separate from Glyphina Koch.

There is considerable difference in the classifications of these two authors, but as far as we are concerned here in California our genera are placed abont the same by both. Following is a translation of Mordwilko's key to the groups :

25The author has under way a more exhaustive study of this subfamily, particularly of the species of Pemphigus and Prociphilus. As this research is still in progress, however, it was thought best to omit any report of it, the author here confining himself merely to the records of the presence of the various species in California. It was hoped to have this study completed at the present time, but the unprecedented conditions of this season have made it necessary to delay further study for the time being. 
1. Winged forms with a cucurbit-shaped cauda. Nymphs that failed to molt with three-jointed antennae. Winged forms with three to five-jointed antennae, which are coarsely ringed from the third on. Wingless parthenogenetic females presenting the appearance of the larvae of other families, as of some kinds of Coccidae, or of species of Aleyrodes. Sexual forms with beaks

Group Hormaphidina

- Winged forms without distinct cauda. Nymphs that failed to molt with four to five-jointed antennae. Antennae of winged females five-to six-jointed. Sensoria may be found on the third and following joints, often in the form of arches or half rings, but never as complete rings

2. Cubitus [third discoidal vein] of the fore wings simple. Cornicles, which are pore or pointlike, present only in some species, and then not in all forms.

Group Pemphigina

- Cubitus [third discoidal vein] of fore wings once-branched. Cornicles mostly point or pore-like

3. Antennae of winged forms six-jointed. Wings held roof-like when at rest.

Group Schizoneurina

- Antennae of winged forms five-jointed. Wings held flat when at rest.

Group Vacunina

\section{Group Hormaphidina Mordw.}

Mordwilko, Ann. Mus. Zool. Imp. Acad. Sci. St. Petersburg, vol. 13, pp. 364-365, 1908.

The antennae of the winged forms are 5- to 3 -jointed (₹). With the exception of the first two joints they are closely and entirely ringed. Even in the genus Hormaphis O.-S., where the antennae are 3-jointed, they may probably be considered morphologically as of five joints. The wings are held flat at rest. There are four transverse veins on the fore wings, the third of which [third discoidal] is simple. The first two [first and second discoidals] originate at the same point on the subcosta. The hind wings have one or two transverse veins, in the latter case both originating at the same point. The wingless parthenogenetic females on the alteruate host plants (for example on birch) are mostly circular in shape, and have small wax tubes around them. Other forms are coccid-like. The sexual forms have beaks. The cornicles are absent.

This is a description as given by Mordwilko in the above mentioned paper. Below is a key to the genera, as given by Mordwilko and by Van der Goot, the latter of whom includes in this group the two genera Hamamelestes Shimmer and Cerataphis Licht.

1. Antennae of winged females plainly five-jointed 2

- Antennae of winged females only three-jointed Hormaphis O.-S.

2. Antennae always five-jointed. Front of head always with two little horns. Third discoidal once-branched Cerataphis Lichtenstein

- Antennae of apterous forms three- or four-jointed. Front without horns. Third discoidal simple Hamamelistes Shim. 


\section{Genus Cerataphis Lichtenstein}

Lichtenstein, Bull. Société ent. de France, vol. 2, p. 16, 1882. Type Coccus lataniae Boisd.

\section{Cerataphis lataniae Boisduval}

Boisduval, Ent. Hort., 1867. Coccus (orig. dese.). Davidson, Jour. Econ. Ent., vol. 5, p. 404, 1912 (list).

Essig, Univ. Calif. Publ. Entom., vol. 1, p. 342, 1917 (list).

Records.-Fern, Stanford University (Davidson); orchid, Oakland (Essig).

This coccid-like species has been reported twice in the San Francisco Bay region, by Davidson and by Essig. Morrison and the author have also taken it on the same ferns on which Davidson found it in the Stanford University nursery.

\section{Group Pemphigina Lichtenstein}

Below is a key to the California genera of this group, adapted from Mordwilko, Tullgren and Del Guercio. Del Guercio described a genus in 1909 for Pemphigus radicicola Essig, which he called Trifidaphis.

1. Antennae of alate females five-jointed Trifidaphis Del Guer

- Antennae of alate females six-jointed 2

2. Stem mothers with five-jointed antennae. Wax-gland plates on head always present and usually large. Spring and fall migrants with wax-gland plates always on mesothorax and abdomen, and usually on head. Dorsal pores never present

- Stem mothers with four-jointed antennae. Head normally without wax-gland plates. Dorsal pores sometimes present. Stem mothers and spring migrants (fundatrix and fundatrigenia) at first live in the same closed galls.

Pemphigus Hartig

3. Secondary sensoria furnished with hairy fringe (Wimperkranz). Wax-gland plates generally large. In stem mothers there appear four very large pronotal wax-gland plates, placed in a transverse row. All plates have a clearly chitinized border. Stem mother and migrants live together.

Prociphilus Koch

- Secondary sensoria without hairy fringe (Wimperkranz). Wax-gland plates generally small. In stem mothers there are six pronotal plates, of which the four middle ones are arranged in the form of a trapezium. In the winged fall migrants (sexupara) there are also transverse abdominal gland plates, which are without clearly chitinized borders. Stem mothers and spring migrants live in separate galls Thecabius Koch 


\section{Genus Trifidaphis Del Guercio}

Del Guereio, Riv. di patal. veg., vol. 3, p. 20, 1909. Type Pemphigus radicicola Essig.

\section{Trifidaphis radicicola Essig}

Essig, Pom. Jour. Ent., vol. 1, p. 8, 1909. Pemphigus (orig. desc.).

Baker, Pom. Jour. Ent., vol. 1, p. 74, 1909. (Translation of Del Guercio's description of the genus.)

Essig, Pom. Jour. Ent., vol. 2, p. 283, 1910 (list).

Essig, Pom. Jour. Ent., vol. 4, p. 699, 1912 (list).

Records.-Amaranthus retroflexus, Solanum douglasii; Claremont, Santa Paula (Essig).

Essig described this species from specimens taken on the roots of Amaranthus retroflexus and Solanum douglasii in Santa Paula and Claremont. Later Del Guercio described a new genus for this species based on the venation and the antennae. It seems that the type specimen of this species had but five-jointed antennae and so of course it could not belong to the genus Pemphigus. On an examination of eight specimens, including the type specimen and seven cotypes, the author finds that the number of joints in the antennae are variable. The type specimens had both antennae with but five joints. Six antennae had but five joints, six had six distinct joints, and four had five joints in which the division into six could be made out. This divison was in the third joint at about one-third the distance from the apex. Consequently one could say that this species was typically fivejointed, but with some specimens with the third joint divided into two, or it could be said that it was typically six-jointed, but in some specimens a reducton occurred through the joining of the third and fourth segments. As but a few specimens were examined the author is not willing to state which is the more common, hence leaves this as a valid genus, although he is of the opinion that this really belongs to the genus Prociphilus Koch.

\section{Genus Pemphigus Hartig}

Hartig, Jahresb. u. d. Fortschr. d. Forstwiss. u. forstliche Naturk., vol. 1, p. 645, 1837. Type Aphis bursarius Linn.

This genus is represented in California by three well known species, ${ }^{26}$ P. betae Doane, $P$. populi-caulis Fitch, and P. populi-trans-

28 There has been taken several times a species forming elongate leaf galls on Populus fremontii, both in the San Francisco Bay region by Davidson and in San Diego County by the author, that structurally seems to be identical with $P$. populicaulis Fitch, but its gall is quite distinct, being more or less similar to that of $P$. betae Doane. Further study may reveal the identity of this form. 
versus Riley. All of these species, during at least a part of their life eycles, infest various species of Populus, where they form more or less distinctive galls.

\section{Key to FundatrigeniaE27}

1. Secondary sensoria present only on III. Galls formed on leaf petioles, with a transverse opening on the outside of the curve ......populi-transversus Riley

- Secondary sensoria on other segments as well as on III 2

2. Secondary sensoria on III to VI inclusive. Galls formed by the twisting of the petiole with an oblique opening on the inside of the curve.

populi-caulis Fiteh

- Secondary sensoria on III and IV.28 Gall formed on the under side of the leaves, being more or less elongate and opening on the upper side.

betae Doane

\section{Pemphigus betae Doane}

Doane, Ent. News., vol. 11, p. 390, 1900 (orig. desc.).

Clarke, Can. Ent., vol. 35, p. 248, 1903 (list).

Davidson, Jour. Econ. Ent., vol. 2, p. 299, 1909 (list).

Davidson, Jour. Ecou. Ent., vol. 3, p. 372, 1910 (list).

Williams, Univ. Neb. Studies, vol. 10, p. 92, 1910. P. balsamiferae n.sp. (desc. fundatrigenia).

Essig, Pom. Jour. Ent., vol. 4, p. 299, 1912 (list).

Maxson, Jour. Econ. Ent., vol. 9, p. 500, 1916 (note).

Records.-Beta vulgaris; San Francisco Bay region, Monterey County, Sacramento Valley. (Rumex spp., Chenopodium spp., etc.?)

Under the name $P$. betae Doane, Clarke, Davidson, and Essig have reported a species of aphid infesting the roots of sugar beets, dock, Chenopodium, and other plants throughout California.

Originally this species was described from specimens taken on sugar beet in Washington, but later ${ }^{29}$ it was proven that a species forming elongated leaf galls on Populus balsamifera in the spring migrated to beets, and was identical with this species. In 1916 Maxson (cited above) states that his investigations point to the fact that in Colorado there are more than onc species of Pemphigus attacking the sugar beet, one of which is this species that forms the elongate leaf gall on poplar in the spring, and which is known now as $P$. betae Doane.

27 At present only a key to the alate migrants or fundatrigeniae occurring in galls on poplar is given. It is hoped that later, keys to all forms may be formulated. At present, however, the life histories of the species are not sufficiently known.

28 The sexupara or alate migrants from beets to poplars have secondary sensoria on III to $\mathrm{V}$ inclusive. These form no galls on poplar, however.

29 Parker, The life history of the sugar-beet root louse, Jour. Econ. Ent., vol. 7, pp. 136-141, 1914;

Gillette, Notes on some Colorado aphids having alternate host plants, Jour. Ecoll. Ent., vol. 8, p. 97, 1915. 
These observations of Maxson's together with those made by the author lead to the eonelusion that all the reported eases of infestation of beets and other hosts by $P$. betae Doane in California do not neeessarily refer to this speeies. Never have the fundatrix or fundatrigenia been taken on poplar in California. This strengthens the point that the aphids on beets and other hosts may not all be $P$. betae Doane. Further studies and observations will have to be made before this point ean be settled, however.

\section{Pemphigus populicaulis Fiteh}

Fitch, Rep. Ins. N. Y., vol. 5, p. 845, 1859 (orig. desc.). Clarke, Can. Ent., vol. 35, p. 248, 1903 (list).

Davidson, Jour Econ. Ent., vol. 2, p. 299, 1909 (list).

Davidson, Jour. Econ. Ent., vol. 3, p. 372, 1910 (list).

Davidson, Jour. Econ. Ent., vol. 3, p. 372, 1910. P. populi-transversus Riley (list).

Davidson, Pom. Jour. Ent., vol. 3, p. 398, 1911. P. populi-transversus Riley (list).

Essig, Pom. Jour. Ent., vol. 4, p. 699, 1912 (list).

Essig, Pom. Jour. Ent., vol. 4, p. 708, 1912 (dese.).

Davidson, Jour. Econ. Ent., vol. 8, p. 420, 1915 (sexuales).

Records.-Populus fremontii, P. trichocarpa; from Placer County to San Diego County (Clarke, Davidson, Essig, Morrison, and the author).

The speeies infests eottonwoods throughout the state, forming a gall by the twisting of the leaf petiole. The sexuales are found, according to Davidson, under the bark where the eggs are also laid. The author has found the speeies in San Diego County, having taken the fundatrix, virgogenia, and fundatrigenia in galls in May, 1916, and the dead sexupara at the same time in old galls. These latter probably died without ever leaving the galls.

\section{Pemphigus populi-transversus Riley}

Riley, U. S. Geog. Geol. Surv., Bull. 5, p. 15, 1880 (orig. dese.).

Essig, Univ. Calif. Publ. Entom., vol. 1, p. 343, 1917 (list).

Records.-Populus fremontii, Berkeley, September, 1914 (Essig), Riverside September to October, 1916, May to July, 1917.

This species forms large galls on the leaf petioles of poplar somewhat similar to the preceding speeies, differing in that the opening is on the opposite side of the gall, and is transverse rather than oblique. Essig's speeimens were determined by Gillette, the author's by Maxson. Davidson reported a species under this name from Stanford 
University, but later wrote the author that he was mistaken in his determination, the species being $P$. populicaulis Fitch instead.

Just recently the author received specimens of the sexupara of this species from J. R. Parker, Bozeman, Montana. These were taken by S. H. Jones in Port Allen, Louisiana, in September, 1915, on the roots of cabbages. Jones notes that cabbage and other cruciferous plants are the alternate host of this species. This spring the author received a large number of apterae of a species of Pemphigus taken in Orange County on the roots of cabbage. A specific determination of the species was impossible but it may have been this one.

\section{Genus Thecabius Koch}

Koch, Die Pflanzenläuse, p. 294, 1857. Type Pemphigus affinis Kalt.

This genus is very similar to Prociphilus, and by some authors, particularly Baker, ${ }^{30}$ is considered as synonymous. However, for present purposes the author proposes to retain it for the three species included herewith.

\section{Key to Californian Species}

1. Antennae short, barely reaching to the metathorax, and not one-third as long as the body. III but slightly longer than VI. populi-monilis Riley

- Antennae longer, reaching beyond the base of the abdomen, and about one-half as long as the body. III considerably longer than VI

2. V and VI with secondary sensoria

- VI without secondary sensoria populi-conduplifolius Cowen californicus Davidson

\section{Thecabius californicus (Davidson)}

Davidson, Jour. Econ. Ent., vol. 3, p. 372, 1910. Pemphigus ranunculi n.sp. (orig. dese.).

Davidson, Jour. Econ. Ent., vol. 4, p. 414, 1911, renamed Pemphigus californicus Dvdn.

Essig, Pom. Jour. Ent., vol. 4, p. 699, 1912. Pemphigus (dese. ala. and apt. female).

Davidson, Jour. Econ. Ent., vol. 7, p. 127, 1914 (note).

Records.-Ranunculus californicus; San Francisco Bay region (Davidson, Morrison, Essig, author): ? Populus sp.; Walnut Creek, Contra Costa County, May, 1915 (Davidson) : Fraxinus oregona; Walnut Creek (Davidson).

This aphid is found quite abundantly on the roots and stems of the small California buttercup in the San Francisco Bay region. According to Davidson there is a migration during April from butter-

30 Baker, A. C., Identity of Eriosome pyri, Jour. Agr. Res., vol. 5, p. 1118, 1916. 
cup to ash. There may be a migration to poplar as well, for the author has specimens that seem to be this species taken by Davidson on poplar. Gillette ${ }^{31}$ places this species as a synonym of $T$. populiconduplifolius Cowen, which attacks both Ranunculus and Populus in Colorado. Davidson, however, is convinced that they are distinct.

\section{Thecabius populiconduplifolius (Cowen)}

Cowen, Colo. Agr. Exp. Sta., Bull. 31, p. 115, 1895. Pemphigus (orig. desc.).

Davidson, Jour. Econ. Ent., vol. 3, p. 374, 1910. Pemphigus (list).

Essig, Pom. Jour. Ent., vol. 4, p. 699, 1912. Pemphigus (list).

Gillette, Annals Ent. Soc. Am., vol. 7, p. 61, 1914 (desc. and life history).

Record.-Populus trichocarpa; Stanford University (Davidson).

This species was reported by Davidson on poplar at Stanford University. Since then no further records of its occurrence in the state have been made. In Colorado, Gillette finds that the common buttercup, Ranunculus sp., is an alternate host and so considers the preceding species as a synonym. This may be possible, but it is quite doubtful.

\section{Thecabius populimonilis (Riley)}

Riley, U. S. Geol. Surv., Bull. 5, p. 13, 1879. Pemphigus (orig. desc.). Davidson, Jour. Econ. Ent., vol. 3, p. 374, 1910. Pemphigus (list) Davidson, Pom. Jour. Ent., vol. 3, p. 398, 1911. Pentphigus (list). Essig, Pom. Jour. Ent., vol. 4, p. 699, 1912. Pemphigus (list). Gillette, Ann. Ent. Soc. Am., vol. 6, p. 485, 1913 (desc. and life history).

Records.-Populus spp.; Tulare and Placer counties (Davidson); Santa Paula (Essig), Riverside, 1916-1917.

Throughout central and southern California this species is found on various species of Populus where it forms more or less globular galls on the upper side of the leaves near the margins. In the vicinity of Riverside the young stem mothers began to appear in April (1917). When first observed in September, 1916, nearly all the galls were empty while a few contained alate migrants (sexupara probably). According to Gillette the eggs are laid on the trunks of Populus, thus the entire life cycle is passed on the one host plant. This is rather unusual for the Pemphiginae of this section.

31 Gillette, C. P., Some Pemphiginae attacking species of Populus in Colorado, Ann. Ent. Soc. Am., vol. 7, pp. 61-65, 1914. 


\section{Genus Prociphilus Koch}

Koch, Die Pflanzenläuse, p. 279, 1857. Type Aphis bumeliae Schrank.

Key to Californian Species

1. Stigma' of forewings conspicuously darkened. V with a few annular secondary sensoria, VI with or without any. Dorsal thoracic wax plates small and oval alnifoliae (Williams)

- Stigma not conspicuously, darkened. V and VI without annular secondary sensoria. Dorsal thoracic wax plates quite large and triangular.

venafuscus Patch

\section{Prociphilus alnifoliae (Williams).}

Williams, Univ. Neb. Studies, vol. 10, p. 91, 1910. Pemphigus (orig. dese.). Baker, Jour. Agr. Res., vol. 5, p. 1118, 1916 (note).

Records.-Heteromeles arbutifoliae; Sespe, Ventura County, March, 1915 (S. H. Essig); May, 1915 (C. P. Clausen).

There has been no record of this species from California heretofore, but the author has specimens taken on California holly or Christmas berry in Sespe Canyon during March and May, 1915, by S. H. Essig and C. P. Clausen.

\section{Prociphilus venafuscus Patch}

Pateh, Ent News, vol. 20, p. 319, 1909. Pemphigus (orig. desc.).

Essig, Pom. Jour. Ent., vol. 3, p. 553, 1911. Pemphigus fraxini-dipetalae n.sp. (orig. desc.).

Essig, Pom. Jour. Ent., vol. 4, p. 699, 1912. Pemphigus fraxini-dipetalae Essig (list).

Childs, Mon. Bull. Cal. Comm. Hort., vol. 3, p. 220, 1914. Pemphigus fraxini-dipetalae Essig (list).

Wilson, Trans. Am. Ent. Soc., vol. 41, p. 85, 1915. Prociphilus fraxinidipetalae (Essig) (note).

Davidson, Jour. Econ. Ent., vol. 8, p. 421, 1915. Prociphilus fraxinidipetalae (Essig) (list).

Baker, Jour. Agr. Res., vol. 6, pp. 1118-1119, 1916 (dese. notes, synonymy).

Records.-Fraxinus dipetala; Santa Paula (Essig), Contra Costa and Santa Clara counties (Davidson): F. oregona; Oregon (Wilson); Berkeley, April, 1915 : Aesculus californicus; Sacramento (Childs): Pseudotsuga taxifolia; Oregon (Wilson).

Occasionally this very large aphid is found infesting the leaves of ash in the San Francisco Bay region and in the mountains of southern California. In early summer it leaves the ash, and according to Wilson infests the roots of Douglas fir in Oregon. At one time Leroy Childs found a few spccimens on buckcye in the vicinity of Sacramento, but it is probable that these were accidental there. 


\section{Group Schizoneurina Lichtenstein}

This group as considered by Mordwilko contains the following genera : Löwia Licht., Colopha Monell, Pachypappa Koch, Schizoneura Hartig, Anoecia Koch, and Mindarus Koch. Tullgren places in his tribe Schizoneurina the two genera, Schizoneura Hartig, and Tetraneura Hartig. Pachypappa Koch he places in his tribe Pemphigina, and he has a separate tribe for each of the genera Anoecia Koch and Mindarus Koch, calling them respectively tribe Anoeciina and tribe Mindarina. Below is a translation of Mordwilko's key.

1. Wings laid flat on back when at rest

Iöwia Licht.

- Wings held roof-like when at rest ?

2. Stigma of forewings trapezoidal in shape, reaching only to the beginning of the curve around the end of the wing, never extending to the tip of the wing. Rasial vein originating from the posterior exterior corner of the stigma

- Stigma linear, very long, reaching to the wing tip on the front side of the wing, and even following the backward curve of the exterior side of the wing to some extent. Radial vein starting almost at the beginning to the interior edge of the stigma. Sexual forms with beaks

Mindarus Koch

3. Hind wings with one transverse vein Colopha Monell

- Hind wings with two transverse veins 4

4. Both transverse veins originating from the same point on the longitudinal veins Pachypappa Koch

- Transverse veins of hind wings originating separately 5

5. Bodies of apterous and alate forms with little hair, and covered at least on the dorsum of the abdomen with waxy powder. Cornicles pore-like (point-like). Sexual forms without beaks

Eriosoma Leach

- Bodies of apterous and alate forms very hairy and not covered with waxy powder or granules (only the stem mothers are weakly pulverulent). Cornicles comparatively large, tuberculate (cone-like). Sexual forms with beaks Anoecia Koch

The genera Löwia Licht., Pachypappa Koch. and Anoecia Koch are not represented in California. Colopha Monell and Mindarus Koch are both represented by their type species. It has been proven that Eriosoma Leach has priority over Schizoneura Hartig, so that genus is now known by that name. It is represented in California by three or four species at present. 


\section{Genus Colopha Monell}

Monell, Can. Ent., vol. 9, p. 102, 1877. Type Byrsocrypta ulmicola Fitch.

\section{Colopha ulmicola (Fitch)}

Fitch, Rept. Ins. N. Y., vol. 4, p. 63, 1858. Byrsocrypta (orig. desc.). Davidson, Jour. Econ. Ent., vol. 2, p. 299, 1909 (list).

Patch, Maine Agr. Exp. Sta., Bull. 181, 196, 1910 (desc.).

Record.-Olmus sp.; Stanford University (Davidson).

Davidson recorded this species from elm at Stanford University in 1909. Since then it has not been found again.

\section{Genus Eriosoma Leach}

Leach, Trans. Hort. Soc. London, vol. 3, p. 54, 1820. Type Aphis lanigerum Hausman.

Until quite recently this genus has been known as Schizoneura Hartig, but as Baker ${ }^{32}$ has pointed out, the name Eriosoma has priority. In California there are three distinct species represented, with a possible fourth. One of these is known only on elm, one on apple (and elm), and one on pear (and elm).

The following key to the fall migrants is adapted partially from a table of Baker and Davidson. ${ }^{33}$

1. Body naked except caudal segment. Distal sensoria of $V$ and VI with fringe. languinosa (Hartig)

- Body with some woolly covering. Distal sensoria without fringe ................... 2

2. Wing veins narrow without brown margins. III longer than IV, V, and VI together lanigerum (Haus.)

- Wing veins broad with brownish margins. III not so long as IV, V, and VI. americana (Riley)

\section{Eriosoma americana (Riley)}

Riley, U. S. Geol. Surv., Bull. 5, p. 4, 1879. Schizoneura (orig. desc.). Clarke, Can. Ent., vol. 35, p. 248, 1903. Schizoneura (list).

Patch, Maine Agr. Exp. Sta., Bull. 220, p. 268, 1913. Schizoneura (dese. note).

Records.-Ulmus americana; Berkeley (Clarke); Walnut Creek, June, 1915 (Davidson); Palo Alto, May, 1915.

This leaf-curling aphid of the American elm is found in the San Francisco Bay region, and in some cases is very abundant. In May

32 Baker, A. C., The woolly apple aphis, U. S. Dept. Agr., Office Sec'y, Report 101, pp. 11-12, 1915.

33 Baker, A. C., and Davidson, W. M., Woolly pear aphis, Jour. Agr. Res., vol. 6, p. $358,1916$. 
and June, 1915, it was especially so on a row of elms on the campus of Stanford University. At that time stem mothers, nymphs, and alate spring migrants were present in the galls. By the last of June all of these had flown away, leaving the galls empty. According to Baker elm is the only host plant of this species.

\section{Eriosoma lanigerum (Hausman)}

Hausman, Mag: Ins., vol. 1, p. 440, 1802. Aphis (orig. desc.). Davidson, Jour. Econ. Ent., vol. 2, p. 299, 1909. Schizoneura (list). Davidson, Jour. Econ. Ent., vol. 3, p. 374, 1910. Schizoneura (list). Baker, U. S. Dept. Agr., Office Sec'y, Report 101, pp. 11-16, 1915 (dese. and biology).

Record.-Pyrus malus, throughout the state.

Wherever apple trees are found in the state this woolly aphis is also found the white masses on the trunks and leaves being very conspicuous, the colonies on the roots more injurious but less conspicuous. In California only the apple has been found to be attacked. The winter is passed by young nymphs on the roots. As the warmer weather of spring comes these migrate up the trunks and out on the branches and twigs. Here they feed throughout the summer. In the fall there is a downward migration, and occasionally a fall migrant is seen. Whether or not these fly to elms as in other parts of the country, is not known, but none have ever been observed on elm.

\section{Eriosoma languinosa (Hartig)}

Hartig, Zeitschr. Ent., vol. 3, p. 359, 1841. Aphis (orig. dese.).

Baker and Davidson, Jour. Agr. Res., vol. 6, pp. 351-360, 1916. E. pyricola n.sp. (desc.).

Baker and Davidson, Jour. Agr. Res., vol. 10, pp. 65-74, 1917. E. pyricola B. \& D. (desc. and biology).

Records.-Pyrus communis, Ulmus campestris; central California.

In 1916 Baker and Davidson described a species of Eriosoma that attacks the roots of pears throughout the central part of the state, naming it $E$. pyricola. Later Davidson found that a species common on Ulmus campestris was the alternate form of this species. This clm form checks up very favorably with specimens of $E$. languinosa Hartig from Europe, and is undoubtedly identical. Thus the name pyricola will have to be dropped in favor of languinosa. These elm galls are of a rather peculiar shape, and, as Patch writes, they have the appearance of a bonnet. 


\section{Genus Mindarus Koch}

Koch, Die Pflanzenläuse, p. 277, 1857. Type M. abietinus n.sp.

\section{Mindarus abietinus Koeh}

Koch, Die Pflanzenläuse, p. 278, 1857 (orig. desc.).

Clarke, Can. Ent., vol. 35, p. 248, 1903. Schizoneura panicola Thos. (list).

Patch, Maine Agr. Fxp. Sta., Bull. 182, p. 242, 1910 (dese.).

Records.-Pinus radiata; Berkeley, Palo Alto (Clarke): Abies cilicia; Stanford University, May, 1915.

This aphid, easily reeognized by the extremely long stigma of the fore wings, has been found in the San Franciseo Bay region infesting the shoots of Monterey pine and Cilician fir.

\section{Group Vacunina Mordwilko}

This group contains but two genera, Vacuna Heyden and Glyphina Koeh. Mordwilko does not reeognize Glyphina as distinet from Vacuna, although Tullgren does. The latter separates the two genera as follows:

1. Last abdominal tergite formed into a knob-shaped tail. Integunent bare, and at most partially set with short laneet-shaped hairs.......Vacuna Heyd.

- Last abdominal tergite half-moon shaped, strongly swollen, but scareely, if at all, separated from the base. Integument set with stiff bristle-like hairs and in apterous females with grain-like elevations ....Glyphina Koch ${ }^{34}$

\section{Genus Vacuna Heyden}

Heyden, Ent. Beitr., vol. 2, p. 289, 1837. Type Aphis dryophila Schrank.

\section{Vacuna dryophila (Schrank) (?)}

Schrank, Fauna Boica, vol. 1, p. 113, 1801. Aphis (orig. dese.).

Davidson, Jour. Econ. Ent., vol. 7, p. 128, 1914. Chaitophorus sp. (dese.). Davidson, Jour. Econ. Ent., vol. 10, p. 290, 1917 (dese.).

Record.-Quercus lobata; Walnut Creek (Davidson).

Recently Davidson described this species from specimens taken on valley oak in Contra Costa County, where he had observed it for three years. The single alate female he has taken does not appear identieal with European specimens of $V$. dryophila, so he lists the speeies under this name provisionally.

\footnotetext{
34 This genus is not represented in California.
} 


\section{Subfamily Phylloxerinae Dreyfus}

This subfamily consists of two groups, the Chermisina and the Phylloxerina. Below is a key to these two groups taken from Van der Goot:

1. Body always with wax glands. Antennae of adults three-jointed, seemingly five-jointed, with three large sensoria. Gonapophyses appearing as three short lips. Sexuales dwarfed, with beak Group Chermisina

- Body usually without wax glands. Antennae of adults three-jointed, with two large sensoria. Gonapophyses seem to be lacking. Sexuales dwarfed, without beak Group Phylloxerina

\section{Group Chermisina Börner}

This group consists of three genera, Pineus Shimmer, Cnapholodes Macq., and Chermes Linn. as it is generally considered, although some authors add more, as Gillettea Del Guercio and Guercioja Mordw. In California but one of these genera is represented, and that by but two species.

\section{Genus Chermes Linnaeus}

Linnaeus, Syst. Nat., vol. 10, 1758., Type Chermes sambuci Linn.

\section{Chermes cooleyi Gillette}

Gillette, Proc. Acad. Nat. Sci. Phila., vol. 69, p. 3, 1907 (orig. dese.). Davidson, Jour. Econ. Ent., vol. 2, p. 299, 1909. C. coweni Gill. (list). Davidson, Jour. Econ. Ent., vol. 3, p. 372, 1910. C. coweni Gill. (list). Brannigan, Mon. Bull. Cal. Comm. Hort., vol. 4, p. 285, 1915 (list).

Records.-Pseudotsuga taxifolia, Pinus pinea; San Franciseo Bay region, Sacramento Valley.

This species was first reported in California by Davidson, who found it on Douglas fir at Stanford University. Essig lists it from San Franeisco, San Mateo, and Santa Clara counties on Douglas fir. In 1915 it was reported twice, onee in Saeramento on Douglas fir, and once on Italian stone pine. The author has specimens from E. J. Vosler taken in Sacramento where it was found infesting the twigs and needles of Italian stone pine. Only the apterous females were present, however. 


\section{Chermes pinicorticis Fitch}

Fitch, Trans. N. Y. State Agr. Soc., vol. 14, p. 971, 1855. Coccus (orig. desc.).

Storment, 20th Ann. Rep. Illinois St. Ent., appendix, 1898 (desc.).

Davidson, Jour. Econ. Ent., vol. 2, p. 299, 1909 (list).

Davidson, Jour. Econ. Ent., vol. 3, p. 372, 1910 (list).

Record.-Pinus pinastér maritima; Stanford University (Davidson).

This species, which is unknown to the author, was reported as present at Stanford University on Pinus pinaster maritima, where it was so abundant as to sometimes kill the young trees.' For a complete description see Storment's paper listed above.

\section{Group Phylloxerina Börner}

There are two genera in this tribe, as considered by Börner and Mordwilko, although the American authors have generally taken cognizance of but one, namely, Phylloxera Boyer. Below is a key from Mordwilko to these genera.

1. Neither wingless females nor any other forms secreting any waxy material.

Phylloxera Boyer

- Wingless females secreting a waxy powder Phylloxerina Börner

\section{Genus Phylloxera Boyer}

Boyer de Fonscolmbe, Ann. Ent. Soc. France, vol. 3, p. 222, 1834. Type $P$. quercus Boyer.

\section{Phylloxera vitifoliae Fitch}

Fitch, Rept. Ins. N. Y., vol. 1, p. 58, 1855 (orig. desc.).

Planchon, C.-R. Acad. Sci. Paris, vol. 67, pp. 588-594, 1868. P. vastatrix (desc.).

Clarke, Can. Ent., vol. 35, p. 248, 1903. P. vastatrix Plan (list).

Davidson, Jour. Econ. Ent., vol. 2, p. 299, 1909. P. vastatrix Plan. (list).

Davidson, Jour. Econ. Ent., vol. 3, p. 372, 1910. P. vastatrix Plan. (list). Records.-Grape; Central and Northern California.

This is the only species of this genus reported in California. It is one of the most destructive species of plant lice in this section of the country, having in its time practically wiped out the grape industry of Santa Clara Valley, and of many other parts of the state. It seems that in California this species infests the roots only of the grape, the forms that produce the leaf galls in the eastern parts of the country not being found here. 


\section{Genus Phylloxerina Börner}

Börner, Arbeiter aus d. kais. biol. Anst. f. Land- und Forstwirtschaft, vol. $6, \mathrm{pp}$. $\mathrm{i}-\mathrm{v}, 81-320,1908$. Type Phylloxera salicis Linn.

This genus is represented in California by two species, one found on the stems of cottonwood (Populus sp.) and the other on the stems and exposed roots of willow (Salix sp.).

\section{Phylloxerina popularia (Pergande)}

Pergrande, Proc. Davenport Acad. Sci., vol. 9, p. 266, 1904. Phylloxera (orig. dese.).

Davidson, Jour. Eeon. Ent., vol. 8, p. 420, 1915. Phylloxera (list).

Records.-Populus spp.; Walnut Creek (Davidson), Merced (Beers).

The only report of this species in California is the one of Davidson who found it on Populus fremonti and Populus trichocarpa at Walnut Creek. On October 14, 1915, A. A. Bcers of Merced sent some specimens to the author from balm of Gilead (Populus balsamifera) in Mcrced. These were all apterous females, and were found in great masses of white wax on the smaller branches and twigs. These reports are the only ones since its original report from Texas and Louisiana by Pergande.

\section{Phylloxrina salicola (Pergande)}

Pergande, Proc. Davenport Acad. Sei., vol. 9, p. 267, 1904. Phylloxera (orig. dese.).

Davidson, Jour. Econ. Ent., vol. 8, p. 419, 1915. Phylloxera (list).

Records.-Salix spp.; Walnut Creek (Davidson); Pasadena (Smith).

This specics was also reported from Walnut Creek by Davidson on arroyo willow (Salix lasiolepis) where he found it on the stems and exposed roots. On October 13, 1915, A. G. Smith sent the author specimens from an ornamental willow (Salix sp.) in Pasadena, where he found it very abundantly that fall. The specimens were all apterous females, and wcre found in the midst of considerable masses of wax. This species has only been reported from Illinois, District of Columbia, and California. 


\title{
APPENDIX 1
}

\section{Keys to the Genera and Tribes of APHididaE}

BY

\author{
P. VAN DER GOOT, 1913
}

\section{Subfamily APHIDINAE}

1. Antennae seven-jointed (better six-jointed). The last true joint with a distinct, more delicate continuation (terminal process). This continuation almost as long as, or even much longer than the last segment; if shorter, the cauda is distinctly wart-shaped, and the number of rudinentary gonapophyses is always two. Cornicles almost always well formed and elearly projecting. Wings with twice-branched cubitus, only once-branched in exceptional cases

- Antennae mostly six-jointed, the last joint with a short projection, this being usually distinctly shorter than half the last segment. Cornicles scarcely projecting, very often only appearing as pores or entirely absent. Wings with a simple or once-branched cubitus .

5

2. Cauda wart-like, occasionally not so, or scarcely separated, but then the number of rudimentary gonapophyses is always distinctly two

3

- Cauda sickle-shaped or knobbed, not wart-like, only very seldom absent. Rudimentary gonapophyses always three

Siphonophorina

3. Cornicles very long, almost cylindrical. Rudimentary gonapophyses three.

Drepanosiphina

- Cornicles very short, somewhat clubbed. Rudimentary gonapophyses two or four

4. Number of rudimentary gonapophyses four. Body never with long clubbed hairs

Chaitophorina

- Number of rudimentary gonapophyses two. Body often with knobbed hairs. Tarsi always with two pulvillae [Haftlappchen] ............................Callipterina

5. Cauda wart-like .......................................................................................................... 6

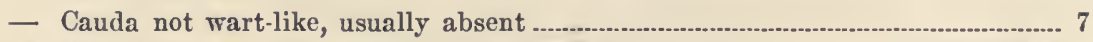

6. Anal plate bilobed. Sensoria of alate females linear ................Hormaphidina

- Anal plate simple. Sensoria of alate females circular ................... Vacunina p.p.

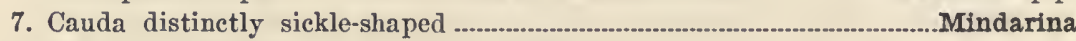

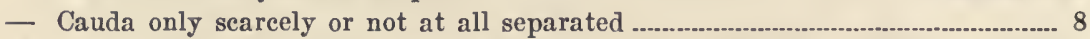

8. Antennae five-jointed. Cornicles very short, only slightly projecting. Body

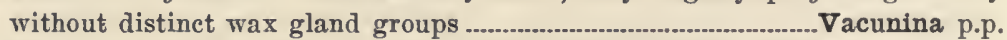

- Antennae six-jointed, those of the apterous forms often only four- or fivejointed. Cornicles often only pores or entirely lacking. Body often with wax gland

9. Body with long, mostly fine hairs; without distinctly facetted wax gland plates. Primary sensoria almost always, without hairy edges ........................10

- Body naked; very often with distinctly facetted wax-gland plates. Primary sensoria often with hairy edges.

10. Rudimentary gonapophyses three. Wings mostly with twice-branched cubitus. Cornicles always prominent

Lachnina

- Rudimentary gonapophyses none. Wings with simple or once-branched cubitus. Cornicles often absent..

Anoeciina 
11. Rudimentary gonapophyses three. Facets of wax-gland plates almost equalsized. Wings with simple cubitus. Sensoria of alate forms long oval, not linear

Pemphigina

- Rudimentary gonapophyses none. Wax gland plates always with at least one large central facet. Sensoria of alate forms linear. Wings with simple or once-branched cubitus

Schizoneurina

\section{Subfamily CHERMISINAE}

1. Rudimentary gonapophyses appearing as three short cones. Wax glands almost always present Chermisina

- Rudimentary gonapophyses seemingly lacking. Wax glands mostly absent.

Phylloxerina

\section{Group SIPHONOPHORINA}

1. Apterous forms with a few sensoria on the third antennal segment. Antennal tubercles usually well formed. Body almost never with lateral tubercles, in any case these are never formed on the seventh abdominal segment .... 2

- Apterous forms without sensoria on the third antennal segment. Antennal tubercles often small or absent. Body with lateral tubereles ....................... 4

2. Cornicles almost cylindrical, or rarely somewhat swollen on the side, but then the body is covered with eapitate hairs

- Cornicles distinctly clavate. Body almost bare, never with eapitate hairs.

Type Amphorophora ampullata Buckton.

Rhopalosiphum Koch

3. Body of apterous forms with long eapitate hairs. First antennal joint drawn out, somewhat tooth-shaped on the inner side ...-.......Myzus Passerini

Type Aphis ribis Linn.

- Body of apterous forms bare or without eapitate hairs. First antennal joint never drawn out, tooth-like.

Macrosiphum Passerini

Type Aphis millifolii Fabr.

4. Body of apterous forms with capitate hairs. First antennal joint more or less toothed on inner side

Capitophorus n.gn.

Type Phorodon carduinum Walker.

- Body of apterous forms without capitate hairs. First antennal joint not toothed

5. Body with many long delicate hairs. Cornicles short, somewhat swollen.

Type Aphis populea Kalt.

Cladobius (Koch.) Pass.

- Body bare or almost so 6

6. Cornicles almost as long or longer than cauda ........................................................ 7

- Cornicles much shorter than cauda .........................................................................16

7. Cornicles always distinetly elavate Type Aphis avenae Fabr.

Siphocoryne Pass.

- Cornicles cylindrical or conical 8

8. Antennal tubercles well formed, very distinctly toothed on the inner side. Tubereles on the side of the body always absent.

9

- Antennal tubereles mostly' small or lacking, never distinctly toothed. Body often with lateral tubercles.

9. Antennal tubercles very strongly toothed, the first joint being distinctly toothed on the inner side

Phorodon Pass.

Type Aphis humuli Schr.

- Antennal tubercles only slightly toothed, first antennal joint being rounded or flat on the inner side, never toothed

Type Ovatus mespili v. d. G.

Ovatus n.gn. 
10. Antennal tubercles well formed, strongly rounded on the inner side.

Type Aphis cerasi Fabr.

Myzoides n.gn.

- Antennal tubercles small or lacking, never drawn out distinctly on inner side

11. Body with small tubereles on the middle of the seventh and eighth abdominal segments, and often also on the head and prothorax

Dentatus n.gn.

Type Aphis sorbi Kalt.

- Body without tubercles on the middle of the seventh and eighth abdominal segments

12. Cubitus of fore wing only once-branched

Toxoptera Koch

Type Toxoptera graminum (Rond.).

- Cubitus of fore wing always twice-branched. Body often with lateral tuber. cles

13. Cornicles short, always distinctly conical. Cauda very short, broad with rounded-tip, usually approximately the length of the cornicles, or entirely lacking. Lateral tubercles lacking or only indistinctly formed on the an. terior abdominal segments

- Cornicles long, almost cylindrical. Cauda sickle- or club-shaped, usually distinctly shorter than cornicles

14. Body long without lateral tubercles. Front often with a very distinct tubercle in the middle

Myzaphis n.gn.

Type Aphis rosarum Walker.

- Body more rounded, with lateral tubercles. Front usually flat, never with a distinct tubercle

Aphis Linn.

Type Aphis rumicis Linn.

15. Cauda distinctly separated, almost as long as broad

Brachycaudus n.gn.

Type Aphis myosotidis Koch.

(A phis cardui Linn. belongs in this genus.)

- Cauda lacking or searcely separated, much shorter than broad....Acaudus n.gn. Type Aphis lychnidis Linn.

16. Cornicles distinctly longer than broad. Cauda usually not conical .17

- Cornicles extremely short, scarcely projecting, cylindrical, usually nearly as long as broad. Cauda always conical with broad base

17. Cornicles only a little longer than broad, distinctly conical. Cauda sickle- or club-shaped Longicaudis n.gn.

-Type Hyalopterus trirhodus (Walker).

- Cornicles cylindrical, at least twice as long as broad

18. Body with lateral tubercles on first and seventh abdominal segments. Cauda small, club-shaped

Hyalopterus Koch

Type Aphis pruni Fabr.

- Body without lateral tubercles on first and seventh abdominal segments. Cauda conical

Semiaphis n.gn.

Type Aphis carotae Koch.

19. Body long, without lateral tubercles. Antennae short, at the most about half the length of the body Brachycolus Buckton

Type Brachycolus stellariae (Hardy).

- Body oval with lateral tubercles on prothorax, first and seventh abdominal segments. Antennae at least about three-fourths as long as the body.

Type Aphis thalictri Koch.

Brachysiphum n.gn.

\section{Group Drepanosiphina}

Genus Drepanosiphum Koch. Type Drepanosiphum platanoides Schrank. 


\section{Group Callipterina}

1. Antennae six-jointed. Cornicles merely pores. Body always with wax glands

Phyllaphis Koch

Type Phyllaphis fagi (Linn.).

- Antennae seven-jointed, the terminal process at least one-half as long as the preceding joint. Cornicles always distinctly projecting. Body almost always without wax glands, these always of similar shape .........-...-..--...... 2

2. Seventh antennal joint distinctly longer than sixth ............................................ 3

- Seventh antennal joint only as long as, or shorter than sixth ........................... 6

3. Cornicles but slightly projecting. Antennae curved as in beetles.

Type Bradyaphis antennata (Kalt.).

Bradyaphis Mord.

- Cornicles distinctly prominent. Antennae straight 4

4. Anal plate only slightly emarginate, never bilobed. Body with tolerably stiff hairs, these are never capitate. Apterous forms always with sensoria on third antennal joint Callipterinella n.gn.

Type Callipterus betularius Kalt.

- Anal plate distinctly bilobed. Body bare or with eapitate hairs 5

5. Apterous forms without sensoria on third antennal joint. The body always with capitate hairs

Callipterus Koch

Type Callipterus coryli (Goetze).

- Apterous forms with a few sensoria on third antennal joint. Body with distinet tubereles

Tuberculatus Mord.

Type Tuberculatus betulicolus (Kalt.).

6. Anal plate distinctly bilobed 8

- Anal plate always simple .................................................................................. 7

7. Cauda wart-like, distinctly separated from base. Apterous forms without sensoria on third antennal joint

Type Callipterus betulae Koch.

- Cauda searcely visible. Sensoria present on third antennal joint of apterous forms

Symydobius Mord.

Type Symydobius oblongus (Heyden).

8. Seventh antennal joint nearly as long as the sixth. Wings with only very small black spots at the tip of the veins

Type Callipterus alni (Fabr.).

- Seventh antennal joint nearly half as long as sixth. Wings black spotted.

Type Pterocallis tiliae (Linn.).

Pterocallis Pass.

\section{Group Chaitophorina}

1. Body with long delicate hairs. Antennae seven-jointed. Cornicles well developed

2

- Body with short thorn-like hairs. Antennae six-jointed, the terminal process always distinetly longer than the preceding joint. Cornicles only slightly projecting Sipha Passerini

Type Sipha glyceriae (Kalt.).

2. Tarsi with two "Haftläppchen" [i.e., the empodial hair is spatula-like].

Type Chaitophorus testudinatus (Thornton).

Chaitophorinella n.gn.

— Tarsi without "Haftläppchen" [i.e. the empodial hair is bristle-like].

Type Chaitophorus leucomelas Koch.

Chaitophorus Koch 


\section{Group LACHNINA}

1. Wings usually with twice-branched cubitus, the radius always straight. Cauda not at all or only slightly separated Lachnus Ill.

Type Lachnus juniperi De Geer.

- Wings with onee- or twice-branchel cubitus and with a eurved radius; the membrane usually with dusky markings. Cauda usually slightly separated ..... 2

2. Beak distinetly longer than the body, strongly retraetile. Cubitus but oncebranched, the wings only slightly darkened

Stomaphis Buckton

Type Stomaphis quercus (Linn.).

- Beak clearly shorter than body and only slightly retractile. Wings beautifully spotted with dark brown ....................................................................................... 3

3. Cubitus twice-branched ................................................................ Dryobius Koeh

Type Dryobius croaticus Koeh.

- Cubitus once-branched Schizodryobius n.gn.

Type Lachnus exsiccator Hart.

\section{Tribe ANOECIINA}

1. Hind tarsi elongate Trama Heyden

Type Trama radicis Koch.

- Hind tarsi not elongate. 2

2. Cubitus onee-branched. Cornicles present, quite prominent. Margin of body with peculiar non-faceted "wax-gland" (?) plates

Anoecia Koeh Type Anoecia corni (Fabr.).

- Cubitus not branched. Cornicles absent. Wax gland plates not present.

Type Tullgrenia phaseoli (Pass.).

Tullgrenia v. d. G.

\section{Tribe HORMAPHIDINA}

1. Antennae always five-segmented. The fronds almost without exception with two little horns. Cubitus once branched Cerataphis Licht.

Type C. lataniae Boisd.

- Antennae of the apterae often only three-segmented. Fronds without protuberances. Cubitus simple

Hamamelistes Schim.

Type $\boldsymbol{H}$. betulae Mordw. 


\title{
APPENDIX 2
}

\author{
Host Plant List of California APHididae ${ }^{35}$ \\ Abies (fir) \\ 45. Lachnus ferrisi Swain \\ 47. Lachnus occidentalis Dvdn. \\ 176. Mindarus abietinus Koch \\ Abutilon (Indian mallow) \\ 146. Aphis senecio Swain \\ 104. Rhopalosiphum persicae (Sulz.) \\ Acer (maple, box elder) \\ 5. Drepanaphis acerifolii (Thomas) \\ 4. Drepanosiphum platanoides (Schrank) \\ 33. Thomasia negundinis (Thomas) \\ Achillea (yarrow) \\ 79. Macrosiphum solanifolii (Ashmead) \\ Aegopodium (goutweed) \\ 108. Siphocoryne capreae (Fabr.) \\ Aesculus (California buckeye) \\ 88. Myzus circumflexus (Buckton) \\ 171. Prociphilus venafuscus Pateh \\ Alder, see Alnus \\ Alfalfa, see Medicago \\ Alfilerilla, see Erodium \\ Alisma (water plantain) \\ 156. Siphocoryne nymphaeae (Linn.)
}

Almond, see Prunus

Alnus (Alder)

9. Eucallipterus flava (Davidson)

8. Euceraphis gillettei Davidson

11. Myzocallis alnifoliae (Fiteh)

Alopecurus (foxtail)

68. Macrosiphum granarium (Kirby)

88. Myzus circumflexus (Buekton)

Althaea (hollyhock)

121. Aphis euonomi Fabr.

Alum root, see Heuchera

35 In the following list only the generie and common names of the plants are employed, the various speeies of plants being omitted. Although in eertain eases aphids are restricted to certain species, as Eriosoma languinosa Hartig on Pyrus communis but not on Pyrus malus, these are in the minority. The botanical names are taken from the following works, with preference as in the order listed:

Bailey, L. H., Standard eyelopedia of hortieulture, vols. 1-6, New York, Maemillan, 1914-1917.

Robinson, B. L., and Fernald, M. L., Gray's New manual of botany, ed. 7, Cambridge, Harvard University, 1908.

Jepson, W. L., A fora of western middle California, ed. 2, San Franeisco, Cunningham, 1911.

Abrams, LeRoy, Flora of Los Angeles and vieinity, Palo Alto, Stanford University Press, 1904. 
Amaranthus (pigweed)

123. Aphis gossypii Glover

132. Aphis middletonii Thomas

104. Rhopalosiphum persicae (Sulz)

163. Trifidaphis radicicola (Essig)

Ambrosia (ragweed)

146. Aphis scnecio Swain

77. Macrosiphum rudbeckiae (Fitch)

Ampelodesma

68. Macrosiphum granarium (Kirby)

Amsinckia (ansinckia)

146. Aphis senccio Swain

104. Rhopalosiphum pcrsicae (Sulz.)

Angclica (angelica)

109. Aphis angclicae Koch

115. Aphis cari Essig

108. Siphocoryne capreae (Fabr.)

Anise, Wild, see Carum

Anthemis (chamomile)

121. Aphis euonomi Fabr.

146. Aphis senecio Swain

123. Aphis gossypii Glover

Apple, see Pyrus

Apricot, see Prunus

Aquilegia (columbine)

85. Myzus aquilegiae Essig

Arbor vitae, see Thuja sp.

Arbutus (madroñe, strawberry tree)

103. Rhopalosiphum nervatum Gillette

Arctostaphylos (manzanita)

1. Phyllaphis coweni (Cockerell)

103. Rhopalosiphum nervatum Gillette

Artemisia (sagebrush, oldman, California mugwort, etc.)

122. Aphis frigidae Oestlund

131. Aphis medicaginis Koch

137. Aphis oregonensis Wilson

146. Aphis senecio Swain

61. Macrosiphum artemisiae (Fonsc.)

62. Macrosiphum artemisicola (Williams)

72. Macrosiphum ludovicianiae (Oestlund)

Artichoke, see Cynara

Arundinaria (bamboo)

12. Myzocallis arundicolens (Clarke)

13. Myzocallis arundinariae Essig

Arundo (giant reed)

12. Myzocallis arundicolcns (Clarke)

13. Myzocallis amendinariae Essig

Asclcpias (milkweed)

123. A phis gossypii Glover

135. Aphis nerii Fonsc.

102. Rhopalosiphum lactucae (Kalt.) 
Ash, see Fraxinus

Arparagus (asparagus, smilax, asparagus fern)

123. Aphis gossypii Glover

88. Myzus circumflexus (Buckton)

Aster (aster)

132. Aphis middletonii Thomas

146. Aphis senccio Swain

Astragalus (loco weed)

131. Aphis medicaginis Koch

Atriplex (orache)

147. Aphis tetrapteralis Cockerell

79. Macrosiphum solanifolii (Ashmead)

Avocado, see Persea

Avena (oats)

111. Aphis avenae Fabr.

68. Macrosiphum granarium (Kirby)

105. Rhopalosiphum rhois Monell

Baccharis (groundsel)

146. Aphis senecio Swain

63. Macrosiphum baccharadis (Clarke)

77. Macrosiphum mudbeckiae (Fitch)

104. Rhopalosiphum persicae (Sulz.)

Bamboo, see Arundinaria, Bambusa, and Phyllostachys

Bambusa (bamboo)

12. Myzocallis arundicolens (Clarke)

Banana, see Musa

Barberry, see Berberis

Barley, see Hordeum

Basswood, see Tilia

Bean, see Phaseolus

Bean, Blackeye, see Vigna

Bean, Broad, see Vicia

Beech, see Fagus

Beet, see Beta

Begonia (begonia)

123. Aphis gossypii Glover

Bell, fairy, see Dipsorum

Berberis (barberry)

154. Liosomaphis berberidis (Kalt.)

Beta. (beet, sugarbeet)

124. Aphis gossypii Glover

164. Pemphigus betae Doane

Betula (birch)

6. Calaphis betulaecolens (Fitch)

27. Callipterinella annulata (Koch)

7. Euceraphis betulae (Koch)

Birch, see Bctula

Blackberry, see Rubus

Bougainvillea (bougainvillea)

104. Rhopalosiphum persicae (Sulz.)

Boxelder, see Acer 
Brassica (eabbage, mustard, turnip, etc.)

112. Aplis brassicae Linn.

144. Aphis pseudobrassicae Davis

166. Pemphigus populi-transversus Riley ( 8 )

102. Rhopalosiphum lactucae (Kalt.)

104. Rhopalosip7um persicae (Sulz.)

Broom, see Cytisus

Buckeye, California, see Aesculus

Buckton, see Rhamnus

Bur clover, see Medicago

Buttereup, see Ranunculus

Cabbage, see Brassica

Calendula (marigold)

113. Aphis calendulicola Monell

121. Aptis euonomi Fabr.

146. Aphis senecio Swain

California buckeye, see Aesculus

California holly, see Heteromeles

California mugwort, see Artemesia

California poppy, see Eschscholtzia

California sagebrush, see Artemisia

California tule, see Typha

Calla, see Zantcdeschia

Camellia (camellia)

152. Toxoptera aurantii (Fonsc.)

Canary grass, see Phalaris

Cantaloupe, see Cucumis

Capsella (shepard's purse)

112. Aphis brassicae Linn.

123. Aphis gossypii Glover

141. Aphis pseudobrassicae Davis

104. Rhopalosiplum persicae (Sulz.)

Capsicum (pepper pimento)

104. Rhopalosiphum persicae (Sulz.)

Caragana (pea tree)

131. Apluis medicaginis Koch."

Carum (wild anise)

115. Aphis cari Essig

155. Siphocoryne capreae (Fabr.)

Castanea (chestnut)

15. Myzocallis castanicola Baker (davidsoni Swain)

Catalpa (catalpa)

123. Aphis gossypii Glover

139. Aplis pomi de Geer

104. Rhopalosiphum persicae (Sulz.)

Carliflower, see Brassica

Ceanothus (mountain lilac)

116. Aphis ceanothi Clarke

Centaurea (tacalote)

130. Aphis marutae Oestlund

Centranthus (red valerian)

76. Macrosiphura rosae (Linn.)

104. Rhopalosiplum persicae (Sulz.) 


\section{Chaerophyllum}

155. Siphocoryne capreae (Fabr.)

Chamomile, see Anthemis

Chaparral broom, see Baccharis

Charlock, see Brassica

Cheeseweed, see Malva

Cheiranthus (wallflower)

88. Myzus circumflexus (Buckton)

Chenopodium (lamb's-quarters, pigweed)

110. Aphis atriplicis Linn.

123. Aphis gossypii Glover

124. Aphis hederae Kalt. (?)

164. Pemphigus betae Doane (?)

104. Rhopalosiphum persicae (Sulz.)

Cherry, see Prunus

Cherry, wild, see Prunus

Chestnut, see Castanea

Chestnut, Horse, see Aesculus

Chieory, see Chicorium

Christmas berry, see Heteromeles

Chrysanthemum (chrysanthemum)

56. Amphorophora latysiphon Davidson

123. Aphis gossypii Glover

146. Aphis senecio Swain

160. Coloradoa rufomaculata Wilson

77. Macrosiphum rudbeckiae (Fitch)

78. Macrosiphum sanborni Gillette

Cichorium (chicory)

71. Macrosiphum lactucae (Kalt.)

Cicuta (water hemlock)

155. Siphocoryne capreae (Fabr.)

Cirsium (thistle)

144. Aphis cardui Linn.

Citrullus (watermelon)

123. Aphis gossypii Glover

Citrus (citrus, orange, lemon, etc.)

118. Aphis cooki Essig

123. Aphis gossypii Glover

131. Aphis medicaginis Koch

79. Macrosiphum solanifolii (Ashmead)

104. Rhopalosiphum persicae (Sulz.)

152. Toxoptera aurantii (Fonsc.)

Clarkia (clarkia)

104. Rhopalosiphum persicae (Sulz.)

Clematis (clematis)

94. Myzus varians Davidson

Clover, see Trifolium

Clover, Sweet, see Melilotus

Coffecberry, see Rhamnus

Columbine, see Aquilegia

Compositae (various species)

131. Aphis medicaginis Koch

65. Macrosiphum chrysanthemi (Oestlund)

77. Macrosiphum rudbeckiae (Fitch) 
Conium (poison hemlock)

159. Siphocoryne pastinacae (Linn.)

Convolvulus (morning glory)

56. Amphorophora latysiphon Davidson

123. Aphus gossypii Glover

72. Macrosiphum ludovicianae (Oestlund)

Corn, see Zea

Cormus (dogwood)

119. Aphis cornifoliae Fiteh

123. Aphis gossypii Glover

Corylus (hazelnut)

16. Myzocallis coryli (Goetze)

100. Rhopalosiphum corylinum Davidson

Cotoneaster (cotoneaster)

139. Aphis pomi de Geer

Cotton, see Gossypium

Cottonwood, see Populus

Cow parsnip, see Heracleum

Cowpea, see Vigna

Cowslip, see Primula

Crab apple, see Pyrus

Cranesbill, see Geranium

Crataegus (hawthorn)

120. Aphis crataegifoliae Fitch

139. Aphis pomi de Geer

Cruciferae (various spp.)

112. Aphis brassicae Linn.

111. Aphis pseudobrassicae Davis

Cucumber, see Cucumis

Cucumis (cucumber, muskmelon, cantaloupe, etc.)

123. Aphis gossypii Glover

Cucurbita (squash, gourd, pumpkin, etc.)

123. Aphis gossypii Glover

66. Macrosiphum cucurbitae (Thomas)

Cupressus (cypress)

161. Cerosipha cupressi Swain

96. Macrosiphum morrisoni Swain

Currant, see Ribes

Cydonia (quince)

139. Aphis pomi De Geer

Cynara (artichoke)

86. Myzus braggii Gillette

Cynoglossum (houndstongue)

104. Rhopalosiphum persicae (Sulz.)

Cypress, see Cupressus

Cyrtomium (holly fern)

162. Cerataphis lataniae (Boisd.)

58. Idiopterus nephrelepidis Davis

88. Myzus circumflexus (Buckton)

Cytisus (broom)

146. Aphis senecio Swain

104. Rhopalosiphum persicae (Sulz.) 
Dandelion, see Taraxacum

Datura (jimson weed)

123. Aphis gossypii Glover

Deinandra

79. Macrosiphum solanifolii (Ashmead)

Digitalis (foxglove)

88. Myzus circumflexus (Buckton)

Dipsacus (fuller's teasel)

76. Macrosiphum rosae (Linn.)

77. Macrosiphum rudbeckiae (Fitch)

104. Rhopalosiphum persicae (Sulz.)

Disporum (fairy bell)

79. Macrosiphum solanifolii (Ashmead)

Dock, see Rumex

Dogwood, see Cornus

Douglas fir, see Pseudotsuga

Dracaena (dragon tree)

111. Aphis avenae Fabr.

Dragon tree, see Dracaena

Eldesberry, see Sambucus

Elm, see Ulmus

Elymus (wild rye)

68. Macrosiphum granarium (Kirby)

English ivy, see Hedera

Epilobium (fireweed)

136. Aphis oenotherae Oestlund

Eriobotrya (loquat)

139. Aphis pomi de Geer

Erodium (alfilerilla)

79. Macrosiphum solanifolii (Ashmead)

104. Rhopalosiphum persicae (Sulz.)

Erysimum (western wallflower)

155. Siphocoryne capreae (Fabr.)

Escallonia (escallonia)

104. Rhopalosiphum persicae (Sulz.)

Fschscholtzia (California poppy)

123. Aphis gossypii Glover

Everlasting, see Gnaphalium

Fagus (beech)

2. Phyllaphis fagi (Linn.)

Fairybell, see Dipsorum

Fennel, see Foeniculum

Fenugreek, see Trigonella

Fern, asparagus, see Asparagus

Fern, Boston, see Nephrolepis

Fern, holly, see Cyrtomium

Fig marigold, see Mesembryanthemum

Figwort, see Scrophularia

Fir, see Abies

Fir, Douglas, see Pseudotsuga

Fireweed, see Epilobium

Foeniculum (fennel)

155. Siphocoryne capreae (Fabr.) 
Foxglove, see Digitalis

Foxtail, see Alopecurus

Fragaria (strawberry)

90. Myzus fragaefolii Cockerell

Fraxinus (ash)

171. Prociphilus venafuscus Patch

167. Thecabius californicus (Davidson)

Fuller's teasel, see Dipsacus

Fuchsia (fuchsia)

79. Macrosiphum solanifolii (Ashmead)

88. Myzus circumflexus (Buckton)

Gambleweed, see Sanicula

Geranium, see Pelargonium

Geranium (cranesbill)

104. Rhopalosiphum persicae (Sulz.)

German ivy, see Senecio

Gladiolus (gladiolus)

88. Myzus circumflexus (Buckton)

Glycyrrhiza (liquorice)

131. Aphis medicaginis Koch

Gnaphalium (everlasting)

146. Aphis senecio Swain

60. Macrosiphum ambrosiae (Thomas)

Gooseberry, see Ribes

Goosefoot, see Chenopodium

Gossypium (cotton)

123. Aphis gossypii Glover

Gourd, see Cucurbita

Goutweed, see Aegopodium

Graminaceae (various species)

111. Aphis avenae Fabr.

67. Macrosiphum dirhodum (Walker)

68. Macrosiphum granarium (Kirby)

105. Rhopalosiphum rhois Monell

Grape, see Vitis

Grindelia (marsh grindelia)

146. Aphis senecio Swain

Hawthorn, see Crataegus

Hazelnut, see Corylus

Hedera (English ivy)

109. Aphis angelicae Koch

124. Aphis hederae Kalt

104. Rhopalosiphum persicae (Sulz.)

Hedge mustard, see sisymbrium

Hedge nettle, see Stachys

Helianthus (sunflower)

123. Aphis gossypii Glover

132. Aphis middletonii Thomas

146. Aphis senecio Swain

60. Macrosipkum ambrosiae (Thomas)

77. Macrosiphum mubeckiae (Fitch)

104. Rhopalosiphum persicae (Sulz.) 
Hemlock, Poison, see Conium

Hemlock, Water, see Cicuta

Heracleum (cow parsnip)

123. Aphis gossypii Glover

125. Aphis heraclei Cowen

Heteromeles (California holly, Christmas berry)

170. Prociphilus alnifoliae (Williams)

103. Rhopalosiphum nervatum Gillette

Heuchera (alum root)

69. Macrosiphum heucherae (Thomas)

Hibiscus (rose mallow)

121. Aphis euonomi Fabr.

Holly fern, see Cyrtonium

Hollyhoek, see Althaea

Holly, mountain, see Heteromeles

Honey flower, see Melianthus

Honeysuckle, see Lonicera

Hop, see Humulus

Hordeum (barley)

111. Aphis avenae Fabr.

68. Macrosiphum granarium (Kirby)

Houndstongue, see Cynoglossum

Humulus (hop)

123. Aphis gossypii Glover

98. Phorodon humuli (Schrank)

Hydrangea (hydrangea)

123. Aphis gossypii Glover

Indian mallow, see Abutilon

Ironweed, see Veronina

Ivy, Engislh, see Hedera

Ivy, German, see Senecio

Jasminum (jessamine)

70. Macrosiphum jasmini (Clarke)

Jessamine, see Jasminum

Jimpson weed, see Datura

Juglans (walnut)

24. Callipterus californicus (Essig)

25. Callipterus caryae Monell

23. Chromaphis juglandicola (Kalt.)

26. Monellia caryella (Fitch)

Knotweed, see Polygonum

Lactuca (lettuce)

79. Macrosiphum solanifolii (Ashmead)

Lamb's-quarters, see Chenopodium

Lathyrus (sweet pea)

74. Macrosiphum pisi (Kalt.)

Laurel, see Laurus

Laurel, California, see Umbellularia

Laurestinus, see Viburnum

Laurus (laurel)

150. Aphis viburnicolens n.sp. 
Lavatcra (tree mallow)

104. Rhopalosiphum persicae (Sulz.)

Leather root, see Psorales

Lemon, see Citrus

Lcpidium (peppergrass)

123. Aphis gossypii Glover

Let:uce, see Lactuca

Ligusticum (lovage)

155. Siphocorync capreae (Fabr.)

Lilac, see Syringa

Lilac, Mountain, see Ceanothus

Lilium (lily)

123. Aphis gossypii Glover

88. Myzus circumflexus (Buckton)

Lily, see Lilium

Lily, Water, see Nymphaea

Linden, see Tilia

Liquorice, see Glycyrriza

Liriodendron (tulip tree)

104. Rhopalosiphum persicae (Sulz.)

Lithospermum

127. Aphis lithospermi Wilson

Loco weed, see Astragalus

Locust, see Robinia

Loganberry, see Rubus

Lonicera (honeysuckle)

157. Siphocoryne pastinacae (Linn.)

Loquat, see Eriobotrya

Lovage, see Ligusticum

Lupinus (lupine)

59. Macrosiphum albifrons Essig

Lycopersicum (tomato)

91. Myzus lycopersicae (Clarke)

104. Rhopalosiphum persicae (Sulz.)

Madia (tarweed)

77a. Mlacrosiphum rudbeckiae "Fitch) var. madia n.var.

Madron, see Arbutus

Mallow, Indian, see Abutilon

Mallow, Rose, see Hibiscus

Mallow tree, see Lavatera

Malva (cheeseweed)

121. Aphis euonomi Fabr.

123. Aphis gossypii Glover

104. Rhopalosiphum persicae (Sulz.)

Manzanita, see Arctostaphylos

Maple, see Acer

Marigold, see Calendula

Marigold, fig, see Mescmbryanthcmum

Matthiola (ten-weeks' stock)

141. Aphis pseudobrassicae Davis

Mayten, see Maytenus

Maytenus (mayten)

121. Aphis euonomi Fabr. 
Medicago (alfalfa, bur clover, etc.)

131. Aphis medicaginis Koch

74. Macrosiphum pisi (Kalt.)

Melianthus (honey flower)

104. Rhopalosiphum persicae (Sulz.)

Melilotus (sweet clover)

131. Aphis medicaginis Koch

Mesembryanthemum (fig marigold)

121. Aphis euonomi Fabr.

Milk thistle, see Silybum

Milkweed, see Asclepias

Morning glory, see Convolvulus

Morus (mulberry)

133. Aphis mori Clarke

Mountain holly, see Heteromeles

Mountain lilac, see Ceanothus

Mugwort, California, see Artemisia

Mulberry, see Morus

Musa (banana)

111. Aphis avenae Fabr.

Muskmelon, see Cucumis

Mustard, see Brassica

Mustard, Hedge, see Sisymbrium

Mustard, Teasel, see Erysimum

Nasturtium, see Tropaeolum

Nectarine, see Prunus

Nephrolepis (Boston fern)

58. Idiopterus nephrelepidis Davis

Nerium (oleander)

135. Aphis nerii Fonse.

Nettle, Hedge, see Stachys

Nettle, Stinging, see Urtica

Nightshade, see Solanum

Ninebark, see Physocarpus

Nymphaea (water lily)

123. Aphis gossypii Glover

156. Siphocoryne nymphaeae (Linn.)

Oak, see Quercus

Oak, Poison, see Rhus

Oak, Tanbark, see Pasania

Oats, see Avena

Oenothera (evening primrose)

136. Aphis oenotherae Oestlund

Oldman, see Artemisia

Oleander, see Nerium

Orange, see Citrus

Orache, see Atriplex

Orchidaceae (orchids)

162. Cerataphis lataniae (Boisd.)

Orthocarpus (owl clover)

73. Macrosiphum orthocarpi Davidson

Owl clover, see Orthocarpus 
Oxalis (oxalis)

97. Macrosiphum solanifolii (Ashmead)

104. Rhopalosiphum persicae (Sulz.)

152. Toxoptera aurantii (Fonse.)

Pansy, see Viola

Papaver (poppy)

121. Aphis euonomi Fabr. (papaveris Fabr. \$)

Parsley, see Petroselinum

Parsnip, see Pastinaca

Parsnip, Cow, see Heracleum

Pasania (tanbark oak)

20. Myzocallis pasaniae Davidson

Pastinaca (parsnip)

156. Siphocoryne pastinacae (Linn.)

Pea, see Pisum

Pea, Cow, see Vigna

Pea, Sweet, see Lathyrus

Pea tree, see Caragona

Peach, see Prunus

Pear, see Pyrus

Pelargonium (geranium)

97. Pentalonia nigronervosa Coquellet

104. Rhopalosiphum persicae (Sulz.)

Pentstemon (pentstemon)

88. Myzus circumflexus (Buckton)

104. Rhopalosiphum persicae (Sulz.)

Pepper, see Capsicum

Peppergrass, see Lepidium

Periwinkle, see Vinca

Persea (avacado)

123. Aphs gossypii Glover

Petroselinum (parsley)

155. Siphocoryne capreae (Fabr.)

Phalaris (canary grass)

111. Aphis avenae Fabr.

153. Hyalopterus arundinis (Fabr.)

Phaseolus (bean)

121. Aphis cuonomi Fabr. (rumicis Linn.?)

131. Aphis medicaginis Koch

74. Macrosiphum pisi (Kalt.)

Phragmites (reed grass)

153. Hyalopterus arundinis (Fabr.)

Phyllostachys (bamboo)

12. Myzocallis arundicolens (Clarke)

Physocarpus (ninebark)

100. Rhopalosiphum corylinum Davidson

Picea (spruce)

46. Lachnus glehnus Essig

55. Lachnus vanduzei n.sp.

158. Myzaphis abietina (Walker)

Pigweed, see Amaranthus, and Chenopodium

Pimento, see Capsicum 


\section{Pimpinella}

155. Siphocoryne capreae (Fabr.)

Pine, see Pinus

Pinus (pine)

178. Chcrmes cooleyi Gillette

179. Chermes pinicorticis Fitch

43. Essigella californica (Essig)

45. Lachnus ferrisi Swain

48. Lachnus oregonensis Wilson

49. Lachnus pini-radiatae Davidson

50. Lachnus ponderosa Williams

52. Lachnus sabinianus n.sp.

53a. Lachnus tomentosa (De Geer) (Addenda)

176. Mindarus abietinus Koch

Pisum (pea)

74. Macrosiphum pisi (Kalt.)

Pittosporum (pittosporum)

139. Aphis pomi De Geer

79. Macrosiphum solanifolii (Ashmead)

104. Rhopalosiphum persicae (Sulz.)

Plantago (plantain)

123. Aphis gossypii Glover

129. Aphis malifoliae Fitch ( ( )

88. Myzus circumflexus (Buckton)

Plantain, see Plantago

Plantain, Water, see Alisma

Platanus (western sycamore)

4. Drepanosiphum platanoides (Schrank)

Plum, see Prunus

Polygonum (knotweed)

100. Rhopalosiphum hippophaes (Koch).

156. Siphocorync nymphaeae (Linn.)

Pomegranate, see Punica

Pondweed, see Potamogeton

Poplar, see Populus

Poppy, see Papaver

Poppy, California, see Eschscholtzia

Populus (poplar, cottonwood)

28. Arctaphis populifolii (Essig)

164. Pemphigus betae Doane

165. Pemphigus populi-caulis Fiteh

166. Pcmphigus populi-transvcrsus Riley

181. Phylloxerina popnlaria (Pergande)

40. Ptcrocomma populifoliae (Fitch)

167. Thecabius californicus (Davidson)

168. Thecabius populiconduplifolius (Cowen)

169. Thecabius populi-monilis (Riley)

34. Thomasia populicola (Thomas)

35. Thomasia salicola (Essig)

Potamogeton (pondweed)

156. Siphocoryne nymphaeae (Linn.)

Potato, see Solarum 
Primrose, Evening, see Oenothera

Primula (cowslip)

56. Amphorophora latysiphon Davidson

Prune, see Prunus

Prunus (almond, apricot, cherry, nectarine, peach, plum, prune)

107. Aphis alamedensis Clarke

114. Aphis cardui Linn.

117. Aphis cerasifoliae Fitch

138. Aphis persicae-niger Sinith

140. Aphis prunorum Dobr.

153. Hyalopterus arundinis (Fabr.

87. MIyzus cerasi (Fabr.)

98. Phorodon humuli (Schrank)

104. Rhopalosiphum persicae (Sulz.)

156. Siphocoryne nymphaeae (Linn.)

Pseudotsuga (Douglas fir)

178. Chermes cooleyi Gillette

43. Essigella californica (Essig)

51. Lachnus pseudotsuga Wilson

53. Lachnus taxifolia Swain

171. Prociphilus venafuscus Patch

Psorales (leather root)

74. Macrosiphum pisi (Kalt.)

Pteris (brake)

75. Macrosiphum pteridis Wilson

Punica (pomegranate)

123. Aphis gossypii Glover

Pumpkin, see Cucurbita

Pyrus (apple, pear)

123. Aphis gossypii Glover

129. Aphis malifoliae Fitch

139. Aphis pomi De Geer

175. Eriosoma languinosa Hartig (pyricola B. \& D.)

174. Eriosoma lanigerum (Hausman)

Quercus (oak)

5. Drepanaphis acerifolii (Fitch) (?)

14. BIyzocallis bellus (Walsh)

15. Myzocallis castanicola Baker (davidsoni Swain)

17. Myzocallis discolor (Monell)

18. Myzocallis punctatus (Monell)

19. Myzocallis californicus Baker (maureri Swain)

21. Myzocallis quercus (Kalt.)

3. Phyllaphis quercicola Baker

36. Symydobius agrifoliae Essig

37. Symydobius chrysolepis Swain

177. Vacuna dryophila Sehrank (?)

Quince, see Cydonia

Radish, see Raphanus

Ragweed, see Ambrosia

Ramona (black sage)

142. Aphis ramona Swain 
Ranunculus (buttercup)

132. Aphis middletonii Thomas

104. Rhopalosiphum persicae (Sulz.)

167. Thecabius californicus (Davidson)

168. Thecabius populiconduplifolius (Cowen)

Raphanus (radish)

112. Aphis brassicae Linn.

141. Aphis pseudobrassicae Davis

104. Rhopalosiphum persicae (Sulz.)

Reed, Giant, see Arundo

Reed grass, see Phragmites

Rhamnus (buckthorn, coffeeberry)

123. Aphis gossypii Glover

92. Myzus rhamnus (Clarke) .

Rhus (poison oak)

105. Rhopalosiphum rhois Monell

Ribes (currant, gooseberry)

126. Aphis houghtonensis Troop

134. Aphis neo-mexicana Ckll. var. pacifica Dvdn.

89. Myzus cynosbati (Oestlund)

93. Myzus ribifolii Davidson

Robinia (locust)

131. Aphis medicaginis Koch

Rosa (rose, wild and cultivated)

67. Macrosiphum dirhodum (Walker)

76. Macrosiphum rosae (Linn.)

159. Myzaphis rosarum (Walker)

103. Myzus nervatum Gillette

Rose, see Rosa

Rose mallow, see Hibiscus

Rubus (blackberry, loganberry, thimbleberry)

143. Aphis rubiphila Patch

57. Amphorophora rubi (Kalt.)

95. Nectarosiphon rubicola (Oestlund)

Rumex (dock, sorrell)

121. Aphis euonomi Fabr. (rumicis Linn.)

123. Aphis gossypii Glover

146. Aphis senecio Swain

164. Pemphigus betae Doane (?)

104. Rhopalosiphum persicae (Sulz.)

Rye, Wild, see Elymus

Sagebrush, see Artemisia

Sage, Black, see Ramona

Salix (willow)

144. Aphis salicicola Thomas

146. Aphis senecio Swain

29. Arctaphis viminalis (Monell)

31. Fullawaya saliciradicis Essig

64. Macrosiphum californicum (Clarke)

30. Micrella monella Essig

182. Phylloxerina salicola (Pergande)

40. Pterocomma flocculosa (Weed) 
41. Ptcrocomma populifoliae (Fitch)

42. Pterocomma smithiae (Monell)

155. Siphocoryne capreac (F'abr.)

38. Symydobius macrostachyac Essig

39. Symydobius salicicorticis Essig

32. Thomasia crucis Essig

34. Thomasia populicola (Thomas)

35. Thomasia salicola (Essig)

44. Tuberolachnus viminalis (Fonse.)

Sambucus (elderberry)

145. Aphis sambucifoliae Fiteh

81. Macrosiphum stanleyi Wilson

104. Khopalosiphum persicae (Sulz.)

Sanicula (gambleweed)

119. Aphis cornifoliae Fitch

104. Rhopalosiphum persicae (Sulz.) Scrophularia (figwort)

99. Phorodon scrophulariae Thamos Senecio (German ivy, ivy senecio)

144. Aphis senecio Swain

88. Myzus circumflexus (Buckton)

104. Rhopalosiphum pcrsicae (Sulz.)

Shepherd's-purse, see Capsella

Silybum (milk thistle)

121. Aphis euonomi Fabr.

130. Aphis marutac Oestlund

Sisymbrium (hedge mustard)

88. Mlyzus circumflexus (Buckton)

Smilax, see Asparagus

Snowball, see Virburnum

Snowberry, see Symphoricarpos

Solanum (potato, nightshade)

56. Amphorophora latysiphon Davidson

79. Macrosiphum solanifolii (Ashmead)

88. Myzus circumflexus (Buckton)

102. Rhopalosiphum lactucac (Kalt.)

104. Rhopalosiphum persicae (Sulz.)

163. Trifidaphis radicicola (Essig)

Sonchus (sow thistle)

79. Macrosiphum solanifolii (Ashmead)

80. Macrosiphum sonchella (Monell)

102. Rhopalosiphum lactucae (Kalt.)

104. Rhopalosiphum persicae (Sulz.)

Sorghum

129. Aphis maidis Fitch

Sorrell, see Rumex

Sow thistle. see Sonchus

Spinacia (spinach)

123. Aphis gossypii Glover

104. Rhopalosiphum persicae (Sulz.)

Spirca (spirea)

148. Aphis spiraecola Patch 
Spruce, see Picea

Squash, see Cucurbita

Stachys (hedge nettle)

73. Macrosiphum ludovicianae (Oestlund)

88. Myzus circumflexus (Buckton)

Stock, Ten-week, see Matthiola

Strawberry, see Fragaria

Strawberry tree, see Arbutus

Sugar beet, see Beta

Sunflower, see Helianthus

Sweet clover, see Melilotus

Sweet pea, see Lathyrus

Sycamore, Western, see Platanus

Symphoricarpos (snowberry)

108. Aphis albipes Oestlund

Syringa (lilac)

131. Aphis medicaginis Koch

Tacalote, see Centaurea

Taraxacum (dandelion)

82. Macrosiphum taraxici (Kalt.)

Tarweed, see Madia and Hemizonia

Teasel, Fuller's, see Dipsacus

Teasel, mustard, see Erysimum

Thimbleberry, see Rubus

Thistle, see Cirsium

Thistle, Milk, see Silybum

Thistle, Sow, see Sonchus

Thuja (arbor vitae)

54. Lachnus tujafilinus (Del Guereio)

Tilia (linden, basswood)

10. Eucallipterus tiliac (Linn.)

Tomato, see Lycopersicum

Trifolium (clover)

146a. Aphis bakeri Cowen

131. Aphis medicaginis Koch

Trigonclla (fenugreek)

69. Macrosiphum pisi (Kalt.)

Triticum (wheat)

111. Aphis avenae Fabr.

64. Macrosiphum granarium (Kirby)

Tropaeolum (nasturtium)

121. Aphis cuonomi Fabr.

88. Myzus circumflexus (Buckton)

104. Rhopalosiphum persicae (Sulz.)

Tule, California, see Typha

Tulip, see Tulipa

Tulip tree, see Liriodcndron

Tulipa (tulip)

83. Macrosiphum tulipae (Monell)

104. Rhopalosiphum persicae (Sulz.)

Turnip, see Brassica 
Typha (California tule)

111. Aphis avenae Fabr.

153. Hyalopterus arundinis (Fabr.)

68. Macrosiphum granarium (Kirby)

156. Siphocoryne nymphaeae (Linn.)

Ulmus (elm)

28. Arctaphis populifolii (Essig) (\&)

172. Colopha ulmicola (Fitch)

173. Eriosoma americana (Riley)

175. Eriosoma languinosa Hartig (pyricola B. \& D.)

174. Eriosoma lanigerum (Hausman)

79. Macrosiphum solanifolii (Ashmead)

22. Myzocallis ulmifolii (Monell)

Umbellularia (California laurel)

88. Myzus circumflexus (Buckton)

104. Rhopalosiphum pcrsicae (Sulz.)

157. Siphocoryne pastinacae (Linn.)

Urtica (stinging nettle)

121. Aphis euonomi Fabr.

Valerian, Red, see Centranthus

Valeriana

84. Macrosiphum valerianae (Clarke)

Vernonia (ironweed)

123. Aphis gossypii Glover

Vetch, see $V$ icia

Viburnum (lauristinus, snowball)

121. Aphis euonomi Fabr.

139. Aphis pomi De Geer

150. Aphis viburnicolens n.sp.

Vicia (horse bean, vetch)

121. Aphis euonomi Fabr. (fabae Scop.)

131. Aphis medicaginis Koch

74. Macrosiphum pisi (Kalt.)

Vigna (blackeye bean, cowpea)

131. Aphis medicaginis Koch

Vineca (periwinkle)

56. Amphorophora latysiphon Davidson

88. Myzus circumflexus (Buckton)

104. Rhopalosiphum persicae (Sulz.)

Viola (pansy, violet)

58. Idiopterus nephrelepidis Davis

74. Macrosiphum pisi (Kalt.)

88. Myzus circumflcxus (Buckton)

106. Rhopalosiphum violae Pergande

Vitis (grape)

180. Phylloxera vitifoliae (Fitch)

Wallflower, see Cheiranthus

Wallflower, Western, see Erysimum

Walnut, see Juglans

Water hemlock, see Cicuta

Watermelon, see Citrullus

Water plantain, see Alisma 
Wheat, see Triticum

Willow, see Salix

Yarrow, see Achillea

Yucca (yucea)

151. Aphis yuccae Cowen

Zantedeschia (calla)

88. Myzus circumflexus (Buckton)

Zea (corn)

111. Aphis avenae Fabr.

128. Aphis maidis Fitch

Zizia

155. Siphocoryne capreae (Fabr.) 


\section{ADDENDA}

Since the preparation of this manuseript there have appeared a few papers ${ }^{36}$ in which there are some new records for certain of the California Aphididae and in which there are notes concerning the synonyiny of some of the species. These records are noted here and are listed in the Host Plant Index (appendix 2).

2. Phyllaphis fagi (Limn.) on Fagus tricolor, Oakland (Essig, p. 321).

7. Euceraphis betulae (Koch) on Betula populifolia laciniata and B. papyrifera (Essig, pp. 322-323).

10. Eucallipterus tiliae (Linn.) on Tilia tomentosa, Berkeley (Essig, p. 323). Baker places this species in the genus Myzocallis, for although it is quite distinct from the type of Myzocallis, various species form definite connections leading to this one.

15. Myzocallis castanicola Baker-(Baker, p. 424). This name has been suggested by Baker to replace M. castaneae (Buckton) (preoceupied by castaneae (Fitch)). Therefore the name suggested by the author, $\boldsymbol{M}$. davidsoni Swain, must be dropped. Essig (p. 323) lists $M$. castaneae (Fitch), but he refers to this species.

19. Myzocallis califormicus Baker (Baker, pp. 421-422). This is the same species as described by the author under the name, Myzocallis maureri Swain, which name will have to be dropped, and replaced by $M$. californicus Baker.

53a. Lachnus tomentosus (De Geer), on Pinus radiata, Berkeley (Gillette, pp. 140-141). This species is very similar to L. pini-radiatae Davidson, according to Gillette. The author finds on looking over his specimens that some of them labeled L. pini-radiatae Dvdn. are this species, particularly those taken on the campus at Berkeley.

56. Amphorophora latysiphon Davidson, on Chrysanthemum and Primula sp., Berkeley (Essig, p. 329).

68. Macrosiphum granarium (Kirby), on Alopecurus pratensis, Ampelodesma. tenax, and Elymus sp., Martinez (Essig, p. 328).

76. Macrosiphum rosae (Linn.) on Dipsacus fullonum and Centrantius ruber, Berkeley (Essig, p. 329).

79. Macrosiphum solanifolii (Ashmead), on Aclillca millefolium and Pittosporum tobira, Berkeley, and on Ulmus amcricanus, San Francisco (Essig, p. 329).

88. Myzus circumflexus (Buckton), on Lilium spp., Pentstemon spectabilis, and Umbellularia californica, Berkeley (Essig, p. 335).

102. Rhopalosiphum lactucae (Kalt.). Dobrovliansky lists this as a synonym of $\boldsymbol{R}$. ribis (Buckton), giving the latter name preference.

36 Baker, A. C., Eastern aphids, new and little known, II, Jour. Econ. Ent., vol. 10, pp. 421-433, 1917.

Baker, A. C.. The correct name for our apple-grain aphis, Science, vol. 46, pp. 410-411, 1917.

Davidson, W. M., The reddisli-brown pluni aphis, Jour. Econ. Ent., vol. 10, pp. 350-353, 1917.

Dobrovliansky, V. V., A list of aphids found on cultivated plants in the government of Kharkov, in Pests of Agriculture, Kharkov, Bull. 1916; revicwed in Rev. Appl. Ent., vol. 5, pp. 561-562, 1917.

Essig, E. O., Aphididae of California, Univ. Calif. Publ. Entom., vol. 1, pp. 301-346, 1917.

Gillette, C. P., Some Colorado species of the genus Lachnus, Ent. Soc. Am., vol. 10, pp. 133-146, 1917.

Van der Goot, P., Zur Kenntnis der Blattläuse Java's, in Contrib. a là fauna der Indes neerlandaises, vol. 1, pp. 1-301, 1916. 
104. Rhopalosiphum persicae (Sulzer), on Baccharis douglasii, Centranthus ruber, Clarkia elegans, Dipsacus fullonum, Escallonia pulverulenta, Helianthus annuus, Lavatcra assurgentiflora, Liriodendron tulipifera, Melianthus major, Pentstemon spcctabilis, Pittosporum spp., and Umbellularia californica, Berkeley (Essig, pp. 331-332).

111. Aphis avenae Fabr. It would appear from a study of Baker's paper in Science that the common California species is Aphis prunifoliae Fitch. It is certain that it is distinct from $A$. cerasifoliae Fitch, which has been taken here once and is described in this paper. If it is possible, as Baker says, that $A$. cerasifoliae Fitch is a synonym of $A$. padi Linn., then our common species must be known as $A$. prunifoliae Fitch. From the brief description of Aphis (Siphonaphis) padi Linn. given by Van der Goot (pp. 71-72) it would appear that our species may be distinct, differing slightly in the comparative lengths of the cornicles and cauda. Consequently the author favors accepting the name, Aphis prunifoliae Fitch, for this species.

123. Aphis gossypii Glover, on Asclepias speciosa, A. vestita, Lilium speciosum rubrum, Lonicera sp., and Rhamnus purshiana, Berkeley and Oakland (Essig, pp. 338-339).

131. Aphis medicaginis Koch, on Citrus sp., Sacramento, and on Vigna sinensis, Moorpark (Essig, p. 340).

139. Aphis pomi De Geer, on Cotoneaster franchetii, Pittosporum eugenioides, and Viburnum tinus, Berkeley (Essig, p. 341). The author is inclined to believe this to be Aphis viburnicolens n.sp. (see no. 150) which is quite similar to Aphis pomi De Geer, but which is common on Viburnum and related plants. He has not, however, seen Essig's specimens, so can not state positively whether or not it is this species.

140. Aphis prunorum Dobr. Dobrovliansky places this species as a synonym of Siphocoryne nymphaeae. (Linn.). This author noted the similarity of these two, but was not certain of their identity, so listed them as distinct species.

141. Aphis pseudobrassicae Davis. Dobrovliansky believes this to be a synonym of Aphis crysimi Kalt.

146. Aphis senecio Swain. Essig (p. 337) lists Aphis bakeri Cowen from Trifolium pratense. This proves to be the true Aphis bakeri Cowen and not A. senecio Swain, which is the species that has been hitherto ealled $A$. bakeri Cowen in California.

152. Toxoptera aurantii (Fonse.) on Camellia japonica, Oakland (Essig, p. $330)$.

153. Hyalopterus arundinis (Fabr.). Both Dobrovliansky and Van der Goot list this as a synonym of $H$. pruni (Fabr.) giving the later preference. According to Hunter, arundinis should have priority, but it is entirely possible that the dates he gives are incorrect. This point the author is unable to settle as he has not access to Fabricius' works.

156. Siphocoryne nymphaeae (Linn.). Davidson gives a brief account of the habits and biology of this species, as well as a description of the various forms.

175. Eriosoma languinosa Hartig (pyricola Baker and Davidson). The species listed by Essig (p. 345) as Eriosoma sp. on Ulmus campestris in Berkeley and in Hayward is this species.

115. Aphis cari Essig. Davidson recently remarked to the author that he could see no difference between this species and Aphis helianthii Monell. It is quite possible that these are synonyms. 


\section{EXPLANATION OF PLATES}

\section{PLATE 1}

Fig. 1. Myzocallis asclepiadis (Fitch), tarsus and claw.

Fig. 2. Aphis senecio Swain, tarsus and claw.

Fig. 3. Essigella californica (Essig), sixth antennal segment and spur.

Fig. 4. Aphis senecio Swain, sixth antennal segment and spur.

Fig. 5. Essigella californica (Essig), cauda and anal plate (lateral view).

Fig. 6. Aphis senecio Swain, cauda and anal plate (lateral view).

Fig. 7. Eucallipterus tiliae (Linn.), cauda and anal plate.

Fig. 8. Thomasia populicola (Thos.), cauda and anal plate.

Fig. 9. Phyllaphis fagi (Linn.), third antennal segment.

Fig. 10. Phyllaphis fagi (Linn.), sixth antennal segment.

Fig. 11. Phyllaphis fagi (Linn.), cauad and anal plate.

Fig. 12. Phyllaphis fagi (Linn.), front of head and antennal tubercles.

Fig. 13. Phyllaphis coweni (Ckll.), Antenna.

Fig. 14. Phyllaphis quercicola Baker, third antennal segment.

Fig. 15. Phyllaphis quercicola Baker, fourth antennal segment.

Fig. 16. Phyllaphis quercicola Baker, fifth antennal segment.

Fig. 17. Phyllaphis quercicola Baker, sixth antennal segment.

Fig. 18. Phyllaphis quercicola Baker, forewing.

Fig. 19. Phyllaphis quercicola Baker, eauda and anal plate.

Fig. 20. Phyllaphis querci, tarsal claw.

Fig. 21. Drepanosiphum platanoides (Schr.), antennal tubereles. 

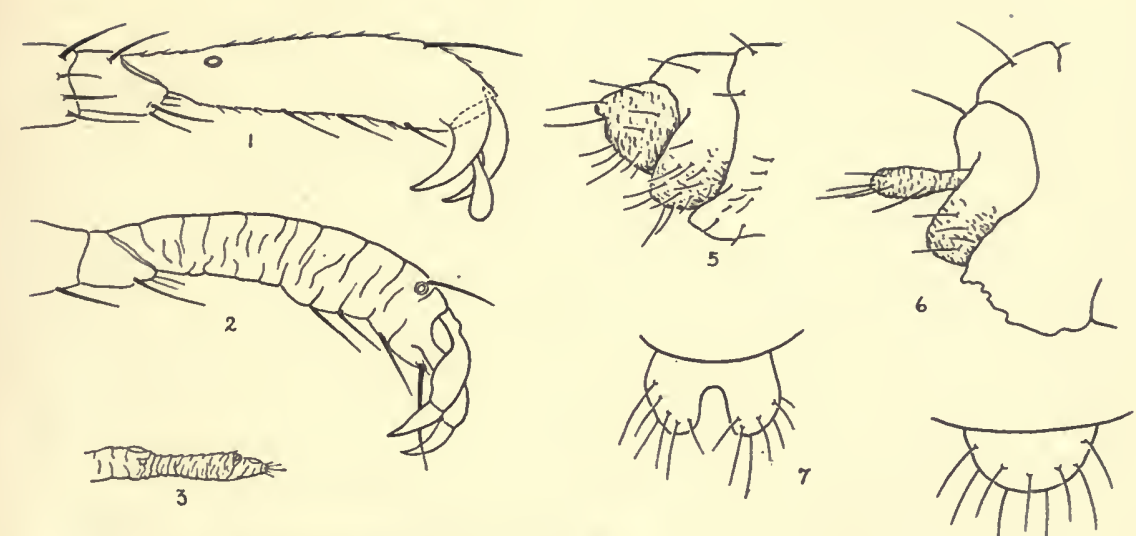

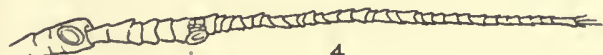
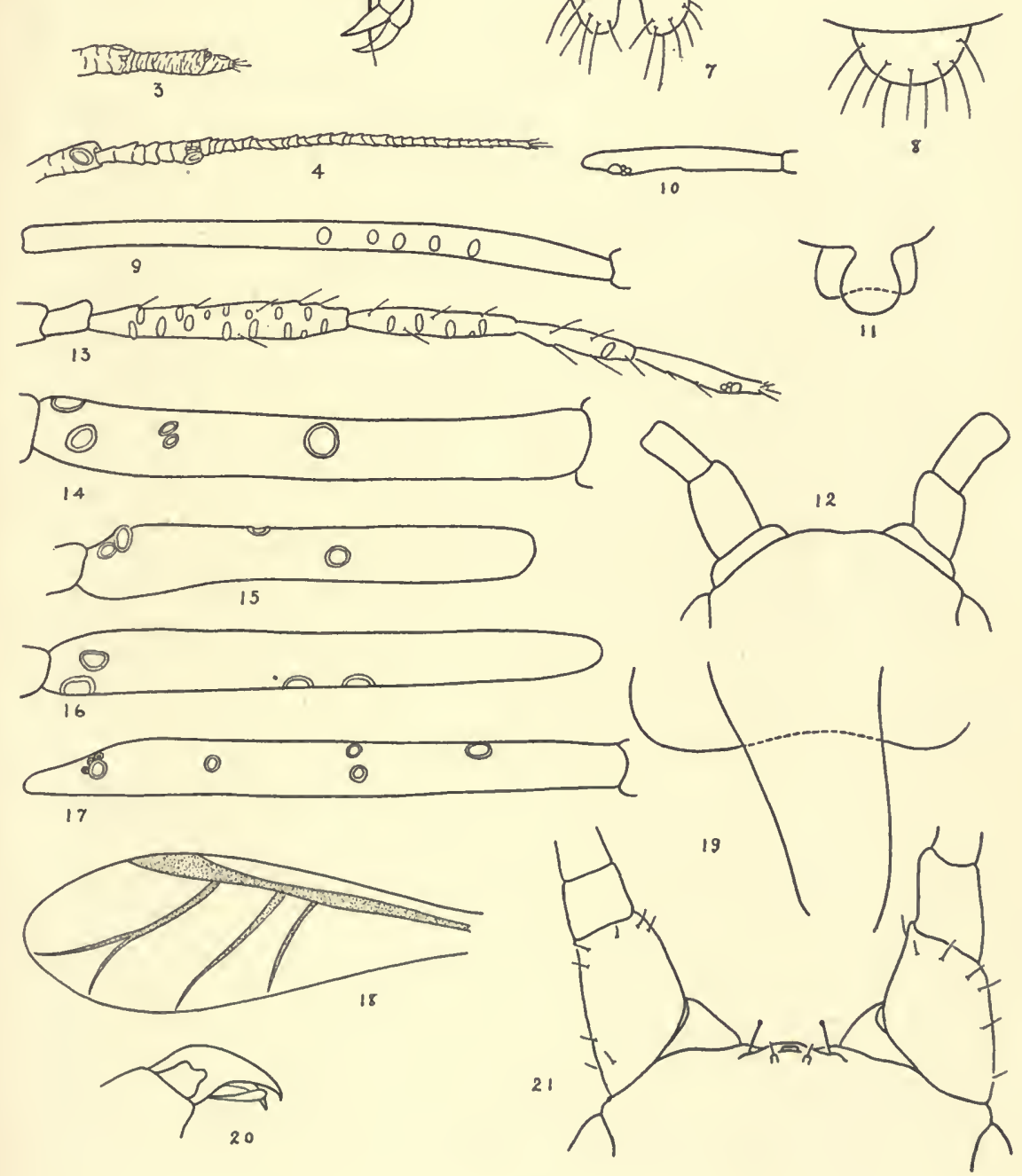

[SWAIN] PLATE 1 


\section{PLATE 2}

Fig. 22. Myzocallis arundicolens (Clarke), antennal tubercles.

Fig. 23. Drcpanaphis acerifolii (Thomas), cornicle.

Fig. 24. Drepanosiphum platanoides (Schr.), cornicle.

Fig. 25. Monellia caryella (Fitch), cornicle.

Fig. 26. Myzocallis bcllus (Walsh), cornicle.

Fig. 27. Calaphis betulaecolens (Fitch), antennal tubercles.

Fig. 28. Calaphis betulella Walsh, antennal tubereles.

Fig. 29. Euceraphis bctulae (Koch), antennal tubercles.

Fig. 30. Eucallipterus tiliae (Linn.), sixth antennal segment and spur.

Fig. 31. Myzocallis quercus (Kalt.), sixth antennal segment and spur.

Fig. 32. Myzocallis quercus (Kalt.), cornicle.

Fig. 33. Eucallipterus tiliae (Linn.), cornicle.

Fig. 34. Chromaphis juglandicola (Kalt.), sixth antennal segment and spur.

Fig. 35. Chromaphis juglandicola (Kalt.), cornicle.

Fig. 36. Drepanosiphum platanoides (Schr.), third antennal segment.

Fig. 37. Drepanaphis acerifolii (Thomas), third antennal segment.

Fig. 38. Calaphis betulae-colens (Fitch), third antennal segment.

Fig. 39. Euceraphis gillettei Dvdn., base of third antennal segment.

Fig. 40. Euceraphis betulae (Koch), base of third antennal segment. 

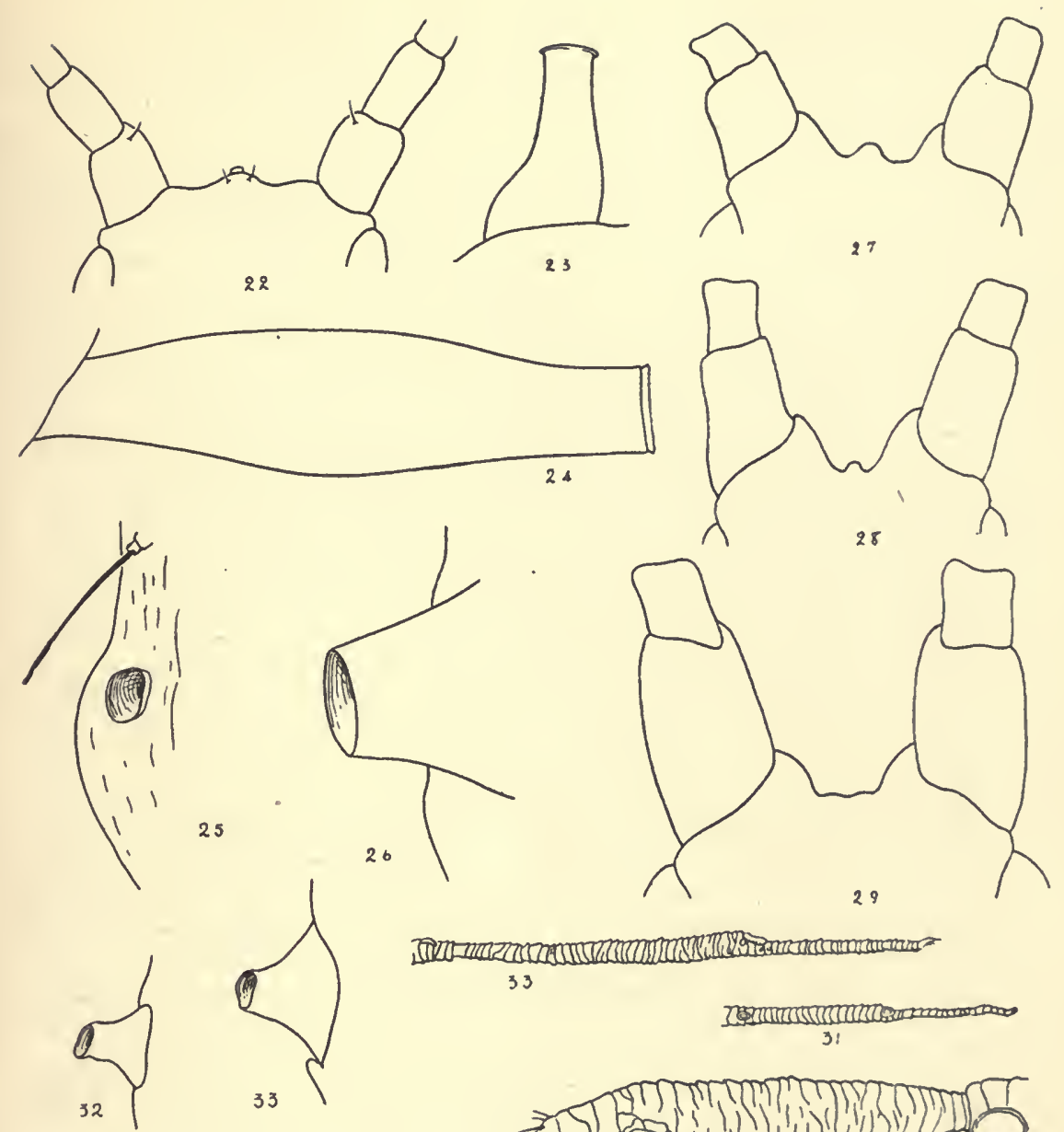

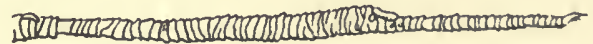
33

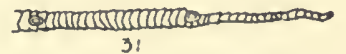

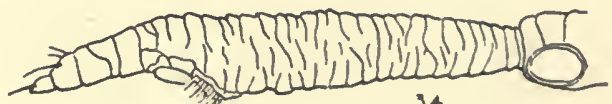

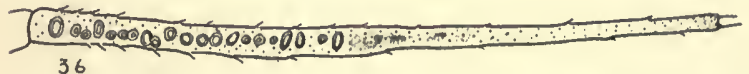
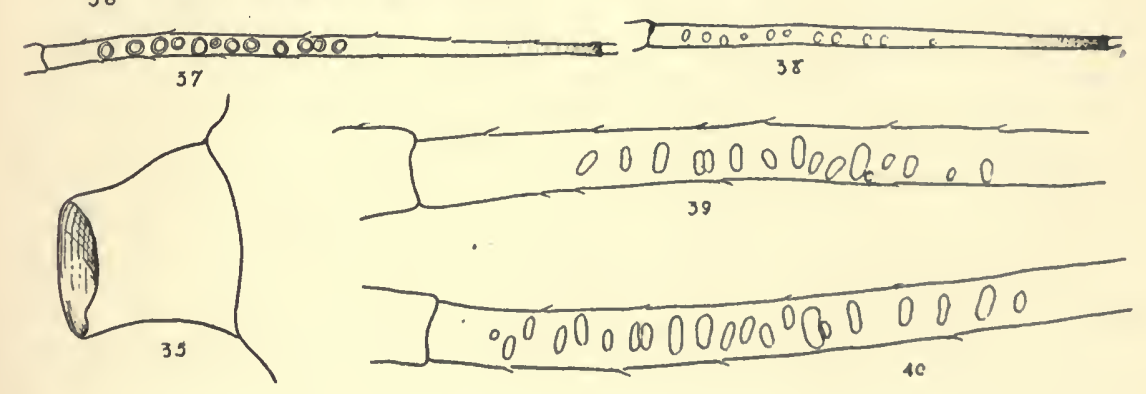

[SWAIN] PLATE 2 
PLATE 3

Fig. 41. Eucallipterus flava (Dvdn.), base of third antennal segment.

Fig. 42. Eucallipterus tiliae (Linn.), third antennal segment.

Fig. 43. Myzocallis coryli (Goetze), third antennal segment.

Fig. 44. Myzocallis coryli (Goetze), sixth antennal segment and spur.

Fig. 45. Myzocallis bellus (Walsh), sixth antennal segment and spur.

Fig. 46. Myzocallis bellus (Walsh), third antennal segment.

Fig. 47. Myzocallis alnifoliae (Fitch), third antennal segment.

Fig. 48. Myzocallis arundicolens (Clarke), third antennal segment.,

Fig. 49. Eucallipterus tiliae (Linn.), cornicle.

Fig. 50. Eucallipterus tiliae (Linn.), anal plate.

Fig. 51. Myzocallis arundicolens (Clarke), cornicle.

Fig. 52. Myzocallis arundicolens (Clarke), anal plate.

Fig. 53. Myzocallis coryli (Goetze), cornicle.

Fig. 54. Myzocallis coryli (Goetze), anal plate.

Fig. 55. Myzocallis californicus Baker, third antennal segment.

Fig. 56. Myzocallis californicus Baker, sixth antennal segment and spur.

Fig. 57. Myzocallis pasaniae Dvdn., third antennal segment.

Fig. 58. Myzocallis quercus (Kalt.), third antennal segment.

Fig. 59. Myzocallis ulmifolii (Monell), third antennal segment.

Fig. 60. Myzocallis castanicola Baker, third antennal segment.

Fig. 61. Myzocallis castanicola Baker, cauda and anal plate.

Fig. 62. Myzocallis castanicola Baker, cornicle.

Fig. 63. Callipterus californicus (Essig), sixth antennal segment and spur.

Fig. 64. Callipterus californicus (Essig), third antennal segment.

Fig. 65. Callipterus caryae Monell, third antennal segment. 


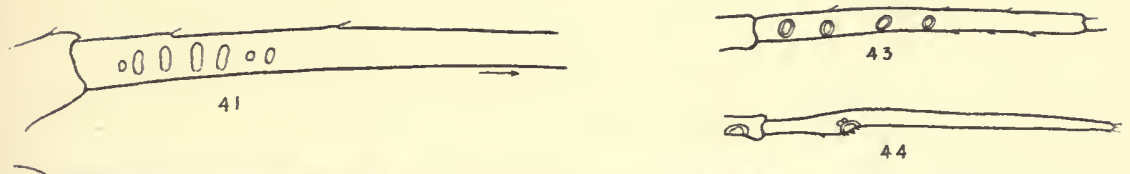

0.008

42

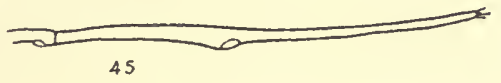

$\int_{46}^{20000}$
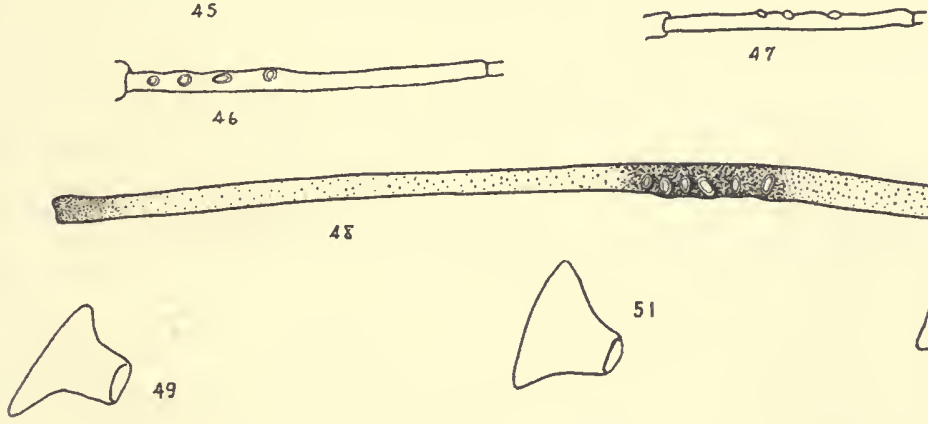

48

550
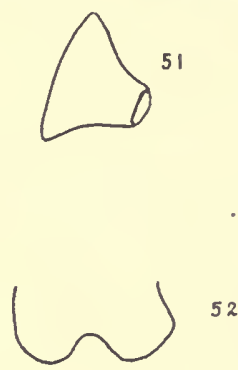

$\triangle^{53}$ ,

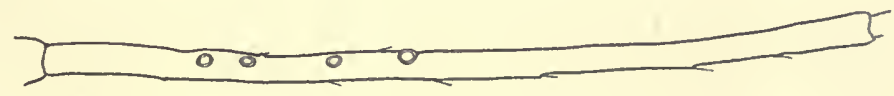

55

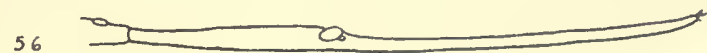

57
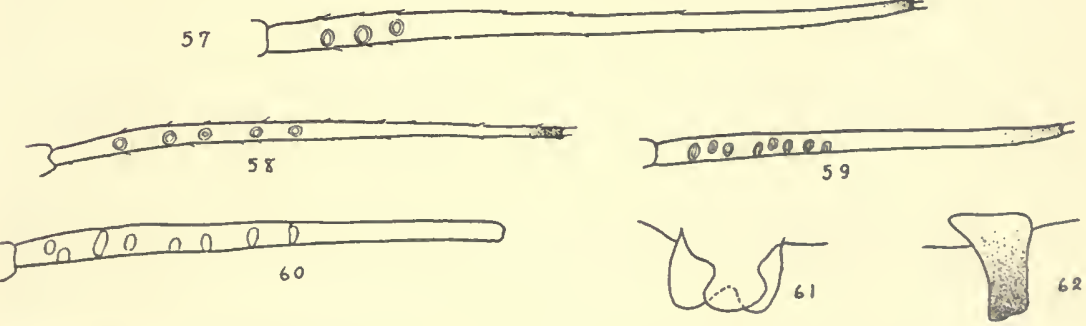

I 63

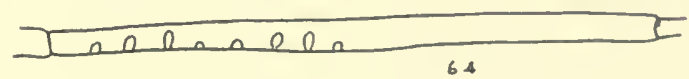

$I-0,00000=$

[SWAIN] PLATE 3 


\section{PLATE 4}

Fig. 66. Callipterus caryae Monell, sixth antennal segment and spur. Fig. 67. Monellia caryella (Fitch), sixth antennal segment and spur. Fig. 68. Monellia caryella (Fitch), third antennal segment.

Fig. 69. Arctaphis populifolii (Essig), cauda.

Fig. 70. Micrella monella Essig, cauda.

Fig. 71. Arctaphis populifolii (Essig), third antennal segment.

Fig. 72. Micrella monella Essig, third antennal segment.

Fig. 73. Symydobius macrostachyac Essig, third antennal segment.

Fig. 74. .Symydobius salicicorticis Essig, third antennal segment.

Fig. 75. Fullawaya saliciradicis Essig, third antennal segment.

Fig. 76. Thomasia crucis Essig, third antennal segment.

Fig. 77. Thomasia populicola (Thomas), third antennal segment.

Fig. 78. Thomasia salicicola (Essig), third antennal segment.

Fig. 79. Lachnus ferrisi Swain, tarsal elaw.

Fig. 80. Pterocomma populifoliae (Fitch), tarsal claw.

Fig. 81. Pterocomma flocculosa (Weed), cornicle.

Fig. 82. Pterocomma populifoliae (Fiteh), cornicle.

Fig. 83. Essigella californica (Essig), antenna.

Fig. 84. Longistigma sp., front wing. 


\section{0}

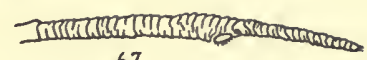

$\frac{00000}{68}$

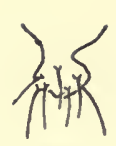

69

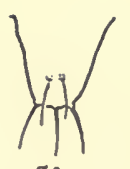

70

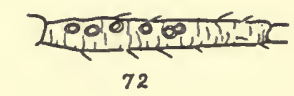

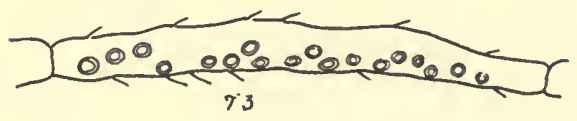

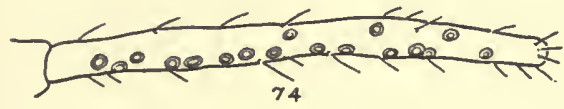
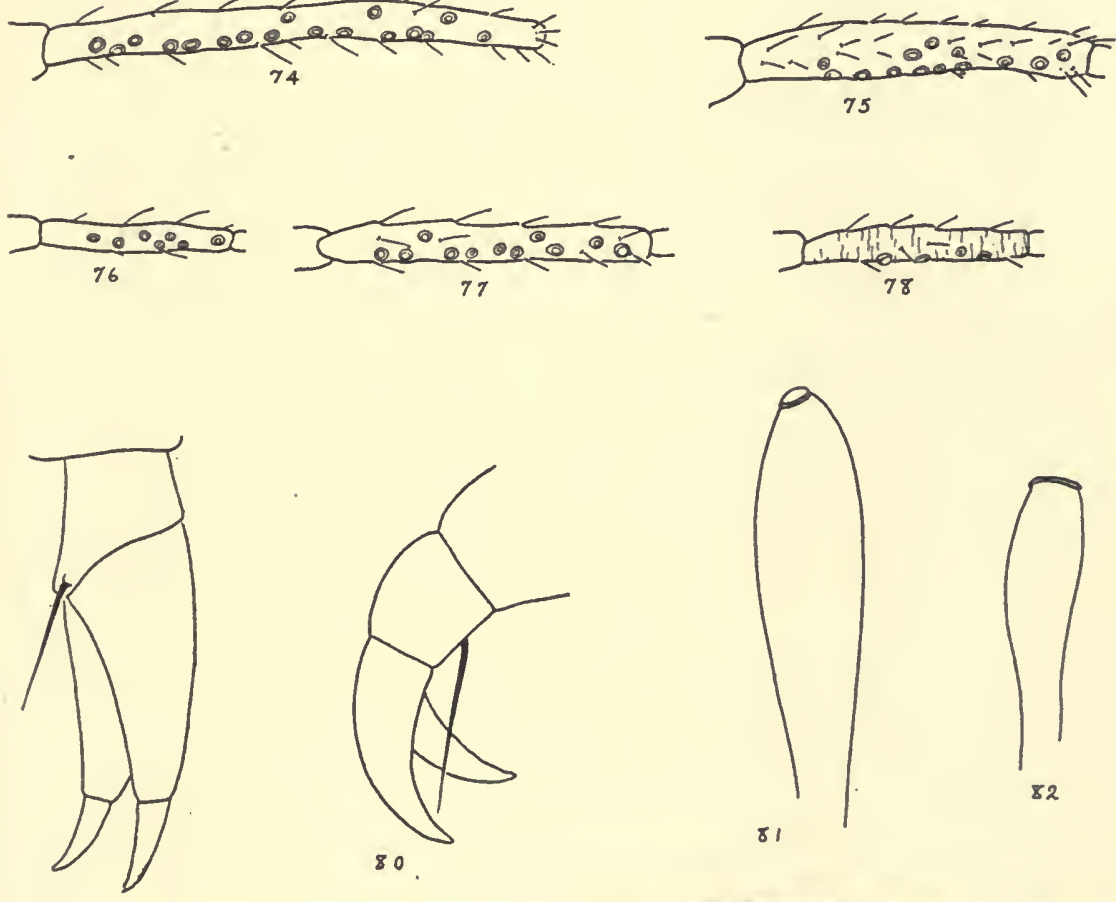

79

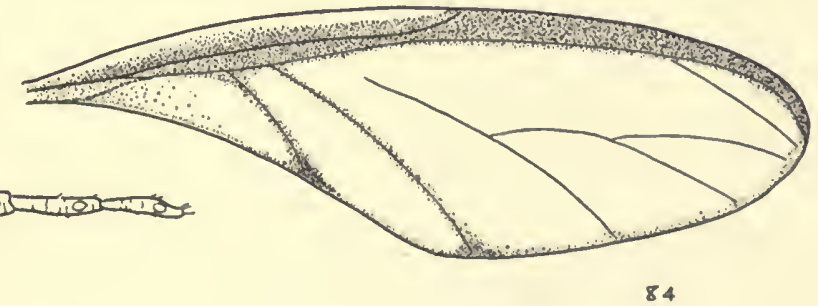

83

[SWAIN] PLATE 4 


\section{PLATE 5}

Fig. 85. Lachnus sp., front wing.

Fig. 86. Tuberolachnus viminalis (Fonse.), hind tarsus.

Fig. 87. Eulachnus rileyi Davis, hind tarsus.

Fig. 88. Lachnus vanduzei n.sp., third antennal segment.

Fig. 89. Lachnus ferrisi Swain, first, second, and third antennal segments.

Fig. 90. Lachnus ferrisi Swain, fourth, fifth, and sixth antennal segments.

Fig. 91. Lachnus ferrisi Swain, cornicle.

Fig. 92. Lachnus pseudotsugae Wilson, tip of front wing.

Fig. 93. Lachnus tujafilinus (Del Guercio), tip of front wing.

Fig. 94. Lachnus occidentalis Dvdn., third antennal segment.

Fig. 95. Lachinus pini-radiatae Dvdn. ( ( ), third antennal segment.

Fig. 96. Lachnus glehnus Essig, third antennal segment.

Fig. 97. Lachnus glehnus Essig, cornicle.

Fig. 98. Lachnus pseudotsugae Wilson, third antennal segment.

Fig. 99. Lachnus taxifolia Swain, hind tarsus.

Fig. 100. Lachnus taxifolia Swain, fourth, fifth and sixth antennal segments.

Fig. 101. Lachnus taxifolia Swain, first, second, and third antennal segments. 

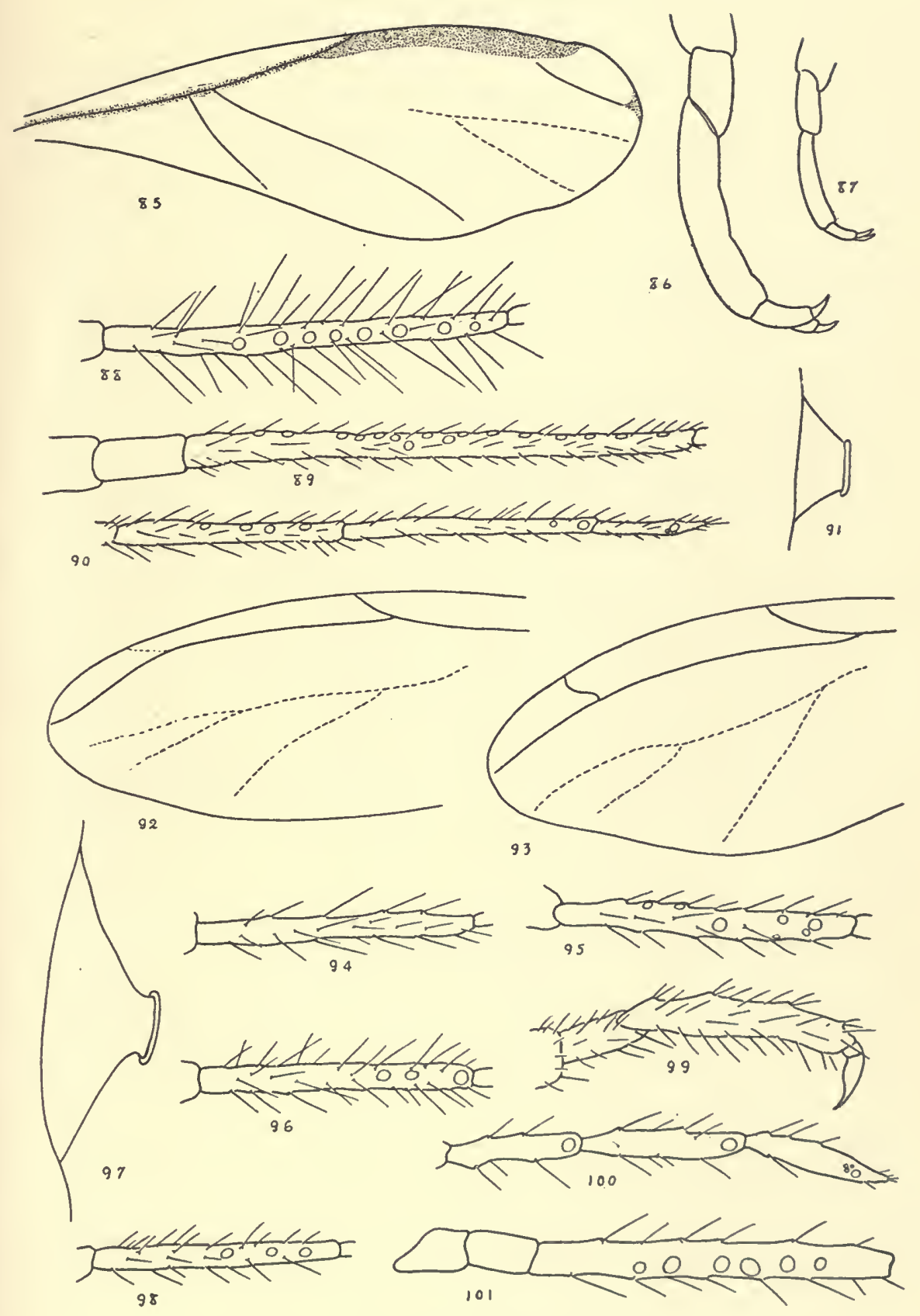

[SWAIN] PLATE 5 


\section{PLATE 6}

Fig. 102. Lachnus taxifolia Swain, wing.

Fig. 103. Lachnus taxifolia Swain, cornicle of apterous female.

Fig. 104. Lachnus ponderosa Williams, third antennal segment.

Fig. 105. Lachnus tujafilinus (Del Guereio), third antennal segment.

Fig. 106. Macrosiphum rosae (Linn.), antennal tubereles.

Fig. 107. Nectaro-siphon rubicola (Oest.), antennal tubercles.

Fig. 108. Rhopalosiphum persicae (Sulz.), antennal tubereles.

Fig. 109. Necturosiphon rubicola (Oest.), cornicle.

Fig. 110. Idiopterus nephrelepidis Davis, wing.

Fig. 111. Amphorophora rubi (Kalt.), antennal tubercles.

Fig. 112. Myzus cerasi (Fabr.), antennal tubercles.

Fig. 113. Amphorophora rubi (Kalt.), cornicle.

Fig. 114. Toxoptera aurantii (Fonsc.), cornicle.

Fig. 115. Phorodon humuli (Schr.), antennal tubercles of alate females.

Fig. 116. Phorodon humuli (Schr.), antennal tubereles of apterous females. 

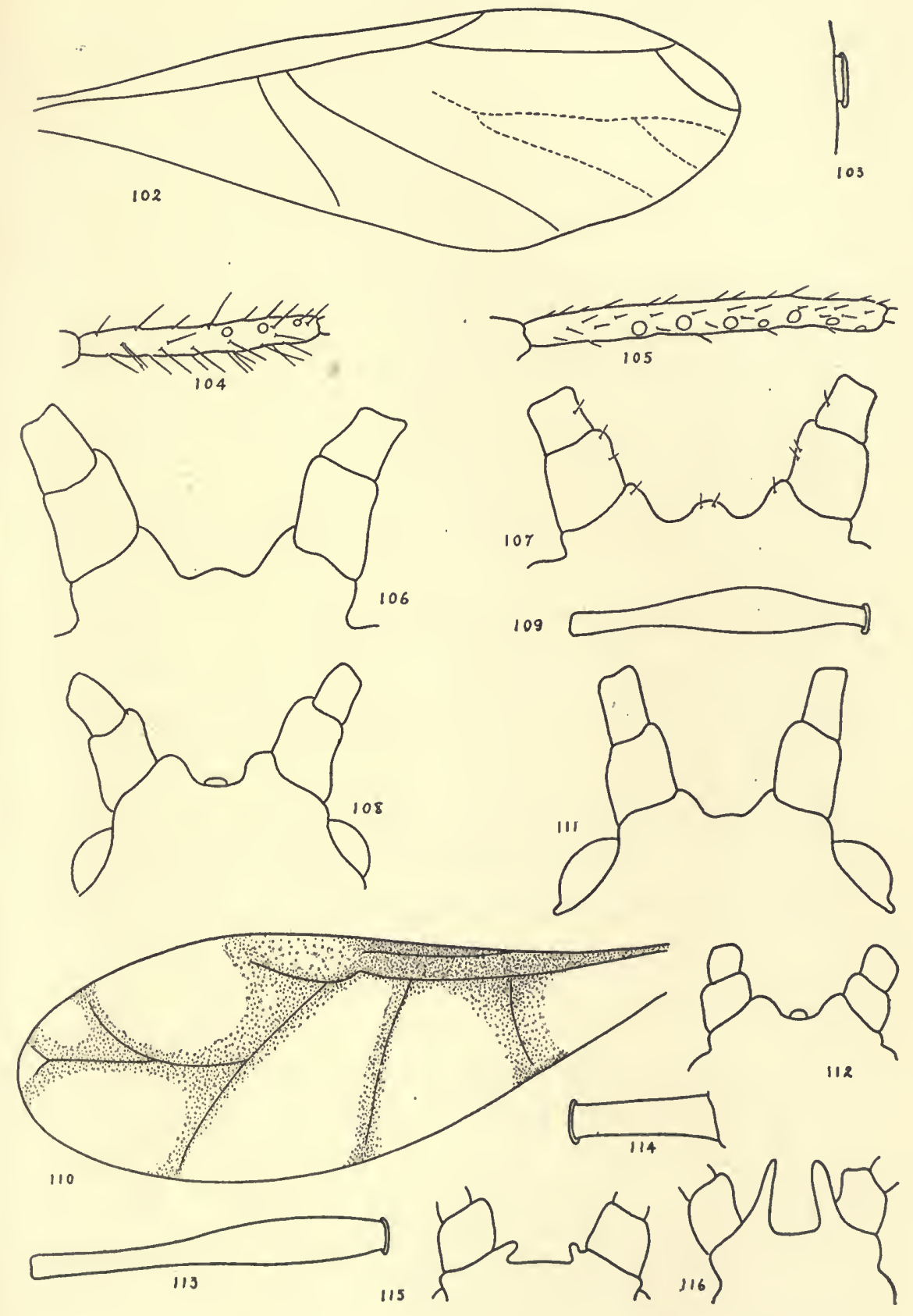

[SWAIN] PLATE 6 


\section{PLATE 7}

Fig. 117. Phorodon humuli Schr., cornicle.

Fig. 118. Phorodon humuli Schr., cauda.

Fig. 119. Rhopalosiphum persicae (Sulz.), cornicle.

Fig. 120. Rhopalosiphum pesicae (Sulz.), cauda.

Fig. 121. Myzus cerasi (Fabr.), cornicle.

Fig. 122. Myzus cerasi (Fabr.), cauda.

Fig. 123. Nectarosiphon rubicola (Oest.), cauda.

Fig. 124. Nectarosiphon morrisoni Swain, antennal tubercles.

Fig. 125. Nectarosiphon morrisoni Swain, third antennal segment.

Fig. 126. Nectarosiphon morrisoni Swain, cauda.

Fig. 127. Nectarosiphon morrisoni Swain, cornicle.

Fig. 128. Macrosiphum stanleyi Wilson, cornicle.

Fig. 129. Macrosiphum solanifolii (Ashm.) (from Sonchus), cornicle.

Fig. 130. Macrosiphum pisi (Kalt.), cornicle.

Fig. 131. Macrosiphum californicum (Clarke), third antennal segment.

Fig. 132. Macrosiphum californicum (Clarke), cornicle.

Fig. 133. Macrosiphum cucurbitae (Thomas), third antennal segment.

Fig. 134. Macrosiphum cucurbitae (Thomas), cornicle.

Fig. 135. Macrosiphum granarium (Kirby), third antennal segment.

Fig. 136. Macrosiphum ludovicianae (Oest.), third antennal segment.

Fig. 137. Macrosiphum solanifolii (Ashm.), cornicle.

Fig. 138. Macrosiphum solanifolii (Ashm.), third antennal segment. 

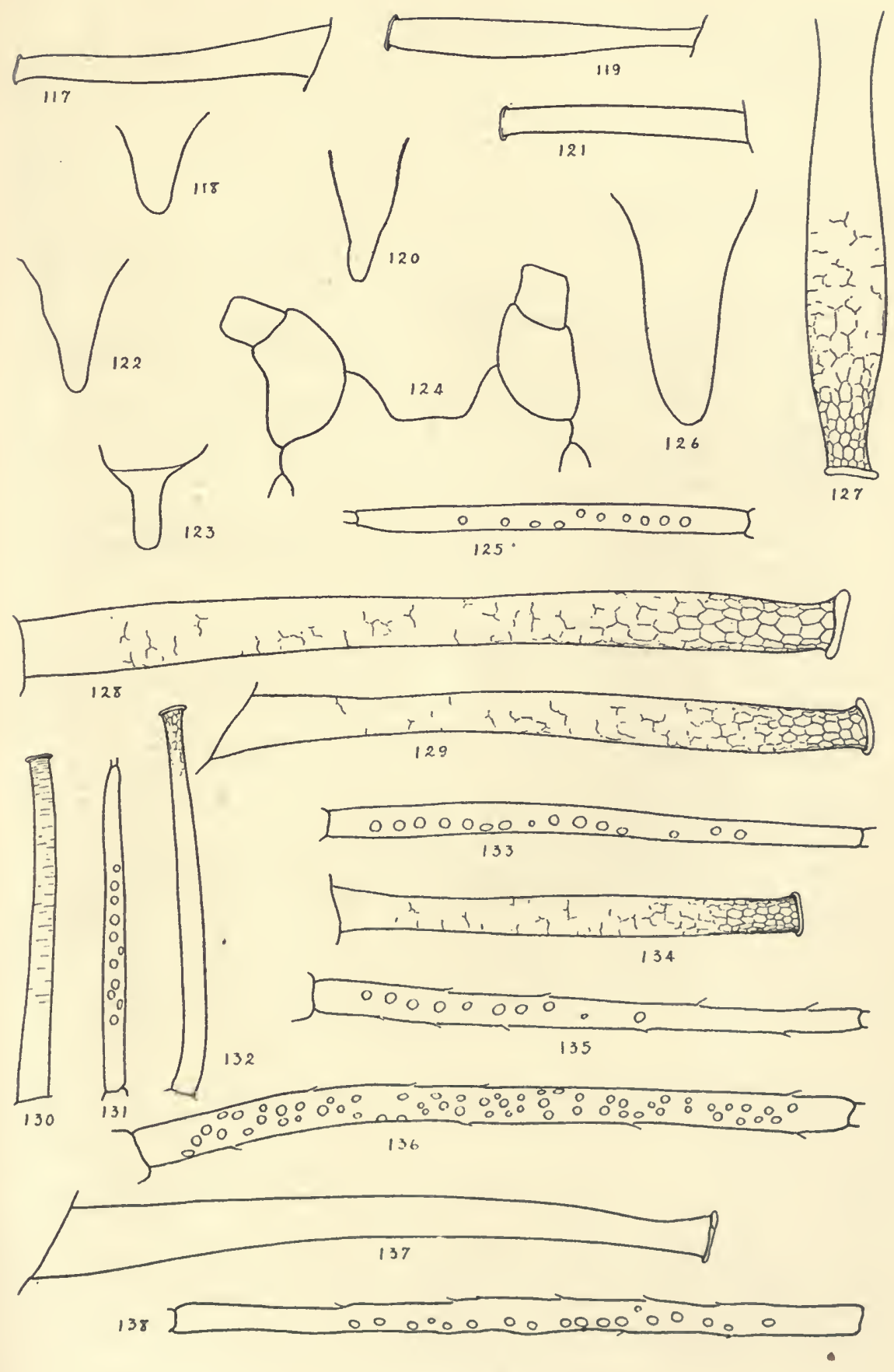

[SWAIN] PLATE 7 


\section{PLATE 8}

Fig. 139. Macrosiphum solanifolii (Ashm.) (from Citrus), cornicle.

Fig. 140. Macrosiphum solanifolii (Ashm.) (from Citrus), third antennal segment.

-Fig. 141. Macrosiphum sanborni Gillette, cornicle of apterous female.

Fig. 142. Macrosiphum artemisiae (Fonse.), cornicle.

Fig. 143. Macrosiphum albifrons Essig, third antennal segment.

Fig. 144. Macrosiphum albifrons Essig, cornicle.

Fig. 145. Macrosiphum artemisiae (Fonse.), third antennal segment.

Fig. 146. Macrosiphum artemisicola (Williams), third antenal segment.

Fig. 147. Macrosiphum artemisicola (Williams), cornicle.

Fig. 148. Macrosiphum granarium (Kirby), cornicle.

Fig. 149. Macrosiphum ludovicianae (Oest.), cornicle.

Fig. 150. Macrosiphum pisi (Kalt.), third antennal segment.

Fig. 151. Macrosiphum rosae (Linn.), third antennal segment.

Fig. 152. MLacrosiphum rosae (Linn.), cornicle.

Fig. 153. Macrosiphum rudbeckiae (Fitch), cornicle.

Fig. 154. Macrosiphum rudbeckiae (Fitch), third antennal segment.

Fig. 155. Macrosiphum sanborni Gillette, cauda apterous female.

Fig. 156. Macrosiphum dirhodum (Walker), cornicle.

Fig. 157. Macrosiphum dirhodum (Walker), third antennal segment.

Fig. 158. Macrosiphum stanleyi Wilson, third antennal segment.

Fig. 159. Macrosiphum solanifolii (Ashm.) (from Souchus), third antennal segment.

Fig. 160. Macrosiphum solanifolii (Ashm.) (from Sonchus), eauda. 

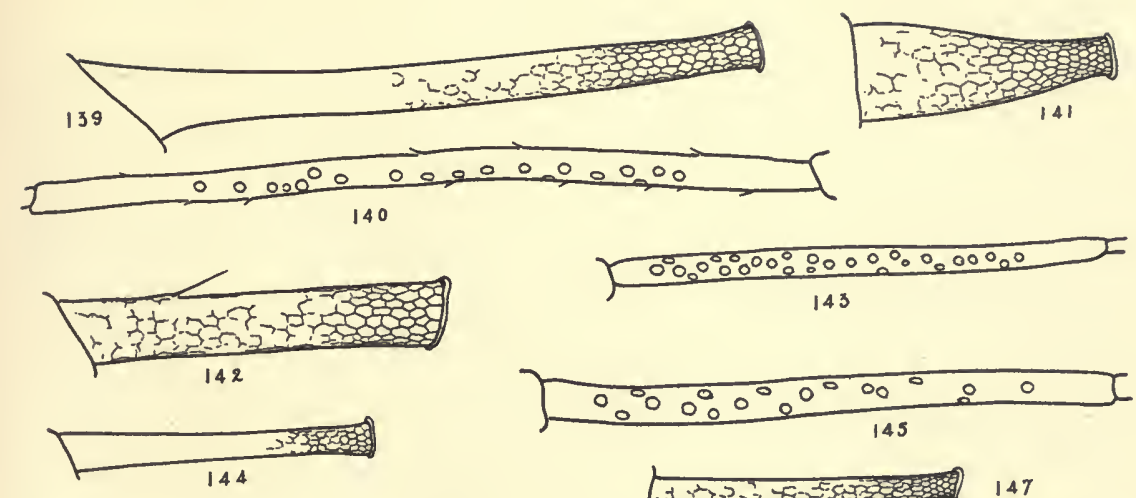

143
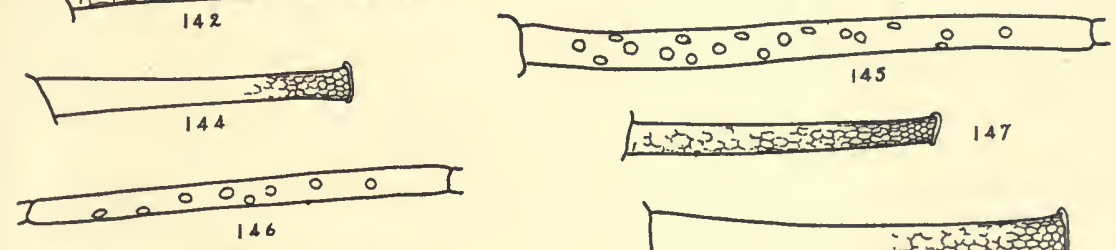

147
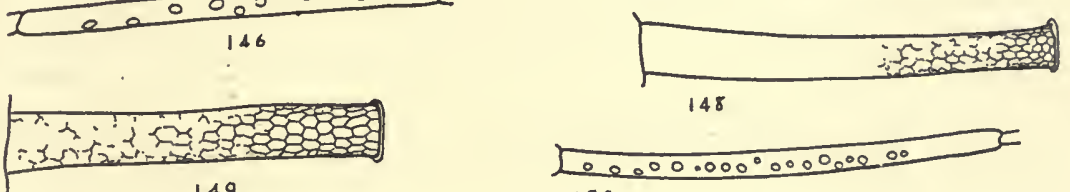

0000.0000000000

149

150

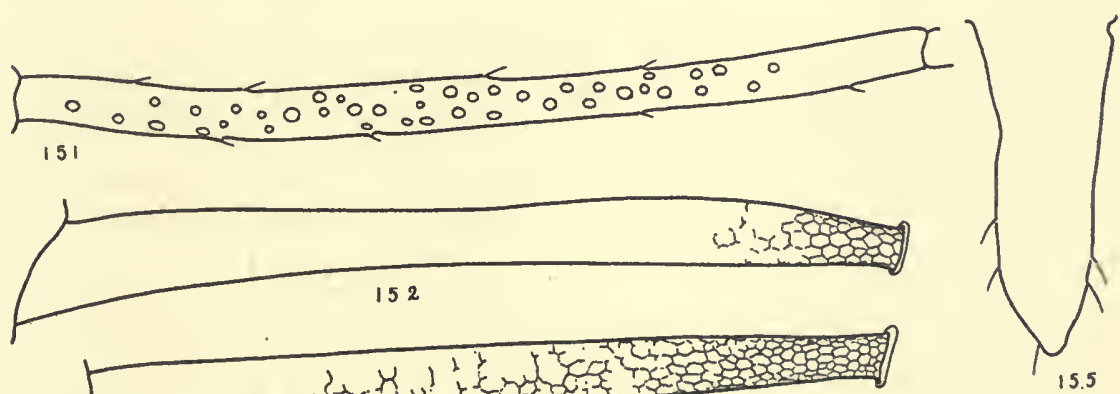

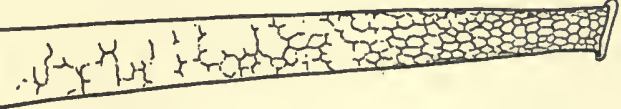

153

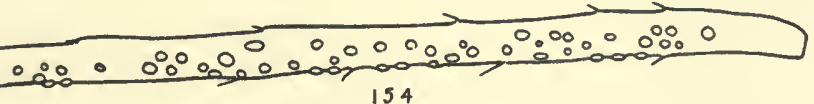

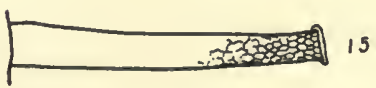

$\frac{0000000000}{157}$

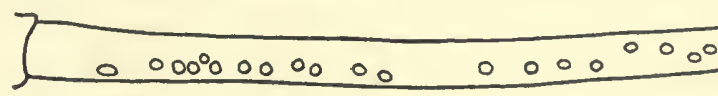

158

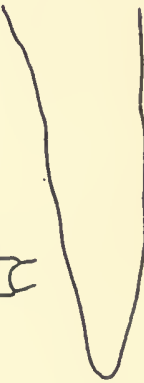

$\sqrt[0000000000000.000]{159}$ 


\section{PLATE 9}

Fig. 161. Amphorophora latysiphon Dvdn., cornicle.

Fig. 162. Amphorophora rubi (Kalt.), cauda.

Fig. 163. Toxoptera aurantii (Fonsc.), third antennal segment.

Fig. 164. Rhopalosiphum violae Pergande, wing.

Fig. 165. Rhopalosiphum hippophaes Koch, cornicle.

Fig. 166. Rhopalosiphum nervatum Gillette (from Arbutus), wing.

Fig. 167. Rhopalosiphum corylinum Dvdn., third antenpal segment.

Fig. 168. Rhopalosiphum persicae (Sulz.), third antennal segment.

Fig. 169. Rhopalosiphum nervatum Gillette (from Arbutus), third antennal segment.

Fig. 170. Rhopalosiphum hippophaes Koch, third antennal segment.

Fig. 171. Rhopalosiphum nervatum Gillette (from rose), third antennal segment.

Fig. 172. Siphocoryne nymphaeae (Linn.), third antennal segment.

Fig. 173. Rhopalosiphum rhois Monell, third antennal segment.

Fig. 174. Rhopalosiphum violae Pergande, third antennal segment.

Fig. 175. Myzus circumflexus (Buckton), third antennal segment.

Fig. 176. Myzus braggii Gillette, third antennal segment.

Fig. 177. Myzus fragaefolii Ckll., third antennal segment.

Fig. 178. Myzus rhamni (Fonse.), third antennal segment.

Fig. 179. Myzus cerasi (Fabr.), third antennal segment.

Fig. 180. Myzus ribis (Linn.), third antennal segment.

Fig. 181. Hyalopterus arundinis (Fabr.), corniele.

Fig. 182. Aphis euonomi Fabr., cornicle.

Fig. 183. Siphocoryne capreae (Fabr.), cornicle.

Fig. 184. Liosomaphis berberidis (Kalt.), conricle.

Fig. 185. Hyalopterus arundinis (Fabr.), third and fourth antennal seg. ments.

Fig. 186. Hyalopterus arundinis (Fabr.), cauda. 


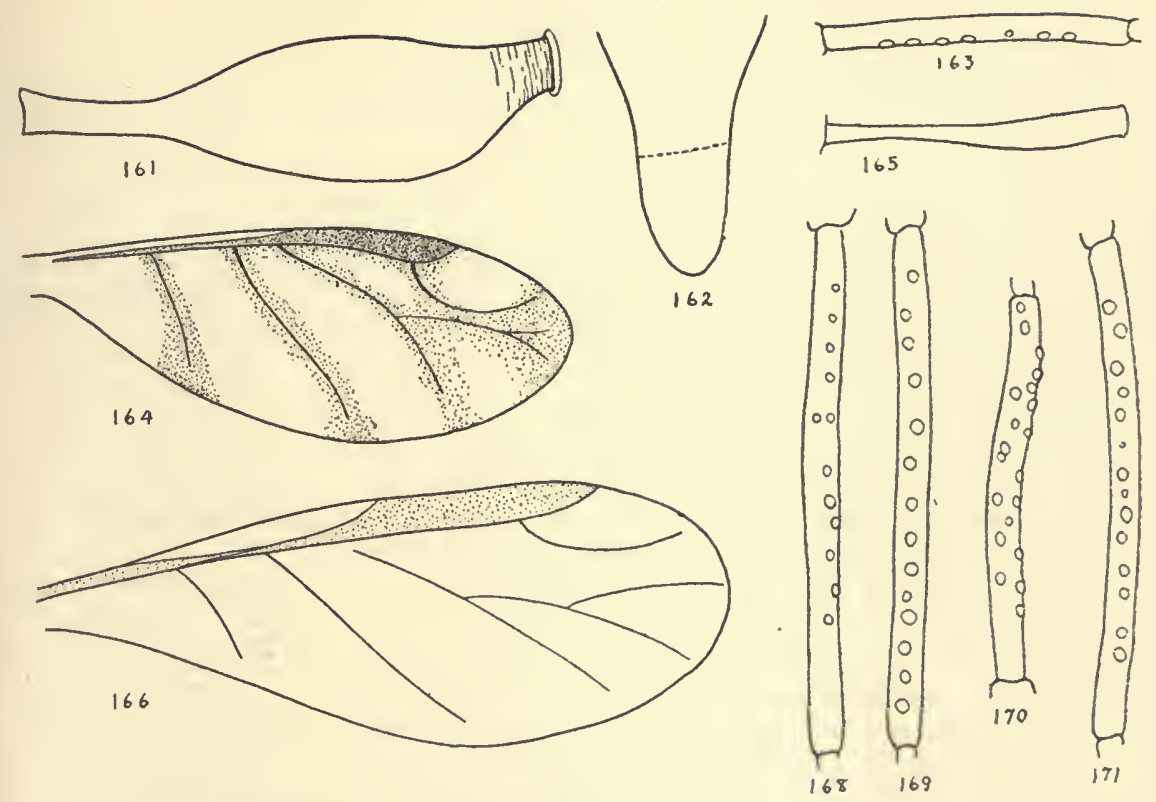

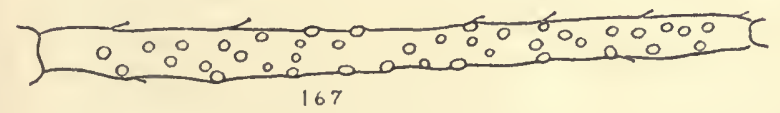

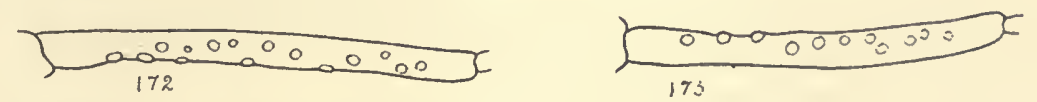

$\frac{\sqrt{600000000000000000}}{174} \frac{\sqrt{000000000000000}}{175}$

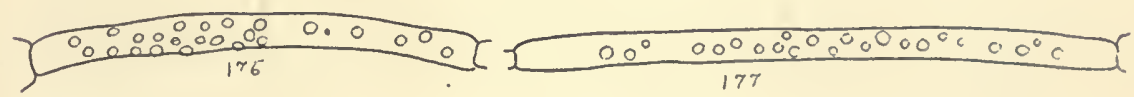

$\sqrt{\frac{000000000000000}{178}} \frac{1000000000 c}{179}$
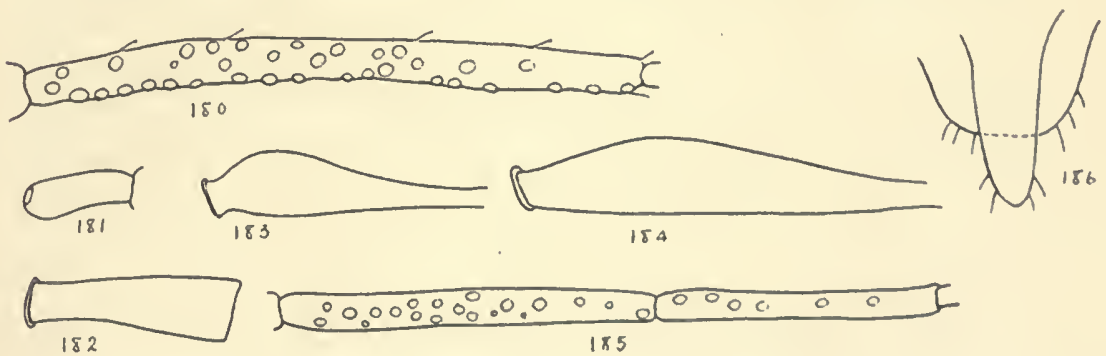

[SWAIN] PLATE ? 


\section{PLATE 10}

Fig. 187. Aphis euonomi Fabr., wing.

Fig. 188. Aphis salicicola Thomas, wing.

Fig. 189. Aphis medicaginis Koch, third and fourth antennal segments.

Fig. 190. Aphis ewonomi Fabr. (9), third and fourth antennal segments.

Fig. 191. Aphis avenae Fabr., wing.

Fig. 192. Aphis gossypii Glover, cornicle.

Fig. 193. Aphis gossypii Glover, cauda.

Fig. 194. Aphis sambucifoliae Fitch, cauda.

Fig. 195. Aphis sambucifoliae Fitch, cornicle.

Fig. 196. Myzaphis abietina (Walker), third and fourth antennal segments.

Fig. 197. Myzaphis abietina (Walker), cornicle.

Fig. 198. Aphis albipes Oest., cornicle.

Fig. 199. Aphis albipes Oest., cauda.

Fig. 200. Aphis albipes Oest., third and fourth antennal segments.

Fig. 201. Aphis avenae Fabr., cornicle.

Fig. 202. Aphis avenae Fabr., third and fourth antennal segments.

Fig. 203. Aphis brassicae Linn., cornicle.

Fig. 204. Aphis brassicae Linn., third and fourth antennal segments.

Fig. 205. Aphis euonomi Fabr., cornicle.

Fig. 206. Aphis euonomi Fabr., cornicle.

Fig. 207. Aphis euonomi Fabr., third and fourth antennal segments.

Fig. 208. Aphis cardui Linn., third and fourth antennal segments.

Fig. 209. Aphis cardui Linn., cornicle.

Fig. 210. Aphis ceanothi Clarke, cornicle.

Fig. 211. Aphis ceanothi Clarke, third and fourth antennal segments.

Fig. 212. Aptis cookii Essig, third and fourth antennal segments.

Fig. 213. Aphis cookii Essig, cauda and anal plate.

Fig. 214. Aphis cookii Essig, cornicle.

Fig. 215. Aphis gossypii Glover, third and fourth antennal segments.

Fig. 216. Aphis maidis Fiteh, cauda.

Fig. 217. Aphis maidis Fitch, antenna.

Fig. 218. Aphis maidis Fitch, cornicle.

Fig. 219. Aphis middletonii Thomas, cornicle.

Fig. 220. Aphis middletonii Thomas, third and fourth antennal segments.

Fig. 221. Aphis nerii Fonse., cornicle.

Fig. 222. Aphis nerii Fonsc., third and fourth antennal segments.

Fig. 223. Aphis persicae-niger Smith, cornicle.

Fig. 224. Aphis persicae-niger Smith, third and fourth antennal segments. 

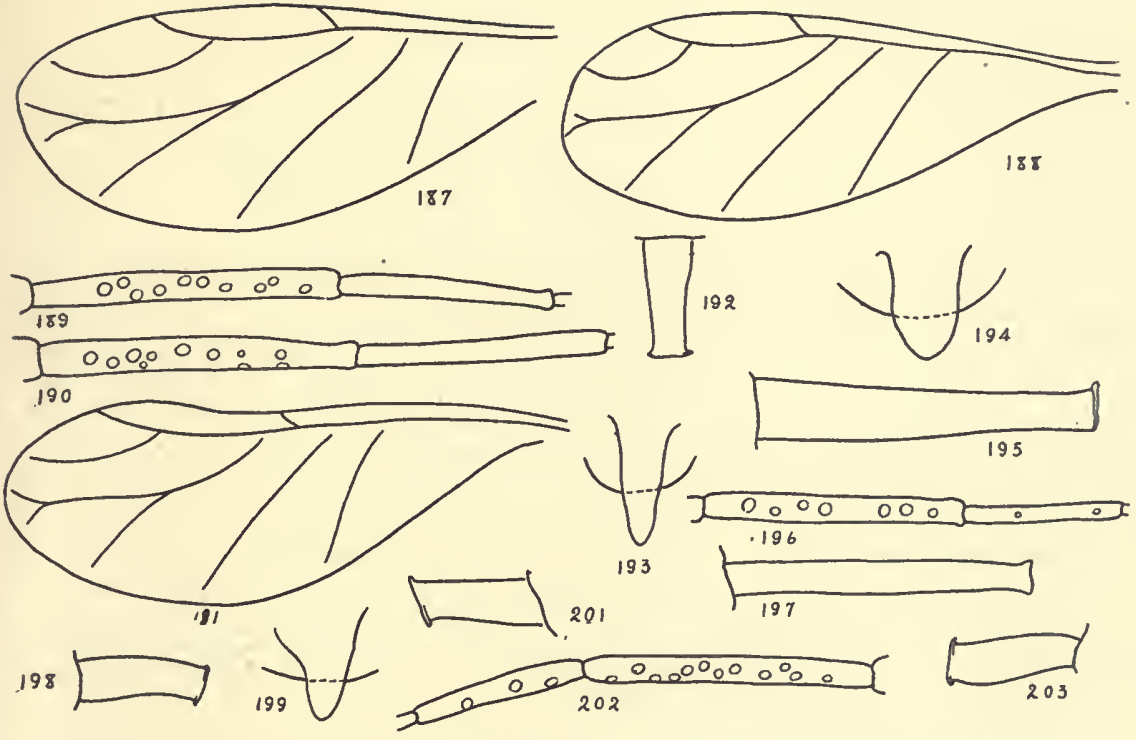

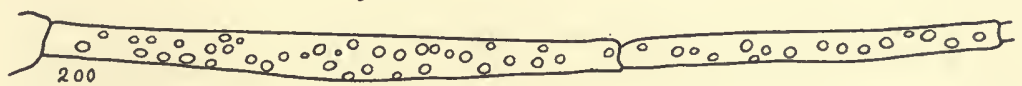
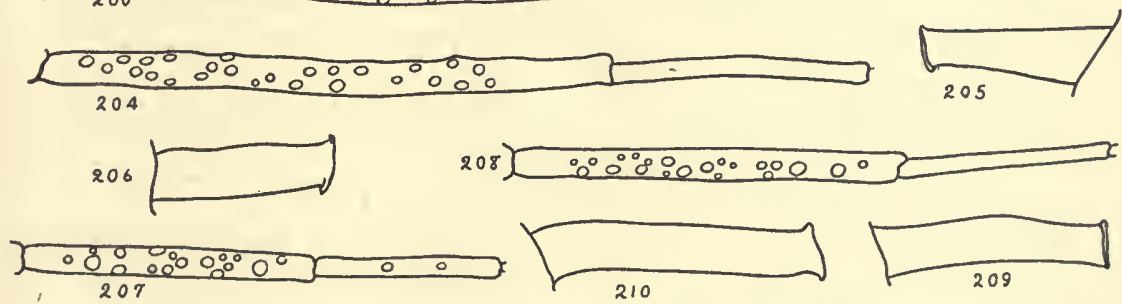

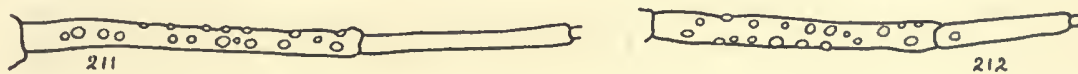
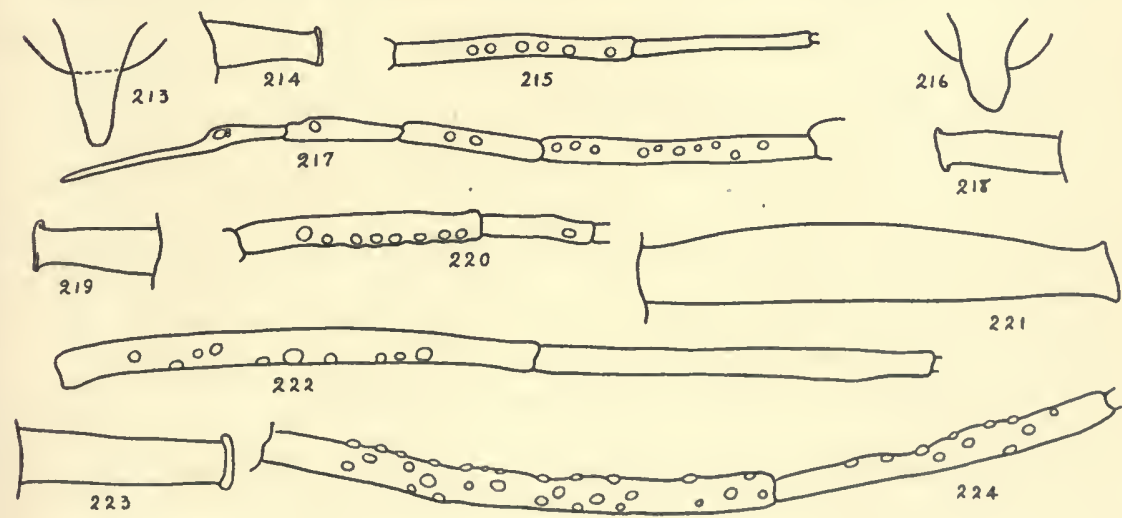

[SWAIN] PLATE 10 


\section{PLATE 11}

Fig. 225. Aphis pomi De Geer, canda.

Fig. 226. Aphis pomi De Geer, antennae.

Fig. 227. Aphis pomi De Geer, cornicle.

Fig. 228. Aphis prunorum Dobr., cauda.

Fig. 229. Aphis prunorum Dobr., third and fourth antennal segments.

Fig. 230. Aphis prunorum Dobr., cornicle.

Fig. 231. Aphis pscudobrassicac Davis, third and fourth antennal segments.

Fig. 232. Aplis ramona Swain, antenna.

Fig. 233. Aphis ramona Swain, front of head.

Fig. 234. Aphis ramona Swain, cauda and anal plate.

Fig. 235. Aphis ramona Swain, cornicle.

Fig. 236. Aphis euonomi Fabr., cornicle.

Fig. 237. Aphis euonomi Fabr., third and fourth antennal segments.

Fig. 238. Aphis salicicola Thomas, cornicle.

Fig. 239. Aphis salicicola Thomas, third and fourth antennal segments.

Fig. 240. Aphis sambucifoliae Fitch, third and fourth antennal segments.

Fig. 241. Aphis senecio Swain, cauda.

Fig. 242. Aphis senecio Swain, cornicle.

Fig. 243. Aphis senecio Swain, front of head.

Fig. 244. Aphis senecio Swain, third and fourth antennal segments.

Fig. 245. Aphis senecio Swain, fifth, sixth antennal segments, and spur.

Fig. 246. Aphis setarae Thomas, cornicle.

Fig. 247. Aphis setarae Thomas, third and fourth antennal segments.

Fig. 248. Aphis malifoliae Fitch, cornicle.

Fig. 250. Aphis malifoliae Fiteh, fourth antennal segment.

Fig. 251. Liosomaphis berberidis (Kalt.), front of head.

Fig. 252. Liosomaphis berberidis (Kalt.), third and fourth antennal segments.

Fig. 253. Siphocoryne capreae (Fabr.), third and fourth antennal segments.

Fig. 254. Siphocoryne capreae (Fabr.), fifth and sixth antennal segments and spur.

Fig. 255. Siphocoryne capreae (Fabr.), cauda and supra-caudal spine of alate females.

Fig. 256. Siphocoryne capreae (Fabr.), cauda and supra-caudal spine of apterous females.

Fig. 257. Siphocorync pastinacae (Linn.), third and fourth antennal segments.

Fig. 258. Siphocoryne pastinacae (Linn.), fifth and sixth antennal segments and spur.

Fig. 259. Siphocoryne pastinacae (Linn.), cauda of apterous female.

Fig. 260. Siphocoryne pastinacae (Linn.), cauda of alate female.

Fig. 261. Siphocoryne pastinacae (Linn.), cornicle. 

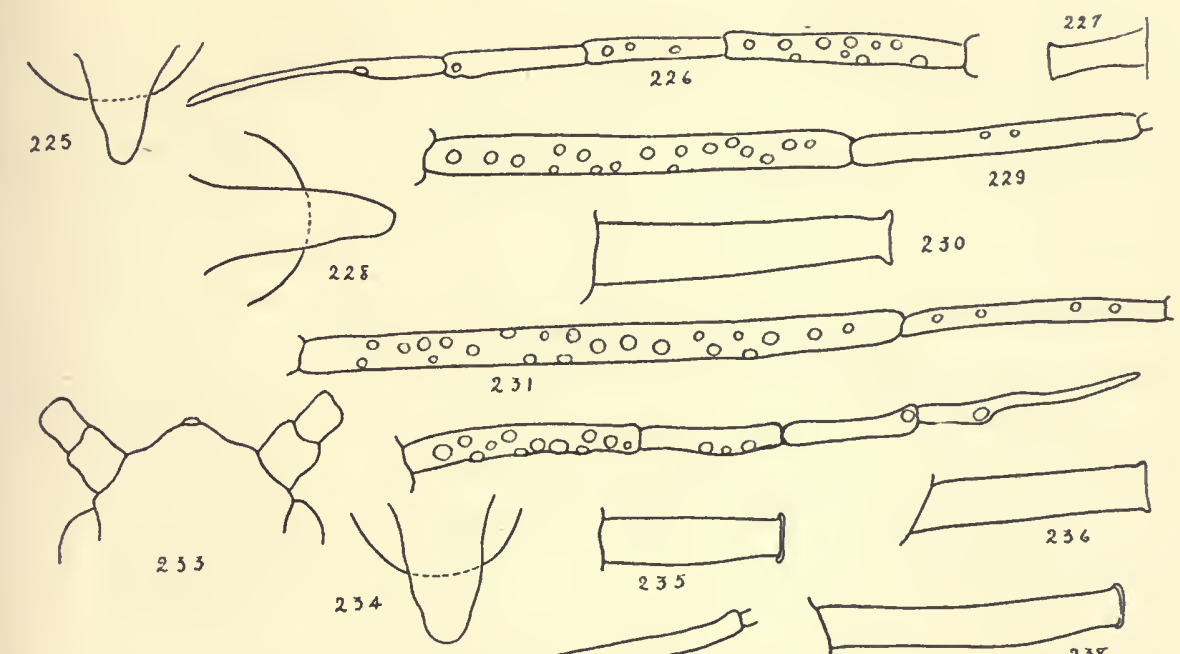

9
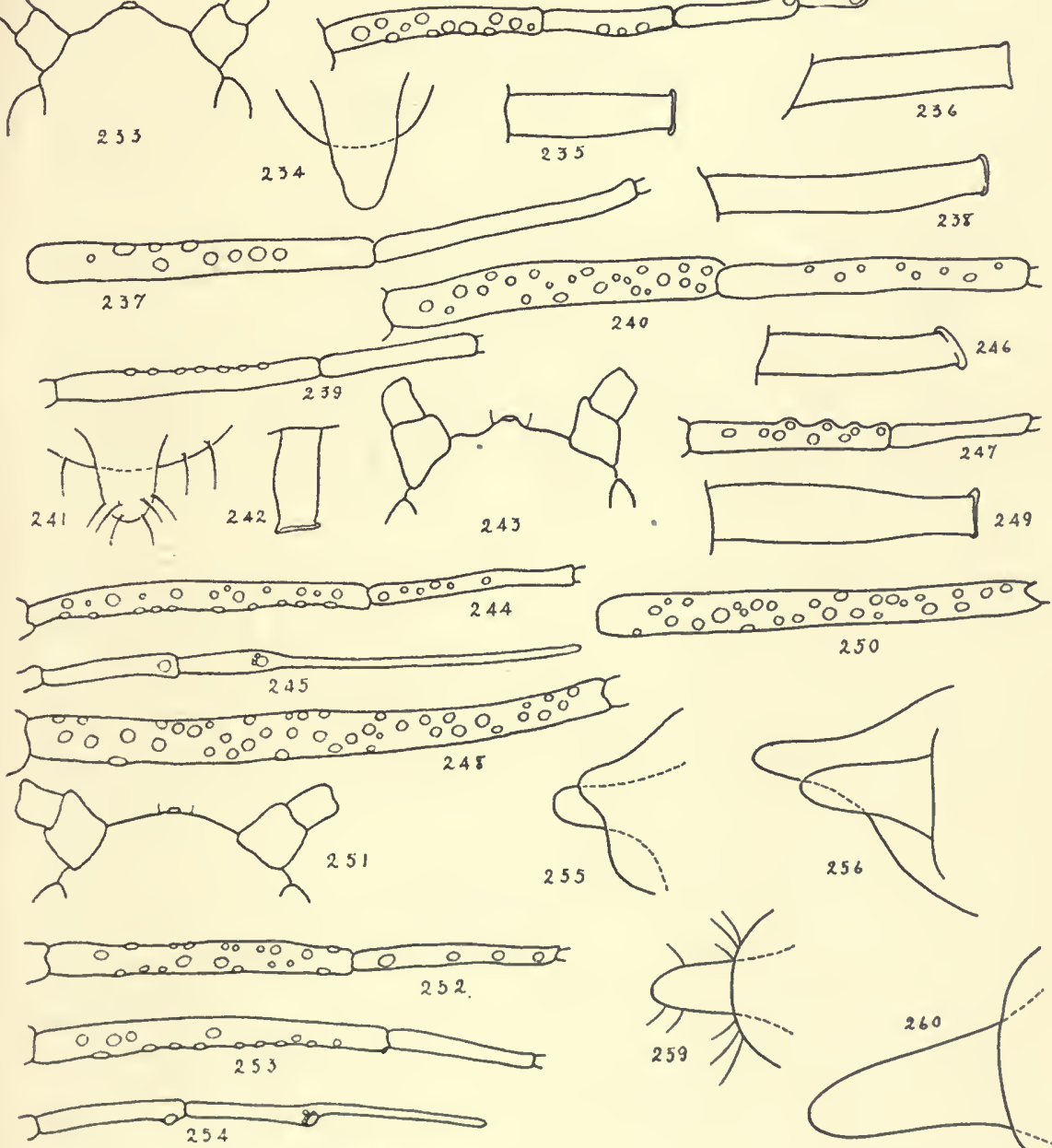

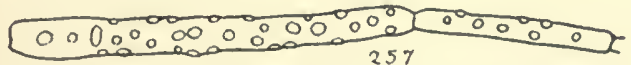
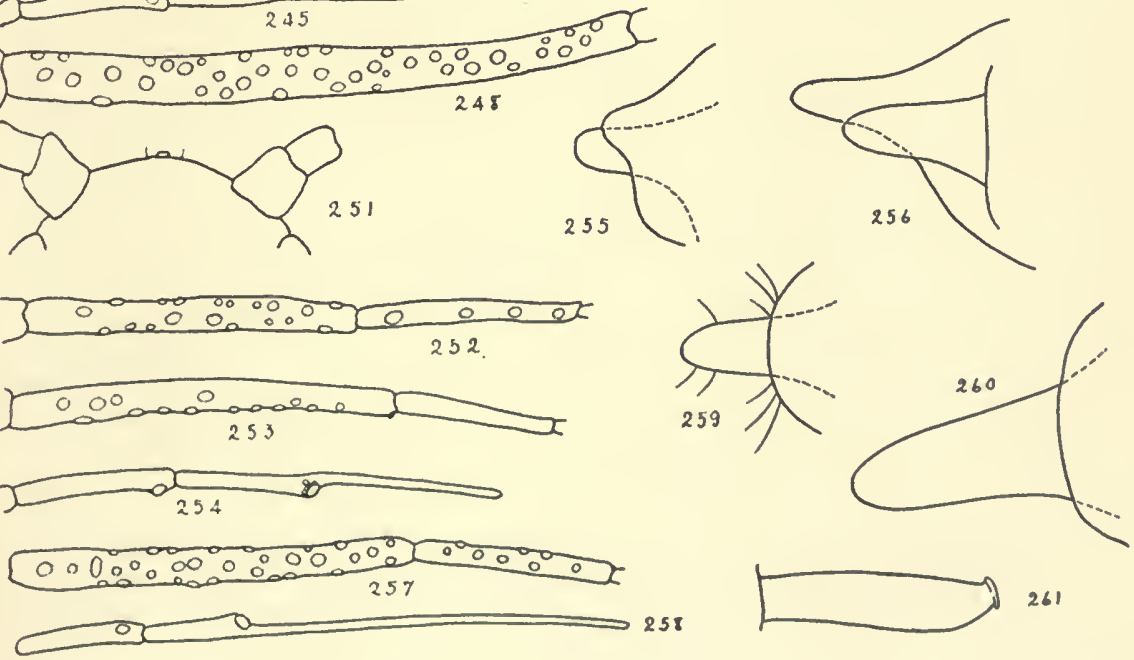

[SWAIN] PLATE 11 
PLATE 12

Fig. 262. Myzocallis discolor (Monell), fore wing.

Fig. 263. Myzocallis discolor (Monell), third antennal segment.

Fig. 264. Myzocallis bellus (Walsh), fore wing.

Fig. 265. Myzocallis bellus (Walsh), third antennal segment.

Fig. 266. Myzocallis californicus Baker (maureri Swain), fore wing.

Fig. 267. Myzocallis castanicola Baker (davidsoni Swain), fore wing.

Fig. 268. Myzocallis arundinariae Essig, third antennal segment. 

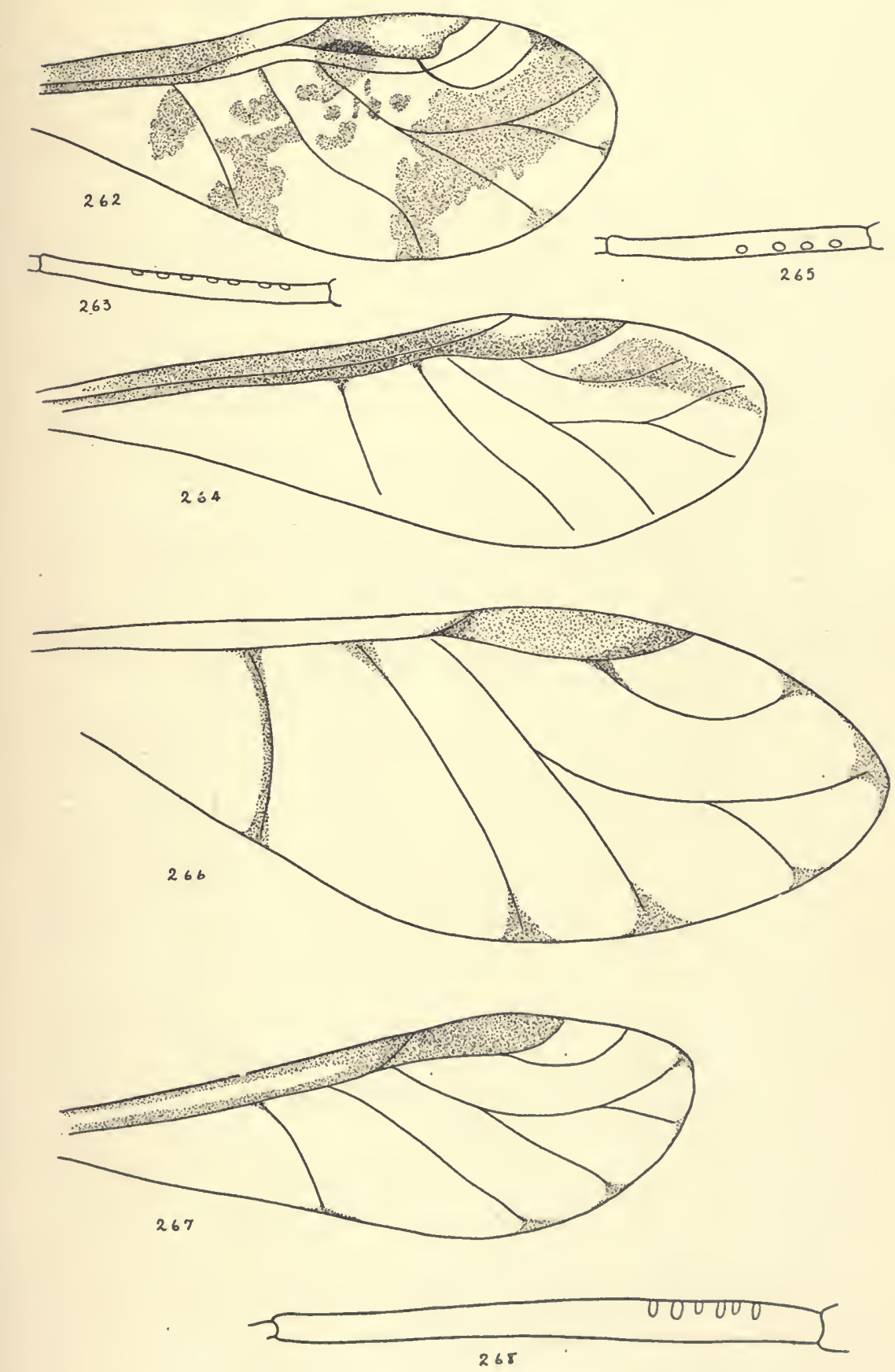

[SWAIN] PLATE 12 


\section{PLATE 13}

Fig. 269. Symydobius chrysolepis Swain, head.

Fig. 270. Synydobius chrysolepis Swain, cornicle.

Fig. 271. Symydobius chrysolepis Swain, anal plate.

Fig. 272. Symydobius chrysolepis Swain, antenna.

Fig. 273. Symydobius chrysolepis Swain, fore wing.

Fig. 274. Symydobius chrysolepis Swain, hind wing.

Fig. 275. Thomasia populicola (Thomas), fore wing. 

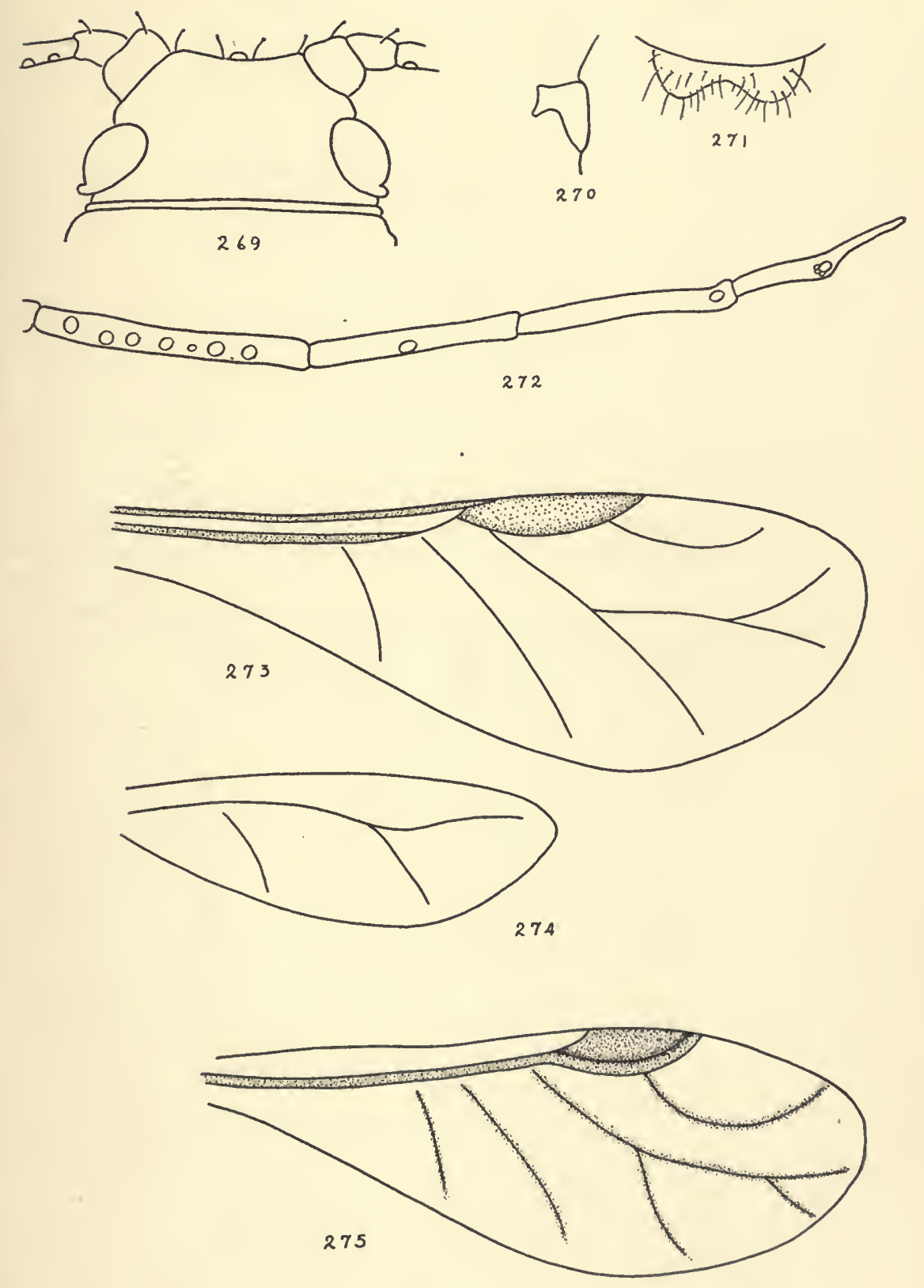

[SWAIN] PLATE 13 


\section{PLATE 14}

Fig. 276. Toxoptera aurantii (Fonsc.), fore wing.

Fig. 277. Rhopalosiphum lactucae (Kalt) head.

Fig. 278. Rhopalosiphum lactucae (Kalt.), third antennal segment, aptera.

Fig. 279. Rhopalosiphum lactucae (Kalt.), third antennal segment, alate.

Fig. 280. Rhopalosiphum lactucae (Kalt.), fourth and fifth antennal segments, alate.

Fig. 281. Rhopalosiphum lactucae (Kalt.), sixth antennal segment, alate.

Fig. 282. Rhopalosiphum lactucae (Kalt.), cornicle, alate.

Fig. 283. Rhopalosiphum lactucae (Kalt.), cauda, alate.

Fig. 284. Rhopalosiphum lactucae (Kalt.), cornicle, aptera.

Fig. 284a. Rhopalosiphum lactucae (Kalt.), cauda, aptera. 

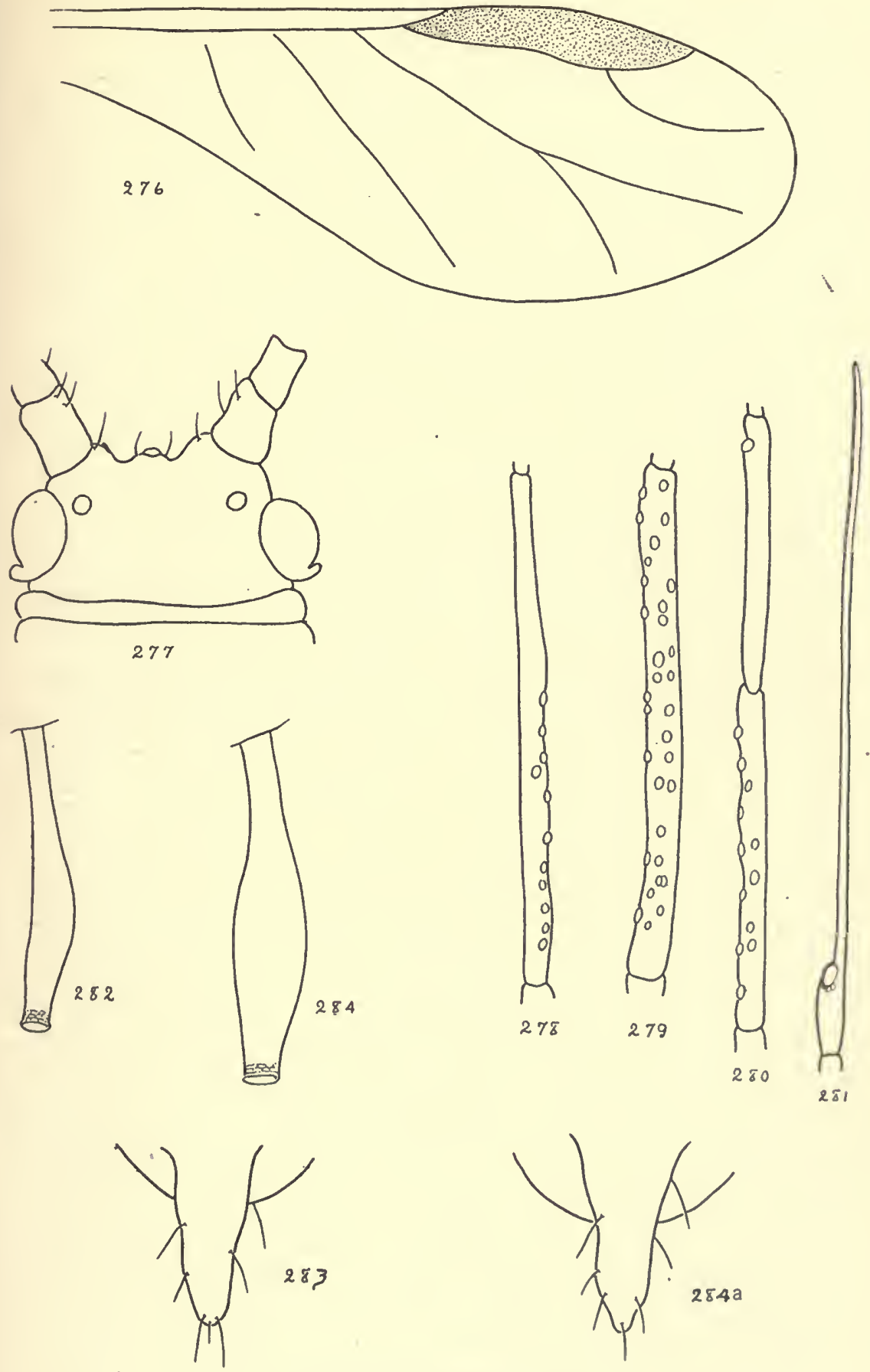

[SWAIN] PLATE 14 


\section{PLATE 15}

Fig. 285. Aphis viburnicolens n.sp., third antennal segment.

Fig. 286. Aphis viburnicolens n.sp., cornicle.

Fig. 287. Aphis viburnicolens n.sp., cauda.

Fig. 288. Aphis cerasifoliae (Fitch), head.

Fig. 289. Aphis cerasifoliae (Fitch), fifth and sixth antennal segments.

Fig. 290. Aphis cerasifoliae (Fitch), third and fourth antennal segments.

Fig. 291. Aphis cerasifoliae (Fitch), end of wing.

Fig. 292. Aphis cerasifoliae (Fitch), side of abdomen showing cauda, cornicle, and lateral tubercles on segments one, two, three, four, and seven. 

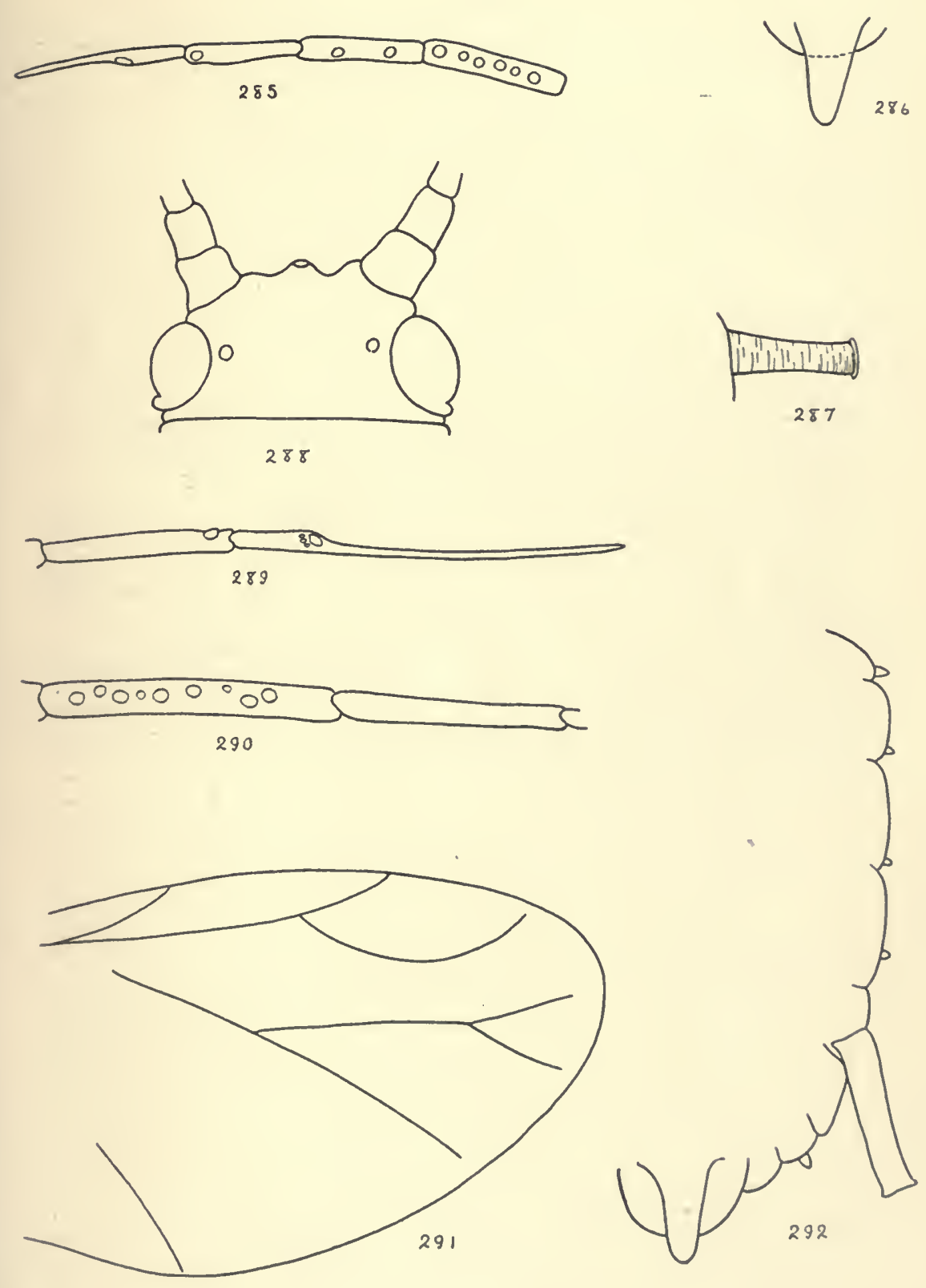

[SWAIN] PLATE 15 


\section{PLATE 16}

Fig. 293. Aphis marutae Oest., head.

Fig. 294. Aphis marutae Oest., third and fourth antennal segments.

Fig. 295. Aphis marutae Oest., fifth and sixth antennal segments.

Fig. 296. Aphis marutae Oest., antenna, aptera.

Fig. 297. Aphis marutae Oest., end of abdomen, aptera.

Fig. 298. Aphis marutae Oest., eauda, alate.

Fig. 299. Aphis marutae Oest., cornicle, alate.

Fig. 300. Aphis neomexicana Ckll., var. pacifica Dvdn., third and fourth antennal segments.

Fig. 301. Aphis neomexicana Ckll. var. pacifica Dvdn., cornicle.

Fig. 302. Aphis neomexicana Ckll. var. pacifica Dvdn., cauda.

Fig. 303. Aphis yuccae Cowen, fourth, fifth, and sixth antennal segments.

Fig. 304. Aphis yuccae Cowen, third antennal segment.

Fig. 305. Aphis yuccae Cowen, tip of abdomen. 

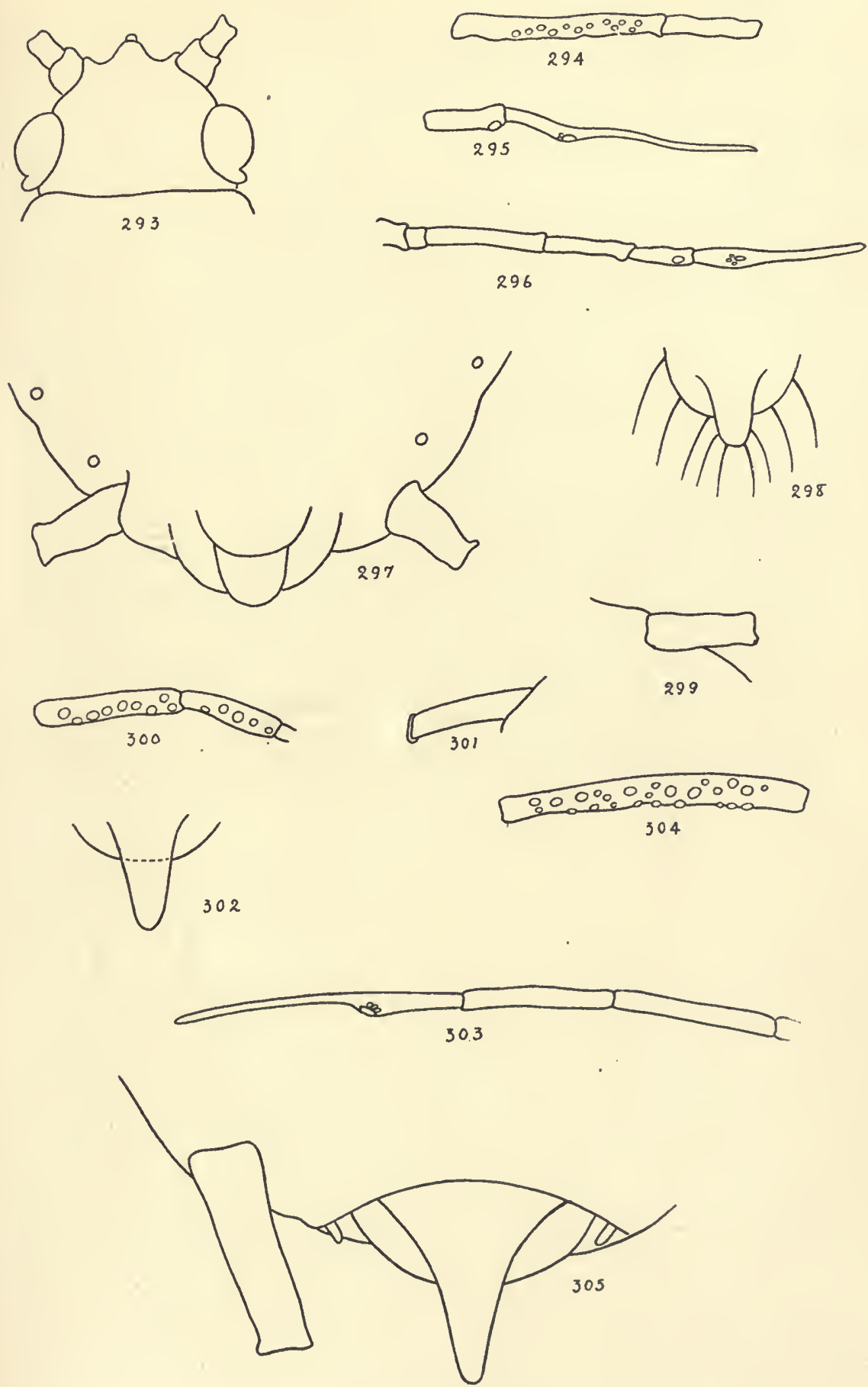

[SWAIN] PLATE 16 


\section{PLATE 17}

Fig. 306. Myzus ribis (Linn.), head.

Fig. 307. Myzus cerasi (Fabr.), head.

Fig. 308. Myzaphis rosarum (Walker), head, alate.

Fig. 309. Myzaphis rosarum (Walker), third and fourth antennal segments.

Fig. 310. Myzaphis rosarum (Walker), fifth and sixth antennal segments.

Fig. 311. Myzaphis rosarum (Walker), tip of wing.

Fig. 312. Myzaphus rosarum (Walker), end of abdomen.

Fig. 313. Myzaphis rosarum (Walker), head, aptera.

Fig. 314. Myzaphis rosarum (Walker), antenna, aptera.

Fig. 315. Myzaphis rosarum (Walker), cornicle, aptera.

Fig. 316. Myzaphis rosarum (Walker), cauda, aptera.

Fig. 317. Myzaphis rosarum (Walker), hind tarsus, aptera. 

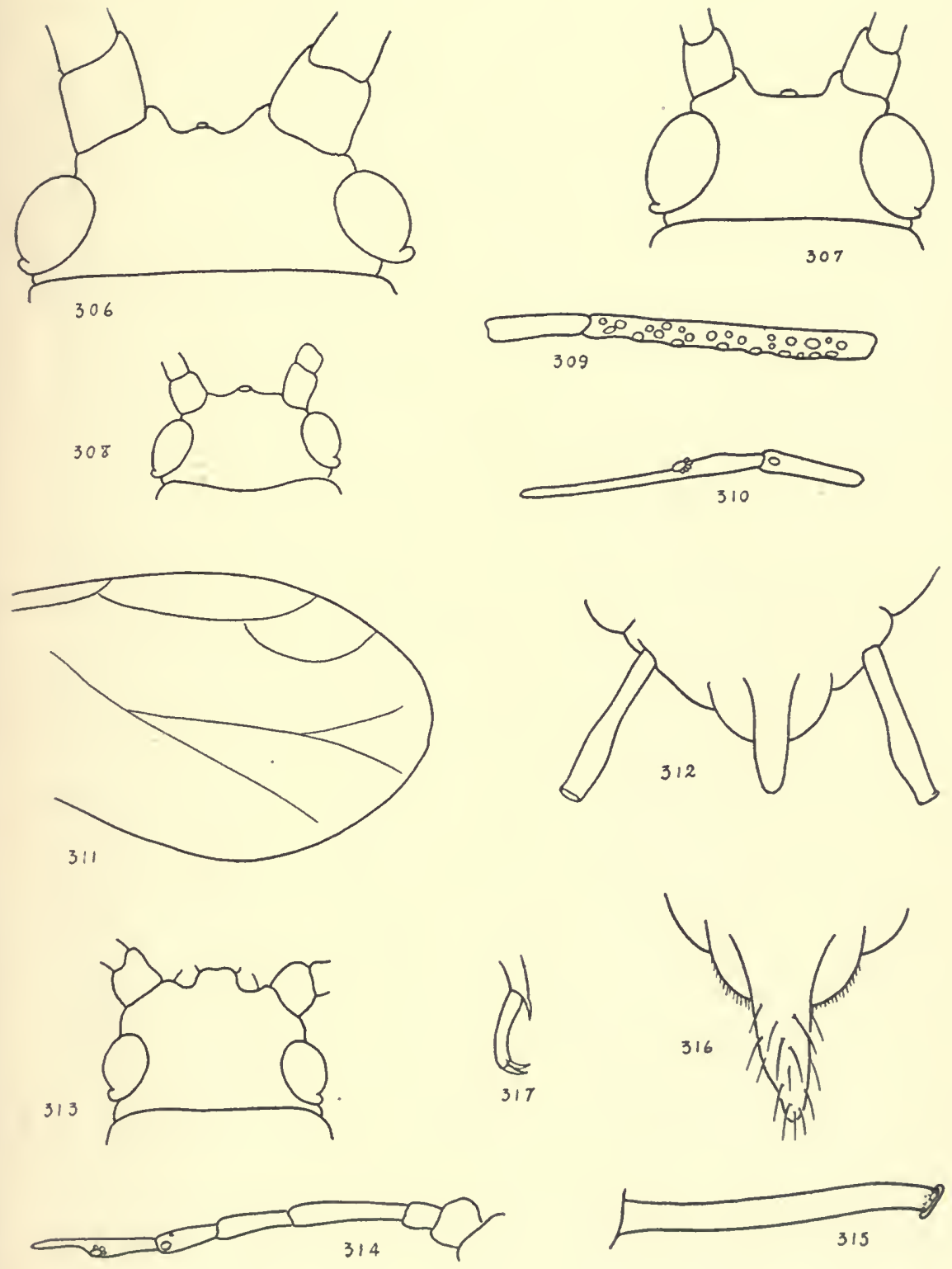

[SWAIN] PLATE 17 



\section{INDEX TO GENERA AND SPECIES}

abietes, Lachnus, 47.

abietina, Myzaphis (Aphis), 134. abietinus, Mindarus, 150.

acerifolii, Drepanaphis (Siphonophora, Macrosiphum), 18.

achyrantes, Rhopalosiphum, 80.

agrifoliae, Symydobius, 38.

alamedensis, Aphis, 93.

albifrons, Macrosiphum, 60.

albipes, Aphis, 93.

alni, Myzocallis, 21.

alnifoliae, Callipterus, 20.

alnifoliae Lachnus, 20.

alnifoliae Myzocallis, 22.

alnifoliae Prociphilus (Pemphigus), 146.

ambrosiae, Macrosiphum (Siphonophora), 60.

americana, Eriosoma (Schizoneura), 148.

Amphorophora, 54.

cicutae, 54.

latvsiphon, 54, 178.

rubi, 54.

rubicola, 77

angelicae, Aphis, 93.

annulata, Callipterinella (Chaitophorus), 31.

Aphis, 88.

abietina, 134.

alamedensis, 93.

albipes, 93.

angelicae, 93.

artemisiae, 61.

arundinis, 130.

atriplicis, 93.

aurantii, 129.

avenae, 94, 179.

bakeri, 123, 124.

bakeri, 6, 179 .

bellus, 24.

berberidis, 130.

betulaecolens, 18.

brassicae, 95.

calendulicola, 96 .

capreae, 132.

cardui, 96.

cari, 96, 179.

caryella, 30 .

ceanothi, 96.

ceanothi-hirsuti, 96.

cerasi, 73 .

cerasifoliae, 97.

citri, 105.

cooki, 100.

cornifoliae, 100.

coryli, 25.

crataegifoliae, 100. dirhodum, 63.

dryophila, 150.

euonomi, 101.

fabae, 102, 104.

fagi, 13.

frigidae, 105.

gossypii, 100.

gossypii, 105, 179.

granarium, 64.

hederae, 106.

heraclei, 107.

houghtonensis, 107.

humuli, 79.

juglandis, 28.

lactucae, 82.

languinosa, 149.

lanigerum, 149.

lithospermi, 108.

lutescens, 117.

maidis, 94.

maidis, 108.

mali, 120.

malifoliae, 108 .

marutae, 112.

medicaginis, 114, 179.

middletonii, 115.

mori, 116.

neomexicana, 116.

nerii, 117.

nymphaeae, 133.

oenotherae, 118.

oregonensis, 119.

padi, 94.

papaveris, 102, 104.

pastinacae, 133.

persicae, 85.

persicae-niger, 119.

pisi, 66.

platanoides, 17.

pomi, 120, 179.

pomi, 109.

populifoliae, 41.

pruni, 96.

prunorum, 121, 179.

prunifoliae, 130, 179.

pseudobrassicae, 122, 179.

quercus, 27.

ramona, 122.

rhamni, 76 .

rosae, 67.

rosarum, 134.

rubi, 54 .

rubiphila, 122.

rudbeckiae, 67.

rufomaculata, 137.

rumicis, 101, 106.

salicicola, 123.

sambucifoliae, 123.

senecio, 123, 179.

setariae, 124. 
sorbi, 108.

spiraecola, 124.

spiraeella, 125, 126.

taraxici, 71.

tetrapteralis, 125 .

tiliae, 21.

viburnicolens, 126, 179.

viminalis, 45.

vuccae, 45.

yuccicola, 128.

aquilegiae, Myzus, 73.

arbuti, Rhopalosiphum, 84.

Aretaphis, 33.

populifolii, 33 .

viminalis, 34 .

artemisicola, Macrosiphum (Siphonophora), 61.

artemisiae, Macrosiphum (Aphis), 61. arundicolens, Eucallipterus (Myzocallis), 24.

arundicolens, Myzocallis (Callipterus), 22.

arundinariae, Myzocallis, 24.

arundinis, Hyalopterus (Aphis), 130, 179.

atriplicis, Aphis, 93.

aurantiae, Toxoptera, 129.

aurantii, Toxoptera (Aphis), 129, 179. avenae, Aphis (Neetarophora, Siphocoryne), 94, 179.

\section{B}

baccharadis, Macrosiphum (Nectarophora), 61.

bakeri, Aphis, 123.

bakeri, Aphis, 6, 179 .

balsamiferae, Pemphigus, 142.

bellus, Myzocallis (Aphis, Callipterus), 24.

berberidis, Liosomaphis (Aphis, Rhopalosiphum), 130.

betae, Pemphigus, 142.

betulae, Chaitophorus, 31.

betulae, Euceraphis (Callipterus), 19, 178.

betulaecolens, Calaphis (Aphis, Callipterus), 18.

braggii, Myzus, 73.

brassicae, Aphis, 95.

Byrsocrypta, 148.

ulmicola, 148.

C

calendulicola, Aphis, 96.

Calaphis, 18.

betulaecolens, 18 .

castaneae, 24.

californica, Essigella (Lachnus), 44. californicum, Macrosiphum (Nectaroplora), 62.

californicus, Callipterus (Monellia), 29.

californicus Myzocallis, 178.

californicus Thecabius (Pemphigus), 144.
Callipterinella, 31 .

annulata, 31 .

Callipterus, 28.

alnifoliae, 20.

arundicolens, 22.

bellus, 24.

betulae, 19.

betulaecolens, 18.

californicus, 29.

caryae, 29.

caryella, 30 .

castaneae, 24.

coryli, 25.

discolor, 25.

hyalinus, 26.

juglandicola, 28.

juglandis, 28.

punctatus, 26.

quercus, 27.

tiliae, 21.

ulmifolii, 27.

viminalis, 34.

capreae, Siphocoryne (Aphis), 132.

cardui, Aphis, 96.

carduinum, Phorodon, 73.

cari, Aphis, 96, 179.

caryae, Callipterus (Monellia), 29.

caryella, Monellia (Aphis, Callipterus), 30.

castaneae, Calaphis (Callipterus), 24.

eastaneae, Myzocallis, 178.

eastanicola, Myzocallis, 178.

ceanothi, Aphis, 96 .

ceanothi-hirsuti, Aphis, 96.

cerasi, Myzus (Aphis), 73.

cerasifoliae, Aphis, 97.

Cerataphis, 140 .

lataniae, 140.

Cerosipha, 137.

cupressi, 137.

Chaitophorus, 33.

annulata, 31 .

betulae, 31 .

negundinis, 36 .

nigrae, 37.

populicola, 36.

populifoliae, 33.

salicicola, 37.

smithiae, 34.

viminalis, 34 .

Chermes, 151.

cooleyi, 151.

coweni, 151.

pinicorticis, 152.

Chromaphis, 28.

juglandicola, 28.

chrysanthemi, Macrosiphum (Siphonophora), 62.

chrysanthemi, Macrosiphum, 69.

chrysolepis, Symydobius, 38.

cicutae, Amphorophora, 54.

circumflexus, Myzus (Siphonophora).

citri, Aphis, 105. 
citrifolii, Macrosiphum (Nectarophora), 69.

Cladobius, 41. rufulus, 41. salicti, 43.

Coccus, 140. lataniae, 140. pinicorticis, 152.

Colopha, 148. ulmicola, 148.

Coloradoa, 137. rufomaculata, 137. conii, Siphocoryne, 133. cooki, Aphis, 100.

cooleyi, Chermes, 151. cornifoliae, Aphis, 100.

coryli, Myzocallis (Aphis, Callipterus), 25.

corylinum, Rhopalosiphum, 81.

coweni, Chermes, 151.

coweni, Phyllaphis (Pemphigus), 13.

crataegifolii, Aphis, 100.

erueis, Thomasia, 36.

Cryptosiphum, 13.

tahoense, 13.

cucurbitae, Macrosiphum (Siphonophora), 62.

cupressi, Cerosipha, 137.

cynosbati, Myzus (Nectarophora), 75.

D

davidsoni, Myzocallis, 24, 178.

dentatus, Lachnus, 45.

destructor, Macrosiphum, 66.

dianthi, Rhopalosiphum, 85.

dirhodum, Macrosiphum (Aphis), 63.

discolor, Myzocallis (Callipterus), 25.

Drepanaphis, 18.

acerifolii, 18.

Drepanosiphum, 17. acerifolii, 18.

platanoides, 17.

dryophila, Vacuna (Aphis, Chaitophorus), 150.

\section{$\mathrm{E}$}

Eichochaitophorus, 33. populifolii, 33.

Eriosoma, 148.

americana, 148.

languinosa, 149, 179.

lanigerum, 149. pyricola, 149.

Essigella, 44. californica, 44.

cssigi, Myzocallis, 27.

Eucallipterus, 20.

arundicolens, 24.

flava, 20 .

tiliae, 21, 178.

Euceraphis, 19. betulae, $19,178$.

flava, $2 \mathrm{v}$.

gillettei, 20.

euonomi, Aphis, 101.
F

fagi, Phyllaphis, 13, 178.

ferrisi, Lachnus, 47.

flava, Eucallipterus (Euceraphis), 20.

floceulosa, Pterocomma (Melanoxanthus), 40 .

foeniculi, Siphocoryne, 132.

fragaefolii, Myzus, 75 .

fraxini-dipetalae, Prociphilus (Pemphigus), 146.

frigidae, Aphis, 105.

frigidae, Macrosiphum, 61.

Fullawaya, 35.

saliciradicis, 35 .

\section{$\mathrm{G}$}

galeopsidis, Phorodon, 81.

gillettei, Euceraphis, 20.

glehnus, Lachnus, 47.

godetiae, Myzus, 85.

gossypii, Aphis, 100.

gossypii, Aphis, 105, 179.

granarium, Macrosiphum (Aphis), 64, 178.

$\mathrm{H}$

hederae, Aphis, 106.

heraclei, Aphis, 107.

heucherae, Macrosiphum (Siphonophora), 64.

hippophoaes, Rhopalosiphum, 81.

houghtonensis, Aphis, 107.

howardi, Rhopalosiphum, 86.

humuli, Phorodon (Aphis), 79.

Hyadaphis, 132.

pastinacae, 132.

umbellulariae, 133.

hyalinus, Myzocallis (Callipterus), 26.

Hyalopterus, 130.

arundinis, 130, 179.

Idiopterus, 56.

nephrelepidis, 56 .

J

jasmini, Macrosiphum (Nectarophora), 64.

juglandicola, Chromaphis (Lachnus, Callipterus), 28.

juglandis, Callipterus (Aphis), 28.

junipcri, Lachnus, 50.

Lachniella, 50.

tujafilinus, 50.

Lachnus, 45 .

abietis, 47.

alnifoliae, 20, 22.

californicus, 44.

dentat?us, 45 .

ferrisi, 47 .

glehnus, 47.

juglandicola, 28.

juniperi, 50 .

L.

22.


oceidentalis, 17.

oregonensis, 48.

pini-radiatae, 48, 178.

ponderosa, 48.

psendotsugae, 48.

sabinianus, 49 .

taxifolia, 50 .

tomentosus, 178 .

tujafilinus, 50 .

vanduzei, 50 .

viminalis, 45.

lactucae, Macrosiplum (Ncctarophora), 65.

lactuea Rhopalosiphum ( $A$ phis), 82.

laevigatae, Macrosiphum, 62.

languinosa, Eriosoma (Aphis), 149, 179.

langermu, Eriosoma (Aphis, Schizoneura), 149.

lataniae, Cerataphis (Coccus), 140.

latysiphon, Amphorophora, 54, 178.

Liosomaphis, 130.

berberidis, 130 .

lithospermi, Aphis, 108.

ludovicianae, Macrosiphum (Siphonophora), 65.

lutescens, Aphis, 117.

lycopersici, Myzus (Ncctarophora), 76.

\section{M}

Macrosiphum, 57.

accrifolii, 18.

albifrons, 60 .

ambrosiae, 60 .

artemisine, 61 .

artemisicola, 61 .

baceliaradis, 61 .

ealifornicum, 62 .

chrysanthemi, 62.

chrysanthemi, 69 .

citrifolii, 69.

cucurbitae, 62

destructor, 66.

dirhodum, 63.

frigidae, 61.

granarium, 64, 178.

heucherae, 64 .

jasmini, 64 .

lactucae, 65.

laevigatae, 62.

ludovicianae, 65 .

orthocarpus, 66 .

pisi, 66.

pteridis, 67.

rosae, 67.

rubicola, 77.

rudbeckiae, 67 .

rudbeckiae var. madia, 68 .

sanborni, 69.

solanifolii, 69,178 .

sonchella, 70 .

sonchi, 60.

stanleyi, 70 . taraxici, 71.

tulipae, 71 .

valerianae, 71 .

macrostachyae, Syındobius, 38.

madia, Macrosiphum (rudbeckiae), 68 .

maidis, Aphis, 84.

maidis, Aphis, 108.

mali, Aphis, 120.

malifoliae, Aplis, 108.

marutae, Aphis, 112.

maureri, Myzocallis, 26, 178.

medicaginis, Aphis, 114, 179.

Melanoxantherium, 41.

rufulum, 41.

salicti, 43.

Mclanoxanthus, 40.

flocculosa, 40 .

Micrella, 35.

monella, 35 .

middletonii, Aphis, 115.

Mindarus, 150.

abietinus, 150 .

monella, Mierella, 35 .

Monellia, 29.

californicus, 29.

caryae, 29.

caryella, 30 .

mori, Aphis, 116.

morrisoni, Neetarosiphon, 78.

Myzaphis, 134.

abietina, 134 .

rosarum, 134.

Myzocallis, 21.

alni, 21.

alnifoliae, 22.

arundicolens, 22.

arundicolens, 24.

arundinariae, 24.

bellus, 24 .

ealifornicus, 178.

castaneae, 178.

castanicola, 178.

coryli, 25.

davidsoni, 24, 178.

discolor, 25.

cssigi, 27.

hyalinus, 26.

maureri, 26, 178.

pasaniae, 26 .

punctatus, 26.

quereus, 27.

uhnifolii, 27.

wooduorthi, 27.

Myzus, 71 .

aquelegiae, 73 .

braggii, 73 .

cerasi, 73 .

circumflexus, 74 .

cynosbati, 75.

fragaefolii, 75 .

godetiae, 85.

lyeopersici, 76 .

persicae, 80,85 .

rhainni, 76. 
ribes, 75 .

ribifolii, 76 .

rosarum, 134.

varians, 77 .

vincae, 74 .

\section{$\mathrm{N}$}

Nectarophora

avenae, 94.

baccharadis, 61.

ealifornicum, 62.

citrifolii, 69.

oynosbati, 75 .

jasmini, 64 .

lactucae, 65.

lycopersici, 76.

pisi, 66.

rhamni, 76.

rosae, 67.

sonchella, 70 .

valerianae, 71 .

Nectarosiphon, 77.

morrisoni, 78 .

rubicola, 77 .

negundinis, Thomasia (Chaitophorus), 36.

neomexicana, Aphis, 116.

nephrelepidis, Idiopterus, 56.

nerii, Aphis, 117.

nervatum, Rhopalosiphum, 84.

nigrae, Chaitophorus, 37.

nigronervosa, Pentalonia, 78.

nymphaeae, Siphocoryne (Aphis, Rhopalosiphum), 133, 179.

\section{0}

oceidentalis, Lachnus, 47.

oenotherae, Aphis, 118.

oregonensis, Aphis, 119.

oregonensis, Lachnus, 48.

orthocarpus, Macrosiphum, 66.

$$
\mathrm{P}
$$

padi, Aphis, 94.

panicola, Schizoneura, 150.

pasaniae, Myzocallis, 26.

pastinacae, Siphocoryne (Aphis, Hy. adaphis), 133.

pastinacae, Hyadaphis, 132.

Pemphigus, 141.

alnifoliae, 146.

balsamiferae, 142.

betae, 142 .

californicus, 144.

coweni, 13.

fraxini-dipetalae, 146.

populieaulis, 143.

populiconduplifolius, 145.

populimonilis, 145.

populi-transversus, 143.

populi-transversus, 143.

radicioola, 141.

ranunculi, 144.

venafuscus, 146.
Pentalonia, 78.

nigronervosa, 78 .

persicae, Rhopalosiphum (Aphis, Myzus), 179, 185.

persicae-niger, Aphis, 119.

Phorodon, 79.

carduinum, 73.

galeopsidis, 81.

humuli, 79.

serophulariae, 80 .

Phyllaphis, 12.

coweni, 13.

fagi, 13,178 .

querci, 15.

quercicola, 15.

Phylloxera, 152.

popularia, 153.

salicola, 153.

vastatrix, 152.

vitifoliae, 152.

Phylloxerina, 153.

popularia, 153.

salicola, 153.

pinicorticis, Chermes, 152.

pini-radiatae, Lachnus, 48, 178.

pisi, Macrosiphum (Aphis, Nectarophora), 66.

platanoides, Drepanosiphum (Aphis), 17.

pomi, Aphis, 109.

pomi, Aphis, 120, 179.

ponderosa, Lachnus, 48.

popularia, Phylloxerina (Phylloxera), 293.

populea, Pterocomma, 41.

populieaulis, Pemphigus, 143.

populicola, Thomasia (Chaitophorus), 36.

populiconduplifolius, Thecabius (Pemphigus), 145.

populifoliae, Chaitophorus, 33.

populifoliae, Pterocomma (Aphis), 41.

populifolii, Arctaphis (Eichochaitophorus), 33.

populimonilis, Thecabius (Pemphigus), 145.

populi-transiersus, Pemphigus, 143.

populi-transversus, Pemphigus, 143.

Prociphilus, 146.

alnifoliae, 146.

fraxini-dipetalae, 146.

venafuseus, 146.

pruni, Aphis, 96.

prunifoliac, Aphis, 130, 179

prunorum, Aphis, 121, 179.

pseudobrassicae, Aphis, 122, 179.

pseudotsugae, Lachnus, 48.

pteridis, Macrosiphum, 67.

Pterocomma, 40.

floceulosa, 40 .

populea, 41.

populifoliae, 41.

smithiae, 43. 
punctatus, Myzocallis (Callipterus), 26.

pyrieola, Eriosoma, 149.

\section{Q}

querci, Phyllaphis, 15.

querci, Schizoneura, 15.

quercicola, Phyllaphis, 15.

quercus, Myzocallis (Aphis, Callipterus), 27.

\section{$\mathrm{R}$}

radicicola, Trifidaphis (Pemphigus), 141.

ramona, Aphis, 122

ranunculi, Pemphigus, 144.

rhamni, Aphis, 76.

rlamni, Myzus (Nectarophora), 76.

rhois, Rhopalosiphum, 86.

Rlopalosiphum, 80 .

achyrantis, 80 .

arbuti, 84.

berberidis, 130.

corylinum, 81.

dianthi, 85.

hippoploaes, 81.

howardi, 86 .

laetueac, 82 .

nervatum, 84 .

nym phacae, 133.

persicae, 85, 179.

rhois, 86.

tulipae, 85.

violae, 86

ribifolii, Myzus, 76.

ribes, Myzus, 75 .

rosae, Macrosiphum (Aphis, Nectarophora), 67.

rosarum, Myzaphis (Aphis, Myzus), 134.

rubi, Amphorophora (Aphis), 54.

rubicola, Nectarosiphum (Macrosiphum) (Amphorophora), 77.

rubiphila, Aphis, 122.

rudbeckiae, Macrosiphum (Aphis), 67.

rudbeckiae var. madia, Macrosiphum, 68.

rufomaculata, Coloradoa (Aphis), 137.

rufulum, Melanoxantherium, 41.

rufulus, Cladobius, 41.

rumicis, Aphis, 101.

\section{$\mathrm{S}$}

sabinianus, Lachuus, 49.

salicicola, Aphis, 123.

salicicola, Thomasia (Chaitophorus), 37.

salicicorticis, Symydobius, 39.

saliciradicis, Fullawaya, 35 .

salicis, Siphocoryne, 132.

salicola, Phylloxerina (Phylloxera), 153.

salicti, Cladobius (Melanoxan. therium), 43 . sambucifoliae, Aphis, 123.

sanborni, Macrosiphum, 69 .

Schizoncura, 148.

amerioana, 148 .

lanigerum, 149.

panicola, 150 .

querci, 15.

scrophulariae, Phorodon, 80.

senecio, Aphis, 123, 179.

setariae, Aphis, 124.

Siphocoryne, 131.

avenae, 84.

capreac, 132.

conii, 133.

foeniculi, 132.

nymphaeae, 133, 179.

pastinacae, 133.

salicis, 132.

xylostei, 133.

Siphonophora, 60.

aecrifolii, 18.

ambrosiae, 60 .

artemisicola, 61.

chrysanthemi, 62.

cireumflcxus, 74.

cueurbitae, 62.

heucherae, 64.

ludovicianae, 65.

solanifolii, 69 .

sonchella, 70 .

tulipae, 71.

smithiae, Pterocomma (Chaitophorus), 43.

solanifolii, Macrosiphum (Siphonophora) , 69, 179 .

sonchella, Macrosiphum (Siphonophora) (Nectarophora), 70.

sonchi, Macrosiphum, 60.

sorbi, Aphis, 108.

spiraccola, Aplis, 124.

spiraeella, Aphis, 125, 126.

stanleyi, Macrosiphum, 70.

Symydobius, 37.

agrifoliae, 38 .

chrysolepis, 38.

macrostachyae, 38 .

salicicorticis, 39 .

\section{$\mathrm{T}$}

tahoense, Cryptosiphum, 13.

taraxici, Macrosiphum (Aphis), 71.

taxifolia, Lachnus, 50 .

tetrapteralis, Aphis, 125.

Thecabius, 144.

californicus, 144.

populiconduplifolius, 145 . populimonilis, 145 .

Thomasia, 35.

crueis, 36.

negundinis, 36 .

populicola, 36 .

salicicola, 37 .

viminalis, 34 . 
tiliae, Eucallipterus (Aphis, Callipterus), $21,178$.

tomentosus, Lachnus, 178.

Toxoptera, 129.

aurantiae, 129.

aurantii, 129, 179.

Trifidaphis, 141.

radicicola, 141.

Tuberolachnus, 45 .

viminalis, 45.

tujafilinus, Lachnus (Lachneilla), 50.

tulipae, Maerosiphum (Siphonophora), 71 .

tulipae, Rhopalosiphum, 85.

\section{$\mathrm{U}$}

ulmicola, Colopha (Brysocrypta), 148. ulmifolii, Myzocallis (Callipterus), 27. umbellulariae, Hyadaphis, 133.

Vacuna, 150.

dryophila, 150.

valerianae, Macrosiphum (Nectarophora), 71. vanduzei, Lachnus, 50 .

varians, Myzus, 77.

vastatrix, Phylloxera, 152.

venafuscus, Prociphilus (Pemphigus), 146.

virburnicolens, A phis, 126, 179.

viminalis, Aretaphis (Callipterus, Chaitophorus, Thomasia), 34.

viminalis, Tuberolachnus (Lachnus) (Aphis), 45.

vincae, Myzus, 74.

violae, Rhopalosiphum, 86.

vitifoliae, Phylloxera, 152.

W

woodworthi, Myzocallis, 27.

X

xylostei, Siphocoryne, 133.

$\mathrm{Y}$

yuccae, Aphis, 128.

yuccicola, Aphis, 128. 



\section{MUTATION IN MATTHIOLA}

BY

HOWARD B. FROST

[University of California Publications in Agricultural Sciences, Vol. 2, No.4, pp. 81-190] 



\section{MUTATION IN MATTHIOLA}

BY

HOWARD B. FROST

\section{CONTENTS}

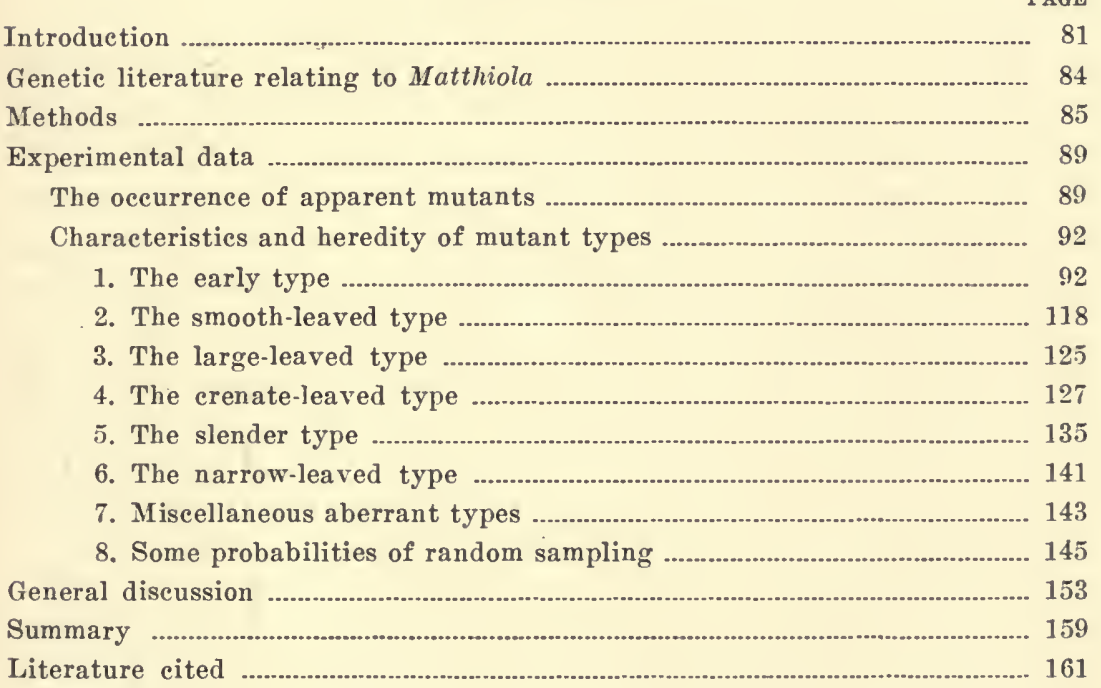

\section{INTRODUCTION}

It is hardly safe to use the term mutation without first defining it. In this paper it will be taken to mean a genotypic change, or a ehange in essential hereditary constitution, due neither to immediate cross fertilization nor to segregation in a heterozygous parent. No attempt will be made to restrict the term to any of the known or supposed types of such genotypie ehange; a limitation of this kind, which restricts the generally accepted sense of a widely used term, seems to tend to confusion rather than to elearness. 
If we use the term factor mutation, ${ }^{2}$ (Babeock, 1918) where the cytological ehange occurs within a locus, transforming a factor into a different factor, two analogous terms will apply where the cytological change is external to the loeus. When the eytologieal change consists of a loss, reduplieation, or transposition of one or more loci it may be called a locus mutation, and when the ehange consists in such phenomena affecting a whole chromosome it may be ealled a chromosome mutation. If the term mutation is applied to the cytological change itself, the last two types of mutation may be grouped together as extralocus mutations, while the first type consists of intralocus mutations. Examples of factor mutation are white eye in Drosoplila. and probably the rubrinervis type in Oenothera; an example of locus mutation is (possibly) "defieiency" in Drosophila; and examples of chromosome mutation are Oenothera gigas and 0 . lata.

It is now evident that the immediate problem with Oenother a relates to the meehanism of heredity in the genus. There are two sharply opposed views. One is that recently emphasized by Atkinson (1917, p. 254), when he says, "The evidence from Oenothera cultures points more and more to the conelusion of Shull that 'a hereditary mechanisul must exist in Oenothera fundamentally different from that which distributes the Mendelian unit-characters.' ", The opposing view is represented by Muller's (1918) strictly Mendelian explanation for Oenothera, based on "an Oenothera-like case in Drosophila"; he says. "The striking parallel between the above behavior and that exhibited in Oenothera makes it practieally eertain that this, too, is a complicated case of balaneed lethal faetors."

A notable feature of the extensive genetic study of Oenothera is the lack of progress toward any definitely supported explanation of its hereditary mechanism, which is not Mendelian. The only definite non-Mendelian hypothesis of chromosome beliavior so far proposed, aside from "merogony" and other hypotheses (Goldschmidt, 1916) apparently possible but not proved for Oenothera, which assume loss of chromatin after fertilization, seems to be Swingle's (1911) "zygotaxis," proposed for the apparently parallel ease of Citrus. This suggestion that $F_{1}$ lybrids may differ, apart from non-uniformity of the $\mathrm{P}_{1}$ gametes, because of the establishment of permanently different arrangements of the chromosomes in the fertilized egg, still scems to be purely speculative.

With more or less "Oenothera-like" cases in other genera, the only definite progress in analysis seems to have resulted from the assump-

2 Muller (1918) has recently used point mutation in the same sense. 
tion of Mendelian segregation. With Oenothera itself, the trend of the evidence tends to favor this form of explanation.

This fact is strikingly illustrated by two papers of de Vries (1918, 1919) which have appeared since the present paper was written, especially as Muller's (1918) complete report on the beaded-wing case in Drosophila (see especially pp. 471-474, 489, and 498-499) indicates that de Vries had hardly yet realized the full possibilities of the balanced-factor hypothesis. In the light of Muller's masterly demonstration of these possibilitics, we may be confident that "mass mutation" is merely ordinary segregation, and that the "unisexual" crosses of Oenothera are really "Mendelian" in their essential phenomena. Some difference of usage respecting the inclusiveness of the term Mendelian may be involved here, it is true, since apparently de Vries would apply it only to cases where strictly homologous factors are opposed in homologous chromosomes. Since, however (Muller, 1918), there are good reasons for expecting the occurrence of gradations of similarity and of synaptic attraction between opposed loci, and hence of gradations of linkage, the criterion of Mendelian behavior should obviously be the occurrence of segregation between homologous chromosomes, whatever their degree of similarity or amount of crossing over. We have no reason to assume that an "unpaircd" factor in a pareut would so divide as to be included in all gametes; on the other hand, we have learned of a mechanism capable of insuring, in certain particular cases, the inclusion of a certain factor or group of factors either in every functional gamete or in every viable zygote.

No doubt, as Davis (1917) says, "A great forward step will be taken in Oenothera genetics when types of proven purity have been cstablished ...." Meanwhile, cases of "Oenothera-like" heredity in species known to possess the Mendelian mechanism deserve most thorough investigation. Special interest consequently attaches to the peculiar inheritance of certain apparent mutations of the ten-wecks stock (Matthiola annua Sweet), a species in which various characteristics are typically Mendelian. A remarkable series of abcrrant forms in this species ${ }^{3}$ has been briefly discussed in two preliminary communications (Frost, 1912 and 1916), and the present paper gives a fuller account of the same phenomena."

\footnotetext{
3 In the variety "Snowflake," a glabrous, double-producing form with white flowers.

4 While this paper, was in press Blakeslee and Avery (1919), have reported the occurrence of apparent mutations in Datura, which seem to be similar in almost every respect to those here discussed.
} 
Apparent mutants werc first found in the course of work on another problem, the relation of temperature to variation (Frost, 1911), conducted at Cornell University. Studied incidentally at first, these new forms were later given special attention. About nine thousand plants, of which about two thousand were progeny of mutant-type parents of peculiar heredity (nearly one-fourth of the latter representing crosses with Snowflake), have been examined altogether. Some of these plants have been grown at Riverside, where hybridization studies with mutant types are in progress. The present account considers the origin and characteristies of these types, their inheritance with self pollination, and the rather meager available data relating to their behavior in crossing.

In connection with the work at Cornell, special acknowledgment is due to the late Professor John Craig, and to Dr. H. J. Webber and Dr. H. H. Love. Facilities for work were furnished by the departments of Horticulturc and Plant Breeding of the New York Statc College of Agriculture.

\section{GENETIC LITERATURE RELATING TO MATTHIOLA}

The work of Correns (1900) on Matthiola furnished one of the earliest confirmations of Mendel's law, and also pointed to complications not found by Mendel. The earlier literature, according to Correns, gives no indication of the study of Matthiola hybrids beyond the first generation.

In his later paper on aberrant hybrid ratios, the same author (1902) discusses complications in maize and in Matthiola. After referring the deviations found in maize to sclective pollination, he considers a suggestion of de Vries relating to environmental modification of Mendelian ratios, and himself suggests the possibility of selective climination of gametes. He says (pp. 171-172), "Solche Einflüsse brauchten nicht alle Sorten Keimzellen des Bastardes gleichmässig zu treffen, sondern sie könnten eine Sorte stärker angreifen als die andere."

Von Tschermak $(1904,1912)$ hías made extensive studies of Matthiola hybrids, considering mainly, as did Correns, pubescence and flower color. The latter of these papers on hybrids in the genera Matthiola, Pisum, and Phaseolus represents a careful analytical test of the "factor hypothesis" of scgregating inheritance, leading to the conclusion that the applicability of this hypothesis is strongly con- 
firmed by the results secured. This work, with that of Miss Saunders, leaves no possibility of doubt that the typical Mendelian mechanism is present in Matthiola.

The most extensive genetic work on Matthiola is evidently that of Miss Saunders, reported by herself (1911, 1911a, 1913, 1913a, 1915, 1916) and by Bateson and Saunders, with others (1902, 1905, 1906, 1908). This also is work on heredity in hybrids, with special emphasis on the factorial interpretation of the various complications relating to pubescence and to "doubleness" of flowers.

Goldschmidt (1913) has explained the inheritance of doubleness by sex linkage and lethal action of a femaleness factor in pollen formation, and his interpretation has been criticized by Miss Saunders (1913). I (Frost, 1915) have presented a somewhat different lethalfactor scheme, and Miss Saunders (1916) has since restated her views and criticized mine.

Muller (1917) has cited the inheritance of doubleness as a case of "balanced factors," in apparent agreement with my formulation.

Apparently no one but the present writer (Frost, 1912, 1916; see also review by Bartlett, 1917) has reported experimental evidence of any notable tendency to apparent mutation in the genus, although de Vries (1906, p. 338) mentions the occasional occurrence of vigorous, rigidly upright individuals (a gigas type?), known at Erfurt as "generals," and refers to the rare mutative occurrence of single flowers on branches of double-flowering plants. Doubleness, and color variations in considerable number, have evidently arisen under cultivation, probably through mutative changes.

\section{METHODS}

The general cultural methods employed for the first three generations have been very briefly deseribed elsewhere (Frost, 1911).

The plants of the first four years were grown in pots in the greenhouse. The plants of the first generation came from one or both of two packets of commercial seed planted in the fall of 1906, and all plants in the later cultures (possibly excepting series 18) were descendants of these. The cultures will in general be designated by the year in which the seed was sown; the field and greenhouse cultures of 1.911 are indicated by $1911 \mathrm{~F}$ and $1911 \mathrm{H}$ respectively.

Part of the seed planted, especially in 1908, came from unguarded flowers. The seed lots where this occurred will be indicated in the 
tabulation of parental data by italie figures, while proteetion possibly defeetive will be indieated by an asterisk. It is not probable that mueh vieinism oeeurred in the greenhouse eultures, sinee this plant is well adapted to self fertilization.

In the first year's (1906) eultures the plants in eaeh experimental environment were separately numbered. Eaeh plant was designated by its number preeeded by two letters indicative of the environment. For.greenhouse temperature these letters were C (eool), M (medium temperature), and W (warm); for potting soil ${ }^{5}$ they were S (sand), L (unfertilized "loam"), and G ("good" soil, fertilized). Thus CS1 CS2, WG9, ete., were pedigree numbers of the first generation, and CG2-M8 and WG9-C10 of the seeond generation. A few syneotyledonous plants outside the regular eultures of 1907 were ealled WG9syn1, ete.

For the work at Riverside a new system of numbering was adopted, better suited to ordinary pedigree eultures, and the numbers from this system are used below in the individual treatment of all but one of the mutant types ("early"). This is essentially Webber's (1906, p. 308) system, exeept that eaeh initial or $P_{1}$ individual of a series is indicated by a letter; a full deseription has been published (Frost. 1917). With Matthiola eaeh type or eross between two types that is tested receives a series number, the apparent mutants themselves always being taken as the initial individuals of their selfed series.

The eultures of 1908 ineluded progeny of various parents, one being WG9-C10, an early and few-noded plant suspected of being a mutant.

The eultures of 1910 eonsisted of a seeond-generation test of WG9$\mathrm{C10}$, and a first-generation test of other possible mutants, with eontrol lots. The plants were all grown on one beneh in one greenhouse (house $\mathrm{C}$ ), from thirty lots of fifteen seeds eaeh, lots 1-17 relating to WG9-C10. The parents deseended from WG9-C10 (see table 7) were seleeted as those with fewest internodes, a medium number of internodes, and most ${ }^{6}$ internodes in each house of the 1908 eultures, earliness of flowering being eonsidered when parents were alike in number of internodes. The eontrol parents were both few-noded and manynoded, relatively to their sibs.

In 1911 eighty progeny lots were grown in the field at Ithaea. Lots 1 to 28, transplanted from the greenhouse, paralleled the test of

5 Soil experimentally varied only in the 1906 cultures, temperature varied in the two following years also.

6 For house M, not the highest, which was exceptionally high, but the next to the highest. 
WG9-C10 made in 1910-11; all available progeny of WG9-C10, except the crenate-leaved apparent mutant WG9-C10-C10, were tested, with check lots between as before. Soil differences and unavoidable differences between lots in time of trausplanting combined with hot weather and drought to reduce the value of the results. The remaining fiftytwo lots, all field-sown, included a further test of the heredity of aberrant types other than early. Most of these lots, however, were progeny of Snowflake parents, grown to obtain evidence on the relation of temperature to mutation and on the inheritance of doubleness of flowers, and therefore the results are not reported here.

The $1911 \mathrm{H}$ cultures constituted a coldframe and greenhouse progeny test of mutant types, mainly in the second generation, the plants being grown in flats.

There was added in 1912-13 a small greenhouse test bearing on the supposed mutative origin of WG9-C10, in view of the apparent possibility that WS1 or WL10, in the same house with the unbagged WG9, might have been heterozygous for the early type-cross pollination then giving the apparent mutant.

Further progeny tests of the mutant types have been made in the field at Riverside, beginning in the fall of 1913. Mainly on account of the unsuitability of the usually hot and dry climate of Riverside, the cultures have been largely experimental and always on a small scale, and germination or development has sometimes been unsatisfactory. Cultures have been started in October, November, January, and February, and a trial culture in progress at the time of writing was started in August. Some of the plants of the 1915-16 cultures were kept until the summer of 1917, and many of them flowered for the first time when about a year old.

In the cultures of 1913, growth was largely unsatisfactory, and with part of the plants aphid injury interfered more or less with the classification of types. In the cultures of 1914, the seeds were largely lost through toxic effects favored by very shallow planting (as at Ithaca) and strong evaporation from the soil. In subsequent planting, the seeds, planted singly in small paper pots, were dropped into relatively deep holes punched in the soil, and covered with sand.

The only field-grown plants closely resembling those grown in the greenhouse at Ithaca, it may be noted, have been those of the 1917 cultures, grown in a lathhouse with added shade from muslin.

In the cultures of 1915-16, with partial shade and more frequent irrigation than before, development was in general good; but even 


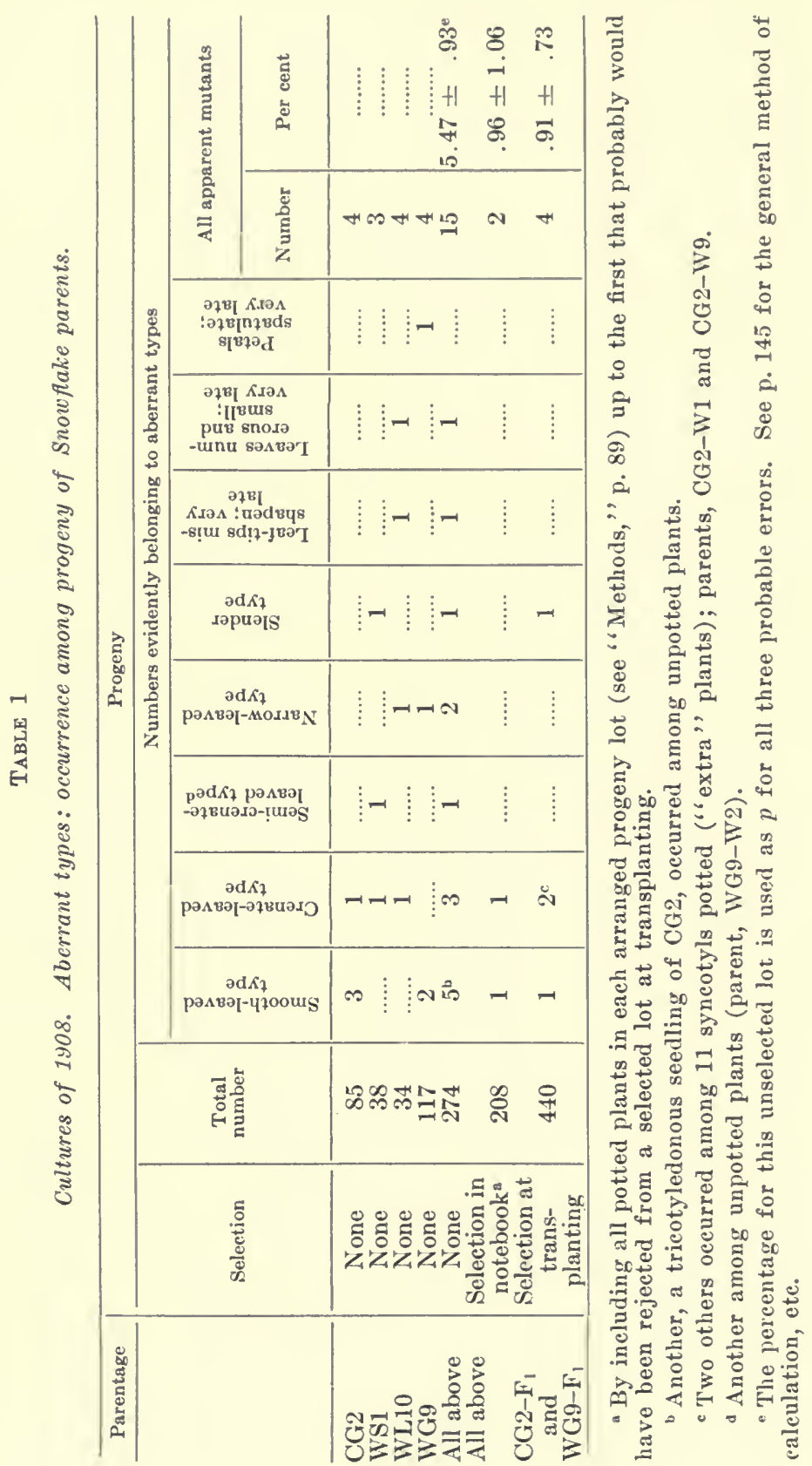


here the mutant types, with one exception, often failed to grow satisfactorily or to set seed. Infection, probably by F'usarium, evidently was the cause of the death of many of these plants in their second season.

With all cultures grown after (probably) those of 1906, special care was taken to secure random samples of seed, and after 1908 no plants were rejected. The only exception to this statement is the rejection of one pot out of every fifteen, by number and systematically, in the first twenty progeny lots of 1910. For the earlier cultures, a certain amount of selection must be recorded, as follows. In 1906 the small and the largest plants were omitted at potting, and probably any weak and abnormal seedlings had been omitted at the preceding transplanting. In 1907 all markedly weak, late, or abnormal seedlings, as determined mainly by the appearance of the cotyledons, were omitted at the first transplanting; and the same was done in 1908, except that certain lots from old seed were unselected. ${ }^{7}$

These last lots were arranged at transplanting in such a way that the weak and abnormal plants came at the end in each lot.

\section{EXPERIMENTAL DATA}

\section{The Occurrence of Apparent Mutants}

In the cultures of 1906,88 plants were grown to maturity, none of these being suspected of mutation. In the cultures of 1907, among 170 plants one striking variant appeared; this plant, WG9-C10, was exceptionally small and early in blooming.

In the cultures of 1908,714 plants were available, including apparent mutants in several hereditary lines as indicated in table 1. A striking feature of the results is the scarcity of apparent mutants among the seedlings classed as strictly normal at transplanting; probably the scarcity in the preceding years was due mainly to the rejection of abnormal seedlings (see "Methods"). The first, second, and fourth of these forms have becn common in later cultures, while the third and fifth have been rarer; the last three, if seen at all elsewhere, have not being recognized as belonging to the same types as these three plants.

\footnotetext{
${ }^{7}$ One tiny plant from WG9, probably not viable, was discarded.
} 
Table 2 shows the numbers and percentages of apparent mutants found in the cultures of 1910 and $1911 \mathrm{~F}$. Since the early type seems to differ from Snowflake only in size and earliness, and is probably inherited without special complications, the available progeny of earlytype parents are included in the totals. The progeny of all parents recognized as belonging to other aberrant types are omitted. The second column under "Percentage of mutants" omits doubtful types and individuals, but includes some individuals for which some doubt was indicated in the original records. One rare type of 1911, large-

TABLE 2

Aberrant types: occurrence among progeny of Snowflake and early parents. Apparent selective elimination at or after germination in

field-sown cultures. ${ }^{\mathrm{a}}$

\begin{tabular}{|c|c|c|c|}
\hline \multirow{2}{*}{ Cultures } & \multirow{2}{*}{ Progeny examined" } & \multicolumn{2}{|c|}{ Percentage of apparent mutants } \\
\hline & & All counted & Doubtful omitterl \\
\hline Greenhouse, 1910 & 338 & $5.03 \pm .82^{c}$ & $4.14 \pm .77$ \\
\hline house-sown & 2072 & $5.31 \pm .33$ & $4.63 \pm .31$ \\
\hline $\begin{array}{l}\text { All above } \\
\text { Same,Snowflake par- }\end{array}$ & 2410 & $5.27 \pm .31$ & $4.56 \pm .29$ \\
\hline $\begin{array}{l}\text { ents only } \\
\text { Field,1911, seed field- }\end{array}$ & 1364 & $4.33 \pm .41$ & $3.74 \pm .38$ \\
\hline $\begin{array}{l}\text { sown(parents all } \\
\text { Snowflake.) }\end{array}$ & 3927 & $2.34 \pm .24$ & $1.55 \pm .22$ \\
\hline
\end{tabular}

a Germination in greenhouse-sown lots, counting only plants examined for type, 93.2 per cent; in field-sown lots, 45.1 per cent.

b Including some plants of uncertain type, indicated for some lots (when apparently not Snowflake) in tables 1 and 3 .

c For the calculation of these probable errors the percentages on the third line are used as $p$.

leaved, here omitted, has proved to be genetic. but its determination in these cultures was in general uncertain. A stricter criterion for the second column, elimination of all individuals not considered positively determined, was used in the calculations for the tables for the inheritance of the separate mutant types.

Evidently the more rigorous field conditions of 1911 eliminated many of the "mutants" at or soon after germination. The "coefficient of mutability" with good germination, as was the case with the unselected cultures of 1908 , seems to be near 5 per cent, a surprisingly high figure if immediate true mutation is responsible.

Before the aberrant types are considered separately, we may examine (table 3) a detailed illustration of their occurrence in larger cultures. It seems probable, from this evidence, that any descendant of WG9 was capable of producing any of the mutant types so far 


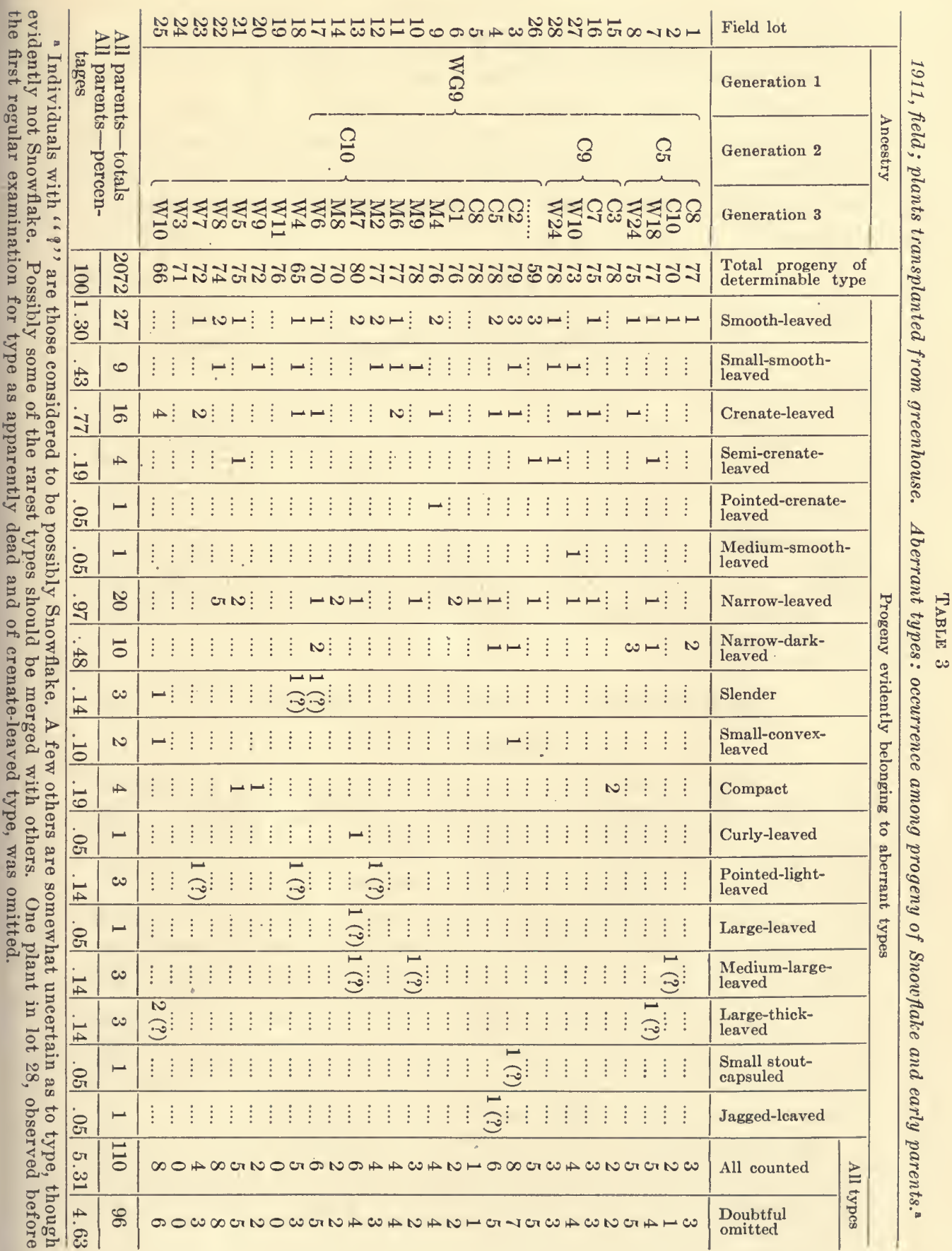


discovered; the occurrence of the various types suggests a random distribution among the progeny lots. This conclusion is confirmed, and extended to CG2, by the field-sown lots of 1911.

Various parents belonging to mutant types have given other mutant types among their progeny. There is some reason, as table 4 indicates, to suppose that parents of the early type have a more marked tendency to produce these other types than have Snowflake parents. ${ }^{8}$

TABLE 4

1910 and $1.911 \mathrm{~F}$; sown in greenhouse. Apparent mutants among descendants of WG9-C10 and other ancestors, comparing early parents (pure or heterozygous) with Snowflake parents.

\begin{tabular}{|c|c|c|c|c|}
\hline \multirow{3}{*}{ Ancestry } & \multirow{3}{*}{ Type of parent } & \multicolumn{3}{|c|}{ Progeny } \\
\hline & & \multirow{2}{*}{$\begin{array}{c}\text { Total } \\
\text { examined }\end{array}$} & \multicolumn{2}{|c|}{ Percentage of mutants } \\
\hline & & & All counted & Doubtful omitted \\
\hline \multirow{2}{*}{ WG9-C10 } & f Early & 1046 & $6.50 \pm .47^{a}$ & $5.64 \pm .44$ \\
\hline & ( Snowflake & 558 & $4.30 \pm .64$ & $3.41 \pm .60$ \\
\hline Pure Snowflake & Snow flake & 806 & $4.34 \pm .53$ & $3.97 \pm .50$ \\
\hline Both & Snowflake & 1364 & $4.33 \pm .41$ & $3.74 \pm .38$ \\
\hline Both & Both & 2410 & $5.27 \pm .31$ & $4.56 \pm .29$ \\
\hline
\end{tabular}

a For the calculation of these probable errors the percentages on the last line are used as $p$.

\section{Characteristics and Heredity of Mutant Types}

\section{THE EARLY TYPE}

So far as is known, WG9-C10 (figs. 1, 2) was the only apparent mutant of the early type in the cultures. Since, however, this type visibly differs from Snowflake only or mainly in quantitative characters, it cannot be positively identified without comparative progeny tests, and therefore may have been represented by mutant individuals not used as parents. WG9-C10 was much smaller proportionately than were its progeny; this difference was probably due to an embryonic abnormality, early blind termination of the main axis, which was occasionally observed elsewhere and probably occurred in this case. Plants of this type, as compared with Snowflake, are, in general, fewer-noded, smaller, and earlier in blooming.

The principal data from the cultures of 1908 are shown in tables 5 and 6 , which also indicate the later conclusions as to the segregation of the early type in the cultures of this year; figures 3 and 4 illustrate

\footnotetext{
8 Inspection of the data in detail indicates that this difference is not due to the possible tendency in parents grown in the warm house to more frequent apparent mutation.
} 
TABLE 5

Cultures of 1908. Time from sowing to emergence of corolla of earliest flower of primary cluster. Frequency distributions. ${ }^{\text {a }}$

\begin{tabular}{|c|c|c|c|c|c|c|c|c|c|c|c|c|}
\hline \multirow[b]{3}{*}{ Parents: } & \multicolumn{6}{|c|}{ Singles } & \multicolumn{6}{|c|}{ Doubles } \\
\hline & \multicolumn{2}{|c|}{ House C } & \multicolumn{2}{|c|}{ House $\mathbf{M}$} & \multicolumn{2}{|c|}{ House W } & \multicolumn{2}{|c|}{ House $\mathbf{C}$} & \multicolumn{2}{|c|}{ House M } & \multicolumn{2}{|c|}{ House $\mathbf{W}$} \\
\hline & $\begin{array}{l}\text { WG9- } \\
\text { C10 }\end{array}$ & Rest & $\begin{array}{l}\text { WG9- } \\
\text { C10 }\end{array}$ & Rest & $\begin{array}{l}\text { WG9- } \\
\mathrm{C} 10\end{array}$ & Rest & $\begin{array}{l}\text { WG9- } \\
\text { C10 }\end{array}$ & Rest & $\begin{array}{l}\text { WG9- } \\
\text { C10 }\end{array}$ & Rest & $\begin{array}{l}\text { WG9- } \\
\text { C10 }\end{array}$ & Rest \\
\hline$D a y_{0}{ }^{b}$ & & & & & & & & & & & & \\
\hline & $\ldots$. & $\ldots$ & $1_{+}^{+}$ & $\ldots$ & $\ldots$ & $\ldots$ & $\ldots$ & $\ldots$ & $\ldots$ & $\ldots$ & $\ldots$ & .... \\
\hline 111 & $\ldots$ & $\ldots$ & $1 \ddagger$ & $\ldots$ & $\ldots$. & $\ldots$. & $\ldots$ & $\ldots$. & $\ldots$. & $\ldots$. & $\ldots$. & $\ldots$ \\
\hline 112 & $\ldots$ & $\ldots$ & .... & $\ldots$ & $\ldots$ & $\ldots$ & $\ldots$ & $\ldots$ & $\ldots$ & $\ldots$ & $\ldots$ & $\ldots$. \\
\hline $11:$ & $\ldots$ & $\ldots$ & $\ldots$ & .... & $\ldots$ & $\ldots$ & $\ldots$ & $\ldots$ & $\ldots$ & $\ldots$. & $\ldots$ & $\ldots$. \\
\hline 114 & $\ldots$. & $\ldots$ & $\ldots$ & $\ldots$ & $\ldots$ & $\ldots$ & $\ldots$ & $\ldots$. & $\ldots$. & $\ldots$. & $\ldots$. & .... \\
\hline 115. & $\ldots$ & $\ldots$ & $\ldots$ & $\ldots$ & $\ldots$ & $\ldots$. & $\ldots$ & $\ldots$ & & .... & $\ldots$. & $\ldots$ \\
\hline 116 & $\ldots$. & $\ldots$ & $\ldots$ & 1 & $\ldots$ & $\ldots$ & $\ldots$ & $\ldots$ & 1 & $\ldots$ & $\ldots$ & $\ldots$ \\
\hline 117 & $\ldots$ & $\ldots$. & & & $1 \ddagger$ & $\ldots$ & $\ldots$ & $\ldots$ & $\ldots$ & $\ldots$ & $\ldots$. & $\ldots$ \\
\hline 118 & $\ldots$. & $\ldots$ & $1 \ddagger$ & 2 & $\ldots$ & $\ldots$ & $\ldots$. & $\ldots$ & $\ldots$ & $\ldots$ & $\ldots$ & $\ldots$ \\
\hline 119 & & $\ldots$ & $\ldots$ & 3 & $\ldots$ & $\ldots$ & $\ldots$ & $\ldots$ & $\ldots$ & $\ldots$ & $\ldots$ & .... \\
\hline 120 & $1 \ddagger$ & $\ldots$. & & 4 & $\ldots$. & $\ldots$. & $\ldots$. & $\ldots$ & .... & $\ldots$ & $\ldots$ & $\cdots$ \\
\hline 121 & $\ldots$ & $\ldots$ & $1 \ddagger$ & 2 & $\ldots$. & $\ldots$ & $\ldots$. & $\ldots$. & $\ldots$. & 1 & $\ldots$ & 1 \\
\hline 12 & .... & $\ldots$ & $\ldots$ & 3 & & $\cdot \ldots$ & $\therefore$. & $\ldots$ & & & $\ldots$ & 2 \\
\hline 12 & $\ldots$. & $\ldots$ & $\ldots$ & 8 & $1 \ddagger$ & $\ldots$ & $\ldots$ & .... & 1 & 1 & $\ldots$. & 2 \\
\hline 12 & $\ldots$. & $\ldots$ & 1 & 4 & & $\ldots$ & $\ldots$. & $\ldots$ & $\ldots$ & 1 & & 2 \\
\hline 12 & $\ldots$ & $\ldots$. & $\ldots$ & 7 & $1 \ddagger$ & $\ldots$ & $\ldots$. & $\ldots$. & $\ldots$ & 5 & 1 & 3 \\
\hline 12 & $\ldots$. & $\ldots$ & $\ldots$ & 16 & & & $\ldots$ & $\ldots$ & $\ldots$ & 7 & $\ldots$ & 7 \\
\hline 12 & $\ldots$ & $\ldots$ & $\ldots$ & 3 & $1 \ddagger$ & 2 & $\ldots$ & $\ldots$ & $\ldots$ & 9 & $\ldots$ & 2 \\
\hline 128 & $\ldots$ & $\ldots$ & $\ldots$ & 4 & & $3 \dagger$ & $\ldots$ & $\ldots$ & $\ldots$ & 8 & $\ldots$ & 5 \\
\hline 12 & $\ldots$ & $\ldots$ & $\ldots$ & 7 & $1 f$ & 4 & … & $\ldots$ & $\ldots$. & 8 & $\ldots$ & 7 \\
\hline 13 & $\ldots$ & $\ldots$ & $\ldots$ & i & $1 \ddagger$ & 3 & $\ldots$ & $\ldots$ & .... & $12 \dagger$ & $\ldots$ & 4 \\
\hline 13 & & 1 & $\ldots$ & 2 & $\ldots$ & 4 & $\ldots$ & $\ldots$ & 2 & 12 & $\ldots$ & 3 \\
\hline & $1+$ & $\ldots$ & .. & 1 & $\ldots$ & 2 & $\ldots$ & $\ldots$ & $\ldots$ & 7 & $\ldots$ & 8 \\
\hline 13 & $1 \dagger \neq$ & $\ldots$ & $\ldots$ & 1 & 1 & 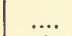 & $\ldots$ & $\ldots$ & $\ldots$ & 4 & $\ldots$ & 7 \\
\hline 13 & 1 & 2 & $\ldots$ & 2 & $\ldots$ & 1 & $\ldots$ & $\ldots$ & $\ldots$ & 2 & $\ldots$ & 7 \\
\hline & $\ldots$ & 4 & …. & 4 & $\ldots$ & 4 & & $\ldots$ & $\ldots$ & 6 & $\ldots$ & 6 \\
\hline 136 & $\ldots$ & 1 & 1 & 1 & $\ldots$ & 3 & 1 & $\ldots$ & $\ldots$ & & $\ldots$ & 4 \\
\hline & $\ldots$ & 7 & & 2 & $\ldots$ & 3 & $\ldots$ & 3 & $\ldots$ & 1 & $\ldots$ & 2 \\
\hline & $\ldots$ & 10 & $\ldots$ & 1 & $\ldots$ & 9 & .... & 4 & $\ldots$ & 1 & … & 1 \\
\hline 13 & $\ldots$ & $18 \dagger$ & $\ldots$ & 1 & 1 & 2 & $\ldots$ & 8 & $\ldots$ & 1 & $\ldots$ & 3 \\
\hline 14 & 1 & 7 & $\ldots$ & $1 \dagger$ & & 4 & $\ldots$ & 13 & & & $\ldots$ & 3 \\
\hline 14 & $\ldots$ & 10 & ..... & $\ldots$ & $\ldots$ & 1 & 1 & 9 & $\ldots$ & 1 & … & 3 \\
\hline & $\ldots$ & 4 & $\ldots$ & $\ldots$ & $\ldots$ & 6 & $\ldots$ & 15 & $\ldots$ & 1 & $\ldots$ & 1 \\
\hline 143 & ... & 4 & $\ldots$ & $\ldots$ & 1 & 5 & 2 & 10 & $\ldots$. & $\ldots$ & .... & 2 \\
\hline 144 & $\ldots$ & 4 & $\ldots$ & $\ldots$ & $\ldots$ & 2 & $\ldots$ & 9 & $\ldots$ & $\ldots$ & $\ldots$ & 2 \\
\hline 14 & $\ldots$ & $\ldots$ & $\ldots$ & $\ldots$ & $\ldots$ & 3 & $\ldots$ & 6 & $\ldots$ & $\ldots$ & $\ldots$ & 3 \\
\hline 146 & $\ldots$ & $\ldots$ & $\ldots$ & $\ldots$ & $\ldots$ & .... & 1 & 5 & $\ldots$ & $\ldots$ & $\ldots$ & 2 \\
\hline 14 & $\ldots$. & $\ldots$ & $\ldots$ & $\ldots$ & $\ldots$ & 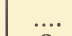 & $\ldots$ & 4 & $\ldots$ & $\ldots$ & $\ldots$ & \\
\hline 14 & $\ldots$. & $\ldots$ & $\ldots$ & $\ldots$ & $\ldots$ & 2 & $\ldots$ & 1 & $\ldots$ & $\ldots$ & $\ldots$ & 1 \\
\hline 14 & $\ldots$ & $\ldots$ & $\ldots$ & $\ldots$ & $\ldots$ & 2 & $\ldots$ & 1 & $\ldots$ & $\ldots$ & $\ldots$ & $\ldots$ \\
\hline 15 & $\ldots$ & 1 & $\ldots$ & $\ldots$ & $\ldots$ & 1 & $\ldots$ & 2 & $\ldots$ & $\ldots$ & $\ldots$ & \\
\hline 151 & $\ldots$ & 1 & $\ldots$ & $\ldots$ & $\ldots$ & $\ldots$ & $\ldots$ & 1 & $\ldots$ & $\ldots$ & $\ldots$ & 1 \\
\hline 15 & $\ldots$ & $\ldots$ & $\ldots$ & $\ldots$ & $\ldots$ & $\ldots$ & $\ldots$ & $\ldots$ & $\ldots$ & $\ldots$ & $\ldots$ & 2 \\
\hline 15 & $\ldots$ & 1 & $\ldots$ & $\ldots$. & $\ldots$. & $\ldots$ & $\ldots$ & $\ldots$ & $\ldots$ & $\ldots$ & $\ldots$ & 1 \\
\hline 154 & $\ldots$ & & $\ldots$ & $\ldots$ & $\ldots$ & $\ldots$ & $\ldots$ & $\ldots$ & $\ldots$ & $\ldots$ & $\ldots$ & $\cdots$ \\
\hline 155 & $\ldots$ & 1 & $\ldots$ & $\ldots$ & $\ldots$ & $\ldots$ & $\ldots$ & 1 & $\ldots$. & $1 \quad \ldots$. & $\ldots$ & 1 \\
\hline
\end{tabular}

a Daggers $(\dagger)$ indicate the position and number of apparent mutants. Double daggers $(\ddagger)$ indicate inheritance of parental type (here, early); all single progeny of WG9-C10 here reported have been tested for inheritance of this type. The conventional statistical constants corresponding to the house totals of tables 5 and 6 have been published (Frost, 1911); the means for flowering given there are too high by one half-day.

b To time of observation (upper limit of one-day class). 
'TABle 5. Cultures of 1908 (Continued)

\begin{tabular}{|c|c|c|c|c|c|c|c|c|c|c|c|c|}
\hline \multirow[b]{3}{*}{ Parents: } & \multicolumn{6}{|c|}{ Singles } & \multicolumn{6}{|c|}{ Doubles } \\
\hline & \multicolumn{2}{|c|}{ House C } & \multicolumn{2}{|c|}{ House M } & \multicolumn{2}{|c|}{ House W } & \multicolumn{2}{|c|}{ House C } & \multicolumn{2}{|c|}{ House M } & \multicolumn{2}{|c|}{ House W } \\
\hline & $\begin{array}{c}\text { WG9- } \\
\text { C10 }\end{array}$ & Rest & $\begin{array}{c}\text { WG9- } \\
\text { C10 }\end{array}$ & Rest & $\begin{array}{c}\text { WG9- } \\
\text { C10 }\end{array}$ & Rest & $\begin{array}{c}\text { WG9- } \\
\text { C10 }\end{array}$ & Rest & $\begin{array}{c}\text { WG9- } \\
\text { C10 }\end{array}$ & Rest & $\begin{array}{c}\text { WG9- } \\
\text { C10 }\end{array}$ & Rest \\
\hline$D_{\text {ays }}$ b & & & & & & & & & & & & \\
\hline 156 & $\ldots$ & $\ldots$ & $\ldots$ & $\cdots$ & $\cdots$ & $\cdots$ & $\cdots$ & $\cdots \cdot$ & $\cdots$ & $\cdots$ & $\cdots$ & $\ldots$ \\
\hline 157 & $\cdots$ & $\ldots$ & $\ldots$ & $\ldots$ & $\ldots$ & $\ldots$ & $\ldots$ & $\ldots$. & $\ldots$ & $\ldots$ & $\ldots$ & $\ldots$ \\
\hline 158 & $\ldots$ & $\ldots$ & $\ldots$. & $\ldots$ & $\ldots$ & $\ldots$ & $\ldots$ & $\ldots$ & $\ldots$ & $\ldots$ & $\ldots$ & $\ldots$. \\
\hline 159 & $\cdots$ & $\cdots$ & $\cdots$ & $\cdots$ & $\cdots$ & $\cdots \cdot$ & $\cdots$ & $\cdots$ & $\cdots$ & $\ldots$. & $\ldots$ & $\ldots$ \\
\hline 160 & $\cdots$ & $\ldots$ & $\ldots$. & $\ldots$. & $\ldots$ & $\ldots$ & $\ldots$. & $\ldots$ & $\ldots$ & $\ldots$ & $\ldots$ & $\ldots$ \\
\hline 161 & $\ldots$ & $\ldots$ & $\cdots$ & $\cdots$ & $\cdots$ & $\ldots$. & $\ldots$ & $\ldots$ & $\ldots$ & $\ldots$ & $\ldots$ & 1 \\
\hline 162 & $\cdots$ & $\ldots$ & $\ldots$ & $\ldots$ & $\ldots$. & $\ldots$ & $\ldots$ & $\ldots$. & $\cdots$ & $\ldots$ & $\ldots$. & $\ldots$. \\
\hline 163 & $\ldots$ & $\ldots$ & $\cdots$ & $\cdots$ & $\cdots$ & $\cdots$. & $\cdots$ & $\cdots$ & $\ldots$ & $\cdots \cdot$ & $\cdots$. & $\ldots$ \\
\hline 164 & $\ldots$. & $\cdots$ & $\cdots$ & $\cdots$ & $\cdots$ & $\cdots$ & $\cdots$. & $\ldots$ & $\cdots$ & $\cdots$ & $\cdots$ & $\cdots$ \\
\hline 165 & $\cdots$ & $\ldots$ & $\ldots$ & $\ldots$ & $\ldots$ & $\ldots$ & $\ldots$ & $\ldots$ & $\ldots$ & $\ldots$ & $\ldots$ & $\ldots$ \\
\hline 166 & $\ldots$ & .. & $\ldots$ & $\ldots$ & $\ldots$ & $\ldots$ & $\ldots$ & $\ldots$. & $\ldots$ & $\ldots$ & $\ldots$. & $\ldots$ \\
\hline 167 & $\ldots$. & $\ldots$ & $\ldots$ & $\ldots$. & $\ldots$ & $\ldots$. & $\ldots$. & $\ldots$. & $\ldots$ & $\ldots$ & $\ldots$. & $1 \uparrow$ \\
\hline 168 & .... & $\ldots$ & $\ldots$ & $\ldots$ & $\ldots$ & $\ldots$. & $\ldots$ & $\ldots$ & $\ldots$ & $\ldots$ & $\ldots$. & $\ldots$ \\
\hline 169 & $\ldots$. & $\ldots$ & $\ldots$ & $\ldots$ & $\ldots$ & $\ldots$. & $\ldots$ & $\ldots$ & $\ldots$ & $\ldots$. & $\ldots$ & $\ldots$. \\
\hline 170 & $\ldots$ & $\ldots$ & $\cdots$ & $\cdots$ & $\ldots$ & $\cdots$ & $\ldots$. & $\cdots$ & $\cdots$ & $\cdots$ & $\cdots$. & $\cdots$ \\
\hline 171 & $\ldots$ & .. & $\ldots$ & $\ldots$. & $\ldots$ & $\ldots$ & $\ldots$ & $\ldots$ & $\ldots$ & $\ldots$ & $\ldots$ & $\ldots$ \\
\hline 172 & $\cdots$ & $\ldots$ & $\ldots$. & $\ldots$. & $\ldots$ & $\ldots$ & $\ldots$ & $\ldots$ & $\ldots$ & $\ldots$ & $\cdots$ & $\ldots$. \\
\hline 173 & $\ldots$ & $1 \dagger$ & $\ldots$ & $\ldots$ & $\ldots$ & $\ldots$ & $\ldots$ & $\ldots$ & $\ldots$ & $\ldots$ & $\ldots$ & $\ldots$ \\
\hline
\end{tabular}

Daggers $(\dagger)$ indicate the position and number of apparent mutants. Double daggers $(\ddagger)$ indicate inheritance of parental type (here, early); all single progeny of WG9-C10 here reported have been tested for inheritance of this type. The conventional statistical constants corresponding to the house totals of tables 5 and 6 have been published (Frost, 1911); the means for flowering given there are too high by one half-day.

b To time of observation (upper limit of one-day class).

the difference in earliness between the early and Snowflake types. The parents grouped under "rest" include CG2 and WG9 themselves, with four progeny of the former and eight of the latter. Of these fourteen parents, not one has produced exceptionally few-noded progeny like those of WG9-Ci0.

Apparently WG9-C10 was heterozygous for a "few-nodedness" factor not carried by any of the other parents tested. Neither in the 1907 cultures nor in the 1908 cultures now under consideration did the data suggest that WG9 itself was similarly heterozygous. Tables 5 and 6 include the first 30 progeny of WG9, for each house, as arranged at the first transplanting, ${ }^{9} 88$ plants altogether ; including the remaining plants, mainly weak or abnormal at transplanting. the total is 116. One of the $\mathrm{F}_{2}$ plants (WG9-syn 3-M10) was very suggestive of the early type, but (tables 12 and 13) it gave only Snowflake progeny in a small test.

9 See page 89. Two plants not producing a normal main inflorescence are omitted. 
TABLE 6

Cultures of 1908. Number of main-stem internodes below first flower-bearing node. Frequency distributions."

\begin{tabular}{|c|c|c|c|c|c|c|c|c|c|c|c|c|}
\hline \multirow[b]{3}{*}{ Parents: } & \multicolumn{6}{|c|}{ Singles } & \multicolumn{6}{|c|}{ Doubles } \\
\hline & \multicolumn{2}{|c|}{ House C } & \multicolumn{2}{|c|}{ House MI } & \multicolumn{2}{|c|}{ House W } & \multicolumn{2}{|c|}{ House C } & \multicolumn{2}{|c|}{ House M } & \multicolumn{2}{|c|}{ House W } \\
\hline & $\begin{array}{l}\text { WG9- } \\
\text { C10 }\end{array}$ & Rest & $\begin{array}{l}\text { WG9- } \\
\text { C10 }\end{array}$ & Rest & $\begin{array}{l}\text { WG9- } \\
\text { C10 }\end{array}$ & Rest & $\begin{array}{c}\text { WG9- } \\
\text { C10 }\end{array}$ & Rest & $\begin{array}{l}\text { WG9- } \\
\text { C10 }\end{array}$ & Rest & $\begin{array}{l}\text { WG9-- } \\
\text { C10 }\end{array}$ & Rest \\
\hline \multicolumn{13}{|l|}{ Internodes } \\
\hline 16 & $1 \neq$ & .... & .... & $\cdots$ & $\ldots$. & $\cdots$ & $\cdots$ & $\ldots$ & & & & \\
\hline 17 & $\ldots$ & $\cdots$ & .... & $\cdots$ & $\ldots$. & $\ldots$ & $\ldots$ & $\ldots$ & $\ldots$. & $\ldots$ & $\ldots$ & $\ldots$. \\
\hline & & .... & ... & $\cdots$. & $\ldots$ & $\ldots$ & $\ldots$ & $\ldots$. & $\ldots$ & .... & $\ldots$ & $\ldots$. \\
\hline 19 & $1 \ddagger \dagger$ & .... & $\cdots$ & $\cdots$ & .... & $\ldots$ & $\ldots$ & .... & $\ldots$. & .... & ... & $\ldots$ \\
\hline 20 & $1 \ddagger$ & .... & & .... & $\cdots$ & .... & 1 & $\cdots$ & .... & .... & $\ldots$. & $\ldots$ \\
\hline 21 & $\ldots$. & $\ldots$ & $2 \ddagger t$ & $\ldots$ & .... & $\ldots$ & & $\ldots$. & $\ldots$ & $\ldots$. & $\ldots$. & $\ldots$. \\
\hline 22 & $\ldots$ & $\ldots$ & $1 \ddagger$ & $\ldots$ & $\ldots$ & $\ldots$ & 1 & $\ldots$ & 1 & $\ldots$ & $\ldots$ & $\ldots$. \\
\hline 23 & .... & $\cdots$. & .... & $\cdots$ & ..... & $\cdots$ & .... & $\ldots$ & 1 & $\ldots$. & $\ldots$. & $\ldots$. \\
\hline 24 & & $2 \dagger$ & $1+$ & 1 & $\ldots$ & ... & & 9 & $\ldots$ & $\ldots$ & $\cdots$ & .... \\
\hline 25 & 1 & $2 \top$ & & 1 & $\cdots$ & .... & 2 & 25 & $\cdots$ & & $\cdots$ & $\ldots$. \\
\hline $\begin{array}{l}26 \\
27\end{array}$ & 1 & 7 & … & 1 & $\cdots$ & $\cdots$ & & 29 & .... & 1 & $\cdots$ & $\cdots$. \\
\hline $\begin{array}{l}27 \\
28\end{array}$ & $\begin{array}{c}1 \\
\ldots .\end{array}$ & 17 & ..... & & $\begin{array}{l}\cdots . \\
\cdots\end{array}$ & $\cdots$ & 1 & 22 & .... & $\frac{2 \dagger}{9}$ & 1 & $\cdots$ \\
\hline $\begin{array}{l}28 \\
29\end{array}$ & $\cdots$. & 24 & $\ldots$ & 1 & $\cdots$. & & $\cdots$ & 6 & $\cdots$ & $\begin{array}{r}9 \\
14\end{array}$ & 1 & .... \\
\hline 29 & & 13 & $\cdots$ & 1 & $\cdots$ & ..: & $\cdots$ & & & & $\cdots$ & \\
\hline 30 & $\cdots$ & & $\cdots$ & $\begin{array}{l}1 \\
2 \\
2\end{array}$ & $\cdots$ & .... & $\ldots$ & 1 & 2 & 22 & .... & 1 \\
\hline 31 & $\cdots$ & $\begin{array}{l}8 \\
2\end{array}$ & $\cdots$ & $\frac{2}{7}$ & $\cdots$ & .... & $\ldots$ & .... & .... & 27 & $\ldots$. & $\ldots$. \\
\hline 32 & $\cdots$ & & .... & & & $\cdots$ & .... & $\ldots$. & $\ldots$ & 5 & $\ldots$. & $\ldots$ \\
\hline 33 & $\cdots$ & 1 & $\ldots$ & 10 & $1 \ddagger$ & .... & .... & .... & $\ldots$. & 3 & .... & .... \\
\hline 34 & $\ldots$. & & 1 & 16 & & .... & $\ldots$ & $\ldots$ & $\ldots$. & 4 & $\ldots$ & 1 \\
\hline 35 & .... & 2 & $\ldots$. & 19 & $1 \ddagger$ & $\ldots$ & $\ldots$ & $\ldots$ & $\ldots$ & & $\ldots$ & 5 \\
\hline 36 & $\ldots$ & $\ldots$. & $\ldots$. & 4 & $1 \ddagger$ & $\ldots$ & $\ldots$ & $\ldots$ & $\ldots$ & 1 & $\ldots$ & 6 \\
\hline 37 & $\ldots$ & $\ldots$ & $\ldots$ & 1 & $1 \ddagger$ & $\ldots$ & $\ldots$ & $\ldots$ & $\ldots$ & $\ldots$ & $\ldots$ & 8 \\
\hline 38 & $\ldots$ & $\ldots$ & $\ldots$ & 8 & $\ldots$ & $\ldots$ & $\ldots$ & $\ldots$ & $\ldots$ & $\ldots$ & $\ldots$ & 5 \\
\hline 39 & $\ldots$ & $\ldots$. & $\ldots$ & 3 & $\ldots$ & $\ldots$ & $\ldots$ & $\ldots$ & $\ldots$ & $\ldots$ & $\ldots$ & 13 \\
\hline 40 & $\ldots$ & $\ldots$ & $\ldots$ & 1. & $\ldots$ & $\ldots$ & $\ldots$ & $\ldots$ & $\ldots$. & $\ldots$ & $\therefore$ & 6 \\
\hline 41 & $\ldots$. & & 1 & $1 \dagger$ & $\ldots$ & $\ldots$ & $\ldots$ & $\ldots$ & $\ldots$ & .... & .... & 8 \\
\hline 42 & $\ldots$ & $1 \dagger$ & $\ldots$ & $\ldots$ & $1_{+}^{+}$ & $\ldots$ & $\ldots$ & $\ldots$ & $\ldots$ & $\ldots$ & $\ldots$. & 6 \\
\hline 43 & $\ldots$. & $\ldots$ & $\ldots$ & $\ldots$. & $\ldots .$. & $1 \dagger$ & $\ldots$ & $\ldots$ & $\ldots$ & $\ldots$ & $\ldots$ & 12 \\
\hline 44 & $\ldots$ & $\ldots$ & $\ldots$ & $\ldots$ & & $\ldots$ & $\ldots$ & $\ldots$ & $\ldots$ & $\ldots$ & .... & 9 \\
\hline 45 & $\ldots$ & $\ldots$ & $\ldots$ & $\ldots$ & $1 \ddagger$ & $\ldots$ & $\ldots$ & $\ldots$ & $\ldots$ & .... & $\ldots$ & 6 \\
\hline 46 & $\ldots$ & $\ldots$ & $\ldots$. & $\ldots$ & $\ldots$ & 4 & $\ldots$ & $\ldots$ & $\ldots$ & $\ldots$ & $\ldots$ & 3 \\
\hline 47 & $\ldots$ & $\ldots$ & $\ldots$ & $\ldots$ & $\ldots$ & 3 & $\ldots$ & $\ldots$ & $\ldots$ & $\ldots$ & $\ldots$ & 3 \\
\hline 48 & $\ldots$ & $\ldots$ & $\ldots$ & $\ldots$ & $\ldots$ & 4 & $\ldots$ & $\ldots$ & $\ldots$ & $\ldots$ & $\ldots$. & \\
\hline 49 & $\cdots$ & $\ldots$ & $\cdots$ & $\ldots$ & 1 & 3 & $\ldots$ & $\ldots$. & $\ldots$ & $\ldots$. & $\ldots$ & 1 \\
\hline 50 & $\ldots$ & $\ldots$ & $\ldots$ & $\ldots$ & & 6 & $\ldots$ & $\ldots$ & $\ldots$ & $\ldots$ & $\ldots$ & \\
\hline 51 & $\ldots$ & $\ldots$ & $\ldots$ & $\ldots$. & 1 & 3 & $\ldots$ & $\ldots$ & $\ldots$ & $\ldots$ & $\ldots$. & $2 \dagger$ \\
\hline 52 & $\ldots$ & $\ldots$ & $\ldots$ & $\ldots$ & $\ldots$ & 10 & $\ldots$ & $\ldots$ & $\ldots$. & $\ldots$ & $\ldots$ & 1 \\
\hline 53 & $\ldots$ & $\ldots$. & $\ldots$ & $\cdots$ & $\ldots$. & 6 & $\cdot \ldots$ & $\ldots$ & $\ldots$ & $\ldots$ & $\ldots$ & \\
\hline 54 & $\ldots$ & $\ldots$ & $\ldots$ & $\ldots$. & & 2 & $\ldots$ & $\ldots$ & $\ldots$ & $\ldots$ & $\ldots$ & 2 \\
\hline 55 & $\ldots$ & $\ldots$ & $\ldots$ & $\ldots$. & 1 & 3 & $\ldots$ & $\ldots$. & $\cdots$ & $\ldots$ & $\ldots$ & \\
\hline 56 & $\ldots$ & $\ldots$ & $\ldots$ & $\ldots$ & $\ldots$ & 7 & $\ldots$ & $\ldots$ & $\ldots$ & $\ldots$ & $\ldots$ & 1 \\
\hline 57 & $\ldots$ & $\ldots$ & $\ldots$ & $\ldots$ & $\ldots$ & 8 & $\ldots$ & $\ldots$ & $\ldots$ & .... & $\ldots$ & $\cdots$ \\
\hline 58 & $\cdots$ & $\ldots$ & $\ldots$ & $\ldots$. & $\ldots$. & 1 & $\ldots$ & $\ldots$ & $\ldots$. & $\ldots$ & $\ldots$ & \\
\hline 59 & $\ldots$ & $\ldots$ & $\cdots$ & $\cdots$ & $\cdots$ & 1 & $\ldots$ & $\cdots$. & $\ldots$ & $\ldots$ & $\ldots$ & 1 \\
\hline 60 & $\ldots$ & $\ldots$ & $\ldots$ & $\ldots$ & $\ldots$ & 3 & $\ldots$ & $\ldots$ & $\ldots$. & $\ldots$ & $\ldots$ & $\ldots$ \\
\hline $\begin{array}{l}61 \\
62\end{array}$ & $\cdots$ & $\cdots$ & $\cdots$ & $\begin{array}{l}\cdots . \\
\ldots .\end{array}$ & $\begin{array}{l}\cdots . \\
\ldots .\end{array}$ & 1 & $\begin{array}{l}\cdots \\
\ldots .\end{array}$ & $\begin{array}{l}\cdots \\
\ldots .\end{array}$ & $\begin{array}{l}\cdots . \\
\ldots .\end{array}$ & $\cdots$ & $\cdots$ & $\cdots$. \\
\hline
\end{tabular}

See note $a$ to table 5. 
The differentiation of the early race is very marked; with the singles, in fact, the later cultures indicate no case of overlapping in the 1908 cultures, in either character, between extracted pure Snowflake and pure or heterozygous early. The total sterility of the doubles necessarily leaves their constitution somewhat in doubt.

The cultures of 1908 so far suggest that WG9-C10 was a mutant. To be reasonably certain, however, we must have further evidence: (1) on the fact and mode of inheritance of the supposed new type, and (2) on the possibility that either WG9 or some other plant of the cultures of 1906 brought the character into the cultures. We shall now consider somewhat extensive evidence bearing on these points, concluding with a special test of the possibility of vicinism.

When I last saw the warm-house plants of 1906, three were known to be singles, and all but two of the rest were recorded as certainly or probably doubles. Seed was secured from these three singles only, and presumably no other singles occurred in the house. Since this seed was all from unguarded flowers, we must consider the possibility that WS1 or WL10, the other warm-house singles, brought the early factor into the cultures. It is also barely possible that pollen was brought to WG9 from some plant not in this greenhouse.

These two parents were tested in supplementary cultures, in house $\mathrm{C}$ in 1907, and in house $\mathrm{W}$ in 1908. The 1907 progeny averaged slightly earlier than those of other parents, but this may have been due to their position, which was much nearer a partition separating the house ${ }^{10}$ from a warm greenhouse. Unfortunately the internodes were not recorded.

In the 1908 cultures these lots were potted two days later than most of the other lots and one day later than the WG9 lot, and for some unknown reason the WL10 lot wilted badly for some days. The parents in question gave singles (16 and 11 plants respectively) which when compared with progeny of CG2 and WG9 (23 and 15) might suggest that the parents were heterozygous for the early type. The results with the similar numbers of doubles decidedly disagree with these, and suggest that cultural accidents produced the differences; the WS1 lot was not exceptional, while all the WL10 progeny were grouped near the lower end of the range of the other lots. In view of all the facts, the data hardly deserve tabular presentation, but they raise a question requiring further study; a later test is reported below.

10 A temporary substitute for the regular house $\mathrm{C}$. 


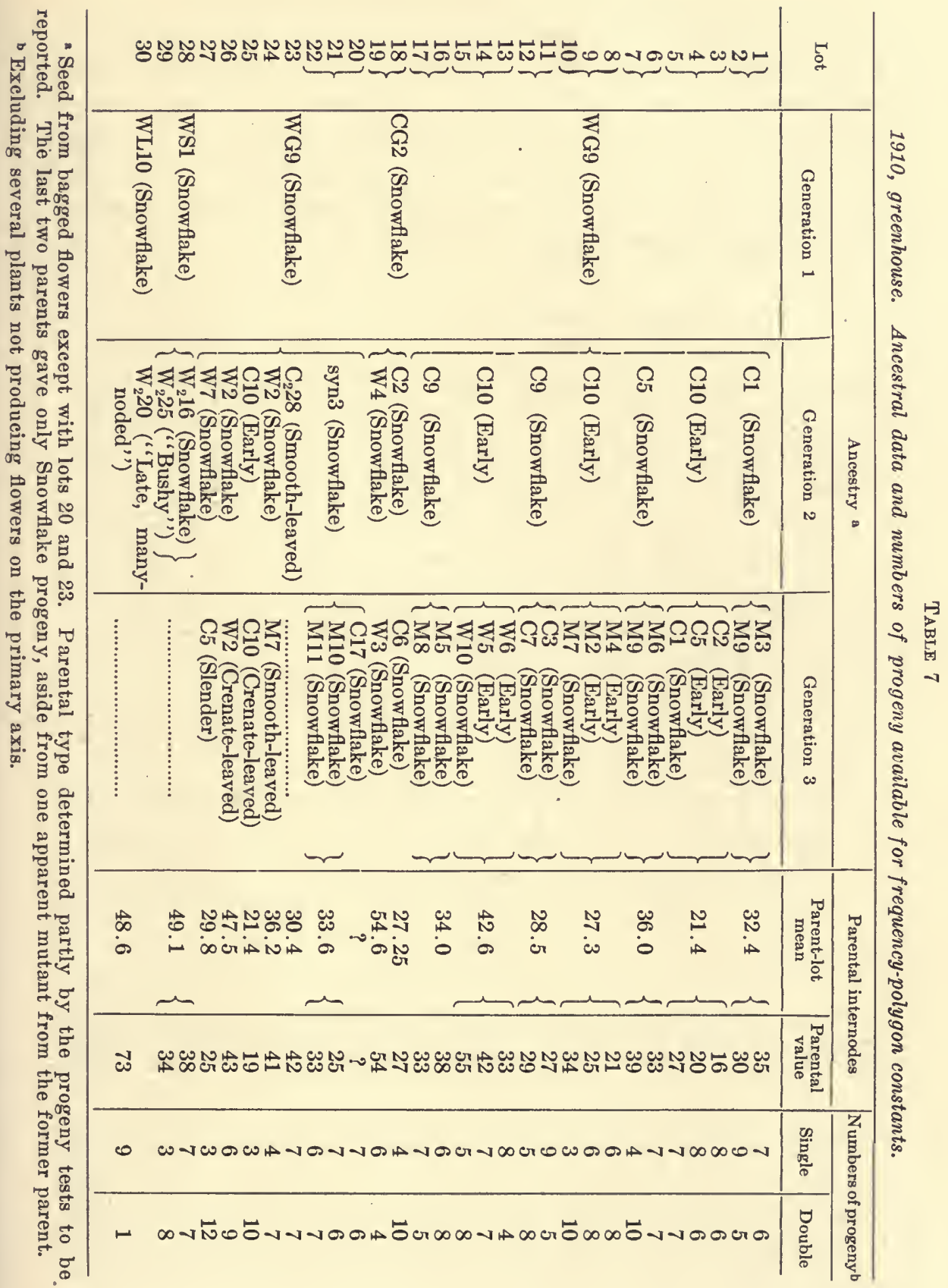


In the eultures of 1910 and $1911 \mathrm{~F}$, all the 1908 progeny of WG9C10 were tested. On account of the variable nature of the quantitative charaeter involved, an elaborate study was neeessary. Only small eultures eould be grown in the greenhouse; these were supplemented by larger lots in the field in 1911, but inhibition of flowering by the hot summer, together with the effects of disease and soil variations, made the field results erratic and necessitated special methods of treatment of the evidence.

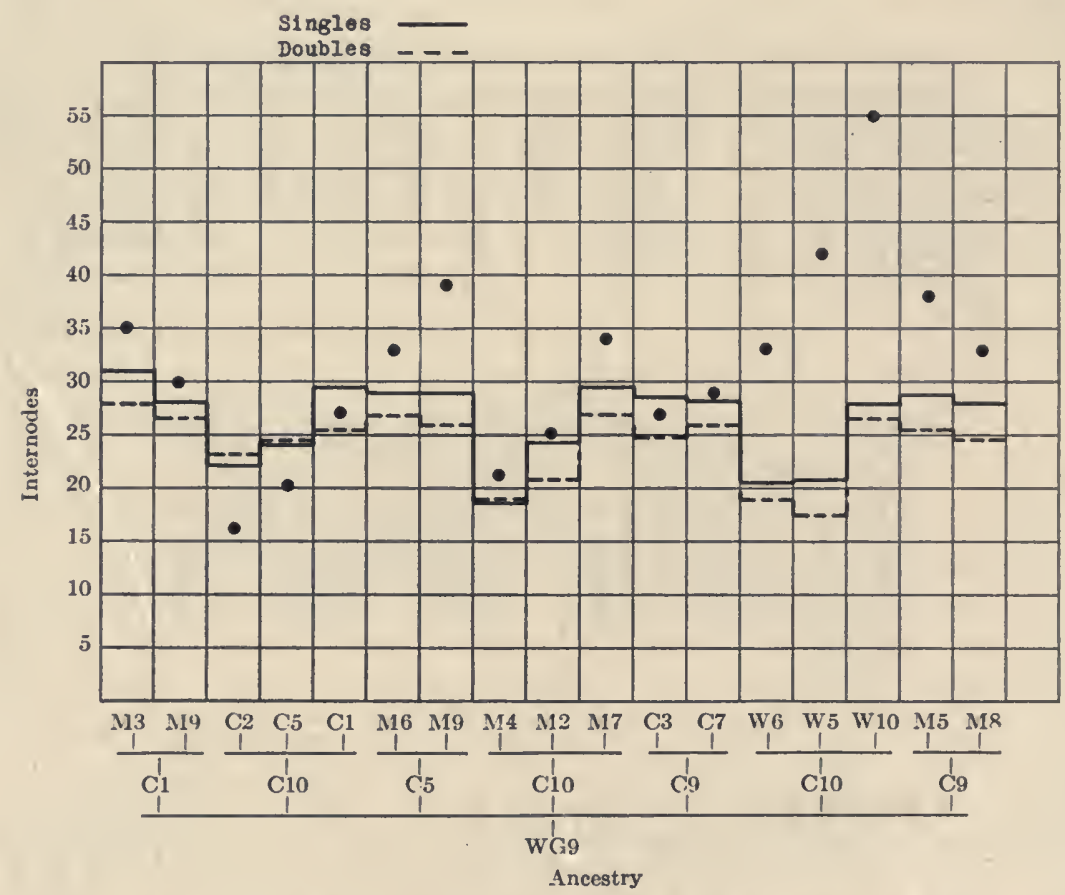

Chart 1. Cultures of 1910. Internodes: parental values and progeny means (respectively shown by dots and lines) for progeny lots 1 to 17, omitting aberrant progeny. Parental values should be compared only for the same house.

Table 7 gives the available data for the parents of the 1910 eultures, and the numbers of progeny available for quantitative data. The order of the pedigree numbers here is the same as that of the progeny lots on the greenhouse beneh. For convenienee, the 1910 tests of other mutant types, together with tests of several Snowflake parents, are. included in the table (lots 18 to 30 ). 
The plants were grown in house $\mathrm{C}$ of the previous work. Two or three plants (one shown in fig. 25) were extremely vigorous, presumably because of some accidental soil difference; aside from these, a few apparent mutants, and a few plants otherwise abnormal, the plants were fairly uniform except where heterozygosis was to be expected.

The data for time of flowering, as with the 1908 cultures, show the same main features as the internode data, and only the latter will be considered in detail. The types were again more widely different in internodes than in earliness, a fact which seems to indicate that the early type grows more slowly than Snowflake.

So large and so regular are the differences in internodes that the means of these very small lots seem worthy of presentation (chart 1). ${ }^{11}$ Apparently the few-noded character was carried, among the nine parents descended from WG9-C10, by all except the three parents having the highest numbers in their respective houses.

Tables 8 and 9 give the internode frequencies for the singles and doubles respectively, by separate progeny lots and by groups of similar ancestry. The range of variation for the check lots, omitting the indicated apparent mutants and other apparently abnormal plants, is rather surprisingly small, as is the case with the cool-house cultures of 1908. The three late progeny of WG9-C10 give lots closely corresponding in range to the check lots, only one individual falling below the range of the combined check lots. The six early and medium progeny of WG9-C10, on the other hand, give distributions of far greater range than do the check parents, extending to much lower values.

Tables 10 and 11 give the ordinary statistical constants for the grouped lots. The mean number of internodes, for both singles and doubles, is about 25 per cent lower in the progeny of the six fewnoded parents, the difference being not far from ten times as great as its probable error. The incrcase in variability with the progeny of the early parents is also striking, and the difference is about five to six times its probable error. With time to flowering, it may be noted, the differences are similar to those with internodes, but somewhat less marked in the case of the mean; the flowering data are not given here.

It is plain that the previous conclusion as to the heterozygous nature of WG9-C10 is sustained. The elimination of the apparent mutants

11 Caleulated with the apparent mutants and four other apparently abnormal plants eliminated; see tables 8 and 9 . 


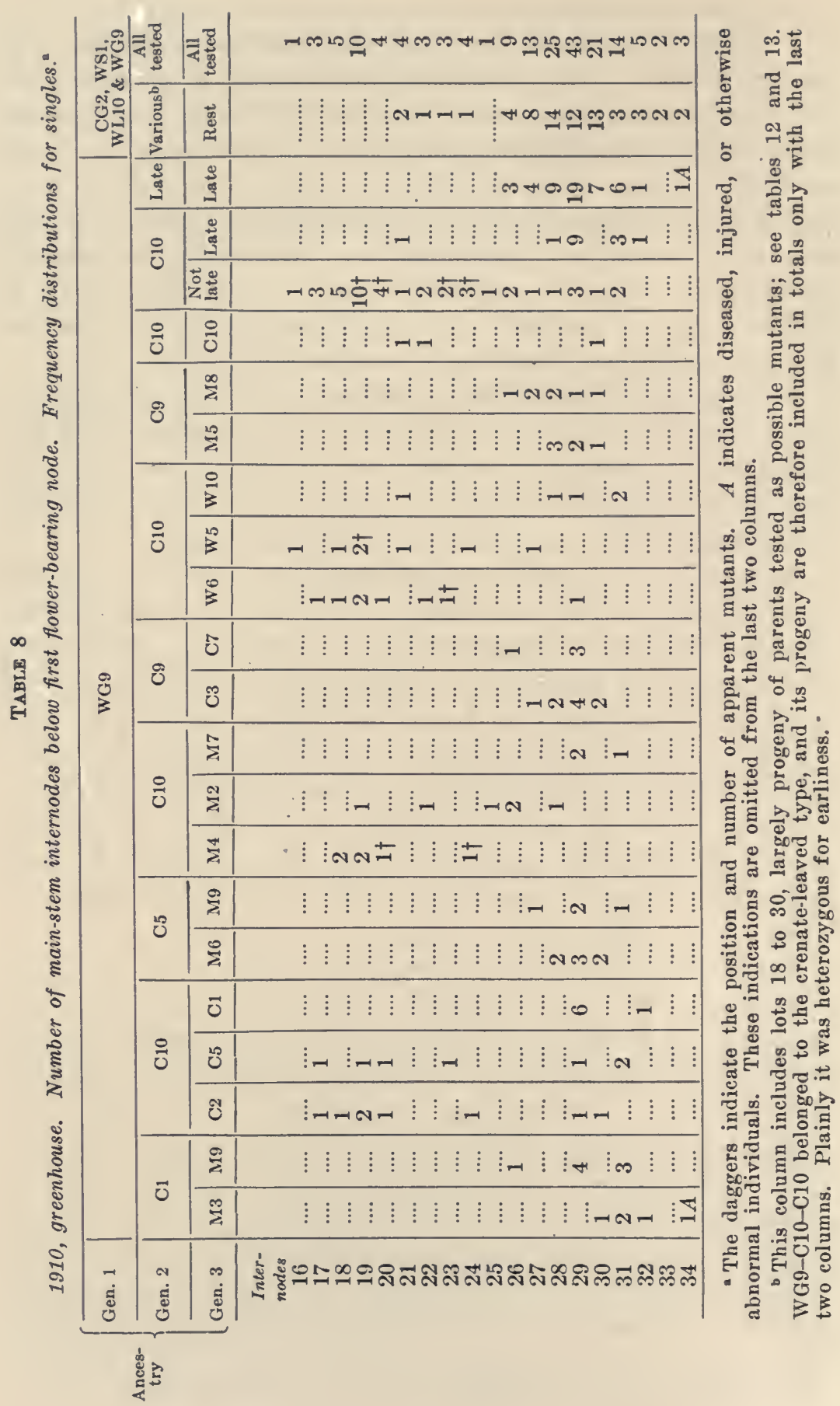




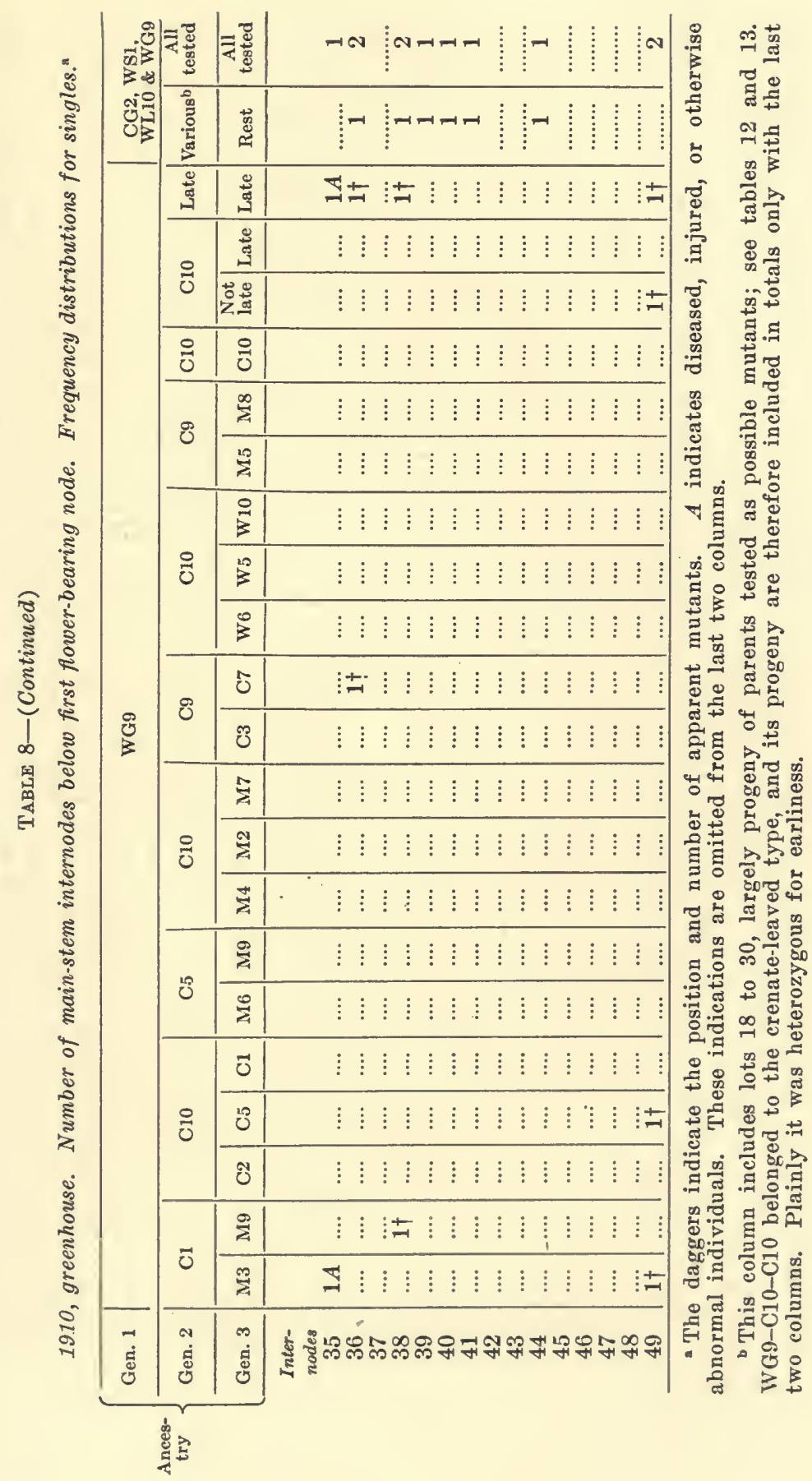




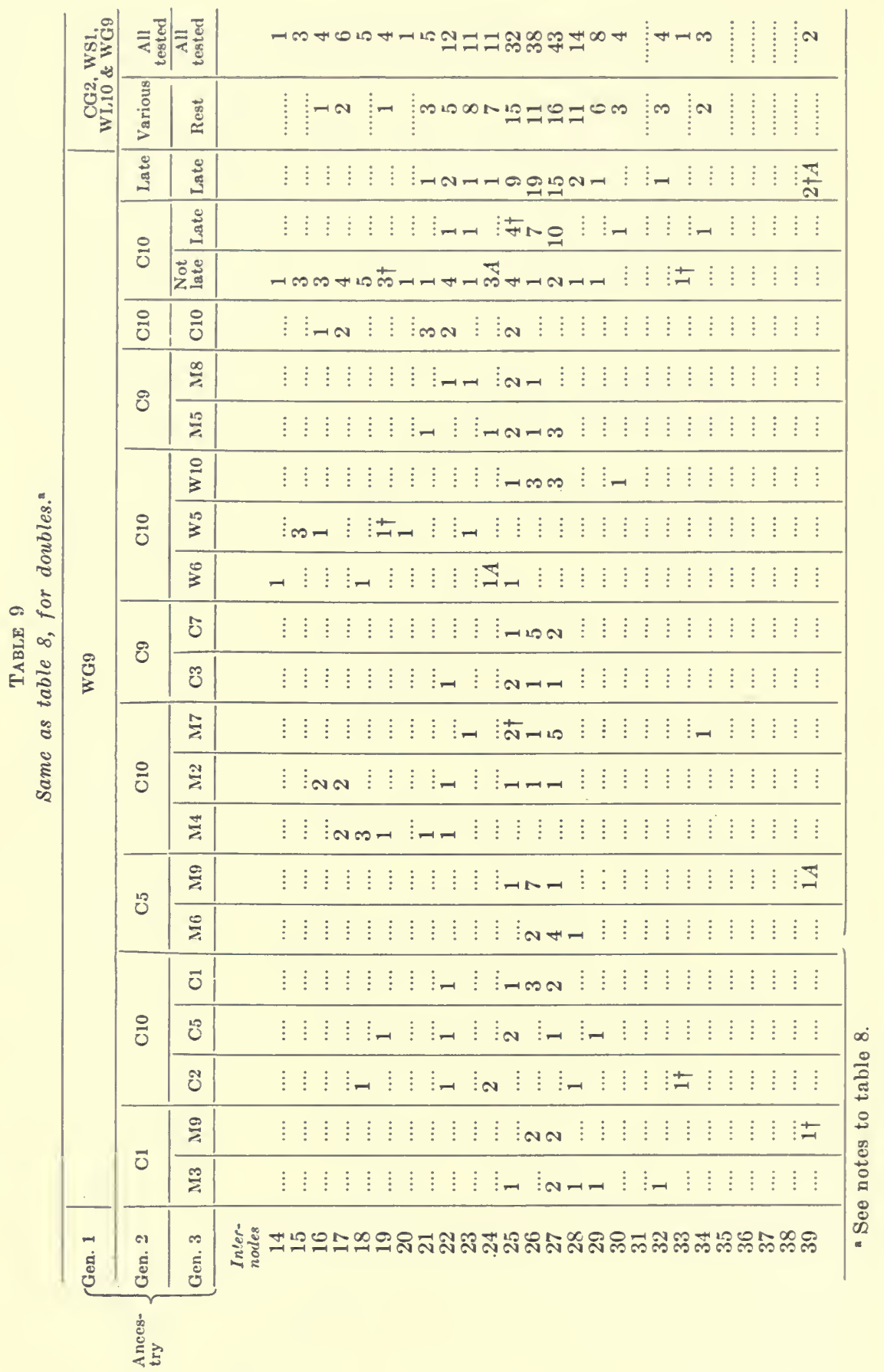




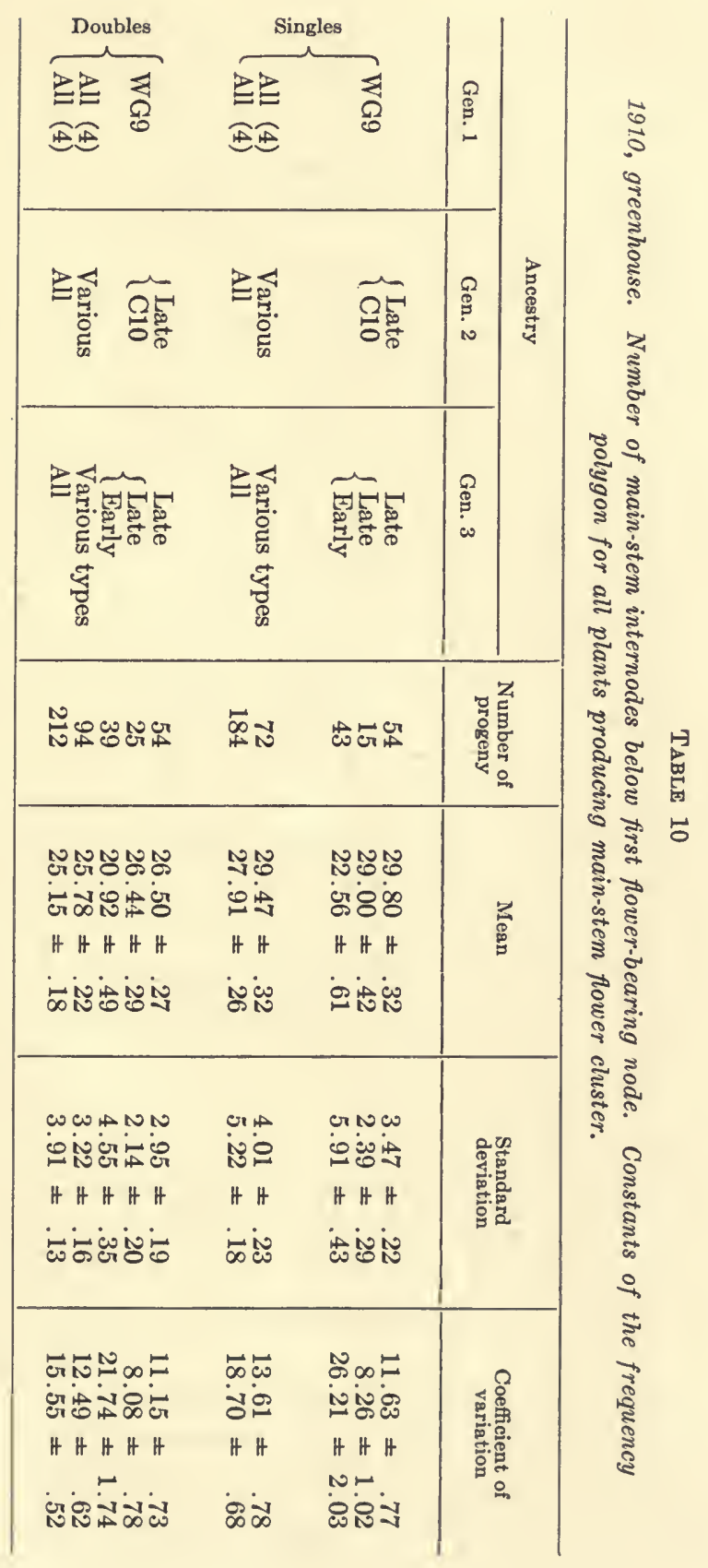




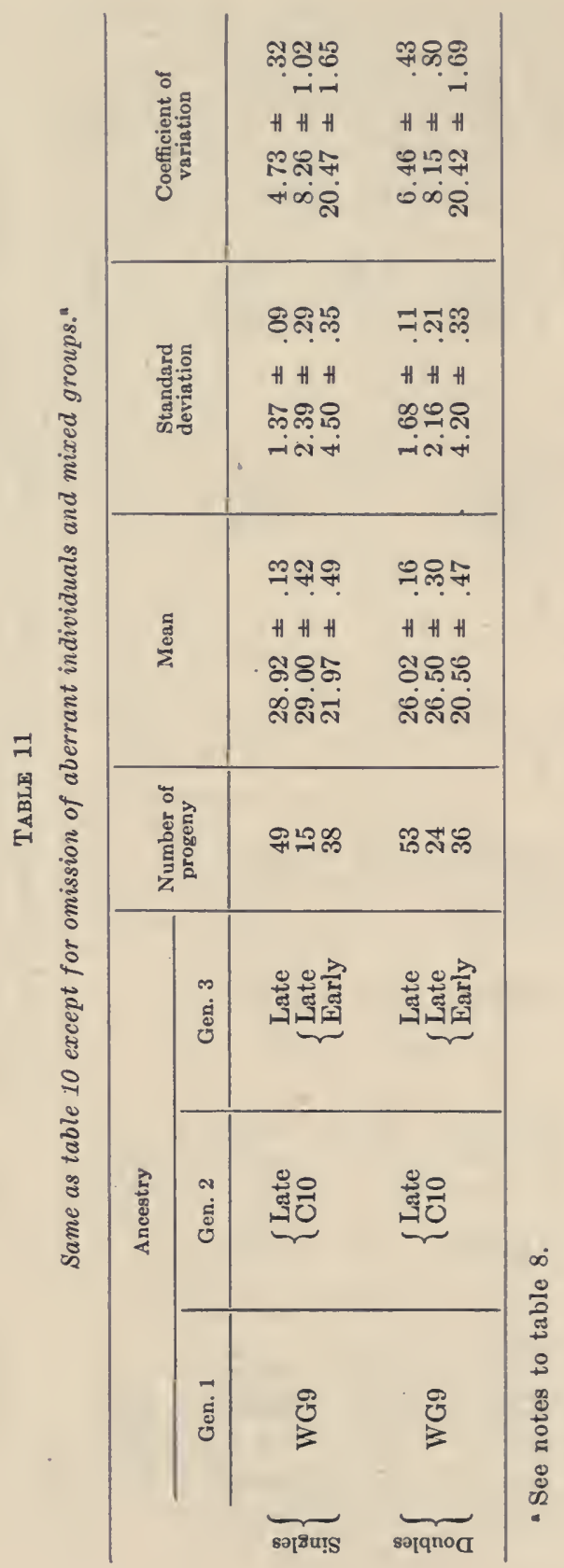


and the other abnormal plants presumably gives a better comparison as to mean and variability, but the conclusion is the same in either case. The three many-noded (late) parents descended from. WG9C10 give no definite indication of being genetically different from the "check" lots not descended from WG9-C10, while the variability constants are sufficient, taken alone, to make probable the genetic differentiation of the fewer-noded progeny of WG9-C10. Apparently all the fewer-noded progeny of WG9-C10 that were tested-seven, when WG9-C10-C10, a crenate-leaved apparent mutant (tables 12 and 13), is included-were either simplex or duplex for presence of an earliness factor or factors.

The variability of all the thirty progeny lots, taken together, is high, as might be expected, though decidedly below that of the progeny of early parents. This high variability is due only in very small part to the progeny of the five or six supposedly mutant parents; the last thirteen lots, alone, are much less variable than the mixed early lots. The portion of the cultures containing these progeny lots from aberrant parents was conspicuous for irregularity of germination, and, on the whole, a relatively low rate of germination.

A few of the last thirteen lots give more evidence bearing on the origin of WG9-C10. The early WG9-syn3-M10 (tables 12 and 13) gives no evidence of genotypic differentiation from its ordinary sib, WG9-syn3-M11; WS1-W 216 , another phenotypically early parent, also failed to transmit earliness to its progeny. CG2-C2-C6, on the other hand, although itself an ordinary plant, shows a rather suspicious tendency to the production of early and few-noded progeny, but better evidence would be required for any positive conclusion. WG9-C10-C10 appears, from the data in tables 12 and 13 and from observation of the flowering of plants of the next generation in the $1911 \mathrm{H}$ cultures, to have been heterozygous for the early type, as well as for the crenate-leaved type. We find in this test no definite indication that the early type has appeared elsewhere than in WG9-C10 and its descendants.

The $\mathrm{F}_{2}$ progeny of WG9-C1, an abnormal plant whose $\mathrm{F}_{1}$ progeny were unusually and uniformly early but not few-noded, have been included with the other check lots without question. This treatment seems justified by the flowering data, which do not indicate any repetition of the precocious development of the first-generation plants; the peculiarities of the $F_{1}$ cultures, if not a mere cultural accident, presumably depended on the very abnormal development of the parent, 
TABLE 12

1910, greenhouse, lots 18 to 30. Number of main-stem internodes below first flower-bearing node. Frequency distributions for singles. ${ }^{a}$

\begin{tabular}{|c|c|c|c|c|c|c|c|c|c|c|c|c|c|c|}
\hline \multirow{3}{*}{$\begin{array}{l}\text { Ances- } \\
\text { try }\end{array}$} & & \multicolumn{2}{|c|}{ CG2 } & \multicolumn{8}{|c|}{ WG9 } & \multicolumn{2}{|c|}{ WS1 } & \multirow{2}{*}{$\frac{\text { WL10 }}{W_{220}}$} \\
\hline & Gen. 2 & $\mathrm{C} 2$ & W4 & \multicolumn{3}{|c|}{$\operatorname{syn}(\mathrm{M}) 3$} & $\mathrm{C}_{2} 28$ & W2 & & W2 & & & $\mathrm{w}_{2} 25$ & \\
\hline & Gen. 3 & $\mathrm{C} 6$ & W3 & $\mathrm{C} 17$ & $\mathbf{M} 10$ & M11 & ….... & M7 & Clo & W2 & C5 & ........ & $\ldots \ldots \ldots$ & ......... \\
\hline - & $\begin{array}{l}\text { Inter- } \\
\text { nodes } \\
21 \\
22 \\
23 \\
24 \\
25 \\
26 \\
27 \\
23 \\
29 \\
30 \\
31 \\
32 \\
33 \\
34 \\
35 \\
36 \\
37 \\
38 \\
39 \\
40 \\
41 \\
43 \\
4\end{array}$ & 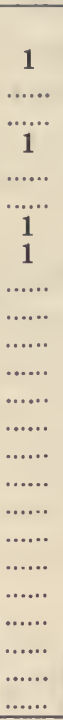 & 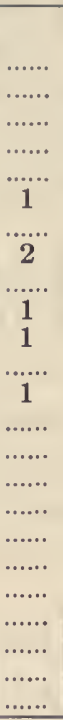 & 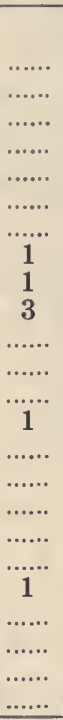 & 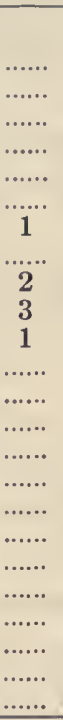 & 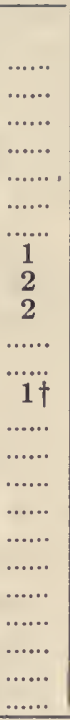 & 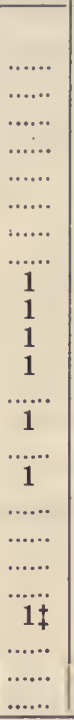 & 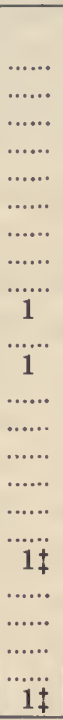 & 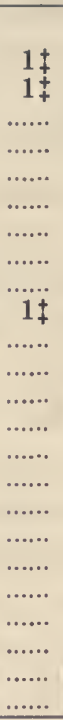 & 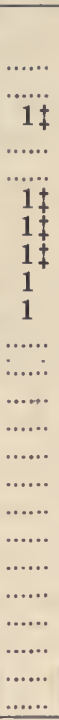 & 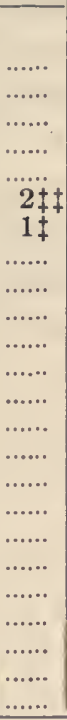 & $\begin{array}{c}\ldots \ldots \\
\ldots \ldots \\
\ldots \ldots \\
\ldots \ldots \\
\ldots \ldots \\
\ldots \ldots \\
2 \\
4 \\
\ldots \ldots \\
\ldots \ldots \\
\ldots \ldots \\
1 \\
\ldots \ldots \\
\ldots \ldots \\
\ldots \ldots \\
\ldots \ldots \\
\ldots \ldots \\
\ldots \ldots \\
\ldots \ldots \\
\ldots \ldots \\
\ldots \ldots \\
\ldots \ldots \\
\ldots \ldots \\
\ldots \ldots \\
\ldots \ldots\end{array}$ & 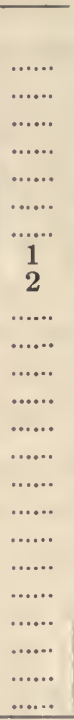 & 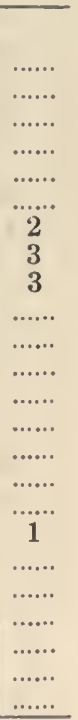 \\
\hline
\end{tabular}

- See table 7 and notes to tables 5 and 8 .

TABIE 13

Same as table 12, for doubles."

\begin{tabular}{|c|c|c|c|c|c|c|c|c|c|c|c|c|c|c|}
\hline \multirow{3}{*}{$\begin{array}{l}\text { Ances- } \\
\text { try }\end{array}$} & Gen. 1 & \multicolumn{2}{|c|}{ CG2 } & \multicolumn{8}{|c|}{ - WG9 } & \multicolumn{2}{|c|}{ WS1 } & \multirow{2}{*}{$\frac{W L 10}{W_{2} 20}$} \\
\hline & \multirow{2}{*}{$\frac{\text { Gen. } 2}{\text { Gen. } 3}$} & $\mathrm{C} 2$ & W4 & \multicolumn{3}{|c|}{$\operatorname{syn}(M) 3$} & \multirow{2}{*}{$\frac{\mathrm{C}_{2} 28}{\ldots \ldots}$} & \multirow{2}{*}{$\frac{W 2}{M 17}$} & \multirow{2}{*}{$\begin{array}{l}\mathrm{C} 10 \\
\mathrm{C} 10\end{array}$} & \multirow{2}{*}{$\begin{array}{l}\text { W2 } \\
\text { W2 }\end{array}$} & \multirow{2}{*}{$\begin{array}{l}\text { W7 } \\
\text { C.5 }\end{array}$} & \multirow{2}{*}{$\frac{W_{2} 16}{\ldots \ldots}$} & \multirow{2}{*}{$\frac{W_{2} 25}{\ldots \ldots}$} & \\
\hline & & C6 & W3 & $\mathrm{C} 17$ & M10 & M11 & & & & & & & & ......... \\
\hline & $\begin{array}{l}\text { Inter- } \\
\text { nodes }\end{array}$ & & & & & & & & & & & & & \\
\hline & 16 & ....... & ....... & ...... & ...... & ...... & ...... & ....... & 1 & ....... & ....... & $\ldots \ldots$ & ...... & $\ldots \ldots$ \\
\hline & 17 & ....... & ....... & ........ & ....... & ....... & ....... & ........ & 2 & ....... & ....... & ........ & ....... & ....... \\
\hline & 18 & $\ldots \ldots$ & ....... & ....... & ....... & ....... & ....... & ....... & $\ldots \ldots$ & ....... & ...... & $\ldots \ldots$. & ...... & ...... \\
\hline & 19 & 1 & ........ & ...... & ....... & ....... & ........ & ....... & ....... & ....... & ....... & ....... & ....... & ...... \\
\hline & 20 & ....... & ....... & ....... & ....... & ....... & ....... & ....... & ....... & ....... & ....... & ...... & $\cdots \cdot \cdot \cdot$ & $\ldots \ldots$. \\
\hline & 21 & ....... & ....... & ....... & ...... & $\ldots \ldots$ & ....... & $\ldots \ldots$ & 3 & ....... & ...... & ....... & $\ldots \ldots$ & $\ldots \ldots$. \\
\hline & 22 & 1 & ....... & ....... & $\ldots \ldots$ & 2 & ...... & ....... & 2 & ....... & ...... & & $\ldots \ldots$ & ...... \\
\hline & 23 & 的 & 1 & ....... & 2 & ....... & ....... & $1 \ddagger$ & ....... & ....... & ....... & $3 \dagger+$ & 1 & ....... \\
\hline & 24 & 2 & 1 & ....... & ....... & ........ & ..... & $1 \ddagger$ & ..... . & $1 \dagger$ & & & 2 & \\
\hline & 25 & 4 & ....... & ....... & ....... & 1 & $3 \ddagger \ddagger$ & ....... & 2 & $1 \ddagger$ & $1 \ddagger$ & 1 & 1 & 1 \\
\hline & 26 & 2 & ....... & 2 & 2 & 1 & $\cdots$ & ....... & ........ & 1 & & 2 & $1 \dagger$ & ....... \\
\hline & 27 & ....... & 2 & ....... & 1 & 2 & 2 & ........ & ....... & 3 & 3 & 1 & 2 & ....... \\
\hline & 28 & ....... & $\ldots \ldots$ & 1 & . & 1 & $\overline{1}$ & ...... & ....... & 2 & 5 & $\ldots \ldots$ & 1 & ...... \\
\hline & 29 & ....... & ........ & 2 & 1 & ....... & 1 & & ........ & ....... & 2 & ....... & ....... & $\ldots \ldots$ \\
\hline & 30 & ....... & ........ & ....... & ....... & ........ & $\ldots \ldots$. & $3 \pm+$ & ...... & ........ & ....... & ...... & ....... & $\ldots \ldots$. \\
\hline & 31 & ....... & ....... & ........ & ........ & ....... & ....... & $\ldots$ & ........ & ....... & ........ & ....... & ....... & ...... \\
\hline & 32 & $\ldots \ldots$ & $\ldots \ldots$ & 1 & ....... & ....... & ...... & 1 & ...... & ....... & $1 \ddagger$ & $\ldots \ldots$ & $\ldots \ldots$. & ...... \\
\hline & 33 & ........ & ....... & ........ & ....... & ....... & ....... & $\ldots$. & ....... & ........ & ....... & ....... & ....... & ....... \\
\hline & 34 & $\ldots \ldots$ & $\ldots \ldots$ & $\ldots \ldots$ & $\ldots \ldots$ & $\ldots \ldots$ & $\ldots \ldots$ & 1 & ....... & 1 & ....... & ....... & ....... & $\ldots \ldots$ \\
\hline
\end{tabular}

- See table 7 and notes to tables 5 and 8 . 
with its aborted main axis and very late production of a flowering shoot.

Table 14 shows the general plan of the house-sown field cultures of 1911. The progeny of WG9-C10 were arranged as before in the order of their numbers of internodes for each house of the 1908 cultures, beginning with the lowest numbers. The parental values for flowering and internodes are the values indicated by " $\ddagger$ "' in tables 5

TABLE 14

1911; field, plants transplanted from greenhouse. Aneestry, seed, and numbers of progeny.a

\begin{tabular}{|c|c|c|c|c|c|c|c|c|}
\hline \multirow{2}{*}{ Lot } & \multicolumn{3}{|c|}{ Ancestry } & \multirow{2}{*}{$\begin{array}{l}\text { Seeds } \\
\text { sown }\end{array}$} & \multirow{2}{*}{$\begin{array}{c}\text { Number of } \\
\text { plants alive } \\
33 \text { days after } \\
\text { sowing }\end{array}$} & \multicolumn{3}{|c|}{$\begin{array}{l}\text { Numbers of plants for data } \\
\text { on mutation and flowering }\end{array}$} \\
\hline & Gen. 1 & Gen. 2 & Gen. 3 & & & Totalb & Singles & Doubles \\
\hline $\left.\begin{array}{l}1 \\
2\end{array}\right\}$ & \multirow{8}{*}{ WG9 } & C5 & $\left\{\begin{array}{l}\text { C8 } \\
\text { C10 }\end{array}\right.$ & $\begin{array}{l}80 \\
71\end{array}$ & $\begin{array}{l}79 \\
71\end{array}$ & $\begin{array}{l}77 \\
70\end{array}$ & $\begin{array}{l}34 \\
36\end{array}$ & $\begin{array}{l}43 \\
34\end{array}$ \\
\hline $\left.\begin{array}{l}3 \\
4 \\
5 \\
6\end{array}\right\}$ & & C10 & $\left\{\begin{array}{l}\text { C2 } \\
\text { C5 } \\
\text { C8 } \\
\text { C1 }\end{array}\right.$ & $\begin{array}{l}80 \\
80 \\
80 \\
80\end{array}$ & $\begin{array}{l}80 \\
79 \\
79 \\
78\end{array}$ & $\begin{array}{l}79 \\
78 \\
78 \\
76\end{array}$ & $\begin{array}{l}39 \\
40 \\
35 \\
36\end{array}$ & $\begin{array}{l}39 \\
38 \\
43 \\
40\end{array}$ \\
\hline $\left.\begin{array}{l}7 \\
8\end{array}\right\}$ & & C5 & $\left\{\begin{array}{l}\text { W18 } \\
\text { W24 }\end{array}\right.$ & $\begin{array}{l}80 \\
80\end{array}$ & $\begin{array}{l}79 \\
76\end{array}$ & $\begin{array}{l}77 \\
75\end{array}$ & $\begin{array}{l}37 \\
41\end{array}$ & $\begin{array}{l}40 \\
34\end{array}$ \\
\hline $\left.\begin{array}{r}9 \\
10 \\
11 \\
12 \\
13 \\
14\end{array}\right\}$ & & C10 & $\left\{\begin{array}{l}\text { M4 } \\
\text { M9 } \\
\text { M6 } \\
\text { M2 } \\
\text { M7 } \\
\text { M8 }\end{array}\right.$ & $\begin{array}{l}80,26 \\
80 \\
80,63 \\
80,71 \\
80 \\
80\end{array}$ & $\begin{array}{l}77 \\
80 \\
77 \\
78 \\
80 \\
74\end{array}$ & $\begin{array}{l}76 \\
78 \\
77 \\
77 \\
80 \\
70\end{array}$ & $\begin{array}{l}30 \\
36 \\
34 \\
36 \\
37 \\
33\end{array}$ & $\begin{array}{l}45 \\
41 \\
42 \\
40 \\
42 \\
37\end{array}$ \\
\hline $\left.\begin{array}{l}15 \\
16\end{array}\right\}$ & & C9 & $\left\{\begin{array}{l}\text { C3 } \\
\text { C7 }\end{array}\right.$ & $\begin{array}{l}80 \\
80\end{array}$ & $\begin{array}{l}78 \\
76\end{array}$ & $\begin{array}{l}78 \\
75\end{array}$ & $\begin{array}{l}30 \\
32\end{array}$ & $\begin{array}{l}48 \\
43\end{array}$ \\
\hline $\left.\begin{array}{l}17 \\
18 \\
19 \\
20 \\
21 \\
22 \\
23 \\
24 \\
25\end{array}\right\}$ & & $\mathrm{C} 10$ & $\begin{array}{l}\text { W6 } \\
\text { W4 } \\
\text { W11 } \\
\text { W9 } \\
\text { W5 } \\
\text { W8 } \\
\text { W7 } \\
\text { W3 } \\
\text { W10 }\end{array}$ & $\begin{array}{l}80 \\
80,21 \\
80 \\
80,19 \\
80 \\
80,1 / 4 \\
80 \\
80 \\
74\end{array}$ & $\begin{array}{l}74 \\
70 \\
78 \\
76 \\
79 \\
76 \\
75 \\
73 \\
72\end{array}$ & $\begin{array}{l}70 \\
65 \\
76 \\
72 \\
75 \\
74 \\
72 \\
71 \\
66\end{array}$ & $\begin{array}{l}31 \\
26 \\
34 \\
24 \\
33 \\
36 \\
32 \\
37 \\
32\end{array}$ & $\begin{array}{l}39 \\
38 \\
42 \\
47 \\
42 \\
36 \\
40 \\
34 \\
34\end{array}$ \\
\hline 26 & & C10 & ........ & 80 & 60 & 59 & 27 & 32 \\
\hline $\left.\begin{array}{l}27 \\
28\end{array}\right\}$ & & C9 & $\left\{\begin{array}{l}\text { W10 } \\
W 24\end{array}\right.$ & $\begin{array}{l}80 \\
80\end{array}$ & $\begin{array}{l}74 \\
80\end{array}$ & $\begin{array}{l}73 \\
78\end{array}$ & $\begin{array}{l}33 \\
32\end{array}$ & $\begin{array}{l}39 \\
45\end{array}$ \\
\hline
\end{tabular}

a For plan of arrangement and parental data, see page 86 and tables 5 and 6 . Seeds from unguarded flowers are indicated by italic figures; where two numbers are given the first is the total.

- Including twelve plants (all late mutants) with which determination of the form of flower was impossible. 
and 6 , in the order there given, except that the arrangement by internodes reverses the two-day difference in carliness of the parents of lots 19 and 20; for convenient comparison, the parental and parentlot internode values are included in table 19.

Two progeny lots were set in each of the fourtecn rows; probably the soil was less favorable at the east end of the plot, and hence for the even-numbered lots, at least in about the last seven rows out of the fourteen.

The plants were beginning to grow very rapidly when moved to the field. On account of deficient soil moisture and excessive heat, the transplanting was slow and in part purposely delayed, covering a period of five days. Lots 21 to 28 were set three days later than lots

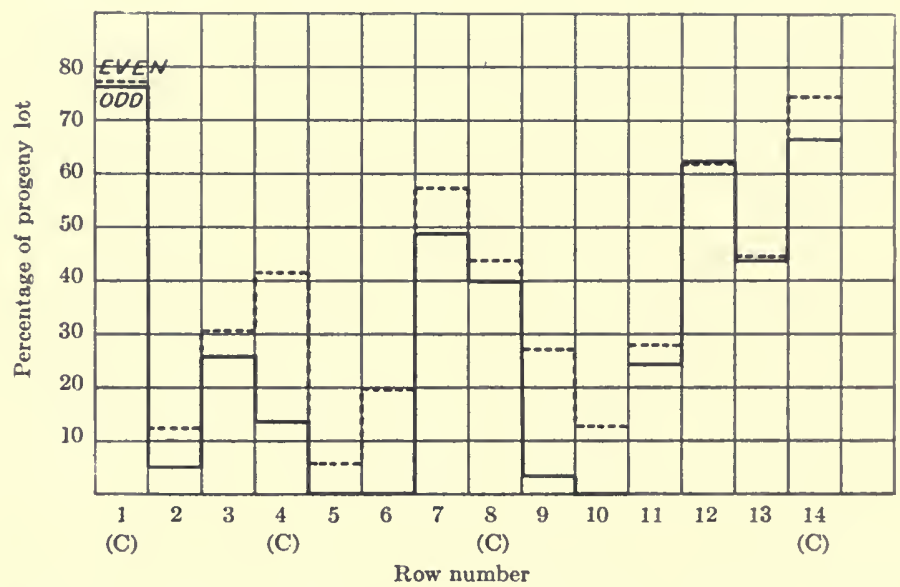

Chart 2. 1911, field; lots transplanted from greenhouse. Percentages of progeny lots not flowering by November 3, for singles. Apparent mutants and injured plants eliminated. Odd-numbered lots represented by solid line. (C) indicate eheck rows. The curves are broken between rows 10 and 11 , where a cultural difference enters.

11 to 20 , and the later loss of roots resulting seems, in spite of rain coming the next day, to have seriously delayed flowering. Lots 1 and 2 wilted badly after transplanting, and some difference in soil conditions in the flats, rather than a genetic difference, was doubtless responsible for the exceptional lateness of these lots. Lot 20 lost an exceptionally large leaf area as a result of transplanting. A fungus disease (a slow stem rot) was more common on lots 20 to 24 than elsewhere; it doubtless killed some young plants and delayed or prevented flowering in some other cases. Possibly the soil was poorer in the later rows. 
TABLE 15

1911, field; plants transplanted from greenhouse. Plants alive November 3 , not having flowered. Singles.

\begin{tabular}{c|c|c|c|c|c|c}
\hline Row & Lot & $\begin{array}{c}\text { Non- } \\
\text { flowering } \\
\text { plants }\end{array}$ & $\begin{array}{c}\text { Non-flowering, } \\
\text { Snowflake and } \\
\text { early types }\end{array}$ & Lot & $\begin{array}{c}\text { Non-flowering } \\
\text { plants }\end{array}$ & $\begin{array}{c}\text { Non-flowering, } \\
\text { Snowflake and } \\
\text { early types }\end{array}$ \\
\hline 1 & 1 & 27 & 26 & 2 & 29 & $28(27)$ \\
2 & 3 & 5 & 2 & 4 & 7 & 5 \\
3 & 5 & 9 & 9 & 6 & 11 & 11 \\
4 & 7 & 7 & 5 & 8 & 17 & 17 \\
5 & 9 & 0 & 0 & 10 & 2 & $2(1)$ \\
6 & 11 & 1 & 0 & 12 & 9 & 7 \\
7 & 13 & 19 & $18(17)$ & 14 & 20 & 19 \\
8 & 15 & 12 & 12 & 16 & 14 & 14 \\
9 & 17 & 1 & 1 & 18 & $8(7 ?)$ & $7(6 ?)$ \\
10 & 19 & 0 & 0 & 20 & 3 & 3 \\
11 & 21 & 8 & 8 & $22^{\mathrm{b}}$ & 11 & 10 \\
13 & 23 & 21 & 20 & 24 & 23 & 23 \\
14 & 25 & 16 & $14(12)$ & 26 & 14 & 12 \\
\hline & 27 & 23 & 22 & 28 & 24 & 24 \\
\hline
\end{tabular}

a Omitting non-flowering apparent mutants. For the numbers in parenthesis, "doubtful mutants" are classed as mutants. Two plants accidentally seriously injured, in lots 14 and 25 , were counted out with the mutants.

b The stem-rot disease (see p. 108) was evidently worst in lot 22; some two or three of the worst infected plants (included above) were nearly or quite dead by November 3 .

TABLE 16

Same as table 15, for doubles.

\begin{tabular}{|c|c|c|c|c|c|c|}
\hline Row & Lot & $\begin{array}{c}\text { Non- } \\
\text { flowering } \\
\text { plants }\end{array}$ & $\begin{array}{l}\text { Non-flowering, } \\
\text { Snowflake and } \\
\text { early types }\end{array}$ & Lot & $\begin{array}{c}\text { Non-flowering } \\
\text { plants }\end{array}$ & $\begin{array}{l}\text { Non-flowering, } \\
\text { Snowflake and } \\
\text { early types }\end{array}$ \\
\hline 1 & 1 & 4 & 2 & 2 & 0 & 0 \\
\hline $\begin{array}{l}2 \\
3\end{array}$ & $\begin{array}{l}3 \\
5\end{array}$ & $\begin{array}{l}3 \\
3\end{array}$ & $\begin{array}{l}1 \\
3\end{array}$ & $\begin{array}{l}4 \\
6\end{array}$ & $\begin{array}{l}1 \\
0\end{array}$ & $l_{0}^{1(0)}$ \\
\hline 4 & 7 & 3 & $2(1)$ & 8 & 3 & 1 \\
\hline $\begin{array}{l}5 \\
6 \\
7\end{array}$ & $\begin{array}{r}9 \\
11 \\
13\end{array}$ & $\begin{array}{l}2 \\
0 \\
4\end{array}$ & $\begin{array}{l}0 \\
0 \\
2(1)\end{array}$ & $\begin{array}{l}10 \\
12 \\
14\end{array}$ & $\begin{array}{l}0 \\
0 \\
1\end{array}$ & $\begin{array}{l}0 \\
0 \\
1\end{array}$ \\
\hline 8 & 15 & 2 & 2 & 16 & 6 & 5 \\
\hline $\begin{array}{r}9 \\
10 \\
11 \\
12 \\
13\end{array}$ & $\begin{array}{l}17 \\
19 \\
21 \\
23 \\
25\end{array}$ & $\begin{array}{l}1 \\
0 \\
3 \\
5 \\
1\end{array}$ & $\begin{array}{l}0 \\
0 \\
1 \\
5 \\
1\end{array}$ & $\begin{array}{l}18 \\
20 \\
22 \\
24 \\
26\end{array}$ & $\begin{array}{l}3 \\
2 \\
1 \\
4 \\
7\end{array}$ & $\begin{array}{l}3(2) \\
2 \\
1 \\
4 \\
5\end{array}$ \\
\hline 14 & 27 & 1 & 1 & 28 & 10 & 8 \\
\hline
\end{tabular}

a See notes to table 15 . 
Altogether, these eultures are doubtless much less reliable for their size than the grcenhouse tests of the early typc, but they nevertheless, with due consideration of the points just mentioned, seem to permit of fairly safe eonelusions for most of the parents.

The plants were examined for flowering every other afteruoon from July 4 to November 3, inelusive (73 to 195 days from sowing). A very large part of the plants flowered in July, some in August, and a few still later. Evidently the ligh summer temperature largely inhibited flowering; many of the singles and a few of the doubles entirely failed to flower.

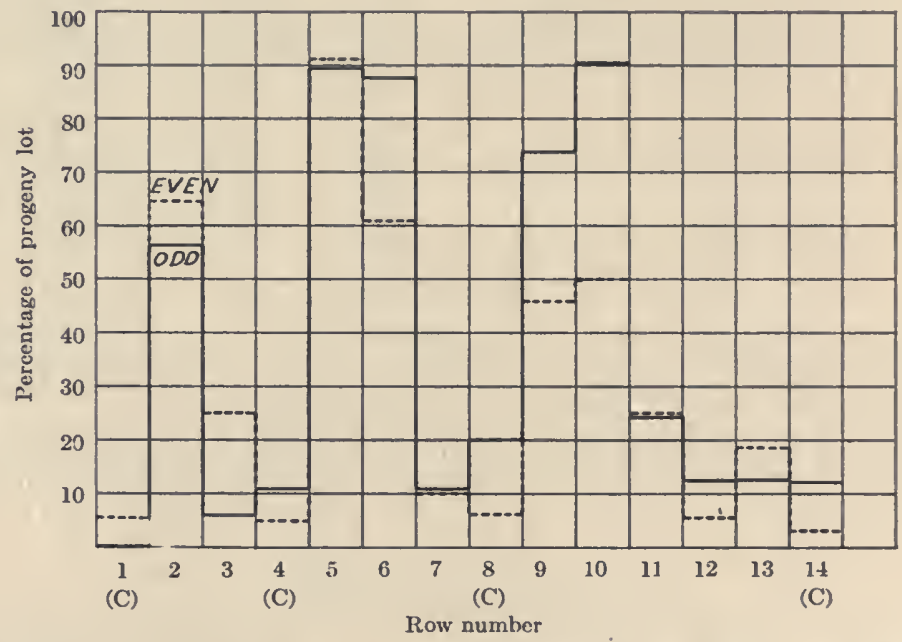

Chart 3. 1911, field; lots transplanted from greenhouse. Percentages of progeny lots with primary cluster flowering or aborted by October 10-16, for singles. Lines as in chart 2.

Figures 5 and 6 show the plants in July. Growth was usually vigorous through the season, but the internodes were very short, the branches numerous, and the region of the terminal inflorescence often abortive, so that determination of the number of main-stem internodes was not practicable. The emergence of the earliest corolla on the plant was recorded at the bi-diumal observations, and at two periods during the season the aborted primary elusters were noted.

The data show very definitely the transmission of "earliness" by the fewer-noded progeny of WG9-C10. Tables 15 and 16 show the numbers of plants alive, without having flowered, on November 3 ; the figures are thus a measure of lateness. The two progeny lots in each row are given one line in each of the tables, in order to facilitate separate comparison of the fourteen lots in each end half of the plot. 
The last column, with the apparent mutants omitted, no doubt gives the best comparison. The data for the singles, reduced to percentages, are also given in chart 2.

The doubles, which are often earlier to flower than the singles under unfavorable climatic conditions, flowered so generally that table 16 presents no significant differences. The singles (table 15), however, give definite evidence of segregation; the lots in rows $2,5,6$, and 9 to 11 all show a tendency to early flowering. Lot 26 , consisting of $\mathrm{F}_{1}$

TABLE 17

1911, ficld; plants transplanted from greenhouse. Singles with primary inflorescence flowering or aborted as indicated."

\begin{tabular}{|c|c|c|c|c|c|c|}
\hline Row & Lot & $\begin{array}{c}\text { Aborted by } \\
\text { July } 29\end{array}$ & $\begin{array}{l}\text { Flowering or } \\
\text { aborted by } \\
\text { Oct. 10-16 }\end{array}$ & Lot & $\begin{array}{c}\text { Aborted by } \\
\text { July } 29\end{array}$ & $\begin{array}{l}\text { Flowering or } \\
\text { aborted by } \\
\text { Oct. 10-16 }\end{array}$ \\
\hline 1 & 1 & 0 & 0 & 2 & 0 & $0(2)$ \\
\hline $\begin{array}{l}2 \\
3\end{array}$ & $\begin{array}{l}3 \\
5\end{array}$ & $\underset{2}{12}(13)$ & $\begin{array}{r}19(22) \\
2\end{array}$ & $\begin{array}{l}4 \\
6\end{array}$ & $\begin{array}{r}20 \\
4\end{array}$ & $\begin{array}{c}24(26) \\
8(9)\end{array}$ \\
\hline 4 & 7 & $2(3)$ & $3(4)$ & 8 & 1 & $1(2)$ \\
\hline 5 & 9 & 22 & 27 & 10 & 26 & 33 \\
\hline 6 & 11 & 25 & $29(30)$ & 12 & 17 & 22 \\
\hline 7 & 13 & 1 & $2(4)$ & 14 & $2(3)$ & $2(3)$ \\
\hline 8 & 15 & 4 & $5(6)$ & 16 & $0(1)$ & $1(2)$ \\
\hline 9 & 17 & $19(20)$ & $20(23)$ & 18 & 9 & 12 \\
\hline 10 & 19 & $25(27)$ & 29 (31) & 20 & 11 & 12 \\
\hline 11 & 21 & 4 & $6(8)$ & 22 & 7 & 9 \\
\hline 12 & 23 & 2 & $3(4)$ & 24 & 1 & $1(2)$ \\
\hline 13 & 25 & 0 & $3(4)$ & 26 & 3 & $4(5)$ \\
\hline 14 & 27 & 1 & $3(4)$ & 28 & 0 & $0(1)$ \\
\hline
\end{tabular}

In this table and also in table 18 the numbers in parenthesis include the probable but somewhat doubtful cases.

progeny of WG9-C10, is decidedly earlier than the adjacent lots. Lot 25 also appcars early, however.

Tables 17 and 18 give a direct measure of earliness, relating to the primary inflorescence alone. The clusters visibly aborted were in general relatively far advanced, and those aborted at the earlicr date correspond to decidedly early flowering; consequently the flowering and aborted clusters are classed together as early. Chart 3 gives the percentages for singles.

Herc the data for the doubles show fairly consistent differences in the number aborted at the earlicr date, while the October totals are 
less regular. There are contrasts similar to those of table 15 up to lot 26, which is late, while the check lots 27 and 28 are carly. The singles show the type differences very strikingly throughout lots 1 to 20 , while lots 21,22 , and 26 give less positive indications of the presence of the early factor.

Table 19 gives the numbers of singles flowering, in primary inflorescence or elsewhere, by November 3, when growth had practically stopped. The indications are in general the same as with the data already discussed, with better evidence than usual that lots 21 and 22

TABLE 18

Same as table 1\%, for doubles."

\begin{tabular}{c|c|l|l|c|c|c}
\hline Row & Lot & $\begin{array}{c}\text { Aborted by } \\
\text { July 29 }\end{array}$ & $\begin{array}{c}\text { Flowering or } \\
\text { aborted by } \\
\text { Oct. 10-16 }\end{array}$ & Lot & $\begin{array}{c}\text { Aborted by } \\
\text { July 29 }\end{array}$ & $\begin{array}{c}\text { Flowering or } \\
\text { aborted by } \\
\text { Oct. 10-16 }\end{array}$ \\
\hline 1 & 1 & 15 & 30 & 2 & 6 & $22(23)$ \\
2 & 3 & 23 & $33(34)$ & 4 & 21 & 35 \\
3 & 5 & 12 & $29(30)$ & 6 & 16 & $30(31)$ \\
4 & 7 & 17 & 30 & 8 & 8 & $22(24)$ \\
5 & 9 & 25 & 41 & 10 & 24 & 41 \\
6 & 11 & $25(26)$ & $40(41)$ & 12 & 23 & 40 \\
7 & 13 & 16 & 28 & 14 & 22 & 31 \\
8 & 15 & 27 & $37(39)$ & 16 & $11(12)$ & $29(32)$ \\
9 & 17 & 20 & 35 & 18 & $20(21)$ & $32(33)$ \\
10 & 19 & 21 & $41(42)$ & 20 & 21 & $42(44)$ \\
11 & 21 & 22 & 35 & 22 & 18 & $27(28)$ \\
12 & 23 & $16(17)$ & $27(28)$ & 24 & 10 & $16(17)$ \\
13 & 25 & 17 & 25 & 26 & 9 & 15 \\
14 & 27 & 21 & $29(30)$ & 28 & 20 & $25(27)$ \\
\hline
\end{tabular}

- See note to table 17.

possessed the early factor. The mean time of flowering is irregular, but shows some effect of the earliness factor. Lot 26 is late as to number flowering, but early as to mean.

Table 20, for doubles flowering by August 1, no doubt gives more reliable means; these means disagree with our scheme only in lot 26 and perhaps lot 22.

According to tables 17-20, the fewer-noded check parent of each check row has usually given the earlier progeny. In fact. the agreement of parental and progeny differences, throughout the cultures, is decidedly remarkable. It is unfortunate that the later parents were always placed in the east half of the row, especially in view of the fact that there was indication of important differences in soil and 
TABLE 19

1911, field; plants transplanted from greenhouse. Time from sowing to emergence of earliest corolla. Singles.

\begin{tabular}{|c|c|c|c|c|c|c|c|c|c|}
\hline \multirow{2}{*}{ Row } & \multirow{2}{*}{$\begin{array}{l}\text { Parent-lot } \\
\text { internode } \\
\text { mean }\end{array}$} & \multirow{2}{*}{ Lot } & \multirow{2}{*}{$\begin{array}{c}\text { Parental } \\
\text { internode } \\
\text { number }\end{array}$} & \multicolumn{2}{|c|}{$\begin{array}{l}\text { Progeny flowering } \\
\text { by Nov. } 3\end{array}$} & \multirow{2}{*}{ Lot } & \multirow{2}{*}{$\begin{array}{c}\text { Parental } \\
\text { internode } \\
\text { number }\end{array}$} & \multicolumn{2}{|c|}{$\begin{array}{l}\text { Progeny flowering } \\
\text { by Nov. } 3\end{array}$} \\
\hline & & & & Number & $\begin{array}{l}\text { Days to } \\
\text { flowering }\end{array}$ & & & Number & $\begin{array}{l}\text { Days to } \\
\text { flowering }\end{array}$ \\
\hline 1 & 29.60 & 1 & 29 & 7 & 147.14 & 2 & 32 & 7 & 128.57 \\
\hline $\begin{array}{l}2 \\
3\end{array}$ & 21.40 & $\begin{array}{l}3 \\
5\end{array}$ & $\begin{array}{l}16 \\
25\end{array}$ & $\begin{array}{l}34 \\
26\end{array}$ & $\begin{array}{r}91.94 \\
119.46\end{array}$ & $\begin{array}{r}4 \\
\cdot \quad 6\end{array}$ & $\begin{array}{l}20 \\
27\end{array}$ & $\begin{array}{l}33 \\
25\end{array}$ & $\begin{array}{l}105.45 \\
104.08\end{array}$ \\
\hline 4 & 49.57 & 7 & 46 & 30 & 103.13 & 8 & 54 & 24 & 105.67 \\
\hline $\begin{array}{l}5 \\
6 \\
7\end{array}$ & 27.33 & $\begin{array}{r}9 \\
11 \\
13\end{array}$ & $\begin{array}{l}21 \\
22 \\
34\end{array}$ & $\begin{array}{l}30 \\
33 \\
18\end{array}$ & $\begin{array}{r}91.73 \\
98.85 \\
100.67\end{array}$ & $\begin{array}{l}10 \\
12 \\
14\end{array}$ & $\begin{array}{l}21 \\
25 \\
41\end{array}$ & $\begin{array}{l}34 \\
27 \\
13\end{array}$ & $\begin{array}{r}91.12 \\
108.30 \\
120.62\end{array}$ \\
\hline 8 & 28.50 & 15 & 27 & 17 & 112.94 & 16 & 29 & 18 & 118.00 \\
\hline $\begin{array}{r}9 \\
10 \\
11 \\
12 \\
13\end{array}$ & $42.56^{\mathrm{a}}$ & $\begin{array}{l}17 \\
19 \\
21 \\
23 \\
25\end{array}$ & $\begin{array}{l}33 \\
36 \\
42 \\
49 \\
55\end{array}$ & $\begin{array}{l}30 \\
34 \\
25 \\
11 \\
15\end{array}$ & $\begin{array}{r}100.27 \\
97.35 \\
129.36 \\
122.00 \\
136.40\end{array}$ & $\begin{array}{l}18 \\
20 \\
22 \\
24 \\
26\end{array}$ & $\begin{array}{l}35 . \\
37 \\
45 \\
51 \\
\cdots . .\end{array}$ & $\begin{array}{l}18 \\
21 \\
25 \\
14 \\
13\end{array}$ & $\begin{array}{l}109.67 \\
117.81 \\
121.76 \\
151.57 \\
121.08\end{array}$ \\
\hline 14 & 47.80 & 27 & 46 & 10 & 159.40 & 28 & 56 & 8 & 162.50 \\
\hline
\end{tabular}

This parent-lot value does not apply to lot 26 , which consists of progeny of WG9-C10 itself.

TABLE 20

Same as table 19, for doubles flowering by August 1.

\begin{tabular}{|c|c|c|c|c|c|c|}
\hline \multirow{2}{*}{ Row } & \multirow{2}{*}{ Lot } & \multicolumn{2}{|c|}{ Progeny flowering by Aug. $1^{\mathrm{a}}$} & \multirow{2}{*}{ Lot } & \multicolumn{2}{|c|}{ Progeny flowering by Aug. 1} \\
\hline & & Number & Days to flowering & & Number & Days to flowering \\
\hline 1 & 1 & 38 & 90.26 & 2 & 33 & 91.03 \\
\hline $\begin{array}{l}2 \\
3\end{array}$ & $\begin{array}{l}3 \\
5\end{array}$ & $\begin{array}{l}36 \\
39\end{array}$ & $\begin{array}{l}80.22 \\
84.46\end{array}$ & $\begin{array}{l}4 \\
6\end{array}$ & $\begin{array}{l}36 \\
39\end{array}$ & $\begin{array}{l}80.00 \\
84.10\end{array}$ \\
\hline 4 & 7 & 36 & 81.28 & 8 & 31 & 84.32 \\
\hline $\begin{array}{l}5 \\
6 \\
7\end{array}$ & $\begin{array}{r}9 \\
11 \\
13\end{array}$ & $\begin{array}{l}.42 \\
42 \\
37\end{array}$ & $\begin{array}{l}75.86 \\
77.90 \\
84.32\end{array}$ & $\begin{array}{l}10 \\
12 \\
14\end{array}$ & $\begin{array}{l}41 \\
40 \\
35\end{array}$ & $\begin{array}{l}76.59 \\
80.25 \\
84.80\end{array}$ \\
\hline 8 & 15 & 46 & 83.87 & 16 & 33 & 85.21 \\
\hline $\begin{array}{r}9 \\
10 \\
11 \\
12 \\
13\end{array}$ & $\begin{array}{l}17 \\
19 \\
21 \\
23 \\
25\end{array}$ & $\begin{array}{l}37 \\
42 \\
39 \\
33 \\
32\end{array}$ & $\begin{array}{l}80.43 \\
78.24 \\
85.95 \\
89.03 \\
88.56\end{array}$ & $\begin{array}{l}18 \\
20 \\
22 \\
24 \\
26\end{array}$ & $\begin{array}{l}34 \\
39 \\
30 \\
26 \\
21\end{array}$ & $\begin{array}{l}84.12 \\
83.85 \\
87.93 \\
88.85 \\
89.05\end{array}$ \\
\hline 14 & 27 & 35 & 88.97 & 28 & 29 & 90.28 \\
\hline
\end{tabular}

anly 48 more doubles altogether flowered by November 3 , and 25 of these were in the even-numbered lots 20 to 28 . 
probably in the incidence of disease, favoring the plants in the west half. The internode data of 1910, however, show a similar tendeney. Small genetic differences are suggested, though it would be remarkable if they were so uniformly present in these plants of a single line of a usually selfed species, descendants of parents and a eommon grandparent growil under glass.

If such differenees exist in the race, eoneeivably some eombination due to erossing might simulate an early mutation. The evidence as a whole, however, does not favor sueh an origin for our early type; it is widely divergent from the Snowflake type, and seems to depend on a single main factor differenee from Snowflake.

TABLE 21

Cultures of 1912. Ancestry and parental data.

\begin{tabular}{|c|c|c|c|c|c|}
\hline \multirow{2}{*}{ Lot } & \multirow{2}{*}{ Parent } & \multicolumn{3}{|c|}{ Parental data } & \multirow{2}{*}{ Seeds sown } \\
\hline & & Probable type & $\begin{array}{l}\text { Days to } \\
\text { flowering d }\end{array}$ & $\begin{array}{l}\text { Inter- } \\
\text { nodesd }\end{array}$ & \\
\hline 1 & $\mathrm{WS}_{1}-\mathrm{W}_{2} 16$ & Snowflake & 120.5 & 38 & 15 \\
\hline 2 & WG9-C10-W6 & Early & 116.5 & 33 & 15 \\
\hline 3 & WL $10-W \cdot 2$ & Snowflake & 139.5 & 51 & 15 \\
\hline 4 & WL10-W 3 & Snowfiake & 120.5 & 38 & 15 \\
\hline 5 & $\mathrm{WS}_{1}-\mathrm{W}_{2} 1$ & Snowflake & 141.5 & 57 & 15 \\
\hline 6 & WL10-W 14 & Snowflake & 126.5 & 38 & 15 \\
\hline 7 & WL10-IV 7 & Snowflake & 145.5 & 54 & 15 \\
\hline 8 & WG9-C10-W8 & Early & 129.5 & 45 & 15 \\
\hline 9 & WS1-W 12 & Crenate-leaved ${ }^{a, b}$ & 119.5 & 34 & $7 c$ \\
\hline
\end{tabular}

a Suspected before testing of belonging to the early type; first parent also tested in 1910 .

- A heterozygote between the crenate-leaved and Snowflake types.

c Probably open pollinated.

d All the parents grew in the same house at the same time.

The essential feature of the supplementary cultures of 1912, sinee no seed of WL10 remained, was a test of two pairs of early and late progeny of WL10 (lots 3 and 4,6 and 7, table 21), in eomparison with two eontrol lots-one (lot 2) from a known early parent, deseended from WG9-C10, and one (lot 5) from a late deseendent of WS1. Incidentally, WS1- $\mathrm{W}_{2} 16$ and WG9-C10-W8 were retested, and the few available seeds of WS1- $\mathrm{W}_{2} 12$ were used to test that phenotypieally early parent.

The results are given in tables 22 and 23 and ehart 4 . The very low individual from WS1- $\mathrm{W}_{2} 16$ eame from a very weak embryo, and should be disregarded; the exeeptionally higl general range of this lot, which was also visibly behind all others in development, was prob- 
TABLE 22

Cultures of 1912. Number of main-stem internodes below first flower-bearing node. Frequency distributions for singles. ${ }^{\mathrm{a}}$

\begin{tabular}{|c|c|c|c|c|c|c|c|c|c|c|}
\hline \multirow{3}{*}{ Ancestry } & \multirow{2}{*}{$\begin{array}{l}\text { Gen. } 1 \\
\text { Gen. } 2\end{array}$} & \multirow{2}{*}{$\frac{\mathrm{WS} 1}{\mathrm{~W}_{2} 16}$} & \multirow{2}{*}{$\frac{\text { WG9 }}{\text { C10 }}$} & \multicolumn{2}{|c|}{ WL10 } & \multirow{2}{*}{$\frac{W_{S 1}}{W_{2} 1}$} & \multicolumn{2}{|c|}{ WL10 } & \multirow{2}{*}{$\begin{array}{c}\text { WG9 } \\
\text { C10 }\end{array}$} & \multirow{2}{*}{$\frac{\mathrm{wS} 1}{\mathrm{w}_{2} 12}$} \\
\hline & & & & $\mathrm{w}_{2} 2$ & $\mathrm{w}_{2} 3$ & & $\mathrm{w}_{2} 14$ & $\mathrm{w}_{2} 7$ & & \\
\hline & Gen. 3 & ......... & $\mathrm{w} 6$ & ......... & ......... & .......... & ......... & ......... & w8 & ......... \\
\hline \multicolumn{2}{|c|}{$\begin{array}{l}\text { Internodes } \\
18\end{array}$} & & & & & & & & & \\
\hline \multirow{2}{*}{\multicolumn{2}{|c|}{19}} & … & 1 & $\cdots$. & $\cdots$. & $\cdots$ & $\cdots \cdot$ & $\cdots$. & $1 \dagger$ & $\cdots$ \\
\hline & & .... & $\begin{array}{l}1 \\
\ldots\end{array}$ & -... & … & $\cdots$. & … & $\begin{array}{l}\cdots . \\
\cdots .\end{array}$ & 1 & … \\
\hline \multirow{2}{*}{\multicolumn{2}{|c|}{$\begin{array}{l}21 \\
22\end{array}$}} & $\ldots$ & & $\ldots$ & $\ldots$. & $\ldots$ & .... & $\ldots$. & $\ldots$. & $\ldots$. \\
\hline & & .... & 1 & .... & .... & .... & .... & .... & .... & $\cdots$ \\
\hline \multicolumn{2}{|c|}{23} & .... & 3 & .... & .... & $\cdots \cdot$ & $\cdots$ & $\cdots$ & $\ldots$ & .... \\
\hline \multirow{2}{*}{\multicolumn{2}{|c|}{24}} & ... & .... & $\cdots$ & … & .... & $\cdots$. & .... & 2 & $\cdots$ \\
\hline & & & .... & .... & & & .... & .... & & $\cdots$ \\
\hline \multicolumn{2}{|c|}{26} & $1 \dagger$ & & & 1 & 1 & $\ldots$ & ... & .... & $\cdots$ \\
\hline \multirow{2}{*}{\multicolumn{2}{|c|}{$\begin{array}{l}27 \\
28\end{array}$}} & .... & 1 & 1 & & 3 & 2 & & & \\
\hline & & & .... & 4 & 1 & 3 & 1 & 3 & 1 & $1 \ddagger$ \\
\hline \multicolumn{2}{|l|}{29.} & 1 & $\ldots$. & 1 & $\ldots$ & 1 & 2 & 2 & $\ldots$. & $1 \ddagger$ \\
\hline \multirow{2}{*}{\multicolumn{2}{|c|}{ ……... }} & 2 & $\ldots$ & $\ldots$ & $\ldots$ & $\ldots$ & 1 & $\ldots$ & $\ldots$ & $\ldots$ \\
\hline & & 1 & .... & $\ldots$. & $\ldots$. & $\ldots$. & .... & .... & .... & .... \\
\hline \multicolumn{2}{|l|}{$32 \ldots \ldots$} & .... & .... & $\ldots$. & $\ldots$. & $\ldots$. & $\ldots$. & $\ldots$. & $\ldots$. & .... \\
\hline \multirow{2}{*}{\multicolumn{2}{|c|}{$\begin{array}{lll}33 & \ldots \ldots \\
34 & \ldots . . .\end{array}$}} & $\cdots$. & .... & .... & $\cdots$. & .... & .... & .... & .... & .... \\
\hline \multirow{2}{*}{\multicolumn{2}{|c|}{$35 \quad \ldots \ldots \ldots \ldots \ldots$}} & $\dddot{n}$ & $\cdots$. & $\cdots$. & .... & ... & ... & $\cdots$ & $\cdots$ & .... \\
\hline & & $2 \uparrow$ & & & & & & & & \\
\hline
\end{tabular}

" See note $a$ to table 5 .

TABLE 23

Cultures of 1912. Same as table 22, for doubles. ${ }^{\mathrm{a}}$

\begin{tabular}{|c|c|c|c|c|c|c|c|c|c|c|}
\hline \multirow{3}{*}{ Ancestry } & \multirow{2}{*}{$\frac{\text { Gen. } 1}{\text { Gen. } 2}$} & \multirow{2}{*}{$\begin{array}{c}\text { wS1 } \\
\mathrm{W}_{2} 16\end{array}$} & \multirow{2}{*}{$\begin{array}{c}\text { WG9 } \\
\text { C10 }\end{array}$} & \multicolumn{2}{|c|}{ WL10 } & \multirow{2}{*}{$\begin{array}{l}\text { WS1 } \\
\mathrm{W}_{2} 1\end{array}$} & \multicolumn{2}{|c|}{ WL10 } & \multirow{2}{*}{$\begin{array}{c}\text { WG9 } \\
\text { C10 }\end{array}$} & \multirow{2}{*}{$\begin{array}{c}\text { WS1 } \\
\mathrm{W}_{2} 12\end{array}$} \\
\hline & & & & $\mathrm{W}_{2} 2$ & $\mathrm{w}_{2} 3$ & & $\mathrm{~W}_{2} 14$ & $\mathrm{~W}_{2} 7$ & & \\
\hline & Gen. 3 & $\ldots \ldots \ldots$ & W6 & ........... & .......... & .......... & $\ldots \ldots$. & ......... & w8 & .......... \\
\hline \multirow{2}{*}{\multicolumn{2}{|c|}{$\begin{array}{l}\text { Internodes } \\
12\end{array}$}} & & & & & & & & & \\
\hline & & $1 \mathrm{~A}$ & .... & .... & .... & ... & ... & .... & ... & .... \\
\hline \multicolumn{2}{|c|}{13} & $\cdots$ & $\cdots \cdot$ & .... & ... & $\cdots$ & $\cdots$ & .... & -... & $\cdots$ \\
\hline \multicolumn{2}{|c|}{15} & … & .... & … & … & -... & $\begin{array}{l}\cdots \\
\cdots .\end{array}$ & $\ldots$. & $\begin{array}{l}\cdots \\
\cdots .\end{array}$ & $\cdots$ \\
\hline \multirow{2}{*}{\multicolumn{2}{|c|}{$\begin{array}{l}16 \\
17\end{array}$}} & $\ldots$ & $\ldots$ & $\ldots$. & $\ldots$ & $\ldots$ & $\ldots$ & $\ldots$. & $\ldots$ & … \\
\hline & & $\ldots$. & & $\ldots$ & $\ldots$. & $\ldots$. & $\ldots$ & $\ldots$. & 1 & .... \\
\hline \multicolumn{2}{|c|}{18} & $\ldots$. & 1 & $\ldots$. & $\ldots$. & $\ldots$. & $\ldots$ & $\ldots$. & .... & .... \\
\hline \multicolumn{2}{|l|}{$19 \ldots .}$. & $\ldots$. & 1 & $\ldots$. & $\ldots$. & $\ldots$. & $\ldots$ & $\ldots$. & $\ldots$. & $\ldots$. \\
\hline \multirow{2}{*}{\multicolumn{2}{|c|}{$\begin{array}{ll}20 & \ldots . . \\
21 & \end{array}$}} & $\ldots$ & 1 & $\ldots$ & $\ldots$ & $\cdots$. & 1 & $\ldots$ & 0 & .... \\
\hline & & & 2 & $\cdots$. & .... & .... & $\cdots$ & 1 & 2 & .... \\
\hline \multicolumn{2}{|l|}{22.} & 1 & 2 & $\cdots$ & & .... & .... & 1 & 2 & $\ldots$. \\
\hline \multicolumn{2}{|l|}{$\begin{array}{l}23 \\
24\end{array}$} & .... & 1 & $\dddot{1}$ & ${ }_{3}^{1 \top}$ & $\cdots$ & $\dddot{1}$ & 1 & $\cdots$ & $\cdots$. \\
\hline \multicolumn{2}{|c|}{25} & … & … & 5 & $\begin{array}{l}5 \\
3\end{array}$ & 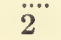 & 3 & 2 & 1 & i. \\
\hline \multirow{2}{*}{\multicolumn{2}{|c|}{26}} & & .... & 1 & 2 & 3 & 1 & 3 & 2 & 1 \\
\hline & & 2 & .... & .... & $\ldots$ & .... & .... & $\ldots$ & $\ldots$ & \\
\hline \multicolumn{2}{|c|}{28} & $3 \dagger$ & $\ldots$ & $\ldots$ & $\ldots$ & $\ldots$ & $\ldots$ & $\ldots$. & $\ldots$ & $1 \dagger$ \\
\hline \multicolumn{2}{|c|}{$\begin{array}{l}29 \\
30\end{array}$} & .... & & .... & .... & .... & $\cdots$. & $\cdots$. & .... & .... \\
\hline \multicolumn{2}{|c|}{31} & $\ldots$. & 1 & .... & $\cdots$ & $\dddot{1}$ & $\cdots \cdot$ & $\cdots$ & $\cdots .$. & $\ldots$. \\
\hline
\end{tabular}

a See note $a$ to table 5 . 
ably due tu some cultural accident, perhaps to an excess of moisture in this row of pots.

The lots of plants may seem rather absurdly small for their purpose, but the uniformity of development here, with the marked normal divergence in internodes of the types in question, seems to justify a fair degree of confidence. Ten plants here were probably worth fifty in the field.

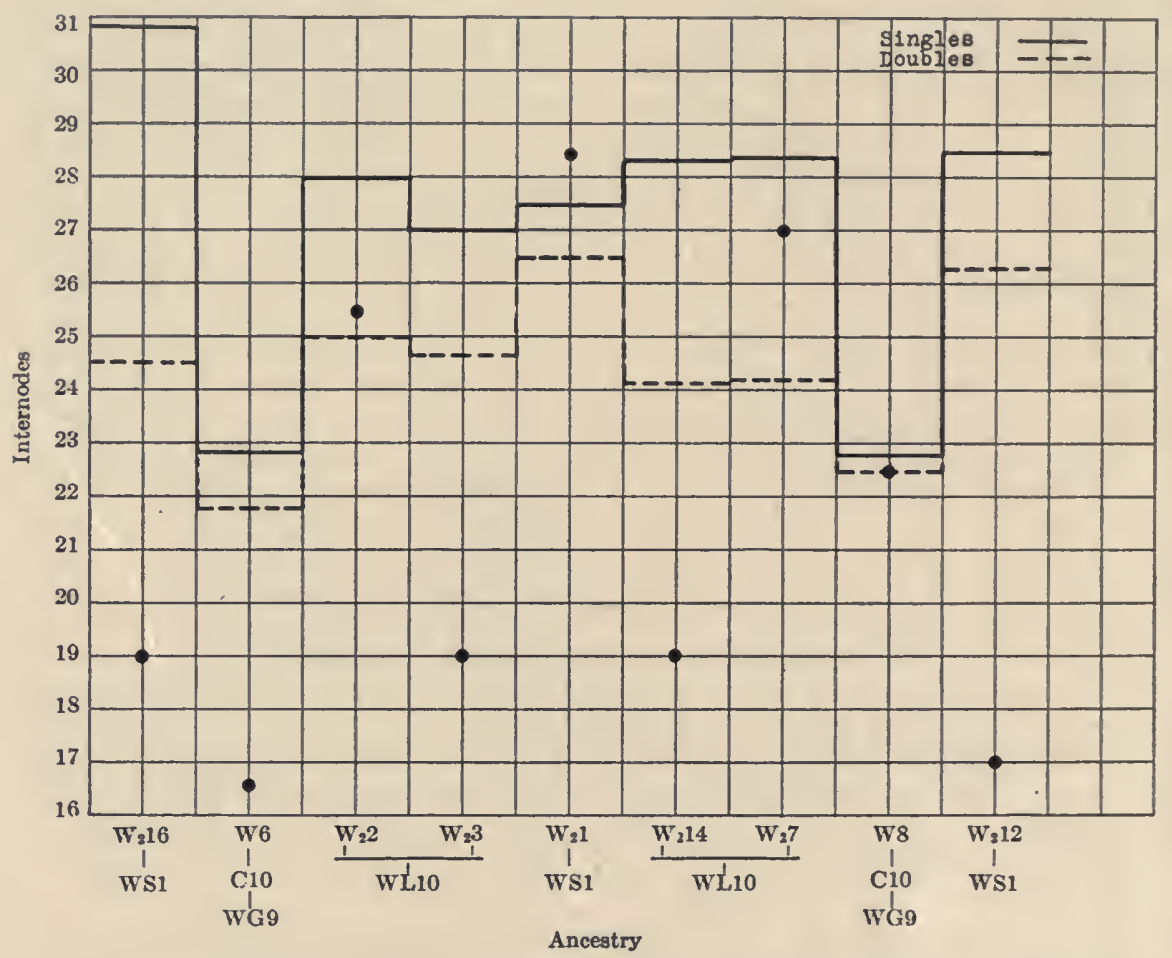

Chart 4. Cultures of 1912. Internodes: parental values and progeny means, shown as in chart 1 . The true parental values are twice those indicated by the ordinate figures, which apply directly to the progeny values.

This test, with that of 1910 , shows very positively that WS1-W 16 was only phenotypically few-noded. Evidently WG9-C10-W8, the parent of field lot 22 , really carried the earliness factor, as was somewhat doubtfully inferred from the field results; the five progeny of WS1- $W_{2} 12$, on the other hand, though from a fewer-noded parent, have values that make the presence of the earliness factor improbable.

On the main point at issue the evidence seems satisfactory. Neither of the two very early and few-noded progeny of WL10 represented 
shows in its progeny any evidence of belonging to the early type; the means are slightly lower than for the many-noded sibs of these parents, but far less so than with the parents descended from WG9-C10.

We conclude, then, that WG9-C10 was probably a monohybrid, and that the early-bearing gamete entering into its composition was of unknown but presumably mutative origin.

Most of the extracted late or many-noded parents may now be selected with practical certainty. WG9-C10-C8 and C1 (lots 5 and.6 in the 1911F cultures) and WG9-C10-M7 and M8 (lots 13 and 14) were genetically very similar to the check parents, as has already been concluded for two of them from the greenhouse cultures; presumably they were pure Snowflake.

The data for WG9-C10 itself (lot 26) seem to indicate that the results from the last eight lots are of very doubtful value; still, they show, especially in the original individual records, some evidence of the earliness factor which must be present in part of the individuals. The poor and slow germination of the old seed available may have had an important influence on the result; many of the early embryos may have been non-viable, and the seedlings may have been weaker than those from fresh seed. The 1911 data and observation of the plants in the field suggest that WG9-C10-W7, W3, and W10 (lots 23, 24, and 25) are the only remaining extracted late parents, WG9-C10-W5 and W8 (lots 21 and 22) carrying the earliness factor, as the four parents just preceding them in the cultures obviously did. Tables 22 and 23 confirm this conclusion for WG9-C10-W8.

It is presumably impossible to make a positive separation of the parents homozygous for the presence of the early factor. The greenhouse data suggest that WG9-C10-M4 was a pure early individual; the field data (see lot 9) agree, and suggest that WG9-C10-M9 (lot 10) and perhaps WG9-C10-M6 (lot 11) belong in the same class. WG9-C10-C2, C5, and C10 (lots 3, 4, and 40) ${ }^{12}$ were all evidently heterozygous. Of the parents grown in house W, it would seem that only WG9-C10-W11 (field lot 19) was homozygous early. We have, provisionally, for the available single progeny of WG9-C10:

\begin{tabular}{|c|c|c|c|}
\hline 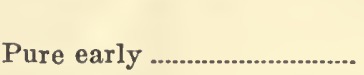 & $\begin{array}{l}\text { House } \mathrm{C} \\
\quad 0\end{array}$ & $\begin{array}{c}\text { House } M \\
\quad 3\end{array}$ & $\begin{array}{c}\text { House W } \\
1\end{array}$ \\
\hline Hybrid early......................... & 3 & 1 & 5 \\
\hline 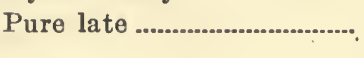 & 2 & 2 & 3 \\
\hline
\end{tabular}

12 Statistical data given for the last only for the 1910 cultures, not for this field lot. 
This corresponds well enough with the monohybrid expectation of $5: 10: 5$; in fact, the deviation is just such as would be expected if there was occasional cross pollination of the unprotected flowers of WG9C10 from Snowflake plants. The large proportion of evidently pure late parents is strong evidence for the monohybrid nature of WG9-C10.

The proportions of the two types among the doubles can only be estimated. The 1908 data suggest that 5 of the 10 doubles there reported were early; this number, with the 13 singles so classed, makes a total of 18 early-type plants out of 30 . The ratio is slightly nearer to $1: 1$ than to $3: 1$, and the former proportion would suggest the peculiar type of inheritance found with the mutant types yet to be described. The evidence of the 1910 distributions, however, shows that the early type largely predominates in the next generation with both singles and doubles, and apparently this is true even when we exclude the progeny of the one parent classed as pure early.

The early factor can be positively detected only by progeny tests. No test has shown the presence of this factor elsewhere than in WG9$\mathrm{C} 10$ and part of its descendants. WG9-C10 produced the early and Snowflake types among 20 single progeny nearly in the typical monohybrid proportions: Inspection of the double progeny in two generations suggests similar or possibly somewhat lower proportions there. A vicinistic origin for WG9-C10 is improbable. Presumably, then, the early type arose from Snowflake by a single factor mutation, the dominant mutant factor being inherited without special complications. We shall now consider certain apparently mutant types which are characterized by peculiar genetic behavior.

\section{THE SMOOTH-LEAVED TYPE}

This type was first obscrved in the cultures of 1908 (table 1) and has occurred frequently in later cultures (table 3). It is perhaps the mutant type of most frequent occurrence among progeny of Snowflake or early parents; 2410 unselected progeny from house-sown seed of such parents (see table 28) included 28 apparent mutants (14 singles, 11 doubles, and 3 undetcrmined), a mutation coefficient of $1.16 \pm .15$ per cent.

As grown in the greenhouse at Ithaca, this type (fig. 7, tables 12 and 13) was often many-noded, with correspondingly late flowering. Its most striking peculiarity, shown especially by young seedlings and not evident in the figures, was a lack of buckling between the veins 


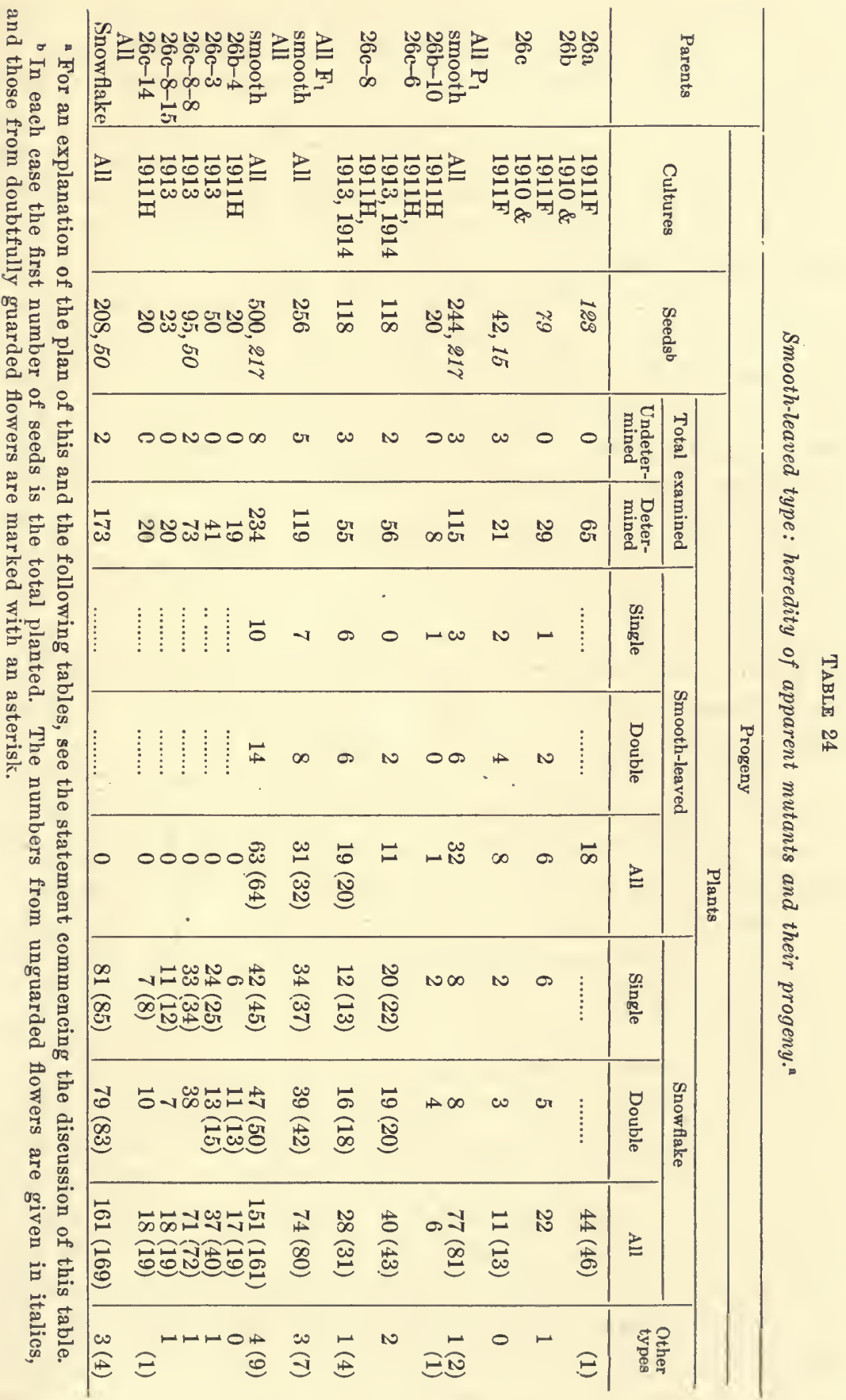


of the leaves, and of gencral eonvexity of the upper surface of the leaves. Mature plants developed under favorable eonditions in the greenhouse elosely resembled Snowflake; the leaves, however, were notieeably brittle, and the dry capsules so brittle that it was often necessary, as it was not with Snowflake, to shell the seeds individually. Probably the fibrovascular system is in some way defective; Oenothera rubrinervis, whieh is also brittle (de Vries, 1906, lecture 18), has thin-walled bast fibers.

In the field eultures, both at Ithaca (fig. 5) and at Riverside, under eonditions less favorable on the whole to the initiation of flowering, this type (fig. 8) differed mueh more widely from Snowflake. Flowering was excessively delayed, and the plants often remained low, with few branches, and rosette-like, with thin, rather narrow leaves. Small brown dead spots, possibly due to exeessive transpiration, oceurred so frequently on the leaves as to eonstitute a good diagnostie character for the type. Another peeuliarity observed in the field is a reflexed position of the tip of the young leaf when first visible-Snowflake leaves being completely ereet from the first.

In the 1914 eultures, with better development than in other field cultures, some smooth-leaved plants (figs. 9 and 10) were again more like Snowflake, though later and evidently more leafy.

Six smooth-leaved parents have been used in progeny tests, three of these being apparent mutants and three being $F_{1}$ progeny of two of those mutants. The results are presented in tables 24 and 25 ; these tables require a brief explanation, whieh will apply also to the similar tables for other types.

For the plan of the new pedigree numbers here used, see "Methods." The initial plants of a series are designated as the $\mathrm{P}_{1}$ generation in the tables, their progeny as $\mathrm{F}_{1}$, ete. In table 24 the eultures are arranged according to their generations and their pedigree numbers under each generation; the smooth-leaved parents $\left(P_{1}\right.$ or of the $P_{1}$ type) are given first, followed by the extraeted Snowflake parents. In table 25 "good germination" indieates that in all lots included (taken as grown, not as summed by parents in table 24) the number of plants determined exeeeds 50 per eent of the number of seeds sown, and vice versa; the weighted mean pereentages obtained by dividing the total numbers of plants by the respeetive total numbers of seeds are given for eaeh table in a footnote.

All six smooth-leaved parents (tables 24 and 25) gave mixed progeny, part smooth-leaved and part Snowflake. The surprising 
fact is that the parental (smooth-leaved) type appears not in threefourths of the progeny, but in only about one-fourth.

The extracted Snowflake parents tested behave like pure recessives, showing no influence of their smooth-leaved ancestry. Only the aberrant ratio seems inconsistent with the assumption that the smoothleaved individuals tested were ordinary heterozygous dominants.

The relatively weak growth of this type and the apparently poor germination of the seed produced by it suggest that normal segregation may be masked by selective elimination. Possibly the smooth-leaved

TABLE 25

Smooth-leaved type: heredity. Summary.

\begin{tabular}{|c|c|c|c|c|c|c|}
\hline \multirow{4}{*}{ Parents } & \multicolumn{6}{|c|}{ Progeny } \\
\hline & \multirow{3}{*}{ Cultures } & \multirow{3}{*}{ Seeds } & \multicolumn{4}{|c|}{ Plants } \\
\hline & & & \multicolumn{2}{|c|}{ Total examined } & \multicolumn{2}{|c|}{ Smooth-leaved } \\
\hline & & & $\begin{array}{l}\text { Undeter- } \\
\text { mined }\end{array}$ & $\begin{array}{l}\text { Deter- } \\
\text { mined }\end{array}$ & Number & Per cent \\
\hline $\begin{array}{l}\text { All smooth- } \\
\text { leaved }\end{array}$ & Ithaca & 304,217 & 7 & 156 & 40 & $25.6 \pm 2.4$ \\
\hline leaved & Riverside & 196 & 1 & 78 & $23(24)$ & $30.8 \neq 3.4$ \\
\hline leaved (6) & All & 500,217 & 8 & 234 & $63(64)$ & $27.4 \pm 2.0$ \\
\hline $\begin{array}{l}\text { All } P_{1} \text { smooth- } \\
\text { leaved (3) }\end{array}$ & All & $244, .217$ & 3 & 115 & 32 & $27.8 \pm 2.8$ \\
\hline leaved (3) & All & 256 & 5 & 119 & $31(32)$ & $26.9 \pm 2.8$ \\
\hline All smooth- & good & 293,138 & 8 & $187^{a}$ & $55(56)$ & $29.9 \pm 2.2$ \\
\hline $\begin{array}{l}\text { leaved } \\
\text { All Snowflake }\end{array}$ & poor & 207,79 & 0 & $47^{a}$ & 8 & $17.0 \pm 4.4$ \\
\hline$\left(5, F_{1}\right.$ and $\left.F_{2}\right)$ & All & 208,50 & 2 & 173 & 0 & 0 \\
\hline
\end{tabular}

${ }^{2}$ Respectively 63.8 and 22.7 per cent of the numbers of seeds planted.

factor is lethal when homozygous, as is often the case (Muller, 1918) with dominant mutant factors in Drosophila; the data for germination, however, indicate that two-thirds of the mature embryos can hardly belong to the mutant type. We might expect, in view of the weak growth of smooth-leaved plants, that partial elimination of heterozygotes would also occur. That this is the case is suggested, though the numbers are small, by the lower proportion of the mutant type with poor germination (table 25; see also tables 39 and 40 ); it should be noted, however, that transferring the first lot of table 24, the only lot between 50 and 73 per cent, to the "poor" total, makes the percentages practically identical. ${ }^{13}$

13 See also table 2 and the second paragraph under "Occurrence of Mutants." 
In connretion with the question of letlal action we must consider the inheritance of doubleness of flowers. Snowflake seed regularly gives a mixture of singles and doubles, about 53 per cent being doubles. The doubles, which arc totally sterile, are probably (Frost, 1915) pure recessives $(d d)$ for a single-double factor pair. The singles are always heterozygous $(D d)$; crosses with pure single races (Saunders, 1911) show that the approximately $1: 1$ ratio and the failure to produce pure singles, witl self pollination, are duc to the fact that all the functional pollen is doubleness-carrying $(d)$. The excess of doubles over 50 per cent has been explained by Miss Saunders (1911) as due to heterozygosis of the singles for two linked complementary factors necessary to singleness, and by the present writer (Frost, 1915) as due to lower viability of the "single" gametes or embryos. The absence of functional single-carrying pollen is apparently due to a lethal factor acting after separation of the microspore tetrads, since the tetrads themselves appear normal.

In any consideration of factors linked with the single-double pair, this semisterility of the pollen must be remembered. For example, any dominant factor completely coupled with $D$ in pollen formation would be totally absent from the functional pollen, and the zygotes produced by selfing would show directly the strength of linkage in the ovules.

The available data for the smooth-leaved type (table 24) are far from constituting an adequate test of linkage, but they suggest that the factors are independent. Certainly no high degree of linkage is indicated by the totals, nor do the detailed data suggest that smoothleavedness is coupled with singleness in some parents and with doubleness in others.

We must admit that the peculiar inheritance of this type is not yet positively explained. Evidently larger cultures are nceded, and crossing with the Snowflake type and with other commercial varicties; cytological study may also be required. Certain comparisons and speculative possibilities descrve mention, however, especially since the types yet to be discussed furnish additional evidence bcaring on them. We may compare the smooth-leaved and double types, as follows :

DOUBLE

1. A rare mutation of pure single ("normal").

2. Recessive; extracted recessives are sterile mutant-type plants.
SMOOTH-LEAVED

1. Apparently a common mutation of pure Snowllake ("normal").

2. Apparently dominant; extracted recessives are fertile normal plants. 


\section{DOUBLe}

3. Homozygous dominants not produced by hybrids, because functional pollen carries recessive factor only.

4. Recessive (mutant) type the more vigorous.

5. Dominant factor or another factor very closely linked with it is incompatible with formation of functional pollen.

6. Recessive type exceeds the expected equality by about 3 per cent among some 7000 individuals.

\section{SMOOTH-LEAVED}

3. Homozygous dominants perhaps not produced by hybrids. 14

4. Recessive (normal) type the more vigorous; difference much greater than with single and double.

5. Relation of dominant factor to viability of pollen not yet determined.

6. Recessive type exceeds equality by about 23 per cent among 234 individuals.

The most probable hypothesis for smooth-leavedness, then, would so far seem to be essentially the same as for doubleness-complete elimination of the weaker type in pollen formation, and partial elimination in embryo-sac formation. Reciprocal crosses with Snowflake are obviously necessary; as we shall soon see, three of the other mutant types have already proved to be carried by both eggs and sperms.

The ease of Oenothera lata (Gates, 1915) suggests the possibility that the smooth-leaved form might arise by reduplication of a chromosome. With ordinary 0 . lata the pollen is sterile, but pollination by O. lamarckiana gives about 15-20 per cent of lata. This deficiency of lata individuals is due, it seems, to a frequent loss of the extra chromosome at meiosis in lata ovules, with a resulting formation of more than 50 per cent of seven-chromosome (lamarckiana) eggs.

If the smooth-leaved type originates through duplication of a chromosome, we might suppose that other types of similar heredity involve other pairs of chromosomes. The apparent parallel with O. lata, which Bartlett (1917) has noted, was long ago suggested by the data, but with at least two or three types to be described linkage phenomena have seemed to conflict with this interpretation. Possibly different processes have produced different mutant types as with Oenothera; as we have considered types suggestive of 0 . rubrinervis (early) and of O. lata (smooth-leaved), we may consider next a form which in appearance is remarkably suggestive of $O$. gigas.

14 This possibility is only suggested by these cultures, but it becomes highly probable when the data for other types are considered. 


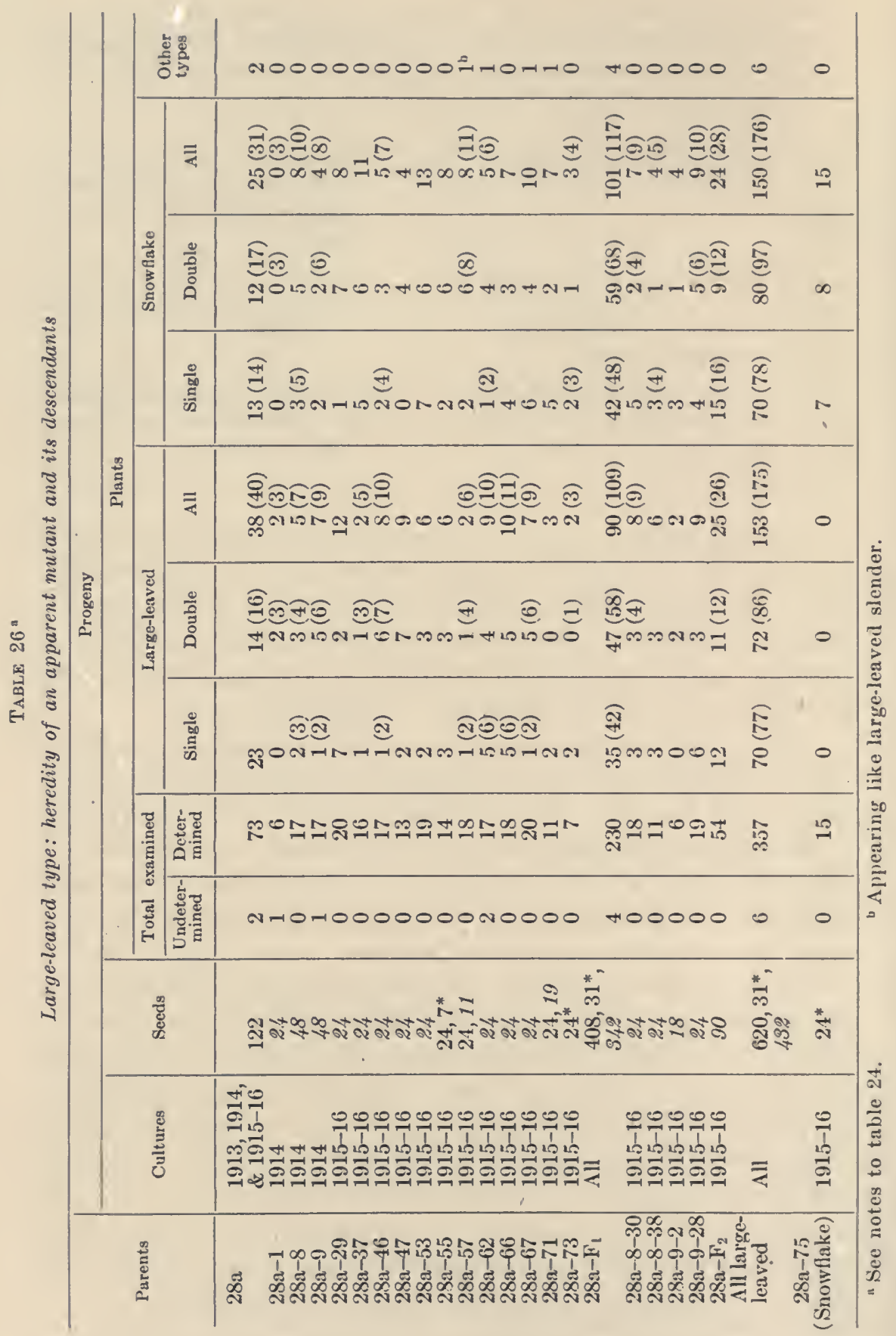


It should, however, first be noted that, as will appear later, phenomena of apparent linkage in the case of certain other types (crenate, slender, and narrow) suggest that these forms commonly arise from Snowflake by segregation rather than by immediate mutation. The obvious objection to this hypothesis is the fact that the apparently mutant types seem to be dominant to the "normal" or Snowflake type. This objection can be met by assuming the presence of dominant inhibiting factors in the Snowflake parents that give apparent mutants. ${ }^{15}$

If the apparent mutants of the smooth-leaved type are thus produced by crossing over in a set of balanced factors, the lethal "balancing" the smooth-leaved factor itself may be distinct from that which sterilizes the singleness-carrying pollen. In considering the results here reported, therefore, we must always bear in mind the possible presence of several unidentified lethal factors. If the apparent absence of linkage between the smooth and double factors is not misleading, we must suppose that these factors are carried by different pairs of chromosomes; considerations advanced by Muller (1918, pp. 479-482), however, make it rather probable that the commoner types of apparent mutants here discussed are all due to factors carried by one pair of chromosomes, the pair containing the factor for doubleness and its normal allelomorph.

\section{THE LARGE-ILAVED TYPE}

A double of this type probably occurred in the 1907 cultures, though its appearance attracted so little attention that no record was made. In the field cultures of 1911 (table 3 ) several individuals suggested a gigas type, though there seemed to be intergradation with Snowflake. In the 1912 cultures a single with leaves "long, rather narrow, thick" developed normally and produced an abundance of good seed; from this individual (28a) all cultures of this type are descended.

This type is stout and coarse throughout, and late to flower. The leaves are strikingly long, thick, and rigid, though as a rule relatively

15 A letter suggesting this explanation was received from Dr. Muller soon after the same idea had been outlined in the "General Discussion" section below. Dr. Muller kindly gave further attention to difficulties at first encountered by the present writer, materially assisting in the formulation of an apparently tenable form of the hypothesis. Since, however, this scheme may seem "farfetched" and unduly complex, it appears desirable to leave the original discussion of the individual types substantially unchanged. When the difficulties encountered by the assumption of frequent true mutation have been more fully. presented, the need for some such addition to the scheme will be more evident: 
narrow; under unfavorable weather conditions the flowers are often few and defective, while the leaves are resistant and long-lived (fig. 11). Figures 12 and 13 show well the coarse leaves and lateness of well developed large-leaved plants in the 1915-16 cultures, the plants in the latter figure being several weeks the older.

The results of the progeny tests are given in tables 26 and 27. All the twenty large-leaved individuals tested have given mixed progeny; the proportion of the mutant type, though much larger than with

TABLE 27

Large-leaved type: heredity. Summary.

\begin{tabular}{|c|c|c|c|c|c|c|}
\hline \multirow{4}{*}{ Parents } & \multicolumn{6}{|c|}{ Progeny } \\
\hline & \multirow{3}{*}{ Cultures } & \multirow{3}{*}{ Seedsa } & \multicolumn{4}{|c|}{ Plant3 } \\
\hline & & & \multicolumn{2}{|c|}{ Total examined } & \multicolumn{2}{|c|}{ Large-leaved } \\
\hline & & & $\begin{array}{l}\text { Undeter- } \\
\text { mined }\end{array}$ & $\begin{array}{l}\text { Deter- } \\
\text { mined }\end{array}$ & Number & Per cent \\
\hline $28 \mathrm{a}$ & $\begin{array}{l}1913,1914, \\
\& 1915-16\end{array}$ & 122 & 2 & 73 & $38(40)$ & $548 \pm 3.9$ \\
\hline $28 a-F_{1}(3)$ & 1914 & 120 & 2 & 40 & $14(19)$ & $47.5=5.3$ \\
\hline $28 \mathrm{a}-\mathrm{F}_{1}(12)$ & $1915-16$ & 288 & 2 & 190 & $76(90)$ & $47.4 \pm 2.4$ \\
\hline $28 \mathrm{a}-\mathrm{F}_{2}(4)$ & $1915-16$ & 90 & 0 & 54 & $25(26)$ & $48.1=4.6$ \\
\hline $28 \mathrm{a}-\mathrm{F}_{1} \& \mathrm{~F}_{2}(19)$ & All & 498 & 4 & 284 & $115(135)$ & $47.5 \pm 2.0$ \\
\hline$(20)$ & All & 620 & 6 & 357 & $153(175)$ & $49.0 \neq 1.8$ \\
\hline Large-leaved & $\begin{array}{l}\text { Germination } \\
\text { good }\end{array}$ & 360 & 3 & $260^{b}$ & 115 (131) & $50.4 \pm 2.1$ \\
\hline Large-leaved & Germination & & & & & $x-1-2$ \\
\hline Snowflake $\left(1, F_{1}\right)$ & $\begin{array}{c}\text { poor } \\
1915-16\end{array}$ & $\begin{array}{r}260 \\
24\end{array}$ & $\begin{array}{l}3 \\
0\end{array}$ & $\begin{array}{l}97^{\mathrm{b}} \\
15\end{array}$ & $\begin{array}{c}38(44) \\
0\end{array}$ & $\underset{0}{45.4}=3.4$ \\
\hline
\end{tabular}

- Mainly from unguarded flowers; see table 26.

bespectively 72.2 and 37.3 per cent of the numbers of seeds planted.

smooth-leaved, approximates to 50 per cent, not 75 per cent, with little indication of selective elimination with poor germination. ${ }^{16}$

Here plainly, as with smooth-leaved, no pure mutant-type parent has yet been tested. Since this is also true of the other types, aside from early, that have been somewhat extensively tested, and fifty-three mutant-type parents in all have given Snowflake progeny, it is probable that homozygous individuals of these types seldom or never develop. The actual adult ratio with large-leaved is plainly not $2: 1$, but rather $1: 1$, a fact that would suggest absence of the mutant-type factor or factors from the pollen. The small trial cultures started in 1917, however, show that the type is carried by both sperm and eggs.

16 Since hybrids are of the mutant type in appearance, the possible cross pollination by Snowflake parents could hardly give Snowflake progeny with any pure large-leaved parent. It may, however, have reduced slightly the proportion of large-leaved progeny from heterozygous parents of this type. 
If we are dealing here with a type cytologically like Oenothera gigas, or rather the triploid semigigas, abnormal distributions of chromosomes may occur at meiosis, giving unpredictable genetic results. There has been special difficulty, as the numbers of doubtful individuals in table 26 suggest, in separating large-leaved from Snowflake, though in part of the cases the difference is extreme. Possibly some of the doubtful individuals are genetic intermediates due to irregular meiosis in triploid nuclei; such irregularities in division (Gates, 1915) occur with Oenothera. Both eytological examination and crosses with Snowflake are plainly required.

TABLE 28

Crenate-leaved type: numbers of apparent mutants and association of the type with singleness of flowers.

\begin{tabular}{l|c|c|c|c|c}
\hline \multirow{2}{*}{ Culture } & \multicolumn{5}{|c}{ Progeny of Snowflake and early parents } \\
\cline { 2 - 6 } & $\begin{array}{c}\text { Total } \\
\text { examined }\end{array}$ & Single & Double & All & $\begin{array}{c}\text { Coefficient of } \\
\text { mutation }\end{array}$ \\
\cline { 2 - 6 } & $725^{\mathrm{b}}$ & 6 & 1 & 7 & $.97 \pm .22$ \\
1908 & 338 & 3 & 0 & 3 & $.89 \pm .32$ \\
1910 & 2072 & 13 & 3 & 16 & $.77 \pm .13$ \\
$1911 F$, seed house- & 3135 & 22 & 4 & 26 & $.83 \pm .11$ \\
$\quad$ Sown & 2410 & 16 & 3 & 19 & $.79 \pm .12$ \\
All above & All unselected &
\end{tabular}

a See note $b$ to table 2 .

${ }^{b}$ See note $c$ to table 1 .

\section{THE CRENATE-IEAVED TYPE}

This type (tables 1 and 3 ) is one of the three aberrant types of most frequent occurrence in the cultures here described, having constituted (table 28) about .79 per cent of the progeny of Snowflake and early parents. A large majority of the individuals have been singles, as table 28 shows. If the apparent mutants are produced by some process of segregation of factors, evidently the crenate and single factors were usually coupled in this material; if they are produced by immediate factor mutation, or are individually due to some change in a particular locus, evidently that locus is linked with the singledouble locus and the change is more frequent in the single-carrying chromosomes; and finally, if they are due to reduplication or loss of a chromosome, the apparent linkage remains to be explained.

The margins of Snowflake leaves vary from entire or slightly sinuate to coarsely and irregularly dentate or serrate, this characteristic being subject to much environmental modification and varying 


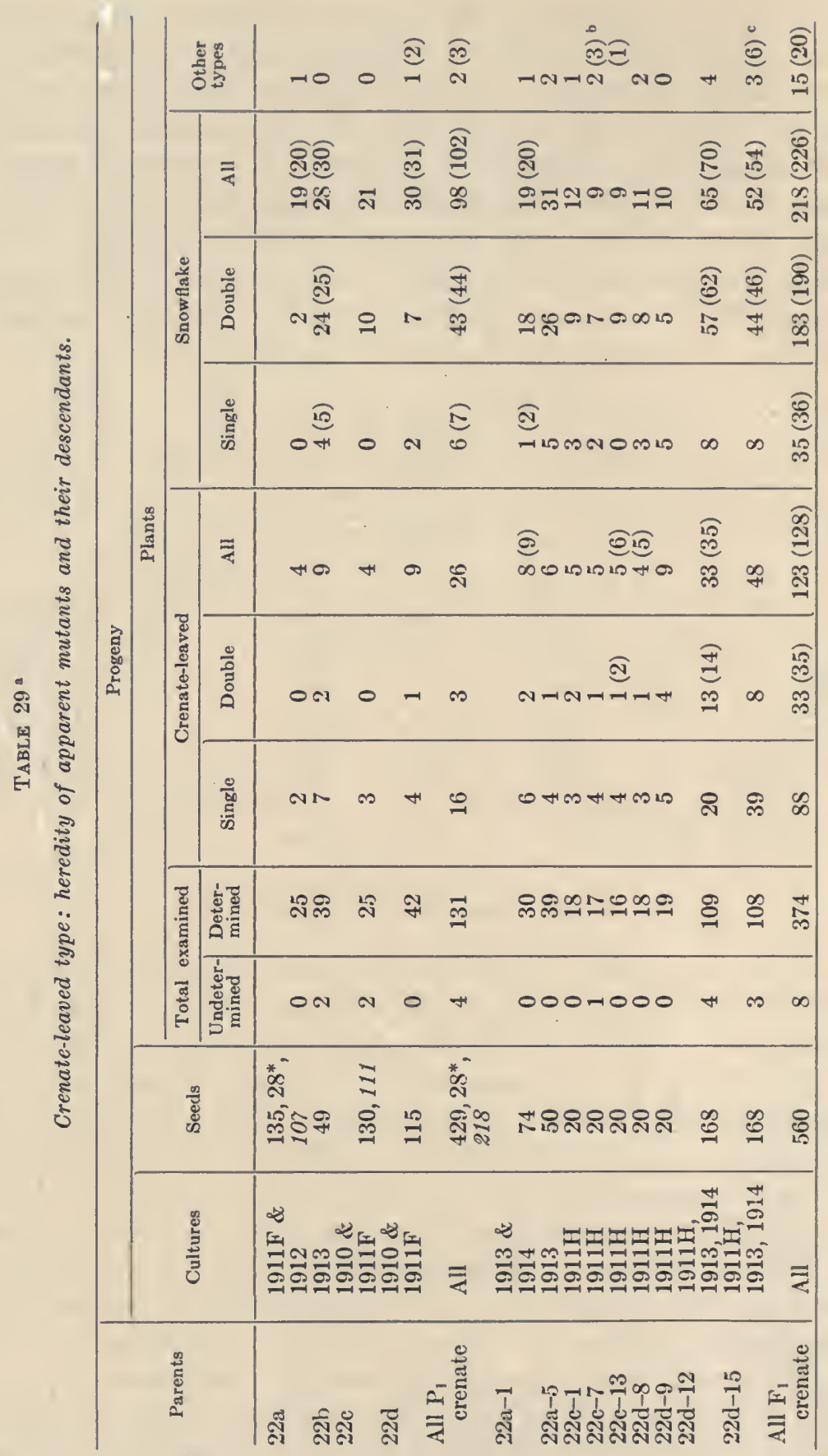




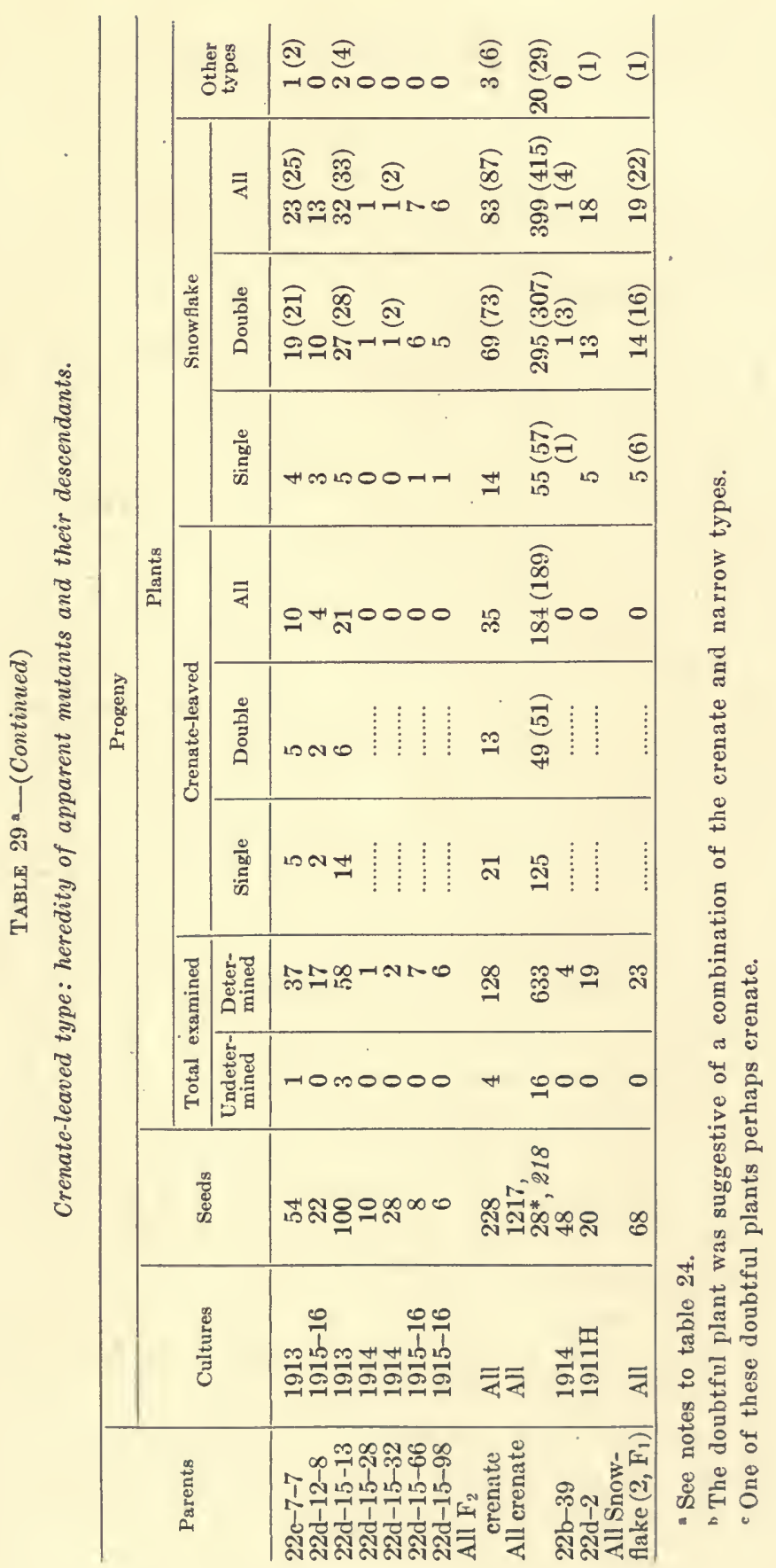


with the position of the leaves on the plant. In the crenate-leaved type this eharacter is much accentuated, as can be seen by comparing figure 14 with figures 1 and 3 ; a warm greenhouse (fig. 14, upper line) gave very marked serration, while a eool greenhouse (lower plant, and also fig. 15) produced leaves mueh more nearly entire.

Under the mueh more extreme eonditions of insolation, temperature, and humidity at Riverside, this type was often mueh dwarfed in eomparison with Snowflake (figs. 16 and 17 ; see also fig. 23). In general, growth is weaker than with Snowflake and the stems more slender. Buds and flowers are often produeed in great abundanee, but the capsules are relatively few, small, and few-seeded. See tables 12 and 13 for internode data.

The progeny tests (table 29) show a slightly higher proportion of mutant-type progeny than occurred with smooth-leaved. A striking new feature. appears for the first time in these results, the regular presence of linkage, or an association simulating linkage, with the single-double allelomorphs. Further, in all the four apparent mutants tested the erenate faetor seems to be coupled with singleness, while among the sixteen $F_{1}$ and $F_{2}$ crenate parents there seem to be no crossovers. ${ }^{17}$ We seem to be justified, for reasons just given, in summing the progeny as in the tables. Two things appear at once in table 29: (1) there is a great excess of total doubles over the usual 53 per eent; (2) there is a mueh greater exeess of doubles with Snowflake than of singles with crenate; (3) the supposed double-recessive class (Snowflake double) is about two and one-half times as large as the double-dominant class (erenate single).

Table 30 adds two features of speeial interest. First, there is good evidence of selective elimination with poor germination; compare the remaining percentages with those for "Ithaea, field," "1915," " $\mathrm{P}_{1}$," and "Germination poor," and see tables 39 and 40 ; the only exceptional ease is the low percentage for the thirty plants of 1915-16. It would be surprising if the slow and weak growth of the crenate plants did not lead to such a result. Seeond, there is evidenee that the erenate individuals are smaller than Snowflake even before germination. The seeds of erenate parents are less uniform in size than those of Snowflake parents; small seeds are numerous, and even the larger ones probably weigh decidedly less than normal Snowflake seeds. With five erenate parents included in the cultures of 1913, random

17 With four of the parents the tests are obviously entirely inadequate; one other, 22d-9, gives no indication of linkage among nineteen progeny. 


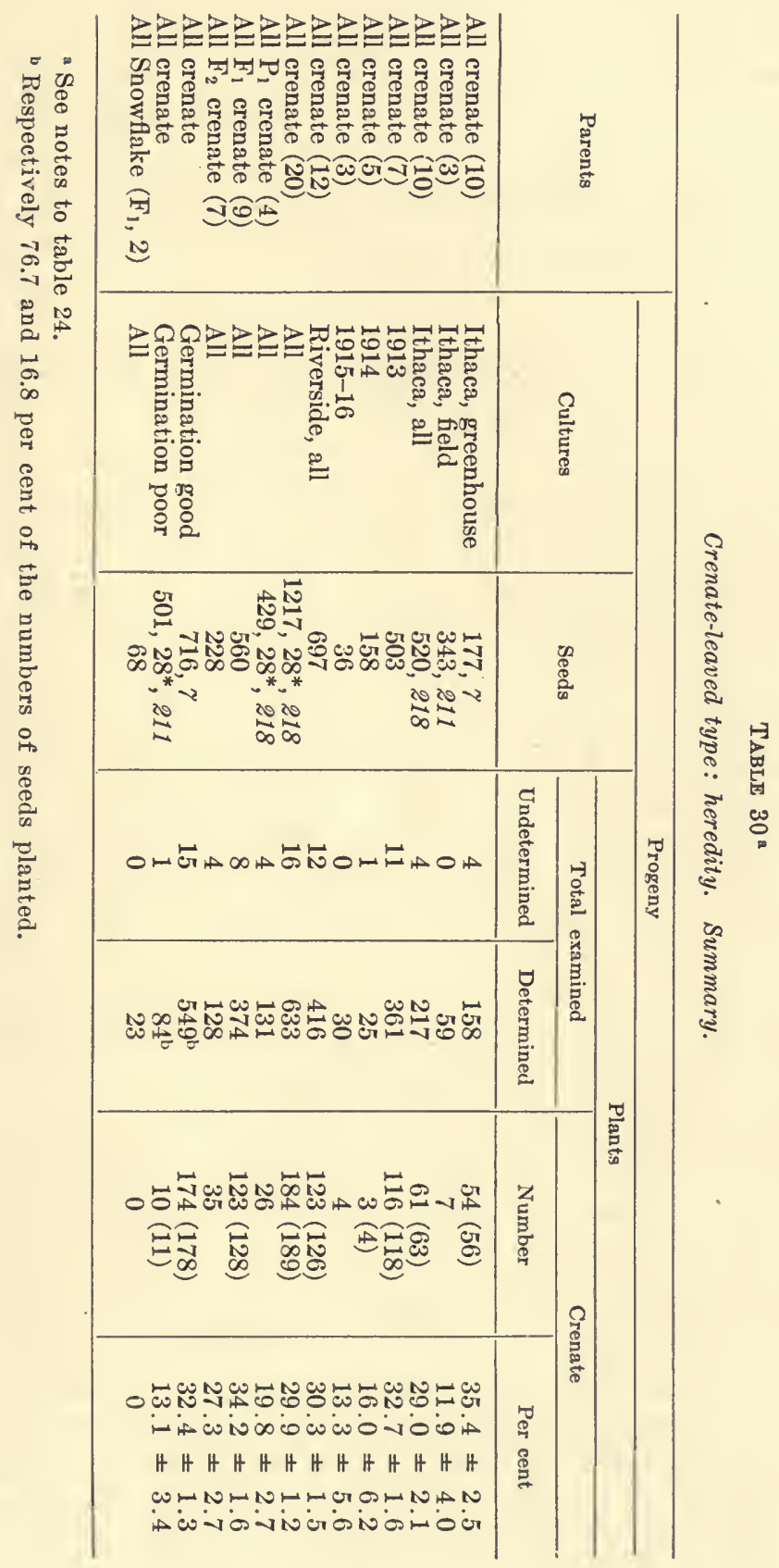


samples of seed were sorted, and the smaller and larger seeds planted separately.

Table 31 gives the data from this test. Here is practically conclusive evidence (see tables 39 and 40) that the smaller seeds much more often contain embryos of the crenate type. ${ }^{18}$ Since the embryo of a Matthiola seed occupies practically all the space within the seed coats, it is evident that even as embryos Snowflake plants exceed

TABLE 31

Cultures of 1913. Crenate-leaved type: proportions from smaller and larger seeds of crenate parents.

\begin{tabular}{|c|c|c|c|c|c|c|c|c|}
\hline \multirow{3}{*}{ Parent } & \multirow{2}{*}{\multicolumn{2}{|c|}{ Seeds }} & \multicolumn{6}{|c|}{ Progeny } \\
\hline & & & \multirow{2}{*}{$\begin{array}{l}\text { Total } \\
\text { deter- } \\
\text { mined }\end{array}$} & \multicolumn{3}{|c|}{ Crenate-leaved } & \multirow{2}{*}{ Snowflake } & \multirow{2}{*}{$\begin{array}{l}\text { Other } \\
\text { types }\end{array}$} \\
\hline & Size & Number & & Number & \multicolumn{2}{|c|}{ Per cent } & & \\
\hline $22 a-1$ & Smaller & 21 & 6 & $4(5)$ & $83.3=$ & \pm 12.9 & 0 & 1 \\
\hline $22 a-1$ & Larger & 29 & 23 & 3 & $13.0=$ & $\pm \quad 6.6$ & $19(20)$ & 0 \\
\hline $22 a-5$ & Smaller & 17 & 11 & 4 & $36.4=$ & 9.5 & 6 & 1 \\
\hline $22 a-5$ & Larger & 33 & 28 & 2 & $7.1=$ & $\pm \quad 6.0$ & 25 & 1 \\
\hline $22 \mathrm{~b}$ & Smaller & 13 & 8 & 5 & $62.5=$ & \pm 11.2 & 3 & 0 \\
\hline $22 \mathrm{~b}$ & Larger & 36 & 31 & 4 & $12.9=$ & \pm 5.7 & $25(27)$ & 0 \\
\hline $22 \mathrm{~d}-12$ & Smaller & 30 & 24 & 17 & $70.8=$ & 6.5 & 5 & 2 \\
\hline $22 \mathrm{~d}-12$ & Larger & 70 & 57 & $11(12)$ & $21.1=$ & 4.2 & $42(44)$ & 1 \\
\hline $22 \mathrm{~d}-15$ & Smaller & 32 & 24 & 17 & $70.8=$ & 6.5 & 3 & $2(4)$ \\
\hline $22 \mathrm{~d}-15$ & Larger & 68 & 54 & 18 & $33.3=$ & 4.3 & $34(35)$ & 1 \\
\hline All & Smaller & 113 & $73^{\mathrm{a}}$ & $47(48)$ & $65.8=$ & 3.7 & 17 & $6(8)$ \\
\hline All & Larger & 236 & $193^{a}$ & $38(39)$ & $20.2=$ & 2.3 & $145(151)$ & 3 \\
\hline All & All & 349 & 266 & $85(87)$ & $32.7=$ & 1.9 & $162(168)$ & $9(11)$ \\
\hline
\end{tabular}

a Respectively 64.6 and 81.8 per cent of the numbers of seeds planted.

crenate plants in size. This fact, obviously, is further evidence in favor of the hypothesis of partial selective elimination of crenate heterozygotes during embryonic development.

It may be worth noting that the 73 plants from the smaller seeds include 6 (8) apparent mutants of other types (mutation coefficient 11.0 per cent), while the 193 plants from the larger seeds include only 3 apparent mutants (1.6 per cent).

Before we can profitably discuss these data further, we must consider the results from cross pollination (tables 32 and 33). The numbers, though small, make it very probable that both eggs and sperms carry the crenate factor. Further, it appears from series 20 that only a small portion of the sperms carry this factor, as we should expect from its apparent linkage with singleness. If homozygotes are nonviable, the combined crenate percentages of reciprocal crosses should

18 The poorer germination of the smaller seeds suggests that the disparity between the two lots of seeds in the proportion of crenate embryos was even greater than the cultures indicate. 


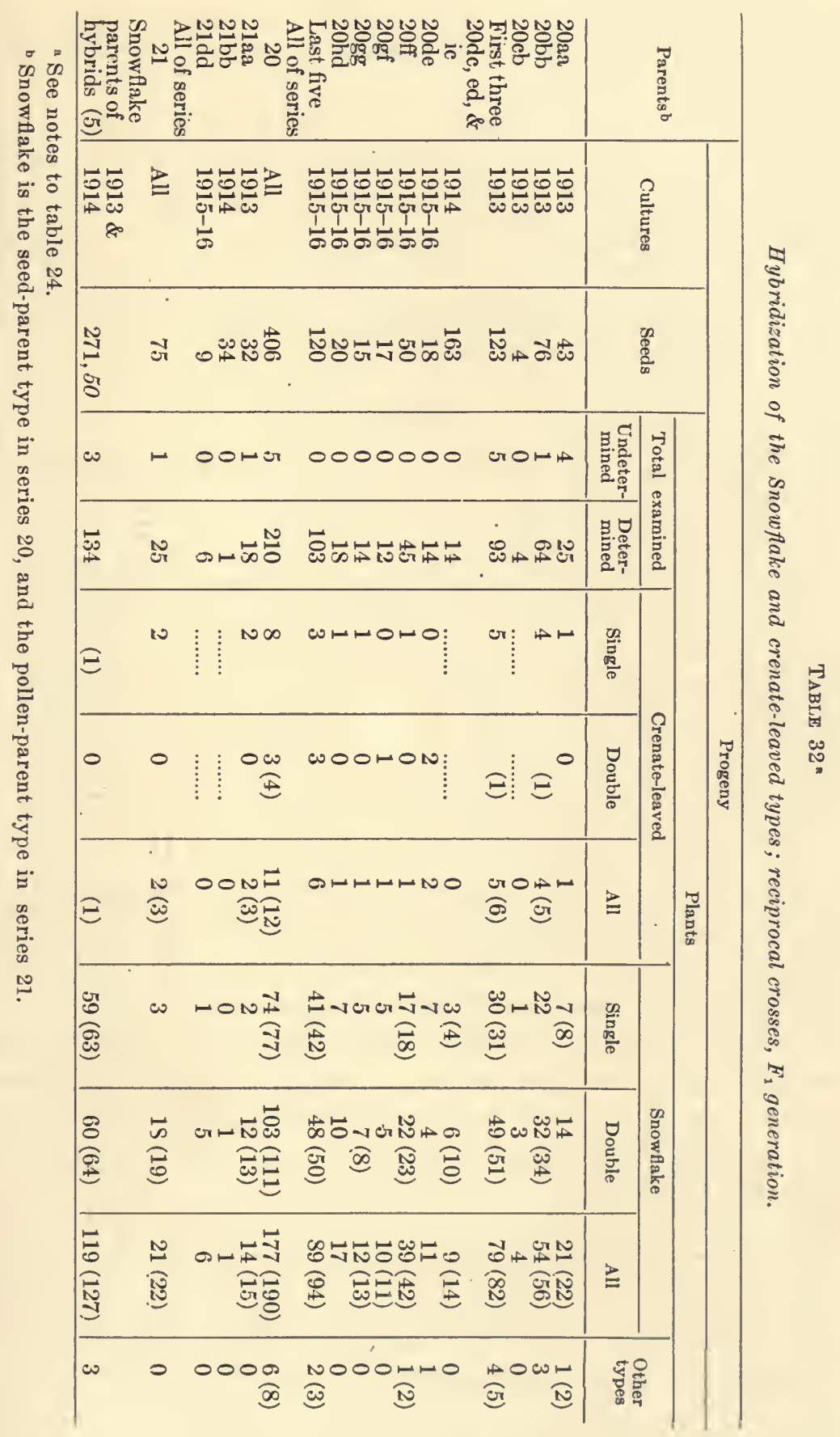


exceed the percentage from selfed parents; the expected high proportion with series 21 , however, might well be realized with adequate numbers and good germination.

In spite of the small totals, it is very probable that linkage similar to that of the selfed cultures prevails with series 21 . Where the crenate type is the pollen parent (series 20) linkage ratios are on our hypothesis impossible, since the eggs are all Snowflake and the sperms all double; the data, however, though statistically inconclusive, suggest that the excess of singles with crenate and of doubles with Snowflake is greatly reduced but not abolished.

TABLE 33

Hybridization of the Snowflake and crenate-leaved types. Summary.

\begin{tabular}{|c|c|c|c|c|c|c|}
\hline \multirow{4}{*}{ Parents } & \multicolumn{6}{|c|}{ Progeny } \\
\hline & \multirow{3}{*}{ Cultures } & \multirow{3}{*}{ Seeds } & \multicolumn{4}{|c|}{ Plants } \\
\hline & & & \multicolumn{2}{|c|}{ Total examined } & \multicolumn{2}{|c|}{ Crenate } \\
\hline & & & $\begin{array}{l}\text { Undeter- } \\
\text { mined }\end{array}$ & $\begin{array}{l}\text { Deter- } \\
\text { mined }\end{array}$ & Number & Per cent \\
\hline $\begin{array}{l}20 \mathrm{aa}, \mathrm{bb}, \& \mathrm{cb} \\
20 \mathrm{dc}, \mathrm{ed}, \& \text { ic } \\
20 \mathrm{de}, \mathrm{ff}, \mathrm{gf}, \mathrm{gg}, \& \mathrm{hd} \\
\text { All of series } 20 \\
21 \mathrm{aa}, \mathrm{bb}, \& \mathrm{dd} \\
\text { Snowflake par- } \\
\text { ents of hybrids } \\
\text { (5) }\end{array}$ & $\begin{array}{l}1913 \\
1914 \\
1915-16 \\
\text { All } \\
\text { All }\end{array}$ & $\begin{array}{r}123 \\
163 \\
120 \\
406 \\
75\end{array}$ & $\begin{array}{l}5 \\
0 \\
0 \\
5 \\
1\end{array}$ & $\begin{array}{r}93 \\
14 \\
103 \\
210 \\
25\end{array}$ & $\begin{array}{c}5(6) \\
0 \\
6 \\
11(12) \\
2(3)\end{array}$ & $\begin{array}{r}6.5 \pm 1.6 \\
0 \\
5.8 \pm 1.5 \\
5.7 \pm 1.1 \\
12.0 \pm 4.4\end{array}$ \\
\hline
\end{tabular}

If we may ignore the doubtful correlation just mentioned a fairly adequate complete hypothesis for the selfing ratio is possible. Assume (1) a gametic ratio ${ }^{19}$ of $5 D C: 1 d C: 1 D c: 5 d c$, or $16 \%$ per cent of crossing over; (2) non-viability of homozygous crenate $(C C)$; (3) low viability of simplex crenate $(C c)$, eliminating an average of 60 per cent of this type; and (4) coupling of $D$ and $C$ in all parents tested. Evidence has already been presented for assumptions (1), (2), and (3), except as to the intensity of linkage, while (4), as will be seen, is not at all improbable.

Random fertilization under these conditions, excepting (3), would give $26 D d C c$ (crenate single) + 10ddCc (crenate double) + $5 D d c c$ (Snowflake single) $+25 d d c c$ (Snowflake double). The other two classes, $5 D d C C$ and $1 d d C C$, would be non-viable pure crenate. Adding assumption (3) gives the following comparison:

10 Representing the singleness and doubleness factors by $D$ and $d$, and the crenate factor and its "normal", allelomorph by $C$ and $c$. 


\begin{tabular}{|c|c|c|c|c|}
\hline & DdCe & ddCe & Ddec & ddec \\
\hline Theoretical ratio $(n=44.4) \ldots . .$. & 10.4 & 4 & 5 & 25 \\
\hline Calculated for $n=540 \ldots \ldots \ldots . . . .$. & 126 & 49 & 61 & 304 \\
\hline Observed $(n=540)^{20} \ldots \ldots$ & 125 & 51 & 57 & 307 \\
\hline
\end{tabular}

This fit surely cannot be criticised, whatever may be thought of the devices employed to obtain it! With cross pollination the agreement is fairly good in the case of series 20, which gives the only fairly reliable data. We are assuming $16 \% 3$ per cent of crossover $d C$ sperms; elimination of .60 of $16 \% / 3$ per cent, or 10 per cent of the total, gives $.062 / 3 / .90=7.4$ per cent expected crenate, as against 5.9 per cent observed. Series 21 is supposed to have 50 per cent of $C$ eggs in the ratio $5 D C: 1 d C$; elimination of .60 of this proportion, or 30 per cent of the total, would leave $.20 / .70=28.6$ per cent, against 12.0 per cent in the very inadequate material observed. An adequate test of the hypothesis obviously requires large hybrid cultures, from vigorous seed sown under favorable conditions for germination.

A scarcity of crossover crenate singles follows from the hypothesis; they constitute only one twenty-sixth of the total number of viable crenate single progeny of crenate parents. No direct evidence indicating that the crenate and double factors are ever coupled in singles has yet been discovered.

If the supposed crenate mutants are due to immediate factor mutation, however, it seems strange that the same locus is changed more readily in a singleness chromosome than in one carrying the doubleness factor, in a ratio similar to the linkage ratio of later generations. If the apparent mutants are really segregates from a balanced-lethal combination, the observed original coupling of crenate with single might be an accident of sampling involved in the original choice of material; other initial parents might give the reverse coupling.

\section{THE SLENDER TYPF}

This type is comparatively rare as an apparent mutant from Snowflake or early; the 3135 plants reported in table 28 gave only 4 (6) mutants ( 2 singles and 4 doubles, 2 of the latter perhaps Snowflake), a mutation coefficient not over .19 per cent. This type seems to occur more frequently among progeny of crenate, a type similar in some

20 Omitting 29 plants classed as neither crenate nor Snowflake, which as probably non-crenate should perhaps be added to Snowflake, and also 64 plants (13 crenate and 51 Snowflake) with flower data incomplete. Complete data for the total of 633 plants would plainly give a somewhat poorer fit, but this could be improved by assuming a slightly greater elimination of Ccii zygotes. 


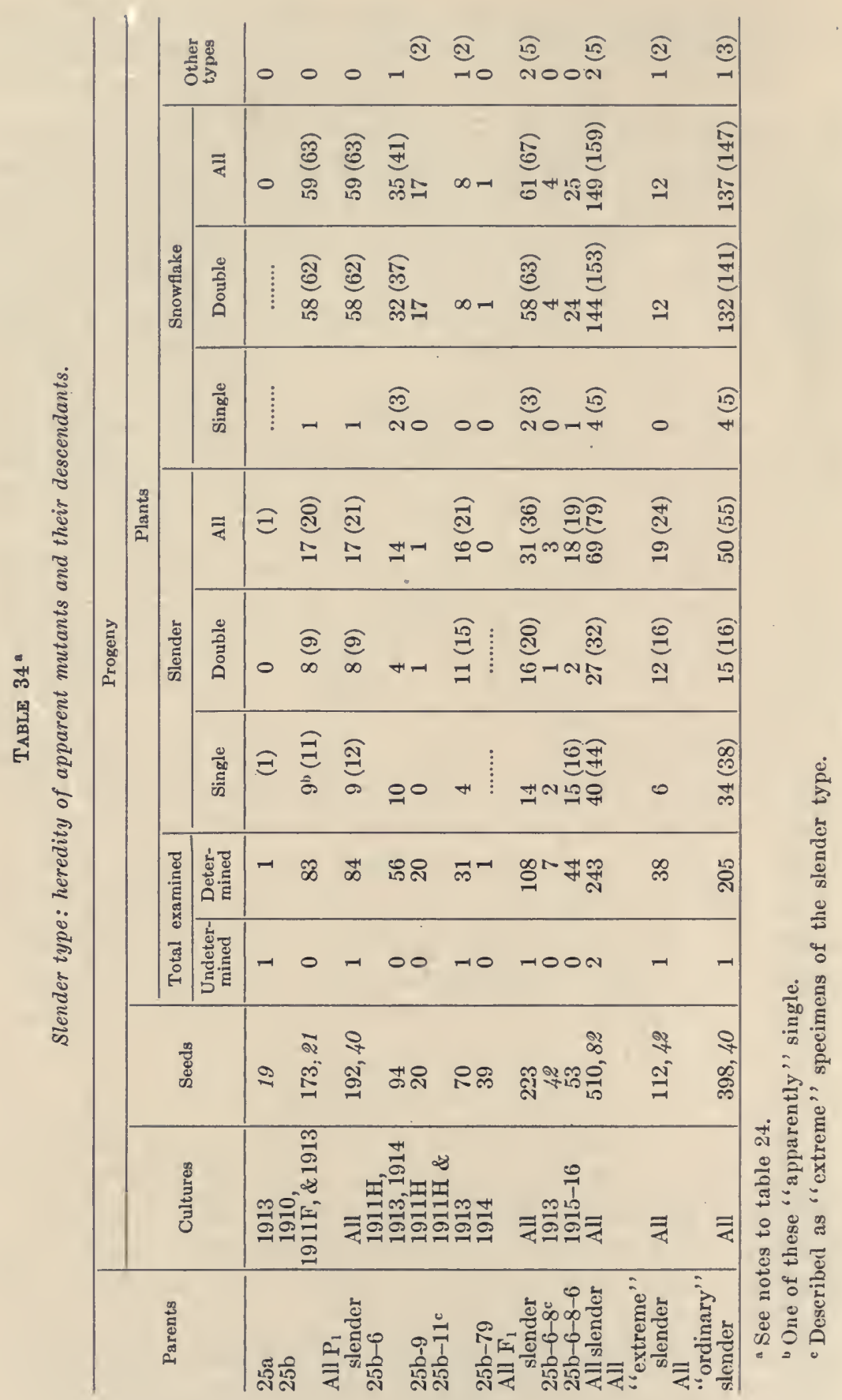


respects, and vice versa. Under favorable conditions this type may closely resemble Snowflake, but is decidedly more slender in stems, leaves, and pedicels. A characteristic drooping of flowers and branches is well shown by two plants in figure 18; the single is $25 \mathrm{~b}$ of the tables. The progeny of $25 \mathrm{~b}$ shown in figure 19 illustrate a variability of the "slender" characteristics which has suggested the presence of genetic differences among plants classed as slender. The leaves often resemble those of crenate more closely than do Snowflake leaves.

In the field at Ithaca flowering was markedly earlier than with Snowflake, and the type seems to be earlier on the whole. The Riverside conditions have commonly given a decided dwarfing as compared with Snowflake, though not to the extreme degree that this has occurred with crenate (figs. 20 and 21).

The results of selfing tests are reported in tables 34 and 35 . The distributions have the same general characteristics as with crenate, with some remarkable differences. The excess of doubles with Snow. flake is very much greater, the ratio being about $30: 1$; with slender, however, the excess of singles is slight in the grand total and perhaps significantly variable with different parents.

Plant 25b-11, the "extreme" individual of figure 19, appears to give a real excess of slender over Snowflake, and of double slender over single slender, though the numbers are much too small for certainty. The two parents classed as "extreme" are (tables 39 and 40) 21 quite probably genetically different from the other slender parents. It should be noted that plant 25b-6-8-6, progeny of one of the parents described as "extreme," has also given a relatively high proportion of slender progeny. Perhaps the "extreme" form is heterozygous for a second slenderness factor similar to the original one.

The percentages of mutant-type progeny are (table 39) much more variable than with smooth, large, or crenate, and (table 40) there is no good evidence of selective elimination; both these facts may depend on genetic differences among the parents tested.

The great modifiability of the various types, including Snowflake, indicated by a comparison of, for instance, figures 14, 15, and 16, greatly complicates the positive determination of types. In the cultures of $1911 \mathrm{H}$ and 1913, where crowing in flats or aphis injury in the field interfered with normal development of some plants, the impression was obtained that the slender type occurred in several grades

21 In the calculation of the probability of simple sampling, $f$ is taken as 3 (the number of cultures), not 2 (the number of parents). 


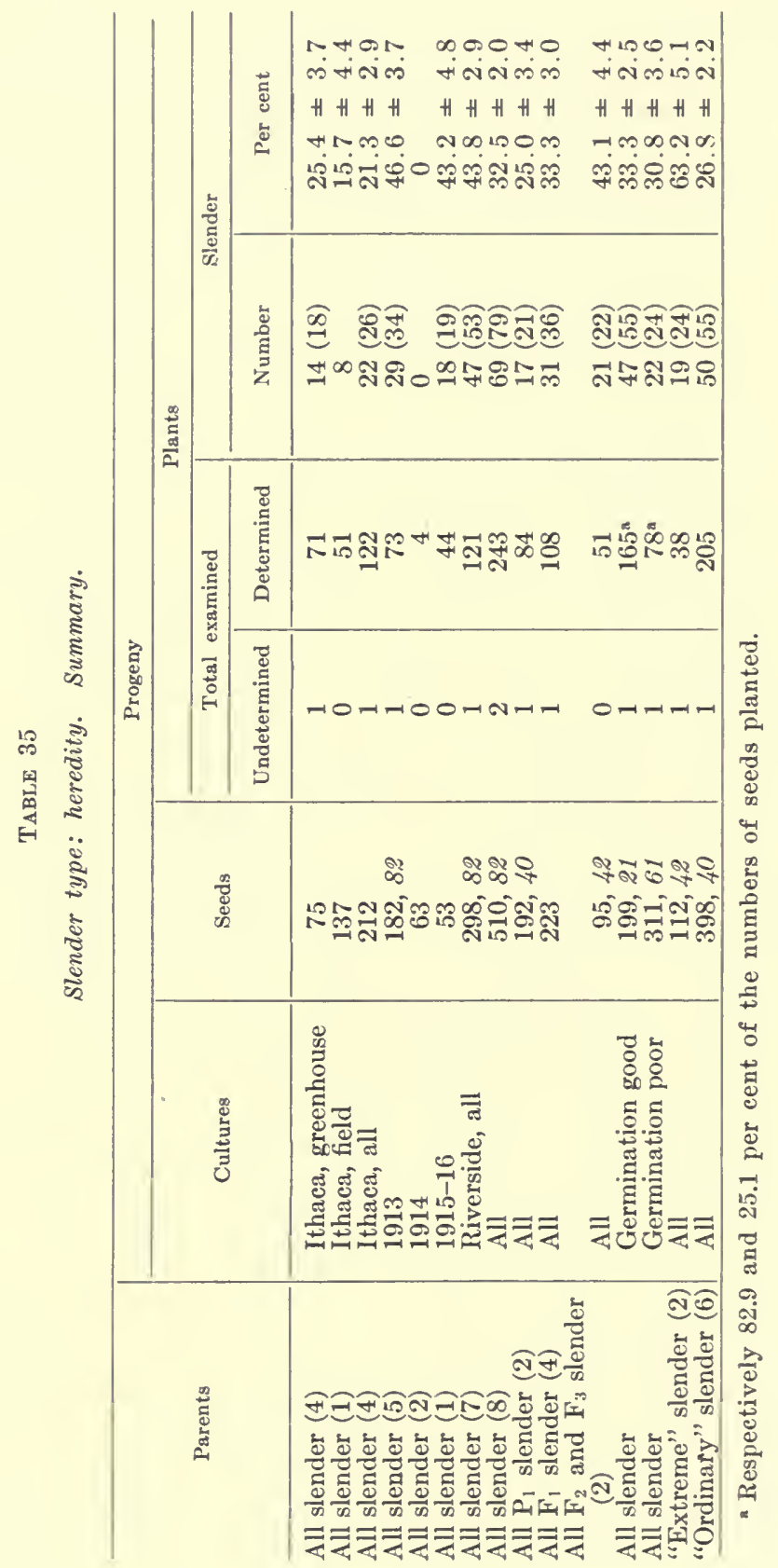


probably unlike genetically. In the 1916 cultures, on the other hand, with better development, this type seemed substantially as uniform as the others.

If we ignore these possible genetic differences and attempt to apply the scheme worked out for crenate, difficulties appear at once. First, the scarcity of Snowflake singles would indicate much closer linkage than with crenate, while the relative abundance of slender doubles apparently contradicts this supposition. Second, the inadequate results from crossing with Snowflake (table 36) suggest that the sperms carry the supposedly crossover slender factor at least as often as do the eggs. While crenate as pollen parent gives results agreeing tolerably with the hypothesis, slender gives results differing from these in the wrong direction.

No doubt, however, the disagreements can be over emphasized. Both crenate and slender as seed parent seem to give the expected relations between singles and doubles, and series 23 also does this with the Snowflake progeny. Obviously the functional sperms and eggs of these mutant-type parents exhibit different ratios between types, and the peculiar results in other respects with slender may be related to the added complication suggested above. The astonishing feature of the data, of course, is the great excess of single slender over double slender in series 23-an excess which suggests an actual significant excess of singles in the totals of all types given by this cross - while with selfed slender there is a great total deficiency of singles. We may at least feel confident that the modifications of the single-double ratio, with this type and with crenate, are due to lethal action which also affects the proportions of viable slender and crenate gametes or zygotes.

If differential viability before germination is an important factor with these types, very probably it differs according as Snowflake or the mutant type is the seed parent, and according to the parental environment. In other words, partial selective elimination during seed formation may vary with the environment of the embryos, according as this environment is affected by either the genetic constitution or the external environment of the seed parent. Until such uncertainties are eliminated, we are hardly justified in ruling out, for the types discussed, the probability that regular segregation and (in the last two cases) true linkage are concerned in these phenomena. In fact, the definite differences in ratios between reciprocal crosses and between at least one of the crosses and selfing encourage further attempts at satisfactory factorial analysis. 


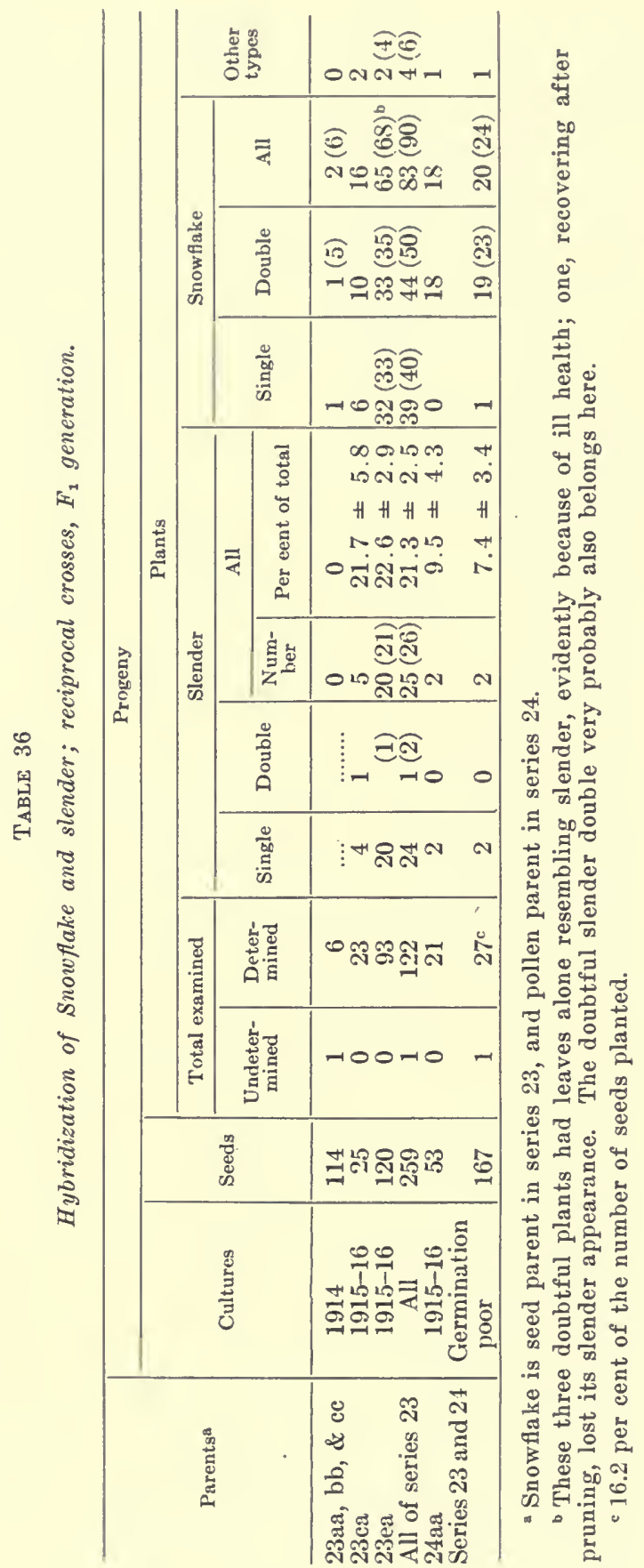




\section{THE NARROW-LEAVED TYPE}

As table 37 indicates, this type competes with crenate for second place in frequency of occurrence in the Ithaca cultures; in fact, when only the strictly unselected cultures are considered the percentage is very close to that for smooth-leaved. A feature of special interest is the apparent association of the mutant type with doubleness.

In a cool greenhouse this type (fig. 22) varied from exceptionally late and many-noded to ordinary in both characters. The leaves (see also fig. 18) were typically narrow, rather strictly entire, often rolled backward or twisted, and typically more ascending than those of

TABLE 37

Narrow-leaved type. Numbers of apparent mutants and association of the type with doubleness of flowers.

\begin{tabular}{|c|c|c|c|c|c|}
\hline \multirow{3}{*}{ Culture } & \multicolumn{5}{|c|}{ Progeny of Snowflake and early parents } \\
\hline & \multirow{2}{*}{$\begin{array}{c}\text { Total } \\
\text { examineda }\end{array}$} & \multicolumn{4}{|c|}{ Narrow-leaved } \\
\hline & & Single & Double & All & $\begin{array}{l}\text { Coefficient of } \\
\text { mutation }\end{array}$ \\
\hline $\begin{array}{l}1908 \\
1910 \\
1911 \mathrm{~F}, \text { house-sown } \\
\text { Al! above } \\
\text { All unselected }\end{array}$ & $\begin{array}{l}725^{b} \\
338 \\
2072 \\
3135 \\
2410\end{array}$ & $\begin{array}{l}0 \\
1 \\
7 \\
8 \\
8\end{array}$ & $\begin{array}{r}2 \\
4 \\
12 \\
18 \\
16\end{array}$ & $\begin{array}{r}2 \\
6 \\
20 \\
28 \\
26\end{array}$ & $\begin{array}{r}.28 \pm .26 \\
1.78 \pm .38 \\
.97 \pm .15 \\
.89 \pm .12 \\
1.08 \pm .14\end{array}$ \\
\hline
\end{tabular}

- See note $b$ to table 2 .

bee note $c$ to table 1 .

Snowflake. The apex of the leaf is often more acute than with Snowflake, and many leaves are mucronate or at least end in a sharp, rigid tip.

A striking characteristic is the narrowness of the sepals, resulting in frequent early separation at the edges, partially exposing the petals in immature buds.

Under the less favorable field conditions the plants often remain long as dwarf rosettes, and flower late and feebly if at all. Figures 23 and 24 show comparatively well developed plants in the field.

The type is on the whole very distinct in the field, though there has been some question whether a greenhouse plant such as that in figure 18 is genetically different from those with short and rigid leaves (figs. 22 and 24); the very great variability in leaf form due to external conditions makes such a question very difficult without extensive progeny tests. It is now (1918) probable that narrow-dark (p. 143) was not distinguished from narrow in the greenhouse. 


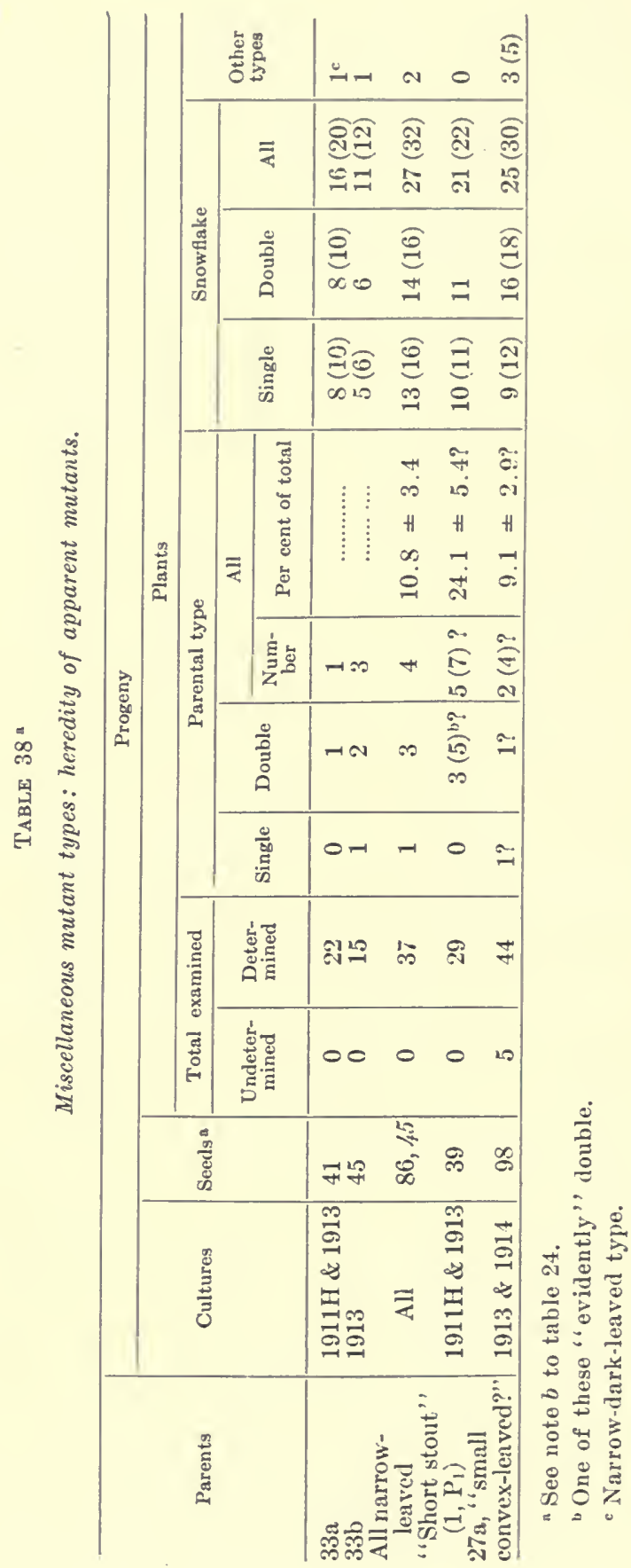


The few singles have produced few seeds, and these were highly variable in size. The capsule often has a defective septum, more or less of the distal portion being absent. Germination was poor in the small cultures secured (table 38, upper part), with only 10.8 per cent of the mutant type among the progeny.

This case agrees in most respects with those previously discussed, but adds one point of interest in the occurrence of apparent coupling of mutant type with doubleness rather than singleness. Seed appears to be less abundant and less well developed than with any of the preceding mutant types, facts probably significant in relation to the low percentage of narrow progeny from narrow parents, though the large probable error of the percentage must be considered.

\section{MISCELLANEOUS ABERRANT TYPES}

As part of the aberrant individuals occurring in the greenhouse were either doubles or singles that produced no seed, while practically no seed was produced by any plants in the field at Ithaca or by even some of the commoner mutant types at Riverside, the opportunity for progeny tests has been almost entirely limited to the types so far discussed.

The narrow-dark-leaved type (table 3 ) was common and distinct in the field at Ithaca, where it constituted about .48 per cent of the 2072 plants from house-sown seed, and has been rcadily identified in several cases at Riverside. It was not distinguished in the greenhouse cultures, but was very probably included under narrow-leaved. Possibly a single described as "small-convex-leaved" belonged to this type, though two field plants were given this name as distinct from narrow-dark; according to a photograph (fig. 25, second plant from left), another greenhouse plant (a double) may have been similar to narrow-dark-leaved. The narrow-dark-leaved type (figs. 26 and 27) has narrow dark-green leaves, strongly convex upward, and evidently tends to compactness of growth and lateness of flowering; under field conditions it seems decidedly more like Snowflake than like narrow: leaved.

The 44 progeny (table 38 ) secured from the greenhousc single mentionad above included 2 (4) narrow-dark-leaved individuals and 3 (5) other plants not Snowflake (the last including two smooth, one large, one slender, and one semicrenate), besides five undetermined plants. Plainly the type of the parent is still in doubt. 
Another very different greenhouse plant, described as "stout dwarf" (fig. 25, third from left), gave among 29 progeny (table 38) $5(7)$ individuals evidently not Snowflake, whieh may have been narrow-dark or may have belonged to another type that was somewhat similar under the conditions of the tests. The parent resembled Snowflake except in its short internodes and short, stout eapsules.

Four other plants suspeeted of mutation apparently entirely failed to repeat their type in their progeny, perhaps beeause of the smallness of the house cultures. One of these was the plant, much branehed for the warm greenhouse, third from the right in figure 18; another was a very late plant with a remarkably large number of main-stem leaves; the others were a plant with unusually small flowers and one witl some of the leaves somewhat spatulate. Possibly all of these were Snowflake, though the second, which gave poor germination, probably was not. All these four plants have been ineluded as Snowflake parents for tables showing numbers of apparent mutants.

The small-smooth-leaved type is well shown in figure 25 (first and fifth from the left). It is the smallest and weakest of the fairly common and definitely identified types; it has small, very smooth leaves, and is late in blooming. The two plants shown were both singles, but they set no seed.

The semicrenate-leaved type (table 3 ) differed slightly but apparently definitely from Snowflake, somewhat resembling erenate-leaved in leaf form. The one "pointed-erenate-leaved" plant of table 3 may have been erenate-leaved. The "compaet" and "eurly-leaved" plants of this table have not been identified with any aberrant types in other eultures. With the remaining six types of table 3 all the individuals have been questioned as possibly Snowflake; it is now praetieally eertain that some of those in the seeond, third, and fourth groups belonged to the large-leaved type sinee studied, but the apparent intergradation with Snowflake makes any attempt at a definite reelassification from the records a matter of doubtful value.

The seeond plant from the right in figure 25 was remarkable for its short stem and few but large leaves. Several other more or less exeeptional individuals have appeared in the eultures, espeeially among some plants with abnormal eotyledons, selected from large numbers of greenhouse seedlings in the 1908 eultures, whieh were examined for syneotyledony. Some of these were very weak plants which finally died without flowering. 
The fluctuations in habit, leaf form, etc., within the type are such that the determination of familiar types is often a matter of some uncertainty, as is shown by data that have been presented. It may well be that among the doubtful types are included several definite but comparative rare mutant forms, which occurred too infrequently to afford adequate material for positive classification.

\section{SOME PROBABILITES OF RANDOM SAMPLING}

For compactness of presentation and convenience of comparison the material in tables 39 and 40, to which some incidental references have already been made, is collected here rather than scattered through the discussions of the various types concerned. Some statements as to methods are also necessary in connection with each of the topics here treated.

First, it should be noted that the percentages previously given have regularly been accompanied by the probable errors of simple sampling. These probable errors have been calculated by the formula $E_{\text {per cent }}=.6744898 \sqrt{\frac{p q}{n}}$, where $p$ is the percentage of the mutant type ("successes"), $q$ is $1-p$, and $n$ is the size of the sample (the number of plants concerned).

In the heredity tables for each type, $p$ has uniformly been taken as the percentage of the total of the lots compared, or $p_{0}$.

For the "mutation coefficient" the percentage of the grand total of unselected house-sown lots has regularly becn used. Evidently the few selected progeny included in tables 1,28 , and 37 should be omitted. All the percentages here are so low that the probable errors descrve littlc confidence, even though $n$ is usually fairly large. The rather close agreement of the percentages of all apparent mutants in the three distinct lots of unselected house-sown cultures suggests that they represent fairly well the population value for the potentialities of the seeds; and even if the mean percentage of the total of the lots for the main comparisons is actually nearer, it is safer to use the larger probable errors resulting from the method here cmployed. Furthermore strict use of $p_{0}$ would sometimes require several slightly different probable errors for the same percentage, for use in different comparisons in the same table. 
If the probable error of the differenee of any two percentages in the same table is to be obtained, therefore, formulae corresponding to those given by Yule (1911, pp. 264-267) are applieable.

Now, it is possible in some of these cases to ealculate the aetual standard deviation of the pereentage in subsamples whieh make up an aggregate sample. Table 39 gives sueh aetual standard deviations, in eomparison with the eorresponding theoretieal or expeeted standard deviations given by

$$
\sigma_{\text {per cent }}=\sqrt{\frac{p q}{\bar{n}-3}} \text {. }
$$

TABLE 39

Standard deviations of percentages of mutant types. Values derived from $\sqrt{p q}$, compared with values expressing the actual variability of subsamples.

\begin{tabular}{|c|c|c|c|c|c|c|c|}
\hline \multirow[b]{2}{*}{$\begin{array}{l}\text { Type of parent and grouping of } \\
\text { progeny }\end{array}$} & \multirow[b]{2}{*}{$N$} & \multirow[b]{2}{*}{$f$} & \multirow[b]{2}{*}{$\bar{n}$} & \multirow[b]{2}{*}{$p$} & \multicolumn{3}{|c|}{ Standard deviation of samples of mean size $\bar{n}$} \\
\hline & & & & & Actual & Theoretical, $\sqrt{\frac{p q}{\bar{n}-3}}$ & $\frac{\text { Difference }}{E \sigma}$ \\
\hline Smooth-leaved type: & & & & & & & \\
\hline $\begin{array}{l}\text { All lots by parentage } \\
\text { All lots as grown }\end{array}$ & $\begin{array}{l}234 \\
234\end{array}$ & $\begin{array}{r}6 \\
12\end{array}$ & $\begin{array}{l}39.0 \\
10.5\end{array}$ & $\begin{array}{l}27.35 \\
27.35\end{array}$ & $\begin{array}{r}7.5 \\
11.3\end{array}$ & $\begin{aligned} 7.4 & \pm 1.4 \\
11.0 & \pm 1.5\end{aligned}$ & $\begin{array}{l}+\quad 1 \\
+\quad 2\end{array}$ \\
\hline Germination good & 187 & 7 & 26.7 & 29.95 & 10.9 & $9.4 \pm 1.7$ & +.9 \\
\hline Germination poor & 47 & 5 & 9.4 & 17.02 & 5.2 & $\left\{\begin{array}{l}14.9 \\
17.6\end{array}\right.$ & -3.0 \\
\hline Large-leaved type: & & & & & & & \\
\hline All lots by parentage & 357 & 20 & 17.85 & 49.02 & 10.7 & $13.0 \pm 1.4$ & -1.6 \\
\hline All lots as grown & 357 & 22 & 16.2 & 49.02 & 10.9 & $13.7 \pm 1.4$ & -2.0 \\
\hline Germination good & 260 & 14 & 18.6 & 50.38 & 11.3 & $\left\{\begin{array}{l}12.7 \pm 1.6 \\
12.7\end{array}\right.$ & -.9 \\
\hline Germination poor & 97 & 8 & 12.1 & 45.36 & 8.7 & $\left\{\begin{array}{l}16.5 \pm 2.8 \\
16.6\end{array}\right.$ & -2.8 \\
\hline Crenate-leaved type: & & & & & & & \\
\hline All lots by parentage & 633 & 20 & 31.65 & 29.86 & 10.6 & $8.6 \pm .9$ & +2.2 \\
\hline All lots as grown & 633 & 28 & 22.6 & 29.86 & 12.5 & $10.3 \pm .9$ & +2.4 \\
\hline Germination good & 549 & 20 & 27.45 & 32.42 & 10.7 & $\left\{\begin{array}{l}9.5 \pm 1.0 \\
9.3\end{array}\right.$ & .2 \\
\hline Germination poor & 84 & 8 & 10.5 & 13.10 & 10.5 & $\left\{\begin{array}{l}12.3 \pm 2.1 \\
16.7\end{array}\right.$ & -.9 \\
\hline Seed-size test, smaller seeds & 73 & 5 & 14.6 & 65.75 & 13.2 & $\left\{\begin{array}{l}13.9 \pm 3.0 \\
13.8\end{array}\right.$ & -.2 \\
\hline Same, larger seeds & 193 & 5 & 38.6 & 20.21 & 9.4 & $\left\{\begin{array}{l}6.7 \pm 1.4 \\
7.9\end{array}\right.$ & +1.9 \\
\hline Same, all seeds, by parentage & 266 & 5 & 53.2 & 32.71 & 10.3 & $6.6 \pm 1.4$ & +2.6 \\
\hline Same, all seeds, as grown & 266 & 10 & 26.6 & 32.71 & 22.9 & $9.7 \pm 1.5$ & +8.8 \\
\hline Slender type: & & & & & & & \\
\hline All lots by parentage & 243 & 8 & 30.4 & 32.51 & 17.5 & $9.0 \pm 1.5$ & +5.7 \\
\hline All lots us grown & 243 & 13 & 18.7 & 32.51 & 19.7 & $11.8 \pm 1.6$ & +4.9 \\
\hline Germination good & 165 & 7 & 23.6 & 33.33 & 14.9 & $\left\{\begin{array}{l}10.4 \pm 1.9 \\
10.3\end{array}\right.$ & +2.4 \\
\hline Germination poor & 78 & 6 & 130 & 30.77 & 27.2 & $\left\{\begin{array}{l}14.6 \pm 2.8 \\
14.8\end{array}\right.$ & +4.5 \\
\hline Parents "extreme" & 38 & 3 & 12.7 & 63.16 & 14.4 & $\left\{\begin{array}{l}15.5 \pm 4.3 \\
15.1\end{array}\right.$ & -.3 \\
\hline Parents "ordinary", & 205 & 10 & 20.5 & 26.83 & 14.7 & $\left\{\begin{array}{l}10.6 \pm 1.6 \\
11.2\end{array}\right.$ & +2.6 \\
\hline $\begin{array}{l}\text { Narrow-leaved type: } \\
\text { All lots as grown }\end{array}$ & 37 & 3 & 12.3 & 10.81 & 8.1 & $10.2 \pm 2.8$ & .75 \\
\hline
\end{tabular}

\footnotetext{
a The second values for some cases in this column are derived from $p_{0}$ (see text).
} 
For example, table 27 gives the percentage of large-leaved plants among the 357 progeny of the 20 large-leaved parents as $49.0 \pm 1.8$ per cent. This probable error is given by $.6744898 \sqrt{\frac{p q}{n}}$, where $p=49.0$ per cent, $q=51.0$ per cent, and $n=357$. These 357 progeny, as table 39 indicates, came from 20 parents which contributed an average of 17.85 progeny each, and the actual standard deviation of the percentage in these 20 sibships was 10.7 per cent.

Obviously the expected standard deviation of simple sampling for comparison must represent samples not of 357 plants each but of 17.85 plants each. Now a percentage is obviously a mean (of values all either 0 or 1). Since "Student" (1908) has shown that the theoretical standard deviation of the mean in samples is given more exactly by

$$
\sigma_{\text {mean }}=\frac{\sigma_{\text {variate }}}{\sqrt{n-3}} \text { than by } \sigma_{\text {mean }}=\frac{\sigma_{\text {variate }}}{\sqrt{n}}
$$

(the value for the normal curve conventionally used for the probable error of the mean) and since $\bar{n}$, the mean size of sample, is small enough to make the correction a matter of consirlerable importance. $\sqrt{\bar{n}-3}$ is here used. Since $\sigma_{\text {variate }}=\sqrt{p q}$, we have $\sigma_{\text {mean }}=$ $\sqrt{\frac{p q}{\bar{n}-3}}$, where $\bar{n}=17.85$. This gives a theoretical standard deviation of 13.0 per cent. ${ }^{22}$

It is true (Yule, 1911, p. 260) that the ordinary method of calculation of the actual standard deviation is not satisfactory for means when the samples vary in size. A method has been used, however, which obviates this difficulty, so that comparison with the results given by $\sqrt{\frac{p q}{\bar{n}-3}}$ is strictly legitimate. Each squared percentage deviation has been weighted by multiplying it by the number of individual plants which it represents, and the summation of squared deviations has then been divided, not by $\Sigma f$, the number of samples, but by $\Sigma f \times \bar{n}$, the number of samples multiplied by the mean weight or average size of sample (in other words, by $N$, the total number of individuals ). ${ }^{23}$

22 In the calculations for table $39 p$ has been taken as the percentage given in this table, to two decimal places, while with all other numbers employed in calculation, including $\bar{n}-3$, three or more decimal places have been used as needed.

23 Algebraic proof of the correctness of the method has kindly been furnished by Frank L. Griffin, Professor of Mathematics, Reed College, Portland, Oregon. If it develops that this rather obvious device has not been suggested for the purpose, it is to be presented elsewhere with the mathematical proof. When the variates are not grouped in classes the calculation is substantially as easy as without weighting, while the theoretical value is found with much less work than by the method given by Yule (1911, p. 260), which requires the harmonic mean of the sample sizes. 


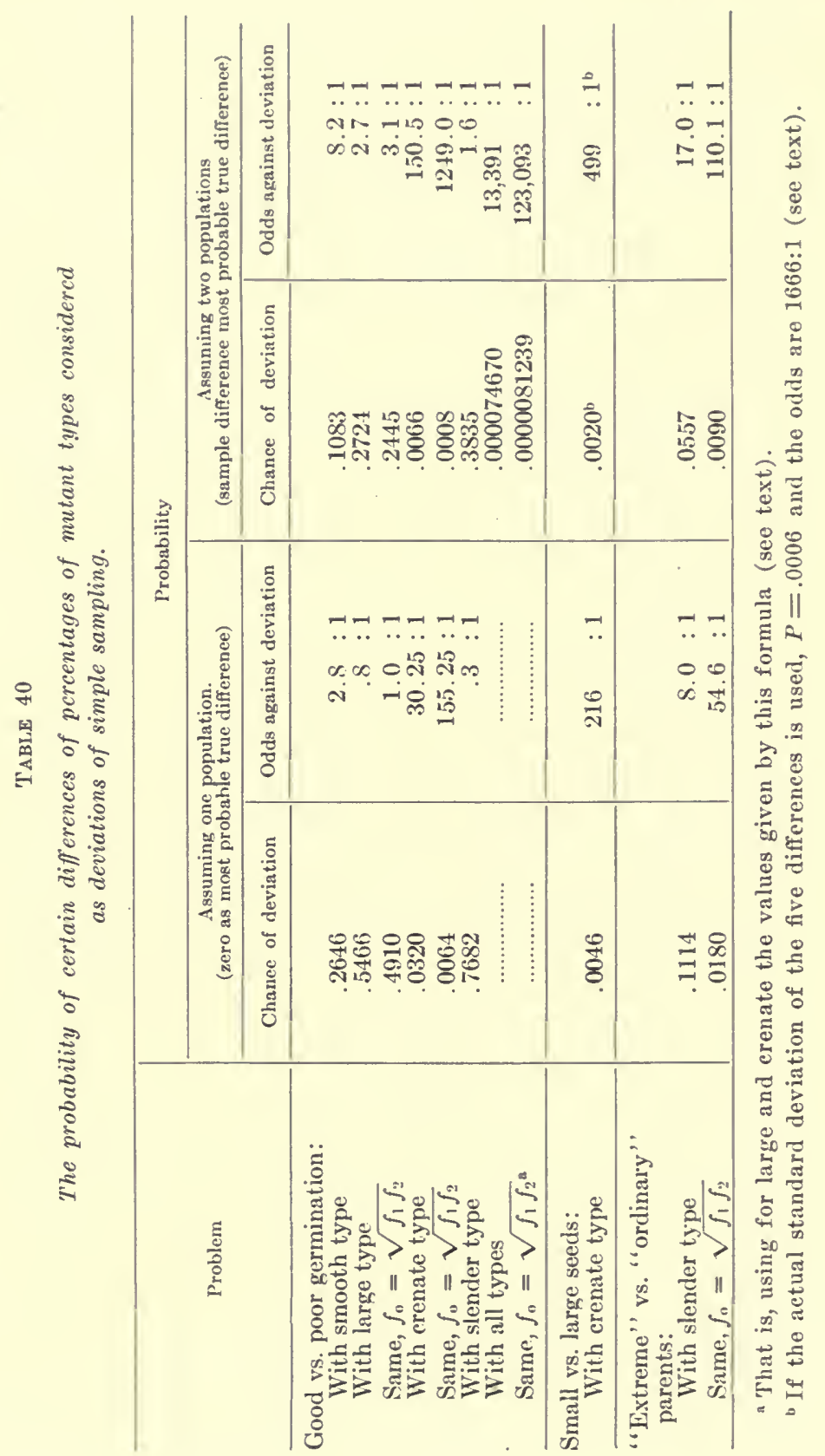


In the calculation the deviations are taken from zero, and with these small numbers of samples the percentages are not thrown into classes ; it suffices, then, to square each number of "successes," divide by the corresponding total of individuals, add the quotients, and divide by the grand total of individuals, correcting this weighted mean squared deviation by subtracting the square of the weighted mean percentage (percentage of grand total). If $s$ is the number of successes and $n$ is the total number of individuals in the subsample, and $M$ is the weighted mean percentage, then $M=\frac{\Sigma s}{\Sigma n}$, and $\sigma_{\text {per cent }}=\sqrt{\frac{\sum \frac{s^{2}}{n}}{\Sigma n}-M^{2}}$.

Table 39 gives, for the most important comparisons of heredity percentages, the total number of progeny $(N)$, the number of cultural groups or (with the first line for each type) the number of parents $(f)$, the average size of the groups of progeny $(\bar{n})$, and the mean percentage of the mutant type $(p)$. This serves as a summary of some of the most important statistical data already presented relating to the inheritance of these types, and also shows the basis of the remaining part of this table and of table 40. For comparison of actual and theoretical standard deviations the theoretical value has been ealculated from the actual percentage as given in this table. For comparison of means (table 40) the percentage of the corresponding total $\left(p_{0}\right)$ has also been used, this theoretical standard deviation being the second in the table in the cases where the two values are not identical.

Since small changes in a percentage have little effect on its theoretical standard deviation, we are fairly well justified in taking the latter, as calculated from the actual percentage in each case, to be the "population" value. Consequently, the difference between the theoretical and actual standard deviations has been expressed in each case as a multiple of the probable error of the theoretical value.

Aside from the last line for crenate-leaved, where there is an obvious artificial reason for high variability, there is no very significant difference except with slender. In this case, the deviation of 5.7 times the probable error (line 1) is probably largely due to the genetic differentiation of "extreme" and "ordinary" parents suggested by their appearance and by the wide difference in the heredity percentages; the differenees become moderate when the progeny of the two classes of parents are separated. 
In the two cases (smooth-leaved and crenate-leaved types) where the pereentages of mutant types differ greatly with good and poor germination, separation aceording to germination gives a mean value of the standard deviation deeidedly lower than the value for all lots taken together. In the case of the large-leaved type there is little ehange, while the considerable reduction with the slender type is probably due to unequal separation of lots from parents genetically different.

Table 40 shows the simple-sampling probability of the most striking differences of heredity percentages, aside from the eharaeteristic differences between different types. "Student's" (1917) table of probabilities of mean deviations with small samples is used, with interpolation by second differences. Where the standard deviation of the difference is required it is found from the theoretical values given in table 39 by the formula (Yule, 1911, pp. 264-265)

$$
\sigma_{\text {difference }}=\sqrt{\sigma_{1}+\sigma_{2}}=\sqrt{\frac{p_{0} q_{0}}{n_{1}-3}+\frac{p_{0} q_{0}}{n_{2}-3}},
$$

when one statistical population is assumed (table 40, columns 2 and 3). When two populations are assumed (table 40, columns 4 and 5 ) the corresponding formula using $p_{1} q_{1}$ and $p_{2} q_{2}$ is employed. In the one ease where this is possible (the seed-size test), it is also calculated from the actual differences of the pairs of percentages in the separate tests, each difference being weighted with the total number of progeny from the parent coneerned. Where two values of $f$ (the $n$ of "Student's" table) are involved, the smaller is taken, giving understatements of the probabilities involved; in the two cases where the difference is more than 2, the values are recalculated, with $f$ as the nearest smaller integer to the geometric mean of the two actual numbers (that is with $f_{0}=\sqrt{f_{1} f_{2}}$ ). In the ease where the probabilities of four deviations all in the same direetion are combined, the four ehances of occurrence are multiplied together; that is, if the $\frac{1}{2}(1+a)$ of "Student's" table is $P$, and $1-P$ is $F$, then $F_{1 \cdot 2 \cdot 3 \cdot 4}=F_{1} \cdot F_{2} \cdot F_{3} \cdot F_{4}$.

"Student" (1908, p. 1) says, "The usual method of determining the probability that the mean of the population lies within a given distanee of the mean of the sample, is to assume a normal distribution about the mean of the sample....' When this is done with a difference of means, it is at once evident that only half of the chances of deviations as great as the distanee of the given difference from zero difference lie below zero differenee; the other half of the chanees of 
such deviations lie in the opposite direction and represent positive differences still greater than the sample difference. In other words, if the implications of a sample difference are to be given full weight, this difference must be considered the most probable value of the theoretical "true" difference between two assumed distinct statistical populations. In the.present case we wish to know the probability that the "true" or theoretical-population means differ in the same sense as the obscrved sample means. This involves calculation of the probability of deviations in one dircetion (beyond zero difference) from the sample differcnce. If the sample difference of means is considercd as positive, then the negative "tail" of the theoretical frequency curve of sample differences (this curve being centered at the observed sample difference) must be compared with the rest of the curve. The positive portion of the curve the $\frac{1}{2}(1+a)^{24}$ of the tables, then gives the chances favoring the hypothesis that the sample means truly represent the population mcans. The odds in favor of the hypothesis are therefore given by the formula

$$
0_{1}=\frac{\frac{1}{2}(1+\alpha)}{\frac{1}{2}(1-\alpha)} \text { or } \frac{\frac{1}{2}+\frac{1}{2} a}{\frac{1}{2}-\frac{1}{2} a} \text {. }
$$

Values calculated from this formula are given in columns 4 and 5 of table 40 .

When other considerations than the sample evidence are to be taken as detcrmining the most probable value of the "true" mean, the case is different. For example, if the probability that our sample percentages are mere sampling deviations from some theoretical Mendelian value were in question, that theoretical value must be taken as the population mean and only the magnitude of the deviations must bc considered.

When a difference of means is considered from this latter standpoint, it is assumed that the two samples come from one statistical population, and henec that zcro is the most probable valuc of the population differcnce. If we choose to assume that the most probable value of the,population difference in our cases is zero, we must calculate the odds against a deviation of the obscrved amount in either direction from zero difference. The formula for these odds is

$$
0_{2}=\frac{\frac{1}{2}(1+a)-\frac{1}{2}(1-a)}{2 \times \frac{1}{2}(1-a)} \text { or } \frac{a}{1-a} \text {. }
$$

24 The whole area of the frequency curve is taken as unity, and $a$ is the area enclosed by any given deviation in both directions from the mean. 
Values from this formula are given in columns 2 and 3 of table 40 ; their magnitude in thrce eases, lowever, and the uniform agreement of the direction of difference with the expectation from biological evidence which has been discussed, weigh heavily in each test against the assumption of random sampling from a single statistical population.

It does not appear necessary, however, thus to weigh the evidence in detail before deciding which formula is suited to the case. There is no evident theoretical value from which these percentages are reasonably likely to be sampling deviations. This being the case, and granting such general possibilities as that of differential viability, it seems most reasonable to use the former $\left(0_{1}\right)$ formula. That is, we should give full weight to the implications of a sample deviation unless there is some definite reason for assuming that some other valuc better represents the mean of the theoretical statistical population.

It must be remembered that the actual probabilities of sampling deviations do not necessarily correspond closely with the probabilities of random sampling. With the material in table 40, however, aside from the germination comparison in the case of the slender type. table 39 suggests a fair agreement with the conditions of random sampling. The actual standard deviations of the subsamples do not in general differ widely from the corresponding theoretical values, and the differences are negative about as often as positive.

The hypothesis of selcetive elimination with poor germination is strongly sustained (table 40), although only one difference (with the crenate typc) has much statistical significance when considered alone. If we may multiply together the members of the four ratios in column 3 of the table, the combined odds (using the $f_{0}$ values) are 130:1 against occurrence of these four deviations as accidents of simple sampling, when magnitude of deviation alone is considered. If direction of deviation alone is considered the random chance of these four deviations all in the same direction is obviously $\left(\frac{1}{2}\right)^{4}$, or the odds favoring the elimination hypothesis are 15:1. Combination. of these two chances indicates a high probability for the hypothesis. When the two-population formula is used in calculating the standard deviation of the difference (columns 4 and 5) the value of $P$ is considerably reduced in some cases, and the combined odds obtained from $F_{1} \cdot F_{2} \cdot F_{3} \cdot F_{4}$ are very high. Evidently the best single expression of the simple-sampling odds, thougl possibly somewhat too high, is the value given last in column 5, or 123,093:1.

With the seed-size test of crenate the odds are $499: 1$ with the thcoretical standard deviation of the difference, or 1666:1 with the 
actual standard deviation. When the relatively small size and weak growth of crenate seedlings are also taken into account, the relatively small average size of crenate embryos may be considered to be demonstrated beyond reasonable doubt.

With "extreme" and "ordinary" slender parents the odds decidedly favor the hypothesis of genetic differentiation of parents, in spite of the small numbers involved. We must remember that definite statistical differentiation of lots of progeny grown under uniform conditions does not necessarily demonstrate genetic differences (differences in output of gametes) between the parents; in this case, however, the difference in the appearance of the parents and in the single-double ratio among the progeny also suggest genetic differentiation.

\section{GENERAL DISCUSSION ${ }^{25}$}

It might be argued with some plausibility that the available evidence hardly justifies conventional factorial analysis, or at least that the data indicate strongly the presence of marked factorial inconstancy. The aberrant types occur in very small proportions among the progeny of selfed Snowflake parents, in much larger proportions from "mutant-type" parents, and in intermediate proportions from crosses with Snowflake. It might be supposed that the Snowflake type has a slight tendency to mutate to the other types, and that these have a much more marked tendency to mutate back to Snowflake. Various considerations, however, especially the occurrence of apparently regular linkage phenomena, seem to favor the general form of hypothesis which has been presented.

As we have seen, it is well known from the behavior of various factors that the typical Mendelian mechanism is present in Matthiola. It cannot be argued here, as sometimes with Oenothera, that the genetic behavior of the genus or species is fundamentally nonMendelian. Since the Mendelian mechanism is demonstrably present. and Muller's (1918) work on beaded wings in Drosophila seems to establish the adequacy of this mechanism in a closely parallel case, surely conventional factorial analysis should be carried as far as possible; in fact (Muller, 1918, p. 423), a Mendelian explanation should not be abandoned for anything short of positively contradictory evidence.

25 Muller's (1918) complete report on the beaded-wing case in Drosophila appeared several months after the present paper had gone to the publisher. Certain conclusions given below, very similar to Muller's but not credited to him, were therefore reached independently. 
In the Drosophila case just mentioned, the "principal" factor for the claracter in question is "dominant for its visible effect and recessive for a lethal effect," so that no pure beaded individuals appear among the progeny of beaded. The original race regularly gave progeny partly heterozygous beaded and partly homozygous normal, while after a long period of selection a true-breeding beaded race appeared. This latter form, it proved, fails to give normals not because of being duplex for beaded-it is still simplex-but because of its possession of another factor, known only by its lethal effect when homozygous, which is carried by the chromosome bearing the normal allelomorph of the factor for beaded. The locus of this recessive lethal factor gives in general about 10 per cent of crossovers with the locus of beaded, but in this case, because of the presence of a factor "which almost entirely prevents crossing over" between the loci of the two lethal factors, viable non-beaded zygotes are very rarely produced. Thus every zygote receiving either two beaded-carrying chromosomes or two non-beaded-earrying chromosomes of the pair concerned fails to develop, and all the insects produced are necessarily heterozygous for both lethal factors.

A point of special interest in this case is the fact that by certain erosses individuals can be produced which give certain types among their progeny in very small percentages. Muller suggests that part at least of the supposed mutants of Oenothera may be due to crossing over between chromosomes carrying lethal factors, by which certain recessive factors are permitted to eome to expression in viable zygotes.

For the inheritance of doubleness of flowers in Matthiola he gives a "balanced-factor" explanation essentially identical with mine (Frost, 1915).

There seems to be little reason to doubt that the differential factors for these aberrant Matthiola types have originated by mutation. On the analogy of Drosophila we might expect that the true mutations would be relatively rare, and that most of the apparent mutants, in cases where they appear frequently, would be due to segregation, appearing as the result of crossing over in chromosomes carrying balanced lethal factors. The evidence seems to indicate, however, that the differential factors for the mutant types at all extensively studied are dominant for their visible effects and usually (probably imperfectly) recessive for a lethal effect, the mutant factors thus being genetically similar to the factor for beaded wings in Drosophila. This would seem to imply the occurrence of certain mutations in pro- 
portions as high as about 1 per cent, and a general mutation coefficient of perhaps 4.5 per cent, while the only Mendelian alternative would seem to be some more complex scheme whose satisfactory formulation might require much more extensive hybridization data.

To be more specific: (1) these types are not single recessives, since they are not homozygous but split into the mutant and "normal" types; (2) they are not simple cases of multiple recessives, as has been proposed by Heribert-Nilsson (1915) for Oenothera mutations, since what is on that hypothesis the full dominant type reappears with selfing; (3) if these types are single dominants, as they appear to be, they cannot (barring the action of inhibiting factors) arise from the pure recessive "normal" or Snowflake type by segregation, but only by immediate mutation; (4) they are not simple cases of complementary dominant factors, since they occur among the progeny of selfed parents.

We might assume that a "mutant" type depends on two pairs of factors, one homozygous and the other heterozygous, while both pairs are heterozygous in the "mutating" Snowflake parent. Thus the crenate type might have the zygotic formula $\frac{D \quad C i}{d \quad c i}$, where $d$ is the factor for double flowers, $C$ a dominant factor for crenate, and $I$ a dominant inhibitor of $C$, all three loci being situated in the same chromosome, at distances of, say, 16 and 4 units apart, in the order indicated. A Snowflake parent producing crenate progeny would then be $\frac{D C I}{d c i}$ or $\frac{D C i}{d c I}$, and crossover combinations would produce the apparently mutant crenate progeny. The crenate progeny would behave as heterozygous dominants when selfed, and if $C C$ zygotes were non-viable would yield constant Snowflake and inconstant crenate; the extracted Snowflake singles, having the composition $\frac{D c i}{d c i}$, could not throw crenate individuals except by true mutation of $c$ to $C$. With selfed Snowflake, if we assume 16 per cent and 4 per cent of crossing over in the two positions, and a 60-per-cent selective elimination of crenate zygotes, all $C C$ zygotes being non-viable, substantially the observed percentages of crenate singles and doubles result. ${ }^{28}$

\footnotetext{
26 See page 125, footnote. This scheme agrees fairly well with the results from crossing, and gives almost exactly the observed proportion of total doubles (a little over 53 per cent) for selfed Snowflake. Its adequate presentation must be reserved for a later paper.
} 
Formerly (Frost, 1916) the hypothesis of frequent dominant mutations seemed the more probable, but there is apparently nonconformable evidence. It is true that the peculiar behavior of the slender type might conccivably depend on an occasional mutation in another locus, or an exchange (Shull, 1914) or duplication of loci, giving two similar or identical factors for slender. An apparently fatal objection, however, is the fact that the supposed mutants scem to show linkage with singleness or doubleness at their origin from Snowflake as well as in subsequent generations-a fact which strongly suggests segregation in the former case.

If the apparent mutants are really due to segregation complicated by lethal action, the origin of the complex heterozygosis indicated for Snowflake is doubtful; it may be due to hybridization, but more probably to a gradual accumulation of mutant factors in balancedlethal combinations. On the analogy of Muller's Drosophila case, especially, it might be expected that the latter would be the true explanation, particularly since self fertilization seems to be the rule in Matthiola. On this basis the term mutant type is used with some confidence in this paper, while the aberrant individuals have been called apparent mutants.

We must not forget that some of the mutant types may arise, as with Oenothera gigas and $O$. lata, by non-disjunction, or reduplication of chromosomes, and that this fact may determine their lieredity. This is not to be expected with the types whose factors show apparent coupling with singleness or doubleness, but it might be true of the apparently unlinked smooth-leaved type. A preliminary study of several types shows that the usual somatic number of chromosomes is probably fourteen, but that positive counts are difficult. While it might be very hard to demonstrate the regular presence of one extra chromosome in an individual or a type, it should be easy to decide between the diploid and triploid numbers. The large-leaved type is so strongly suggestive of $O$. gigas that it would not be surprising to find the triploid number in the material now on hand for examination.

In a preliminary paper on these types the writer (Frost, 1916) discussed some possible relations of mutation, heterozygosis, and partial sterility, with special reference to Oenothera, mentioning the possibility that special prevalence of heterozygosis in the genus may be, "in large part, a result rather than a cause of mutation." This suggestion is evidently justified even if much of the supposed mutation of Oenothera is really segregation, since it is highly probable that 
the peculiar phenomena depend on lethal factors or combinations of factors originally due to mutation.

Another possibility there mentioned, advanced by Belling (1914) and since specially discussed by Goodspeed and Clausen (1917), is that of the occurrence of lethal combinations of certain factors which in other combinations may be in no way prejudicial to normal development. As the latter paper shows, it is probable that in certain crosses between "good species" most of the new combinations brought together in the formation of $F_{1}$ gametes are incompatible with the production of functional gametes. Perhaps in the case of Oenothera there may exist within a species factors lethal in any combination when homozygous, and other factors lethal only in certain combinations.

A balanced-factor explanation for the inheritance of doubleness ${ }^{27}$ in Matthiola, a case which Muller (1918) discusses, seems to have been first definitely stated by Goldschmidt (1913), though he failed to provide for one feature of the evidence, the deviation of the heredity ratio from 50 per cent. As has been shown (Frost, 1915), this peculiarity may be due to greater viability of the homozygotes (sterile doubles) during embryonic development, since the doubles are more viable in the mature seeds and more vigorous in later development (Saunders, 1915). In this case the "normal" factor is completely eliminated in favor of the mutant (sterile-double) factor in the formation of the sperms, and probably is partially eliminated in the formation of either the eggs or the embryos or both.

Here the normal singleness (sporophyll) factor $D$ may act as a lethal in the heterozygous parent, possibly from its general relations of growth vigor in the presence of the more vigorous $d$-carrying cells. If the lethal factor is situated in a distinct locus, evidently crossovers are at most extremely rare. It is true that Miss Saunders (1911) finds that $F_{1}$ hybrids with pure single forms produce functional single-carrying pollen; with the pure single forms from which the original "double-throwing" mutants arose, however, this might not be true, or a lethal change may have occurred in the singleness factor itself rather than in a factor coupled with it. The Drosophila case would suggest a lethal change in another locus of the single-carrying chromosome.

In my paper of 1915 this lethal change in one chromosome apparently accompanying the mutation of $D$ to $d$ in the homologous

27 For a brief outline of the genetic behavior of doubleness see the discussion of the experimental data for the smooth-leaved type. 
chromosome was considered puzzling. Evidently, however, it may have occurred in one chromosome before $D$ mutated to $d$ in the other, and even then may have produced its lethal effect. It is evident that if doubleness should arise in the absence of the lethal effect it would tend to be eliminated by the return of one-third of the singles to the homozygous condition in each generation. In fact, it is possible that the lethal change arose later than doubleness, as in the Drosophila case, or was brought in later by cross pollination, and happened to be preserved as a result of horticultural selcetion for a high proportion of doubles.

A parallel-column comparison between the double type and the types especially discussed above has already. been given, in connection with the smooth-leaved type. It will now be seen that this comparison scems to apply to all mutant types, except early, that have been genetically tested, the principal differences between these types relating to the heredity percentage and the apparent presence or absence of linkage with the single-double factors.

From the standpoint of its relation to genetic analysis the doubleness factor is remarkably similar to the sex factor in animals. There are two types in each generation, one heterozygous and the other evidently homozygous, and these types are produced by the fertilization of two kinds of eggs, produced in equal or nearly equal numbers, by a single kind of sperm. Although one of the somatic types is sterile, and the uniformity of the sperms produced by the other is due (evidently) to lethal action, the opportunity for chromosome analysis is similar to that with sex chromosomes.

We may say that the doubleness factor and its normal allelomorph ( $d$ and $D$ ) are carried by chromosome pair I. Already we know several other pairs of factors evidently carried by this pair of chromosomes. These are, to name only the mutant or possibly mutant member of each pair of factors: $P$ (pale sap color) and $W$ (colorless plastids), both studied by Miss Saunders $(1911,1911 a)$; $C$ (erenateleaved), $S$ (slender; possibly two factors), and $N$ (narrow-leaved). As we have seen, the last three of these are probably lethal when homozygous, and one or more unidentified lethal factors may be concerned in the breeding results, while the doubleness factor affects the race much like a recessive lethal, since all $d d$ individuals are completely sterile. 


\section{SUMMARY}

This paper deseribes the oceurrenee, eharaeteristies, and heredity of eertain aberrant plant types which deeidedly resemble some of the "mutant" types produeed by Oenothera lamarckiana. The parent form is Matthiola annua Sweet, of the hortieultural variety "Snowflake."

These aberrant forms may be ealled mutant types, sinee it is highly probable that they are originally produeed by mutation. The aberrant individuals may be termed apparent mutants, sinee it may be eonsidered uneertain whether they usually-arise by immediate mutation or by segregation. The ease aequires speeial signifieanee beeause individuals belonging to the mutant types, although the speeies is known to be typieally Mendelian with respect to various eharaeters, give erratie heredity ratios suggestive of Oenothera.

At least eight types have been somewhat earefully studied, and six of these have shown their heritability in progeny tests. Several other types have been named, but for various reasons their distinetness is more or less doubtful.

Some of the eommoner types have each been produced by many parents, and in several pure lines isolated from the original eommereial variety. The apparent mutants other than the early type compose about four or five per eent of the progeny of Snowflake and early parents, the separate types ranging down from about one per eent.

Most of the mutant types are in general inferior to Snowflake in vigor, and the differenee in development is greatly inereased by eertain unfavorable environmental eonditions. The proportion of apparent mutants in eultures from Snowflake parents appears to be definitely lower where germination is eomparatively poor.

The mutant types differ from Snowflake and from each other in various respeets. The early type is praetieally a smaller and earlier Snowflake. The other mutant types, on the other hand, differ marliedly from Snowflake in vigor, fertility, and various form and size eharaeters. Each type is named from some eonspieuous eharaeteristic difference from Snowflake, but usually various other differenees ean readily be found.

Somewliat extensive progeny tests have been made for five of the mutant types, and a little evidenee seeured for two or three other types. 
The carly type is probably due to a single dominant mutant factor segregating normally from the corresponding Snowflake factor; the quantitative nature of its differences from Snowflake, however, makes positive determination of this point a matter of great difficulty.

At least five other types plainly reproduce themselves, but about 50 to 70 per cent of the progeny are usually Snowflake; no trucbreeding individual of any generation of any of these types has yet been tested. Genetic work with most of these types has been much hampered or even prevented by low vigor and fecundity, and the aggregate data from progeny of parents of four types strongly indicate selective viability at germination. It has been determined by crossing that in three of the types the mutant factor (or factors) is carried both by eggs and by sperms. From these facts it seems probable that homozygotes of the mutant types arc non-viable, and that severe selective elimination occurs during embryonic development; or, in other words, that the mutant factor is imperfectly recessive for a lethal effect.

In three types there appears to be linkage with the factor pair for singleness and doubleness of flowers, the mutant factor being coupled with singleness in the tested apparent mutants of two types, and with doubleness in the third type. With two other types these factors seem to be independent. No reversal of coupling has been found in later generations of the former two types, but on the scheme presented crossover singles should be scarce.

For one type (crenatc-leaved) a hypothesis based on the facts stated gives very closely the ratio obtained from selfed parents. Reciprocal crosses with Snowflake conform less closely to the requirements of the hypothesis, but do not definitely contradict it. The slender type, which shows similar apparent linkage, seems to disagree definitely with the hypothesis; there is strong evidence, however, that slender individuals may differ genetically among themselves.

A more complex scheme providing also for the usual origin of these types from Snowflake by segregation is briefly outlined.

The selfing ratios are very suggestive of duplication of a chromosome (non-disjunction), as in Oenothera lata, but it is hard to reconcile the cases of apparent linkage with this hypothesis. It seems probable that these three linked types have originated and are transmitted in the same general way as the double-flowered type, and that all of these four mutant factors (including double) represent changes of some sort within a chromosome of the same pair, which may be 
numbered I. Miss Saunder's work shows that two flower-color factors also belong to this linked group.

The large-leaved type strikingly resembles Oenothera gigas, and it may prove to be triploid in nuclear constitution. In that case segregation may be irregular and genotypically intermediate individuals may be more or less frequently produced.

It is probable that further study of these types will help to explain the remarkable genetic hehavior of Oenothera and of Citrus.

\section{LITERATURE CITED*}

AtKinson, George F.

1917. Quadruple hybrids in the $F_{1}$ generation from Oenothera nutans and Oenothera pycnocarpa, with $\mathbf{F}_{2}$ generations and back- and intercrosses. Geneties, vol. 2, pp. 213-260, 11 tables, 1 diagr., 15 figs.

Babcock, ERNest B.

1918. The rôle of factor mutations in evolution. Am. Naturalist, vol. 52, pp. 116-128.

BARTLETT, I. H.

1917. Mutation in Matthiola annua, a "Mendelizing"' species. [A review of paper of same title by H. B. Frost.] Bot. Gaz., vol. 63, pp. 82-83.

Bateson, Wlliam, and Saunders, Edith R.

1902. Experimental studies in the physiology of heredity. I. Experiments with plants. Matthiola. III. Discussion. Roy. Soc. London, Reports to the Evolution Committee, vol. 1, pp. 32-87, 125-160, 15 tables.

Bateson William, Saunders, Edith R., and Punnett, Reginald C.

1905. Experimental studies in the physiology of heredity. Matthiola. Roy. Soc. London, Reports to the Evolution Committee, rol. 2, pp. 5-44, tables.

1906. Ibid. Stocks. Ibid., vol. 3, pp. 38-53, 4 tables, 2 figs.

Bateson, William, Saunders, Edith R., Punnett, Reginald C., and Killby (Miss) H. B.

1908. Experimental studies in the physiology of heredity. Stocks. Roy. Soc. London, Reports to the Evolution Committee, vol. 4, pp. 35-40, 3 tables.

Belling, John.

1914. The mode of inheritance of semi-sterility in the offspring of certain hybrid plants. Zeitschr. f. indukt. Abstam.- u. Vererbungsl., vol. 12, pp. 303-342, tables, 17 figs.

Blakeslee, Albert F., ANd Avery, B. T. Jr.

1919. Mutations in the jimson weed. Jour. Heredity, vol. 10, pp. 111-120, 11 figs.

* An asterisk prefixed to the date indicates that the paper cited has not been seen by the present writer. 
Correns, Carl E.

1900. Uber Levkojenbastarde. Zur Kenntniss der Grenzen der Mendel'sehen Regeln. Bot. Centralbl., vol. 84, pp. 97-113.

1902. Scheinbarc Ausnahme von der Mendel'schen Spaltungsregel für Bastarde. Deutsch. bot. Ges., Ber., vol. 20, pp. 159-172, 4 tables.

Davis, Bradley, M.

1917. A criticism of the evidence for the mutation theory of de Vries from the behavior of species of Oenothera in crosses and in selfed lines. Nat. Acad. Sci., Proc., vol. 3, pp. 705-710.

Frost, Howard B.

1911. Variation as related to the temperature environment. Am. Brecders' Assoc., Ann. Rept., vol. 6, pp. 384-395, 4 tables, 4 charts.

1912. The origin of an early variety of Matthiola by mutation. Ibid., vol. 8 , pp. 536-545, 5 tables.

1915. The inheritance of doubleness in Matthiola and Pctunia. I. The hypotheses. Am. Naturalist, vol. 49, pp. 623-636, 1 fig., 2 diagr.

1916. Mutation in Matthiola annua, a "Mendelizing" species. Am. Jour. Bot., vol. 7 , pp. 37 $7-383,3$ figs.

1917. A method of numbering plants in pedigree cultures. Am. Naturalist, vol. $51, \mathrm{pp} .429-43 \%$.

Gates, R. Ruggles.

1915. The mutation factor in evolution. London, Macmillan, xiv $+353 \mathrm{pp}$., 1 map, 114 figs., bibl.

GoLDSCHMIDT, RICHARD.

1913. Der Vererbungsmodus der gefüllten Lerkojenrassen als Fall geschlechtsbegrenzter Vererbung? Zeitschr. f. indukt. Abstam.- u. Vererbungsl., vol. 10, pp. 74-98, diagr.

1916. Nochmals über die Merogonie der Oenotherabastarde. Genetics, vol. 1, pl. 348-353, 1 pl.

Goodspeed, Thonas H., and Clausen, R. E.

1917. Mendelian-factor differences versus reaction-system contrasts in heredity. Am. Naturalist, vol. 51, pp. 31-46, 92-101.

\section{HERIBERT-NILSSON, N.}

*1915. Die Spaltungserscheinungen der Ocnothera lamarcliana. Lunds Univ. Årsskrift, vol. 12, pp. 4-131. (Review by Ben C. Helmick in Bot. Gaz., vol. 63, 1917, pp. 81-82.)

Muller, Hermann J.

1917. An Oenothera-like case in Drosophila. Nat. Acad. Sci., Proc., vol. 3, pp. 619-626.

1918. Genetic variability, twin hybrids and constant hybrids, in a case of balanced lethal factors. Genetics, vol. 3, pp. 422-499', 1 table, 1 fig., 1 diagr.

SAUNDERS, EDITH R.

1911. Further experiments on the inheritance of doubleness and other characters in stocks. Jour. Genetics, vol. 1, pp. 303-376, 8 tables.

1911a. The breeding of double flowers. Fourth Intern. Conf. on Genetics, Proc., pp. 397-405, diagr.

"1913. Double flowers. Roy. Hort. Soc., Jour., vol. 38, pt. 3, pp. 469-482. 
1913a. On the mode of inheritance of certain characters in double-throwing stocks. A reply. Zeitschr. f. indukt. Abstam.- u. Vererbungsl., vol. 10, pp. 297-310.

1915. A suggested explanation of the abnormally high records of doubles quoted by growers of stocks (Matthiola). Jour. Genetics, vol. 5, pp. 137-143, 3 tables.

1916. On selective partial sterility as an explanation of the behavior of the double-throwing stock and the petunia. Am. Naturalist, vol. 50, pp. 486-498.

SHULL, GEORGE H.

1914. Duplicate genes for capsule form in Bursa bursa-pastoris. Zeitschr. f. indukt. Abstam.- u. Vererbungsl., vol. 12, pp. 97-149, 5 tables, 7 figs.

"STudent."

1908. The probable error of a mean. Biometrika, vol. 6, pp. 1-25, tables, 4 diagr.

1917. Tables for estimating the probability that the mean of a unique series of observations lies between - $\sim$ and any given distance of the mean of the population from which the sample is drawn. Ibid., vol. 11, pp. 414-417, tables.

SWingre, WaLter T.

1911. Variation in first-generation hybrids (imperfect dominance): its possible explanation through zygotaxis. Fourth Intern. Conf. on Genetics, Proc., pp. 381-393, 10 figs.

TSChermak, Erich von.

*1904. Weitere Kreuzungsstudien an Erbsen, Levkojen u. Bohnen. Zeitschr. f. d. landw. Versuchswesen in Oesterreich, 1904, pp. 533-638.

1912. Bastardierungsversuche an Erbsen, Levkojen, und Bohnen mit Rücksicht auf die Faktorenlehre. Zeitschr. f. indukt. Abstam.- u. Vererbungsl., vol. 7, pp. 81-234, tables.

Webber, Herbert J.

1906. Pedigree records used in the plant-breeding work of the Department of Agriculture, in L. H. Bailey, Plant Breeding (New York, Macmillan), pp. 308-319.

de Vries, Hugo.

1906. Species and varieties: their origin by mutation. Ed. 2, Chicago, Open Court Pub. Co., xviii +847 pages.

1918. Twin hybrids of Oenothera hookeri T. and G. Genetics, vol. 3, pp. 39i421, 14 tables.

1919. Oenothera rubrinervis, a half mutant. Bot. Gaz., vol. 67, pp. 1-26, tables.

YULE, G. UdNY.

1911. An introduction to the theory of statistics. London, Charles Griffin \& Co., xiii $+3 \pi 6$ pages, 53 figs. 


\section{PLATE 22}

THE EARLY TYPE

Fig. 1. March 20, 1908. The single progeny of WG9. Plants from house M to the reader's left from stake, from house W to right of stake, from house C below. WG9-C10, the early apparent mutant, is the middle plant in the lower row. The stake indicates inches.

Fig. 2. About May 1, 1908. WVG9-C10 at the left, WG9-C9 (Snowflake) at the right. 


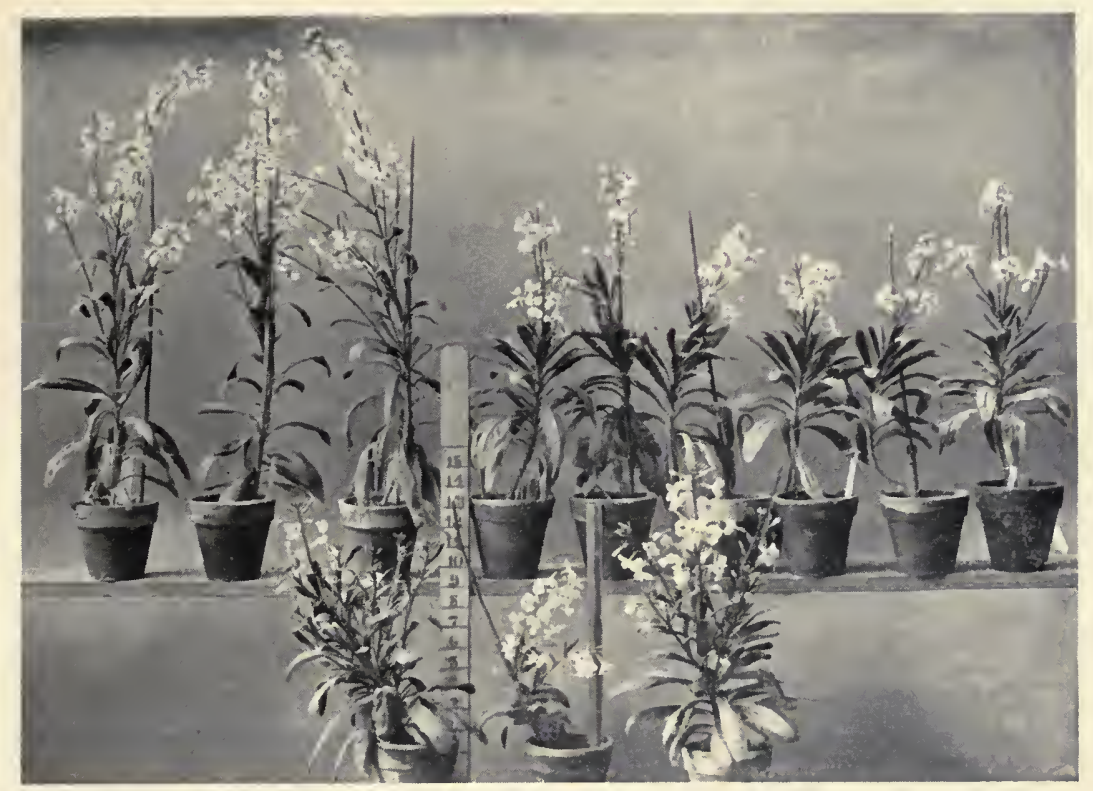

Fig. 1

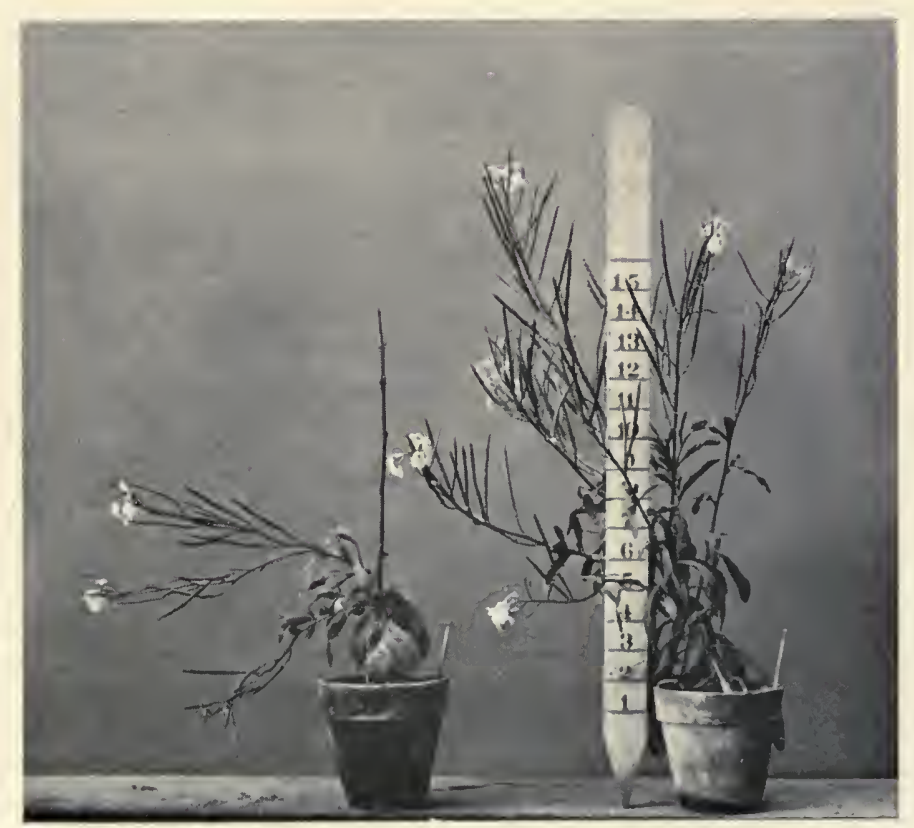

Fig. 2

[FROST] PLATE 22 

-

$=$ 
PLATE 23

The EARLy TyPe

Fig. 3. April 8, 1909. The single progeny of WG9-C9 (Snowflake); arrangement as in figure 1.

Fig. 4. April 9, 1909. The single progeny of WG9-C10 (heterozygous early). Warm-house plants partly at right of stake in lower row; arrangement otherwise as in figure 3. Compare with figure 3, house by house. 


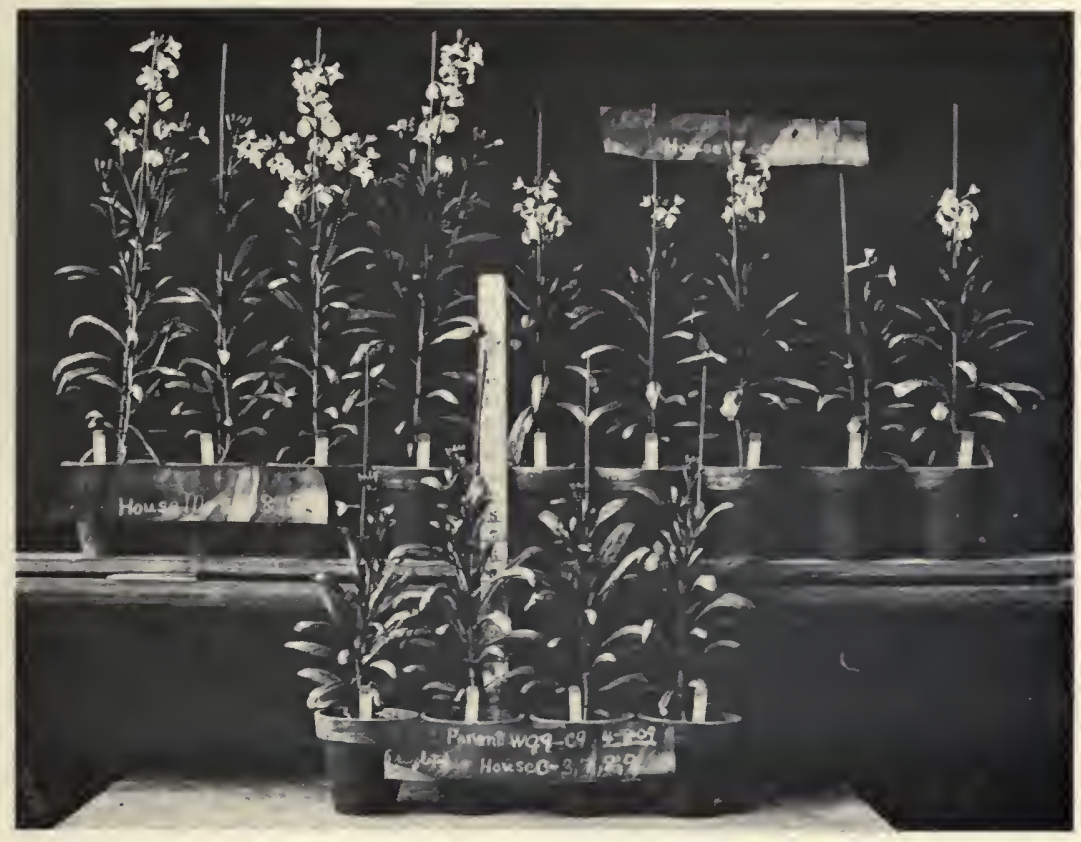

Fig. 3

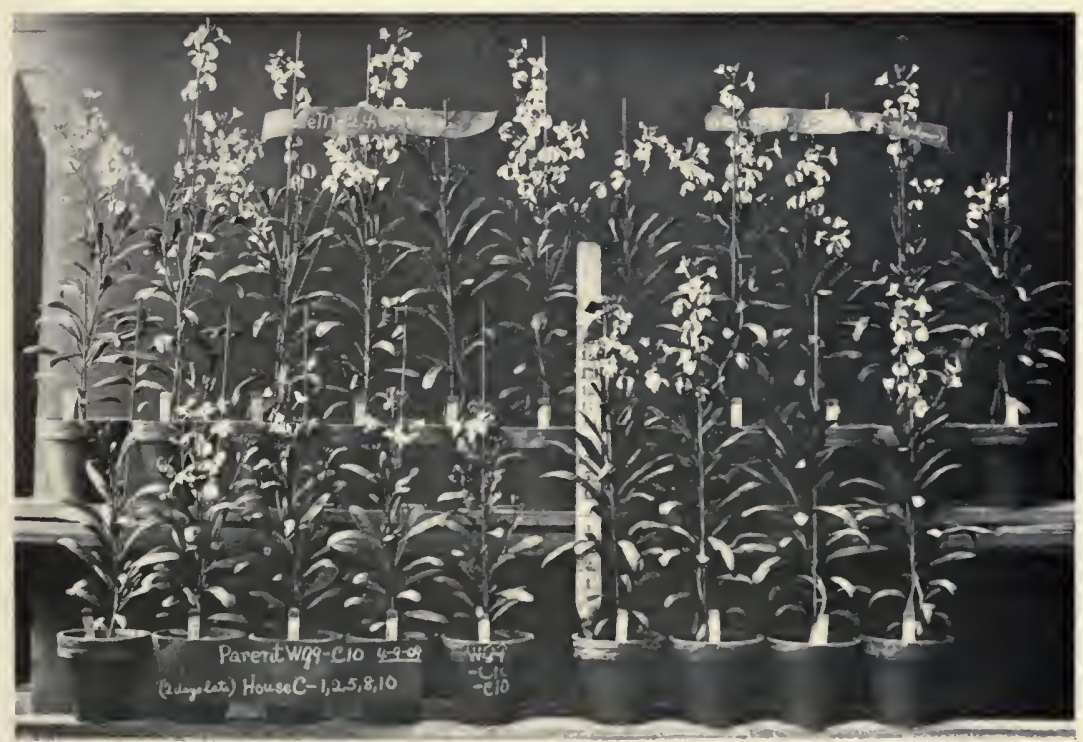

Fig. 4 


PLATE 24

THE EARLy TyPE

Fig. 5. July 19, 1911. Lots 1 to 10 , with lots 11 to 14 mostly in sight at the right. Odd-numbered lot in nearer (west) half of each row.

Fig. 6. July 19,1911 . Lots 19 to 28 , with lots 15 to 18 mostly in sight at the left. 


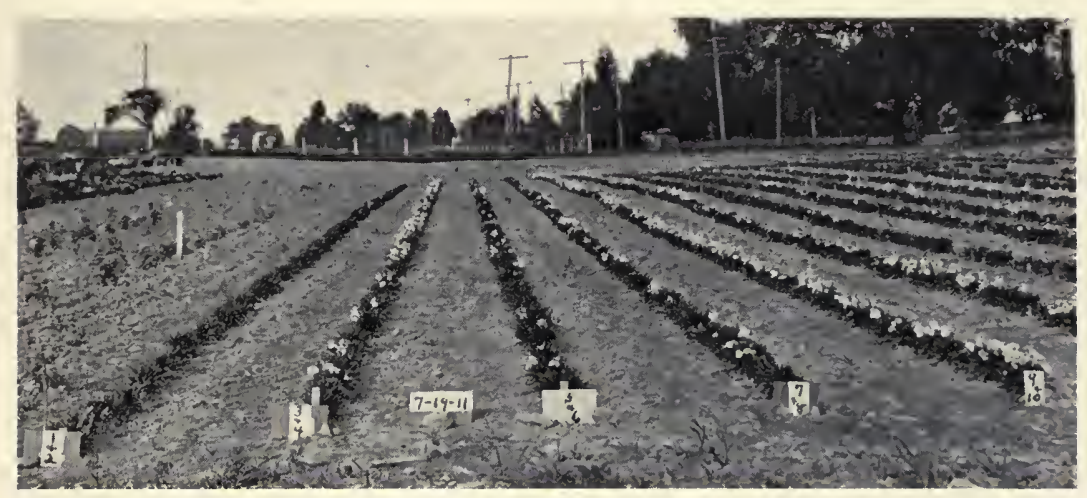

Fig. 5

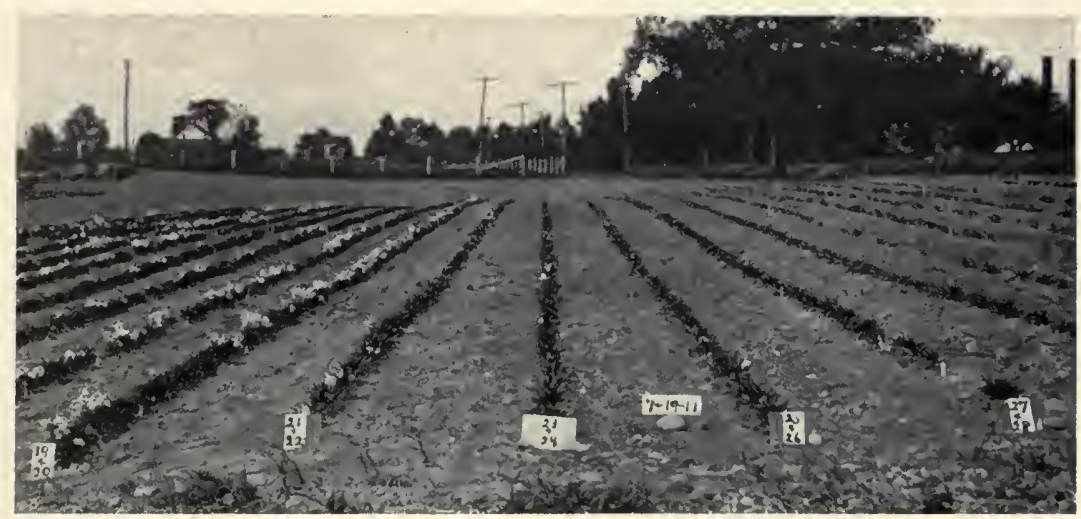

Fig. 6

[FROST] PLATE 24 




\section{PLATE 25}

\section{The SMooth-Leaved TyPe}

Fig. 7. April 27, 1909. Smooth-leaved apparent mutants. Compare with figures 3 and 4 as to earliness, noting the difference in date.

Fig. 8. May 29, 1914. Progeny of a smooth-leaved parent. Plant at right Snowflake single, the others smooth. 


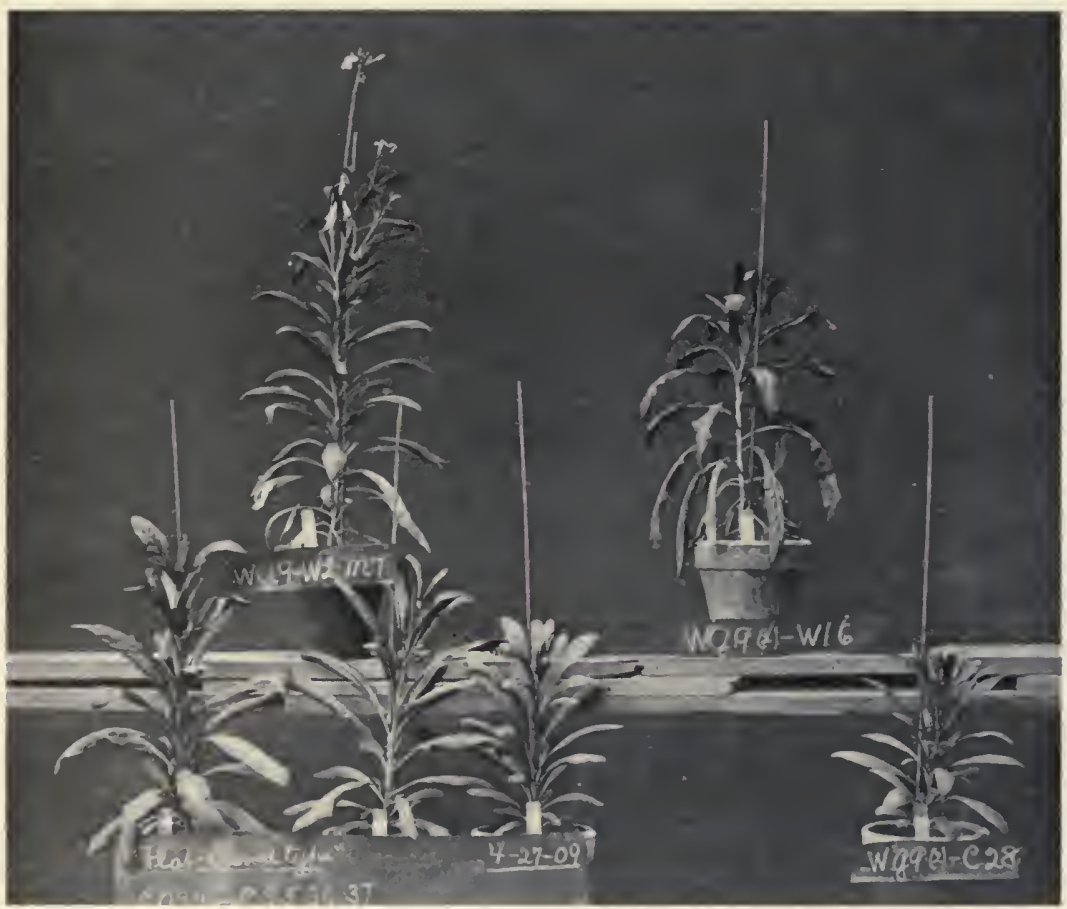

Fig. 7

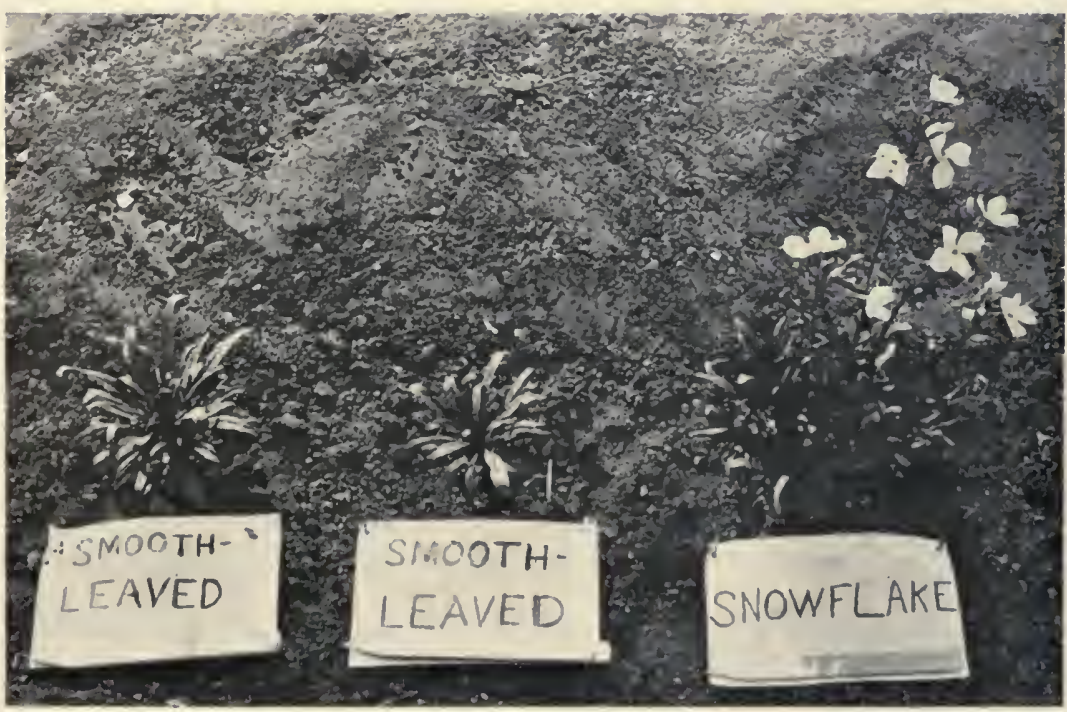

Fig. 8 

$$
\text { . }
$$ 


\section{PLATE 26}

THE SMOOTH-LEAVEd TYPE

Fig. 9. June 28, 1915. Progeny of a smooth-leaved parent. Smooth single at left, Snowflake double at right.

Fig. 10. Same date and parent as with figure 9. From left to right: Snowflake double (also shown in figure 9), Snowflake single, smooth double. 


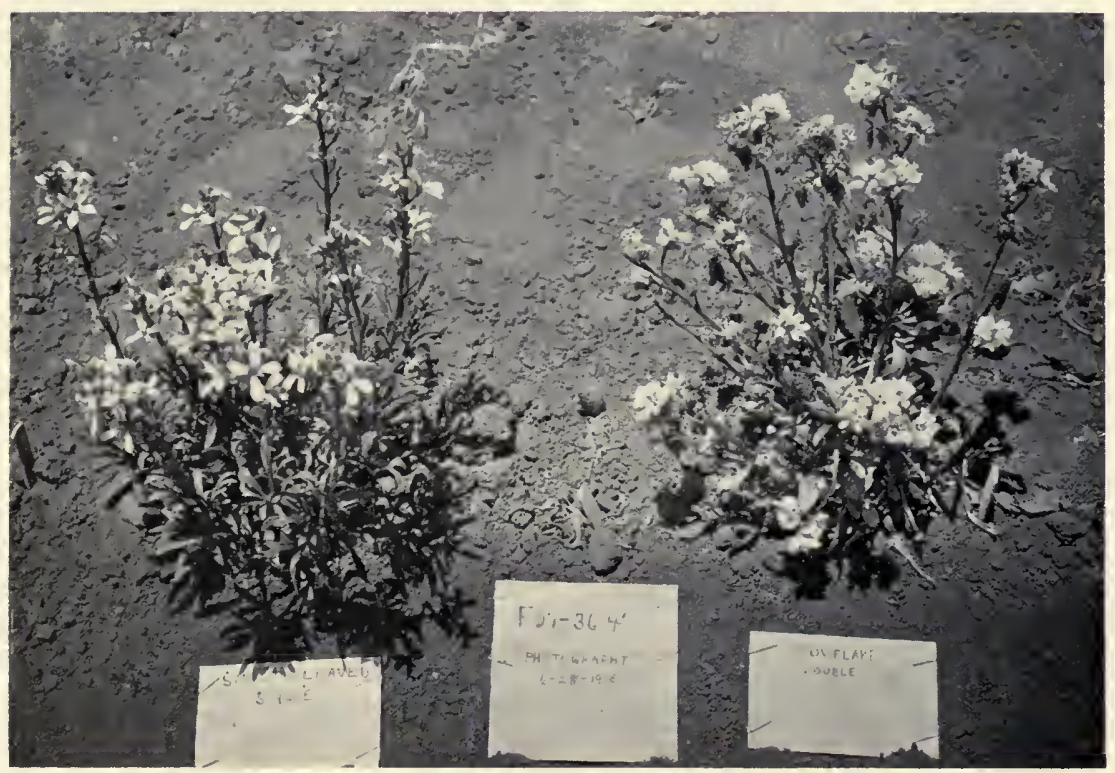

Fig. 9

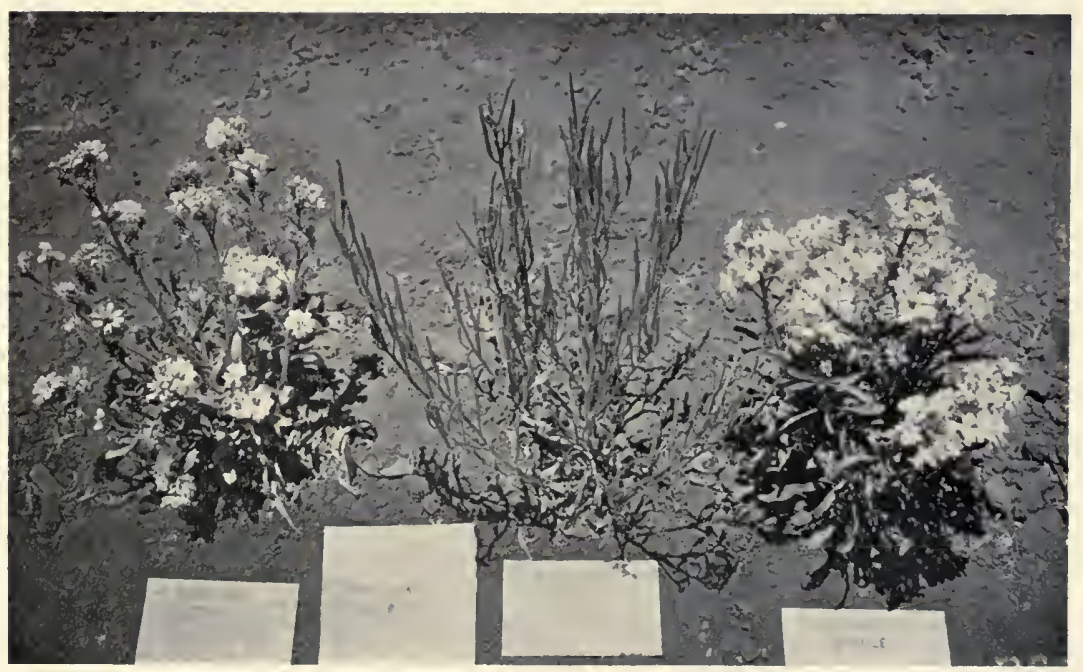

Fig. 10 




\section{PLATE 27}

\section{The Large-Leaved TyPe}

Fig. 11. August 29, 1914. Progeny of a large-leaved parent (28a), near the close of the hot Riverside summer. From left to right: large single, large double, Snowflake single (two, the first injured by aphids). 


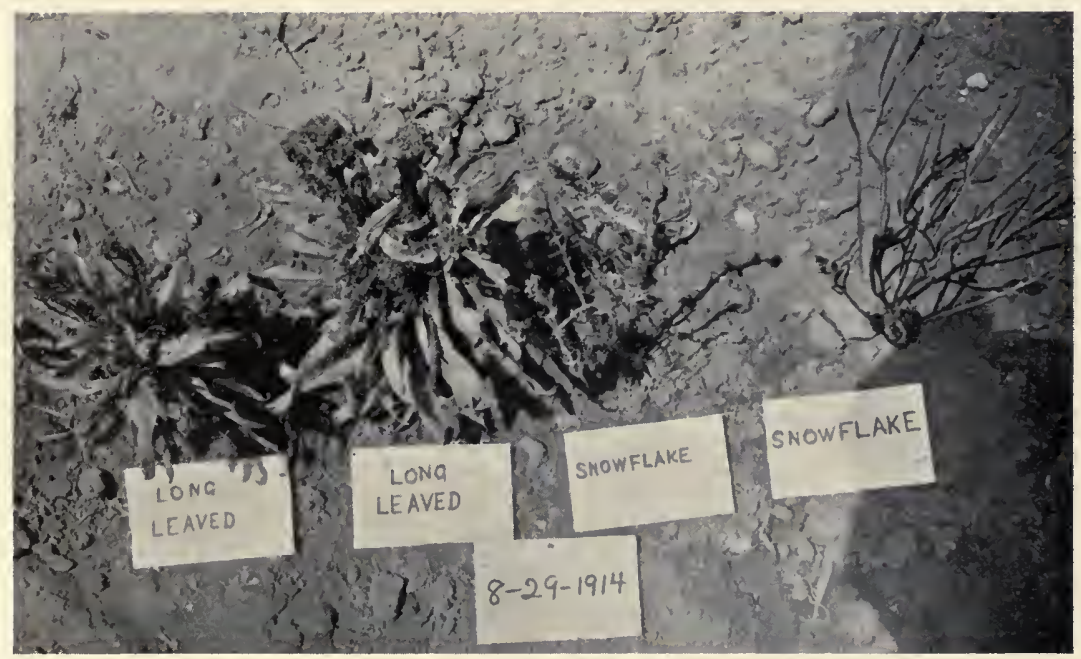

Fig. 11

[FROST] PLATE 27 




\section{PLATE 28}

\section{The LARge-LeAVED TyPe}

Fig. 12. July 8, 1916. Progeny of a large-leaved parent. Middle plant Snowflake; the rest large; all single.

Fig. 13. July 8, 1916. Progeny of a large-leaved parent, more than a month older than those shown in figure 12. From left to right: large double, Snow. flake double, large single. 


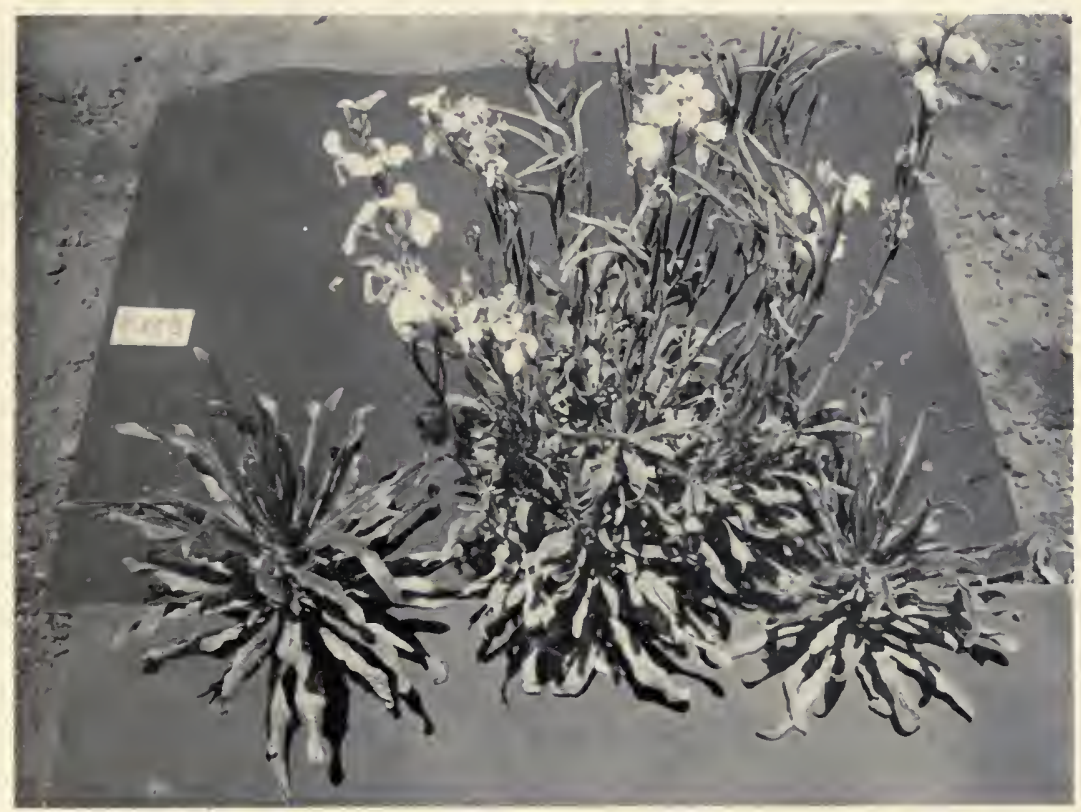

Fig. 12

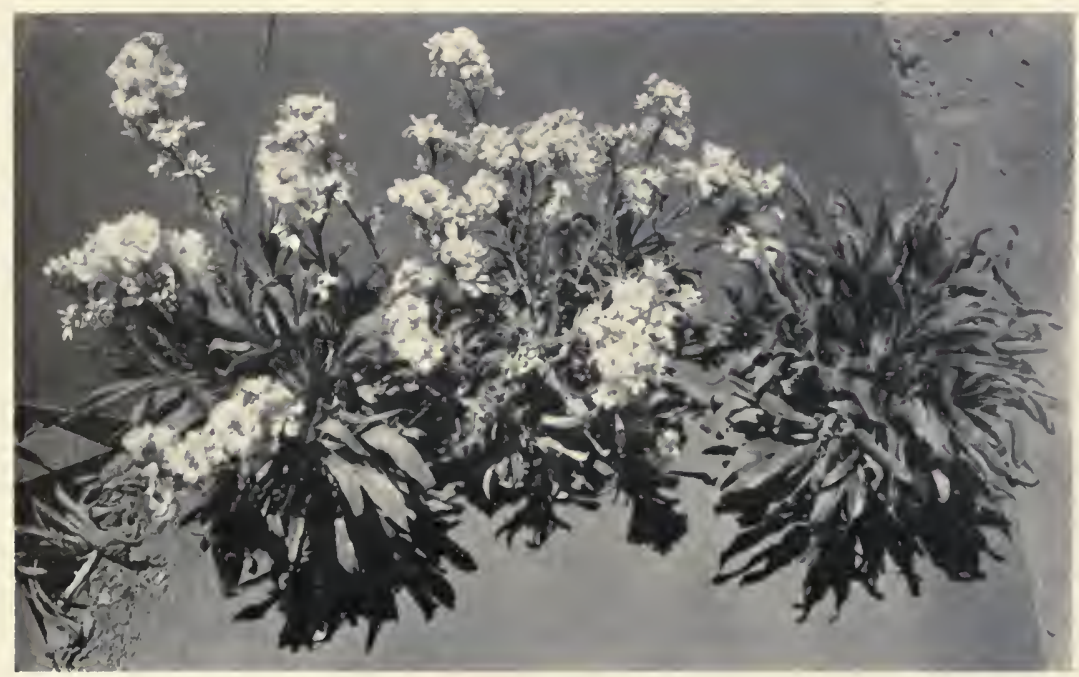

Fig. 13 




\section{PLATE 29}

\section{The CRENate-LEaved TyPe}

Fig. 14. April 6, 1909. Crenate-leaved apparent mutants. Note the variation in leaf serration, and especially the slightness of the serration (or crenation) with the one cool-house plant (below).

Fig. 15. April 14, 1911. Progeny of a crenate-leaved parent, grown in a cool greenhouse. The first two plants at the right are Snowflake, the rest erenate. 


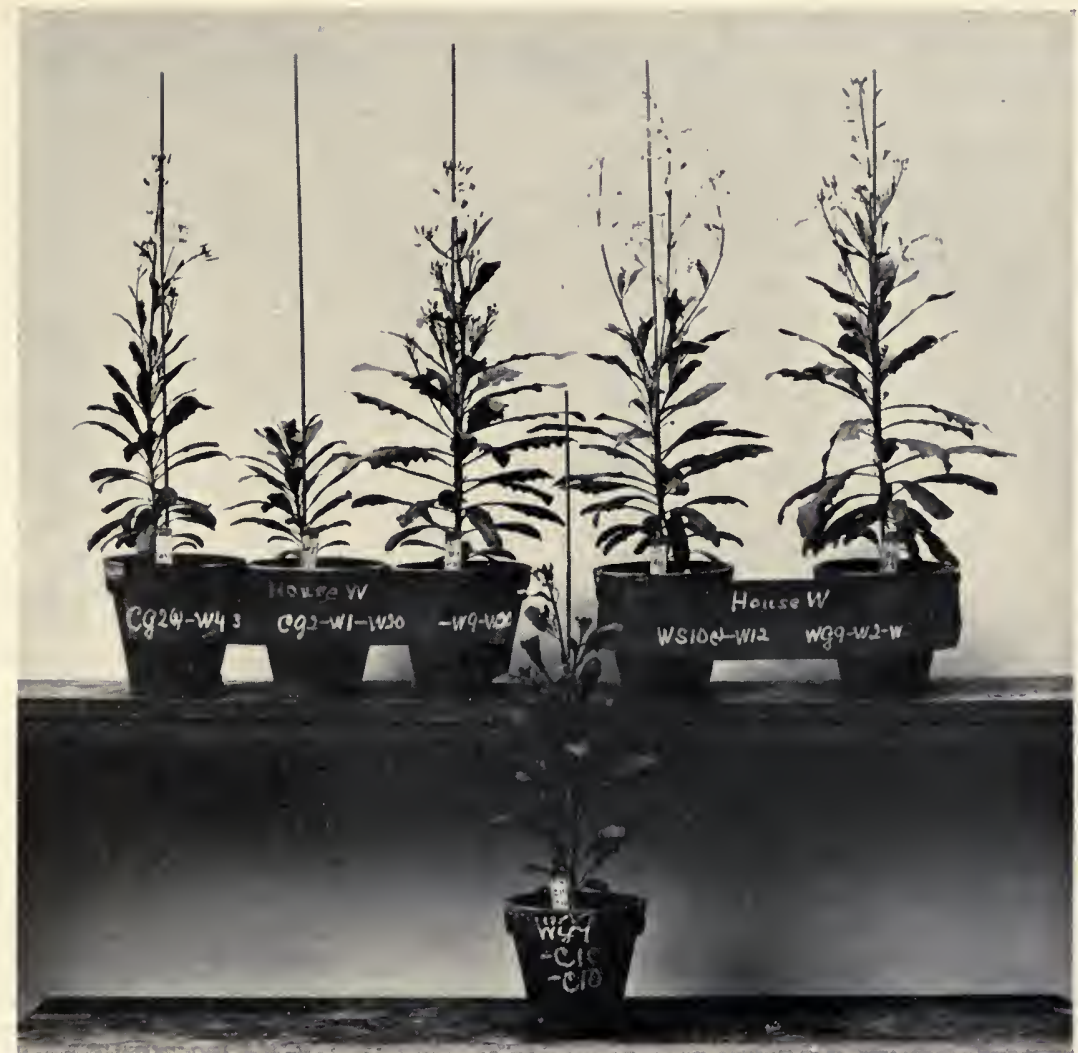

Fig. 14

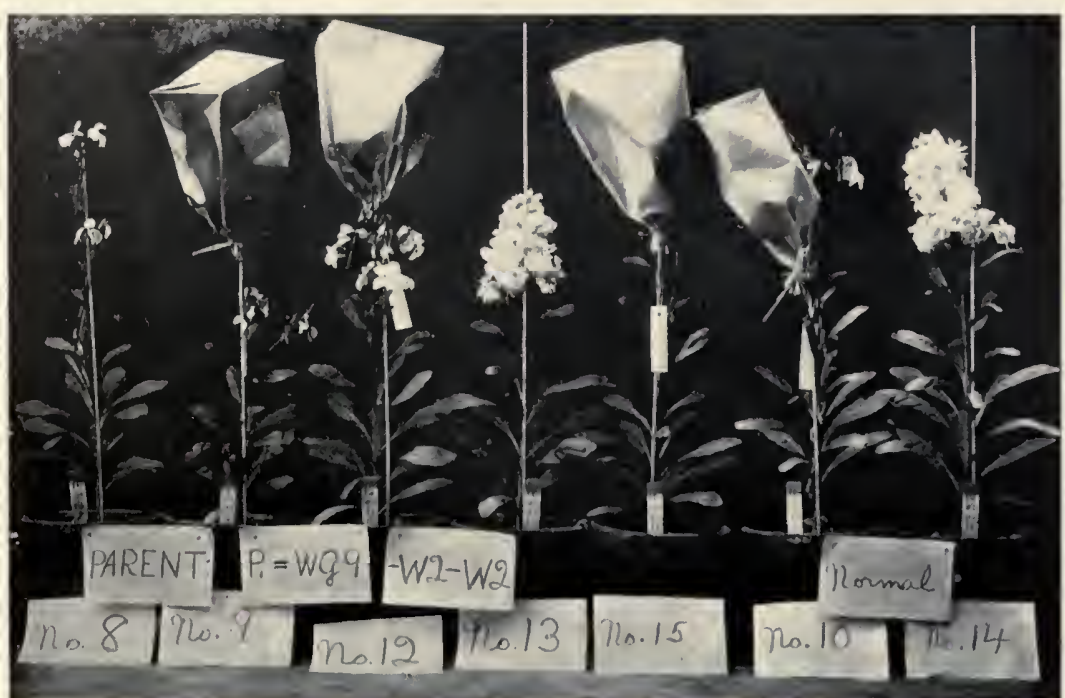

Fig. 15

[FROST] PLATE 29 


PLATE 30

The Crenate-I.f.aved TyPe

Fig. 16. July 8, 1916. Progeny of a crenate-leaved parent. From left to right: crenate single (two), crenate double, Snowflake double.

Fig. 17. July S, 1916. Snowflake $X$ crenate-leaved, $F_{1}$. From left to right: smooth, Snowflake single, crenate double (two). 


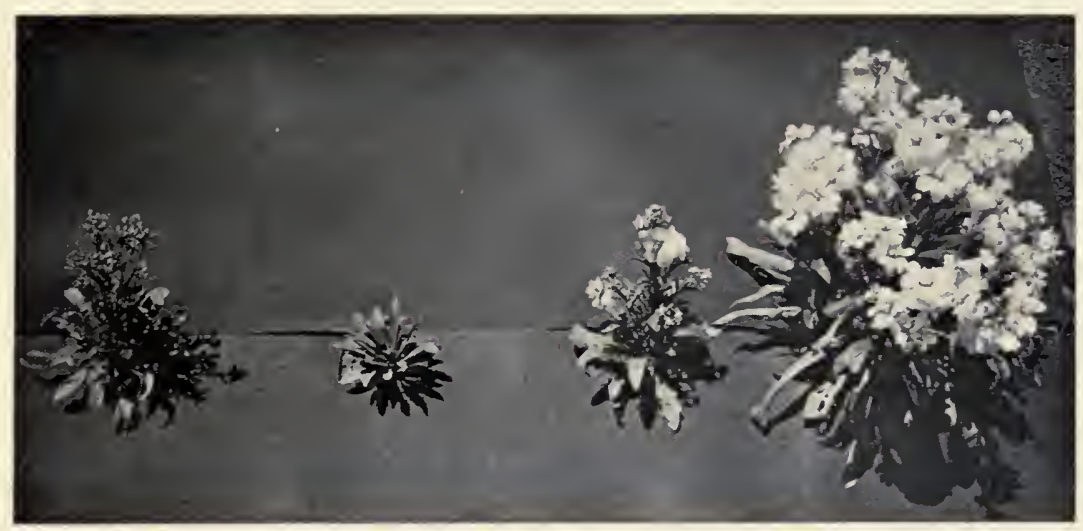

Fig. 16

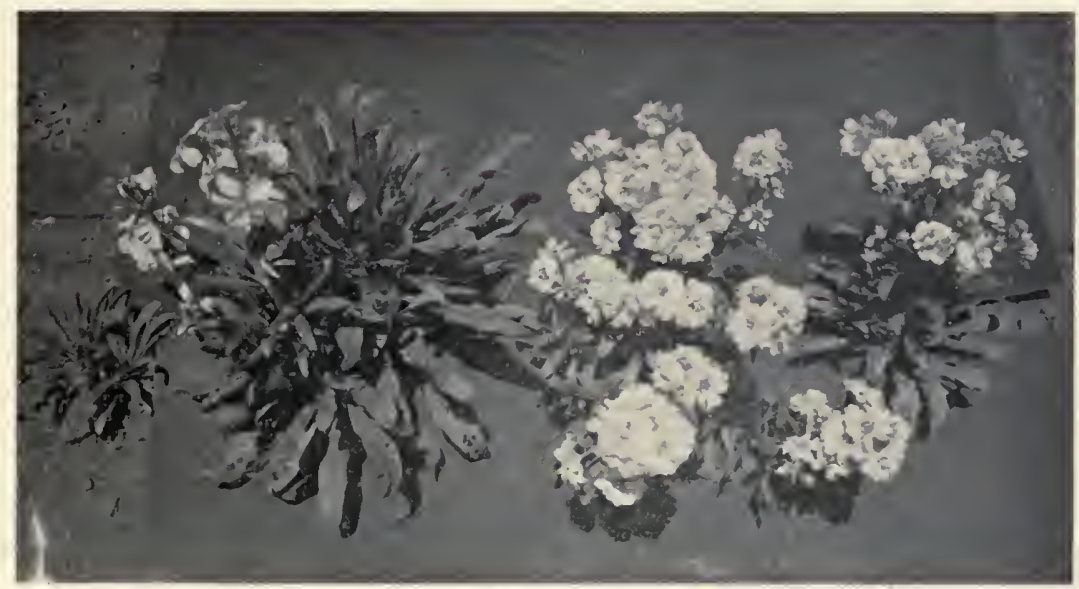

Fig. 17

[FROST I PLATE 30 




\section{PLATE 31}

\section{The Slender Type}

Fig. 18. April 27, 1909. Miscellaneous aberrant individuals, with two typical Snowflake plants (third from the left above, second from the left below). In upper row: second from left, narrow double; second from right, slender double. In lower row at left, slender single (25b).

Fig. 19. April 14, 1911. Progeny of a slender parent (25b). Two at the right Snowflake, the rest slender. 


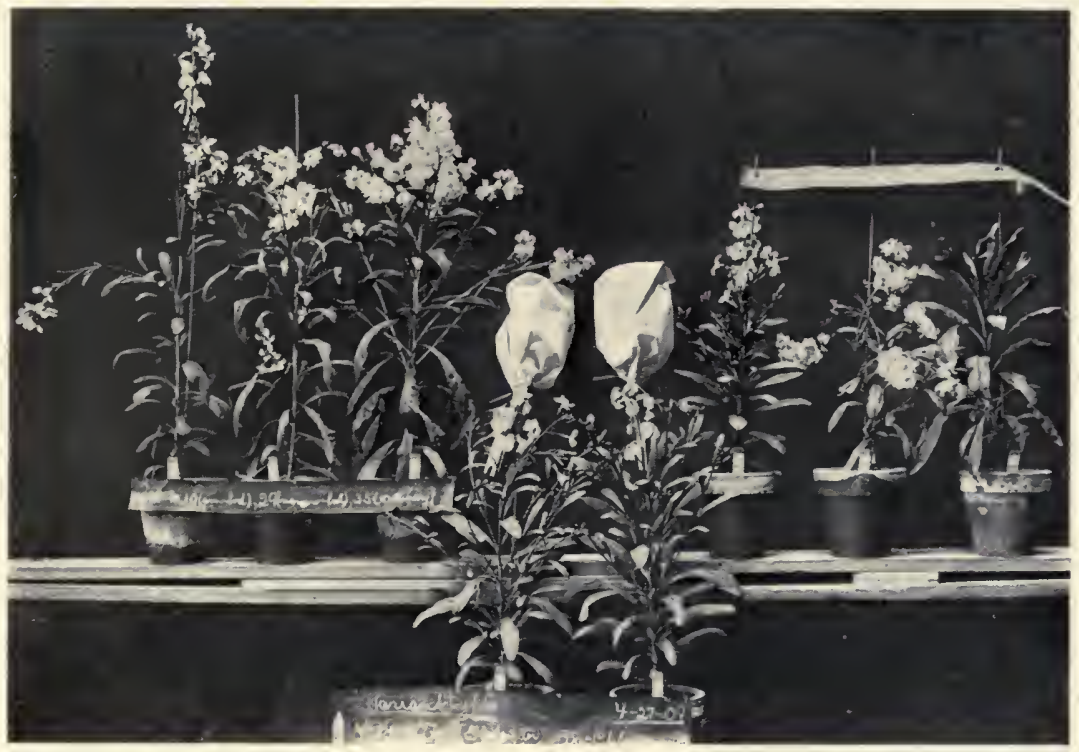

Fig. 18

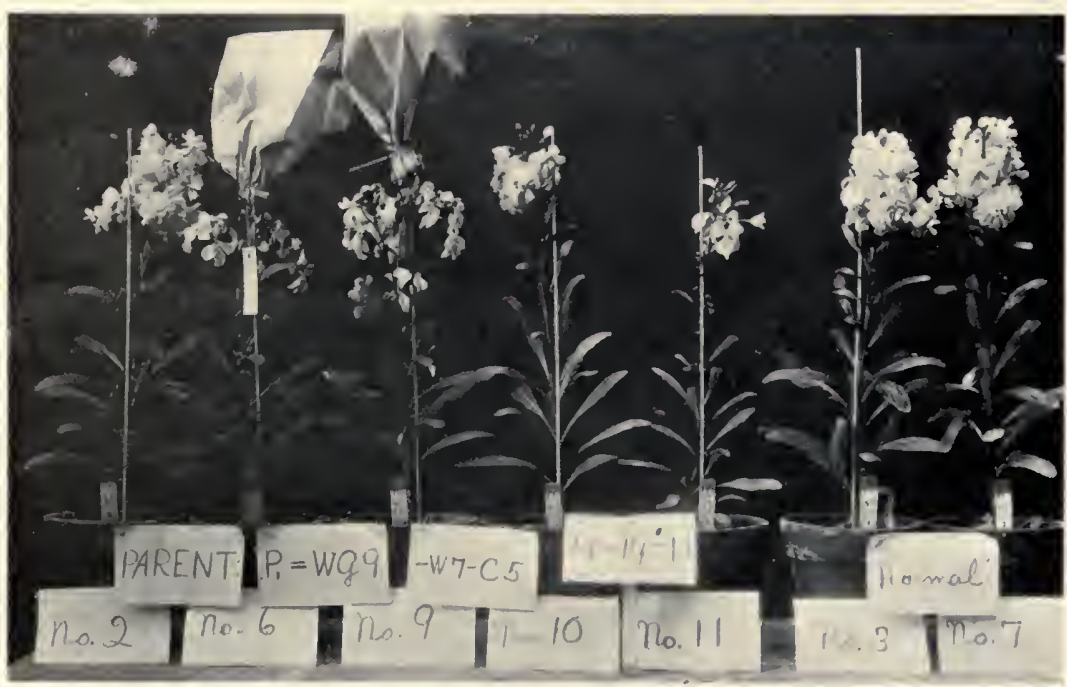

Fig. 19 


PLATE 32

\section{The Slender Type}

Fig. 20. June 3, 1914. Progeny of slender parents. From left to right: slender single, slender double, Snowflake double.

Fig. 21. July 7,1916 . Snowflake $\times$ slender, $F_{1}$. Middle plant Snowflake; the others slender; all single. 


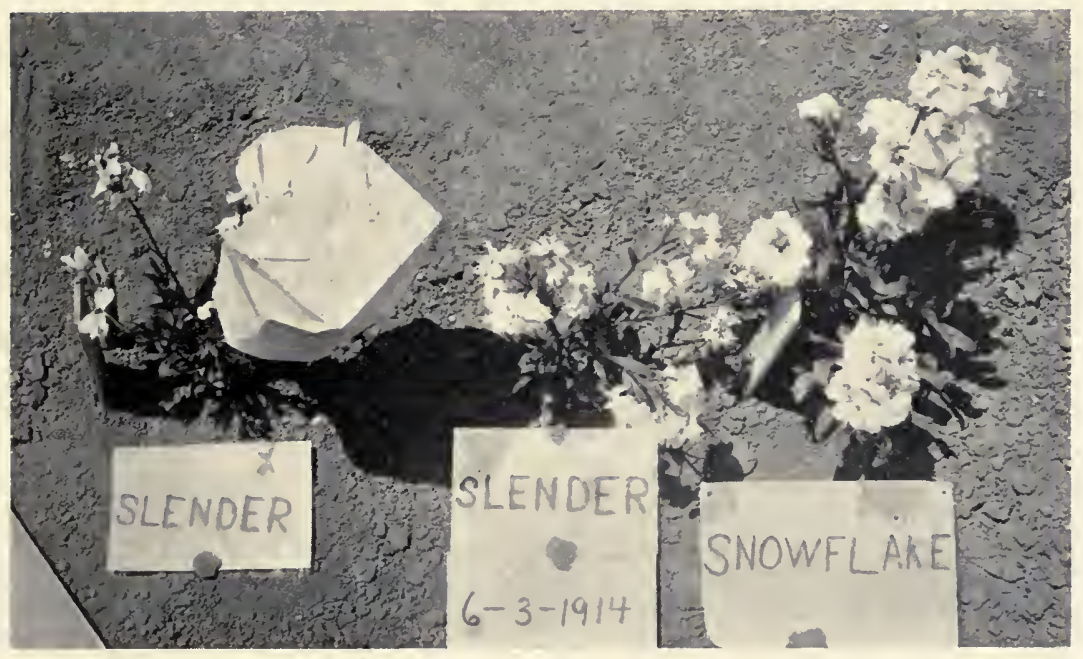

Fig. 20

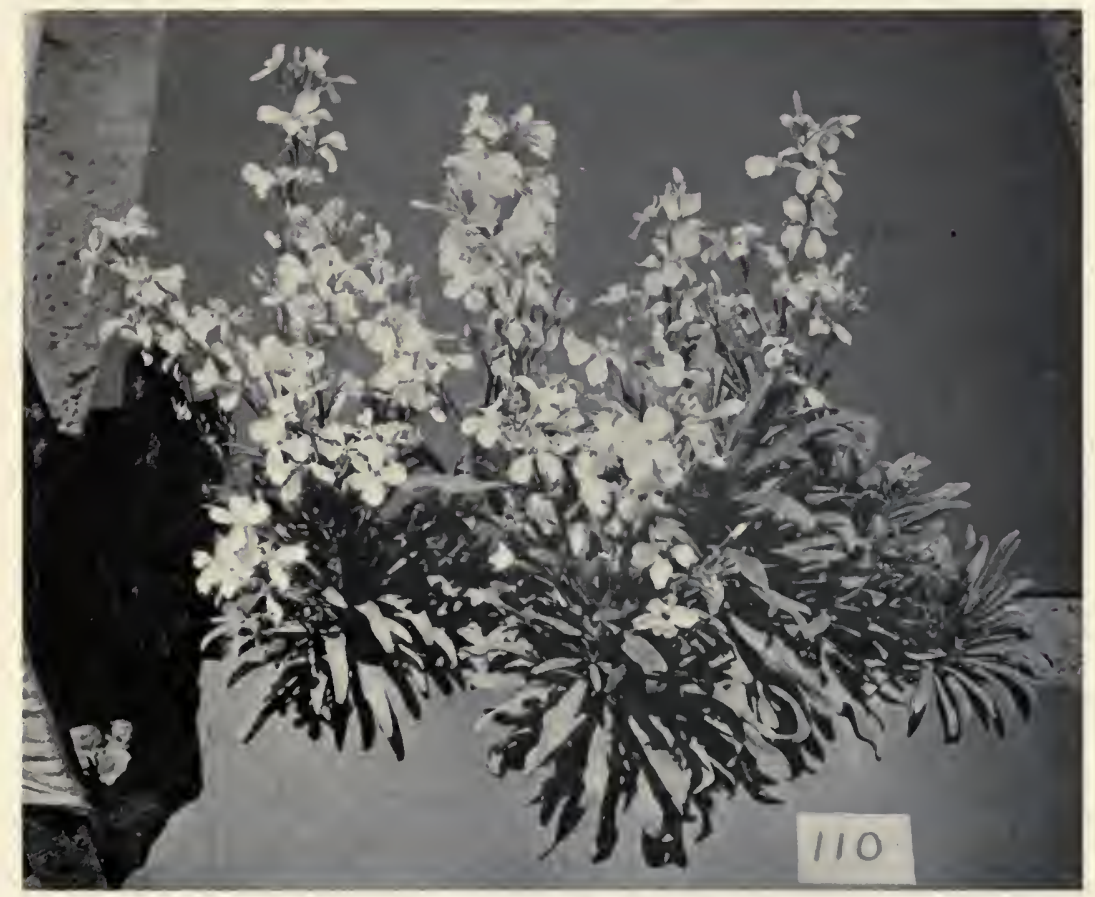

Fig. 21 

PLATE 33

THE NARROW-LEAVED TYPE

Fig. 22. April 13, 1911. Narrow-leaved apparent mutants.

Fig. 23. June 3, 1914. A narrow-leaved apparent mutant among progeny of a crenate-leaved parent. From left to right: narrow double, crenate single (two). 


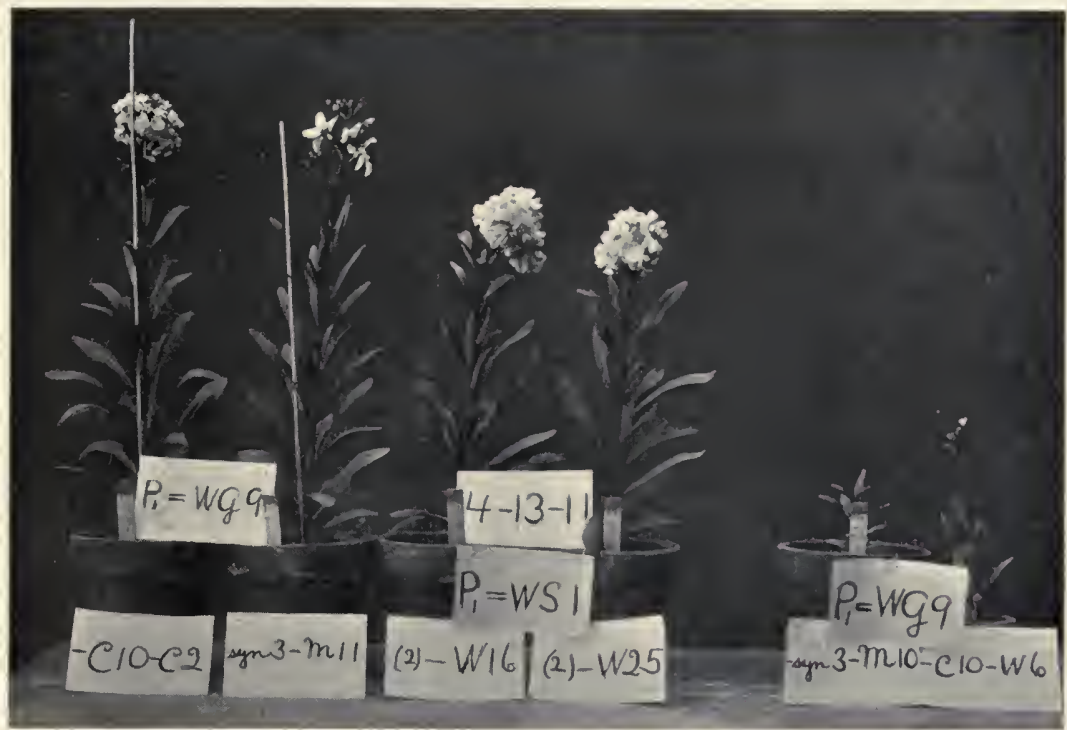

Fig. 22

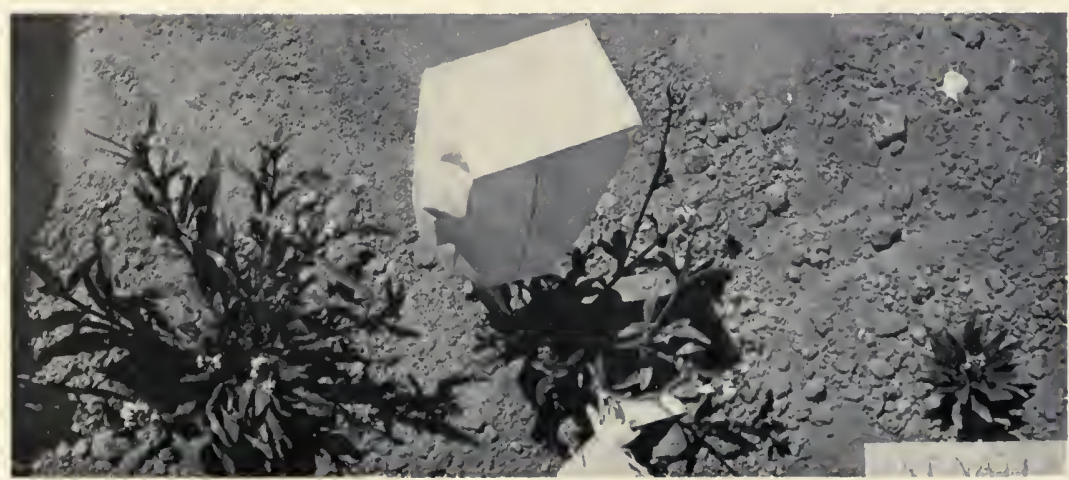

Fig. 23 


PLATE 34

The Narrow-Leaved aNd SMall-SMOOTh-Leaved Types

Fig. 24. June 28, 1915. A narrow-leaved apparent mutant among $F_{2}$ progeny from Snowflake $\times$ slender. Narrow double at left; the rest Snowflake single.

Fig. 25. April 14, 1911. Miscellaneous aberrant plants, some being apparent mutants. From the left: first and fifth small-smooth, third stout dwarf, seventh slender. See text. 


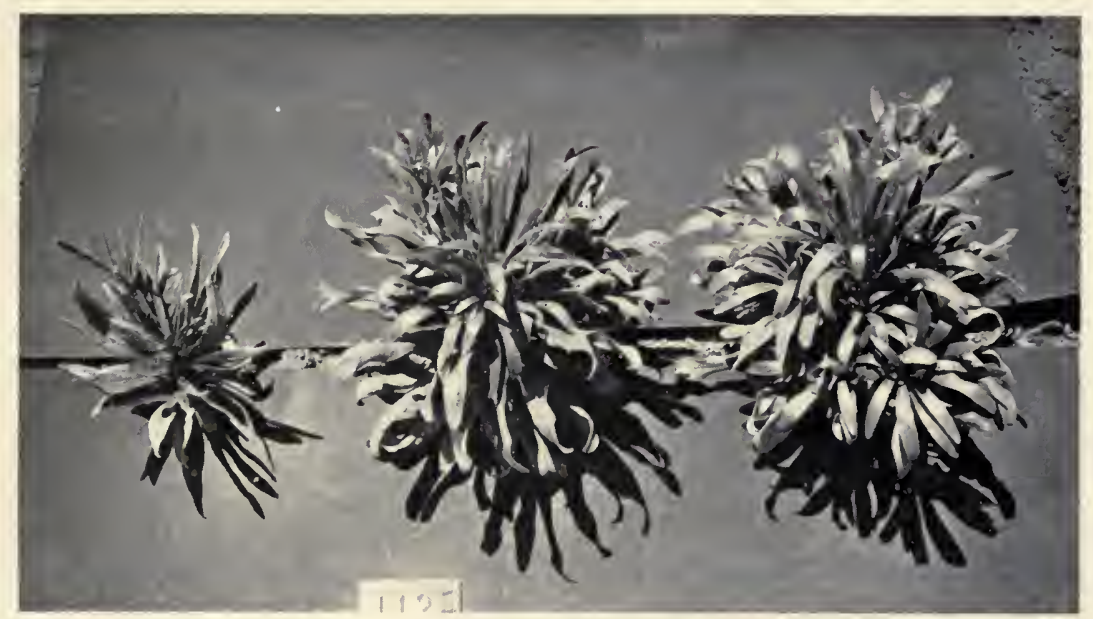

Fig. 24

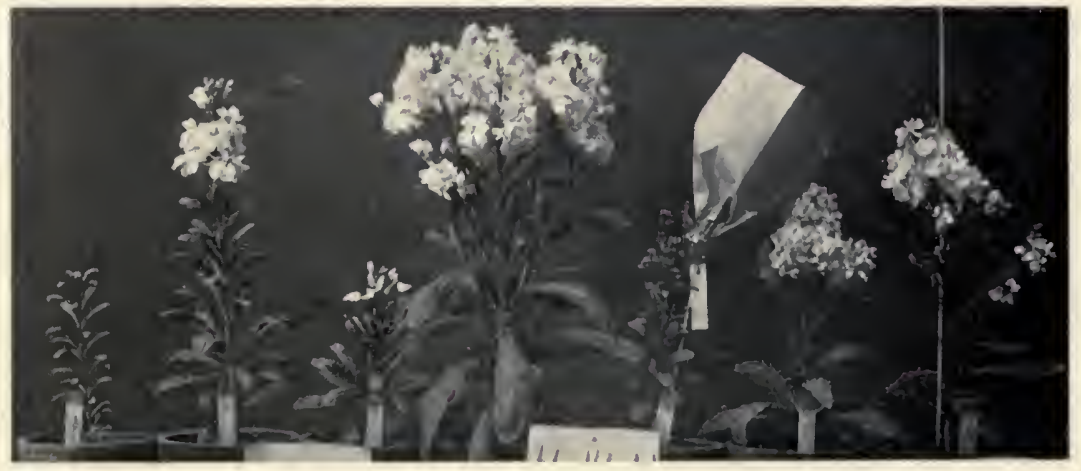

Fig. $2 \tilde{5}$

[FROST ] PLATE 34 




\section{PLATE 35}

The NARROW-DARK-LEAved Type

Fig. 26. June 3, 1914. A narrow-dark-leaved apparent mutant among progeny of a narrow-leaved parent. Third plant from left narrow-dark single; the other three Snowflake double.

Fig. 27. June 28, 1915. Progeny of a "small-convex-leaved(?)" parent (2ia). From left to right: narrow-dark single, Snowflake double, smooth single. 


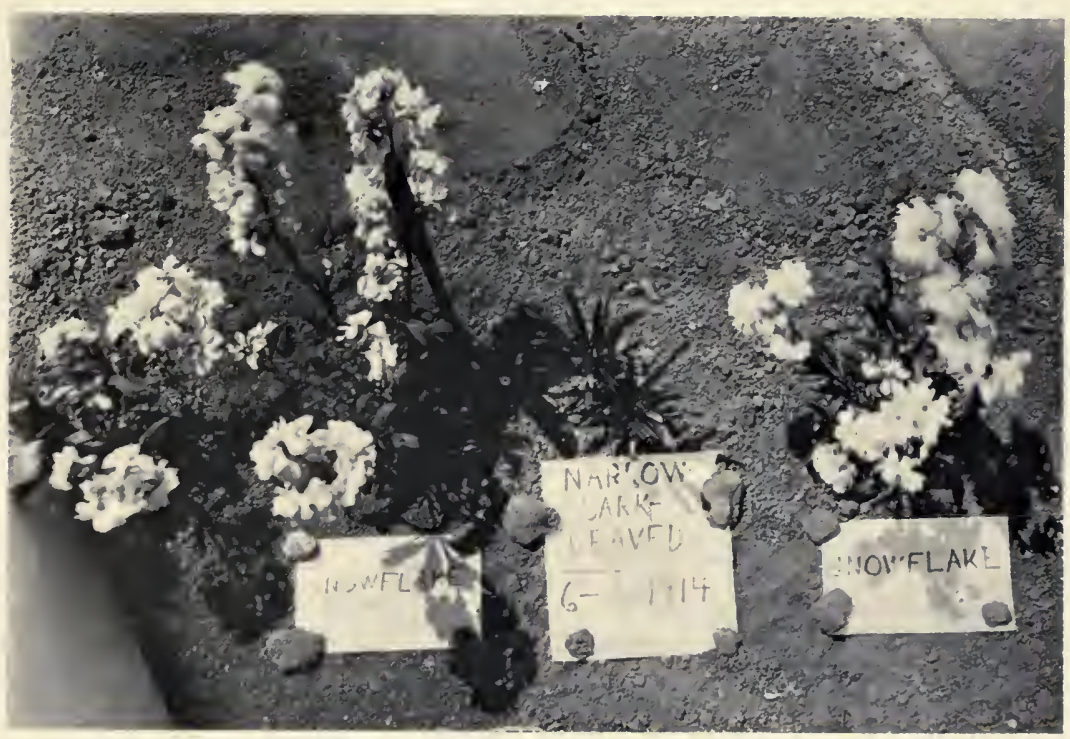

Fig. 26

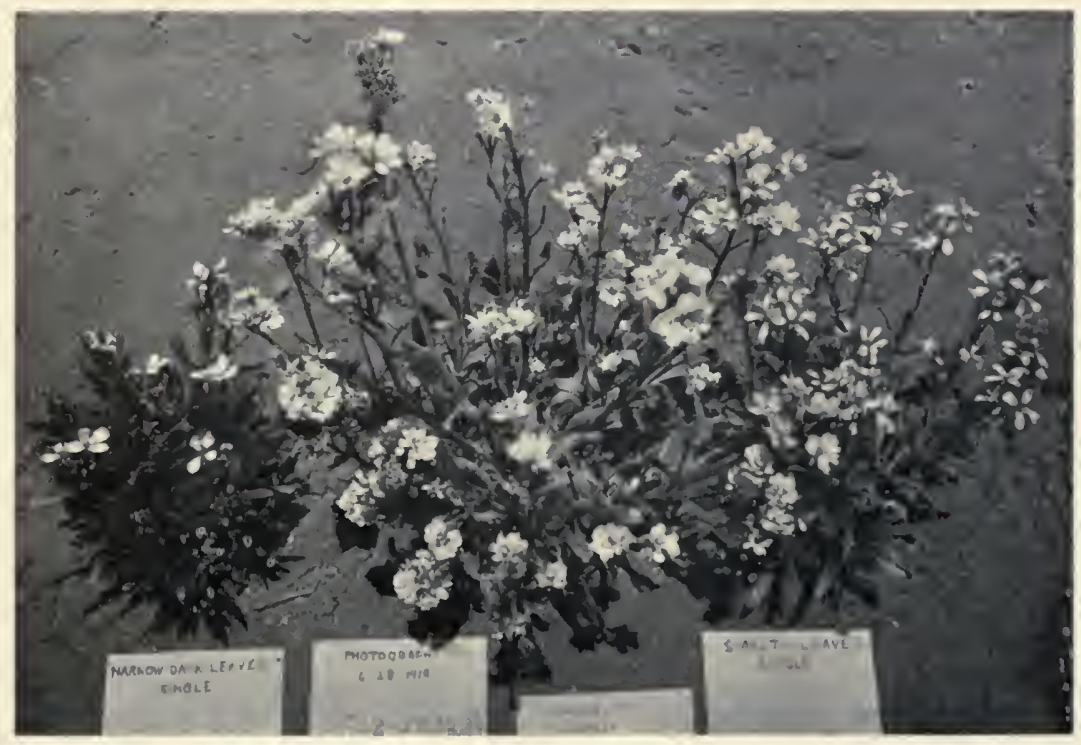

Fig. 27 


$$
\text { . }
$$




\section{OCEAN TEMPERATURES}

GEORGE F. McEWEN 



\title{
OCEAN TEMPERATURES, THEIR RELATION TO SOLAR RADIATION AND OCEANIC CIRCULATION
}

QUANTITATIVE COMPARISONS OF CERTAIN EMPIRICAL RESULTS WITH THOSE DEDUCED BY PRINCIPLES AND METHODS OF MATHEMATICAL PHYSICS

\author{
BY \\ GEORGE F. MCEWEN \\ Oceanographer of the Scripps Institution for Biological Research \\ of the University of California
}





\section{CONTENTS}

Introduction. The place of mathematical methods in researches on oceanographic problems

Solar radiation and surface temperature, assuming the average rate of flow of the water to be zero

Preliminary discussion, and statement of certain generally accepted conclusions as to the process by which the water gains and loses heat ...... 338

Statement of assumptions, mathematical formulation of the problem and its solution

Determination of the numerical values of the constants in the solution.... 344

Observed and thcoretical lag of temperature maxima and minima behind the radiation maxima and minima; comparison of computed and observed normal temperatures.

Numerical estimates of the coefficient of absorption of solar radiation in sea water.

Deduction of the change in surface temperature produced by a horizontal flow of water.

Preliminary discussion, statement of assumptions, and mathematical formulation of the problem.

Solution for the case in which the flow is constant

Solution for the case in which the flow is a periodic function of the time.

Solution for the particular case in which the time interval is so small that the solar radiation may be assumed to depend only upon the latitude.

The rate of horizontal flow in the North Pacific off the California const from latitude $40^{\circ} \mathrm{N}$ to $30^{\circ} \mathrm{N}$ and in the Nortl Atlantic off the west coast of Africa from latitude $30^{\circ} \mathrm{N}$ to $20^{\circ} \mathrm{N}$.

The rate of flow off the coast of California deduced from surface temperatures.

The rate of flow deduced from temperature data compared with that expected from the empirically ascertained relation of winds to currents and with dircet observations on currents.

The surface current prevailing for a short time interval near the northwest coast of Africa, estimated from surface temperatures, compared with direct observations and with results deduced from the empirically ascertained relation of winds to currents. 
The rclation of the teinperature to timc, depth and rate of vertical flow in the deptl interval from 40 to 600 meters.

Statcment of assumptions and mathematical formulation of the problem 367

Solution for the case in which the vertical flow is constant. 369

Solution for the case in which the vertical flow is a periodic function of the time.

Numerical values of the constants in the solution, determined from temperaturc obscrvations in the Pacific near San Diego.

Comparison of thcorctical and observed monthly temperatures at depths from 40 to 600 mcters in the San Diego region.

Solution of the problcm of tempcraturc reduction duc to upwclling, with numerical applications relative to the 40 metcr level in the San Dicgo region.

Deduction of the changc in surfacc temperaturcs duc to a vertical flow of watcr near the surfacc.

Statcment of assumptions and mathematical formulation of the problem and solution for the casc in which the flow is constant.

Solution for the casc in which the flow is a periodic function of the time.... 391

Theoretical reduction of the surface tempcrature for each month in the San Diego region due to upwelling, and comparison with observations.

Deductions relative to oceanic circulation in the San Diego region, based on Ekman's hydrodynamical theory.

Deduction of the upwclling velocity in the San Diego region from the observed relation of salinity to depth, and comparison with that deduced from temperature data.

Conclusion

Literature cited 419-421 


\section{INTRODUCTION}

\section{The Place of Mathematical Methods in Researches on Oceanographic Problems}

The present paper deals with the formulation and solution of several quantitative problems suggested by data on oeean winds, temperatures, and circulation. Before formulating these problems a brief general diseussion of the plaee of mathematieal methods in oceanographie researehes is given.

The proeess of testing physieal laws in the laboratory is greatly faeilitated by devising appropriate experiments in whieh the variables are largely under the control of the investigator. Even under thesc favorable conditions the aetual phenoniena are too complex for detailed representation in a mathematical formula, and an appropriate simplifieation by abstraetion is required to formulate problems that are amenable to mathematical treatment. This is true in a much greater degree of the more eomplex phenomena oeeurring in nature; yet a rigorous mathematieal treatment of natural problems eapable of yielding results in agreement with observations, while in general more diffieult, is necessary and fully justifies the inereasing attention being given to terrestrial and eosmie physies.

The actual phenomena of heating and eooling of the water in the oeean are far too complex to be eonsidered in detail. Therefore, in order to apply rigorous mathematical reasoning to these phenomena, it is neeessary to devise a comparatively simple ideal system whieh would behave in essentially the same way as the aetual one with referenee to the observations in question. Certain problems ean then be formulated definitely in such a way as to permit of the precise calculation of results, the comparison of which with observations tests the praetieal value of the abstraet system.

It is fortunate for the problems eonsidered in this paper that the proper choice of the simple assumptions needed in devising the ideal system is facilitated by eertain gencral results of numerous and extended ocean as well as laboratory observations. An abstract system founded on sueh assumptions would in general agree much better with the eonditions in nature than one in whieh the assumptions were hypothetical or carried over from some other field. Evidently deduetions from any group of simple assumptions calnot have the same degree 
of eertainty as direct observations, sinee the ideal system eamnot conform aecurately to all the details of the phenomena of the aetual one. However, if in this way a logieal and reasonably aecurate deseription of a wide range of physieal quantities is obtained there is good reason to believe that deduetions or predictions relative to quantities not yet observed will be in agreement with the facts. This is especially true if two or more lines of reasoning converge to the same conelusion.

When it is impossible or impracticable to make the appropriate direct observations the theoretical results must be regarded as the best estimates, even though it is not impossible that future observations may show important deviations from theory. Finally, while the existing observations may be logieally deseribed by means of the ideal system, and deductions based on it, extended results reaehed by applying purely deductive methods to the ideal system are not substitutes for a eorrespondingly extended series of new observations. The neessity for making observations will always exist.

\section{Solar Radition and Surface Temperature, Assuming the}

Average Rate of Fiow of the Water to be Zero

Preliminary discussion, and statement of certain generally accepted conclusions as to the way in which the water gains and loses heat.

In order to have a basis for estimating the effect of eirculation on ocean temperatures it is neeessary to work out quantitatively the rate at which the heat of the water is gained and lost under the more simple eondition of no flow. This will be done by devising an ideal ocean. based on assumptions agreeing as nearly as possible with the following eonelusions whieh are founded on mumerous and widely extended ocean observations.

1. The primary souree of heat is the radiant energy of the sun. both direet and diffuse, that penetrates the water (Murray. 1912, p. 225, Gehrke, 1910, p. 67. Helland-Hansen, 1911-12, pp. 6t-66).

2. Absorption of this radiation directly heats the water in the upper layers (Nansen, 1913, pp. 21-22), and only a small fraction of this radiant energy penetrates below 25 meters (Krümmel. 1907, pp. 253-270, Helland-Hansen, 1911-12, pp. 65-68, and Knott. 1903-05).

3. There is always a eomplex vertieal eireulation (Helland-Hansen, 1911-12, p. 68, Gehrke, 1910, p. 68, Nansen, 1913. p. 21, Murray. 1912 , p. 226) due to a lack of balance of the many forees aeting on the water particles. The resultant vertieal flow through a finite seetion due to this motion may be very small and may be either upward 
or downward. That is, at the same time, some portions of the water are moving upward and others downward, thus tending to mix up the water at different levels. In this problem the resultant of the upward and downward flow will be assumed to be zero.

4. 'This "mixing process" is most intense in the layers nearest the surface, owing to wave motion and other surface disturbances due to wind, but is present in some degree at all depths (Gehrke, 1909, p. 12, Murray, 1898, p. 127).

5. The amount of heat transferred from one level to another by conduction through the water is a negligible fraction of that carried by the water particles themselves as a result of the mixing process (Gehrke, 1909, p. 12).

6. The mean annual rate of change of temperature with respeet to latitude is practically independent of the depth within the upper hundred meters. This is revealed by a study of the average temperatures of the North Pacific, tabulated with respect to latitude, longitude, and depth (Schott, 1910, p. 14).

7. At the time of year when the surface temperature is a minimum there is practically no variation of the temperature with respect to depth in the upper thirty meters (MeEwen, 1916, p. 272).

Statement of assumptions; mathematical formulation of the problem and its solution.

Let $K_{1} f_{1}(L, t)$ equal $Q_{1}$, the amount of radiant energy available per month per unit area of horizontal surfaee at the latitude $L$ and tinne $t$, where. $K_{1}$ is proportional to the solar eonstant and $f_{1}(L, t)$ is a function of the latitude $L$ and the time $t$. Let $Q$ equal the amount of radiant energy used directly in heating the water, that is, the amount passing into the water. Also let

$y$ equal the distance in meters from the surfaee of the water, the positive direction bcing downwards,

$\sigma$ cqual the speeifie heat of sea water per unit volume,

$\theta$ equal the temperature, eentigrade.

$t$ equal the time, the unit being 1 month, and $t$ equal 1 for January,

$\theta_{1}$ equal a temperature assumed to depend only on the latitude and depth $y$, and

$\beta_{1}$ equal the average transmission cocffieient of sea water for the solar radiation, that is, the proportion of radiation at any level that passes through unit thickness of water measured from that level. 
Sinee the solar radiation eonsists of a series of waves of varying length, eaeh having a different eoeffieient of transmission (Murray, 1912. p. 248, Krüminel, 1907, p. 263), the use of a single average value is only a simple approximation to the true relation.

No analysis will be attempted of the eomplex way in whieh the lieat in an element of volume, speeified by given values of $y$ and $L$, is lost. This loss depends upon evaporation at the surfaee and on the mixing proeess at all depths, and the rate of evaporation inereases as the temperature inereases. Also heat tends to flow from regions

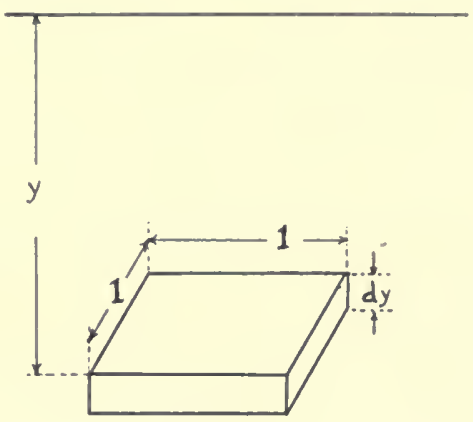

Fig. 1.

of high temperature to those of low temperature (Gehrke, 1910, p. 68). It seems reasonable to suppose, therefore, that the rate of loss would be greater, the greater the temperature.

Although the preeise manner in which the rate of loss of heat depends upon the temperature is not known, some definite form of relation must be assumed in order to formulate thie temperature problem mathematieally. For simplieity assume the rate of loss at any depth to be proportional to $\left(\theta-\theta_{1}\right)$ at that depth, where $\theta_{1}$ is a function of the depth and latitude only. Consider now the time rate at which heat is gained and lost in a given reetangular element of volume of unit eross seetion and thiekness $d y$ whose upper surfaee is at the depth $y$ (fig. 1).

The rate of ehange of heat in this volume element is evidently

$$
\frac{\partial[\sigma(d y) \theta]}{\partial t}=\sigma(d y) \frac{\partial \theta}{\partial t} \text {. }
$$

sinee the volume speeifie heat multiplied by the volume of the element equals the ehange in the amount of heat per degree ehange of temperature. 
The rate of gain of heat in this element of volume due to the absorption of solar radiation equals the difference between the rate at which the radiant energy passes in through its upper surface and out through its lower surface. At the upper surface the rate is $Q \beta_{1}{ }^{y}$ and at the lower surface it is $Q \beta_{1}{ }^{y+d y}$. Therefore the rate of gain due to absorbed radiation is

since

$$
Q \beta_{1}{ }^{y}-Q \beta_{1}{ }^{y+d y}=Q \beta_{1}{ }^{y}\left(1-\beta_{1}{ }^{d y}\right)=-Q\left(\log _{e} \beta_{1}\right) \beta_{1}{ }^{y} d y
$$

$$
1-\beta_{1}^{d y}=1-\left[1+\left(\log \beta_{1}\right) d y\right]=-\left(\log \beta_{1}\right) d y
$$

The rate of loss of heat will be assumed to be $k \sigma\left(\theta-\theta_{1}\right) d y$ where $k$ is a function of $y$ only.

Equating the rate of change of heat in the element to the rate of gain from solar radiation less the rate of loss, we have the following differential equation

$$
\sigma(d y) \frac{\partial \theta}{\partial t}=-Q\left(\log \beta_{1}\right) \beta_{1} y d y-k \sigma\left(\theta-\theta_{1}\right) d y
$$

which becomes

$$
\frac{\mathrm{d} \theta}{\mathrm{dt}}=-\frac{Q\left(\log \beta_{1}\right)}{\sigma} \beta_{1}{ }^{y}-k\left(\theta-\theta_{1}\right)
$$

after division by $\sigma d y$.

Let $L=L_{1}+x$ where $L_{1}$ is a standard latitude chosen arbitrarily and $x$ is the distance in degrees from this position. $x$ is positive for latitudes higher than $L_{1}$ and negative for lower latitudes. The function $f_{1}(L, t)$, (p. 339), then becomes $f(x, t)$, which expresses the way in which the radiation varies with respect to latitude and time. The precise form of $f(x, t)$ is unknown; however, estimates of the amount of radiant energy available at the earth's surface made by Angot (Hann, 1915, p. 40) can be closely approximated to within a ten-degree interval of latitude by an expression of the form

$$
Q_{1}=K_{1}\left[\left(a_{1}+a_{2} x\right) \cos \alpha t+a_{3} x+1\right]
$$

where $a=\frac{\pi}{6}$, and the coefficient of $\cos a t$ is negative.

Assuming the amount of energy $Q$ that enters the water to be proportional to the amount available $Q_{1}$

$$
Q=K\left[\left(a_{1}+a_{2} x\right) \cos \alpha t+a_{3} x+1\right]
$$


where the constant $K \leqq K_{1}$, since the amount of energy used cannot execed the amount available. Equation (4) then becomes

$$
\frac{\partial \theta}{\partial t}=-\frac{\hbar\left(\log \beta_{1}\right) \beta_{1}^{y}}{\sigma}\left[\left(a_{1}+a_{2} x\right) \cos a t+a_{3} x+1\right]-k\left(\theta-\theta_{1}\right)
$$

Let

$$
-\frac{K \log \beta_{1}}{\sigma}=\frac{K b_{1}}{\sigma}=B
$$

where $B$ is a constant and

$$
\beta_{1}=e^{-b_{1}}
$$

where $b_{1}$ is the absorption coefficicnt (Kriimmel, 1907, p. 263). Equation (7) then reduecs to the ordinary linear differential equation

$$
\frac{d \theta}{d t}+k \theta=B\left[\left(a_{3}+a_{2} x\right) \cos a t+a_{3} x+1\right] e^{-u_{1} y}+k \theta_{1}
$$

Therefore

$\theta=e^{-k t}\left\{e^{-b_{1} y} \int e^{k t} B\left(a_{1}+a_{2} x\right) \cos a t d t+e^{-b_{1} y} \int e^{k t}\left(a_{3} x+1+k_{1} \theta_{1}\right) d t+F(x, y)\right\}$

where $F^{\prime}(x, y)$ is an arbitrary function of $x$ and $y$. Integrating equation (11) gives

$\theta=B e^{-b_{1} y}\left(a_{1}+a_{2} x\right) \frac{a \sin a t+k \cos a t}{a^{2}+k^{2}}+\frac{B e^{-b_{1} y}\left(1+a_{3} x\right)}{k}+\theta_{1}+e^{-k t} F(x, y)$

which can be readily transformed into

where

$$
\theta=\frac{B\left(a_{1}+a_{2} x\right) e^{-b_{1} y}}{\sqrt{a^{2}+k^{2}}} \cos (a t-\epsilon)+e^{-b_{1} y}\left\{\frac{B a_{3} x}{k}+\frac{B}{k}\right\}+\theta_{1}
$$

$$
\tan \epsilon=\frac{a}{k}
$$

and only the periodic part of the integral is retained.

If $\theta_{1}$ is assumed to be independent of $x$ the latitude gradient $g$ of the mean amnual temperature is, from equation (13).

$$
g=e^{-b_{1} y}\left(\frac{B a_{3}}{k}\right)
$$

Therefore, sinee $g$ is independent of $y$ (sixth statement, p. 339)

$$
k_{i}=k_{1} e^{-b_{1} y}
$$

where $k_{1}$ is a constant. That is,

$$
g=\frac{B a_{3}}{k_{1}}
$$


Corresponding to the time of year $t_{0}$ when the surfaee temperature has the minimum value $\theta_{0}$ equation (13) becomes

$$
\theta_{0}=\frac{B \cdot\left(a_{1}+a_{2} x\right) e^{-b_{1} y}}{\sqrt{a^{2}+k^{2}}}+\theta_{1}+\frac{B a_{3} x}{k_{1}}+\frac{B}{k_{1}}
$$

Sinee the coefficient of $\cos (a t-\epsilon)$ is negative (see p. 341) $\cos \left(a t_{0}-\epsilon\right)$ must equal plus 1; therefore from the seventh general statement (p. 339)

$$
\theta_{1}=\theta_{3}-\frac{B\left(a_{1}+a_{2} x\right) e^{-b_{1} y}}{\sqrt{a^{2}+k^{2}}}
$$

where $\theta_{3}$ is a constant.

Making use of the results just found equation (13) becomes

$$
\theta=\frac{B\left(a_{1}+a_{2} x\right) e^{-b_{1} y}}{\sqrt{a^{2}+k^{2}}}[\operatorname{eos}(a t-\epsilon)-1]+\frac{B a_{3} x}{k_{1}}+\frac{B}{k_{1}}+\theta_{3}
$$

where

$$
\tan \epsilon=\frac{a}{k}=\frac{a}{k_{1} e^{-b_{1} y}}
$$

The small variation in temperature with respect to depth in the upper six meters indieates that these upper water layers are very thoroughly mixcd (Miehael and MeEwen, 1915, 1916). Aceordingly temperatures in this 6 meter interval will be eomputed by using 3 meters, the average value of the depth. That is, $(y-3)$ will be substituted for $y$ when the depth execeds 6 meters and the constant valuc $(6-3)=3$ for all depths between 0 and 6 meters. From equation (20) it follows that at the time of minimum temperature the temperature is independent of the depth $y$ in aceordanee with the seventh general statement (p. 339). But the latitude gradient whieh is the part of the eoefficient of $x$ in equation (20) not involving the time is

$$
-\frac{B a_{2} e^{-b_{1} y}}{\sqrt{a^{2}+k^{2}}}+\frac{B a_{3}}{k_{1}} .
$$

This is not in aecordance with the observed fact that the latitude gradient is independent of $y$; but the relative error will depend upon the ratio of the first term to the sceond term, and may not be important. As will be seen later (p. 345) it proves to be a negligible elyor if we add to $\theta_{1}$ of equation (19) the term $\frac{B a_{2} x e^{-3 b_{1}}}{\sqrt{a^{2}+k^{2}}}$.

Therefore equation (20) with this modification and the use of $(y-3)$ for the depth $y$ gives the approximate form of the relation between 
temperature, time, depth, and latitude, in accordance with the assumptions and general results of temperature observations already stated. The modified equation is

$\theta=\frac{B\left(a_{1}+a_{2} x\right) e^{-b_{1}(y-3)}}{\sqrt{\alpha^{2}+k^{2}}}[\cos (\alpha t-\epsilon)-1]+\frac{B a_{3}}{k_{1}} x+\frac{B}{k_{1}}+\frac{B a_{2} x e^{-3 b_{1}}}{\sqrt{\alpha^{2}+k^{2}}}+\theta_{3}$

Also from equations (19) and (20)

where

$$
\left(\theta-\theta_{1}\right)=\frac{B}{k_{1}}+\frac{B a_{3} x}{k_{1}}+\frac{B\left(a_{1}+a_{2} x\right) e^{-b_{1}(y-3)}}{\sqrt{\alpha^{2}+k^{2}}} \cos (\alpha t-\epsilon)
$$

$$
\tan \epsilon=\frac{\alpha}{k}=\frac{\alpha}{k_{1} e^{-b_{1}(y-3)}}
$$

Determination of the numerical values of the constants in the solution.

In applying mathematical methods to physical problems the functional relation between the variables involves certain constants which must be determined from observed values of these variables. The constants in equation (22) are

$$
\begin{array}{lllllllll}
a_{1} & a_{2} & a_{3} & \alpha & k_{1} & \theta_{3} & B & \text { and } & b_{1}
\end{array} \text {. }
$$

Also from equation (8) we have $B=\frac{K b_{1}}{\sigma}$. The first four constants are found by fitting the function

$$
K_{1}\left[\left(a_{1}+a_{2} x\right) \cos \alpha t+a_{3} x+1\right]
$$

(equation 5) to the estimated values of solar radiation, as given for example by Angot's tables (Hann, 1915, p. 40). The next three require observations on temperature. For example, they can be found from the observed values of the normal annual range of temperature at a series of latitudes and from the mean annual temperature at these latitudes.

The coefficient of absorption $b_{1}$ can be estimated from direct measurements of the intensity of radiation in the ocean at different depths (Grein, 1913), or from observations on water samples taken to the laboratory (Petersen, 1912, p. 39). Also an indirect estimate can be made from temperature and solar radiation data (pp. 350-352) by means of equation (22). However, in the problem of surface temperature in which the vertical flow is neglected the value of $b_{1}$ is not required. 
Choosing $30^{\circ} \mathrm{N}$ for the standard latitude $L_{1}$, the data on solar radiation taken from Angot's tables and based on the atmospheric transmission coefficient of 0.60 gives the following values of the first four constants :

$$
a_{1}=-.47 \quad a_{2}=-.0128 \quad a_{3}=-.0159, \quad a=\frac{\pi}{6}=0.523 .
$$

A later and more accurate estimate of the radiant energy available at the ocean's surface (Schmidt, 1915, p. 121) gives smaller values, on the average, than those of Angot; also instead of the value -.0159 for $a_{3}$ his results give $-\frac{53}{217 \times 10}=-.0244$, which will be used in in this paper.

Krümmel (1907, p. 413) gives the observed normal mean annual temperature and the normal annual temperature range for the surface of the ocean corresponding to a series of latitudes. These values are in part presented in the following table.

\section{TABLE 1}

Observed values of the normal mean annual temperature and the normal annual range for the surface of the ocean at latitudes $10^{\circ} \mathrm{N}$ to $50 \mathrm{~N}$

\begin{tabular}{|c|c|c|c|c|c|}
\hline North latitude... & $10^{\circ}$ & $20^{\circ}$ & $30^{\circ}$ & $40^{\circ}$ & $50^{\circ}$ \\
\hline Mean Annual temperature...... & 27.2 & 25.4 & 21.3 & 14.1 & 7.9 \\
\hline Annual range & 2.2 & 3.6 & 6.7 & 10.2 & 8.4 \\
\hline 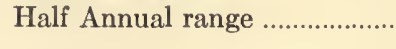 & 1.1 & 1.8 & 3.35 & 5.1 & 4.2 \\
\hline$x \ldots \ldots \ldots \ldots \ldots \ldots \ldots$ & $-20^{\circ}$ & $-10^{\circ}$ & $00^{\circ}$ & $+10^{\circ}$ & $+20^{\circ}$ \\
\hline
\end{tabular}

From the tabulated values it follows that the gradient of the half range is .175 and the gradient of the mean annual temperature is .72 from latitudes $30^{\circ} \mathrm{N}$ to $40^{\circ} \mathrm{N}$. Let $m_{1}$ equal $e^{-3 b_{1}}$ where 3 is the mean depth of the upper homogeneous layer. From these values and equation (22) we have

$$
\begin{aligned}
& \frac{B a_{1} m_{1}}{\sqrt{a^{2}+k_{1}^{2} m_{1}^{2}}}=-3.35=\frac{B a_{1} m_{1}}{a}\left[1-\frac{1}{2}\left(\frac{k_{1} m_{1}}{a}\right)^{2}\right], \\
& \frac{B a_{2} m_{1}}{\sqrt{\alpha^{2}+k_{1}^{2} m_{1}^{2}}}=-.175=\frac{B a_{2} m_{1}}{a}\left[1-\frac{1}{2}\left(\frac{k_{1} m_{1}}{a}\right)^{2}\right]
\end{aligned}
$$

and

$$
\frac{B a_{3}}{k_{1}}=-.72
$$


in which the last members of equations (24) and (25) are approximately correct if $\left(\frac{k_{1} m_{1}}{\alpha}\right)$ is small.

Substituting the numerical values of $a_{1} a_{2} a_{3}$ and $a$ from page 345 we have

$$
B=\frac{-.72}{-.0244} k_{1}=29.5 k_{1}
$$

From equations (24) and (27) neglecting $\frac{1}{2}\left(\frac{k_{1} m_{1}}{a}\right)^{2}$ we have the first approximation

$$
29.5 k_{1} m_{1} \times 1.910 \times(-.47)=-3.35
$$

from which

$$
k_{1} m_{1}=\frac{3.35}{29.5 \times 1.910 \times .47}=.1265 .
$$

Therefore

$$
\begin{aligned}
1+1 / 2\left(\frac{k_{1} m_{1}}{a}\right)^{2} & =1.0292 \\
k_{1} m_{1}=1.0292 \times .1265 & =.1302
\end{aligned}
$$

and

$$
B=\frac{29.5 \times .1302}{m_{1}}=\frac{3.84}{m_{1}}
$$

Similarly from equations (25) and (27) we have

$$
29.5 k_{1} m_{1} \times 1.910 \times .0128=.175
$$

from which

$$
k_{1} m_{1}=\frac{.175}{29.5 \times 1.190 \times .0128}=.2427
$$

Therefore

$$
\begin{gathered}
1+1 / 2\left(\frac{k_{1} m_{1}}{a}\right)^{2}=1.1075 \\
k_{1} m_{1}=1.1075 \times .2427=.2688
\end{gathered}
$$

and

$$
B=\frac{29.5 \times .2688}{m_{1}}=\frac{7.927}{m_{1}}
$$

The difference between the values of $B$ and $k_{1}$ found by these two methods of computation is due to the fact that the ratio between the 
half range of radiation at the standard latitude to the gradient of the half range of the radiation is not quite consistent with the ratio of the half range of temperature at that latitude to its gradient.

It seemed best to take the average of the two values and to apply corrections to $a_{1}$ and $a_{2}$, making them agree with the temperature data; then the difference between the corrected values $a_{1}^{\prime}$ and $a_{2}^{\prime}$ and the original values will indicate the magnitude of this discrepancy between temperature data and solar radiation data. Accordingly

$$
1 / 2\left(\frac{3.84}{m_{1}}+\frac{7.927}{m}\right)=\frac{5.883}{m_{1}}=B=\frac{5.9}{m_{1}}
$$

and

$$
1 / 2(.1302+.2688)=.1995=k_{1} m_{1}=.20 .
$$

From equations (24) and (25) the new values $a_{1}^{\prime}$ and $a_{2}^{\prime}$ of $a_{1}$ and $a_{2}$ are

$$
a_{1}^{\prime}=\frac{-3.35 \sqrt{.274+.04}}{B m_{1}}=\frac{-3.35 \sqrt{.314}}{5.9}=-.318
$$

and

$$
a_{2}^{\prime}=\frac{-.175 \sqrt{.314}}{5.9}=-.0166 .
$$

Substituting these numerical valuations in equation (22) and determining $\theta_{3}$ from the observed surface temperature 21 :3 when $x$ equals 0 we have, expressing the angle in degrees

$$
\begin{aligned}
& \theta=\frac{\frac{5.9}{m_{1}}(-.318-.0166 x) e^{-b_{1}(y-3)}}{\sqrt{.274+.04\left(\frac{e^{-2 b_{1} y}}{m_{1}{ }^{2}}\right)}}[\cos (30 t-\varepsilon)-1] \\
& -.72 x-\frac{5.9(.0166) x}{\sqrt{.274+.04}}+17.95
\end{aligned}
$$

where

$$
\tan \epsilon=2.62 \frac{m_{1}}{e^{-b_{1}(y-3)}} .
$$

For the surface temperature, put $y=6$ and we have

$$
\begin{gathered}
\theta=\frac{5.9(-.318-.0166 x)}{.56}\left[\cos (30 t-69)^{\circ}-1\right]-.72 x-\frac{5.9(.0166) x}{.56} \\
+17.95=-(3.35+.175 x) \cos (30 t-69)^{\circ}+21.30-.72 x .
\end{gathered}
$$


In the same way the following values of the eoustants for the latitude interval from $20^{\circ} \mathrm{N}$ to $30^{\circ} \mathrm{N}$ were determined:

$$
a_{1}^{\prime}=-.343, \quad a_{2}^{\prime}=-.0159, \quad a_{3}=-.0161, \quad k_{1} m_{1}=.217,
$$

$\frac{B a_{3}}{k_{1}}=$ the latitude gradient $=-.41$,

$-.155=$ the latitude gradient of the half range,

$$
B=\frac{5.535}{m_{1}}, \text { and } \tan \epsilon=-\frac{.523}{217} \frac{m_{1}}{e^{-b_{1}(y-3)}}=2.41 \frac{m_{1}}{e^{-b_{1}(y-3)}}
$$

Substituting these numerical values in equation (22) gives for the surface temperature

$$
\theta=-(3.35+.155 x) \cos (30 t-67.5)^{\circ}+21.30-.41 x
$$

Observed and theoretical lag of temperature maxima and minima

behind the radiation maxima and minima. Comparison of computed and observed normal temperatures.

The value of $\epsilon=69^{\circ}$, eorresponding to the latitude interval $30^{\circ} \mathrm{N}$ to $40^{\circ} \mathrm{N}$, was dedueed from theory; and sinee $30^{\circ}$ eorresponds to one month, $69^{\circ}$ eorresponds to $\frac{69}{30}=2.3$ months, the theoretical lag of the $\left\{\begin{array}{l}\text { maximum } \\ \text { minimum }\end{array}\right\}$ temperature behind the $\left\{\begin{array}{l}\text { maximum } \\ \text { minimum }\end{array}\right\}$ radiation.

The theoretieal time of the maximum temperature is therefore 8.3, or about halfway between August and September; while the theoretieal time of the minimum temperature is 2.3 , or about halfway between February and Mareh. Aeeording to Krümmel (1907. p. 407) from numerous and extended oeeanie observations the average time of the lowest temperature is February $(t=2)$ and that of the highest is August $(t=8)$.

Again, from the three eurves (Makaroff, 1894, pl. 26) giving the mean monthly surfaee temperature observed in the North Paeific between latitudes $30^{\circ} \mathrm{N}$ and $45^{\circ} \mathrm{N}$ the minimum temperature oeeurred when

$$
t=1.8,3.0 \text { and } 2.5
$$

and the maximum temperature oeeurred when

$$
t=8.1,8.3 \text { and } 7.8
$$

respeetively. The average of the above values of $t$ is 2.4 for the minimum and 8.1 for the maximum. Thus the predieted value of the 
lag agrees very closely with the observed value. Since this value was computed from that of the period of the temperature change, which is accurately known to be twelve months, and from the foregoing determination of the value of $k_{1} m_{1}$ this agreement between theory and observation affords strong evidence in favor of the reliability of the value .2 adopted for $k_{1} m_{1}$, which is an important constant in the investigation of ocean currents presented later.

From numerous surface temperature observations in the Pacific at long. $173^{\circ} \mathrm{W}$, lat. $20^{\circ} \mathrm{N}$ (Puls, 1895, pls. 1-4), off Madeira in the Atlantic, lat. $32^{\circ} 30^{\prime} \mathrm{N}$ (Krümmel, 1907, p. 407) and off Yokohama and at long. $140^{\circ} \mathrm{W}$ in the Pacific, lat. $35^{\circ} \mathrm{N}$ (Krümmel, 1907, p. 408; Thorade, 1909, pls. 1-3) it was found that the mean annual temperatures agreed well with the normal values for the latitude. Therefore there is good reason to suppose that the condition giving rise to the temperatures at these places approximates closely to the normal condition. Thus a comparison between the theoretical monthly temperatures given by equations (39) and (40) with the observed values will give a still more detailed test of the theory (table 2).

\section{TABLE 2}

Theoretical and observed normal surface temperatures at a series of latitudes

\begin{tabular}{|c|c|c|c|c|c|c|c|c|c|c|c|c|c|c|}
\hline \multicolumn{4}{|c|}{ Latitude $20^{\circ} \mathrm{N}$} & \multicolumn{3}{|c|}{$21^{\circ} 18^{\prime} \mathrm{N}$} & \multirow{2}{*}{ 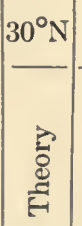 } & \multicolumn{3}{|c|}{$32^{\circ} 30^{\prime} \mathrm{N}$} & \multicolumn{3}{|c|}{$35^{\circ} \mathrm{N}$} & \multirow{2}{*}{$\frac{40^{\circ} \mathrm{N}}{2}$} \\
\hline 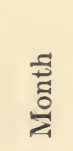 & $\begin{array}{l}\overrightarrow{8} \\
\stackrel{8}{8} \\
E\end{array}$ & 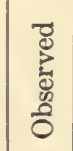 & 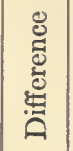 & 总 & $\begin{array}{l}\overrightarrow{0} \\
\sum_{0}^{\circ} \\
0 \\
0 \\
*\end{array}$ & 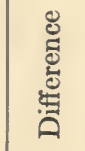 & & 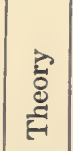 & 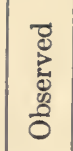 & 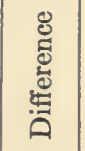 & 苞 & $\begin{array}{l}\overline{0} \\
\stackrel{0}{0} \\
0 \\
0 \\
0\end{array}$ & 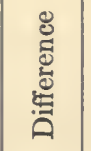 & \\
\hline 1 & $24^{\circ} 0$ & $24^{\circ} 1$ & $+: .1$ & $23: 3$ & $21^{\circ} 6$ & -1.9 & $18^{\circ} .7$ & $16^{\circ} 6$ & $18^{\circ} .0$ & +1.4 & $14^{\circ} 4$ & $130^{\circ}$ & -1.0 & $10^{\circ} 1$ \\
\hline 2 & & & & 220 & 20.8 & -2.1 & & & 17.2 & & & & +.2 & \begin{tabular}{|l|}
9.1 \\
\end{tabular} \\
\hline 3 & & & & 23.3 & 21.6 & -1.7 & & & & & & & -.4 & \\
\hline 4 & & & & & 22.1 & -2.0 & & & & & & & -.91 & 10.9 \\
\hline 5 & & & & 25.2 & 23.0 & -2.2 & 20 & 18 & .7 & -0 & & & +.2 & 13 \\
\hline 6 & & & & 26.1 & 24.4 & -1.7 & & 20.9 & 20.3 & -0 & & & -.7 & 1 \\
\hline 7 & & & & & & -1.2 & & 22.4 & .8 & & & & +.6 & 18.1 \\
\hline 8 & & & & & & -1 & & & & & & & & \\
\hline 9 & & & & & & -1 & & & & & & & & \\
\hline & & & & & & -1 & & & & & & & & \\
\hline & & & & & 23 & -1.6 & 21.6 & 20 & 20 & & & .2 & -1.2 & \\
\hline 12 & 24.3 & 24.8 & + & 23.7 & 21.1 & -2.6 & 20.3 & 18.1 & 19.0 & +0.9 & 16.2 & 16.4 & +.21 & 12.3 \\
\hline & & & & & & & & & 19.9 & & & 17.5 & & \\
\hline
\end{tabular}

*Air temperatures at Honolulu (Monthly Weather Review, 1903, pp. 225-226). 
It appear's that the theoretical results agree well with observation. If the difference between the theoretical and observed mean annual temperatures due to the average departure of the loeal conditions from the normal is applied as a eorreetion to the observed monthly temperatures the agrecment between theory and obscrvation is very elose.

Numerical estimates of the coefficient of absorption of solar radiation in sea water.

A lower limit of the value of the absorption eoefficient $b_{1}$ ean be determined from quantities depending on surface temperatures and the amount of solar radiation at the surface of the ocean by the following method. The value of $K_{1}$ (p. 344) obtained from Angot's data (Hann, 1915, p. 40) was

$$
K_{1}=5.18 \times 10^{7} \lambda
$$

where $\lambda$ is the solar constant. The more aceurate result of Sehmidt's later investigation $(1915 ;$ p. 121) (p. 345) is

$$
K_{1}=217 \times 30 \times 10^{4}=3.255 \times 10^{7} \lambda .
$$

Since $B=\frac{K b_{1}}{\sigma}$ and $B m_{1}=5.9$ (p. 347 )

$$
K=\frac{.94 \times 10^{6} \times 5.9}{m_{1} b_{1}}=\frac{5.54}{m_{1} b_{1}} \times 10^{6} \text {. }
$$

But since $\frac{K}{K_{1}}$ is the ratio of the amount of energy supplied to the water by solar radiation to the amount available at the surface, $\frac{K}{K_{1}}<1$.

Therefore

$$
\frac{K}{K_{1}}=\frac{5.54 \times 10^{8}}{m_{1} b_{1} \times 3.255 \times 10^{7} \lambda}=\frac{5.54}{32.55 m_{1} b_{1} \lambda}<1 .
$$

Using the aecepted value 2.00 for $\lambda$ we have

$$
m_{1} b_{1}=b_{1} e^{-3 b_{1}}>.0851 \text {. }
$$

TABLE 3

\begin{tabular}{c|c|c|c|c|c|c|c|c}
\hline$b_{1}$ & 0 & .05 & .10 & .12 & .15 & .20 & .25 & .30 \\
\hline$b e^{-3 b_{1}}$ & 0 & .043 & .074 & .083 & .096 & .110 & .118 & .122 \\
\hline
\end{tabular}


From the values of $b_{1} e^{-3 b_{1}}$ given in table 3 it follows that $b_{1}>.12$ or $e^{-b_{1}}=\beta_{1}<.887$ where $\beta_{1}$ equals the proportion of incident light that passes through one meter of sea water. Direct observations of the proportion of solar radiation passing through samples of sea water taken from the Nördlichen Ostsee and the Bottensee (Petersen, 1912, p. 39) give values of $\beta_{1}$ varying from .60 to .86 , which are less than the upper limit .887 deduced from theory.

The variation with respect to depth of the heat absorbed by the water tends to maintain a temperature gradient which would be greater the smaller the transmission coefficient, and the mixing process tends to reduce the gradient by transferring heat from warm to cooler layers. That is, the rate at which heat is supplied to a given laver is equal to that due to direct absorption of radiation plus the amount due to the alternating vertical circulation of the water. But the rate of gain of heat was assumed in the theory to be due entirely to the absorption of radiation; and therefore the estimate of the value of the transmission coefficient deduced from observed temperatures at different depths would be larger than the true value. This conclusion is confirmed by the following computation, based on temperature observations near San Diego (McEwen, 1916, pl. 26). The general equation (22) (p. 344), is of the form

$$
\theta=R_{1} e^{-b_{1}(y-3)}[\cos (a t-\epsilon)-1]+R_{2}
$$

where $R_{1}$ and $R_{2}$ are constants, for a given latitude. Therefore, $R_{1} e^{-b_{1}(6-3)}$ equals the half range of temperature at the surface, $R_{1} e^{-b_{1}(10-3)}$ equals the half range at the depth of 10 meters and $\left[R_{1} e^{-b_{1}(6-3)}-R_{1} e^{-b_{1}(10-3)}\right]$ equals the difference between the mean annual temperature at the surface and at the depth of 10 meters. If there is a vertical flow (p. 374) the general temperature equation reduces to the same form (equation 155, p. 390), and can therefore be applied to temperatures in the San Diego region.

Substituting the observed average values of these quantities (McEwen, 1916, pl. 26) gives

$$
\begin{array}{ll}
R_{1} e^{-3 b_{1}}=3.15 & \text { half range at surface } \\
R_{1} e^{-7 b_{1}}=2.70 & \text { half range at depth of } 10 \text { meters } \\
R_{1}\left[e^{-3 b_{1}}-e^{-7 b_{1}}\right]=.40 & \text { difference in mean annual tem- } \\
\text { perature at surface and at } 10 \text { meters. }
\end{array}
$$


From equations (41) and (42)

$$
\mathrm{e}^{4 b_{1}}=\frac{3.15}{2.70}=1.168 \quad \text { or } \quad b_{1}=.039
$$

and

$$
R_{1}\left[e^{-3 b_{1}}-e^{-7 b_{1}}\right]=R_{1}(.1285)=.45 \quad \text { or } \quad R_{1}=3.50 \text {. }
$$

From equation (43) and the value, 3.5, alrcady found for $R_{1}$

$$
e^{-3 b_{1}}-e^{-7 b_{1}}=\frac{.40}{3.5}=.1142 \text { and } b_{1}=.034
$$

which agrees approximately with the value .039 obtained from the first equation. The average value .0365 should be used instead of the large value of $b_{1}$ excecding .12 (p. 351), in order to obtain the actual rate at which the water gains heat as a result of both absorption and mixture of water from other layers. That is, the rate of gain of heat in the actual system takes place as if there were no such mixture of the water and the coefficient of absorption were less than the truc value. Hence, as far as the rate of gain and loss of heat is concerned we can substitute this more simple ideal system for the actual one. We have now determined all of the constants of the original differential equation (4), on page 341, which expresses the time rate of change of heat in an element of volume, on the assumption that the average flow, either vertically or horizontally, is zero. The modified temperature resulting from any additional factor, for example a current, can be deduced by solving the above differential equation, to which has been added the rate of change of heat due to this factor.

\section{Deduction of the Change in Surface Temper.ture Produced} by a Horizontal Flow of Water

Preliminary discussion. Statement of assumptions and mathematical formulation of the problem.

It is well known, as stated by a prominent British hydrograpler, Wharton (1894, pp. 699-712), that "the most obvious phenomenon of the ocean is the constant horizontal movement of its surface water, which in many parts takes well defined directions."

The work of both practical seamen and scientists has after many years revealed the essential features of the main occan currents, and in a few limited regions a fairly detailed knowledge of the currents has been obtained. However, all investigators agree that the esti- 
mation of the direction and rate of flow of water in the ocean is attended with many difficulties. Some of the methods of making such estimates will now be briefly reviewed.

The most direct and widely used method is the comparison of the position of a ship every noon determined from astronomical observation and from the $\log$ and course during the previous twenty-four hours. The set of a current estimated in this way is subject to large errors, unless special care is taken in making the observations. Under ordinary conditions such estimates of currents less than ten miles in twenty-four hours are quite uncertain (Krümmel, 1911, p. 420).

Another method of studying currents is to use drift bottles enclosing slips of paper on which to enter information as to when and where they were found. A sufficient number of records of the initial and final positions of these bottles and the corresponding time intervals will, under favorable conditions, yield information especially as to the average direction of the surface drift. This method is best adapted to small enclosed seas as the bottles may then be easily recovered soon after reaching the shores. For the open oceans it is not satisfactory. Other floating objects, such as wrecks, icebergs, trees, and plankton also furnish some information about the horizontal circulation.

Under favorable conditions the current at a given place can be measured directly by means of a current meter or by observing a floating object designed to move with the current. In the open ocean the difficulty of holding a ship in a reasonably fixed position usually renders these methods impracticable.

Investigations of the causes of ocean currents and their relation to these causes provide indirect methods of determining them. Ocean currents are directly due to various external forces, the wind or friction of a neighboring current, differences in pressure resulting from evaporation, precipitation and differences in specific gravity, and are modified by the deflecting force due to the earth's rotation and by internal friction of the water. Thus, any theory of ocean currents capable of yielding even a rough approximation to the quantitative relations between the complex system of causes and the resulting motion of the water would necessarily be highly complicated. As a matter of fact, great difficulties always arisc in attempts to establish a connection between practical hydrography and theoretical hydrodynamics, and deductions of currents from their causes are quite uncertain except in special cases in which the conditions in the ideal 
problem agree well with those in nature. The applieation of theory to practieal problems is rendered especially diffieult, first, beeause of lack of knowledge of the frictional resistance to the motion of sea water, and, second, beeause of the uneertainty regarding the current produeed by a wind of given veloeity and direetion.

One of the most important needs now is a eomprehensive programme of observations at sea, of the eurrents themselves and their eauses, supplemented by attempts to formulate hydrodynamieal problems whose solution shall be eonsistent with the observations. Mueh eredit is due to the pioneer investigators, Zöppritz, Moln, Bjerknes, Sandström, Ekman, Jacobsen, and others, for their development of methods of dealing with sueh problems.

Another important aid to the determination of oceanie cireulation is found in the faet that a eurrent consists of water partieles tending to preserve their temperature and salinity as they move along. These eharaeters ehange slowly and thus serve to depiet the eurrents somewhat as do floating objeets that are readily identified.

This part of the paper presents an attempt to develop, along the line suggested in the following translation from Krïmmel (1911, p. 439), a method of deducing eurrents from the temperature distribution :

No simple rule has been formulated for determining currents from teniperature charts. But it is conceivable if not certain that a systematic investigation of the so-called individual temperature changes will give a reliable basis for the estimation of currents from temperatures. (We must distinguish betreen the annual temperature range, corresponding to definite geographical positions, and the practically uninvestigated temperature changes which one and the same water particle undergoes along the great horizontal current systems. In a continuous current, for example, the Gulf Stream, these individual temperature changes which must be distinguished from changes at a given position may run through the whole range from tropical heat to the freezing point.) The problem is, however, very difficult, and a cursory comparison of the current charts in the Atlantic as prepared from the Log Book of the "Seewarte" reveals the great complexity of these closely inter-related phenomena. In general, in connection with all water motions time is an all important factor. Rapid and slow currents behave very differently as regards their heat content, and can therefore give rise to widely different types of isotherms. No constant angle between stream lines and isotherms can be proposed; the angle can vary between $0^{\circ}$ and $90^{\circ}$. The most frequent case is that of stream lines cutting the isotherms obliquely.

In general, the rate of ehange of heat in an element of volume ean be expressed by adding to the right-hand member of the differential equation (3) the rate of change due to other factors not considered on 
page 339, and the solution of the new equation will give the temperature under the new conditions. The rate of change of heat due to a horizontal flow $H$ of the water can be readily derived as follows : consider a rectangular element of volume (fig. 2) of unit length perpendicular to the direction of flow and of breadth $d z$ measured in the direction of flow and thickness $d y$ normal to the direction of flow.

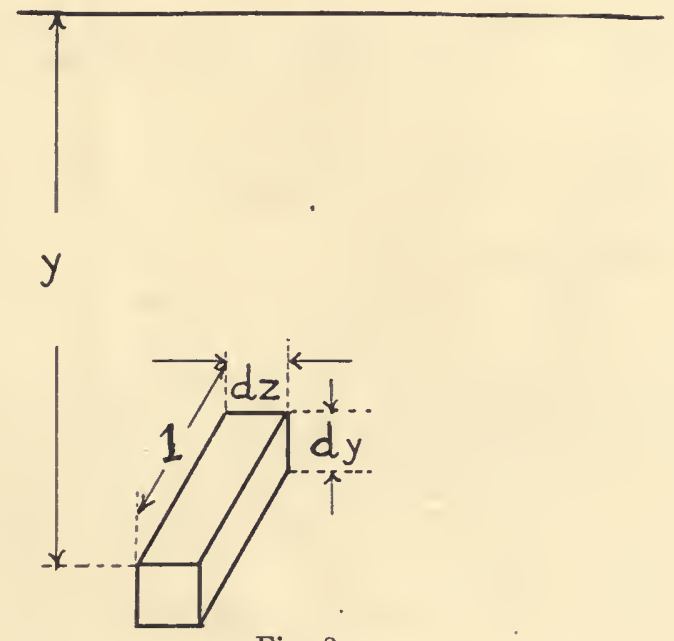

Fig. 2.

Then the rate at which heat enters into the element less the rate at which it is removed will be

$$
H \sigma \theta d y-H_{\sigma}(\theta+d \theta) d y=-H \sigma d \theta d y=-H \sigma \frac{\partial \theta}{\partial z} d z d y
$$

which is the time rate of change of heat in the element due to the flow of water. Multiplying equation (3) by $d z$ to make it apply to the element of volume now considered and adding the above expression for rate of change of heat gives the new equation

$$
\sigma \frac{\partial \theta}{\partial t} d y d z=-Q\left(\log _{e} \beta_{1}\right) \beta_{1}{ }^{y} d y d z-k \sigma\left(\theta-\theta_{1}\right) d y d z-H_{\sigma} \frac{\partial \theta}{\partial z} d y d z
$$

Dividing through by $\sigma d y d z$ and substituting the value of $Q$ and $\beta_{1}$ from page 341 we have

$$
\frac{\partial \theta}{\partial t}=B e^{-b_{1} y}\left[\left(a_{1}+a_{2} x\right) \cos a t+a_{3} x+1\right]-k\left(\theta-\theta_{1}\right)-H \frac{\partial \theta}{\partial z}
$$

which is the same as the temperature equation (10) with the term 
$\left(-H \frac{\mathrm{d} \theta}{\mathrm{d} z}\right)$ added. $x$ is the distance north or south from the latitude ehosen for reference. $z$ is the distance from the same point measured in the direetion of flow, making an angle $\psi$ with the $x$ direction; therefore $x$ equals $n z$ where $\psi$ is measured from the positive (north) direetion of $x$, and $n$ equals $\cos \psi$. Making this substitution in equation (46) gives

$$
\frac{\mathrm{d} \theta}{\mathrm{d} t}=B\left[\left(a_{1}+a_{2} n z\right) \cos \alpha t+a_{3} n z+1\right] e^{-b_{1} y}-k\left(\theta-\theta_{1}\right)-H \frac{\mathrm{d} \theta}{\mathrm{d} z}
$$

Solution for the case in which the flow is constant.

To solve equation (47) let

$$
\theta=\theta^{\prime}+\theta^{\prime \prime}+\theta^{\prime \prime \prime}
$$

where $\theta^{\prime}$ is the solution already found (equation 22, p. 344) eorresponding to $H=0, \theta^{\prime \prime}$ a function of $y$ and $t$ only is to be determined, and $\theta^{\prime \prime}$ is a general solution of the part left after substituting $\left(\theta^{\prime}+\theta^{\prime \prime}\right)$. Substituting the value $\theta^{\prime}+\theta^{\prime \prime}+\theta^{\prime \prime \prime}$ for $\theta$ in equation (47) we have

$$
\begin{aligned}
& \frac{\mathrm{\partial} \theta^{\prime}}{\mathrm{\partial} t}+\frac{\mathrm{\partial} \theta^{\prime \prime}}{\mathrm{\partial} t}+\frac{\mathrm{\partial} \theta^{\prime \prime \prime}}{\mathrm{\partial} t}=B\left[\left(a_{1}+a_{2} n z\right) \cos a t+a_{3} n z+1\right] e^{-b_{1} y} \\
& -k\left(\theta^{\prime}+\theta^{\prime \prime}+\theta^{\prime \prime \prime}-\theta_{1}\right)-H \frac{\mathrm{\partial} \theta^{\prime}}{\mathrm{d} z}-H \frac{\mathrm{\partial} \theta^{\prime \prime}}{\mathrm{d} z}-H \frac{\mathrm{\partial} \theta^{\prime \prime \prime}}{\mathrm{d} z}
\end{aligned}
$$

From the definitions of $\theta^{\prime}, \theta^{\prime \prime}$ and $\theta^{\prime \prime \prime}$ this equation reduees to

$$
\frac{\mathrm{\partial} \theta^{\prime \prime}}{\mathrm{d} t}+\frac{\mathrm{\partial} \theta^{\prime \prime \prime}}{\mathrm{dt}}=-k \theta^{\prime \prime}-k \theta^{\prime \prime \prime}-H \frac{\mathrm{\partial} \theta^{\prime}}{\mathrm{d} z}-H \frac{\mathrm{\partial} \theta^{\prime \prime \prime}}{\mathrm{d} z}
$$

which ean be broken up into two equations

$$
\frac{\mathrm{\partial} \theta^{\prime \prime}}{\mathrm{d} t}=-k \theta^{\prime \prime}-H \frac{\mathrm{d} \theta^{\prime}}{\mathrm{d} z}
$$

and

$$
\frac{\mathrm{d} \theta^{\prime \prime \prime}}{\mathrm{d} t}+k \cdot \theta^{\prime \prime \prime}+H \frac{\mathrm{d} \theta^{\prime \prime \prime}}{\mathrm{d} z}=0
$$

From equation (22) which gives the value of $\theta^{\prime}$ we have

$$
\begin{aligned}
\frac{\mathrm{d} \theta^{\prime}}{\mathrm{d} z}= & \frac{B a_{3} n}{k_{1}}+\frac{B a_{2} n e^{-b_{1}(y-3)}}{\sqrt{a^{2}+k_{1}^{2} e^{-2(y-3) b_{1}}}}[\cos (a t-\epsilon)-1]+\frac{B a_{2} n e^{-3 b_{1}}}{\sqrt{a^{2}+k_{1}^{2} e^{-2 b_{1}(y-3)}}} \\
= & n\left\{g-K_{2} e^{-b_{1}(y-3)}\left[1-\left(A_{1} \cos a t+B_{1} \sin a t\right)\right]\right\}
\end{aligned}
$$


where $g, K_{2}, A_{1}$ and $B_{1}$ are constants having the following values :

$$
\begin{gathered}
g=\frac{B a_{3}}{k_{1}}+\frac{B a_{2} e^{-b_{1} 3}}{\sqrt{a^{2}+k^{2}}}, \quad K_{2}=\frac{B a_{2}}{\sqrt{a^{2}+k^{2}}} \\
A_{1}=\frac{k}{\sqrt{a^{2}+k^{2}}} \text { and } \quad B_{1}=\frac{a}{\sqrt{a^{2}+k^{2}}}
\end{gathered}
$$

Substituting the above value of $\frac{\partial \theta^{\prime}}{\partial z}$ in equation (50) gives

$$
\frac{\partial \theta^{\prime \prime}}{\partial t}+k \theta^{\prime \prime}=-H\left\{g-e^{-b_{1}(y-3)} K_{2}\left[1-\left(A_{1} \cos a t+B_{1} \sin \alpha t\right)\right]\right\} n
$$

remembering that $k$ equals $k_{1} e^{-b_{1}(y-3)}$ and for depths between zero and six meters the constant value $y$ equals 6 is to be used for $y$, while for other depths the actual value of the depth is to be used for $y$ (p. 343).

$H$, the horizontal velocity, may be any function of the time, but it is assumed to be independent of $z$ and $y$. Having in mind a numerical application to be made later it will be convenient to let $H$ equal the periodic function of the time

$$
H=H_{1}\left(1+a_{4} \sin a t+a_{5} \cos \alpha t\right)
$$

where $H_{1}, a_{4}$ and $a_{5}$ are constants. Equation (53) then becomes the ordinary linear differential equation of the first order in $\theta^{\prime \prime}$ and $t$

$$
\begin{aligned}
\frac{d \theta^{\prime \prime}}{d t} & +k \theta^{\prime \prime}=-H_{1} n\left\{g-K_{2}\left(\frac{k}{k_{1}}\right)\left[1-\left(A_{1} \cos a t+B_{1} \sin a t\right)\right]\right\} \\
& \times\left(1+a_{4} \sin a t+a_{5} \cos a t\right)
\end{aligned}
$$

Solving by the corresponding standard formula we have

$$
\begin{aligned}
\theta^{\prime \prime} & =-e^{-k t} \int\left\{H_{1} n\left[g-\frac{k}{k_{1}} K_{2}\left(1-\overline{A_{1} \cos a t+B_{1} \sin a t}\right)\right]\right. \\
& \left.\times\left[1+a_{4} \sin a t+a_{5} \cos a t\right] e^{k t}+C\right\} d t
\end{aligned}
$$

where $C$ is arbitrary but independent of $t$ and $z$. Under these conditions $C e^{-k t}$ will evidently be included in a general solution of equation (51), and will therefore be neglected in the expression for $\theta^{\prime \prime}$. Equation (55) can be directly integrated with the aid of well known standard forms and the result for $H$ equal to a constant velocity $H_{1}$ is

$$
\begin{aligned}
\theta^{\prime \prime} & =-\frac{H_{1} n}{k}\left[g-\frac{B a_{2} e^{-b_{1}(y-s)}}{\sqrt{a^{2}+k^{2}}}\right]-\frac{I_{1} n B a_{2} e^{-b_{1}(y-s)}}{\left(a^{2}+k^{2}\right)^{2}} \\
& \times\left[2 a k \sin a t+\left(k^{2}-a^{2}\right) \cos a t\right]
\end{aligned}
$$


Equation (51) in which $H_{1}\left(1+a_{4} \sin \alpha t+a_{5} \cos a t\right)$ is substituted for $H$ beeomes

$$
\frac{\mathrm{d} \theta^{\prime \prime \prime}}{\mathrm{d} t}+k \theta^{\prime \prime \prime}+H_{1}\left(1+a_{4} \sin a t+a_{5} \cos a t\right) \frac{\mathrm{\partial} \theta^{\prime \prime \prime}}{\mathrm{d} z}=0
$$

In the speeial ease where $a_{4}=a_{5}=0$ the solution is

$$
\theta^{\prime \prime \prime}=e^{-\frac{k\left(z-z_{n}\right)}{H_{1}}} f\left(t-\frac{z-z_{n}}{H_{1}}\right)
$$

where $f\left(t-\frac{z-z_{0}}{H_{1}}\right)$ is an arbitrary function of $\left(t-\frac{z-z_{0}}{H_{1}}\right)$. This solution ean be easily verified by substitution in equation (57).

For a eonstant veloeity $I$ equals $H_{1}$, the general solution of the differential equation (47) is the sum of the three quantities $\theta^{\prime}+\theta^{\prime \prime}+\theta^{\prime \prime \prime}$ already found, and ean be put in the form

$$
\begin{aligned}
\theta & =\left\{\frac{B\left(a_{1}+a_{2} n z\right) e^{-b_{1}(y-3)}}{\sqrt{a^{2}+k^{2}}}[\operatorname{eos}(a t-\epsilon)-1]+\frac{B a_{3} n z}{k_{1}}+\frac{B}{k_{1}}+\frac{B a_{2} n z e^{-b_{1} 3}}{\sqrt{a^{2}+k^{2}}}+\theta_{3}\right\}_{1} \\
& -\left\{\frac{H_{1} n}{k}\left[\frac{B a_{3}}{k_{1}}+\frac{B a_{2} e^{-b_{1} 3}}{\sqrt{a^{2}+k^{2}}}-\frac{B a_{2} e^{-b_{1}(y-3)}}{\sqrt{a^{2}+k^{2}}}\right]+\frac{H_{1} n B a_{2} e^{-b_{1}(y-3)}}{\left(a^{2}+k^{2}\right)^{2}}\right. \\
& \left.\times\left[2 a k \sin a t+\left(k^{2}-a^{2}\right) \cos a t\right]\right\}_{2}+\left\{e^{-\frac{k\left(z-z_{0}\right)}{H_{1}} f}\left(t-\frac{z-z_{0}}{H_{1}}\right)\right\}_{2}
\end{aligned}
$$

Suppose the relation of the temperature to the time at a given position $z_{0}$ is known and that there is a eonstant horizontal veloeity $\Pi_{1}$ from that point in any given direetion. From equation (59) the temperature at any time and at any point along the stream line down stream from the point $z$ equals $z_{0}$ ean be found by giving the arbitrary funetion $f\left(t-\frac{z-z_{0}}{\Pi_{1}}\right)$ sueh values that when $z$ equals $z_{0}$ $\theta=\theta^{\prime}+\theta^{\prime \prime}+\theta^{\prime \prime \prime}$ will equal the observed temperature, whieh is a known function of the time at that point. All of the eonstants in the equation are given on page 347 . Therefore $f\left(t^{\prime}\right)$ being known, when $t^{\prime}$, the time at the position, $z$ equals $z_{0}$ is known, the arbitrary funetion is determined. For a time $t$ and a value $\left(z-z_{0}\right)$ of the distanee from $z_{0}$ the expression

$$
f\left(t-\frac{z-z_{0}}{H_{1}}\right)=f\left(t^{\prime}\right)
$$

where

$$
\left(t-\frac{z-z_{0}}{H_{1}}\right)=\left(t^{\prime}\right)
$$

sinee, in general, the function is determined by the values of the independent variable

$$
\left(t-\frac{z-z_{0}}{H_{1}}\right) \text {. }
$$


Solution for the case in which the flow is a periodic function of the time.

If the flow is the periodic function of the time

$$
H=H_{1}\left(1+a_{4} \sin a t+a_{5} \cos a t\right)
$$

the term $\theta^{\prime}$ (equation 22 , p. 344 ) will be the same as before, but $\theta^{\prime \prime}$ will be given by equation (55) where $a_{4}$ and $a_{5}$ are retained. The integrations can be readily performed with the aid of well known standard forms and the result is

$$
\begin{aligned}
& \theta^{\prime \prime}=-\frac{H_{1} n}{k}\left[\left(g-\frac{B a_{2} e^{-b_{1}(y-3)}}{\sqrt{a^{2}+k^{2}}}\right)+\frac{B a_{2} e^{-b_{1}(y-3)}}{2\left(a^{2}+k^{2}\right)}\left(k a_{5}+a a_{4}\right)\right] \\
& -\frac{H_{1} n}{a^{2}+k^{2}}\left\{\left(g-\frac{B a_{2} e^{-b_{1}(y-3)}}{\sqrt{a^{2}+k^{2}}}\right)\left(k a_{4}+a a_{5}\right)+\frac{B a_{2} e^{-b_{1}(y-3)}}{a^{2}+k^{2}} 2 a k\right\} \sin a t \\
& \quad-\frac{H_{1} n}{a^{2}+k^{2}}\left\{\left(g-\frac{B a_{2} e^{-b_{1}(y-3)}}{\sqrt{a^{2}+k^{2}}}\right)\left(-a a_{4}+k a_{5}\right)+\frac{B a_{2} e^{-b_{1}(y-3)}}{a^{2}+k^{2}}\left(k^{2}-a^{2}\right)\right\} \\
& \cos a t-\frac{H_{1} n B a_{2} e^{-b_{1}(y-3)}}{2\left(k^{2}+4 a^{2}\right)\left(a^{2}+k^{2}\right)}\left\{\left[k^{2} a_{4}+3 a k a_{5}-2 a^{2} a_{4}\right] \sin 2 a t\right. \\
& \left.\quad+\left[k^{2} a_{5}-3 a k a_{4}-2 a^{2} a_{5}\right] \cos 2 a t\right\}
\end{aligned}
$$

The solution of equation (57) when $a_{4}$ and $a_{5}$ are retained, found by Lagrange's method, is

$$
\theta^{\prime \prime \prime}=e^{-k t} f_{1}\left[\left(t-\frac{a_{4}}{a} \cos a t+\frac{a_{5}}{a} \sin \alpha t\right)-\frac{z}{H_{2}}\right]
$$

where $f_{1}[]$ is an arbitrary function of

$$
\left[\left(t-\frac{a_{4}}{a} \cos \alpha t+\frac{a_{5}}{\alpha} \sin \alpha t\right)-\frac{z}{H_{1}}\right] .
$$

This solution can be verified by substitution in equation (57), and can be readily changed into the more suitable form

$$
\begin{aligned}
& \theta^{\prime \prime \prime}=e^{-} \frac{k\left(z-z_{0}\right)}{\Pi_{1}}-\frac{k\left(a_{4} \cos a t-a_{5} \sin a t\right)}{a} f\left[\left(t-\frac{a_{4}}{a} \cos \alpha t+\frac{a_{5}}{a} \sin a t\right)\right. \\
& \left.-\frac{z-z_{0}}{\Pi_{1}}\right]
\end{aligned}
$$


which reduces to equation (58) when $a_{4}$ and $a_{5}$ equal zero. The tempcrature at any time and place down stream from the position where $z$ equals $z_{0}$ ean be found if the relation of the temperature to the time is known where $z$ equals $z_{0}$, by giving the arbitrary function $f\left[\right.$ ] values such that for $z$ equals $z_{0}, \theta=\theta^{\prime}+\theta^{\prime \prime}+\theta^{\prime \prime \prime}$ will equal the observed temperature which is a known funetion of the time at that position. Thus the arbitrary function is determined since its value is known for a scries of values of the independent variable $\left(t^{\prime}-\frac{a_{4}}{a} \cos a t^{\prime}+\frac{a_{\tilde{z}}}{\alpha} \sin a t^{\prime}\right)$, using $t^{\prime}$ for the time where $z$ equals $z_{0}$. For any other value of the time $t^{\prime}$ and for a distance $\left(z-z_{0}\right)$ down stream

$$
\begin{gathered}
f\left[\left(t-\frac{a_{4}}{a} \cos a t+\frac{a_{5}}{a} \sin a t\right)-\frac{z-z_{0}}{H_{1}}\right] \\
=f\left[t^{\prime}-\frac{a_{4}}{a} \cos a t^{\prime}+\frac{a_{5}}{a} \sin a t^{\prime}\right],
\end{gathered}
$$

where

$$
\begin{gathered}
{\left[\left(t-\frac{a_{4}}{a} \cos a t+\frac{a_{5}}{a} \sin a t\right)-\frac{z-z_{0}}{\Pi_{1}}\right]} \\
=\left(t^{\prime}-\frac{a_{4}}{a} \cos a t^{\prime}+\frac{a_{5}}{a} \sin a t^{\prime}\right) .
\end{gathered}
$$

Solution for the particular case in which the time interval is so small that the solar radiation may be assumed to depend

$$
\text { only on the latitude. }
$$

In certain eases it will be eonvenient to take a time interval so short that the insolation may be regarded as independent of the time and the eurrent may be assumed to have a eonstant velocity from a position $z$ equals $z_{0}$ where the temperature may be assumed eonstant. Under these eonditions the temperature at any point distant $\left(z-z_{0}\right)$ down stream will be independent of the time if suffieient time has elapsed for an element of volume of the water passing through the position $z_{0}$ and having the given eoustant temperature to move through a distance equal to or greater than $\left(z-z_{0}\right)$. For this steady state, equation (47) becomes

$$
B\left[b_{2}+b_{3} n z\right] e^{-b_{1}(y-3)}-k\left(\theta-\theta_{1}\right)-H_{1} \frac{\mathrm{d} \theta}{\mathrm{d} z}=0
$$

where

$$
\begin{aligned}
& b_{2}=1+a_{1} \cos a t_{1} \\
& b_{3}=a_{2} \cos a t_{1}+a_{3}
\end{aligned}
$$


and $t_{1}$ is the average of the values of $t$ for the beginning and end of the time interval. Let $\theta=\theta^{\prime}+\theta^{\prime \prime}$ where $\theta^{\prime}$ is the solution when $H_{1}=0$. Then

$$
\theta^{\prime}=\theta_{1}+\frac{B e^{-b_{1}(y-3)}\left(b_{2}+b_{3} n z\right)}{k}
$$

Substituting $\left(\theta^{\prime}+\theta^{\prime \prime}\right)$ in equation (68) gives

$$
\frac{d \theta^{\prime \prime}}{d z}+\frac{k}{\widetilde{H}_{2}} \theta^{\prime \prime}=-\frac{\mathrm{d} \theta^{\prime}}{\mathrm{d} z}
$$

For $\theta^{\prime}$ use the normal value determined from the expression \{\} , of equation (59) for $t=t_{1}$ then for surface temperatures using the value 6 for $y$ (see page 343 )

$$
\frac{\mathrm{d} \theta^{\prime}}{\mathrm{d} z}=\frac{B a_{3} n}{K_{1}}+\frac{B a_{2} n e^{-3 b_{1}}}{\sqrt{\boldsymbol{a}^{2}+k^{2}}} \cos \left(a t_{1}-\epsilon\right)=g_{1}
$$

where

$$
\tan \epsilon=\frac{a}{k}
$$

This is consistent with equation (69) since $\theta_{1}$ may be any function of $z$. Equation (70) then becomes

$$
\frac{d \theta^{\prime \prime}}{d z}+\frac{k}{H_{2}} \theta^{\prime \prime}=-g_{1}
$$

Integrating equation (71) gives

$$
\theta^{\prime \prime}=\bar{\theta} e^{-\frac{k\left(z-z_{0}\right)}{H_{1}}}-\frac{g_{1} H_{1}}{k}
$$

where $\bar{\theta}$ is arbitrary. Adding the two solutions $\theta^{\prime}$ and $\theta^{\prime \prime}$ gives

$$
\begin{aligned}
\theta= & \theta^{\prime}+\theta^{\prime \prime}=\left\{\frac{B\left(a_{1}+a_{2} n z\right) e^{-3 b_{1}}}{\sqrt{a^{2}+k^{2}}} \cos \left(a t_{1}-\epsilon\right)+\frac{B a_{3} n\left(z-z_{0}\right)}{k_{1}}+\frac{B a_{3} n z_{0}}{k_{1}}+\frac{B}{k_{1}}\right. \\
& \left.+\theta_{3}\right\}_{1}+\left\{\bar{\theta} e^{-\frac{k\left(z-z_{0}\right)}{H_{1}}}-\frac{g_{1} H_{1}}{k}\right\}
\end{aligned}
$$

where the expression $\{\quad\}_{1}$ is the normal temperature. To determine the temperature at a given position, distant $\left(z-z_{0}\right)$ from the initial position $z_{0}$, give $\bar{\theta}$. such a value that the expression for $\theta$ in equation (73) will reduce to the given temperature when $z=z_{0}$. Then substitute this value and the given value of $z$ in equation (73). 
Consider two parallel stream lines, $A$ and $B$, the veloeity being $H_{\mathrm{A}}$ along the first and $H_{\mathrm{B}}$ along the seeond, then the temperature in $A$ for any value of $z$ minus the temperature in $B$ for the same value of $z$ is

$$
\theta_{\mathrm{A}}-\theta_{\mathrm{B}}=\bar{\theta}_{\mathrm{A}} \theta^{-\frac{k\left(z-z_{\mathrm{n}}\right)}{\Pi_{\mathrm{A}}}}-\bar{\theta}_{\mathrm{B}} e^{-\frac{k\left(z-z_{\mathrm{n}}\right)}{\Pi_{\mathrm{B}}}}+\frac{g_{1}}{k}\left(H_{\mathrm{B}}-H_{\mathrm{A}}\right)=\Delta \theta
$$

Denote $H_{\mathrm{A}}-H_{\mathrm{B}}$ by $\Delta H$, then

$$
\Delta \theta=-\frac{g_{1}}{k} \Delta H+\bar{\theta}_{\mathrm{A}} e^{-\frac{k\left(z-z_{n}\right)}{n_{\mathrm{B}}+\Delta H}}-\bar{\theta}_{\mathrm{B}} e^{-\frac{k\left(z-z_{n}\right)}{H_{\mathrm{B}}}}
$$

Also if $\frac{\Delta H}{\Pi_{\mathrm{A}}}$ is small we have approximately

$$
\Delta \theta=-\frac{g_{1}}{k} \Delta H+\left(\bar{\theta}_{\mathrm{A}}-\bar{\theta}_{\mathrm{B}}\right) e^{-\frac{k\left(z-z_{0}\right)}{H_{\mathrm{B}}}}+\dot{\bar{\theta}}_{\mathrm{A}} e^{-\frac{k\left(z-z_{0}\right)}{H_{\mathrm{B}}}}\left\{\left(\frac{\Delta H}{H_{\mathrm{B}}}\right) \frac{k\left(z-z_{0}\right)}{H_{\mathrm{B}}}\right\}
$$

The Rate of Horizontal Flow in the North Pacific off the California Coast from Lat. $40^{\circ} \mathrm{N}$ to $30^{\circ} \mathrm{N}$ and in the Nortir Atlantic off the West Coast of Africa from Lat. $30^{\circ} \mathrm{N}$ to $20^{\circ} \mathrm{N}$.

\section{The rate of flow deduced from surface temperatures.}

From the hydrographie eharts (Thorade, 1909) of the region of the Paeifie off North Ameriea, it appears that that the average direetion of the surfaee drift from Cape Mendocino, Lat. $40^{\circ} \mathrm{N}$, does not at any season differ greatly from a straight line determined by the points. Lat. $40^{\circ} \mathrm{N}$, Long. $124^{\circ} \mathrm{W}$, and Lat. $30^{\circ} \mathrm{N}$. Tong. $126^{\circ} \mathrm{W}$. Assuming that there is a surfaee drift in this eonstant average direetion whieh is proportional to the average wind veloeity over this eourse, will some numerieal value of the drift aeeount for the monthly temperatures at the down-stream end of the line? From the monthly isotherms worked out by Thorade (1909), the observed mean monthly temperatures at any point of the region ean be found. From these observed monthly temperatures at the upper end of the line and a mean value of the drift veloeity determined by trial, the temperatures at the down-stream end will be eomputed aeeording to the theory on page 359. A eomparison of these theoretieal temperatures with the observed ones and of this theoretieal value of the drift with estimates made in other ways will indicate the praetieal value of the theory. The observed temperatures taken from Thorade's ehart (1909), and the numerieal values of the other quantities eomputed 


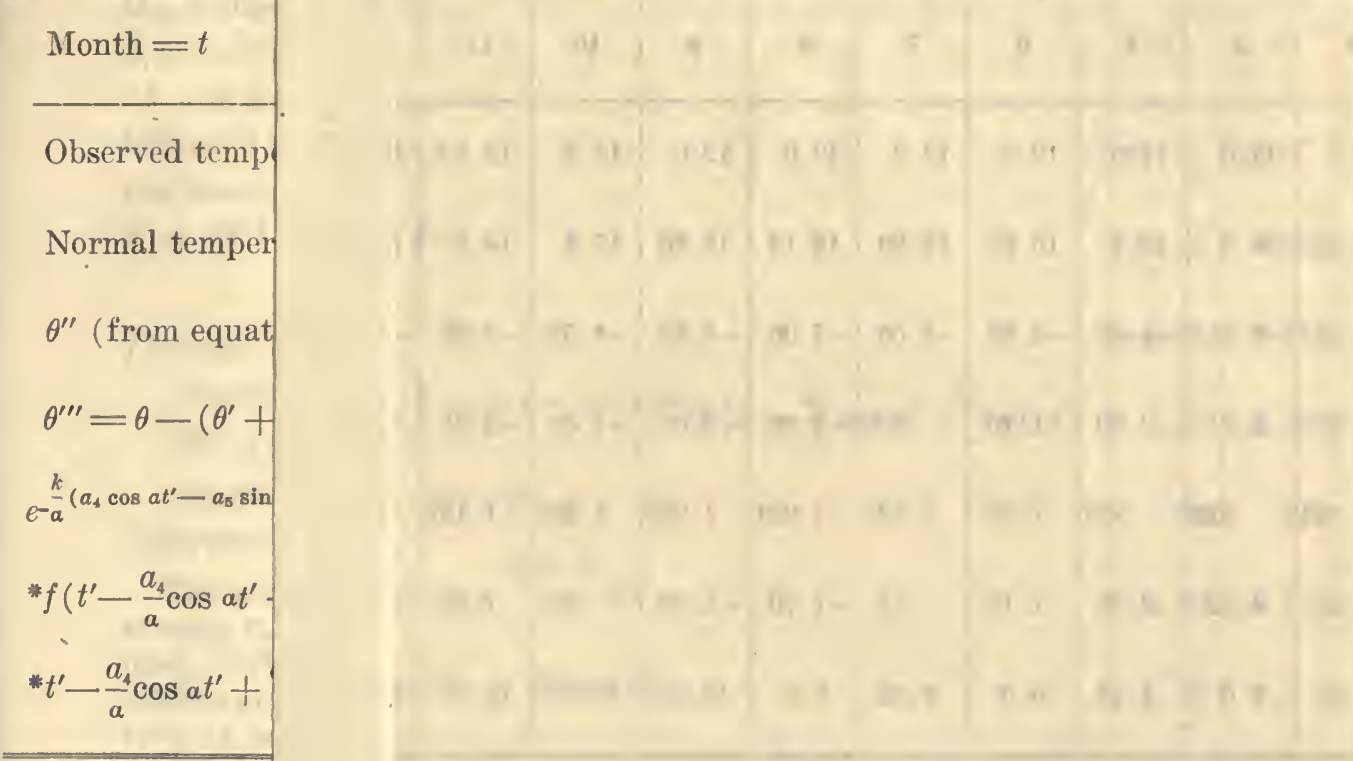

Normal temper $\theta^{\prime}+\theta^{\prime \prime}$

$\left(t-\frac{a_{4}}{a} \cos a t+\frac{a}{a}\right.$ $f\left[\left(t-\frac{a_{4}}{\alpha} \cos \alpha t\right.\right.$ $e^{-\frac{k\left(z-z_{0}\right)}{H_{1}}-\frac{k}{\alpha}(}$ $\theta^{\prime \prime \prime}=.188 e^{-}$ $\theta^{\prime}+\theta^{\prime \prime}+\theta^{\prime \prime \prime}=$ Observed temp Computed min 
$12=x$

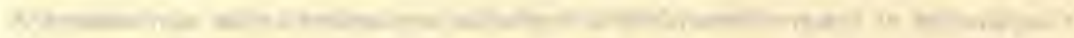

$1+20$

(1)

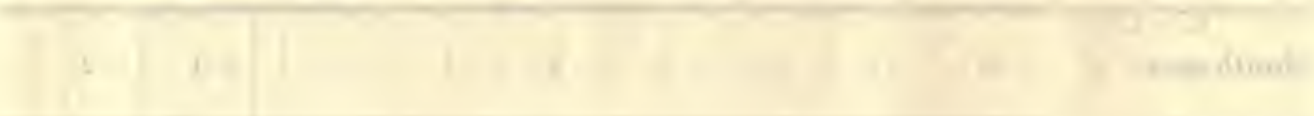

it in

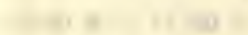

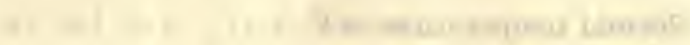

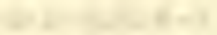

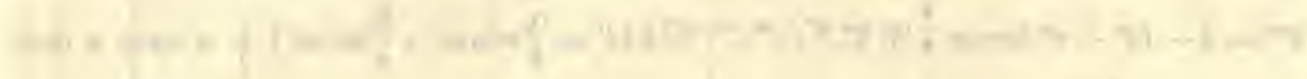

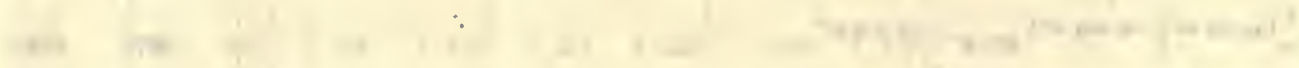

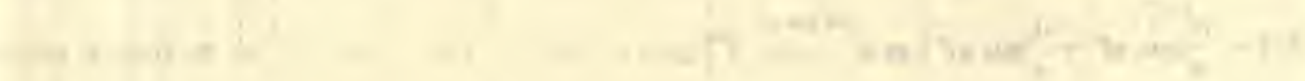

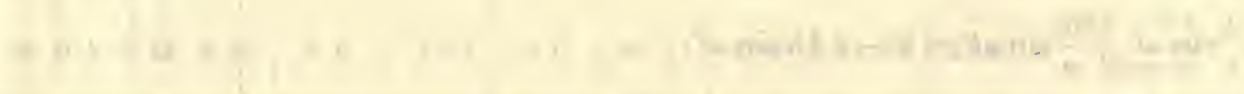

1

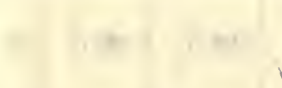

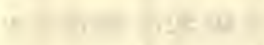

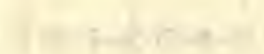

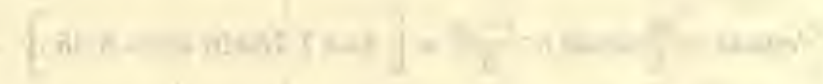

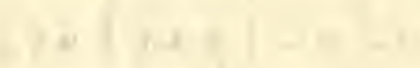

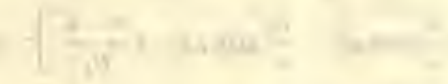

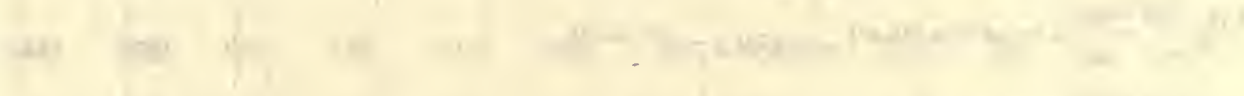

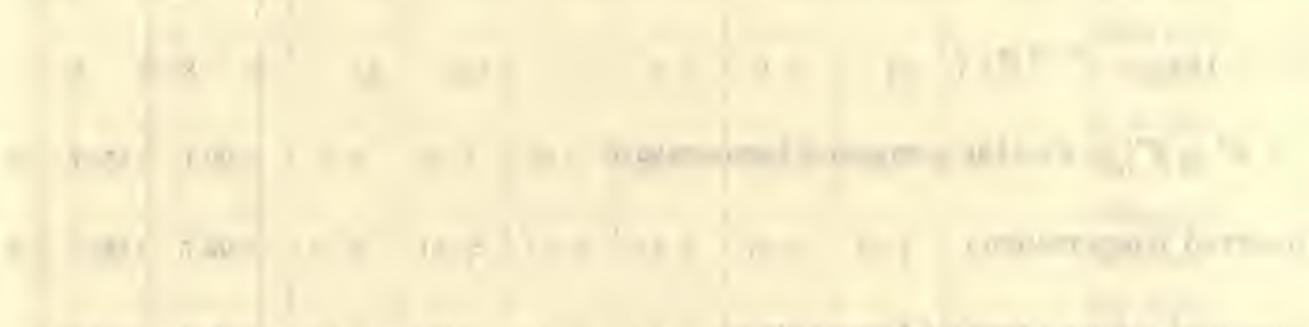

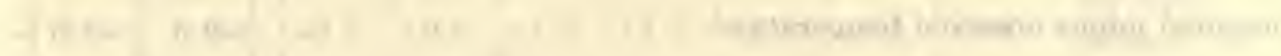

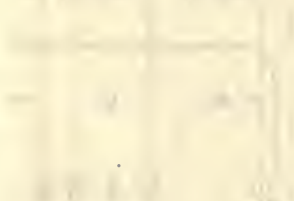


from the theory (pp. 355-360) are condensed in table 4, in which the following values of the constants are used: $a_{4}=0, a_{5}=-.6$, $a_{1}=-.318, \quad a_{3}=-.0244, \quad a_{2}=-.0166, \quad k=.20$, and $H=-1.2$ $\left(1-.6 \cos 30^{\circ} t\right)$ equals the drift, in degrees per month equals 1.0 to 3.8 miles in twenty-four hours. The mean wind velocity in miles per hour over the course considered (Moore, 1908-11) is approximately $V=10\left[1-.6 \cos (30 t)^{\circ}\right]$.

The rate of flow deduced from temperature data compared with that expected from the empirical relation of winds to currents and with direct observations on currents.

As stated by Helland-Hansen in his paper on physical oceanography (Murray and Hjort, 1912, p. 247) :

The wind may produce a current, particularly in the surface layers, thus altering the direction and velocity of the existing current. We know very little, however, about the relation between wind and current, through lack of detailed observations, although the question is naturally of the first importance from an oceanographical point of view, as well as from its bearings on the conditions of everyday life. This is one of the principal tasks for the oceanographer of the future; such observations are difficult to make, no doubt, but with modern methods much can be done.

However, numerous observations of winds and currents have been made. And, although the relation of wind and current varies with the wind velocity, the latitude, coast line, depth, and distribution of specific gravity, some progress has been made in estimating the drift that a given wind velocity will produce. A careful investigation of this question based on Ekman's theory $(1905,1906)$ and a large mass of available data made by Thorade (1914) yielded the following results. In case the coast is sufficiently distant and the effect of the pressure gradient due to differences in specific gravity is small, the drift will be directed at an angle of $45^{\circ}$ to the right of the wind direction in the northern hemisphere. The relation of the drift to the wind velocity estimated by Thorade $(1914$, p. 387) is

and

$$
H=\frac{.0259 \sqrt{V}}{\sqrt{\sin \phi}}, V \equiv 4.5 \frac{\text { meters }}{\text { sec. }}-\bar{c} .74 \frac{\mathrm{mi} .}{\text { hour }}
$$

$$
H=\frac{.0126 \mathrm{~V}}{\sqrt{\sin \phi}}, V \equiv 4.5 \frac{\text { meters }}{\text { sec. }} \gtreqless 8.74 \frac{\mathrm{mi} \text {. }}{\text { hour }}
$$

where $V$ is the wind velocity, $H$ is the current in meters per second, and $\phi$ is the latitude. 
The mean latitude of the drift computed from temperature data (p. 362) is $35^{\circ}$ and its direetion was $45^{\circ}$ to the right of the mean wind veloeity in aeeordance with Ekman's theory (1906) and Thorade's estimate from observations (1914). From equation (78) and the observed value of $V$ (p. 363) the drift would be 3.9 miles in twentyfour hours if it were due entirely to the observed winds, uninflueneed by the eoast and differenees in speeifie gravity. This estimate is of the same order as 2.4, that made from temperature observations (p. 363). Again, direet observations of the drift having a southerly component (Thorade, 1914, p. 283) near the head of the stream, Lat. $40^{\circ} \mathrm{N}$ to $50^{\circ} \mathrm{N}$, gave the values presented in table 5 .

TABLE 5

Observed surface drift, and values computed from temperature data

\begin{tabular}{c|c|c|c|c}
\hline Month & 4 & 5 & 10 & Mean \\
\hline Observed drift in 24 hours............................. & 3.69 & 2.05 & 2.41 & 2.6 \\
\hline No. of observations.......................................... & 21 & 24 & 54 & \\
\hline Computed drift in 24 hours.......................... & 3.12 & 3.65 & 1.68 & 2.8 \\
\hline
\end{tabular}

Thus the theoretieal drift estimated from temperature data agrees as well with the observations as eould be expeeted. And it appears from the eomparisons made that estimates of the drift from temperature data will prove to be as reliable as those made by other methods.

The surface current during a short time interval near the northwest coast of Africa, estimated from surface temperatures, and compared with direct observations, and with results deduced from the empirically ascertained relation of winds to currents.

From a series of direct measurements by means of a float designed especially for the purpose (Sehott et al., 1914), the average flow between latitudes $20^{\circ} \mathrm{N}$ and $28^{\circ} \mathrm{N}$, off the west eoast of Afriea, was found to be nearly parallel to the eoast and toward the southwest. These eurrent measurements were aceompanied by observations of surface temperatures and winds, and the stations were distributed along a line nearly parallel to the average surfaee drift and abont 150 miles offshore. All of the observations were made during the 
short time interval from June 2 to June 15, 1911, and are therefore appropriate for the application of the theory developed on pages 360362 for estimating surface currents from temperatures.

The mean position during the three days, June 2, 3, and 12, was Lat $30^{\circ} \mathrm{N}$, Long. $14: 6 \mathrm{~W}$, and that during the three days, June 13 , 14 , and 15 , was Lat. $24^{\circ} \mathrm{N}$, Long. $17.3 \mathrm{~W}$. The distance between these positions is 6.74 , the unit being a degree of latitude, and the mean surface temperatures were respectively 18.32 and $19: 12$, each value being the average of eighteen observations. In equation (73), page $361,\left(z-z_{0}\right)$ is the distance, measured in degrees of latitude in the direction of the drift, and the initial position is in this case at Lat. $30^{\circ} \mathrm{N}$. The direction of the drift was found to be to the south at an angle of about $27^{\circ}$ to the right (west) of the meridian, therefore the change in latitude corresponding to the distance $\left(z-z_{0}\right)$ along the line of the flow is $\left(\cos 27^{\circ}\right)\left(z-z_{0}\right)=.891\left(z-z_{0}\right)$. From these values and the numerical values of the constants given on page 346 , equation (73) becomes

$$
\theta=22.6-(.891)(.41)\left(z-z_{0}\right)+\bar{\theta} e^{\frac{-.217\left(z-z_{n}\right)}{H_{1}}}+(.891)\left(1.88 H_{1}\right)
$$

which gives the temperature at any point along the stream line, the mean velocity being $\Pi_{1}$ degrees per month.

To determine $H_{1}$ substitute the two mean temperatures with the corresponding values of $\left(z-z_{0}\right)$, thus obtaining two equations

$$
18.32=-22.6+\bar{\theta}+1.685 H_{1}
$$

and

$$
19.12=22.6+(.365)(6.74)+\bar{\theta} e^{\frac{1.461}{I I_{1}}}+1.685 H_{1}
$$

Eliminating $\bar{\theta}$ gives the equation

$$
-\left(4.28+1.685 H_{1}\right) e^{\frac{1.461}{H_{1}}}+1.685 H_{1}=-5.94
$$

from which the value of $H_{1}$, found by trial is

$$
H_{1}=-9.4 \text { degrees per month }=-.78 \text { miles per hour. }
$$

Using this value of $H_{1}$ the theoretical temperature at any point along the stream line is

$$
\theta=6.75-.365\left(z-z_{0}\right)+11.57 e^{.0231\left(z-z_{0}\right)}
$$

where $\left(z-z_{0}\right)$ is negative since the latitude decreases in the downstream direction. 
Direet estimates of the drift were made at six stations along this line from angular measurements relative to a float, the ship being manoeuvered in sueh a way as to keep the sounding eable as nearly vertieal as possible. The values obtained at eaeh station in the order from north to south are $1.0,0.7,0.9,0.8,0.9,1.3$ miles per hour in a southwesterly direetion. Eaeh value is the mean of about twenty-five

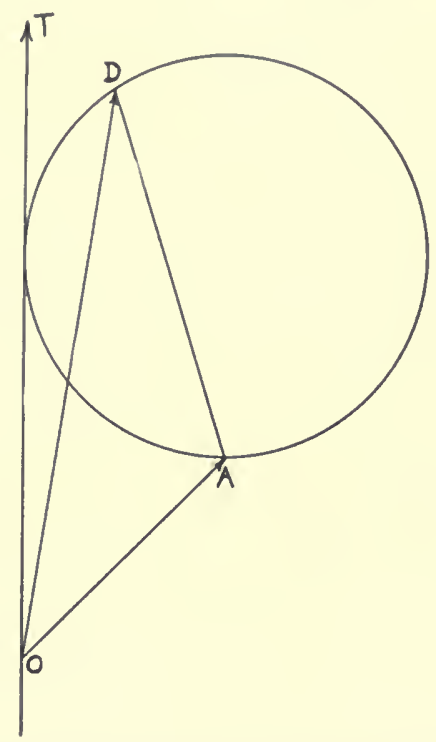

Fig. 3. Geometrical construction for determining the effect of a coast on the surface current produced by wind.

observations. The eomponents parallel to a line from the first to the last station having the mean direetion of the observed drift are 0.99 , $0.7,0.9,0.7,0.86$, and 1.11 miles per hour, and the mean value is 0.88 .

From the four estimates based on "dead reekoning" and the position of the ship determined from astronomieal observations at noon, the drift appeared to be direeted to the west of the direetion determined by the "float" method. The values are $0.4,0.5,0.4,0.4$ and the eomponents parallel to the mean direetion of the drift found by the float method are $0.3,0.2,0.16,0.19$, the mean value is 0.21 .

The wind blew steadily from the northeast, the observed veloeities in miles per hour being $28,23,28,34,3,18,13,28,28,28,34$, and 34 ; the mean is 25 .

From equation (78), page 363 , using $24^{\circ}$, the mean latitude of the stream line for $\phi$, the drift due to a wind veloeity of $V$ miles per hour would be $.01975 V$ miles per hour. Using the value 25 for $V$ the un- 
disturbed drift due to the wind would be 0.494 directed at an angle of $45^{\circ}$ to the right of the wind direction; this direction of drift is nearly the same as that obtained from dead reckoning. If the same wind velocity prevailed over the whole coastal belt, a correction to the above estimate of the drift must be made (Ekman, 1906, p. 23). The computation can be carried out graphically as follows (fig. 3). Let $O T$ be the direction of the wind, and $O A$ represent in magnitude and direction the "undisturbed drift". computed from equation (78). If a circle is described through $A$ tangent to $O T$, and a line $A D$ is drawn parallel to the coast then $O D$ will represent in magnitude and direction the corrected surface drift. In the case under consideration the corrected estimate $O D$ is twice the value of $O A$ and makes an angle of about $27^{\circ}$ to the right (west) of the observed mean direction. Therefore the component parallel to this observed direction is

$(O D) \cos 27^{\circ}=0.89(O D)=(0.89) 2(O A)=1.78(O A)$.

The results corresponding to various values of the wind $(V)$ are presented in the following list.

\begin{tabular}{c|c|c|c}
\hline$V$ & $O A$ & $O D$ & $(O D) \cos 27$ \\
\hline 13 & .257 & .51 & .46 \\
18 & .356 & .71 & .63 \\
25 & .494 & .99 & .88 \\
34 & .672 & 1.34 & 1.20 \\
\hline
\end{tabular}

Finally it is evident that the velocity of 0.78 miles per hour deduced from surface temperatures agrees well with the estimates made by the other methods.

\section{The Relation of Temperature to Time, Depth and Rate of Vertical Flow in the Interval from 40 to 600 Meters \\ Statement of assumptions and mathematical formulation of the problem.}

It has been found (p. 351) that the direct heating of the sea water by the absorption of solar radiation is proportional to $e^{-b_{1} y}$ where $b_{1}>.12$ and $y$ is the depth in meters. Hence at the depth exceeding 40 meters this direct heating effect would be less than 1 per cent of that at the surface. Also the temperature range at that depth would bear the same proportion to that at the surface if the variation in rate of gain of heat were due only to the variation in this rate of absorption. 
However, observation shows that there is a seasonal variation of $5^{\circ}$ at 40 meters and exceeding $1^{\circ}$ at 100 meters (Murray, 1898, p. 127; McEwen, 1916, p. 268) ; thus something other than the direct absorption of solar radiation must be the main factor in heating the water of these lower levels.

These facts show that there must be a transfer of heat between the upper and lower level, but the ordinary process of heat conductivity, as illustrated by laboratory experiments on still water, is wholly inadequate to effect this transfer at a sufficiently rapid rate (Wegemann, 1905a, 1905b). It is now generally recognized that this transfer of heat results from an alternating vertical (p. 338) eirculation of the water (Helland-Hansen, 1911-12, pp. 68, 69), in which at any given instant certain portions of the water are moving upward while others are moving downward. The resultant flow of a given column of water may be either upward or downward, or may be zero. Without analyzing the complicated process by which heat is transferred from one level to another in the ocean, it will be assumed to be similar to ordinary conduction. But the coefficient of conductivity corresponding to conditions in the ocean will depend mainly on the intensity of the circulation or mixing process (Gehrke, 1910, p. 68; Jacobsen, 1913, p. 71), and might be called the "coefficient of convective conductivity" to distinguish it from the ordinary laboratory coefficient. In the following investigation this coefficient of conductivity will be used and the direct effect of solar radiation will be neglected. If the resultant vertical flow is zero, the well known partial differential equation

$$
\frac{\partial \theta}{\partial t}=\mu^{2} \frac{\partial^{2} \theta}{\partial y^{2}}
$$

applies, where $\theta$ is the temperature, $t$ is the time, $y$ is the distance below the surface, and $\mu^{2}$ is the diffusivity, a constant proportional to conductivity. If the resultant vertical flow is $w$ it follows, as on pages $354-355$ that the time rate of change of temperature due to this flow is $\left(-w \frac{\partial \theta}{\partial y}\right)$ and the temperature equation then becomes

$$
\frac{\partial \theta}{\partial t}=\mu^{2} \frac{\partial^{2} \theta}{\partial y^{2}}-w \frac{\partial \theta}{\partial y}
$$

Equation (80) is a special case of the general equation of the conductivity in a moving medium (Winkelmann, 1906, p. 444). Equation (79), a special case of Fourtier's equation of the flow of heat in a 
stationary medium, has been applied to the problem of temperature distribution in the ocean by Wegemann (1905a, 1905b), using the laboratory value of $\mu^{2}$, but the theoretical results were of an entirely different order of magnitude from those given by observation.

Jacobsen (1913, p. 71) has successfully applied the equation of the form (79) to some data on the distribution of salinity and currents in the sea near Denmark. He determined $\mu^{2}$, the Mischungsintensität from field observations, using the idea that salt content, quantity of motion, temperature, and other properties of sea water vary because of the alternating changes in the position of the water particles. The writer is, however, not aware of any application of equation (80) to oceanographic problems.

Solution for the case in which the vertical flow is constant.

If the vertical velocity has the constant value $w_{1}$ then we have (p. 368) to find a solution of the following linear partial differential equation with constant coefficients

$$
\frac{\partial \theta}{\partial t}-\mu^{2} \frac{\partial^{2} \theta}{\partial y^{2}}+w_{1} \frac{\partial \theta}{\partial y}=0
$$

satisfying certain boundary conditions. To determine the temperature at any depth, having given that at the upper level $y=y_{2}$, we must have a solution reducing to the given function of the time $t$ (in this paper it will be a periodic function of $t$ ) at the upper level and having a given constant value at the lower boundary. A convenient method of solution is to assume

$$
\theta=M e^{a y+b t}
$$

and substitute in equation (81). The result is

$$
b+w_{1} a-\mu^{2} a^{2}=0 .
$$

Therefore $e^{a y+b t}$ is a solution of equation (81) for all values of the constant $M$ and for all values of $a$ and $b$ satisfying equation (83). Let

$$
a=a_{1} \pm b_{1} i
$$

where $a_{1}$ and $b_{1}$ are real, then from equation (83) we have

$$
b=\left[\mu^{2}\left(a_{1}^{2}-b_{1}^{2}\right)-w_{1} a_{1}\right] \pm\left[\left(2 a_{1} \mu^{2}-w_{1}\right) b_{1}\right] i
$$


and, if the solution is to be a periodic function of the time having the period $\frac{2 \pi}{a_{1}}$ where $\alpha_{1}$ is positive

$$
\begin{gathered}
\mu^{2}\left(a_{1}{ }^{2}-b_{1}{ }^{2}\right)-w_{1} a_{1}=0 \\
\left(2 a_{1} \mu^{2}-w_{1}\right) b_{1}=a_{1}
\end{gathered}
$$

Solving equation (86) for $a_{1}$ and equation (87) for $b_{1}$ we have

$$
a_{1}=\frac{w_{1} \mp \sqrt{w_{1}^{2}+4 \mu^{4} b_{1}^{2}}}{2 \mu^{2}}
$$

and

$$
b_{1}=\frac{a_{1}}{2 a_{1} \mu^{2}-w_{1}}
$$

Since the temperature and the amplitude of the temperature decrease as the depth increases, the exponent $a_{1} y$ and hence $a_{1}$ must be negative ( $y$ is positive in the direction from the upper surface downward): Therefore only the negative sign is admissible before the radical in equation $(88)$ and

$$
a_{1}=\frac{w_{1}-\sqrt{w_{1}^{2}+4 \mu^{4} b_{1}^{2}}}{2 \mu^{2}}=\frac{w_{1}}{2 \mu^{2}}-\frac{\sqrt{w_{1}^{2}+4 \mu^{4} b_{1}^{2}}}{2 \mu^{2}}
$$

is definitely determined by given values of $u_{1}, \mu^{2}$ and $\pm b_{1}$. Solving equation (87) for $a_{1}$ gives

$$
a_{1}=\frac{w_{1}}{2 \mu^{2}}+\frac{a_{1}}{2 b_{1} \mu^{2}}
$$

therefore because of equation (90) $\frac{a_{1}}{2 b_{1} \mu^{2}}$ must be negative, or $b_{1}$ must be negative since $a_{1}$ is assumed to be positive. From equations (90) and (91) we have

and

$$
a_{1}^{2}=b_{1}^{2} w_{1}^{2}+4 \mu^{4} b_{1}^{4}
$$

$$
b_{1}{ }^{2}=\frac{-w_{1}{ }^{2} \pm \sqrt{w_{1}^{4}+16 \mu^{4} a_{1}{ }^{2}}}{8 \mu^{4}}
$$

where only the plus sign is admissible since $b_{1}{ }^{2}$ is necessarily positive. Substituting this value of $b_{1}{ }^{2}$ in equation (90) gives

$$
a_{1}=\frac{w_{1}}{2 \mu^{2}}-\frac{\sqrt{w_{1}^{2}+\sqrt{w_{1}^{4}+16 \mu^{4} a_{1}^{2}}}}{2 \mu^{2} \sqrt{2}}
$$


substituting this value of $a_{1}$ in equation (89) gives

$$
b_{1}=\frac{a_{1}}{-\sqrt{\frac{w_{1}^{2}+\sqrt{w_{1}^{4}+16 \mu^{4} a_{1}^{2}}}{2}}}
$$

which agrees with the result already found on page 370 , that $\frac{a_{1}}{b_{1}}$ must be negative. From pages 369 and $370, \theta=M e^{a y+b t}$, where $a=a_{1} \pm b_{1} i$ and $b= \pm a_{1}= \pm\left(2 a_{1} \mu^{2}-w_{1}\right) b_{1}$.

The solution of equation (81) is therefore

$$
\theta=M e^{a_{1} y} \pm\left(b_{1} y+a_{1} t\right) i
$$

where $M$ and $a_{1}$ are arbitrary constants, $a_{1}$ and $b_{1}$ are given by equations (94) and (95) and the same value of $a_{1}$ is to be used with either the plus or the minus sign before the expression in brackets. From the properties of imaginary exponents equation (96) can be put in the real periodic form

$$
\theta=e^{a_{1} y}\left\{A_{1} \sin \left(b_{1} y+a_{1} t\right)+B_{1} \cos \left(b_{1} y+a_{1} t\right)\right\}
$$

where $A_{1}, B_{1}$ and $\alpha_{1}$ are arbitrary conștants.

Also since the differential equation is linear the sum of any number of such expressions will be a solution. Therefore the following more general expression

$$
\theta=\sum_{n=0}^{n=\infty} e^{a_{n} y}\left\{A_{n} \sin \left(b_{n} y+a_{n} t\right)+B_{n} \cos \left(b_{n} y+a_{n} t\right)\right\}
$$

is a solution, where $A_{n}, B_{n}$ and $a_{n}$ are arbitrary constants and $a_{n}$ and $b_{n}$ have the values

$$
a_{n}=\frac{w_{1}}{2 \mu^{2}}-\frac{\sqrt{w_{1}^{2}+\sqrt{w_{1}^{4}+16 \mu^{4} a_{n}^{2}}}}{2 \mu^{2} \sqrt{2}}
$$

and

$$
b_{n}=\frac{\sqrt{2 a_{n}}}{-\sqrt{w_{1}^{2}+\sqrt{w_{1}^{4}+16 \mu^{4} a_{n}^{2}}}}
$$

Denoting $-\frac{1}{\mu} \sqrt{\frac{a_{n}}{2}}$ by $\lambda_{n}$ and $\frac{W_{1}}{\mu^{2}}$ by $\lambda$ the following approximate expression for $a_{n}$ and $b_{n}$ can be easily derived

$$
\begin{gathered}
a_{n}=\frac{\lambda}{2}+\left(1+h_{n}^{2}+h_{n}^{4}\right) \lambda_{n} \\
b_{n}=\left(1-h_{n}{ }^{2}-h_{n}^{4}\right) \lambda_{n}
\end{gathered}
$$


where $h_{n}{ }^{2}=\frac{w_{1}{ }^{2}}{8 \mu^{2} a_{n}{ }^{2}}$ is small. If the velocity $w_{1}$ equals 0 , $a_{n}=b_{n}=-\frac{1}{\mu} \sqrt{\frac{a_{n}}{2}}$ and equation (98) reduces to the well known form

$$
\begin{aligned}
& \theta=\sum_{n=0}^{n=\infty} e^{-\frac{1}{\mu}}\left(\sqrt{\frac{a_{n}}{2}}\right) y\left\{A_{n} \sin \left(a_{n} t-\frac{1}{\mu} \sqrt{\frac{a_{n}}{2}} y\right)+B_{n} \cos \left(a_{n} t\right.\right. \\
& \left.\left.-\frac{1}{\mu} \sqrt{\frac{a_{n}}{2}} y\right)\right\}
\end{aligned}
$$

A solution independent of the time results, if in equation (83) we make $b=0$ and $a=\frac{W_{1}}{\mu^{2}}$, or $b=a=0$. The result is

$$
\theta=C e^{\frac{W_{1}}{\mu^{2} y}}+D=C e^{\lambda y}+D
$$

where $C$ and $D$ are arbitrary constants. This expression for $\theta$ can be added to the right-hand member of equation (98), giving the more general solution

$$
\theta=C e^{\lambda y}+D+e^{a_{1} y}\left\{A_{1} \sin \left(b_{1} y+a_{1} t\right)+B_{1} \cos \left(b_{1} y+a_{1} t\right)\right\}
$$

Solution for the case in which the vertical flow is a periodic function of the time.

If the vertical velocity has the value $w=w_{1}[1+r \cos$ at $]$ the general equation (80) becomes

$$
\frac{\partial \theta}{\partial t}=\mu^{2} \frac{\partial^{2} \theta}{\partial y^{2}}-w_{1}[1+r \cos a t] \frac{\partial \theta}{\partial y}
$$

Let

$$
\theta=e^{a y+f(t)}
$$

and substitute in equation (106), the result is

$$
\frac{d f(t)}{d t}-\mu^{2} a^{2}+a w_{1}[1+r \cos a t]=0
$$

from which

$$
f(t)=\left(\mu^{2} a^{2}-a w_{1}\right) t-\frac{a w_{1} r}{a} \sin a t+\bar{c}
$$

where $\bar{c}$ is an arbitrary constant. 
Let

$$
a=a_{1} \pm b_{1} i \text { or } a^{2}=a_{1}{ }^{2}-b_{1}{ }^{2} \pm 2 a_{1} b_{1} i
$$

then

$$
\theta=M e^{a_{1} y \pm i b_{1} y+\left[\mu^{2}\left(a_{1}{ }^{2}-b_{1}{ }^{2} \pm 2 a_{1} b_{1} i\right)-a_{1} w_{1} \mp b_{1} w_{1} i\right] t-\frac{a w_{1} r}{\alpha} \sin a t}
$$

the arbitrary constant of equation (109) being so chosen, that when $r$ equals zero, equation (111) reduces to equation (82) derived for a constant velocity.

Rearranging the terms in the exponent of $e$ in equation (111) gives

$$
\theta=M e^{a_{1} y+\left[\mu^{2}\left(a_{1}{ }^{2}-b_{1}{ }^{2}\right)-a_{1} w_{1}\right] t \pm i b_{1}}\left[y+\left(2 \mu^{2} a_{1}-w_{1}\right) t-\frac{w_{1} r}{\alpha} \sin a t\right]-\frac{a_{1} w_{1} r}{\alpha} \sin \alpha t
$$

Let

$$
b_{1}\left(2 \mu^{2} a_{1}-w_{1}\right)=a_{1}
$$

and

$$
\mu^{2}\left(a_{1}^{2}-b_{1}^{2}\right)-a_{1} w_{1}=0
$$

as before (p. 370). Substituting in equation (112) and making use of the properties of imaginary exponents gives

$$
\begin{aligned}
\theta & =M e^{a_{1} y \pm\left(a_{1} t+b_{1} y\right) i \mp \frac{b_{1} w_{1} r i}{a} \sin a t-\frac{a_{1} w_{1} r}{a} \sin a t} \\
& =\left(e^{a_{1} y-\frac{a_{1} w_{1} r}{a} \sin a t}\right)\left\{A_{1} \sin \left(a_{1} t+b_{1} y-\frac{b_{1} w_{1} r}{a} \sin a t\right)\right. \\
& \left.+B \cos \left(a_{1} t+b_{1} y-\frac{b_{1} w_{1} r}{a} \sin a t\right)\right\}
\end{aligned}
$$

where $a_{1}$ and $b_{1}$ have the values given on page 370 and $A_{1}, B_{1}$ and $a_{1}$ are arbitrary. The values

$$
b_{1}=a_{1}=0 \text { and } a_{1}=0 \text { or } \lambda
$$

are also consistent with equations (113) and (114) and lead to the solution

$$
C e^{\lambda y}+D-C\left(1-e^{-\frac{\lambda w_{1} r}{\alpha} \sin \alpha^{t}}\right) e^{\lambda y}
$$

where $C$ and $D$ are arbitrary constants and $\lambda$ has the value $\frac{W_{1}}{\mu^{2}}$. 
The differestial equation being linear, this solution can be added to the right-hand member of equation (115) giving the solution

$$
\begin{aligned}
& \theta=C e^{\lambda y}+D-C\left(1-e^{-\frac{\lambda w_{1} r}{\alpha} \sin \alpha t}\right) e^{\lambda \nu} \\
& +e^{a_{1} y-\frac{a_{1} w_{1} r}{a} \sin a t}\left\{A_{1} \sin \left[a_{1} t+b_{1} y-\frac{b_{1} w_{1} r}{a} \sin a t\right]\right. \\
& \left.+B_{1} \cos \left[a_{1} t+b_{1} y \frac{b_{1} w_{1} r}{a} \sin a t\right]\right\} \\
& =C e^{\lambda y}+D+\left\{A_{1} \sin \left[a_{1} t+b_{1} y-\frac{b_{1} w_{1} r}{a} \sin a t\right]\right. \\
& \left.+B_{1} \cos \left[a_{1} t+b_{1} y-\frac{b_{1} w_{1} r}{a} \sin a t\right]\right\}-\left(1-e^{-\frac{\lambda w_{1} r}{a} \sin a t}\right) \\
& \left\{C e^{\lambda y}+e^{a_{1} y}\left(A_{1} \sin \left[a_{1} t+b_{1} y \frac{b_{1} w_{1} r}{a} \sin \alpha t\right]\right.\right. \\
& \left.\left.+B_{1} \cos \left[a_{1} t+b_{1} y-\frac{b_{1} w_{1} r}{a} \sin a t\right]\right)\right\}
\end{aligned}
$$

which reduces to equation (105) corresponding to a constant velocity when $r=0$. If the product of $\lambda, a_{1}$ or $b_{1}$ by $\left(\frac{w_{1} r}{\alpha} \sin a t\right)$ is small equation (116) can be transformed into the following approximate form, retaining only the first powers of the small quantities.

$$
\begin{aligned}
\theta= & C e^{\lambda y}+D-C\left(\frac{\lambda w_{1} r}{a} \sin a t\right) e^{\lambda y} \\
& +e^{a_{1} y}\left\{A_{1} \sin \left(a_{1} t+b_{1} y\right)+B_{1} \cos \left(a_{1} t+b_{1} y\right)+\frac{w_{1} r}{2 a}\left[\left(B_{1} b_{1}-A_{1} a_{1}\right)\right.\right. \\
& \left(\cos \left(\overline{a-a_{1}} t-b_{1} y\right)-\cos \left(\overline{a+a_{1}} t+b_{1} y\right)\right)-\left(B_{1} a_{1}+A_{1} b_{1}\right) \\
& \left.\left.\left(\sin \left(\overline{a+a_{1}} t+b_{1} y\right)+\sin \left(\overline{a-a_{1}} t-b_{1} y\right)\right)\right]\right\}
\end{aligned}
$$

Numerical values of the constants in the solution, determined from temperature observations in the Pacific near San Diego.

It is well known that the waters of certain inshore regions. including that off the west coast of North America, have a temperature significantly below the normal for the latitude. Various explanations of this phenomena off the California coast have been offered, but (Holway, 1905, and McEwen, 1912, 1914, 1916) the only one so far proposed that is consistent with all of the known facts is that of an upward flow of cold water from lower levels. 
Assuming this upward flow to be the only cause of the temperature reduction, the theory developed on pages 372-374 will now be applied to the series of temperature observations made off the Coronado Island about twenty miles from San Diego (McEwen, 1916, pp. 267, 268 and pl. 26). It follows from Ekman's theory (p. 401) that the vertical velocity off the California coast is proportional to the component of the wind velocity parallel to the coast, and decreases in magnitude as the distance from the coast increases. For this reason the velocity estimated from the temperature data mentioned above will be less than that nearer the coast.

TABLE 6

Average of observed and computed monthly temperatures off San Diego at a series of depths.

\begin{tabular}{|c|c|c|c|c|c|c|c|c|c|c|c|c|c|c|}
\hline Month. & & 1 & 2 & 3 & 4 & 5 & 6 & 7 & 8 & 9 & 10 & 11 & 12 & mean \\
\hline \multicolumn{15}{|c|}{ Depth in meters } \\
\hline & & 15.0 & 14.3 & 14.6 & 15.2 & 16.1 & 17.8 & 19.7 & 20.6 & 20.2 & 18.8 & 16.8 & 15.5 & 17.0 \\
\hline \multirow[t]{2}{*}{0} & $\mathrm{C}$ & & $\ldots$ & $\ldots$ & $\ldots$ & $\ldots$ & $\ldots$ & $\ldots$ & $\ldots$ & $\ldots$ & $\ldots$ & $\ldots$ & $\ldots$ & ....... \\
\hline & & 15.0 & 14.6 & 14.5 & 14.7 & 15.4 & 16.6 & 18.2 & 19.5 & 19.9 & 18.8 & 16.8 & 15.4 & 16.6 \\
\hline \multirow[t]{2}{*}{10} & & .... & .... & $\ldots$. & .... & $\ldots$. & .... & $\ldots$. & .... & $\ldots$. & .... & $\ldots$ & .... & ....... \\
\hline & & 14.2 & 14.2 & 14.0 & 13.6 & 13.0 & 14.2 & 15.0 & 16.0 & $\mid 18.2$ & 19.0 & 16.2 & 15.0 & 15.2 \\
\hline \multirow[t]{2}{*}{20} & C & $\ldots$ & $\ldots$ & $\ldots$ & $\ldots$ & $\ldots$ & $\ldots$ & $\ldots$ & $\ldots$ & $\ldots$ & $\ldots$ & $\ldots$ & $\ldots$ & ....... \\
\hline & & 13.8 & 13.8 & 13.5 & 12.6 & 11.0 & 12.2 & 13.0 & 14.0 & 17.8 & 18.0 & 15.8 & 14.5 & 14.2 \\
\hline \multirow[t]{2}{*}{30} & C & 1 & .... & .... & .... & .... & $\ldots$. & .... & $\ldots$ & $\ldots$. & .... & .... & .... & ....... \\
\hline & & 13.4 & 13.4 & 13.0 & 11.0 & 10.5 & 10.8 & 11.8 & 12.7 & 14.8 & 16.8 & 15.4 & 14.0 & 13.1 \\
\hline \multirow[t]{2}{*}{40} & & 13.4 & 11.9 & 10.6 & 9.9 & 9.9 & 10.6 & 11.9 & 13.4 & 14.7 & 15.5 & 15.5 & 14.7 & ....... \\
\hline & & 13.1 & 13.0 & 12.3 & 10.5 & 10.0 & 10.5 & 11.0 & 12.0 & 13.6 & 15.0 & 15.1 & 13.5 & 12.5 \\
\hline \multirow[t]{2}{*}{50} & & 13.2 & 11.9 & 10.6 & 9.8 & 9.8 & 10.4 & 11.6 & 12.9 & 14.2 & 14.9 & 15.0 & 14.4 & $\ldots$ \\
\hline & & 12.8 & 12.6 & 11.7 & 10.0 & 9.9 & 10.2 & 10.7 & 11.0 & 12.8 & 14.3 & 14.7 & 13.2 & 12.0 \\
\hline \multirow[t]{2}{*}{60} & C & 13.1 & 11.8 & 10.6 & 9.9 & 9.7 & 10.2 & 11.2 & 12.5 & 13.7 & 14.4 & 14.6 & 14.1 & ....... \\
\hline & 0 & 12.4 & 12.1 & 11.0 & 9.9 & 9.8 & 10.0 & 10.5 & 10.8 & 12.2 & 13.8 & 14.1 & 12.9 & 11.6 \\
\hline \multirow[t]{2}{*}{70} & $\mathrm{C}$ & 12.9 & 11.7 & 10.6 & 9.8 & 9.6 & 10.0 & 10.9 & 12.0 & 13.2 & 13.9 & 14.2 & 13.8 & 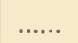 \\
\hline & 0 & 12.0 & 11.7 & 10.7 & 9.8 & 9.7 & 9.8 & 10.3 & 10.7 & 11.8 & 13.0 & 13.7 & 12.7 & 11.3 \\
\hline \multirow[t]{2}{*}{80} & $\mathrm{C}$ & 12.7 & 11.6 & 10.6 & 9.8 & 9.5 & 9.8 & 10.6 & 11.6 & 12.7 & 13.5 & 13.7 & 13.4 & ...... \\
\hline & 0 & 11.7 & 11.3 & 10.3 & 9.6 & 9.6 & 9.8 & 10.2 & 10.5 & 11.2 & 12.8 & 13.2 & 12.3 & 11.0 \\
\hline \multirow[t]{2}{*}{90} & $\mathrm{C}$ & 12.5 & 11.5 & 10.5 & 9.8 & \begin{tabular}{|l|} 
\\
\end{tabular} & 9.7 & 10.3 & 11.3 & 12.3 & 13.0 & 13.3 & 13.1 & ....... \\
\hline & $\mathrm{O}$ & 11.3 & 11.0 & 10.0 & 9.5 & 9.5 & 9.7 & 10.0 & 10.3 & 11.0 & 12.4 & 12.8 & 11.9 & 10.8 \\
\hline \multirow[t]{2}{*}{100} & C & 12.2 & 11.4 & 10.4 & \begin{tabular}{|l|} 
\\
\end{tabular} & 9.4 & 9.5 & 10.1 & 10.9 & 11.9 & 12.6 & 13.0 & 12.8 & $\ldots \ldots$ \\
\hline & $\mathrm{O}$ & 10.3 & 9.9 & 9.2 & 9.0 & 9.0 & 9.2 & 9.5 & 9.8 & 10.2 & 10.9 & 11.0 & 10.7 & 9.9 \\
\hline \multirow[t]{2}{*}{150} & $\mathrm{C}$ & 11.2 & 10.7 & 10.0 & 9.4 & 9.0 & 8.9 & 9.1 & 9.6 & 10.2 & 10.9 & 11.3 & 11.4 & \\
\hline & $\mathrm{O}$ & 9.5 & 9.0 & 8.8 & 8.7 & 8.8 & 8.9 & 9.1 & 9.4 & 9.7 & 10.2 & 10.4 & 10.0 & 9.4 \\
\hline \multirow[t]{2}{*}{200} & C & 10.1 & 9.9 & 9.5 & 9.1 & 8.7 & 8.5 & 8.5 & 8.7 & 9.1 & 9.6 & 10.0 & 10.2 & $\ldots .$. \\
\hline & $\mathrm{O}$ & 8.4 & 8.1 & 8.3 & 8.2 & 8.2 & 8.2 & 8.4 & 8.7 & 9.0 & 9.4 & 9.4 & 8.7 & 8.6 \\
\hline \multirow[t]{2}{*}{300} & C & 8.5 & 8.5 & 8.4 & 8.2 & 8.0 & 7.8 & 7.7 & 7.7 & 7.8 & 8.0 & 8.2 & 8.4 & \\
\hline & $\mathrm{O}$ & 7.8 & 7.7 & 7.6 & 7.5 & 7.6 & 7.6 & 7.7 & 7.8 & 8.0 & 8.4 & 8.4 & 7.8 & 7.8 \\
\hline \multirow[t]{2}{*}{400} & C & 7.4 & 7.5 & 7.5 & 7.5 & 7.4 & 7.2 & 7.1 & 7.0 & 7.0 & 7.1 & 7.2 & 7.3 & \\
\hline & $\mathrm{O}$ & $\ldots$ & $\ldots$ & $\ldots$ & $\ldots$ & $\ldots$ & $\ldots$ & $\ldots$ & $\ldots$ & $\ldots$ & $\ldots$. & $\ldots$ & $\ldots$ & 7.0 \\
\hline 500 & C) & 6.8 & 6.8 & 6.8 & 6.8 & $6.7 \mid$ & 6.7 & 6.7 & 6.6 & 6.6 & 6.6 & 6.7 & 6.7 & \\
\hline
\end{tabular}


From table 6, which gives the observed temperature averages at different depths and months, the constants of equation (116) or the simpler approximate form equation (117) will now be determined. The mean annual temperature $\theta_{m}$ is given by the first two terms

$$
C e^{\lambda y}+D=\theta_{m}
$$

which can be put in the linear form

$$
\log _{e}\left(\theta_{m}-D\right)=\log _{e} C+\lambda y .
$$

Assuming different values of $D$, plotting the results, and selecting the value of $D$, for which the points fell most nearly on a straight line, resulted in the following values of the constants:

$$
D=5.6, \quad C=8.3, \quad \lambda=-.004
$$

or

$$
\theta_{m}=5.6+8.3 e^{-.004 y}
$$

where $y$ is the depth in meters.

The satisfactory agreement between the computed and observed values of $\theta_{m}$, shown by table 7 , proves that the form of the function deduced from theory differs but little from the true form.

TABLE 7

Computed and observed mean annual temperatures at a series of depths from 40 to 700 meters

\begin{tabular}{c|c|c|c|c|c|c|c|c|c|c|c|c|c|c}
\hline Depth & 40 & 50 & 60 & 70 & 80 & 90 & 100 & 150 & 200 & 300 & 400 & 500 & 600 & 700 \\
\hline$\theta_{m}$ computed & 12.7 & 12.4 & 12.1 & 11.9 & 11.6 & $11: 4$ & 11.2 & 10.2 & 9.3 & 8.1 & 7.3 & $6: 7$ & 6.4 & $6^{\circ} 0$ \\
$\theta_{m}$ observed.. & 13.1 & 12.5 & 12.0 & 11.6 & 11.3 & 11.0 & 10.8 & 9.9 & 9.4 & 8.6 & 7.8 & 7.0 & 6.3 & 5.5 \\
Differcnce .... & -.4 & -.1 & +.1 & +.3 & +.3 & +.4 & +.4 & +.3 & -.1 & -.5 & -.5 & -.3 & +.1 & +.5 \\
\hline
\end{tabular}

The time of minimum wind velocity is in December, that of the maximum is in July (McEwen, 1912, p. 265), and the magnitude of the wind velocity, and therefore the vertical velocity of the water, is approximately proportional to $1+r \cos \frac{\pi t}{6}$ where $t=12$ corresponds to the time halfway between June and July and $r=0.2$. Also since, as shown by table 6 , the temperatures have the same period as the wind, $a_{1}=\alpha=\frac{\pi}{6}$ in equation (117). In order to determine the remaining constants substract from the observed temperature for 
each month and depth the observed mean annual temperature for that depth. Then subtract the expression

$$
-C\left(\frac{\lambda w_{1} r}{a} \sin a t\right) e^{\lambda y}
$$

from each of these values using a provisional value of $w_{1}$. Then fit

$$
M e^{a_{1} y} \cos \left(a t+b_{1} y-\epsilon^{\prime}\right)
$$

the equivalent of the expression

$$
e^{a_{1} y}\left\{A_{1} \sin \left(a t+b_{1} y\right)+B_{1} \cos \left(a t+b_{1} y\right)\right\}
$$

(p. 374) to these remainders, thus determining $M, \epsilon^{\prime}, a_{1}$ and $b_{1}$. The last part of equation (117) is neglected at first and its value estimated later. Assuming $w_{1}$ to be $-31 \frac{\text { meters }}{\text { month }}$ the expression $-C \frac{\lambda w_{1} r}{a}(\sin a t) e^{\lambda y}$ becomes $-.38\left(\sin \frac{\pi t}{6}\right) e^{-.004 y}$.

The following formulae corresponding to the special case when $a=a_{1}=\frac{\pi}{6}$ are useful in determining $a_{1}, b_{1}, w_{1}$ and $\mu^{2}$, and follow from equations (89, 91, 94 and 95) remembering that $\lambda=\frac{W_{1}}{\mu^{2}}$.

$$
\begin{gathered}
b_{1}=-\frac{.741}{\sqrt{w_{1}^{2}+\sqrt{w_{1}{ }^{2}+4.4 \mu^{4}}}}=+\frac{.524}{2 \mu^{2} a_{1}-w_{1}}=\frac{.524}{\mu^{2}\left(2 a_{1}-\lambda\right)} \\
a_{1}=\frac{w}{2 \mu^{2}}+\frac{.2619}{\mu^{2} b_{1}} ; \quad \mu^{2} b_{1}=\frac{.524}{2 a_{1}-\lambda} \\
(\lambda \mu)^{4}=\frac{4.4}{\left[\left(\frac{.55}{\left[\lambda\left(\mu^{2} b_{1}\right)\right]^{2}}\right)^{2}-1\right]}
\end{gathered}
$$

$a_{1}$ can readily be determined from the rate at which the annual range varies with the depth. $\lambda$ was determined from the mean annual temperature at different depths. These values substituted in equation (122) give $\mu^{2} b_{1}$ from which $\mu^{2}$ and $b_{1}$ can be found by substituting in equations (123) and (122), and finally the product $\lambda \mu^{2}$ gives the velocity $w_{1} \cdot *$

* If $\lambda$ and $b_{1}$ are given, the following equations derived from equations 90 and 95 can be used for computing the remaining quantities:

$$
\mu^{2}=\frac{-a_{1}}{b_{1} \sqrt{\left(2 b_{1}\right)^{2}+\lambda^{2}}}, \quad w_{1}=\frac{-\lambda a_{1}}{b_{1} \sqrt{\left(2 b_{1}\right)^{2}+\lambda^{2}}}, \quad a_{1}=\frac{\lambda}{2}-\frac{1}{2} \sqrt{\left(2 b_{1}\right)^{2}+\lambda^{2}}
$$


The eonstants obtained in this way are listed below:

$$
\begin{aligned}
& \lambda=-.004, a_{1}=-.008, \mu^{2}=7760, b_{1}=-.00560, w_{1}=-31 \frac{\text { meters }}{\text { month }} \\
& \lambda_{1}=-\frac{1}{\mu} \sqrt{\frac{\pi}{12}}=-.0058, \quad M=4.40, \quad \epsilon^{\prime}=-61^{\circ} .
\end{aligned}
$$

Assuming $t=1$ for January, and using the same origin for determining the time in the expression for wind veloeities, the expression for the temperature beeomes

$$
\begin{aligned}
& \theta=5.6+8.3 e^{-.004 y}+4.4 e^{-.008 y} \cos (30 t-.32 y+61)^{\circ} \\
& -.38 e^{-.004 y} \cos (30 t+75)^{\circ}
\end{aligned}
$$

remembering that $C=8.3$ and $D=5.6$ (p. 376).

The value of $\mu^{2}=7760$, when expressed in c.g. s. units is

$$
7760 \frac{(100)^{2}}{30 \times 24 \times 3600}=30,
$$

which is about 25,000 times the laboratory value (Wegemann, 1905a, p. 139). But this quantity $\mu^{2}$ is the same as the Mischungsintensität (Jacobsen, 1913, p. 71), whieh is a measure of the rate of transfer of salts, heat, or other properties of sea water arising from the mixing of water partieles in the alternating eireulation (p. 368). Suppose the diffusion of salts and the moleeular eonduetivity of heat to be negligible in eomparison to the rate of transfer due to the alternating or reeiproeal ehanges in the positions of the water partieles: then as Jacobsen (1913, p. 71) says, the value of this eoeffieient, the Mischungsintensität, determined from any of the properties should be the same under the same eonditions. He found values ranging from 1.9 to 3.8 from observations on eurrents and the distribution of salinities in the sea near Denmark. From observations on tidal eurrents and salinities in a neighboring region he obtained the values ranging from 0.3 to 11.4. The value 30 obtained from temperatures in the San Diego region is of the some order of magnitude, but the intensity of the eireulation in the two regions would probably be different, henee the eoeffieients would be expeeted to differ.

The idea regarding the alternating motion of water in the oeean held by Krümmel and Ruppin (1905, p. 36) may be summarized as follows: The coefficient of viseosity determined from laboratory experiments, in whieh the motion of the water is slow and takes place along 
parallel surfaces, varies from .008 to .02 for a wide range of temperatures and salinities. But the idea of laminar flow no longer holds when one considers the motion of whole volumes of water, hundreds of meters in thickness, throughout which there is a pressure gradient, as is often the case in oceanographic problems. In such cases one should not use innere Reibung (viscosity), but Massenwiderstand (hydraulic friction).

The character of the motion is no longer simply laminar (one of simple sliding to and fro, parallel to a given plane) but the particles of fluid leave their surfaces and move in vortices along stream lines transverse to the laminar motion. Thus a much greater resistance is developed. For example, the values of the coefficient of viscosity obtained by Nansen in his ocean rescarches are 200 to 40,000 times the laboratory value.

The same general idea has been successfully applied to certain meteorological problems relative to wind, temperature, and humidity by G. I. Taylor (1915). He found that the transfer, in a vertical direction, of heat and water vapor in the atmosphere followed the law of heat conductivity in solids, and that the effect of friction on the motion of the air could be taken into account by substituting in the general equations of motion a quantity called "eddy viscosity" for the laboratory value of the coefficient of viscosity.

From the observed relation of air temperature to height off the coast of Labrador, he obtained values of the coefficient; of "eddy conductivity" from $.57 \times 10^{3}$ to $3.4 \times 10^{3}$, corresponding to wind velocities varying from 2 to 3.4 Beaufort. Also from observations on the relation of wind velocity and direction to height he obtained values of the coefficient of cddy viscosity varying from $.77 \times 10^{3}$ to $6.9 \times 10^{3}$. The values of these coefficients are more than 10,000 times the laboratory values, the ratio being of the same order of magnitude as that obtained for sea water.

In general, comparisons of his theoretical results with observations indicated a very satisfactory agreement. An especially good agreement was found between the predicted and the observed values of the angle between the wind and the horizontal pressure gradient at different levels. 

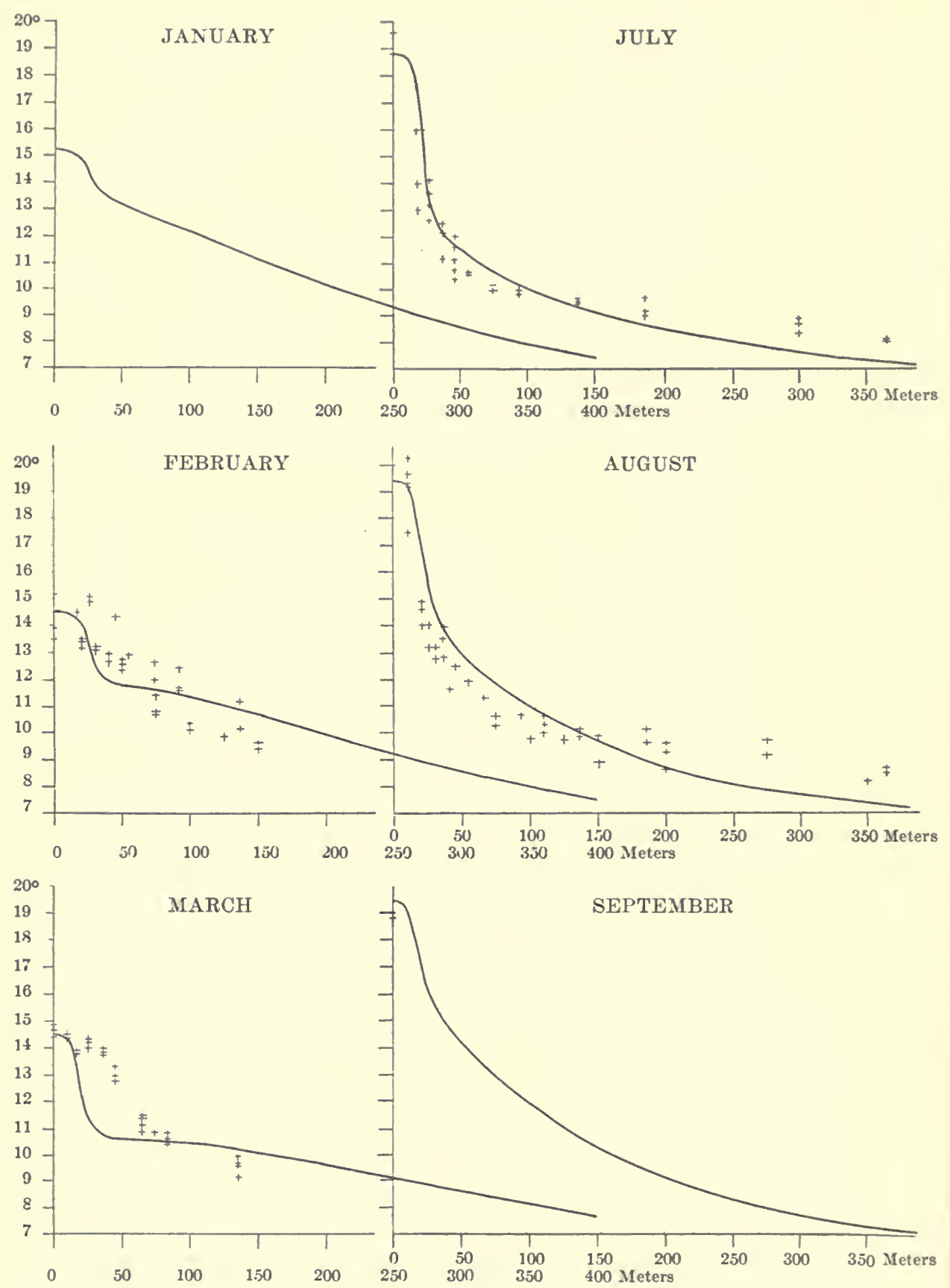

Figs. 4, 5, 6, 7, 8, and 9. Curves showing the theoretical relation of ocean temperatures to depth in a region approximately eight miles west of the Coronado Islands. The crosses $(t)$ correspond to observed temperatures. 

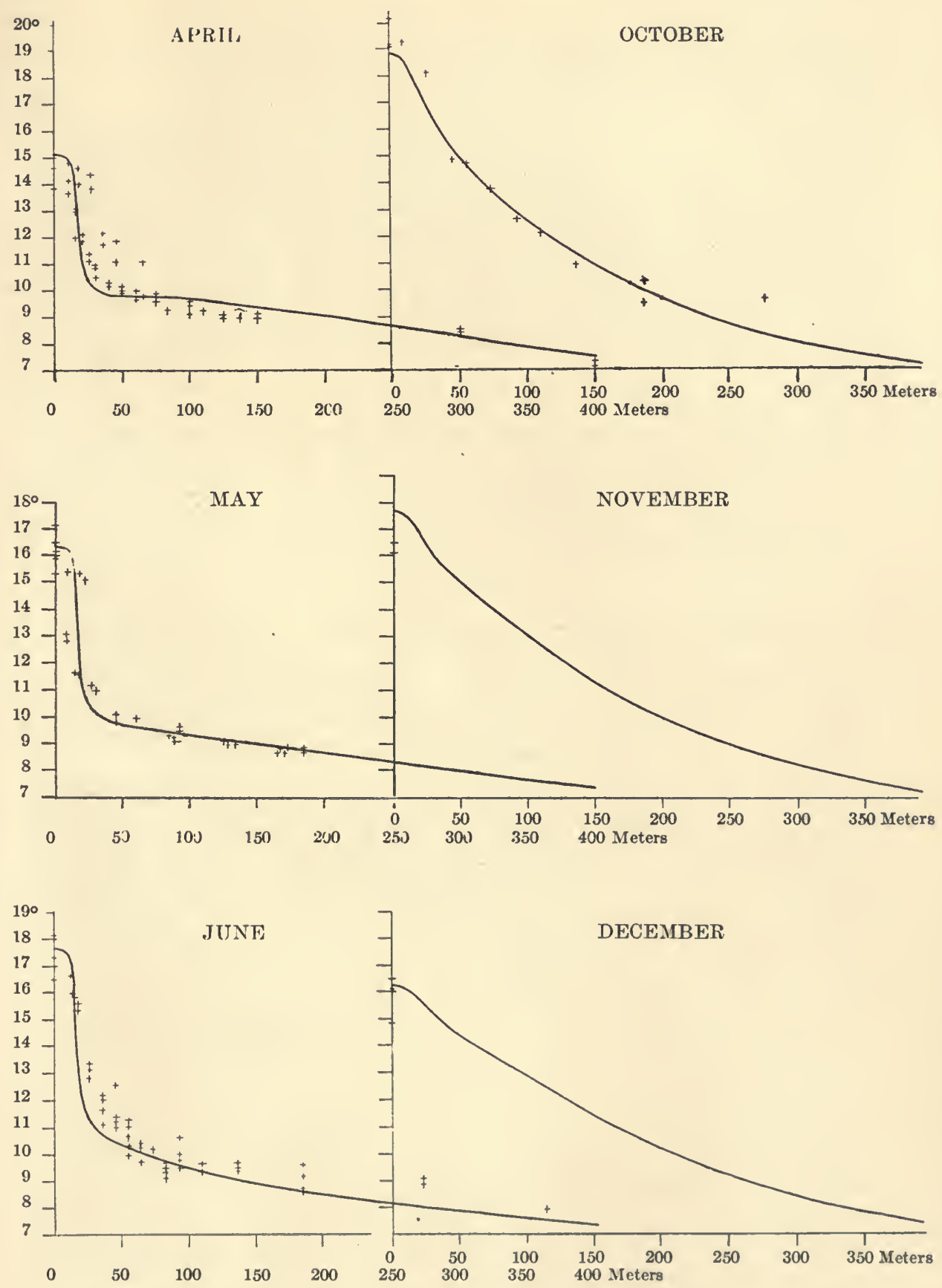

Figs. 10, 11, 12, 13, 14, and 15. Curves showing the theoretical relation of ocean temperatures to depth in a region approximately eight miles west of the Coronado Islands. The crosses $(t)$ correspond to observed temperatures. 
Comparison of theoretical and observed monthly temperatures at depths from 10 to 600 meters in the San Diego region.

The values computed from equation (124) and entered under the observed temperatures given in table 6 are seen to agree well with the mean of the observed values, thus proving the approximate correctness of the form of the function deduced from theory. These computed values and those from table 12 for the surface are also shown graphically by figures 4 to 15 , on which are entered a number of points corresponding to actual observations (Michael and McEwen, 1915, 1916).

Solution of the problem of temperature reduction due to upuelling with application relative to the 40 meter level in the San Diego region.

In the relation of mean anmual temperature to depth

$$
\theta_{m}=C e^{\lambda y}+D=\phi
$$

deduced from the differential equation (80), $\lambda=\frac{w_{1}}{\mu^{2}}$ equals the velocity divided by the diffusivity, but $C$ and $D$ are constants of integration. From observations of the mean annual temperature at a series of deptlis these constants can be determined as was done on pages 372 to 376 , and they correspond to the particular physical conditions under which the observations were made. For the same value of $D$, the deep water temperature, but a different value of one of the physical conditions, say the velocity $w_{1}$, what will the temperature $\phi$ be? To answer this question it is necessary to know the relation of each constant to the velocity $w_{1}$. The relation of $\lambda$ to $w_{1}$ is known and it remains to find the relation of $C$ to $w_{1}$.

In the limiting case in which $\lambda \doteq 0$, denote the new value of the constants by $C^{\prime}, D^{\prime}$ and $\lambda^{\prime}$; then expanding the exponential gives

$$
\phi^{\prime}=C^{\prime} e^{\lambda^{\prime} y}+D^{\prime}=C^{\prime} \lambda^{\prime} y+C^{\prime}+D^{\prime}=B^{\prime} y+D_{1}{ }^{\prime}
$$

where $B^{\prime}=C^{\prime} \lambda^{\prime}$ is the constant temperature gradient corresponding to zero vertical velocity.

Let

$$
C=\frac{B^{\prime}}{\lambda} f_{1}(\lambda)
$$

and

$$
D=D^{\prime} f_{2}(\lambda)
$$

where $f_{1}(0)=f_{2}(0)=1$, since, as $\lambda \doteq 0, C \doteq C^{\prime}$ and $D \doteq D^{\prime}$. 
Substituting in equation (125) gives

$$
\phi=+\frac{B^{\prime}}{\lambda} f_{1}(\lambda) e^{\lambda y}+D^{\prime} f_{2}(\lambda)
$$

where the forms of the functions $f_{1}(\lambda)$ and $f_{2}(\lambda)$ are to be determined. At the greatest depth, $y_{1}$ for which the theory is valid, assume the temperature to have the constant value $\phi_{1}$ for all values of $\lambda$. What effect will a vertical velocity have on the temperature above this level? The right-hand members of the equations (126) and (129) are equal for $y=y_{1}$, since $\phi_{1}$ is assumed to be independent of $\lambda$ at that depth, that is,

$$
\phi_{1}=\frac{B^{\prime}}{\lambda} f_{1}(\lambda) e^{\lambda y_{1}}+D^{\prime} f_{2}(\lambda)=B^{\prime} y_{1}+D^{\prime}+C^{\prime}
$$

Therefore from equations (129) and (130)

$$
\begin{aligned}
\phi & =\frac{B^{\prime}}{\lambda} f_{1}(\lambda) e^{\lambda y}+D^{\prime} f_{2}(\lambda)-\frac{B^{\prime}}{\lambda} f_{1}(\lambda) e^{\lambda y_{1}}-D^{\prime} f_{2}(\lambda)+B^{\prime} y_{1}+D^{\prime}+C^{\prime} \\
& =\frac{B^{\prime}}{\lambda} f_{1}(\lambda)\left[e^{\lambda y}-e^{\lambda y_{1}}\right]+B^{\prime} y_{1}+D_{1}^{\prime} .
\end{aligned}
$$

Subtracting the general value of $\phi$ given by equation (131) from the particular value $\phi^{\prime}$ corresponding to the case of no upwelling given by equation (126) gives

$$
\phi^{\prime}-\phi=B^{\prime}\left(y-y_{1}\right)-\frac{B^{\prime}}{\lambda} f_{1}(\lambda)\left(e^{\lambda y}-e^{\lambda y_{1}}\right)=\Delta \phi
$$

the reduction in temperature due to the upwelling velocity $w_{1}=-\mu^{2} \lambda$. It remains to determine $\mathrm{B}^{\prime}$ and the form of the function $f_{1}(\lambda)$.

The temperature change due to the variation of velocity with the time was found to be approximately

$$
-C e^{\lambda y}\left(1-e^{-\frac{\lambda w_{1} r}{a} \sin a t}\right)
$$

(equation 116), where the velocity is

$$
w=w_{1}\left(1+r^{\prime} \cos \alpha t\right)
$$

and the value of $r$ in the remaining terms is neglected, for the following reasons. The values of the constants $A_{1}$ and $B_{1}$ depend mainly on the seasonal variation in temperature due to radiation; if there were no such variation they would be zern, in which case the variation in temperature with respect to time would be due entirely to that of the wind. The temperature reduction is therefore approximately

$$
\left.R+e^{\lambda y} C\left(1-e^{-\frac{\lambda w_{1} r}{a} \sin a t}\right)\right]
$$


where $\mathrm{R}$ is the constant average reduetion. A variation of the velocity from its minimum to its maximum value, that is, from 0 to $2 w_{1}$ as at varies from 0 to $2 \pi$ produees a variation of temperature reduction from

$$
\left[R+e^{\lambda \nu}\left(1-e^{\frac{\lambda w_{1}}{a}}\right) C\right] \text { to }\left[R+e^{\lambda \nu}\left(1-e^{-\frac{\lambda w_{1}}{a}}\right) C\right]
$$

that is, as the velocity varies from 0 to $2 w_{1}$ the temperature reduetion inereases by the amount

$$
\begin{aligned}
& C e^{\lambda y}\left\{\left[\left(1-e^{-\frac{\lambda w_{1}}{a}}\right)+\frac{R}{C}\right]-\left[\left(1-e^{\frac{\lambda w_{1}}{a}}\right)+\frac{R}{C}\right]\right\} \\
& =C e^{\lambda y}\left(e^{\frac{\lambda w_{1}}{a}}-e^{-\frac{\lambda w_{3}}{a}}\right)
\end{aligned}
$$

from which the temperature reduetion due to the velocity $w_{1}$ is

$$
\Delta \phi=C\left(e^{\lambda y}\right) \frac{1}{2}\left(e^{\frac{\lambda w_{1}}{a}}-e^{-\frac{\lambda w_{1}}{a}}\right)=C e^{\lambda y} \sinh \left(\frac{\lambda w_{1}}{a}\right)
$$

The approximate temperature reduetion deduced by two independent methods is given by equations (132) and (133), respeetively. Equating these two values and using equation (127) gives

$$
\begin{gathered}
C e^{\lambda y} \sinh \left(\frac{\lambda w_{1}}{a}\right)=B^{\prime}\left(y-y_{1}\right)-\frac{B^{\prime}}{\lambda} f_{1}(\lambda)\left(e^{\lambda y}-e^{\lambda y_{1}}\right) \\
=\frac{B^{\prime}}{\lambda} f_{1}(\lambda) e^{\lambda y} \sinh \left(\frac{\lambda w_{1}}{a}\right)=\Delta \phi
\end{gathered}
$$

Solving for the unknown funetion $f_{1}(\lambda)$ gives

$$
f_{1}(\lambda)=\frac{\lambda\left(y-y_{1}\right)}{e^{\lambda y}-e^{\lambda y_{1}}+e^{\lambda y} \sinh \left(\frac{\lambda w_{1}}{a}\right)}
$$

Since $\lambda$ is assumed to be independent of $y$, the variation of the right-hand member of equation (135) with respeet to $y$ is a measure of the error in the two expressions for $\Delta \phi$. Also a eomparison of the theoretical temperature gradient, $B^{\prime}=\frac{\lambda C}{f_{1}(\lambda)}$ (equation 126), whieh would be expected in ease of no upwelling with observations of deep water temperature in sueh regions affords an additional test of the theory. The following values of the eonstants of equations (125) and 
(133) eomputed on pages 376 to $378, C=8.3, D=5.6, \lambda=-.004$, $w_{1}=-31, y_{1}=600, \frac{\lambda w_{1}}{\alpha}=.237$ and $\sinh \frac{\lambda w_{1}}{\alpha}=.24$ are used in table 8 , which gives the relation of $f_{1}(\lambda)$ (equation 135) to $y$.

TABLE 8

The variation of $f_{1}(\lambda)$ with respect to $y$.

\begin{tabular}{r|c|c|c}
\hline$y$ & $\lambda\left(y-y_{1}\right)$ & $e^{\lambda y}-e^{\lambda y_{1}}+e^{\lambda y} \sinh \left(\frac{\lambda w_{1}}{\alpha}\right)$ & $f_{1}(\lambda)$ \\
\hline 30 & & 1.009 & 2.26 \\
40 & 2.28 & 0.965 & 2.32 \\
50 & 2.24 & 0.924 & 2.38 \\
60 & 2.16 & 0.885 & 2.44 \\
70 & 2.12 & 0.846 & 2.51 \\
80 & 2.08 & 0.809 & 2.57 \\
90 & 2.04 & 0.744 & 2.63 \\
100 & 2.00 & 0.740 & 2.70 \\
200 & 1.60 & 0.466 & 3.59 \\
300 & 1.20 & 0.282 & 4.26 \\
400 & 0.80 & 0.160 & 5.00 \\
500 & 0.40 & 0.076 & 5.26 \\
600 & 0.00 & 0.022 & 0.00 \\
700 & $\ldots \ldots .$. & $\ldots \ldots \ldots .$. & $\ldots \ldots .$. \\
800 & $\ldots \ldots \ldots$. & $\ldots \ldots \ldots .$. & $\ldots \ldots .$. \\
\hline
\end{tabular}

Table 8 shows the variation of $f_{1}(\lambda)$ with respeet to depth to be less than 20 per eent in the depth interval from 30 to 100 meters, henee the two methods (equation 134) of estimating $\Delta \phi$ are in good agreement within this interval. The value of $f_{1}(\lambda)$, eorresponding to 30 meters, the smallest value of $y$ for which the theory is valid, gives the best estimate of $f_{1}(\lambda)$, and henee of $B^{\prime}$, sinee the variation of $f_{1}(\lambda)$ with respeet to $y$ is least for small values of $y$. Substituting the numerieal values gives

$$
B^{\prime}=\frac{\lambda C}{f_{1}(\lambda)}=-.0148
$$

the mean annual theoretieal temperature gradients that would be expeeted at latitude $32^{\circ} 30^{\prime}$ if there were no upwelling and the other eonditions remained the same as those prevailing when the observations in the San Diego region were made. The observed temperature gradient at the depth of 600 meters not near shore would be independent of seasonal variations and would be but little affeeted by horizontal eurrents, and is in the depth interval of the observations from whieh the eonstants of the theoretieal formula for mean annual temperatures were eomputed. 
T'ABLE 9

Vertical temperature gradients in degrees per meter at the depth of 600 meters.

\begin{tabular}{c|c|c}
\hline $\begin{array}{c}\text { Indian Ocean } \\
\text { Lat. } 30^{\circ} \text { to } 35 \mathrm{~S}\end{array}$ & $\begin{array}{c}\text { South Atlantic Ocean } \\
\text { Lat. } 30^{\circ} \mathrm{S}\end{array}$ & $\begin{array}{c}\text { North Atlantic Ocean } \\
\text { Lat. } 30^{\circ} \mathrm{N}\end{array}$ \\
\hline-.004 & -.0135 & -.0025 \\
-.006 & -.0160 & -.0080 \\
-.007 & -.0160 & -.0090 \\
-.0085 & -.0165 & -.0110 \\
-.0095 & -.0210 & -.0150 \\
-.0115 & -.0260 & -.0155 \\
-.0130 & $\ldots \ldots \ldots \ldots \ldots$ & -.0160 \\
-.0140 & $\ldots \ldots \ldots \ldots \ldots$ & -.0175 \\
\hline & North Pacific Ocean & \\
\hline & Lat. $30^{\circ}$ to $35^{\circ} \mathrm{N}$ & \\
\hline-.0075 & -.0140 & -.0215 \\
-.008 & -.0150 & -.0215 \\
-.0095 & -.0150 & -.0220 \\
-.0095 & -.0150 & -.0235 \\
-.0100 & -.0155 & -.0245 \\
-.0100 & -.0155 & -.0250 \\
-.0105 & -.0160 & -.0260 \\
-.0120 & -.0170 & -.0290 \\
-.0120 & -.0195 & -.0305 \\
-.0125 & -.0205 & -.0315 \\
$\ldots \ldots \ldots \ldots . . . \ldots \ldots \ldots . .0$ & -.0350 \\
\hline
\end{tabular}

Table 9 shows the observed temperature gradient at the depth of 600 meters and at the approximate latitude $32^{\circ} 30^{\prime}$, corresponding to widely different positions between latitudes $30^{\circ} \mathrm{S}$ to $35^{\circ} \mathrm{S}$ and $30^{\circ} \mathrm{N}$ to $35^{\circ} \mathrm{N}$, and their average is probably a good approximation to the normal gradient at 600 meters. The average of the 22 observations in the Indian and Atlantic oceans (Schott, 1902, pp. 158-160) is -.0126 degrees per meter, and the average of the 31 observations in the North Pacific (Makaroff, 1894, pp. 456-464) is -.0179. The theoretical result -.0148 agrees well with these observations.

The reduction of the mean annual temperature at a given level $y$ for a given velocity $w_{1}$ is proportional to $C e^{\lambda y}$ (equation 133), that is. the reduction is proportional to the difference between the temperature at the depth $y$ and the constant $D$. Therefore the temperature reduction corresponding to a given month is proportional to the difference between the temperature at that time and the same constant $D$. That is,

$$
\frac{\Delta \phi_{t}}{\Delta \phi}=\frac{\phi_{t}-D}{\left(C e^{\lambda y}+D\right)-D}=\frac{\phi_{t}-D}{\phi_{m}-D}
$$


where $\phi_{t}$ is the temperature at the time $t, \Delta \phi_{t}$ is the corresponding reduction, $\phi_{m}$ is the mean annual temperature, and $\Delta \phi$ is the reduction of the mean annual temperature. Substituting the numerical values for $y$ equals 40 meters, from page 385, equation (137) reduces to

$$
\Delta \phi_{t}=\frac{\phi_{t}-5.6}{13.1-5.6}(8.3)(.852)(.24)=\left(\frac{\phi_{t}-5.6}{7.5}\right) 1.7=.227 \phi_{t}-1.27
$$

Substituting the observed values of $\phi_{t}$ at the depth $y$ equals 40 from table 6 in equation (138) gives the values of $\Delta \phi_{t}$ entered in the second line of table 10 .

\section{TABLE 10}

The monthly temperature reduction at the depth of 40 meters near San Diego.

\begin{tabular}{|c|c|c|c|c|c|c|c|c|c|c|c|c|}
\hline$t$ & 1 & 2 & 3 & 4 & 5 & 6 & 7 & 8 & 9 & 10 & 11 & 12 \\
\hline$\Delta \phi_{t}$ & 1.75 & 1.75 & 1.68 & 1.23 & 1.11 & 1.18 & 1.41 & 1.61 & 2.09 & 2.55 & 2.23 & 1.91 \\
\hline$\Delta \phi_{r}$ & -.10 & -.27 & -.37 & -.37 & -.27 & -.10 & -.10 & .27 & .37 & .37 & .27 & .10 \\
\hline$\Delta \theta_{t}$ & 1.65 & 1.48 & $\mid 1.31$ & $|0.86|$ & 0.84 & $\mid 1.08$ & 1.51 & 1.88 & 2.46 & 2.92 & 2.50 & 2.01 \\
\hline
\end{tabular}

But the vertical velocity is $w_{1}\left(1+.2 \cos \frac{\pi}{6} t\right)$, and because of its variation with respect to time a correction equal to $e^{y \lambda} C \frac{\lambda w_{1} r}{a} \sin a t$ (equation 116) must be added to these values. The correction for this case is

$$
.38 e^{-.16} \cos (30 t+75)^{0}=.324 \cos (30 t+75)^{0}=\Delta \phi_{r}
$$

(last term of equation 124, p. 378), and the values are entered in the third line of table 10. Finally the fourth line gives $\Delta \phi_{t}+\Delta \phi_{r}=\Delta \theta_{t}$ the total temperature reduction at the depth $y=40$ meters.

Computing $C$ from equations (136) and (135) and substituting the result in equation (133) gives the expression

$$
\frac{(y-600)(-.0148) \sinh \left(\frac{w_{1}^{2}}{4062}\right) e^{\frac{w_{1} y}{7760}}}{e^{\frac{w_{1} y}{7760}}-e^{\frac{600 w_{1}}{7760}}+\sinh \left(\frac{w_{1}^{2}}{4062}\right) e^{\frac{w_{1} y}{7760}}}
$$

for the mean annual reduction in temperature at the depth $y$ due to the mean annual velocity of upwelling $w_{1}$. The values of this expression corresponding to a series of values of $w_{1}$ (expressed in meters per month are presented in table 11 for the depth $y=40$ meters. 
TABLE 11

Theoretical temperature reduction at the depth of 40 meters corresponding to a series of values of the vertical velocity $w_{1}$.

\begin{tabular}{c|c|c|c|c|c|c|c|c|c|c|c}
\hline$W_{1}$ & 0 & 10 & 20 & 30 & 40 & 50 & 60 & 70 & 80 & 90 & 100 \\
\hline $\begin{array}{l}\text { Temperature } \\
\text { reduction }\end{array}$ & $0^{\circ} .0$ & $0^{\circ} .38$ & $0^{\circ} .95$ & $1^{\circ} .67$ & $2^{\circ} .48$ & $3^{\circ} .34$ & $4^{\circ} .18$ & $5^{\circ} .00$ & $5^{\circ} .80$ & $6^{\circ} .48$ & $7^{\circ} .07$ \\
\hline
\end{tabular}

From plates 24 and 36 (McEwen, 1916), and from an examination of the temperature data (Michael and MeEwen, 1915, 1916) it appears that the temperaturc reduction at the 40 meter level, inshore averages from $2^{\circ}$ to $3^{\circ}$ more than that ten miles offshore. Also surface temperatures as much as $9^{\circ}$ below the normal have at times been found close inshore in July or August, when the normal temperature is about $23^{\circ}$, while the reduction of the surface tempcrature ten miles offshore does not at any time exceed $3: 5$ (table 12). If, corresponding to a temperature reduction of 1.7 ten miles offshore, the inshore reduction is 1.7 plus 2.5 equals 4.2 , the corresponding velocity of upwelling inshore would, from table 11, be about twice as great as that ten miles offshore.

Deduction of the Change in Surface Temperatures Due to a

Vertical Flow of Water near the Surface

Statement of assumptions and mathematical formulation of the problem, and solution for the case in which the flow is constant.

The temperature reduction at the 40 meter level due to upwelling applies also to the surface water, but owing to the upwelling in this upper level the surface temperature will be still more reduced. The time rate of change of temperature in the case of no resultant flow given by the differential equation (10) on page 342 plus the term $-w_{0} \frac{\partial \theta}{\partial y}$ will be the modified rate due to the vertical flow $w_{0}$ as on page 354. Hence the new differential equation corresponding to a vertical flow near the surface is

$$
\frac{\mathrm{\partial} \theta}{\mathrm{d} t}=B e^{-b_{1} y}\left[\left(a_{1}+a_{2} x\right) \cos \alpha t+a_{3} x+1\right]-k\left(\theta-\theta_{1}\right)-w_{0} \frac{\mathrm{d} \theta}{\mathrm{\partial} y}
$$

where $k=k_{1} e^{-b_{1} y}$. 
In case $w_{0}$ is constant, assume for the form of the solution

$$
\theta=f_{1}(y) \sin a t+f_{2}(y) \cos a t+f_{3}(y) x+f_{4}(y)+\theta_{1}
$$

where $\theta_{1}$ is independent of $t$ and $x$. Substitute this expression in equation (139), thus obtaining the following equations:

$$
\begin{aligned}
& (\sin a t)\left[a f_{2}(y)-k_{1} e^{-b_{1} y} f_{1}(y)-w_{0} \frac{d f_{1}(y)}{d y}\right]=0 \\
& (\cos a t)\left[-a f_{1}(y)+B e^{-b_{1} y}\left(a_{1}+a_{2} x\right)-k_{1} e^{-b_{1} y} f_{2}(y)-w_{0} \frac{d f_{2}(y)}{d y}\right]=0 \\
& x\left[a_{3} B e^{-b_{1} y}-k_{1} e^{-b_{1} y} f_{3}(y)-w_{0} \frac{d \theta_{1}}{d y}-w_{0} \frac{d f_{3}(y)}{d y}\right]=0 \\
& {\left[B e^{-b_{1} y}-k_{1} e^{-b_{1} y} f_{4}(y)-w_{0} \frac{d \theta_{1}}{d y}-w_{0} \frac{d f_{4}(y)}{d y}\right]=0}
\end{aligned}
$$

in which $x$ is regarded as a constant.

In ease of no vertical velocity the variation of $\left(\theta-\theta_{1}\right)$ with respect to time is small compared to its mean value, which is independent of the time (p. 344). Therefore, assuming this to be true for the present case, a good approximation would result if the constant part were multiplied by the correct factor $k_{1} e^{-b_{1} y}$ and the variable part by an average value $\bar{k}$. Making this change in equations (141) to (144) we have the much simpler ones

$$
\begin{gathered}
\left\{\begin{array}{c}
a f_{2}(y)-\bar{k} f_{1}(y)-w_{0} \frac{d f_{1}(y)}{d y}=0 \\
-a f_{1}(y)-\bar{k} f_{2}(y)-w_{0} \frac{d f_{2}(y)}{d y}=-B e^{-b_{1} y}\left(a_{1}+a_{2} x\right)
\end{array}\right. \\
\left\{\begin{array}{c}
k_{1} e^{-b_{2} y} f_{3}(y)+w_{0} \frac{d f_{3}(y)}{d y}=\mathrm{a}_{3} B e^{-b_{1} y} \\
k_{1} e^{-b_{1} y} f_{4}(y)+w_{0}\left(\frac{d f_{4}(y)}{d y}+\frac{d \theta_{1}}{d y}\right)=B e^{-b_{1} y}
\end{array}\right.
\end{gathered}
$$

From equations (145) and (146)

$$
\theta=\frac{P\left(a_{1}+a_{2} x\right) e^{-b_{1} y}}{\sqrt{a^{2}+\left(\bar{k}_{2}\right)^{2}}} \cos \left(a t-\epsilon_{2}\right)+f_{3}(y) x+f_{4}(y)+\theta_{1}
$$

where $\bar{k}_{2}=\bar{k}-w_{0} b_{1}$ and $\tan \epsilon_{2}=\frac{a}{\bar{k}_{2}}$. 
From equation (147)

and from equation (148)

$$
f_{3}(y)=\frac{B a_{8}}{k_{1}}
$$

$$
f_{4}(y)=\frac{M_{1} b_{1} w_{0}+B}{k_{1}}
$$

where $\frac{d \theta_{1}}{d y}$ equals $-b_{1} M_{1} \mathrm{e}^{-b_{1} y}$ which gives

$$
\theta_{1}=M_{1} e^{-b_{1} y}+\theta_{2}^{\prime}
$$

where $\theta_{2}^{\prime}$ is a eonstant of integration. Substituting these values in equation (149) gives

$$
\theta=\frac{B\left(a_{1}+a_{2} x\right) e^{-b_{1} y}}{\sqrt{a^{2}+\left(\bar{k}_{2}\right)^{2}}} \cos \left(a t-\epsilon_{2}\right)+\frac{B a_{3} x}{k_{1}}+\theta_{2}^{\prime}+\frac{M_{1} b_{1} w_{0}+B}{k_{1}}+M_{1} e^{-b_{1} y}
$$

As on page 343

$$
M_{1}=-\frac{B\left(a_{1}+a_{2} x\right)}{\sqrt{a^{2}+\left(\bar{k}_{2}\right)^{2}}}
$$

and since the ehange in temperature due to upwelling near the surfaee is due to the gradient $\frac{\partial \theta}{\partial y}$, only terms involving $y$ should be functions of $w_{0}$. Moreover, as $w_{0}$ increases indefinitely the temperature at the lower boundary of this upper layer should approach the eonstant value

$$
\left(\frac{B a_{3}}{k_{1}} x+\frac{B}{k_{1}}+\theta_{2}\right) \text { where } \theta_{2}=\theta_{2}^{\prime}+\frac{M_{1} b_{1} w_{0}}{k_{1}} .
$$

Therefore, as on page 344

$$
\begin{aligned}
\theta & =\frac{B\left(a_{1}+a_{2} x\right) e^{-b_{1}(y-3)}}{\sqrt{a^{2}+\left(\bar{k}_{2}\right)^{2}}} \operatorname{eos}\left(a t-\epsilon_{2}\right)+\frac{B a_{3} x}{k_{1}}-\frac{B\left(a_{1}+a_{2} x\right)}{\sqrt{x^{2}+\left(\bar{k}_{2}\right)^{2}}} e^{-b_{1}(y-3)} \\
& +\frac{B a_{2} x}{\sqrt{a^{2}+k_{1}^{2}}} e^{-3 b_{1}}+\frac{B}{k_{1}}+\theta_{2}
\end{aligned}
$$

which reduees to equation (22), (p. 344), when $w_{0}=0$, except that $\theta_{2}$ takes the place of $\theta_{3}$ and the average value of $\bar{k}^{2}$ takes the place of $\left[k_{1} e^{-b_{1}(y-s)}\right]^{2}$. The latter quantities are small eompared to $a^{2}$ and therefore the differenee between their values makes but little differenee in the result. This differenee or error eomes from the approximation made in solving the differential equation (139), (p. 388). $\theta_{2}$ is found by subtraeting the temperature reduetion due to upwelling at and below the surfaee ( 3 meter level) from $\theta_{3}$, therefore in case of no 
upwelling $\theta_{2}$ equals $\theta_{3}$. A second approximation to the solution of equation (139) can be found by substituting for $\frac{\partial \theta}{\partial y}$ its value from the first approximation. The solution is then reduced to

$$
\begin{aligned}
\theta & =\frac{B\left(a_{1}+a_{2} x\right) e^{-b_{1}(y-3)}}{\sqrt{a^{2}+\left(\overline{k_{2}}\right)^{2}}} \sqrt{\frac{a^{2}+\bar{k}^{2}}{a^{2}+k^{2}}}\left[\cos \left(a t-\epsilon_{2}\right)-1\right]+\frac{B a_{3} x}{k_{1}} \\
& +\frac{B a_{2} x e^{-3 b_{1}}}{\sqrt{a^{2}+k_{1}^{2}}}+\frac{B}{k_{1}}+\theta_{2}
\end{aligned}
$$

where

$$
\tan \epsilon_{2}=\left\{\frac{1+\frac{w_{0} b_{1}\left(k+\bar{k}_{2}\right)}{a^{2}+\left(\bar{k}_{2}\right)^{2}}}{1+\frac{w_{0} b_{1}\left(\bar{k}_{2}-\frac{a^{2}}{k}\right)}{a^{2}+\left(\bar{k}_{2}\right)^{2}}}\right\} \frac{a}{k} .
$$

If $w_{0}=0$, equation (156) is identical with equation (22).

Solution for the case in which the flow is a periodic function

$$
\text { of the time. }
$$

If the vertical velocity equals

$$
w_{0}\left[1+r \cos \left(a t-\epsilon_{1}\right)\right]
$$

the time rate of change of temperature can be obtained from the differential equation (139) in which the last term is multiplied by

$$
\left[1+r \cos \left(a t-\epsilon_{1}\right)\right] \text {. }
$$

The new differential equation is therefore $\frac{\partial \theta}{\partial t}=B e^{-b_{1} y}\left[\left(a_{1}+a_{2} x\right) \cos a t+a_{3} x+1\right]-k\left(\theta-\theta_{1}\right)-w_{0}\left[1+r \cos \left(a t-\epsilon_{1}\right)\right] \frac{\partial \theta}{\partial y}$

Let $\theta^{\prime}$ be the solution already found when $r=0$, and let $\theta^{\prime \prime}$ be the correction due to $r$, then $\theta=\theta^{\prime}+\theta^{\prime \prime}$, and the result of substituting in equation (157) is

$$
\frac{\partial \theta^{\prime \prime}}{\partial t}+k \theta^{\prime \prime}+w_{0} \frac{\partial \theta^{\prime \prime}}{\partial y}+w_{0} r \cos \left(a t-\epsilon_{1}\right) \frac{\partial \theta^{\prime}}{\partial y}+w_{0} r \cos \left(a t-\epsilon_{1}\right) \frac{\partial \theta^{\prime \prime}}{\partial y}=0
$$


Equation (155), using $y$ instead of $(y-3)$, gives approximately $\theta^{\prime}$ and

$$
\frac{\partial \theta^{\prime}}{\partial y}=\frac{B\left(a_{1}+a_{2} x\right)\left(-b_{1}\right)}{\sqrt{\alpha^{2}+\left(\bar{k}_{2}\right)^{2}}}\left[\cos \left(a t-\epsilon_{2}\right)-1\right] e^{-\mho_{1} y}
$$

Substituting this value of $\frac{\partial \theta^{\prime}}{\partial y}$ in equation (158) and letting $\theta^{\prime \prime}=v e^{-b_{1} y}$ results in the ordinary differential equation

$$
\begin{aligned}
& \frac{d v}{d t}+k v-w_{0} b_{1} v-\left[u_{0} r \cos \left(\alpha t-\epsilon_{1}\right)\right] \frac{B\left(a_{1}+a_{2} x\right) b_{1}}{\sqrt{\alpha^{2}+\bar{k}_{2}^{2}}}\left[\cos \left(a t-\epsilon_{2}\right)-1\right] \\
& \quad-r w_{0} b_{1} v \cos \left(\alpha t-\epsilon_{1}\right)
\end{aligned}
$$

where $v$ is a function of $t$ only. Let

$$
k-u_{0} b_{1}=k_{2} \text { and } \bar{M}_{2}=\frac{u_{0} B b_{1}\left(a_{1}+a_{2} x\right)}{\sqrt{\alpha^{2}+\bar{k}_{2}{ }^{2}}}
$$

then equation $(160)$ can be put in the form

$$
\begin{aligned}
& \frac{d v}{d t}+k_{2} v=-r \bar{M}_{2}\left\{\cos \left(\alpha t-\epsilon_{1}\right)-\frac{1}{2}\left[\cos \left(2 \alpha t-\epsilon_{3}\right)+\cos \epsilon_{4}\right]\right\} \\
& \quad+r w_{0} b_{1} v \cos \left(\alpha t-\epsilon_{1}\right)
\end{aligned}
$$

where $\epsilon_{2}+\epsilon_{1}=\epsilon_{3}$ and $\epsilon_{2}-\epsilon_{1}=\epsilon_{4}$.

When the vertical velocity is directed upward $w_{0}$ is negative, therefore

$$
k_{2}=\left(k-w_{0} b_{1}\right)>\left|w_{0} b_{1}\right|
$$

and the last term of equation (161) can be neglected in the first approximation, which is

$$
\begin{aligned}
v & =e^{-k_{2} t}\left\{-r \cdot \bar{M}_{2} \int e^{k_{2} t}\left[\cos \left(a t-\epsilon_{1}\right)-\frac{1}{2} \cos \left(2 \alpha t-\epsilon_{3}\right)-\frac{1}{2} \cos \epsilon_{4}\right] d t+C\right\} \\
& =-r \bar{M}_{2}\left\{\left[\frac{\alpha \cos \epsilon_{1}+k_{2} \sin \epsilon_{1}}{\alpha^{2}+k_{2}{ }^{2}}\right] \sin \alpha t+\left[\frac{k_{2} \cos \epsilon_{1}-\alpha \sin \epsilon_{1}}{\alpha^{2}+k_{2}{ }^{2}}\right] \cos \alpha t\right. \\
& -\left[\frac{2 \alpha \cos \epsilon_{3}+k_{2} \sin \epsilon_{3}}{2\left(4 \alpha^{2}+k_{2}{ }^{2}\right)}\right] \sin 2 \alpha t \\
& \left.-\left[\frac{k_{2} \cos \epsilon_{3}-2 \alpha \sin \epsilon_{3}}{2\left(4 \alpha^{2}+k_{2}{ }^{2}\right)}\right] \cos 2 a t-\frac{\cos \epsilon_{4}}{2 k_{2}}\right\}
\end{aligned}
$$

The arbitrary constant $C$ is 0 , since from physical considerations the solution must be a periodic function of the time. Substituting 
$(y-3)$ for $y$ in the exponential $v e^{-b_{1} y}$ and adding the result to $\theta$ from equation (156) gives the following approximate value of the temperature in case the velocity of upwelling is $w_{0}\left[1+r \cos \left(a t-\epsilon_{1}\right)\right]$

$$
\begin{aligned}
\theta & =\left\{\frac{B\left(a_{1}+a_{2} x\right) e^{-b_{1}(y-3)}}{\sqrt{a^{2}+\left(\bar{k}_{2}\right)^{2}}}\left[\cos \left(a t-\epsilon_{2}\right)-1\right]\right\} \sqrt{\frac{a^{2}+\bar{k}^{2}}{a^{2}+k^{2}}} \\
& +\frac{B a_{3}}{k_{1}} x+\theta_{2}+\frac{r w_{0} B b_{1}\left(a_{1}+a_{2} x\right)}{\sqrt{a^{2}+\left(\bar{k}_{2}\right)^{2}}}\left\{-\left[\frac{a \cos \epsilon_{1}+k_{2} \sin \epsilon_{1}}{a^{2}+k_{2}{ }^{2}}\right] \sin a t\right. \\
& -\left[\frac{k_{2} \cos \epsilon_{1}-a \sin \epsilon_{1}}{a^{2}+k_{2}{ }^{2}}\right] \cos a t+\frac{\cos \epsilon_{4}}{2 k_{2}} \\
& \left.+\left[\frac{2 a \cos \epsilon_{3}+k_{2} \sin \epsilon_{3}}{2\left(4 a^{2}+k_{2}{ }^{2}\right)}\right] \sin 2 a t+\left[\frac{k_{2} \cos \epsilon_{3}-2 a \sin \epsilon_{3}}{2\left(4 a^{2}+k_{2}{ }^{2}\right)}\right] \cos 2 a t\right\} e^{-b_{1}(y-3)} \\
& +\frac{B a_{2} x e^{-3 b_{1}}}{\sqrt{a^{2}+k_{1}{ }^{2}}+\frac{B}{k_{1}}}
\end{aligned}
$$

where

$$
\tan \epsilon_{2}=\left\{\frac{1+\frac{w_{0} b_{1}\left(k+\bar{k}_{2}\right)}{a^{2}+\left(\bar{k}_{2}\right)^{2}}}{1+\frac{w_{0} b_{1}\left(\bar{k}_{2}-\frac{a^{2}}{k}\right)}{a^{2}+\left(\bar{k}_{2}\right)^{2}}}\right\} \frac{a}{k} .
$$

Theoretical Reduction of the Surface Temperature for Each Month in the San Diego Region, Due to Upwelling; AND COMPaRison with OBSERVations

The theoretical relation of ocean temperatures to time and depth developed in pages 368-381 was found to agree well with observations from 40 to 700 meters in the San Diego region. The theory developed in pages $388-393$ is valid for only the upper ten meters; but no satisfactory theory for the intermediate interval from 40 to 10 meters or to the surface has been worked out. Now since the temperature reduction at the surface depends upon the upwelling in all three intervals, it is necessary to estimate the reduction in this intermediate interval for which we have no theory. A method of making this estimate is included in the following plan of computing the theoretical temperature reduction at the surface. 
An explauation of symbols used in making the computations will be given for reference:

$\theta^{\prime}$ equals the normal surface temperature.

$\theta$ equals the theoretical surface temperature when the effect of upwelling is considered.

$\bar{\theta}^{\prime}$ equals the mean annual normal temperature at the surface.

$\theta_{b}$ equals the constant temperature at the depth 600 .

$\Delta \theta^{\prime}$ equals the total theoretical reduction of the surface temperaturc.

$\Delta \theta^{\prime}{ }_{8}$ equals the theoretical reduction of the temperature at the depth of 3 meters which corresponds to surface conditions (p. 343 ).

$\Delta \phi^{\prime}$ equals the theoretical reduction of the surface temperature due to upwelling in the interval from 3 to 600 meters..

$\Delta \bar{\phi}$ ' equals the mean annual temperature reduction at the 3 meter level due to upwelling in the interval from 3 to 600 meters.

$\Delta \bar{\phi}_{s}$ equals the mean annual temperature reduction due to upwelling at the 3 meter level.

$\Delta \overline{\theta^{\prime}}$ equals the total theoretical reduction of the mean annual temperature at the depth of 3 meters.

$\Delta \bar{\psi}_{3}^{\prime}$ equals the mean annual temperature reduction due to upwelling in the interval from 40 to 3 meters.

$\Delta \bar{\psi}_{40}^{\prime}$ equals the mean annual temperature reduction due to upwelling in the interval from 600 to 40 meters.

Throughout the interval from 100 to 40 meters the temperature reduction increases at a constant rate by the amount .36 (table 8), the velocity is practically constant $\left(=w_{1}\right)$, and the mean annual temperature gradient is $\frac{2.3}{60}$. In the interval from 40 to 3 meters the mean annual gradient is $\frac{17.0-13.1}{37}=\frac{3.9}{37}$ (table 6 ), but the mean velocity is approximately $\frac{1}{2}(1+q) w_{1}$ where $q w_{1}$ is the velocity at the depth 3 meters. Assuming provisionally that $q=0.1$ (p.403) the mean velocity in this interval is $.55 v_{1}$. The temperature reduction in any depth interval is proportional to the length of the interval, as was shown to be the case in the interval from 100 to 40 meters, and 
is proportional to the temperature gradient (p. 386). Therefore if the velocity were the same in the interval from 40 to 3 meters, as at the levels below 40 meters, the following relation would hold

$$
\frac{\Delta \psi_{3}^{\prime}}{.36}=\frac{\left(\frac{3.9}{37}\right) 37}{\left(\frac{2.3}{60}\right) 60}=\frac{3.9}{2.3} \quad \text { or } \quad \Delta \psi^{\prime},=(.36)\left(\frac{3.9}{2.3}\right)=.61
$$

But using the provisional estimate $0.55 u_{1}$ of the mean velocity in this interval we have $\Delta \psi_{3}^{\prime}=.55 \times .61=.34$. Using the principle $(p .386)$ that for a given velocity the temperature reductions are proportional to the temperature gradients

$$
\Delta \phi^{\prime}=\frac{\left(\theta^{\prime}-\Delta \theta^{\prime}\right)}{\overline{\theta^{\prime}-\theta_{b}-\Delta \bar{\theta}^{\prime}}}\left(\Delta \bar{\phi}^{\prime}\right)=\frac{\theta^{\prime}-\Delta \phi^{\prime}-\theta_{b}-\Delta \theta_{s}^{\prime}}{\bar{\theta}^{\prime}-\theta_{b}-\Delta \bar{\theta}^{\prime}}\left(\Delta \bar{\phi}^{\prime}\right)
$$

Solving for $\Delta \phi^{\prime}$ gives

$$
\Delta \phi^{\prime}=\left(\frac{\theta^{\prime}-\theta_{b}-\Delta \theta_{s}^{\prime}}{\bar{\theta}^{\prime}-\theta_{b}-\Delta \bar{\theta}_{s}^{\prime}}\right)\left(\Delta \bar{\phi}^{\prime}\right)
$$

From page 387 , and the value of $\Delta \psi^{\prime}{ }_{3}$ we have $\Delta \bar{\phi}^{\prime}=1.7+.34=2.04$. From page 347 , the normal temperature is

$$
\theta^{\prime}=-3.79 \cos (30 t-69)^{\circ}+19.5
$$

therefore

$$
\Delta \phi^{\prime}=\left(\frac{-3.79 \cos (30 t-69)^{\circ}+13.2-\Delta \theta^{\prime}{ }_{s}}{12.75}\right) 2.04
$$

since $\theta_{600}=6.3$ (p. 376).

The observed mean annual surface temperature is $17: 0$ (p. 375) but the normal value less $\Delta \phi^{\prime}$ equals $(19: 5-2: 04)$ equals $17: 46$, which is $: 46$ higher than the observed value. This indicates that there is a still further temperature reduction of the surface temperature due to upwelling at the 3 meter level. From page $390, \theta_{2}=\theta_{3}-\Delta \phi^{\prime}$; therefore, if $\Delta \phi^{\prime}$ is added to both members of equation (163) we can replace $\theta_{2}$ by $\theta_{3}$, and the value of $\theta+\Delta \phi^{\prime}$ differs from the normal surface temperature solely because of the upwelling at the 3 meter level. Therefore $\theta^{\prime}-\left(\theta+\Delta \phi^{\prime}\right)$ equals the temperature reduction $\Delta \theta^{\prime}{ }_{8}$ due to upwelling at this depth. Since only the surface tempera- 
tures are rcquired $\bar{k}$ can be put equal to $k$, then $k_{2}$ will equal $\bar{k}_{2}$. From the value of $\theta^{\prime}$ (equation 24) and equation (163) we have for the value of $\Delta \theta^{\prime}{ }_{s}=\theta^{\prime}-\left(\theta+\Delta \phi^{\prime}\right)$

$$
\begin{aligned}
\Delta \theta^{\prime}{ }_{s} & =B e^{-3 b_{1}}\left(a_{1}+a_{2} x\right)\left\{\frac{\cos (a t-\epsilon)}{\sqrt{a^{2}+k^{2}}}-\frac{\cos \left(a t-\epsilon_{2}\right)}{\sqrt{a^{2}+k_{2}{ }^{2}}-\frac{1}{\sqrt{a^{2}+k^{2}}}}\right. \\
& \left.+\frac{1}{\sqrt{a^{2}+k_{2}^{2}}}\right\}-\frac{r w_{0} B b_{1}\left(a+a_{2} x\right)}{a^{2}+k_{2}{ }^{2}}\left\{\frac{\cos \epsilon_{4}}{2 k_{2}}-\left[\frac{a \cos \epsilon_{1}+k_{2} \sin \epsilon_{1}}{a^{2}+k_{2}{ }^{2}}\right]\right.
\end{aligned}
$$

$\sin a t-\left[\frac{k_{2} \cos \epsilon_{1}-a \sin \epsilon_{1}}{a^{2}+k_{2}{ }^{2}}\right] \cos a t+\left[\frac{2 a \cos \epsilon_{3}+k_{2} \sin \epsilon_{3}}{2\left(4 a^{2}+k_{2}{ }^{2}\right)}\right]$

$\left.\sin (2 a t)+\left[\frac{k_{2} \cos \epsilon_{3}-2 a \sin \epsilon_{3}}{2\left(4 a^{2}+k_{2}{ }^{2}\right)}\right] \cos (2 a t)\right\} e^{-3 b_{1}}$

Leaving $u_{0}$ and thercfore $k_{2}$ and $\epsilon_{2}$ undetermined for the present; equation (169) can be reduced to the form

$$
\begin{aligned}
& \Delta \theta^{\prime}{ }_{8}=2.12\left\{\frac{1}{.560}-\frac{1}{\sqrt{.274+k_{2}^{2}}}\right\}+\frac{\left(.00775 w_{0}\right) \cos \epsilon_{4}}{k_{2}\left(.274+k_{2}{ }^{2}\right)} . \\
& +2.12\left\{\frac{\cos \left(30 t-\epsilon_{2}\right)}{\sqrt{.274+k_{2}{ }^{2}}}-\frac{\cos (30 t-69)}{.560}\right\}+\frac{.0155 w_{0}}{\left(.274+k_{2}{ }^{2}\right)} \\
& \left\{\left[\frac{.506+.259 k_{2}}{.274+k_{2}{ }^{2}}\right] \sin a t+\left[\frac{.966 k_{2}-.136}{.274+k_{2}{ }^{2}}\right] \cos a t\right. \\
& +\left[\frac{1.046 \cos \epsilon_{3}+k_{2} \sin \epsilon_{3}}{2\left(1.096+k_{2}{ }^{2}\right)}\right] \sin 2 a t+\left[\frac{k_{2} \cos \epsilon_{3}-1.046 \sin \epsilon_{3}}{2\left(1.096+k_{2}{ }^{2}\right)}\right] \\
& \cos 2 a t\}
\end{aligned}
$$

using the following values of the remaining constants: $a_{1}=-.318$, $a_{2}=-.0166, B e^{-3 b_{1}}=5.9, \epsilon_{1}=195, \epsilon=69, \epsilon_{3}=\left(\epsilon_{1}+\epsilon_{2}\right), \epsilon_{4}=\left(\epsilon_{2}-\epsilon_{1}\right)$, $r=.2, \quad a=.523, \quad b_{1}=.0365, \quad($ pp. $347,351,376), \quad k=.2, \quad k_{2}=$ $.2-.0365 w_{0}, \tan \epsilon_{2}=\frac{a}{k_{2}}$ (p. 394). Assume $w_{0}$ equals -3 , then $\Delta \theta^{\prime}{ }_{8}=.448-3.78 \cos (30 t-60)+3.48 \cos (30 t-69)$

$$
-.113\{1.58 \sin 30 t+.441 \cos 30 t\}=.448-.69 \cos 30 t-.18 \sin 30 t
$$

The values of the temperatures and their reductions are given in table 12 . 
TABLE 12

Normal surface temperatures and temperature reductions in the San Diego region.

\begin{tabular}{c|r|r|r|r|r|r|r|r|r|r|r|r|r}
\hline$t=$ & \multicolumn{1}{|c|}{1} & \multicolumn{1}{|c|}{2} & \multicolumn{1}{|c|}{4} & \multicolumn{1}{|c|}{5} & \multicolumn{1}{|c|}{6} & \multicolumn{1}{c|}{7} & \multicolumn{1}{|c|}{8} & 9 & 10 & 11 & 12 & means \\
\hline$\theta^{\prime}$ & 16.55 & 15.75 & 15.95 & 17.11 & 18.91 & 20.86 & 22.45 & 23.25 & 23.05 & 21.89 & 20.09 & 18.14 & 19.50 \\
$\Delta \theta_{s}^{\prime}$ & -.24 & -.06 & +.27 & +.64 & +.96 & +1.14 & +1.14 & +.96 & +.63 & +.26 & -.06 & -.24 & +.45 \\
$\Delta \phi^{\prime}$ & 1.66 & 1.52 & 1.50 & 1.63 & 1.86 & 2.15 & 2.40 & 2.56 & 2.58 & 2.45 & 2.22 & 1.93 & 2.02 \\
$* \Delta \phi_{r}$ & -.10 & -.27 & -.37 & -.37 & -.27 & -.10 & +.10 & +.27 & +.37 & +.37 & +.27 & +.10 & .00 \\
$\cdot \Delta \theta^{\prime}$ & 1.32 & 1.19 & 1.40 & 1.90 & 2.55 & 3.19 & 3.64 & 3.79 & 3.58 & 3.08 & 2.43 & 1.79 & 2.47 \\
$\Delta \theta^{\prime}$ obs. & 1.55 & 1.35 & 1.35 & 1.91 & 2.81 & 3.06 & 2.75 & 2.65 & 2.85 & 3.09 & 3.29 & 2.64 & 2.50 \\
$\theta$ comp. & 15.23 & 14.56 & 14.55 & 15.21 & 16.36 & 17.67 & 18.81 & 19.46 & 19.47 & 18.81 & 17.66 & 16.35 & 17.03 \\
$\theta$ obs. & 15.00 & 14.30 & 14.60 & 15.20 & 16.10 & 17.80 & 19.70 & 20.60 & 20.20 & 18.80 & 16.80 & 15.50 & 17.00 \\
Difference & $+.23+.26$ & -.05 & +.01 & +.26 & -.13 & -.89 & -1.14 & -.73 & +.01 & +.86 & +.85 & +.03 \\
\hline
\end{tabular}

* From line 3, table 10 (p. 387 ).

The agreement between the predicted monthly temperatures and - the observed averages is very satisfactory. Moreover, from the relation of the vertical velocity to depth deduced from hydrodynamical principles, and shown by table 13 , the velocity $w_{0}$ at the 3 meter level, would be $.116 w_{1}$, where $w_{1}$ is the velocity below the 40 meter level. That is, the value of $w_{0}$ to be expected from that deduced from deep water temperautres (p. 403) is $.116 \times(-31)$ equals -3.6 , which agrees well with the value -3.0 deduced from the surface temperature.

\section{Deductions Relative to Oceanic Circulation in the San Diego 'Region Based on Ekman's Hydrodynamical Theory}

Zöppritz (1878) obtained some theoretical results relative to oceanic circulation, from the general equations of motion of a viscous fluid, and some of his conclusions have been widely used by oceanographers and geographers; but a critical examination made in the light of later observations showed that his conclusions do not apply to conditions found in nature. These erroneous conclusions are due to his failure to take into account the deflecting force of the earth's rotation and to his use of the laboratory value of the coefficient of viscosity. The importance of the effect of the earth's rotation on currents in the air and ocean was pointed out long ago by Hadley, Coriolis, and Ferrel; but with the exception of free currents, that is, currents moving by their own inertia, the deflecting force dae to the earth's rotation was thought to be so small that it could be neglected until Bjerknes (1901) first made clear the importance of this deflecting force in the case of forced currents. 
Ekman (1905) also used the general equations of the motion of a viscous fluid, but included the deflecting forec duc to the earth's rotation, and used in place of the coefficient of viscosity a constant whose value was estimated by applying his formal solution of the equations to field data. That is, he used a virtual value of the coefficient of viseosity in order to take into account the effect of the irregular vortex motion which greatly inereases the magnitude of the mutual reaction between the adjacent water layers.

On the simple assumption that the depth of the region considered is large and the coast is at a sufficiently great distance Ekman (1905, p. 7) deduced the effect of a wind, constant in magnitude and dircetion, over the whole region. His results for the northern hemisphere are, for the velocity of the water, perpendicular and parallel respectively to that of the wind,

$$
\begin{aligned}
& U^{\prime}=V_{0} e^{-a y} \cos \left(\frac{\pi}{4}-a y\right) \\
& V^{\prime}=V_{0} e^{-a y} \sin \left(\frac{\pi}{4}-a y\right)
\end{aligned}
$$

Where $V_{0}$ is the absolute velocity of the water at the surface $y$ is the depth below the surface and $a$ is a constant. The value of $a$ (Ekman,

1905 , p. 6) is $\quad a=\sqrt{\frac{q \omega \sin \phi}{\mu^{2}}} \quad$ where $\omega$ is the angular velocity. of the earth, $\phi$ is the latitude, $\mu^{2}$ is the virtual cocfficient of viscosity, and $q$ is the density of the water. From equations (172) and (173) it follows that the surface water velocity (where $y$ equals zero) makes an angle of 45 degrees to the right of the wind velocity, and the angle increases as $y$ increases. When $y$ has such a value (denoted by $D$ ) that the water velocity has the opposite direction to that of the surface, that is, when

$$
a y=a D=\pi=D \sqrt{\frac{q \omega \sin \phi}{\mu^{2}}}
$$

the magnitude of the velocity is $e^{-\pi}$ or .043 times its surface value. $D$ is called the "depth of frictional influence," since the water velocity below that depth produced by a wind over the open ocean is but a small fractoin of that at the surface. From an estimate of the relation between the wind velocity and its tangential pressure and the corre- 
sponding ocean current produced, Ekman (1905, p. 42) concluded that the surface velocity $V_{0}$ would be approximately $\frac{.0127}{\sqrt{\sin \phi}} h$ and that $D$ would have the approximate value

$$
D=\left[\frac{7.6}{\sqrt{\sin \phi}} h\right] \text { meters }
$$

where $h$ is the wind velocity in meters per second. Thus for a wind velocity of ten miles per hour (5.1 meters per second) and at the

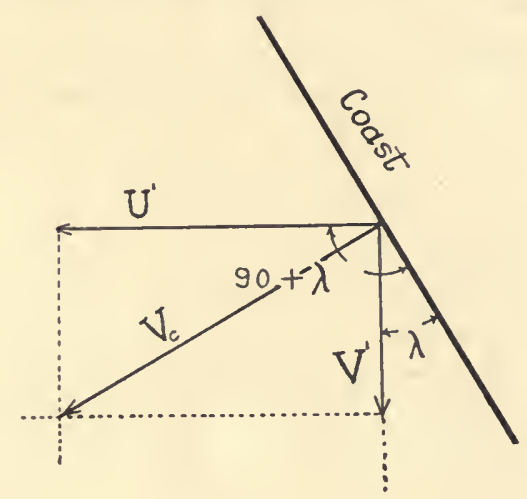

Fig. 16. Components of the water velocity $U^{\prime}$ and $V^{\prime}$ perpendicular and parallel respectively to the wind, and the velocity of $V_{c}$ in a direction perpendicular to the coast.

latitude $35^{\circ} D$ would equal $\frac{7.6 \times 5.1}{\sqrt{\sin \phi}}=51$ meters, and for a velocity of fifteen miles per hour $D$ would equal 75 meters. Solving equation (174) for $\mu^{2}$ gives

$$
\mu^{2}=\frac{D^{2}}{\pi^{2}} q \omega \sin \phi=\frac{.0000729}{\pi^{2}}(\sin \phi) D^{2}
$$

which equals 217 in c.g.s. units, when $D$ equals $7500 \mathrm{~cm}$. and $\phi$ equals $35^{\circ}$.

The relation of vertical velocity to depth will now be deduced from the results of Ekman's theory.

Let $V^{\prime}$ make an angle $\lambda$ with the coast (fig. 16) and $U^{\prime}$ the angle $(90+\lambda)^{\circ}$ with the coast, then the velocity perpendicular to the coast is, from equations (172) and (173),

$$
V^{\prime} \sin \lambda+U^{\prime} \sin (90+\lambda)=V_{o}
$$


where a velocity directed away from the coast is regarded as positive. That is,

$$
\begin{aligned}
V_{c} & =V_{0} e^{-a y}\left\{\cos \lambda \cos \left(\frac{\pi}{4}-a y\right)+\sin \lambda \sin \left(\frac{\pi}{4}-a y\right)\right\} \\
& =V_{0} e^{-a y} \cos \left(\frac{\pi}{4}-a y-\lambda\right)
\end{aligned}
$$

Let $z$ equal the distance perpendicular to the coast, then $V_{c}$ from equation (176) is the limiting value of the velocity perpendicular to the coast as $z$ increases. Also, adjacent to the coast where $z$ equals zero, the velocity perpendicular to the coast must be zero. Let the velocity perpendicular to the coast at the distanec $z$ be given by the equation

$$
V=V_{c} f(z)
$$

where $f(0)=0$ and $f(z) \doteq 1$ as $z$ increases. The removal of water at and near the surface due to a flow away from the coast decreases the pressure at the lower levels, and gives rise to a compensating flow of deep watcr toward the coast. Thereforc in a coastal region where the surface water flows away from the coast there is a compensating upward flow of deep water.

Denoting the vertical velocity by $W$, the equation of continuity is

$$
\frac{\partial V}{\partial z}+\frac{\partial W}{\partial y}=0
$$

neglecting the variation of the component parallel to the coast. Therefore from equation (177), assuming

$$
W=f_{1}(z) f_{2}(y)
$$

we have

$$
V_{c} \frac{d f(z)}{d z}+f_{1}(z) \frac{d f_{2}(y)}{d y}=0
$$

To solve equation (180) let

$$
\frac{d f(z)}{d z}=M f_{1}(z)
$$

where $M$ is a constant. Then from equation (176) and (180)

$$
\frac{d f_{2}(y)}{d y}=-M V_{c}=-M V_{0} e^{-a y} \cos \left(\frac{\pi}{4}-a y-\lambda\right)
$$


from which we have

$$
\begin{aligned}
f_{2}(y) & =-M V_{0} \int e^{-a y} \cos \left(\frac{\pi}{4}-a y-\lambda\right) d y+C_{1} \\
= & -\frac{M V_{0} \sqrt{2}}{2 a}\{\sin \lambda \sin a y-\cos \lambda \cos a y\} e^{-a y}+C_{1} \\
= & \frac{M V_{0} \sqrt{2}}{2 a} e^{-a y} \cos (a y+\lambda)+C_{1}
\end{aligned}
$$

where $C_{1}$ is the constant of integration which must have the value $-\frac{M V_{0} \sqrt{2}}{2 a} \cos \lambda$ in order that $f_{2}(0)$ may equal zero.' From equations $(176,177,179$, and 181$)$ it follows that the horizontal and vertical components of the velocity are respectively

$$
\begin{aligned}
V & =f(z) V_{0} e^{-a y} \cos \left(\frac{\pi}{4}-a y-\lambda\right) \\
W & =-f_{1}(z)\left\{-\frac{\cos \lambda}{\sqrt{2 a}}+\int e^{-a y} \cos \left(\frac{\pi}{4}-a y-\lambda\right) d y\right\} M V_{0} \\
& =-\frac{d f(z)}{d z}\left\{\int e^{-a y} \cos \left(\frac{\pi}{4}-a y-\lambda\right) d y-\frac{\cos \lambda}{\sqrt{2 a}}\right\} V_{0} \\
& =-\frac{V_{0}}{\sqrt{2 a}}\left\{e^{-a y} \cos (a y+\lambda)-\cos \lambda\right\} \frac{d f(z)}{d z}
\end{aligned}
$$

Since the horizontal velocity of the surface water is proportional to the wind velocity (pp. 363, 398) it follows from equation (185) that the vertical velocity of the water is also proportional to the wind velocity.

The differential equation of a stream line is in general $\frac{d y}{d z}$ equals the slope of the curve equals $\frac{W}{V}$ equals

$$
\frac{d y}{d z}=\frac{-\left\{\int e^{-a y} \cos \left(\frac{\pi}{4}-a y-\lambda\right) d y-\frac{\cos \lambda}{\sqrt{2 a}}\right\} \frac{d f(z)}{d z}}{e^{-a y}\left\{\cos \left(\frac{\pi}{4}-a y-\lambda\right)\right\} f(z)}
$$

which can be reduced to the exact differential equation

$$
\frac{d f(z)}{f(z)}=-\frac{e^{-a y} \cos \left(\frac{\pi}{4}-a y-\lambda\right) d y}{\left\{\int e^{-a y} \cos \left(\frac{\pi}{4}-a y-\lambda\right) d y-\frac{\cos \lambda}{\sqrt{2 a}}\right\}}
$$

whose solution is

$$
\left[\cos \lambda-e^{-a y} \cos (a y+\lambda)\right] f(z)=C_{2}
$$


where $C_{2}$ is a constant of integration corresponding to a given stream line. From equation (185) the upward flux through a horizontal area of unit width and length $z$ measured perpendicularly to the coast is

$$
\left.\int_{0}^{z} W d z=-\frac{V_{0}\left[\cos \lambda-e^{-a y} \cos (a z+\lambda)\right] f(z)}{a \sqrt{2}}\right]_{0}^{z}
$$

Rembering that $f(0)=0$ and $f(z) \doteq 1$ as $z \doteq \infty$

$$
\int_{0}^{z} W d z=-\frac{V_{0}\left[\cos \lambda-e^{-a y} \cos (a y+\lambda)\right] f(z)}{a \sqrt{2}}
$$

and that the maximum numerical value for a given value of $y$ is

$$
\int_{0}^{\infty} W d z=-\frac{V_{0}\left[\cos \lambda-e^{-a y} \cos (a y+\lambda)\right]}{a \sqrt{2}}
$$

which approaches the value $-\left(\frac{V_{0} \cos \lambda}{a \sqrt{2}}\right)$ as $y$ increases, the ratio $R$ of the upward flux through a horizontal area at the depth $y$ of unit width and length $z$ measured perpendicularly to the coast to the total upward flux is

$$
R=\frac{\int_{0}^{z} W d z}{-\frac{V_{0} \cos \lambda}{a \sqrt{2}}}=\frac{\left[\cos \lambda-c^{-a y} \cos (a y+\lambda)\right] f(z)}{\cos \lambda}
$$

Therefore the parameter $C_{2}$ in the equation of the stream line (equation 188) equals the ratio $R$ multiplied by $\cos \lambda$, and the flux betwecn any two adjacent stream lines of a scries in which the increments of $C_{2}$ are equal is constant.

The mean wind velocity of the 5 degrees square of the U. S. Coast Pilot Charts (Moore, 1908-11) west of San Diego was found to be about fiftecn miles per hour in a southeasterly direction, approximately parallel to the coast. Therefore for the San Diego region the angle $\lambda$ in equation (185) is zero, and the vertical velocity at the depth $y$ is, from equation (185), proportional to $\left[1-e^{-a y} \cos a y\right]$ where $a=\frac{\pi}{D}=\frac{\pi}{75} \quad$ (p. 398). The values of this function are tabulated with respect to depth in table 13. 
TABLE 13

Tabulation of the function $\left(1-e^{-\frac{\pi y}{75}} \cos \frac{\pi y}{75}\right)$

\begin{tabular}{r|c||c|c}
\hline$y$ & $1-e^{-\frac{\pi y}{75}} \cos \frac{\pi y}{75}$ & $y$ & $1-e^{-\frac{\pi y}{75}} \cos \frac{\pi y}{75}$ \\
\hline 0 & 0 & 18 & .658 \\
1 & .043 & 19 & .685 \\
2 & .085 & 20 & .710 \\
3 & .116 & 21 & .737 \\
4 & .166 & 22 & .760 \\
5 & .207 & 23 & .783 \\
6 & .246 & 24 & .805 \\
7 & .288 & 25 & .825 \\
8 & .325 & 30 & .913 \\
9 & .361 & 35 & .977 \\
10 & .399 & 40 & 1.02 \\
11 & .436 & 50 & 1.067 \\
12 & .471 & 60 & 1.065 \\
13 & .515 & 70 & 1.052 \\
14 & .535 & 80 & 1.034 \\
15 & .568 & 90 & 1.019 \\
16 & .600 & 100 & 1.007 \\
17 & .630 & infinity & 1.000 \\
\hline
\end{tabular}

The relation of the velocity to depth was deduced from hydrodynamical considerations, but its relation to distance from the coast, which requires the determination of the function $f(z)$ (equation 177. p. 400), did not result from the foregoing reasoning, but will now be considered. From equation (177), page $400 f(0)=0$ and $f(z) \doteq 1$ as $z$ increases, and for large values of $y$ off San Diego, equation (185) becomes

$$
W=W_{1}=-\frac{V_{0}}{a \sqrt{2}} \frac{d f(z)}{d z}
$$

where (pp. 377, 388) $W_{1}=-31$ meters per month where $z$ equals 10 miles, and equals double that value or 62 meters per month, where $z$ equals zero. From page 363 , for an average wind velocity of 15 miles per hour or 7.5 meters per second

$$
V_{0}=\frac{.0126 \times 7.5}{\sqrt{\sin 35^{\circ}}}=.125 \text { meters per second }
$$


equals 324,000 meters per month and $a$ equals $\frac{\pi}{75}$ (p. 402). Substituting these numerical values in equation (193) and expressing $z$ in miles gives

$$
\frac{d f(z)}{d z}=.0210 \text { for } z=0
$$

and

$$
\frac{d f(z)}{d z}=.0105 \text { for } z=10
$$

While these eonditions, which $f(z)$ and $\frac{d f(z)}{d z}$ must satisfy, do not determine the functions preeisely, they suffice for a rough estimate. The following form

$$
f(z)=1-\dot{k_{1}} e^{-h_{1} z}-\left(1-k_{1}\right) e^{-h_{2} z}
$$

has the value zero when $z$ equals zero and approaehes 1 as $z$ increases indefinitely for all positive values are of $h_{1}$ and $h_{2}$, and differentiating with respect to $z$

$$
\frac{d f(z)}{d z}=h_{1} k_{1} e^{-h_{1} z}+h_{2}\left(1-k_{1}\right) e^{-h_{2} z}
$$

The above expression for $\frac{d f(z)}{d z}$ satisfies the conditions expressed by equation (194) for the following values of the constants found by trial :

$$
h_{1}=01, \quad k_{1}=.93, \quad h_{2}=.17, \quad\left(1-k_{1}\right)=.07 .
$$

Therefore from equation (193) the vertical velocity at any depth $y$ equals

$$
W=-2960 \frac{d f(z)}{d z}=-2960\left(.0093 e^{-.01 z}-.0119 e^{-.17 z}\right)
$$

and from equation (192) the ratio of the upward flux within a distanee $z$ from the eoast to the total flux is proportional to

$$
f(z)=1-.93 e^{-.01 z}-.07 e^{-.17 z}
$$

where $z$ is the distance from the coast in miles. The values of $f(z)$ and $\frac{d f(z)}{d z}$ are tabulated with respeet to $z$ in table 14 . 
TABLE 14

Tabulation of the functions $f(z)$ and $\frac{d f(z)}{d z}$

\begin{tabular}{|c|c|c|c|c|c|}
\hline$z$ & $f(z)$ & $\frac{d f(z)}{d z}$ & $z$ & $f(z)$ & $\frac{d f(z)}{d z}$ \\
\hline 0 & 0 & .0212 & 40 & .380 & .0062 \\
\hline 1 & .020 & .0192 & 50 & .430 & .0057 \\
\hline 2 & .040 & .0175 & 70 & .530 & .0046 \\
\hline 3 & .060 & .0161 & 100 & .660 & .0035 \\
\hline 4 & .075 & .0150 & 200 & .870 & $: 0013$ \\
\hline 5 & .090 & .0139 & 300 & .950 & .00046 \\
\hline 10 & .150 & .0105 & 400 & .980 & .00020 \\
\hline 15 & .190 & .0089 & 500 & .994 & .00006 \\
\hline 20 & .240 & .0080 & 700 & .9992 & .00000 \\
\hline 30 & .310 & .0070 & 1000 & .99995 & .00000 \\
\hline
\end{tabular}

Thus it appears that 90 per cent of the upward flux is confined to a coastal belt about 250 miles wide. Finally the stream line equation (188) becomes

$$
\left[1-e^{-\frac{\pi y}{75}} \cos \frac{\pi y}{75}\right]\left[1-.93 e^{-.01 z}-.07 e^{-.17 z}\right]=C_{2}
$$

for the San Diego region, and the stream lines corresponding to $C_{2}$ equal $0,0.1,0.2,0.3,0.4,0.5,0.6,0.7,0.8,0.9$, and 1.0 are shown in figure 17.

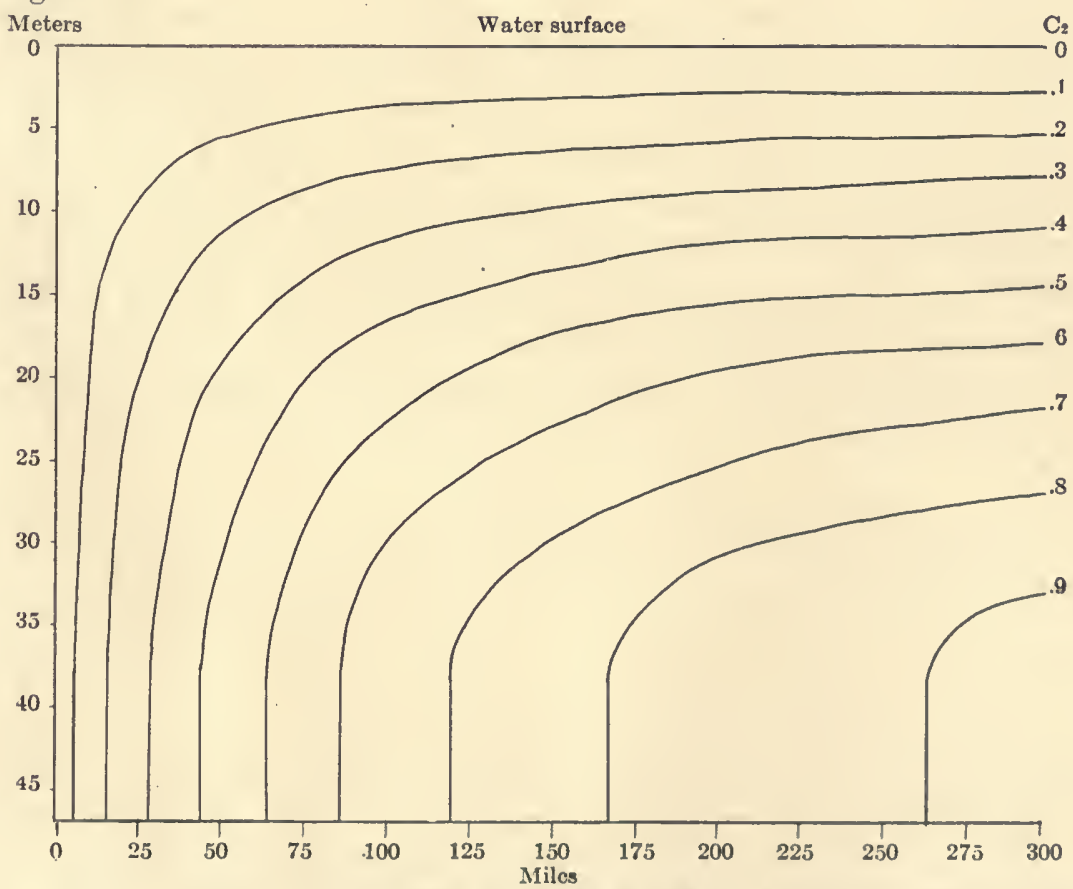

Fig. 17. Traces of theoretical surfaces of flow on a vertical plane perpendicular to the coast. The flow included between any two consecutive surfaces is one-tenth of the total amount. 
Figure 17 represents the eomponent of the hypothetieal cireulation in a plane perpendieular to the coast eorresponding to a uniform wind over the whole region, in whieh the bottom bends sharply upward at the coast, but gives some idea of the actual eireulation. In examining the figure it must be noted that the vertieal is very mueh greater than the horizontal scale. In faet, if the horizontal seale were the same as the vertical one actually used the diagram would be about one and one-lialf miles in length.

\section{Deduction of the Upweiling Velocity off San Diego from the Observed Relation of Salinity to Depth}

If the rates of molecular diffusion of salts and conduction of heat are relatively very small as compared with the rate of transfer due to the alternating circulation (p. 368), the differential equation

$$
\frac{\partial \theta}{\partial t}=\mu^{2} \frac{\partial^{2} \theta}{\partial y^{2}}-W \frac{\partial \theta}{\partial y}
$$

(equation 80, p. 368) applies in general where the eonstant $\mu^{2}$. is a measure of the rate of transfer, and the dependent variable is the salt coneentration or temperature. An application to temperature data has already been made, and we have only to replaee $\theta$ by the salinity $S$ in the temperature equation and its solution already worked out (pp. 375-378) in order to obtain the corresponding formulae for salinity. However, the salinity data are too incomplete to furnish reliable estimates of averages for each month, and it seemed best to use the data taken in the same region (Seetion $40_{4}$ ) for each of the three months, August, 1912, February, 1913, and April, 1913, whieh eorrespond to an interval of less than one year. These data are presented in table 15 . 
TABLE 15

Observed Salinities for August, 1912, February, 1913, and April, 1913, in Section $4 \mathrm{O}_{4}$

\begin{tabular}{|c|c|c|c|c|}
\hline \multirow{2}{*}{$\begin{array}{c}\text { Depth } \\
\qquad y\end{array}$} & \multicolumn{4}{|c|}{ Salinities } \\
\hline & $\begin{array}{c}(t=2) \\
\text { February }\end{array}$ & $\begin{array}{c}(t=4) \\
\text { April }\end{array}$ & $\begin{array}{l}(t=8) \\
\text { August }\end{array}$ & $\begin{array}{l}\text { Mean annual } \\
\text { values }\end{array}$ \\
\hline 0 & 33.47 & 33.58 & 33.75 & 33.61 \\
\hline 10 & 33.47 & 33.58 & 33.69 & 33.58 \\
\hline 20 & 33.44 & 33.58 & 33.58 & 33.51 \\
\hline 30 & 33.42 & 33.61 & 33.54 & 33.48 \\
\hline 40 & 33.46 & 33.66 & 33.57 & 33.52 \\
\hline 50 & 33.50 & 33.73 & 33.65 & 33.57 \\
\hline 60 & 33.54 & 33.79 & 33.73 & 33.63 \\
\hline 70 & 33.57 & 33.85 & 33.57 & 33.67 \\
\hline 80 & 33.62 & 33.90 & 33.81 & 33.72 \\
\hline 90 & 33.66 & 33.94 & 33.85 & 33.76 \\
\hline 100 & 33.70 & 33.99 & 33.88 & 33.79 \\
\hline 150 & 34.03 & 34.19 & 34.07 & 34.05 \\
\hline 200 & 34.25 & 34.30 & 34.17 & 34.21 \\
\hline 300 & 34.32 & 34.33 & 34.23 & 34.27 \\
\hline 400 & 34.33 & 34.34 & 34.28 & 34.30 \\
\hline 500 & 34.36 & 34.35 & 34.32 & 34.34 \\
\hline 600 & ............... & ............ & ............ & 34.40 \\
\hline 800 & ............ & ............. & ............. & 34.48 \\
\hline 1100 & ................. & ……............ & ............. & 34.53 \\
\hline
\end{tabular}

From the formula for salinity (replacing $\theta$ by $S$ in equation 117) it follows that the mean of any two salinities corresponding to a time interval of six months would equal approximately the mean annual salinity. Accordingly, the means of the salinities for February and August are assumed to be the mean annual salinities in this case. The constants $C, D$, and $\lambda$ of equation (117) were found as in the case of temperature data by fitting the equation

$$
S_{m}=C e^{\lambda y}+D
$$

to the observed mean annual salinities, $S_{m}$. Then the observed mean annual salinity was subtracted from each of the entries under February and April, and the expression

$$
C\left(\frac{\lambda w_{1} r}{a}\right) e^{\lambda y} \cos (30 t+75)^{\circ}
$$

was subtracted from each of these, using the same numerical values for $w_{1}, r$ and $a$ as on page 377, and the value of $C$ determined above. The remaining expression

$$
M e^{a_{1} y} \cos \left(a t+b_{1} y-\epsilon^{\prime}\right)
$$


(p. 377) was fitted to these remainders. The values of the eonstants thus found are $D=34.55, \quad C=-1.25, \quad \lambda=-.005, \quad M=-.6$, $\epsilon^{\prime}=-65, \mathrm{a}_{1}=-.0075, \mu^{2}=10,600, w_{3}=-53, b_{1}=-.00495$. The value of $b_{1}$ determined from equation (121) exceeds numerieally the value -.00175 determined from the observations. Expressing the angle in degrees, these values are -.28 and -.10 respeetively. The values $\mu^{2}=10,600$ and $w_{1}=-53$ obtained from the salinity data are in good agreement with the values 7760 and -31 obtained from the more eomplete and extensive temperature data (p. 378). The computed and observed values of the remainders and of the mean annual salinities are entered in table 16 as an additional test of the theory. The eomputed remainders were obtained from

$$
-.6 e^{-.0075 y} \cos (30 t-.1 y+65)^{\circ}
$$

and the computed mean annual salinities were obtained from

$$
34.55-1.25 e^{-.005 y}
$$

TABLE 16

Computed and Observed Remainders for February and April, and the Computed

\begin{tabular}{|c|c|c|c|c|c|c|}
\hline \multirow{3}{*}{$\begin{array}{c}\text { Depth } \\
y\end{array}$} & \multicolumn{4}{|c|}{ Remainders } & \multirow{2}{*}{\multicolumn{2}{|c|}{$\begin{array}{c}\text { Mean annual } \\
\text { Salinities }\end{array}$}} \\
\hline & \multicolumn{2}{|c|}{$t=2 \quad$ Feb. } & \multicolumn{2}{|c|}{$t=4 \quad$ April } & & \\
\hline & Computed & Observed & Computed & Observed & Computed & Observed \\
\hline 50 & .14 & -.07 & .32 & .16 & 33.53 & 33.57 \\
\hline 100 & .07 & -.09 & .21 & .20 & 33.74 & 33.79 \\
\hline 150 & .02 & -.02 & .13 & .14 & 33.96 & 34.05 \\
\hline 200 & .00 & .04 & .08 & .09 & 34.04 & 34.21 \\
\hline 300 & -.01 & .05 & .03 & .06 & 34.22 & 34.27 \\
\hline 400 & -.01 & .03 & .01 & .04 & 34.33 & 34.30 \\
\hline 500 & -.01 & .02 & .00 & .01 & 34.40 & 34.34 \\
\hline 600 & ....... & ........ & ........ & ........ & 34.44 & 34.40 \\
\hline 800 & ........ & ....... & ....... & ....... & 34.48 & 34.48 \\
\hline 1100 & ........ & $\ldots \ldots$ & $\ldots \ldots$ & $\ldots \ldots$ & 34.50 & 34.53 \\
\hline
\end{tabular}
and Observed Mean Annual Salinites

The mean veloeity of upwelling can also be estimated from the salinity distribution in the upper 30 meter layer, and by an entirely different method. A eomparison of this value with the two estimates made with the aid of theoretical results already presented affords a severe test of the theories and gives an idea of the reliability of the 
results. In dealing with mean annual values we can assume all conditions to be independent of the time, from which it follows that the total amount of water in a given volume remains constant and the total amount of salts remain constant. Therefore the rate of flow of

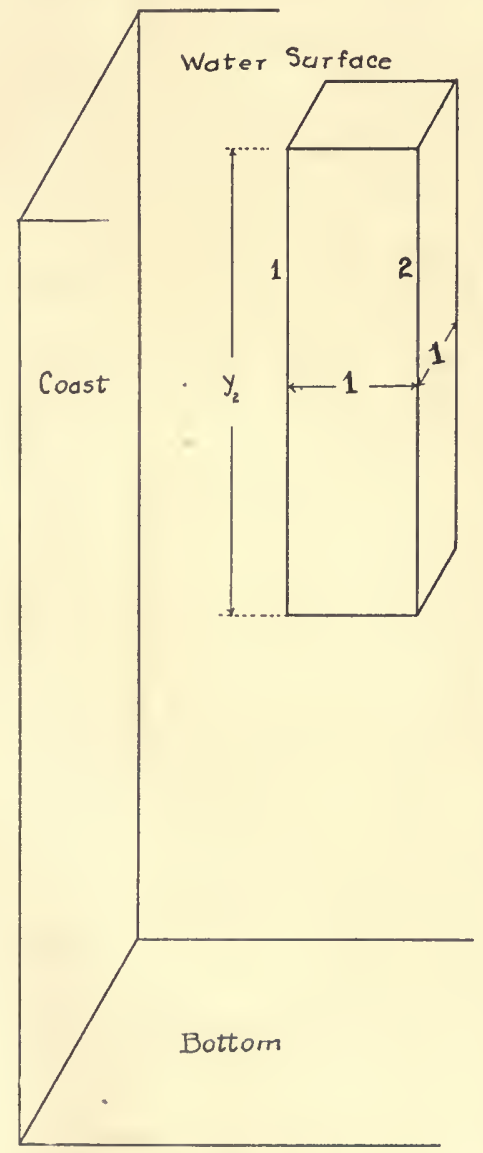

Fig. 18. Rectangular volume of water from the lepth $y_{2}$ of minimum salinity to the surface, used in determining the velocity of upwelling from salinity. water and salts into the volume must equal the rate of flow out of the volume.

This principle will be applied to two different volumes, thus giving two estimates of the velocity of the upwelling. First, consider a vertical column (fig. 18) whose cross section is a square of unit area and whose base is at the depth $y_{2}$ where the salinity has its minimum value (McEwen, 1916, p. 272).

The explanation of symbols used follows :

$S=$ the salinity at any depth $y$.

$S_{0}=$ the salinity at the surface.

$S_{2}=$ the salinity at the depth $y_{2}$.

$r_{2} W_{1}=$ the vertical velocity at the

depth $y_{2}, W_{1}$ is the maximum value, and corresponds to large values of $y$ (table 13).

$V=$ the horizontal velocity.

$E=$ the rate of evaporation at the surface.

A flow into the volume is regarded as negative, and a flow out is regarded as positive, the vertical distances and velocities are regarded as positive when directed downward from the surface, and horizontal distances and velocities are positive when directed away from the coast. Because of the invariability of the amount of water in the volume

$$
r_{2} W_{1}-E+\int V d A=0
$$


where $d A$ is an element of the vertieal surface enclosing the eolumn, and the integral is taken over the whole vertical surface. Similarly because of the invariability of the amount of salts in the volume

$$
r_{2} W_{1} S_{2}+\int V S d A=0
$$

Let

$$
S=\bar{S}+\Delta S
$$

where $\bar{S}$ is the constant mean salinity for the whole volume and $\Delta S$ is a variable increment. Then equation (203) becomes

$$
r_{2} W_{1} S_{2}+\bar{S} \int V d A+\int V(\Delta S) d A=0
$$

and substituting the value of $\int V d A$ from equation (202) we have

$$
r_{2} W_{1} S_{2}-\bar{S}\left(r_{2} W_{1}-E\right)+\int V(\Delta S) d A=0
$$

or solving for $W_{1}$

$$
W_{1}=\frac{-\bar{S} E-\int V(\Delta S) d A}{r_{2}\left(S_{2}-\bar{S}\right)}
$$

An estimate of $\int V(\Delta S) d A$ can be made as follows: Let the volume be so turned that two of its parallel faees are parallel to the eoast line and therefore perpendieular to the horizontal velocity $V$ direeted away from the eoast and given by cquation (p. 401)

$$
V=f(z) V_{0} e^{-a y} \cos \left(\frac{\pi}{4}-a y\right)
$$

Then neglecting the variation of the salinity in a direetion parallel to the eoast, the integral

$$
\int V(\Delta S) d A=-\int_{0}^{y_{2}} V_{1}(\Delta S)_{1} d y+\int_{0}^{y_{2}} V_{2}(\Delta S)_{2} d y
$$

where $V_{1}$ and $(\Delta S)_{1}$ eorrespond to the face next to the eoast and $V_{2}$ and $(\Delta S)_{2}$ to the faee farthest from the coast. From a study of our salinity observations (McEwen, 1916, especially plates 20, 21, 22, and 24) made from five to fifteen miles offshore, it appears that the horizontal gradient parallel to the eoast is negligible as eompared to that perpendieular to the coast, thus justifying equation (209). The numerieal values of the horizontal salinity gradient per meter cstimated from our observations are given for a series of depths in table 17. 
TABLE 17

Mean horizontal salinity gradient per meter during the summer for a series of depths

\begin{tabular}{c|c|c|c|c|c|c|c}
\hline Depth, $y$ & 0 & 5 & 10 & 15 & 20 & 25 & 30 \\
\hline $\begin{array}{l}\text { Salinity } \\
\text { gradient. } \Delta S^{\prime}\end{array}$ & $6 \times 10^{-6}$ & $6 \times 10^{-6}$ & $3 \times 10^{-6}$ & 0 & $-10^{-6}$ & $-3 \times 10^{-6}$ & $-6 \times 10^{-6}$ \\
\hline
\end{tabular}

Our salinity data indicate that $\left(\Delta S^{\prime}\right)$ is practically zero in winter, hence the mean annual value would be about half of that entered in the table.

Owing to the small value of $\left(V_{1}-V_{2}\right)$ compared to the mean value $V$ and because $\Delta S^{\prime}=(\Delta S)_{2}-(\Delta S)_{1}$ equation (209) can be written in the form

$$
\int V(\Delta S) d A=\int_{0}^{y_{2}} V\left(\Delta S^{\prime}\right) d y
$$

From equations (207, 208, and 210) we have finally

$$
W_{1}=\frac{-\bar{S} E-V_{0} f(z) \int_{0}^{y_{2}}\left(\Delta S^{\prime}\right) e^{-a y} \cos \left(\frac{\pi}{4}-a y\right) d y}{r_{2}\left(S_{2}-\bar{S}\right)}
$$

In order to check the above results the same principle will be applied to a different volume (fig. 19). The stream lines (fig. 17) being traces of surfaces of flow on a plane perpendicular to the coast, two such planes, two surfaces of flow, and two horizontal planes inclose a volume such that the component of the velocity along a line parallel to the coast is the same for each vertical plane. Hence the vertical flux through a horizontal section of this volume nust be independent of the depth of the section, in order that the total quantity of water inclosed by these surfaces may be constant. Consider the volume inclosed by two surfaces of flow, two vertical faces perpendicular to the coast and parallel to the plane of the paper at unit distance apart (fig. 19), and two horizontal sections at the depths $y_{2}$ and $y_{1}$ of which the upper forms the base of a rectangular prism extending upward to the surface of the water.

Let $r_{1} W_{1}$ be the mean vertical velocity at the depth $y_{1}$, and $r_{2} W_{1}$ that at the depth $y_{2}$, then $r_{1} W_{1} B_{1}$ must equal $r_{2} W_{1} B_{2}$ where $B$, and $B_{2}$ are the areas of the upper and lower sections respectively, whenee the section areas $B_{1}$ and $B_{2}$ must satisfy the equation

$$
\frac{B_{1}}{B_{2}}=\frac{r_{2}}{r_{1}}
$$


For the whole volume inclosed, from the base $B_{2}$ to the water surface, the condition of the constancy of the quantity of water requires that

$$
r_{2} W_{1} B_{2}-E B_{1}+\int V_{4} d A_{4}-\int V_{3} d A_{3}=0
$$

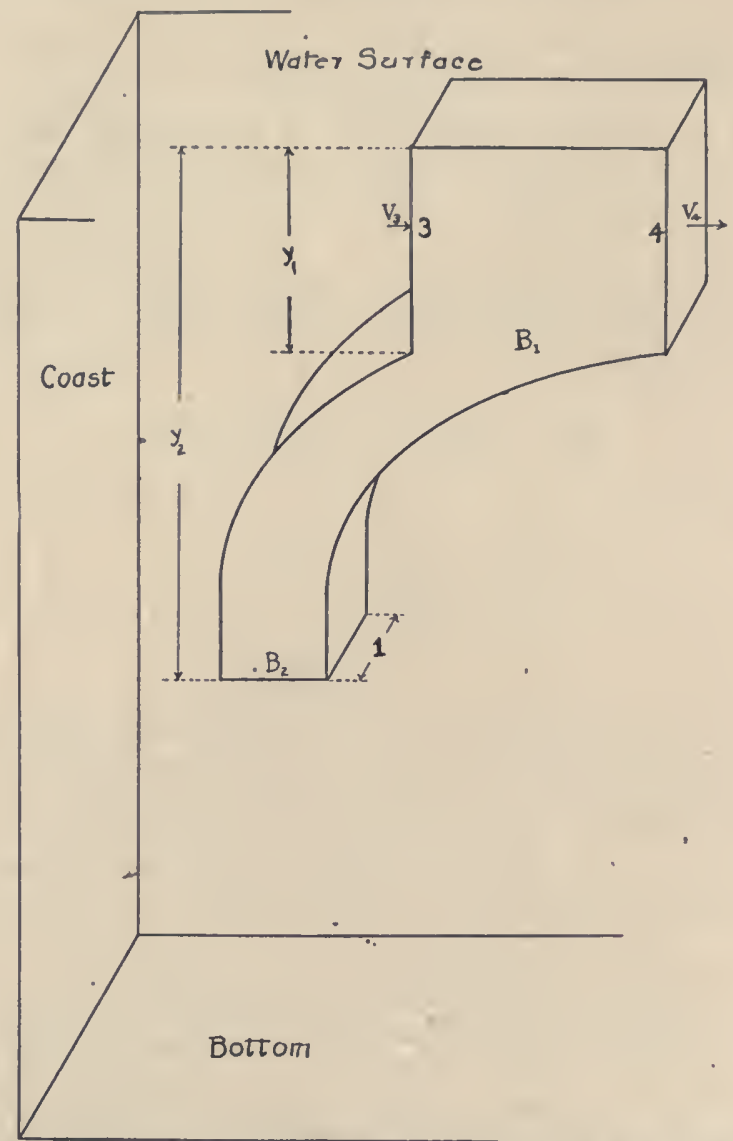

Fig. 19. Volume of water included in part by two surfaces of flow from the depth $y_{3}$ of minimum salinity to a depth $y_{1}$, used in determining the velocity of upwelling from salinity.

where $\left(d A_{3}\right)$ is an element of area of the vertical face of the prism next to the coast, $\left(d A_{4}\right)$ is an element of the other parallel face, and $V_{3}$ and $V_{4}$ are the corresponding horizontal velocities.

Similarly, in order that the total amount of salts may remain constant,

$$
r_{2} W_{1} S_{2} B_{2}+\int V_{4} S_{4} d A_{4}-\int V_{3} S_{3} d \cdot A_{3}=0
$$

where $S_{3}$ and $S_{4}$ are the salinities corresponding to the elements of area $\left(d A_{3}\right)$ and $\left(d A_{4}\right)$. 
Let

and

$$
S_{3}=\bar{S}_{1}+\Delta S_{3}
$$

$$
S_{4}=\bar{S}_{1}+\Delta S_{4}
$$

where $\bar{S}_{1}$ is the constant mean salinity for the prismatie volume from the surface to the depth $y_{1}$ and $\Delta S_{3}$ and $\Delta S_{4}$ are variable inerements. Then equation (216) beeomes

$$
\begin{aligned}
r_{2} W_{1} S_{2} B_{2} & +\bar{S}_{1}\left\{\int V_{4} d A_{4}-\int V_{3} d A_{3}\right\} \\
& -\int V_{4}\left(\Delta S_{4}\right) d A_{4}-\int V_{3}\left(\Delta S_{3}\right) d A_{3}=0
\end{aligned}
$$

and substituting the value of

$$
\left\{\int V_{4} d A_{4}-\int V_{3} d A_{3}\right\}
$$

from equation (215) we have

$$
W_{1}=\frac{-\bar{S} E}{r_{1}\left(S_{2}-\bar{S}_{1}\right)}-\frac{\int_{0}^{y_{1}} V\left(\Delta S^{\prime}\right) d y}{r_{1}\left(S_{2}-\bar{S}_{1}\right)}
$$

where $\left(\Delta S^{\prime}\right)$ is defined on page 411 , and finally, substituting for $V$ the value given by equation (208)

$$
W_{1}=-\frac{-\bar{S}_{1} E}{r_{1}\left(S_{2}-\bar{S}_{1}\right)}-\frac{V_{0} f(z) \int_{n}^{y_{1}}\left(\Delta S^{\prime}\right) e^{-a y} \cos \left(\frac{\pi}{4}-a y\right) d y}{r_{1}\left(S_{2}^{\prime}-\bar{S}_{1}\right)}
$$

If the depth of the upper seetion is at the level $y_{2}$ we must substitute $y_{2}$ for $y_{1}$ and $r_{2}$ for $r_{1}$ in equation (220), which then becomes identieal with equation (211). But in equation (220) $y_{1}$ can have any valuc between the limits, zcro and $y_{2}$, where $y_{2}$ is the depth of minimum salinity, and estimates of the velocity based on different values of $y_{1}$ should give the same result. Some divergence of these values in any actual ease is to be expeeted, since the different estimates are based on different observations that are subject to errors of measurement and sinee the actual rclation of the velocity to depth may differ from the theoretieal rclation (p. 403).

In table 18 , where $V_{0}=324000$ (p. 404) and $-E$ for the latitude of San Diego is .0754 meters per month (Schmidt, 1915, p. 121) are presented the results based upon the mean value of $\left(\Delta S^{\prime}\right)$, that is, half the value entered in table 17, the mean annual salinities as shown by plate 11 and table 3 (MeEwen, 1916) and the values of $r_{1}$ and $f(10)$ from tables 13 and 14. 


\begin{tabular}{|c|c|}
\hline 2 & $\begin{array}{llllllll}1 & 1 & 1 & 1 & 1\end{array}$ \\
\hline$V_{\circ} f(z) \int_{0}^{y_{1}}\left(\Delta S^{\prime}\right) e^{-a y} \cos \left(\frac{\pi}{4}-a y\right) d y$ & \multirow[t]{2}{*}{ 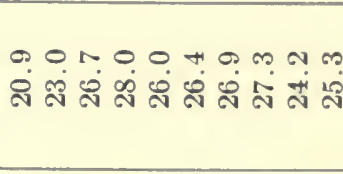 } \\
\hline$r_{1}\left(S_{2}-\overline{S_{1}}\right)$ & \\
\hline $.05 \int_{0}^{y_{1}}\left(\Delta S^{\prime}\right) e^{-a y} \cos \left(\frac{\pi}{4}-a y\right) d y$ & 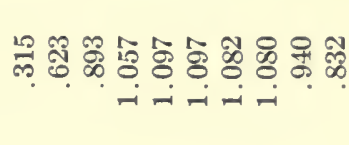 \\
\hline $\int^{y_{1}}\left(\Delta S^{\prime}\right) e^{-a y} \cos \left(\frac{\pi}{4}-a y\right) d y$ & 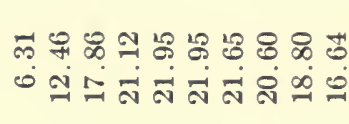 \\
\hline 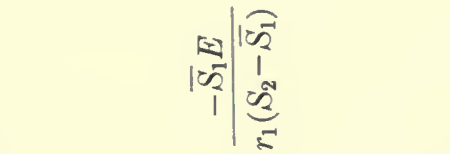 & $\begin{array}{lllllll}1 & 1 & 1 & 1 & 1\end{array}$ \\
\hline$\frac{10}{\operatorname{lon}}$ & 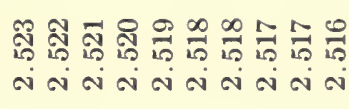 \\
\hline$=$ & 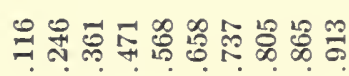 \\
\hline $\begin{array}{l}\mid \overrightarrow{2} \\
1 \\
\text { कर }\end{array}$ & 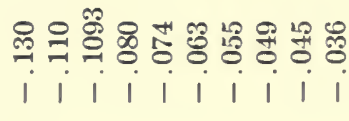 \\
\hline $\mid \overrightarrow{\sigma \Omega}$ & 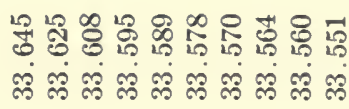 \\
\hline ה & 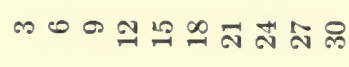 \\
\hline
\end{tabular}


Except for the first two values of $y_{1}$ near the surface, where the water is most disturbed, and for the largest value of $y_{1}$, where the difference $\left(S_{2}-\bar{S}_{1}\right)$ is so small that it is subject to the largest proportional error, the computed values of the velocity $W_{1}$ shown in the last column are in good agreement. And the mean of the central values, which are subject to the least error, is about - 35 , which is the best estimatc from the available data and agrees well with the values -31 and -53 found before, page 408 .

\section{Conclusion}

In the case of no average flow of the water the form of a function giving the rate of gain of heat and of another giving the rate of loss of heat from a small volume of water at a given latitude and depth, was developed from a few simple assumptions, suggested by laboratory experiments as well as field obscrvations. Equating the sum of these two expressions to the product of the specific heat by the volume by the rate of change of temperature resulted in a differential equation whose solution gave the temperature from the surface to a depth of ten meters as a known function of time, depth, latitude, and certain physical constants, under the conditions of no average flow of water.

From observations on the relation to latitude of the mean annual surface temperature and the annual temperature range and the relation to latitude of the mean annual solar radiation and its annual range, all of the physical constants of the formula were computed.

The lag between the time of the temperature maxima and minima and the time of the maximum and minimum values of the solar radiation deduced from these constants agreed well with the observed valuc. Also the mean monthly temperature at a region whose mean annual tempcratures agree well with the normal value for the latitude, that is, the value corresponding to no average flow, would be expected to agree with those computed from the formula for normal temperature. A comparison of such computed and obscrved tempcratures for a scries of latitudes from $20^{\circ} \mathrm{N}$ to $40^{\circ} \mathrm{N}$ indicated a very satisfactory agreement.

If the rate of change of temperature due to some factor not included in the above reasoning is known this quantity can be added to the differential equation already derived. Since all of the constants of the original differential equation are known the solution of the modified equation will give the temperature due to the new factor: 
If, for example, there is a flow of the water, the rate of flow multiplied by the temperature where the water enters a given element of volume gives the rate at which the heat is carricd into the volume. The rate at which the heat leaves the volume, computed in the same way, subtracted from the rate at which it enters gives the rate of change of heat in the volume due to the corresponding ocean current, whether horizontal or vertical. A term expressing this rate of change of heat in the case of a horizontal current was added to the differential equation, and the solution furnished a means of estimating the magnitude of horizontal currents from surface temperatures without considering the causes of the currents.

Numerical applications of this formula to a region of the North Pacific off the California coast and of the North Atlantic off the African coast gave estimates of the horizontal flow in good agreement with direct observations and with what would be expected from the observed wind velocity.

Conclusive evidence of the presence of currents directed upward from the bottom along the California ccast which cause reduction in temperature has been published before; but to test this conclusion further it was assumed that the reduction of the temperature of the coastal water was due entirely to the upwelling of deep water, and the temperature distribution at depths exceeding 40 meters was assumed to result from a flow of heat according to Fourier's well known conductivity equation, in which a term expressing the rate of loss of heat due to upwelling was added. The formal solution of this equation contained certain physical constants whose evaluation required the observed monthly temperatures at a series of depths. Our temperature data for a deep water region twenty miles offshore from San Diego were sufficient for making approximate estimates of all of the constants, of which the velocity of upwelling and the term corresponding to conductivity are of special interest. The latter constant depends largely upon the eddy motion, or alternating circulation, which tends to mix the water and has been called eddy conductivity or Mischungsintensität, and was found in this case to be several thousand times the laboratory value. In dealing with salinities the same formula can be used; and a similar constant appears, which also depends largely on the mixing motion of the water, and would be expected to have practically the same value as that determined from temperatures. Our salinitiy data, though not so complete as the temperature data, confirmed this conclusion and gave approximately 
the same velocity of upwelling. Moreover, in applying hydrodynamical equations to problems of oceanic circulation the coefficient of viscosity must be replaced by another constant depending on the eddy, or turbulent motion, and having a much greater value than the laboratory value obtained from observations on a slow laminar flow free from irregular motions. Similar results have also been found by G. I. Taylor in certain recent studies of the temperature, water vapor, and velocity in the atmosphere. The results of laboratory experiments and theories based on them were helpful but could not provide the numerical values required; in each case field observations were necessary. Furthermore, since the eddy conductivity, or Mischungsintensität, is not a physical constant of the substance, sea water or air, but depends upon the intensity and character of the circulation, its value will vary accordingly. The following approximate values of these constants, the coefficient of viscosity, diffusion, and conductivity under laboratory conditions and estimated from field observations in the ocean and the atmosphere, illustrate the great differences between field and laboratory conditions.

TABLE 19

Estimatcs of the coefficients of viscosity, diffusion, and heat conductivity made from field observations in the occan and atmosphere compared with values obtained in laboratory experiments

\begin{tabular}{|c|c|c|c|c|}
\hline \multicolumn{5}{|c|}{ Sea Water } \\
\hline Observer & Coefficient & $\begin{array}{l}\text { Laboratory value } \\
\text { in c. g. s. units }\end{array}$ & $\begin{array}{l}\text { Value from field } \\
\text { observations in } \\
\text { c. g. s. units }\end{array}$ & $\begin{array}{c}\text { Ratio of the field } \\
\text { to the laboratory } \\
\text { value }\end{array}$ \\
\hline Ekman & Viscosity $^{1}$ & .014 & 217 & 15,500 \\
\hline Jacobsen & Diffusion & .0000125 & .3 to 11.4 & $\begin{array}{l}24,000 \text { to } \\
320,000\end{array}$ \\
\hline McEwen & Diffusion & .0000125 & 40 & \\
\hline McEwen & Conductivity ${ }^{2}$ & .0012 & 30 & 25,000 \\
\hline \multicolumn{5}{|c|}{ Air } \\
\hline Taylor & Viscosity ${ }^{1}$ & .13 & 770 to 6,900 & 6,000 to 50,000 \\
\hline Taylor & Conductivity $^{2}$ & .20 & 570 to 3,400 & 3,000 to 17,000 \\
\hline
\end{tabular}

The estimation of the effect of upwelling on the surface temperature made necessary the consideration of results obtained for depths 
below the 40 meter level and the solution of the original differential equation for surfaee temperatures after adding a term giving the rate of temperature ehange due to upwelling. The monthly values dedueed in this way for the San Diego region agree very well with those afforded by the observations.

From the magnitude of the vertieal velocity found from temperatures and from eertain results deduced from Ekman's hydrodynamieal theory, the distribution of the horizontal and vertieal velocity of the water in a vertieal plane perpendicular to the eoast was deduced and represented graphieally.

An independent estimate of the velneity of upwelling made from the distribution of salinities in the upper 30 meter layer and of the rate of evaporation at the surface agreed well with the other two estimates. Moreover, the estimates of the veloeity of upwelling from the temperature or salinity distribution did not depend upon the eause of the upwelling; but it is an interesting fact that sueh a vertieal eurrent would be expected along the California eoast from Ekman's hydrodynamieal theory.

I wish to express my obligation to Dr. W. E. Ritter of this institution, and to my laboratory assistant, Mr. Nephi W. Cummings, for his aid in making the eomputations and for his suggestions while preparing the manuscript.

Transmitted June 26, 1918.

Scripps Institution for Biological Research

of the University of California, La Jolla, California. 


\section{LITERATURE CITED}

BJERKNeS, V. F. K.

1901. Cirkulation relative zu der Erde. Ofversikt af Kongl. Vet.-Akad. Förhandl., 58, 739-757.

EKMAN, V. W.

1905-06. On the influence of the earth's rotation on ocean currents. Arkiv for Matematik, Astronomi och Fysik, 2, 1-53, 1 pl. and 10 figs.

1906. Beiträge zur Theorie der Meereströmungen. Ann. d. Hydrog. u. marit. Meteor., 34, 423-430, 472-484, 527-540, 566-583, 38 figs.

GeHRKe, Johan.

1909. Beitrag zur Hydrographie des finnischen Meerbusens. Finnländische hydrographisch-biologische Untersuchungen, III. (Leipzig, Engelmann), pp. 1-39, pls. 1-3, 7 figs. in text.

1910. Beiträge zur Hydrographie des Ostseebassins. Cons. perman. explor. Mer., Cire. 52, 1-195, 2 pls.

GreIN, K.

1913. Untersuchungen über die Absorption des Lichts in Seewasser. I. Die selektive Absorption des Sonnenlichts im Meer nebst einer Besehreibung des Instruments und der Methode. Ann. Inst. Oceanogr., 5, fasc. 6 , pp. 1-23, 7 figs. in text.

HaNn, Julius.

1915. Lehrbuch der Meteorologie. (Leipzig, Tauchnitz), xiv +847 pp., 28 pls., 69 figs. in text.

Helidand-Hansen, B.

1911-12. The ocean waters, an introduction to physical oceanography. I, General part (methods). Intern. Rev. d. ges. Hydrobiol. u. Hydrog., 3, Hydrog. Suppl., pp. 1-84, figs. $1-46$ in text.

JACOBSEN, J. P.

1913. Beitrag zur Hydrographie der dänischen Gewässer. Medd. Komm. Havandersogelser (Hydrografi), 1, no. 2, 94 pp., 14 pls., 17 figs. in text.

KRÜMMFL, O.

1907. Handbuch der Ozeanographie. (Stuttgart, Engelhorn), 1, xv +526 pp., 60 figs. in text.

1911. Irandbuch der Ozeanographie. (Stuttgart, Engelhorn), 2, xvi +766 pp., 182 figs. in text.

KRÜMMEL, O., AND RUPPIN, E.

1905. Ueber die innere Reibung des Seewasser. Wiss. Meeresuntersuchungen, N. F., 9, 29-36.

Клотт, C. G.

1903-05. Ocean temperatures and solar radiation. Proc. Royal Soc. Edinburgh, 25, part 1, pp. 173-184.

MAKAROFF, S.

1894. Le "Vitiaz" et l'ocean Pacifique. (St. Petersburg, Kummar), 1, xliii $+337 \mathrm{pp}$. 
McEwen, G. F.

1912. The distribution of ocean temperatures along the west coast of North America deduced from Ekman's theory of the upwelling of the cold water from the adjacent ocean depths. Intern. Rev. d. ges. Hydrobiol. u. Hydrog., 5, 243-286, 21 figs. in text.

1914. Peculiarities of the California climate explained on the basis of general principles of atmospheric and oceanic circulation. U. S. Mon. Weather Rev., 42, 14-23, 13 figs.

1916. Summary and interpretation of the hydrographic observations made by the Scripps Institution for Biological Research of the Univer. sity of California, 1908-1915. Unjv. Calif. Publ. Zool., 15, 255-356, pls. $1-38$.

Michael, E. L., and McEwen, G. F.

1915-16. Hydrographic, plankton and dreaging records of the Scripps Institution for Biological Research of the University of California, 1901-12. Univ. Calif. Publ. Zool., 15, 1-206, 4 figs. and 1 map in text; ibid., 16, 207-254, 4 figs. in text.

MoHN, H.

1887. The Norwegian North Atlantic expedition, 1876-1878: The North Sea, its depths, temperature and circulation. (Christiania, Gro dahl), 212 pp., 48 pls.

Moore, W. I.

1908-11. Meteorological charts of the North Pacific Ocean. U. S. Weather Bureau, Washington, D. C.

Murray, Sir JoHN.

1898. On the annual range of temperature in the surface waters of the ocean and its relation to other oceanographic phenomena. Geog. Jour., $12,113-137$.

Murray, Sir John, ANd HJort, Johan.

1912. The depths of the ocean. (London, Macmillan), $\mathbf{x x}+821$ pp., 9 pls., 575 figs. in text.

Nansen, F.

1913. The waters of the north-eastern North Atlantic. Intern. Rev. d. ges. Hydrobiol. u. Hydrog., 4, 1-139, pl. 17, figs. 1-52 in text.

Petersen, Johannes

1912. Hydrographie und Meteorologie Finnlands und der benachbarten Meere, nach "Atlas de Finlande." Ann. Hydr. u. marit. Meteor., $40,131-145,4$ figs. in text.

PUls, CAsar.

1895. Oberflächentemperaturen und Stromungsverhältnisse des Aequatorialgürtels des Stillen Ozeans. Aus dem Archiv der deutschen Seewarte, $18,1-38$, pls. 1-4.

SCHMIDT, WILHELM.

1915. Strahlung und Verdunstung an freien Wasser flächen. Ein Beitrag zum Wärmehaushalt des Weltmeers und um Wasserhaushalt der Erde. Ann. Hydr. u. marit. Meteor., 43, 111-124. 
Sснотт, G.

1895. Die jährliche Temperaturschwankung des Oceanwassers. Petermanns Mittelungen, 41, 153-159, pl. 10.

1902. Oceanographie und maritime Meteorologie. Wissenschaftliche Ergebnisse der deutschen Tiefsee-Expedition auf dem Dampfer "Valdivia," 1898-1899. (Jena, Fischer), 1, xii + 403 pp., 26 pls. and 35 figs in text.

Schott, Gerhard, Und Schu, Fritz.

1910. Die Wärmeverteilung in den Stillen Ozeans. Ann. Hydr. u. marit. Meteor., 38, 1-26, 15 pls. 1 fig. in text.

Schott, G., Schulz, B., Und Perlewitz, P.

1914. Die Forschungsreise S.M.S. "Möwe," im Jahre 1911. Aus dem Arehiv der deutsehen Seewarte, 37, vi +104 pp., 8 pls. and 16 figs. in text.

TAYLOR, G. I.

1915. Eddy motion in the atmosphere. Philos. Trans. Royal Soc. London, 215, ser. A, pp. 1-26, figs. 1-5 in text.

THORADE, H.

1909. Ueber die Kalifornische Meeresströmungen, Oberflächentemperaturen und Strömungen an der Westküste Nordamerikas. Ann. Hydr. u. marit. Meteor., 37, 17-34, 63-77, pls. 5, 10, 11, 5 figs. in text.

- 1914. Die Geschwindigkeit von Triftsströmungen und die Ekmansche Theorie. Ibid., 42, 379-391, 3 figs. in text.

IVEgEMANN, G.

1905a. Die vertikale Temperaturverteilung im Weltmeere durch Wärmeleitung. Wissenschaftliche Meeresuntersuchungen, herausgegeben von der Kommission zur Untersuchung der deutschen Meere in Kiel und der Biologischen Anstalt auf Helgoland. Abteilung Kiel, N. F., 8, 137-143.

1905b. Ursachen der vertikalen Temperaturverteilung im Weltmeere unter besonderer Berücksichtigung der Wärmeleitung. Ann. Hydr. u. marit. Meteor., 33, 206-211.

WhaRTON, W. J. L.

1894. Presidential address, Section E, Geography. Rept. Brit. Assoc. Adv. Sei.

Winkelmann, A.

1906. Handbuch der Physik. (Leipzig, Barth), 3, xiv $+1178,206$ figs. in text.

ZÖPPRITZ, K.

1878. Hydrodynamische Probleme in Beziehung zur Theorie der Meeresströmungen. Wiedemanns Annalen, 3, 582-607. 



\section{CHANGES IN THE \\ CHEMICAL COMPOSITION \\ OF GRAPES DURING RIPENING}

BY

F. T. BIOLETTI, W. V. CRUESS, AND H. DAVI

[University of California Publications in Agricultural Sciences, Vol. 3, No. 6, pp. 103-130] 



\section{CHANGES IN THE CHEMICAL COMPOSITION OF GRAPES DURING RIPENING}

BY

F. T. BIOLETTI, W. V. CRUESS, AND H. DAVI

The investigations reported in this paper were undertaken to determine the changes in chemical composition of vinifera varieties of grapes in California during the growing and ripening stages. A survey of the literature indicated that, although the subject had been quite fully investigated in Europe with vinifera varieties and in America with the native varieties, very little had been published upon the ripening of vinifera varieties under California Conditions. A great many analyses of different varieties of grapes have been made by chemists of the University of California Experiment Station, notably by G. E. Colby, and are reported in the publications of this station. ${ }^{1}$ A paper by G. E. Colby ${ }^{2}$ gives data upon the nitrogen content of a number of varieties of ripe vinifera grapes. Most of the analyses, however, do not show the changes in composition during ripening.

Of the more recent European investigations ${ }^{3}$ some deal with the changes in general composition, others are confined to a discussion of a single component, such as sugar, or coloring matter, or acid principles.

The changes in composition of American varieties of grapes during ripening have been studied quite thoroughly by W. B. Alwood ${ }^{4}$ and his associates. These investigations gave particular attention to the

1 Hilgard, E. W., The composition and classification of grapes, musts, and wines. Rept. of Viticultural Work, Univ. Calif. Exper. Sta. Rep., 1887-93, pp. $3-360$.

2 Colby, G. E., On the quantities of nitrogenous matters contained in California musts and wines. Ibid., pp. 422-446.

3 Kelhofer, W., The grape in the various stages of nuturity; trans. by E. Zardetti. Gior. Vin. Ital., vol. 34 (1908), no. 30, pp. 475-477.

Barberon, G., and Changeant, F., Investigations on the develıpnient and 
increase in sugar content and changes in acidity during the period in which the grapes were under observation. Alwood and other members of the Burcau of Chemistry, United States Department of Agriculture, have also published a number of reports ${ }^{4}$ on the general composition of American varicties of grapes as affected by scason, locality, etc.

The most notablc changes taking place during ripening were found by the European and American investigators mentioned above to be: (1) increase in total sugar ; (2) decreasc in ratio of glucose to fructose; (3) decrease in total acid; (4) increase in ratio of cream of tartar to total acid due to decrease in total acid; (5) decrease in tannin ; and (6) increase in coloring matter. The cream of tartar and protein change very little in percentage during ripening, although, according to the

composition of varieties of grapes in Abraon-Durso. Ann. Soc. Agr Sei. et Ind., Lyon (8), vol. 1 (1903), pp. 97-159.

Laborde, J., The transformation of the coloring matter of grapes during ripening. C. R. Acad. Sci. (1908), vol. 17, pp. 753-755.

Martinand, V., On the occurrence of sucrose and saccharose in different parts of the grape. C. R. Acad. Sci. (1907), vol. 24, pp. 1376-79.

Roos, L., and Hughes, E., The sugar of the grape during ripening. Ann. Falsif. (1910), vol. III, p. 395.

Bouffard, A., Observations in regard to the proportion of sugar during ripening. Ann. Falsif. (1910), vol. III, pp. 394-5.

Zeissig, Investigations on the process of ripening on one-year-old grape wood. Ber. k. Lehranst. Wien, Obst-u. Garten-bau (1902), pp. 59-64.

Koressi, F., Biological investigations of the ripening of the wood of the grape. Rev. Gen. Bot., vol. 13 (1901), no. 149, pp. 193-211; no. 150, pp. 251-264; no. 151 , pp. 307-325.

Brunet, R., Analysis and composition of the grape during ripening. Rev. de Viticulture, vol. 37, pp. 15-20.

Garina, C., Variations in the principal acids of grape juice during the process of maturing. Canina. Ann. R. acad. d'agricultura di Torino, vol. 57 (1914), p. 233. Cf. Ann. Chim. applicata, vol. 5 (1914), pp. 65-6. See also Ann. r. acad. d'agr. di Torino, vol. 57, pp. 233-90.

Baragolia, W. I., and Godet, C., Analytical chemical investigations on the ripening of grapes and the formation of wine from them. Landw. Jahrb., vol. 47 (1914), pp. 249-302.

Rivière, G., and Bailhache, G., Accumulation of sugar and decrease of acid in grapes. Chem. Abs. Jour. (1912), p. 1022; Jour. Soc. Nat. Hort. France (4), pp. 125-7; Bot. Cent., 1912, pp. 117, 431.

Pantanelli, Enzyme in must of overripe grapes. Chem. Abs. Jour., vol. VI (1912), p. 2447.

4 Alwood, W. B., Hartmann, J. B., Eoff, J. R., and Sherwood, S. F., Development of sugar and acid in grapes during ripening. U. S. Dept. Agric. Bull. 335, April 11, 1916.

- The occurrence of sucrose in grapes. Jour. Indust., vol. II, Eng. Chem. (1910), pp. 481-82.

- Sugar and acid content of American native grapes. 8th Inter. Cong. Appl. Chem. (1912), Sect. VIa-XIv, pp. 33, 34.

- Enological Studies: the chemical composition of American grapes grown in Ohio, New York, and Virginia. U. S. Dept. Agric. Bur. Chem. Bull. 145, 1911. Crystallization of cream of tartar in the fruit of grapes. U. S. Dept. Agric. Jour. Agric. Research (1914), pp. 513, 514.

Alwood, W. B., Hartmann, B. G., Eoff, J. R., Sherwood, S. F., Carrero, J. O., and Harding, T. J., The chemical composition of American grapes grown in the central and eastern states. U . S. Dept. Agric.( 1916) Bull. 452. 
investigations referred to, there is a slight increase in both of these constituents.

In the investigations reported in the present paper, particular attention was given to increase in total solids and sugar, decrease in total acid, and changes in protein and cream of tartar in the must or juice of the grapes. The ripening of the leaves was traced by noting the changes in starch, sugar, acid, and protein content.

Sampling.-During 1914 and 1915 samples of fruit were taken from the time the grapes had reached full size but were still hard and green until they had become overripe. During 1916 the first samples were taken shortly after the berries had set and before the seeds had formed. The last samples were taken when the grapes had become overripe. Samples of leaves were also taken in 1916 on the same dates that samplings of the grapes were made. The samples were taken at intervals of approximately one week. They were in all cases taken from the experimental vineyard at Davis. ${ }^{5}$

Five-pound samples of grapes were used. The grapes werc picked from the first crop, except in 1914, when a comparison of the ripening of first and second crops was made. An ordinary five-pound grapc basket was filled with leaves at each sampling. The samples of grapes and leaves were shipped from the vineyard to the laboratory at Berkeley, where the grapes were placed in an Enterprise fruit crusher and pressed. The juice was sterilized in bottles at $212^{\circ} \mathrm{F}$. The lcaves were ground in an Enterprise food chopper and sterilized at $212^{\circ} \mathrm{F}$ in wide mouth, air tight bottles. The samples were then reserved for chemical examination.

In 1914 it was found that there was considerable irregularity in the variation of samples from week to week. For cxample, instead of an increase of total solids during the periods between samplings, a slight decrease was found in a few samples. During the 1915 scason it was therefore considered of interest to note what effect certain factors might have upon the composition of samples taken on the same date.

1. Effect of Age of Vine. The cntirc first crop from three large old vines and from three small young vines, all of the Muscat variety, was picked, crushed, and pressed. Analyses of the juices werc made with the following results :

5 The authors wish to express their appreciation of the assistance of $F$. C. Flossfeder, of the University Farm at Davis, who gathered most of the samples reported upon in this paper. 
Table 1-Effect of Age of Vine on Balling and Acid of Must of Muscat Grapes

\begin{tabular}{|c|c|c|}
\hline Vine & Balling & Acid \\
\hline 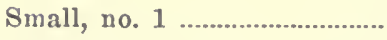 & 24.7 & .67 \\
\hline 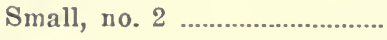 & 27.7 & .49 \\
\hline 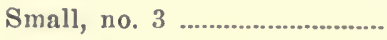 & 27.6 & .67 \\
\hline Large, no. 1 & 22.0 & .88 \\
\hline Large, no. 2 & 23.5 & .75 \\
\hline 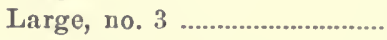 & 23.6 & .76 \\
\hline Average, small ....................... & 26.7 & .61 \\
\hline Average, large & 23.0 & .81 \\
\hline 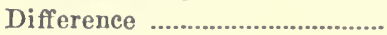 & 3.7 & -20 \\
\hline
\end{tabular}

The results show rather strikingly that young vines ripen their fruit earlier than do mature vines. This fact makes it essential that samples, to be comparative, must be taken from vines of the same age.

2. Comparison of Grapes from North and South Sides of Vines. The whole first crop from three large Muscat vines was picked. The bunches from the north and south sides of each vine were kept separate. They were crushed, pressed, and analyzed for Balling and acid content.

Table 2-Comparison of Balling and Acid of Juice from Grapes Picked from North and South Sides of Vines

\begin{tabular}{|c|c|c|}
\hline Vine and side of vine & Balling & Acid \\
\hline $1-\mathrm{N}$ & 21.3 & .92 \\
\hline $1-\mathrm{S}$ & 22.7 & .84 \\
\hline $2-\mathrm{N}$ & 23.5 & .81 \\
\hline $2-\mathrm{S}$ & 23.5 & .80 \\
\hline $3-\mathrm{N}$ & 23.1 & .81 \\
\hline $3-\mathrm{S} \quad \ldots$ & 24.1 & .71 \\
\hline Average, $\mathrm{N}$ side & 22.63 & .85 \\
\hline 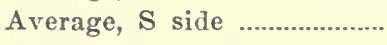 & 23.43 & .78 \\
\hline 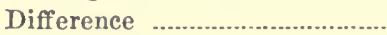 & .80 & -.07 \\
\hline
\end{tabular}

The tests indicate that grapes located on the south side of the vine ripen more rapidly than those on the north side. This difference is apparently due to the fact that the south side of the vine receives more heat than the north side.

3. Effect of Location of Bunch on Cane. Grapes of first crop, from canes showing two bunches each, were picked and the bunches from near the bases of the canes kept separate from those near the tip of the cane. They were crushed, pressed, and analyzed for Balling and acid. 
Table 3-Effect of Location of Bunch on Cane

\begin{tabular}{|c|c|c|c|c|}
\hline \multirow[b]{2}{*}{ Vine } & \multicolumn{2}{|c|}{ Nearest base of cane } & \multicolumn{2}{|c|}{ Nearest tip of cane } \\
\hline & Balling & Acid & Balling & Acid \\
\hline Muscat, no. 1 , cane 1 ..................... & 25.1 & .73 & 23.7 & .83 \\
\hline Muscat, no. 1 , cane 2 ................... & 25.6 & .79 & 24.8 & .80 \\
\hline Muscat, no. 2, cane 1 .................. & 25.1 & .85 & $\dot{2} 4.6$ & .87 \\
\hline Muscat, no. 2 , cane 2 ................... & 25.2 & .78 & 24.7 & $\cdot .85$ \\
\hline Muscat, no. 3 , cane 1 .................. & 23.0 & .79 & 22.6 & .82 \\
\hline Muscat, no. 3 , cane 2 ................... & 24.5 & .73 & 23.8 & .73 \\
\hline 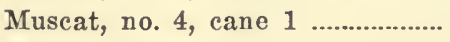 & 24.2 & .90 & 25.2 & .90 \\
\hline Muscat, no. 4, cane 2 ................... & 24.5 & .68 & 23.8 & .83 \\
\hline 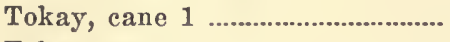 & 21.2 & .67 & 21.2 & .80 \\
\hline Tokay, cane 2 & 23.0 & .63 & 22.4 & .76 \\
\hline 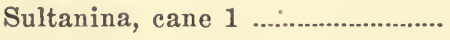 & 23.3 & .61 & 22.3 & .62 \\
\hline Sultanina, cane 2 & 22.5 & .61 & 23.0 & .63 \\
\hline Sultana, cane 1 & 23.2 & .78 & 21.6 & .70 \\
\hline Sultana, cane 2 & 21.1 & .90 & 20.0 & 1.20 \\
\hline Palomino, cane 1 ............................. & 25.1 & -..... & 23.5 & ....... \\
\hline Palomino, cane 2 & 22.0 & ...... & 23.7 & ...... \\
\hline 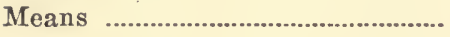 & 24.9 & .75 & 23.1 & .81 \\
\hline
\end{tabular}

The data indicate that bunches at the basc of the cane ripen in most cases more rapidly than those near the tip, although this relation docs not always hold and may be reversed in some instances.

4. Variation in Balling Degree of Must from Bunches of Similar Appearance and Size from Same Vineyard and Gathered on Same Date. A five-pound basket of grapes of first crop and selected for similarity of color, size of bunch, and general appearance was picked from each of a number of vines in the same vineyard. Vines of similar size and appcarance were chosen. Several varieties were represented in the experiment. Tests of Balling degree only were made.

Table 4-Variation in Balling in Must From Grapes of Same Variety Picked From Different Vines of Similar Appearance

\begin{tabular}{|c|c|c|c|c|}
\hline Variety & $\begin{array}{c}\text { Vine } \\
\text { number }\end{array}$ & Balling & $\begin{array}{c}\text { Mrean } \\
\text { Balling }\end{array}$ & $\begin{array}{c}\text { Maximum } \\
\text { variation }\end{array}$ \\
\hline Cornichon & 3 & 14.5 & ...... & ....... \\
\hline Cornichon & 6 & 15.0 & ....... & ....... \\
\hline Cornichon & 9 & 14.2 & ....... & $\ldots . .$. \\
\hline Cornichon & 11 & 14.7 & ....... & ....... \\
\hline Cornichon & $\ldots . .$. & 16.1 & 14.9 & 1.9 \\
\hline Emperor & 10 & 12.0 & ...... & ...... \\
\hline Emperor & 11 & 14.5 & ....... & ....... \\
\hline Emperor & 13 & 15.2 & ...... & ....... \\
\hline Emperor & 14 & 15.5 & ....... & ....... \\
\hline Fmperor & 17 & 15.0 & 14.4 & 3.5 \\
\hline Malaga & 5 & . 18.5 & ....... & ....... \\
\hline Malaga & 6 & 17.2 & ....... & ....... \\
\hline
\end{tabular}




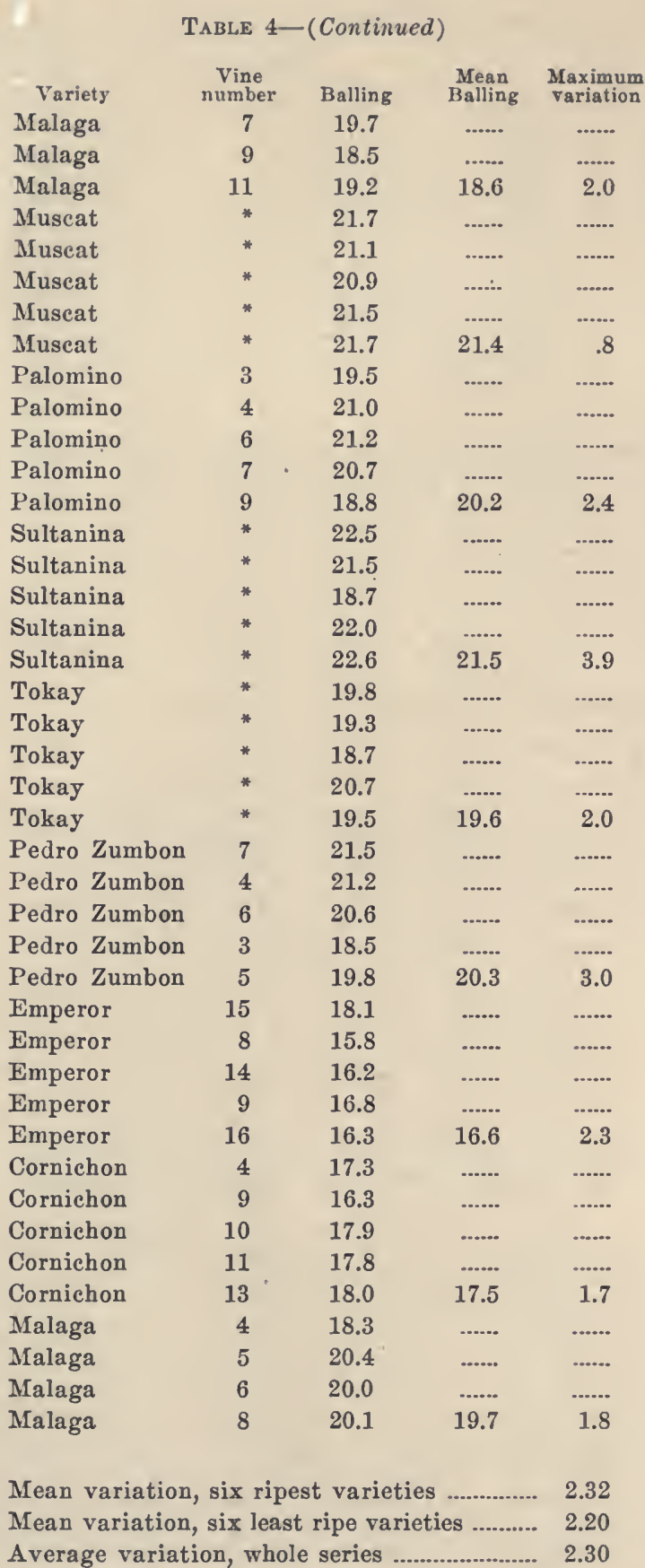

* Adjacent vines. 
The data illustrate the difficulty of seleeting five-pound lots of the same variety that will represent average samples.

5. Effect of Location of Berries on the Bunch. All of the bunches of the first crop were taken from two Muscat vines.' The bunehes were cut into top and bottom halves. These lots were crushed separately, pressed, and the juices analyzed.

\begin{tabular}{|c|c|c|c|c|}
\hline & Sample & Balli & & Acid \\
\hline Vine & no. 1 , stem end of bunch & .......... & 23.6 & .76 \\
\hline Vine & no. 1, apical end of bunch & & 22.7 & .87 \\
\hline Vine & no. 2, stem end of bunch & ............ & 21.3 & .92 \\
\hline Vine & no. 2, apical end of bunch & & 21.3 & .93 \\
\hline
\end{tabular}

The results show that considerable variation in eomposition of the berries may exist within the same bunch.

6. Effect of Thoroughness of Pressing. About ten pounds of Muscat grapes were crushed and lightly pressed. The pulp and skins left from this pressing were then thoroughly crushed and pressed a seeond time. The juiecs from the two lots were analyzed scparately.

\begin{tabular}{|c|c|c|}
\hline Siample & Balling & Acid \\
\hline First pressing ............................ & 22.8 & .78 \\
\hline Second pressing ...................... & 22.8 & .79 \\
\hline
\end{tabular}

There was practically no difference between the juiees from lightly and thoroughly pressed grapes of the same lot.

The data from the above six tests indieate that it is a very diffieult mattcr to select grapes that will represent a fair average sample of the grapes to be studied. The size and age of the vine, the side of the vines, the loeation of the buneh on the eane, and individual vines, all affect the eomposition of the juice from the grapes very materially, and these factors should be taken into aeeount whell samples are taken.

Preservation of Samples and Preparation for Analysis.-In 1914 the samples of juiec werc preserved with $\mathrm{HgCl}_{2}, 1: 1000$. In 1915 and 1916 the samples were stcrilized at $100^{\circ} \mathrm{C}$. Before analysis the bottles were heated to $100^{\circ} \mathrm{C}$ for an hour to dissolve any eream of tartar whieh might have separated. The juices were filtered before analysis. Considerable eoagulation of dissolved solids took plaee during sterilization. 
Methods of Analysis.-The samples were analyzed by the methods in use in the Agricultural Chemistry Laboratory and the Nutrition Laboratory of this station. A brief deseription of the methods follows:

1. Total Solids. The juice was filtered elcar and cooled below $15^{\circ} \mathrm{C}$. The specific gravity was determined by a pyenometer at $15: 5 \mathrm{C}$. The corresponding total solids, or extract, was found from Windisch's tables in Leach's Food Analysis, page 697. This table gives the extract as "grams per 100 grams"; that is, per eent by weight. To ealculate the corresponding grams per 100 c.c., the per cent by weight was multiplicd by the specific gravity. This gives a figure not very much greater than grams per 100 grams in juiees of low specific gravity, but gives a figure as mueh as 2 per eent greater where the total solids are much above 20 per cent. The two methods of reporting total solids lias in the past led to much unnecessary confusion. It is therefore urged that the reader bear in mind the distinetion between the two methods when reading the discussions in this paper or examining the curves.

2. Sugar. The samplc was filtered; an aliquot was treated with lead acetatc; diluted to mark; filtered; lead removed with anhydrous $\mathrm{Na}_{2} \mathrm{CO}_{3}$, and the sugar determined in an aliquot by the gravimetrie method, using Soxhlet's modification of Fehling's solution. The $\mathrm{Cu}_{2} \mathrm{O}$ was weighed directly after drying at $100^{\circ} \mathrm{C}$. The corresponding sugar as invert sugar was obtained from Munson and Walker's table in Leach's Food Analysis. The grams of invert sugar per 100 c.c. found in this way was divided by the specific gravity of the must to obtain the corresponding grams pcr 100 grams of juice.

3. Total acid was determined by titration of a 10 c.c. sample with $\mathrm{N} / 10 \mathrm{NaOH}$, using phenolphthalein as an indicator, and is reported as tartaric acid, grams per 100 e.c.

4. Cream of tartar was estimated by a method suggested by Professor D. R. Hoagland of the Division of Agricultural Chemistry. Ten e.c. of the juiec was incinerated at a low heat in a muffle furnace until well carbonized, but not to a white ash. (Excessive heating results in loss of $\mathrm{K}$ by volatilization.) The $\mathrm{K}_{2} \mathrm{CO}_{3}$ formed by incineration was leached out with hot water and a known excess of $\mathrm{N} / 10$ $\mathrm{HCl}$ added. This was titrated back with $\mathrm{N} / 10 \mathrm{NaOH}$, using methyl orange as an indicator. The $\mathrm{K}_{2} \mathrm{CO}_{3}$ is obtained by difference and calculated back to cream of tartar, assuming that all of the $\mathrm{K}_{2} \mathrm{CO}_{3}$ is formed by the oxidation of cream of tartar, $\mathrm{KH}\left(\mathrm{C}_{4} \mathrm{H}_{4} \mathrm{O}_{6}\right)$. It is 
reported as grams $\mathrm{KH}\left(\mathrm{C}_{4} \mathrm{H}_{4} \mathrm{O}_{6}\right)$ per 100 c.c., and also as tartaric acid.

5. Free Tartaric Acid was obtained by difference between total acid and cream of tartar calculated as tartaric acid. It is reported as grams per 100 c.c.

6. Protein in the juice was determined by the usual KjeldahlGunning method upon a 10 c.c. sample. It is reported as grams per 100 c.c.

7. Moisture in the leaves was determined by drying the sample at $100^{\circ} \mathrm{C}$.

8. Sugar in the leaves was estimated by leaching the dried sample with cold water and determining sugar by the gravimetric Fehling method in the filtrate.

9. Starch in the leaves was determined by hydrolysis of the dried ground sample with dilute $\mathrm{HCl}$ at $100^{\circ} \mathrm{C}$., followed by filtration and the usual gravimetric Fehling method for juice described above.

10. Protein in the leaves was determined by the Kjeldahl-Gunning method on .5 gram samples.

11. Acid in the leaves was estimated by leaching in hot water and titrating in the presence of the leaves, using litmus paper as indicator.

Analyses of Musts from Grape-Ripening Samples, 1914, 1915, 1916. The data from the analyses have been assembled in the following tables. Owing to the size of the tables, abbreviations have been necessary for the headings of the columns.

\section{Explanations of Headings of Tables}

1. Sp.gr. = Specifie gravity at $15: 5 \mathrm{C}$.

2: T. S. G. $=$ Total solids in grams per 100 grams.

3. T.S. C. $=$ Total solids in grams per 100 c.e.

4. S. G. $=$ Sugar in grams per 100 c.c.

5. S. I. = Sugar in grams per 100 grams.

6. Tl. A. $=$ Total acid in grams per 100 c.c.

7. C. T. $=$ Cream of tartar in grams per 100 c.c.

8. C. T. T. $=$ Cream of tartar as tartaric acid, grams per 100 c.c.

9. T. A. $=$ Total free acid as tartaric obtained by subtracting cream of tartar as tartaric from total acid as tartaric.

10. P. $=$ Protein, grams per 100 c.e.

11. S. = Sum of sugar, cream of tartar, tartaric acid, and protein in grams per 100 c.c.

12. T.S. $-\mathrm{S} .=$ Total solids $(\mathrm{T} . \mathrm{S} . \mathrm{C}.) \longrightarrow \mathrm{S}$ (preceding column). 
'Pable 7-Grape Ripening Tests, 1914

Malaga

(Grapes from Davis)

First crop:

\begin{tabular}{|c|c|c|c|c|c|c|c|c|c|c|c|c|}
\hline $\begin{array}{l}\text { Variety } \\
\text { and date }\end{array}$ & $\stackrel{1}{1}$ Sp. gr. & T. s. s. & T. $\stackrel{3}{\text { S. C. }}$ & S. G. & S. I. & T7. A. & c. $\stackrel{7}{T}$. & c. T. T. & T. A. & $\begin{array}{l}10 \\
\text { P. }\end{array}$ & $\begin{array}{c}11 \\
8 .\end{array}$ & T. S. S: \\
\hline Aug. 19 & 1.0396 & 10.25 & 10.65 & 7.32 & 7.04 & 2.78 & .35 & .13 & 2.65 & .21 & 10.53 & .12 \\
\hline Aug 26 & 1.0413 & 10.69 & 11.13 & 7.84 & 7.53 & 2.65 & .36 & .14 & 2.51 & .25 & 10.96 & .17 \\
\hline Aug. 26 & 1.0595 & 15.42 & 16.33 & 13.37 & 12.62 & .77 & .48 & .19 & .58 & .55 & 14.98 & 1.41 \\
\hline Aug. 26 & 1.0613 & 15.87 & 16.84 & 14.31 & 13.50 & 1.46 & .31 & .12 & 1.34 & .33 & 16.29 & .55 \\
\hline Aug. 26 & 1.0694 & 18.01 & 19.25 & 16.59 & 15.52 & 1.00 & .36 & .14 & .86 & .38 & 18.19 & 1.06 \\
\hline Aug. 31 & 1.0732 & 19.00 & 20.39 & 17.65 & 16.45 & .87 & .55 & .22 & .65 & .45 & 19.30 & 1.09 \\
\hline Sept. 23 & 1.0736 & 19.10 & 20.50 & 17.83 & 16.60 & .74 & .38 & .15 & .59 & .52 & 19.32 & 1.18 \\
\hline Oct. 5 & 1.0965 & 25.12 & 27.54 & 24.89 & 22.70 & .72 & .50 & .20 & .52 & .57 & 26.48 & 1.06 \\
\hline \multicolumn{13}{|c|}{ cond erop: } \\
\hline Aug. 10 & 1.0213 & 5.51 & 5.62 & 2.07 & 2.03 & 3.22 & .23 & .09 & 3.13 & .17 & 5.60 & .02 \\
\hline Aug. 31 & 1.0495 & 12.82 & 13.45 & 9.58 & 9.13 & 2.51 & .40 & .16 & 2.35 & .28 & 12.61 & .84 \\
\hline Sept. 14 & 1.0532 & 13.78 & 14.51 & 11.89 & 11.30 & 2.07 & .37 & .15 & 1.92 & .31 & 14.49 & .02 \\
\hline Sept. 23 & 1.0670 & 17.43 & 18.60 & 15.29 & 14.33 & 1.54 & .50 & .20 & 1.35 & .29 & 17.43 & 1.17 \\
\hline Sept. 23 & 1.0869 & 22.59 & 24.55 & 22.04 & 20.19 & 1.07 & .45 & .18 & .89 & .41 & 23.79 & .76 \\
\hline Oet. 5 & 1.0930 & 24.20 & 26.45 & 23.90 & 21.87 & .94 & .48 & .19 & .75 & .41 & 25.54 & .91 \\
\hline
\end{tabular}

\section{Tokay}

First crop:

$\begin{array}{lrrrrrrrrrrrr}\text { Aug. 2 } & 1.0454 & 11.75 & 12.28 & 8.73 & 8.35 & 2.63 & .46 & .18 & 2.45 & .32 & 11.96 & .32 \\ \text { Aug. 10 } & 1.0624 & 16.08 & 17.08 & 14.28 & 13.44 & 1.56 & .45 & .18 & 1.38 & .27 & 16.38 & .70 \\ \text { Aug. 19 } & 1.0682 & 17.69 & 18.90 & 15.94 & 14.92 & 1.32 & .45 & .18 & 1.14 & .27 & 17.80 & 1.10 \\ \text { Aug. 31 } & 1.0849 & 22.09 & 23.97 & 21.87 & 20.16 & .63 & .59 & .23 & .40 & .40 & 23.26 & .71 \\ \text { Sept. 4 } & 1.0865 & 22.49 & 24.44 & 22.21 & 20.44 & .77 & .43 & .17 & .60 & .32 & 23.56 & .88 \\ \text { Sept. 4 } & 1.0912 & 23.72 & 25.88 & 23.44 & 21.48 & .59 & .64 & .25 & .44 & .41 & 24.93 & .95 \\ \text { Sept. 23 } & 1.0937 & 24.38 & 26.66 & 24.15 & 22.08 & .58 & .49 & .19 & .30 & .39 & 25.33 & 1.33 \\ \text { Oct. 14 } & 1.0991 & 25.80 & 28.36 & 25.55 & 23.25 & .45 & .54 & .21 & .24 & .45 & 26.78 & 1.58 \\ \text { Oct. 14 } & 1.1000 & 26.04 & 28.64 & 25.78 & 23.44 & .52 & .58 & .23 & .29 & .58 & 27.23 & 1.41\end{array}$

Second crop:

$\begin{array}{lrrrrrrrrrrrr}\text { Aug. 19 } & 1.0657 & 17.04 & 18.16 & 15.03 & 14.10 & 1.91 & .50 & .20 & 1.70 & .32 & 16.55 & .61 \\ \text { Sept. 14 } & 1.0701 & 18.19 & 19.47 & 16.68 & 15.59 & 1.29 & .52 & .21 & 1.11 & .33 & 18.64 & .83 \\ \text { Sept. 23 } & 1.0769 & 19.95 & 21.48 & 19.22 & 17.85 & 1.01 & .48 & .19 & .82 & .40 & 20.92 & .56 \\ \text { Oct. 14 } & 1.0911 & 23.70 & 25.86 & 23.43 & 21.47 & .69 & .60 & .24 & .45 & .40 & 24.88 & .98\end{array}$

Table 8-Grape Ripening Tests, 1915

Cornichon

\section{(Grapes from Davis)}

\begin{tabular}{|c|c|c|c|c|c|c|c|c|c|c|c|c|}
\hline $\begin{array}{l}\text { Variety } \\
\text { and date }\end{array}$ & $\begin{array}{c}1 \\
\text { Sp. } g r .\end{array}$ & T. S. G. & T. $\stackrel{3}{\text { S. }}$ c. & S. ${ }^{4}$ G. & s. I. & T7. A. & c. ${ }^{7}$. & C. T. T. & T. A. & $\begin{array}{l}10 \\
P .\end{array}$ & $\begin{array}{l}11 \\
\mathrm{~S} .\end{array}$ & $\begin{array}{l}12 \\
\text { T. S. S. }\end{array}$ \\
\hline Aug. 22 & 1.0324 & 8.38 & 8.65 & 3.99 & 3.86 & 3.05 & .58 & .23 & 2.82 & .38 & 7.77 & .88 \\
\hline Sept. 1 & 1.0514 & 13.31 & 13.99 & 10.70 & 10.18 & 1.62 & .61 & .25 & 1.37 & .42 & 13.10 & .89 \\
\hline Sept. 15 & 1.0688 & 17.85 & 19.08 & 15.94 & 14.91 & .97 & .70 & .28 & .69 & .43 & 17.76 & 1.32 \\
\hline .22 & 1.0723 & 18.76 & 20.12 & 16.97 & 15.83 & .94 & .71 & .28 & .66 & .46 & 30 & 1.32 \\
\hline ept. 29 & 1.0737 & 19.13 & 20.54 & 18.31 & 17.05 & .87 & .75 & .30 & .61 & .66 & 20.33 & .21 \\
\hline Oct. 7 & 1.0781 & 20.28 & 21.86 & 19.41 & 18.02 & .71 & .73 & .29 & .42 & .48 & 21.04 & .82 \\
\hline Oct. 14 & 1.0843 & 21.91 & 2376 & 20.40 & 18.81 & .78 & .68 & .27 & .62 & .66 & & 1.40 \\
\hline Oct. 22 & 1.0873 & 22.70 & 24.68 & 21.06 & 19.37 & .75 & .78 & .31 & .44 & .46 & 22.74 & 1.94 \\
\hline
\end{tabular}


TABLE 8-(Continued)

\section{Emperor}

\begin{tabular}{|c|c|c|c|c|c|c|c|c|c|c|c|c|}
\hline $\begin{array}{l}\text { Variety } \\
\text { nd date }\end{array}$ & $\begin{array}{c}1 \\
\text { Sp. gr. }\end{array}$ & T. S. G. & T. $\stackrel{3}{\text { s. C. }}$ & S. G. & S. I. & $\begin{array}{c}6 \\
\text { Tl. A. }\end{array}$ & c. $\stackrel{7}{\text { T. }}$. & c. T. T. & T. A. & $\begin{array}{l}10 \\
P .\end{array}$ & $\begin{array}{l}11 \\
\mathrm{~S} .\end{array}$ & $\begin{array}{l}12 \\
\text { T. A. }\end{array}$ \\
\hline ug. 19 & 1.0420 & 10.87 & 11.33 & 6.96 & 6.68 & 2.33 & .38 & .15 & 2.18 & & 9.90 & 1.43 \\
\hline ept. 1 & & & & .82 & 37 & & & & & & & \\
\hline ept. 7 & & & & & & & & & & & & 1.0 \\
\hline & & & & & & 0 & & & & & & \\
\hline 22 & & 60 & 8.01 & .46 &. .51 & .93 & & & & & & \\
\hline pt. 29 & 72 & 1743 & 18.60 & .37 & 5.34 & .91 & 4 & 1 & .72 & & & .3 \\
\hline et. 7 & & 9.3 & 0.7 & .82 & & .79 & & & 5 & & & \\
\hline et. 14 & & & & & 17.06 & .79 & .5 & .2 & .56 & .6 & & 1.2 \\
\hline at & 0792 & 20.57 & 2.20 & 19.81 & 18.36 & .75 & .63 & .25 & .49 & .66 & 21.59 & \\
\hline
\end{tabular}

\section{Malaga}

$\begin{array}{lrrrrrrrrrrrr}\text { Aug. 19 } & 1.0546 & 14.14 & 14.91 & 12.47 & 11.82 & 2.05 & .36 & .15 & 1.90 & .75 & 15.48 & .57 \\ \text { Aug. 2ن } & 1.0651 & 16.86 & 17.96 & 14.53 & 13.64 & 1.66 & .46 & .18 & 1.48 & .90 & 17.37 & .59 \\ \text { Sept. 1 } & 1.0678 & 17.59 & 18.78 & 16.75 & 15.69 & 1.38 & .44 & .18 & 1.20 & .89 & 19.28 & .50 \\ \text { Sept. 7 } & 1.0719 & 18.66 & 19.50 & 17.00 & 15.86 & 1.29 & .44 & .18 & 1.11 & .70 & 19.25 & .25 \\ \text { Sept. 15 } & 1.0758 & 19.68 & 21.17 & 18.17 & 16.89 & 1.21 & .62 & .25 & .96 & .70 & 20.45 & .72 \\ \text { Sept. 22 } & 1.0760 & 19.81 & 21.32 & 18.39 & 17.09 & 1.18 & .61 & .25 & .93 & .74 & 20.67 & .65 \\ \text { Sept. 29 } & 1.0812 & 21.20 & 22.92 & 18.48 & 17.09 & 1.07 & .58 & .23 & .84 & .75 & 20.65 & 2.27 \\ \text { Oct. } 7 & 1.0838 & 21.78 & 23.61 & 21.03 & 19.40 & 1.07 & .65 & .26 & .81 & .73 & 23.22 & .39 \\ \text { Oct. 14 } & 1.0970 & 25.25 & 27.70 & 24.58 & 22.41 & .59 & .83 & .33 & .26 & .88 & 26.55 & 1.15\end{array}$

\section{Muscat}

$\begin{array}{lrrrrrrrrrrrr}\text { Aug. 19 } & 1.0615 & 15.94 & 16.92 & 13.93 & 13.12 & 1.70 & .36 & .15 & 1.55 & .70 & 16.54 & .38 \\ \text { Aug. 25 } & 1.0744 & 19.31 & 20.75 & 17.96 & 16.72 & 1.21 & .62 & .25 & .96 & .62 & 20.16 & .59 \\ \text { Sept. 1 } & 1.0805 & 20.91 & 22.59 & 19.50 & 18.05 & .79 & .63 & .25 & .54 & .63 & 21.30 & 1.29 \\ \text { Sept. 7 } & 1.0827 & 21.47 & 23.25 & 20.39 & 18.83 & .76 & .65 & .26 & .50 & .66 & 22.20 & 1.05 \\ \text { Sept. 15 } & 1.0917 & 23.85 & 26.04 & 23.49 & 21.52 & .96 & .58 & .23 & .73 & .58 & 25.38 & .66 \\ \text { Sept. 22 } & 1.0954 & 24.14 & 26.44 & 24.54 & 22.40 & .77 & .62 & .25 & .52 & .85 & 26.53 & .09 \\ \text { Sept. 29 } & 1.1048 & 27.30 & 30.16 & \mathbf{2 7 . 0 1} & 24.45 & .72 & .72 & .29 & .44 & .72 & 28.89 & 1.27 \\ \text { Oct. 7 } & 1.1079 & 28.12 & 31.15 & 28.28 & 25.53 & .66 & .59 & .23 & .43 & .66 & 29.96 & 1.19\end{array}$

\section{Pedro Zumbon}

$\begin{array}{lrrrrrrrrrrrr}\text { Aug. 19 } & 1.0555 & 14.38 & 15.18 & 11.96 & 11.33 & 1.81 & .68 & .27 & 1.54 & .33 & 14.51 & .67 \\ \text { Aug. 25 } & 1.0588 & 15.24 & 16.14 & 13.77 & 13.01 & 1.09 & .57 & .23 & .86 & .53 & 15.73 & .41 \\ \text { Sept. 1 } & 1.0642 & 16.64 & 17.71 & 15.61 & 14.67 & .58 & .52 & .21 & .37 & .43 & 16.93 & .78 \\ \text { Sept. 7 } & 1.0693 & 17.98 & 19.23 & 16.55 & 15.48 & .84 & .48 & .19 & .65 & .73 & 18.41 & .82 \\ \text { Sept. 15 } & 1.0708 & 18.37 & 19.67 & 18.17 & 16.97 & .56 & .58 & .23 & .33 & .64 & 19.72 & .05 \\ \text { Sept. 22 } & 1.0912 & 23.72 & 25.88 & 23.02 & 21.10 & .53 & .87 & .35 & .19 & .64 & 24.72 & 1.16\end{array}$

\section{Sultana}

$\begin{array}{lrrrrrrrrrrrr}\text { Aug. 19 } & 1.0673 & 17.80 & 19.00 & 15.63 & 16.64 & 1.69 & .33 & .13 & 1.56 & .32 & 17.84 & 1.16 \\ \text { Aug. 25 } & 1.0746 & 19.37 & 20.82 & 17.96 & 16.71 & 1.44 & .37 & .14 & 1.30 & .38 & 20.01 & .81 \\ \text { Sept. 1 } & 1.0815 & 21.17 & 22.90 & 20.26 & 18.73 & 1.14 & .54 & .22 & .02 & .50 & 22.22 & .68 \\ \text { Sept. 7 } & 1.0893 & 23.22 & 25.29 & 23.02 & 21.13 & .78 & .44 & .18 & .60 & .34 & 24.40 & .89 \\ \text { Sept. 22 } & 1.0902 & 23.39 & 25.50 & 23.10 & 21.19 & 1.24 & .50 & .20 & 1.04 & .38 & 25.02 & .48 \\ \text { Sept. 29 } & 1.0922 & 23.99 & 26.20 & .24 .04 & 22.01 & .80 & .41 & .17 & .63 & .42 & 25.50 & .70\end{array}$


TABLE $8-$ (Continued)

Sultanina

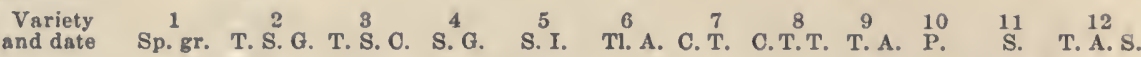

$\begin{array}{lllllllllllll}\text { Aug. } 19 & 1.0673 & 17.46 & 18.64 & 15.87 & 14.87 & 1.27 & .44 & .18 & 1.09 & .42 & 17.82 & .82\end{array}$

$\begin{array}{lllllllllllll}\text { Aug. } 25 & 1.0743 & 19.26 & 20.69 & 18.30 & 17.03 & 1.19 & .47 & .19 & 1.00 & .37 & 20.14 & .55\end{array}$

$\begin{array}{lllllllllllll}\text { Sept. } 1 & 1.0771 & 20.02 & 21.56 & 18.98 & 17.62 & .85 & .49 & .20 & .65 & .42 & 20.54 & 1.02\end{array}$

$\begin{array}{lllllllllllll}\text { Sept. } 7 & 1.0892 & 23.20 & 25.27 & 22.42 & 20.58 & .72 & .80 & .32 & .40 & .62 & 24.24 & 1.03\end{array}$

$\begin{array}{lllllllllllll}\text { Sept. } 15 & 1.0927 & 24.12 & 26.36 & 23.62 & 21.62 & .79 & .76 & .30 & .39 & .45 & 25.22 & 1.14\end{array}$

$\begin{array}{llllllllllllll}\text { Sept. } 22 & 1.0984 & 25.62 & 28.14 & 25.71 & 23.41 & .60 & .58 & .23 & .37 & .45 & 27.11 & 1.03\end{array}$

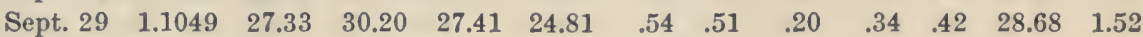

Tokay

$\begin{array}{lrrrrrrrrrrrr}\text { Aug. 19 } & 1.0598 & 15.50 & 16.43 & 14.41 & 13.60 & 1.74 & .41 & .16 & 1.58 & .29 & 16.69 & .26 \\ \text { Aug. 25 } & 1.0676 & 17.54 & 18.73 & 15.63 & 14.64 & 1.24 & .39 & .15 & 1.09 & .69 & 17.80 & .93 \\ \text { Sept. 1 } & 1.0757 & 19.65 & 21.14 & 18.17 & 16.89 & .84 & .47 & .19 & .66 & .44 & 19.74 & 1.40 \\ \text { Sept. 7 } & 1.0781 & 20.28 & 21.86 & 19.11 & 17.73 & .79 & .45 & .18 & .61 & .37 & 20.54 & 1.32 \\ \text { Sept. 15 } & 1.0785 & 20.39 & 21.99 & 19.26 & 17.86 & .74 & .48 & .19 & .55 & .40 & 20.69 & 1.30 \\ \text { Sept. 22 } & 1.0798 & 20.73 & 22.38 & 20.17 & 18.68 & .59 & .51 & .20 & .39 & .36 & 21.43 & .95 \\ \text { Sept. 29 } & 1.0823 & 21.38 & 23.14 & 20.76 & 19.18 & .85 & .58 & .23 & .62 & .28 & 22.24 & .90 \\ \text { Oct. 7 } & 1.0830 & 21.57 & 23.36 & 20.87 & 19.27 & .69 & .63 & .25 & .44 & .42 & 22.36 & 1.00 \\ \text { Oct. 14 } & 1.0851 & 22.12 & 24.00 & 21.53 & 19.84 & .65 & .69 & .28 & .38 & .36 & 22.96 & 1.04 \\ \text { Oct. 22 } & 1.0895 & 23.28 & 25.36 & 22.91 & 21.03 & .66 & .72 & .29 & .37 & .37 & 24.37 & .99\end{array}$

\section{Burger}

Table 9-Grape Ripening Tests, 1916

\begin{tabular}{|c|c|c|c|c|c|c|c|c|c|c|c|c|}
\hline $\begin{array}{l}\text { Variety } \\
\text { and date }\end{array}$ & Sp. $\stackrel{1}{g r .}$ & T. $\stackrel{2}{\text { S. G. }}$ & T. S. C. & S. $^{4}$ & S. I. & $\begin{array}{l}6 \\
\text { TI. A. }\end{array}$ & c. ${ }^{7}$. & c. ${ }^{8} \mathrm{~T}$. & $\stackrel{9}{\text { T. A. }}$ & $\begin{array}{l}10 \\
P .\end{array}$ & 11. & T. S. S \\
\hline June 12 & 1.0212 & 5.48 & 5.59 & 1.29 & 1.55 & 2.95 & .55 & .22 & 2.73 & .44 & 5.27 & .32 \\
\hline June 19 & 1.0195 & 5.04 & 5.88 & .87 & .88 & 2.88 & .51 & .21 & 2.67 & .45 & 4.51 & 1.37 \\
\hline June 27 & 1.0220 & 5.69 & 5.82 & 1.25 & 1.28 & 2.94 & .33 & .13 & 2.81 & .45 & 4.87 & .95 \\
\hline July 7 & 1.0220 & 5.69 & 5.82 & 1.11 & 1.28 & 2.98 & .49 & .20 & 2.78 & .31 & 4.86 & .96 \\
\hline July 10 & 1.0200 & 5.17 & 5.27 & .93 & .95 & 3.32 & .57 & .23 & 3.09 & .37 & 4.97 & .30 \\
\hline July 19 & 1.0205 & 5.30 & 5.41 & 1.03 & 1.05 & 3.13 & .55 & .22 & 2.91 & .35 & 4.86 & .55 \\
\hline July 27 & 1.0225 & 5.82 & 5.95 & 1.13 & 1.15 & 2.93 & .48 & .19 & 2.74 & .34 & 4.71 & 1.24 \\
\hline Aug. 3 & 1.0258 & 6.67 & 6.84 & 2.14 & 2.19 & 2.71 & .63 & .25 & 2.46 & .40 & 5.68 & 1.16 \\
\hline Aug. 7 & 1.0330 & 8.53 & 8.83 & 3.36 & 3.46 & 2.67 & .87 & .35 & 2.32 & .47 & 7.12 & 1.21 \\
\hline Aug. 16 & 1.0391 & 10.11 & 10.51 & 5.90 . & 6.13 & .2 .41 & .95 & .38 & 2.03 & .46 & 9.57 & .94 \\
\hline Aug. 23 & 1.0422 & 10.92 & 11.38 & 6.03 & 6.27 & 2.10 & .98 & .39 & 1.71 & .63 & 9.59 & $1.8 \mathrm{~s}$ \\
\hline Aug. 30 & 1.0529 & 13.70 & 14.42 & 9.95 & 10.42 & 1.15 & 1.03 & .41 & $.7 \pm$ & .49 & 12.70 & 1.72 \\
\hline Sept. 5 & 1.0645 & 16.73 & 17.81 & 14.51 & 15.43 & 1.01 & 1.07 & .43 & .68 & .61 & 17.79 & .0 \\
\hline Sept. 12 & 1.0717 & 18.61 & 19.94 & 16.27 & 17.36 & .95 & .98 & .39 & .56 & .82 & 19.72 & \\
\hline Sept. 20 & 1.0765 & 19.86 & 21.37 & 17.44 & 18.73 & .87 & 1.06 & .42 & .45 & .62 & 20.86 & \\
\hline Sept: 26 & 1.0808 & 20.99 & 22.68 & 18.48 & 19.99 & .81 & 1.01 & .40 & .41 & .83 & 22.24 & \\
\hline \multicolumn{13}{|l|}{ rnichon } \\
\hline June 12 & 1.0202 & 5.22 & 5.32 & .91 & .93 & 3.15 & .64 & .26 & 2.89 & .32 & 4.78 & .54 \\
\hline June 19 & 1.0200 & 5.17 & 5.27 & .86 & .88 & 2.96 & .62 & .25 & 2.71 & .42 & 4.63 & .64 \\
\hline June 27 & 1.0193 & 4.99 & 5.08 & .84 & .86 & 2.89 & .39 & .16 & 2.73 & .56 & 4.54 & .44 \\
\hline July 7 & 1.0201 & 5.19 & 5.29 & .87 & .89 & 2.88 & .44 & .18 & 2.70 & .52 & 4.55 & .74 \\
\hline July 10 & 1.0206 & 5.32 & 5.43 & .85 & .87 & 3.27 & .54 & .22 & 3.05 & .53 & 4.99 & .4 \\
\hline uly 19 & 1.0225 & 5.82 & 5.95 & 1.28 & 1.30 & 3.11 & .57 & .23 & 2.88 & .55 & 5.30 & .6 \\
\hline July 27 & 1.0242 & 6.25 & 6.40 & 1.63 & 1.66 & 2.94 & .54 & .22 & 2.72 & . 44 & 5.26 & \\
\hline Iug. & 1.0373 & 9.65 & & 5.00 & 5.19 & 2.87 & .59 & .24 & 2.63 & .56 & 8.97 & \\
\hline
\end{tabular}




\section{TABLE 9-(Continued)}

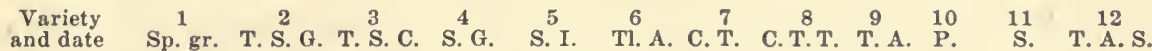

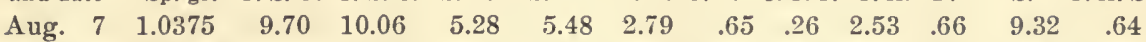

$\begin{array}{lllllllllllll}\text { Aug. } 16 & 1.0434 & 11.23 & 11.71 & 6.30 & 6.57 & 2.75 & 1.06 & .43 & 2.32 & .53 & 10.48 & 1.23\end{array}$

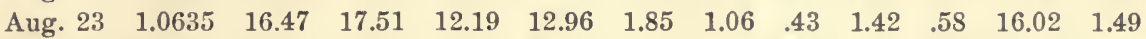

$\begin{array}{lllllllllllll}\text { Aug. 30 } & 1.0685 & 17.77 & 18.97 & 14.75 & 15.61 & 1.16 & 1.10 & .44 & .72 & .63 & 18.06 & .91\end{array}$

$\begin{array}{lllllllllllll}\text { Sept. } 5 & 1.0694 & 18.01 & 19.25 & 15.03 & 16.07 & .93 & .90 & .36 & .57 & .58 & 18.12 & 1.13\end{array}$

$\begin{array}{lllllllllllll}\text { Sept. } 12 & 1.0757 & 19.65 & 21.09 & 16.37 & 17.60 & .87 & 1.14 & .46 & .41 & .78 & 19.97 & 1.12\end{array}$

$\begin{array}{lllllllllllll}\text { Sept. } 20 & 1.0786 & 20.41 & 22.00 & 17.52 & 18.88 & .84 & .94 & .37 & .44 & .59 & 20.85 & 1.15\end{array}$

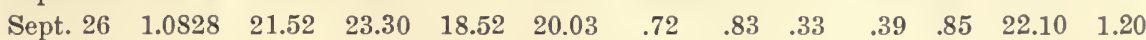

\begin{tabular}{|c|c|c|c|c|c|c|c|c|c|c|c|c|}
\hline e 12 & 1.0203 & 5.25 & 5.35 & .91 & & & & & & & & \\
\hline June 19 & 1.0199 & 5.14 & 5.24 & .70 & .72 & & & .25 & & & & \\
\hline June 27 & 1.0210 & 5.43 & 5.54 & 1.33 & 1.36 & 3.33 & .48 & .19 & 3.14 & .49 & 5.47 & .07 \\
\hline July 7 & 1.0210 & 5.43 & 5.54 & 1.63 & 1.66 & 3.32 & .54 & .22 & 3.10 & .45 & 5.75 & .21 \\
\hline July 10 & 1.0195 & 5.04 & 5.14 & 1.33 & 1.36 & 3.60 & .55 & .22 & .38 & .36 & & .51 \\
\hline July 19 & 1.0251 & 6.49 & 6.65 & 2.55 & 2.61 & 3.40 & .58 & .23 & 3.17 & .4 & & .20 \\
\hline July 27 & 1.0308 & 7.97 & 8.22 & 3.56 & 3.67 & 2.67 & .66 & .26 & 01 & .45 & & 1.43 \\
\hline Aug. 3 & 1.0488 & 12.64 & 13.26 & 9.72 & 10.19 & 1.77 & .68 & .27 & 1.50 & .46 & 3 & .43 \\
\hline Aug. 7 & 1.0582 & 5.68 & 6.58 & 12.72 & 13.53 & 1.60 & .73 & .29 & 1.31 & .55 & 16.12 & .46 \\
\hline Aug. 16 & 1.0803 & 20.86 & 2.53 & 16.81 & 18.15 & 1.16 & .94 & .38 & .78 & .51 & 0.38 & 1.70 \\
\hline Aug. 23 & & 3.67 & 5.82 & 20.20 & 22.04 & .82 & 1.04 & .42 & .40 & .56 & 4.04 & 1.78 \\
\hline Aug. 30 & 1.0972 & 25.30 & 27.75 & 21.87 & 22.99 & .65 & 1.21 & .49 & .16 & .58 & 25.94 & 1.81 \\
\hline Sept. 5 & 1.1023 & 26.64 & 29.36 & 23.28 & 24.74 & .60 & 1.17 & .47 & .13 & .65 & 26.69 & 2.67 \\
\hline Sept. 12 & 1.1101 & 28.70 & 31.85 & 25.95 & 27.83 & .56 & 1.35 & .54 & .02 & .69 & 29.89 & 1.96 \\
\hline Sept. 20 & 1.1122 & 29.25 & 32.72 & 26.43 & 29.39 & .68 & 1.56 & .63 & .05 & .58 & 31.27 & 1.45 \\
\hline Sept. 26 & 1.1133 & 29.54 & 32.89 & 26.68 & 29.70 & .56 & 1.39 & .56 & .00 & .59 & 31.57 & 1.32 \\
\hline
\end{tabular}

Table 10-Catawba Grape Ripening Tests

(Table from U. S. Dept. Agric. Bulletin 335, by W. B. Alwood)

Catawba 1912:

\begin{tabular}{|c|c|c|c|c|c|c|c|c|c|}
\hline $\begin{array}{l}\text { Variety } \\
\text { and date }\end{array}$ & $\begin{array}{c}1 \\
\text { Sp. gr. }\end{array}$ & T. S. G. & T. $\stackrel{3}{\text { S. C. }}$ & S.I. & s. $\mathbf{5}$. & Tl. ${ }^{6}$ A. & c. ${ }^{7}$. & c. $\stackrel{8}{\mathrm{~T}}$. & $\begin{array}{c}9 \\
\text { Dars }\end{array}$ \\
\hline Sept. 4 & 1.0329 & 8.51 & 8.84 & 3.60 & 3.72 & 3.68 & .39 & .16 & 0 \\
\hline Sept. 9 & 1.0419 & 10.84 & 11.29 & 6.68 & 6.96 & 3.02 & .41 & .16 & 5 \\
\hline Sept. 12 & 1.0515 & 13.34 & 14.03 & 9.35 & 9.78 & 2.48 & .46 & .18 & 8 \\
\hline Sept. 17 & 1.0537 & 13.91 & 14.66 & 10.38 & 10.95 & 2.12 & .45 & .18 & 13 \\
\hline Sept. 24 & 1.0569 & 14.74 & 15.58 & 11.33 & 11.96 & 1.74 & .53 & .21 & 20 \\
\hline Oct. 1 & 1.0614 & 15.92 & 16.89 & 12.75 & 13.48 & 1.63 & .54 & .22 & 27 \\
\hline Oct. 7 & 1.0663 & 17.20 & 18.34 & 13.79 & 14.71 & 1.53 & .61 & .24 & 33 \\
\hline Oct. 16 & 1.0725 & 18.82 & 20.18 & 15.35 & 16.46 & 1.34 & .61 & .24 & 42 \\
\hline Oct. 23 & 1.0716 & 18.58 & 19.90 & 15.01 & 16.09 & 1.28 & .59 & .24 & 47 \\
\hline Oct. 29 & 1.0769 & 19.97 & 21.50 & 16.49 & 17.75 & 1.22 & .57 & .23 & 53 \\
\hline Nov. 4 & 1.0790 & 20.52 & 22.14 & 16.77 & 18.08 & 1.28 & .71 & .28 & 59 \\
\hline Nov. 8 & 1.0755 & 19.60 & 21.07 & 16.39 & 17.61 & 1.09 & .52 & .21 & 63 \\
\hline
\end{tabular}


Curves of Total Solids, Sugar, Total Acid, Frec Acid, and Cream of Tartar.-In order to present the data in a form in which they may bc readily studied, graphs have bcen constructed using time in days as abscissae and the above constituents expressed in grams per 100 c.c. as ordinates. The curves represent the data for 1914, 1915, and 1916 . For comparison, curves of the changes in composition of Catawba grapes reported by W. B. Alwood in the United States Department of Agriculture Bulletin 335 have been included. The acid principles have been plotted to a scalc five times as great as that used for total solids and sugar in order that the variations in acidity might be more apparent.

Discussion of Graphs of Total Solids, Sugar, Total Acid, Cream of Tartar, and Free Acid.-(1) Total Solids and Sugar. The data are more complete for 1916 than for 1914 or 1915, and include the period during which the berries are growing to full size as well as the ripening period itself, during which the rapid increase in sugar occurs. The curves for 1916, therefore, are of more interest than those for 1914 and 1915. In the case of the Burger variety, total solids and sugar remained constant for approximately forty days after the tests were started. There was then a slight rise in these components for a period of about ten days. From that point on the rise in total solids and sugar was very rapid and fairly uniform. The behavior of the Cornichon was very similar.

The Muscat began ripening about ten days earlier than the Burger and Cornichon, and proceeded much more rapidly up to about the ninetieth day after the experiment was started. There was then a slowing up in the increase in total solids and sugar corresponding to the period of over-ripeness. This slower increase in total solids is also evident in the curves for Emperor, Muscat, Sultana, and Tokay for the 1915 season, and would undoubtedly show in all cases if the observations were continued sufficiently.

The effect of the season upon the rate of ripening is shown by a comparison of the Cornichon and Muscat varicties for 1915 and 1916. All varieties ripened morc slowly in 1915 than in 1916, resulting in steeper curves for 1916. However, owing to the fact that sampling was started later in 1914 and 1915 than in 1916, the curves for the former two years show only the changes taking place during the latter half of the ripening period. No very close comparisons therefore can be made of the three years.

The Catawba reported by Alwood, and for which curves appear 

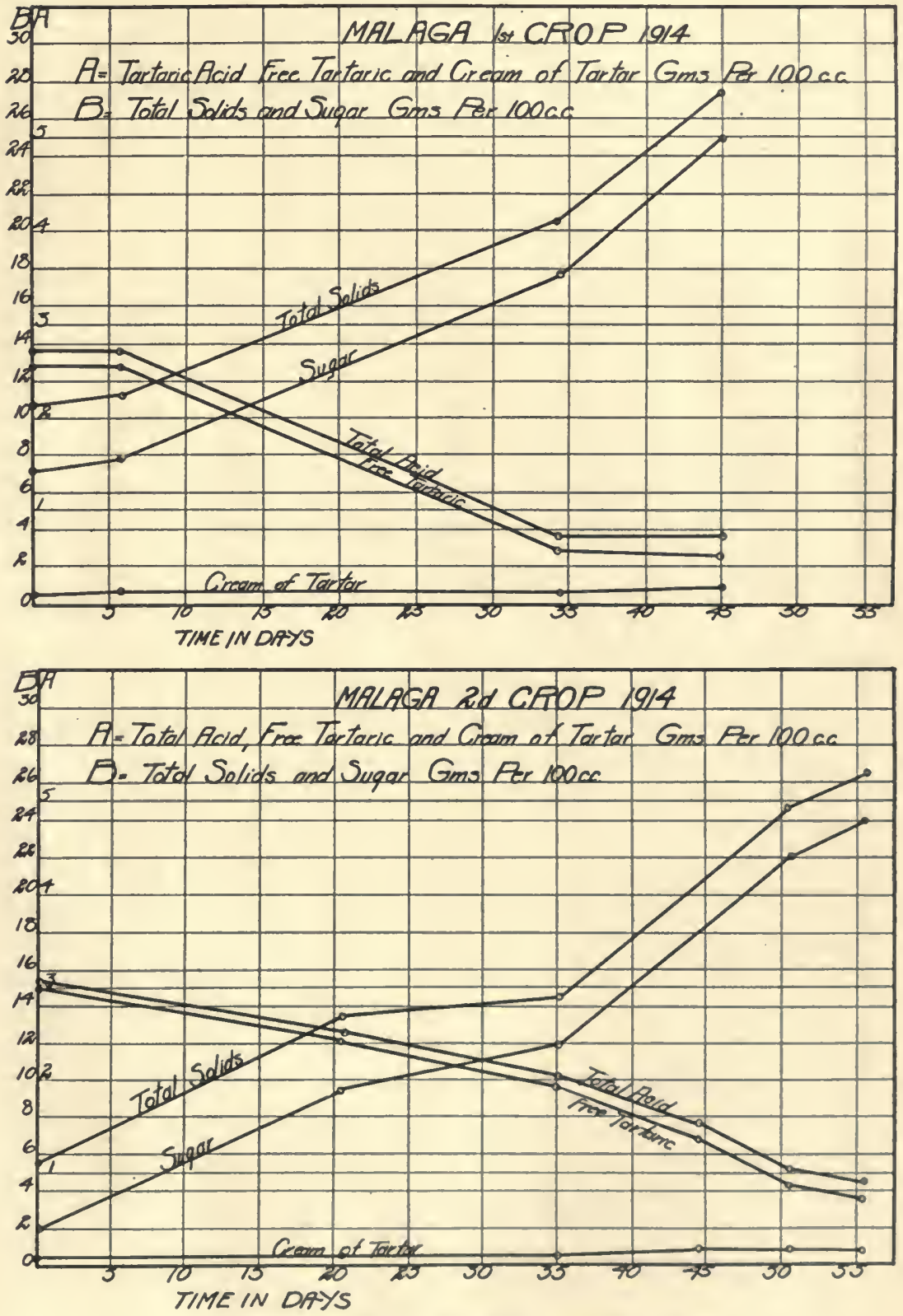

Fig. 1-Malaga first and second crops, 1914. 

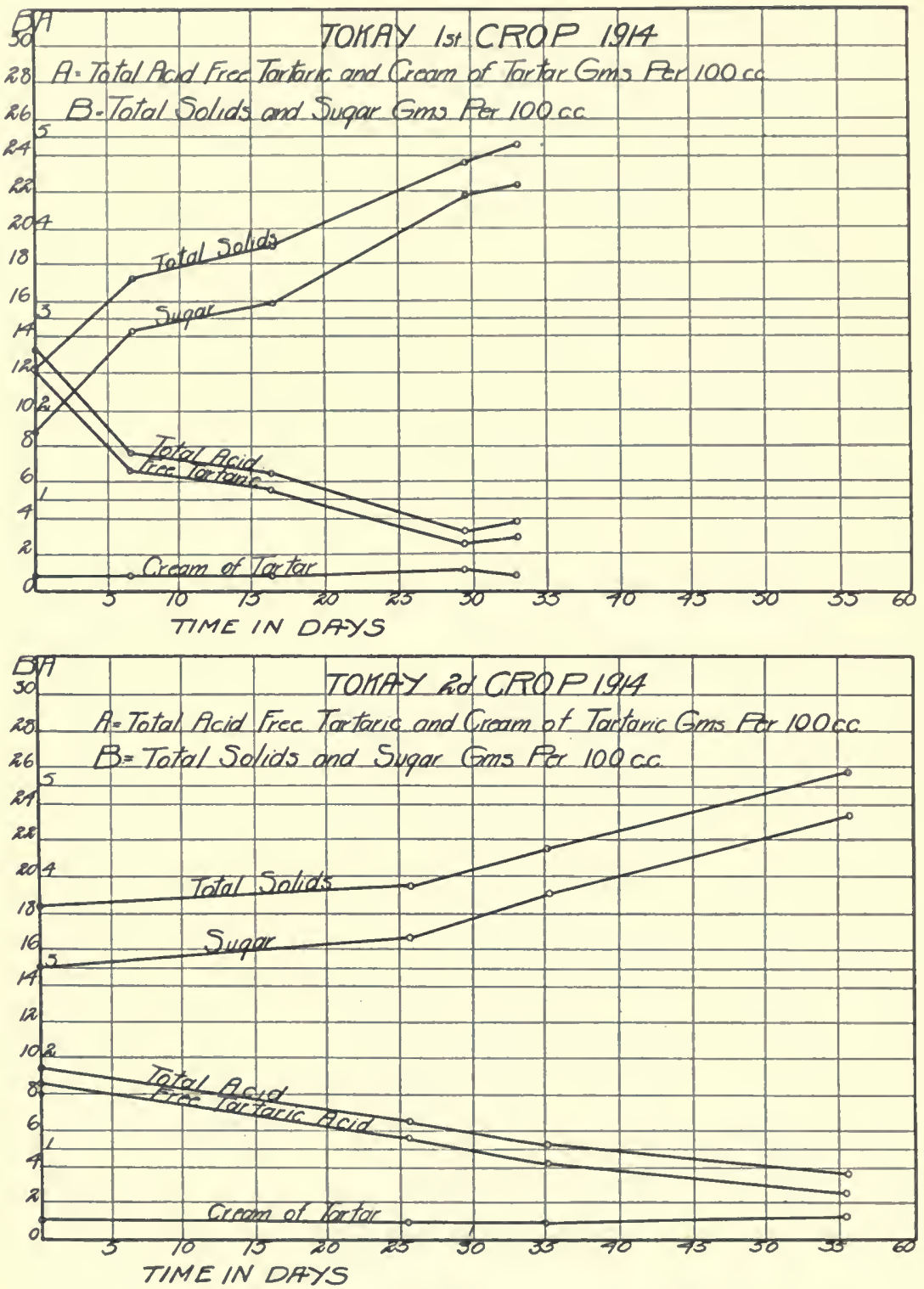

Fig. 2-Tokay first and second crops, 1914. 

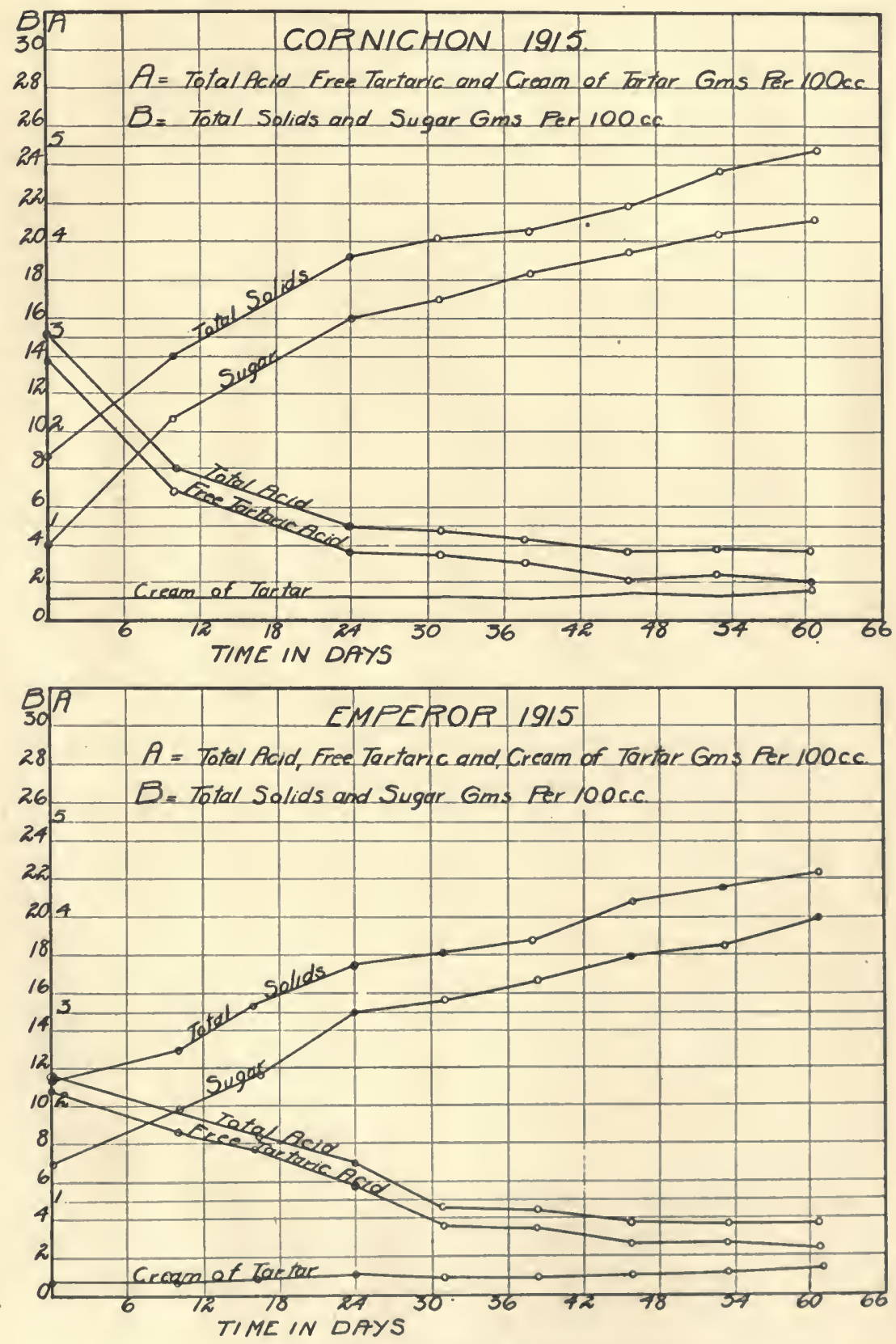

F'ig. 3-Cornichon and Emperor, 1915. 

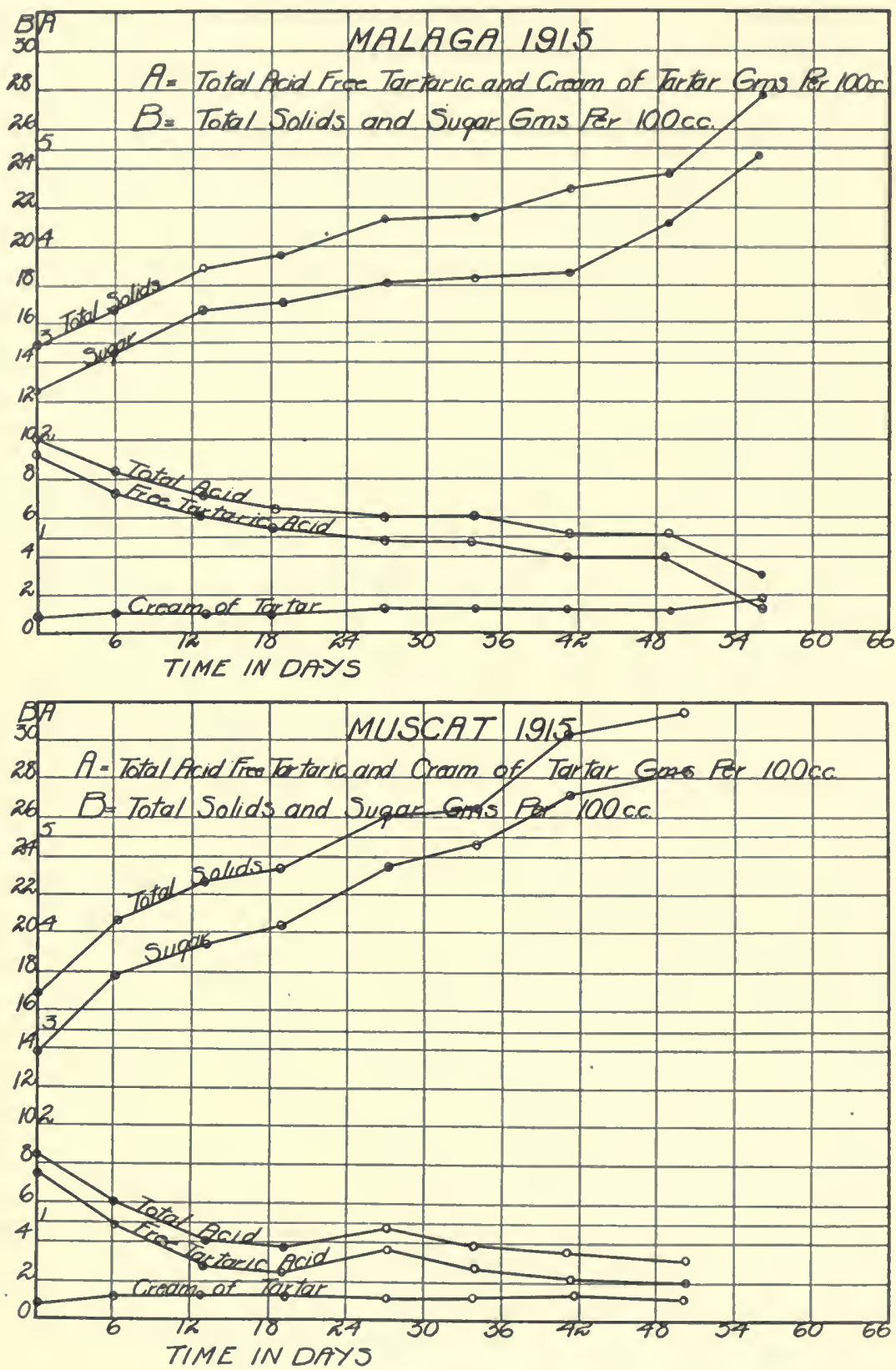

Fig. 4-Malaga and Museat, 1915. 

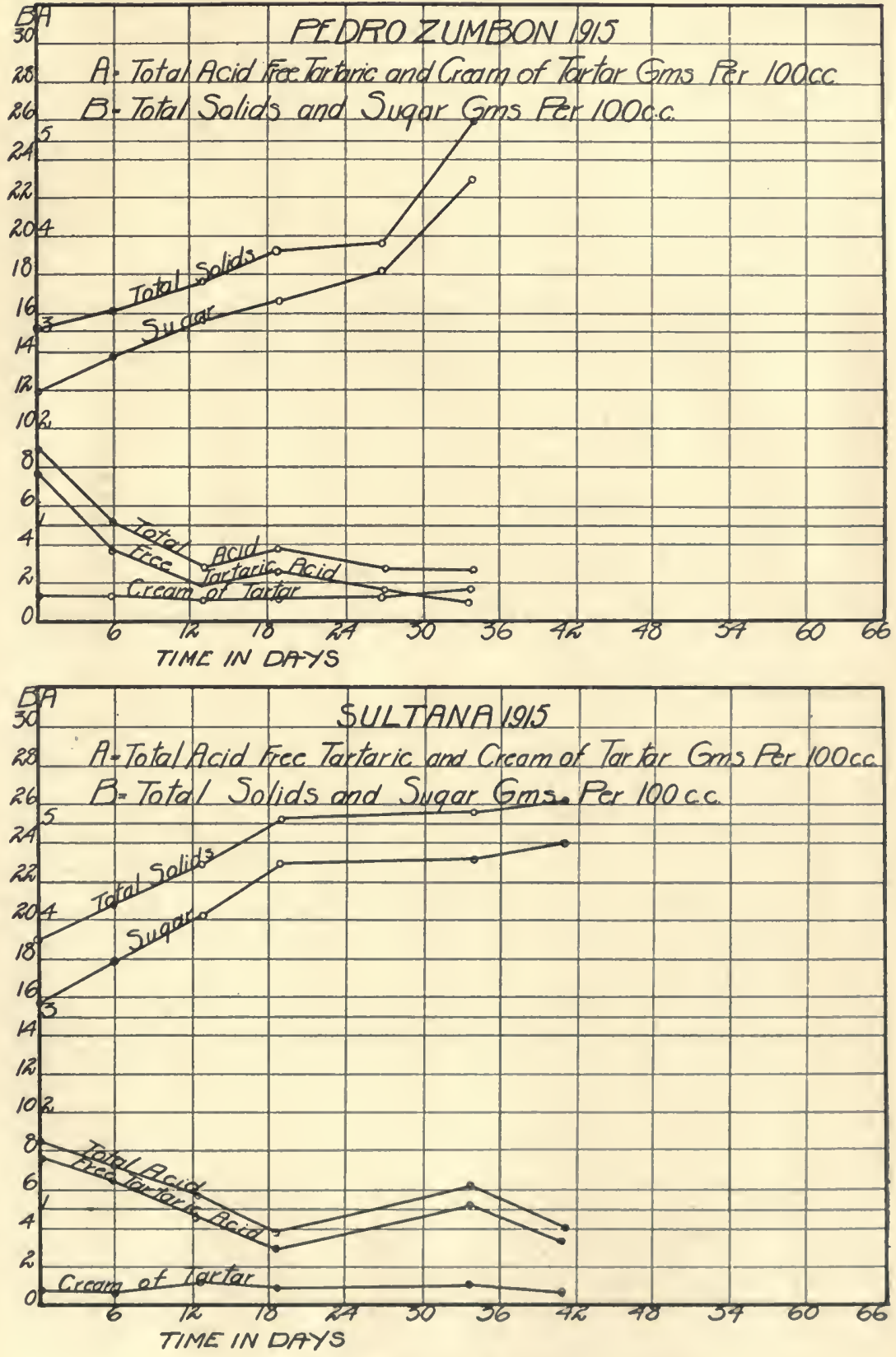

Fig. 5-Pedro Zumbon and Sultand, 1915. 

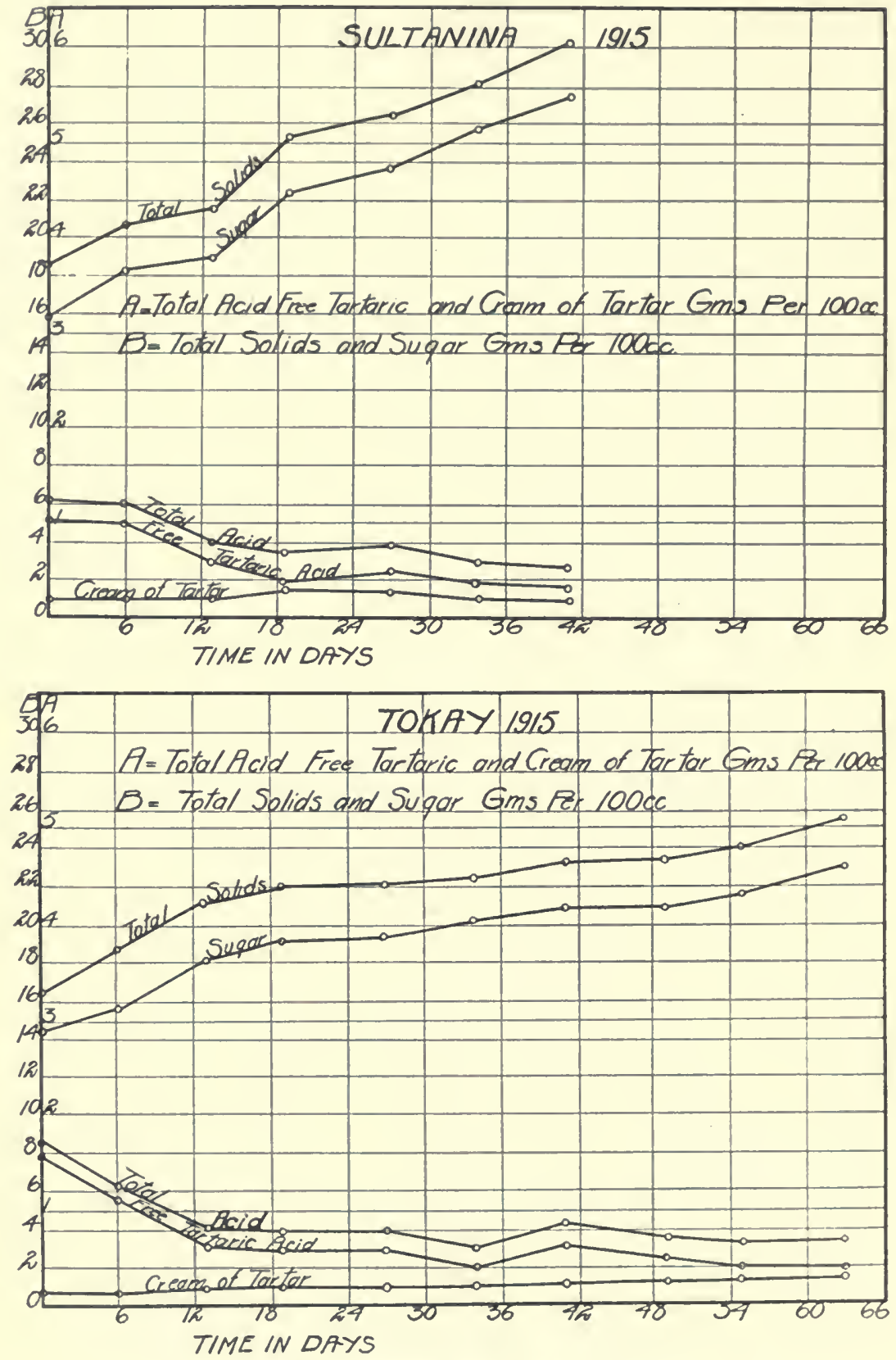

Fig. 6-Sultanina and Tokay, 1915. 

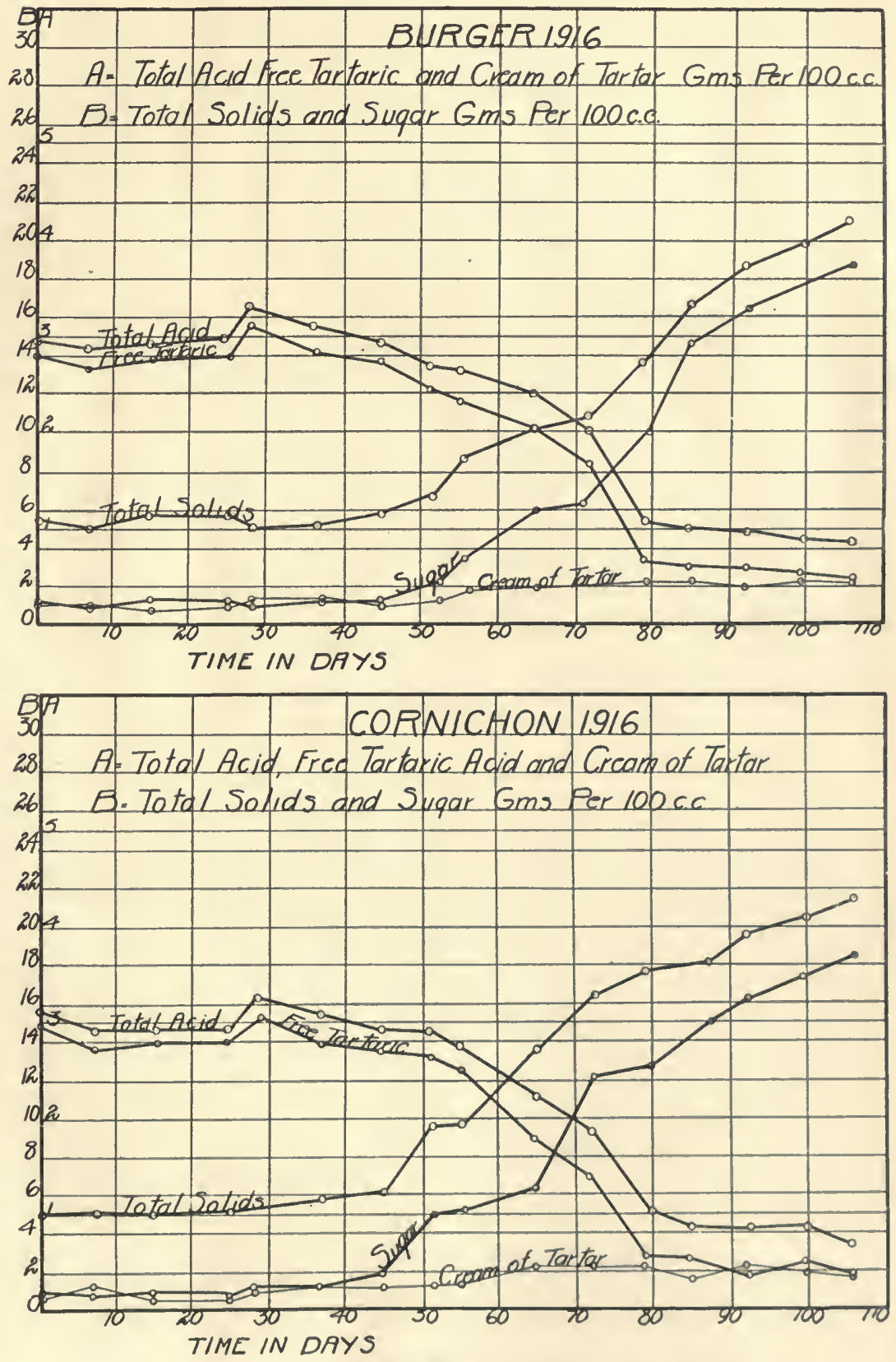

Fig. 7-Burger and Cornichon, 1916. 


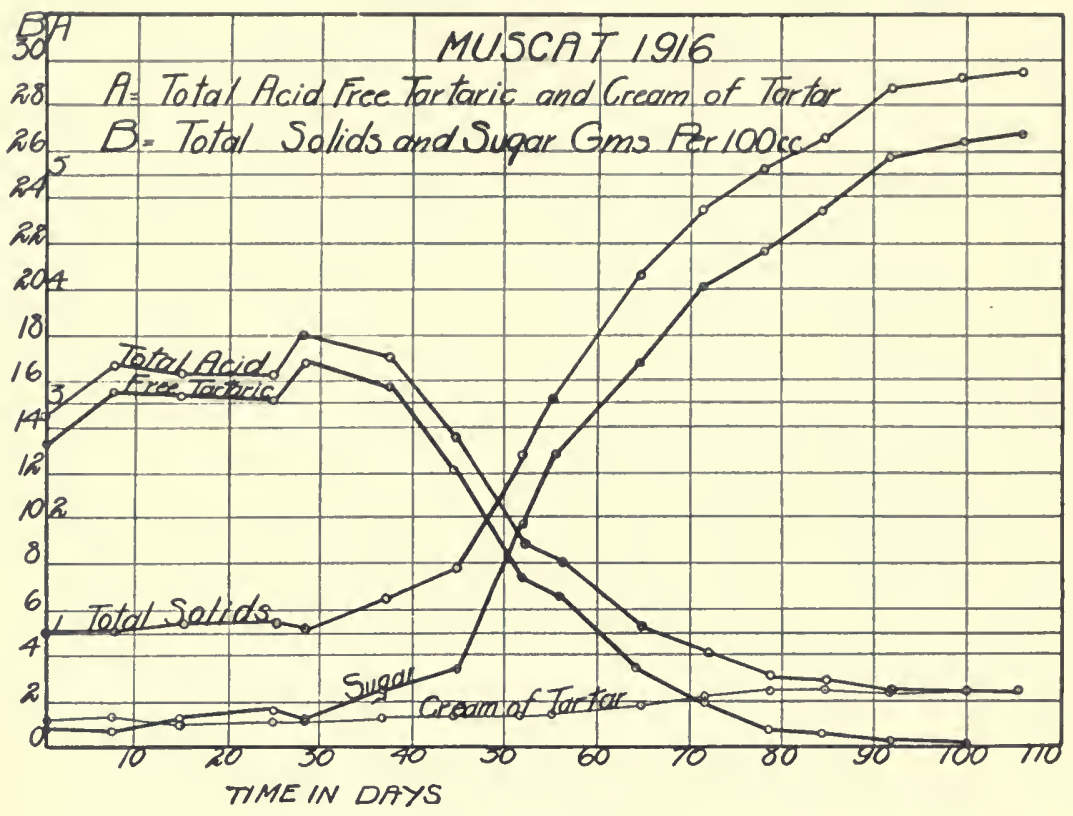

Fig. 8-Muscat, 1916.

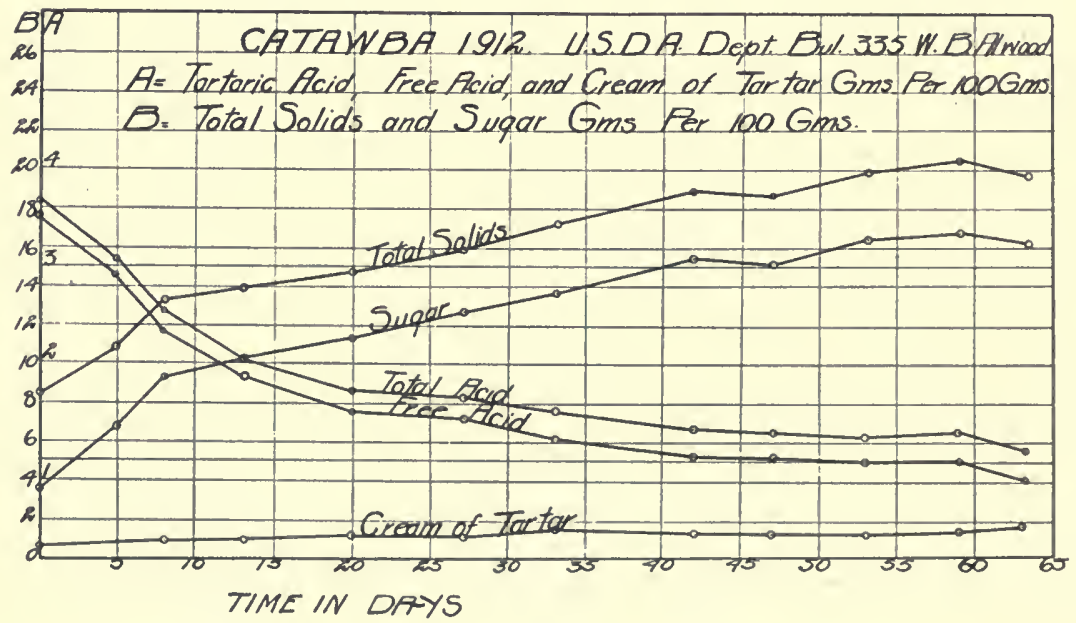

Fig. 9-Catawba (U. S. Dept. Agric. Bull. 335). 
in figure 9, ripened more slowly than the Vinifera varieties. For example, during a period of fifty days, the total solids increased only 4 per cent. It can not be said from the data at hand whether this slow ripening is due to the conditions under which the grapes were grown or to the variety.

By reference to figures 1 and 2 it may be seen that the general form of the ripening curves is the same for the first and for second crop. In one case, the Malaga, the curves are almost identical for the period common to both, i.e., from 10.6 Bal. to $26.3 \mathrm{Bal}$., showing an equal rate of ripening. In the other, the Tokay, the curve of the second crop, from 18.2 Bal. to $24.6 \mathrm{Bal}$., is much flatter than that of the first, indicating a rate of ripening with the latter of about two and a half times that of the former. This difference can be accounted for by the cooler weather during the time the second crop Tokay was ripening, which was about ten days later than in the case of the second crop Malaga. The slower ripening is probably due both to the direct effect of the cool weather and to the decreased activity of the leaves at lower tempcratures.

(2) Changes in Total Acid, Cream of Tartar, and Free Acid. Owing to the fact that the analyses were started in 1914 and 1915 after ripening had commenced, the curves for these years show a decrease in acid throughout the period of the tests. In 1916, however, a rise in total acid occurred during the growing stage, as shown by a rise in the curve during the first thirty days of the experiment. Although this rise is not very large, it is quite definite, and occurs in all three varieties tested. The risc was most positive in the case of the Muscat grape, and amounted to .67 per cent acid as tartaric. From the point of maximum acidity, the total decreases slowly until the period of rapid ripening sets in. The total acid then decreases very rapidly for a time and more or less in proportion to the increase in total solids and sugar. As the grapes near maturity, the rate of decrease of total acid becomes less and the total remains practically constant after the grapes have reached maturity.

The eream of tartar in gencral increases very slightly during the periods of growth and ripening.

The increase in total acid during the first stages of growth is duc to increase in the frec acid. Since the eream of tartar remains almost constant throughout the ripening period, the curve of the free acid is practically parallel with that of the total acid.

As the grapes approach maturity, the cream of tartar ealeulated as 
tartaric acid approaches the total acid, and in one casc, (Musct, 1916), actually bccame equal to the total acid, indicating that in this instance no free acid remained.

Sccond crop grapes were found to be higher in free acid than first crop grapes of the same total solids and sugar content. The Catawba grape grown under eastern conditions (fig. 9) exhibits relatively high free acid. Alwood ${ }^{6}$ has found this frce acidity in eastcrn grapes to be due largely to malic acid. No attempt was made in the analyses of the California samples to identify the various acids making up the free acidity which was calculated as tartaric acid.

Mean Differences Between Total Solids and Sugar.-The following table contains figures representing the differences betwcen total solids and sugar at the various percentages of total solids indicated at the tops of the columns. The data represent a range of total solids from 5 per cent to 30 per cent. The figures were taken from the data reported in tables 7 to 9 , and represcnt several varietics of grapes. Only a few determinations of total solids and sugar were available for the lower concentrations ( 5 pcr cent to 15 per cent), and thereforc the figurcs for this range may not represent averages so accurately as the figures above 15 per cent total solids.

Between 5 per cent and 11 per cent solids, the average difference between total solids and sugar remains practically constant. From 11 per cent to 17 per cent total solids, the mean difference decreases quite rapidly. From 17 per cent to 30 per cent, the difference remains fairly constant. The variations noted after 17 per cent total solids

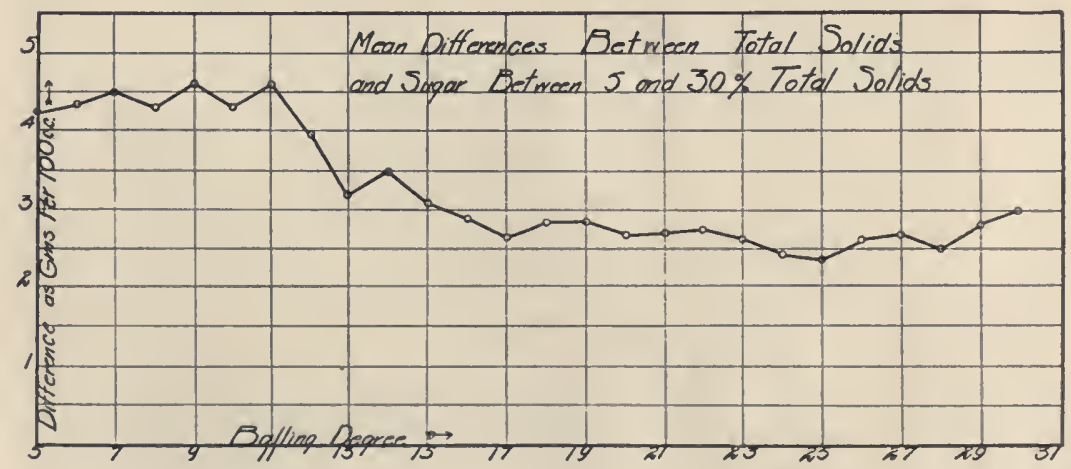

Fig. 10-Mean differences between total solids and sugar between 5 per cent and 30 per cent total solids.

6 U. S. Dept. Agric. Bull. 335. 


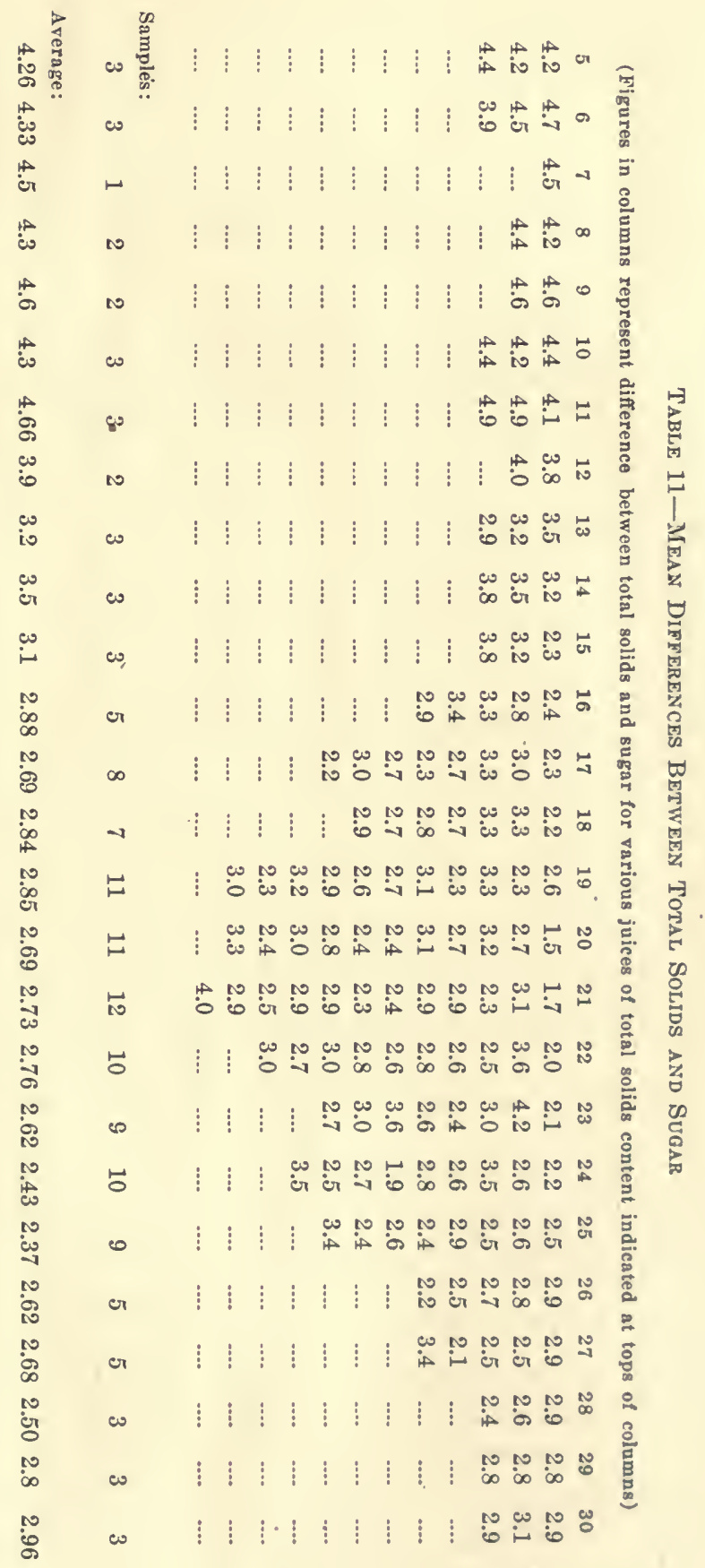


was reaehed are probably within the experimental error. The large difference between the total solids and sugar noted during the first stages of ripening is no doubt due to the high acid eontent of the unripe grapes. The fact that the differenee remains fairly eonstant after the grapes have become mature is to be expeeted, beeause the eream of tartar, total aeid, and protein remain fairly eonstant as maturity is approached and during the periods of maturity and overripeness.

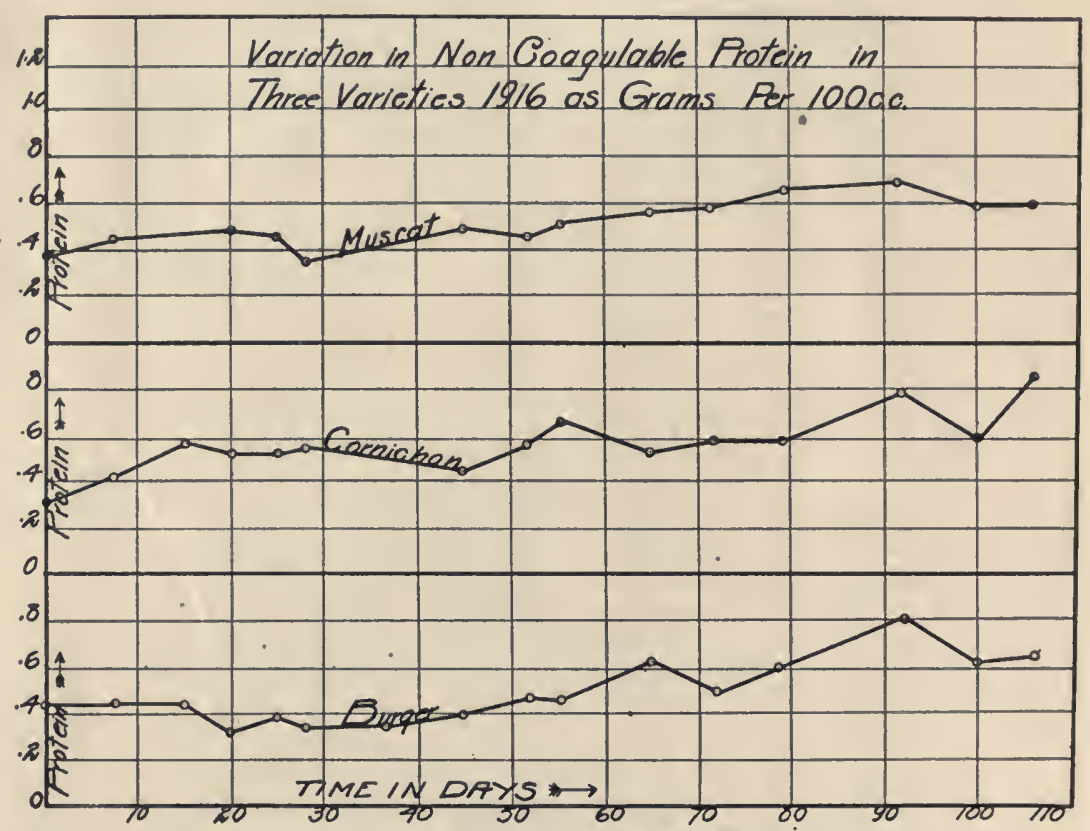

Fig. 11-Variation in non-coagulable protein content for three varieties, 1916.

Protein.-The total nitrogen content of the various samples was multiplied by 6.25 to convert it into its protein equivalent. Owing to the fact that the samples were sterilized by heat and filtered before analysis, the figures represent only the protein not eoagulated by heat.

The curves show that there is a slow increase in protein eontent during growth and ripening and the greatest increase oeeurs during the period of most rapid increase of sugar and most rapid decrease of acid. The inerease amounted to about .2 per cent in the case of the Muscat and .6 per cent in the case of the Cornichon. The inerease seems to be quite definite, although the protein curves are not so regular as those of total solids, sugar, and total aeid. 


\section{Summary of Changes in Must of Grapes During Growth and RIPENING OF BERRIES}

1..Total Solids.-The total solids remain fairly constant during the period of growth, corresponding to the period between setting of the berries and the time at which the berries have reached almost full size but are still hard and green. From this point on, there is a rapid increase in total solids due to inerease in sugar.

After the period usually eonsidered as full maturity is reached, the inerease in total solids is slow. The question may be raised as to whether this last increase is due to an actual synthesis and seeretion of sugar or other solids, or simply to evaporation of water. The fact that there is no change in the eurve of the aeid deerease at this time indicates that the same processes are eontinuing and that the inereased Balling degree represents an aetual inerease of solids. This view is fortificd by observations regarding the inerease of weight of solids during the ripening of raisin grapes. It has been shown that the weight of dried grapes shows a continuous increase up to the highest degree observed, 28.75 Balling. ${ }^{\text {? }}$

2. Sugar.-The total sugar during the growth period eomprises only a small amount of the total solids. During ripening, the sugar. rapidly increases and then eonstitutes a much greater proportion. During ripening, the sugar eurve follows the total solids eurve elosely. It is more or less the mirror image of the total aeid curve multiplied by five, i.c., inereases as the aeid decreases.

3. Total Acid and Free Acid.-During the early stages of the growth of the berries, the acidity inereases owing to an inerease of free acid. This is a faet that the authors have not found mentioned in the literature. During ripening, the total and free aeid rapidly deerease. After maturity is reaehed, the deerease is very slow.

4. Cream of Tartar.-There is a very slow, but usually fairly definite, inerease in eream of tartar during ripening. This inerease is very much less than the deerease in free aeid, and therefore ean not aeeount for any great part of this deerease.

7 Bioletti, Frederic T., Relation of the maturity of the grapes to the quantity and quality of the raisins. Proc. Inter. Cong. of Viticulture, San Francisco, 1915, pp. 307-314. 
5. Protein.-The protein not eoagulated by heat inereased definitely during growth and ripening, although the increase was not so regular nor so marked as the inerease in sugar or the decrease in total aeid.

6. Difference Between Total Solids and Sugar.-This factor remained eonstant for the lower pereentages of total solids, deereased during the rapid ripening stage, and remained constant through maturity and over-ripeness. 



Q California. University

111 Miscellaneous studies in

C34 agriculture and biology

\title{
P\&A $\mathrm{SCH}]$
}

\author{
PLEASE DO NOT REMOVE \\ CARDS OR SLIPS FROM THIS POCKET
}

UNIVERSITY OF TORONTO LIBRARY 
